\title{
ANalysis OF High Bay HangaR Facilities FOR FIRE DETECTOR SENSITIVITY AND PLACEMENT
}

\author{
Joseph E. Gott, Naval Facilities Engineering Command \\ and \\ Darren L. Lowe, Kathy A. Notarianni and William Davis \\ National Institute of Standards and Technology
}
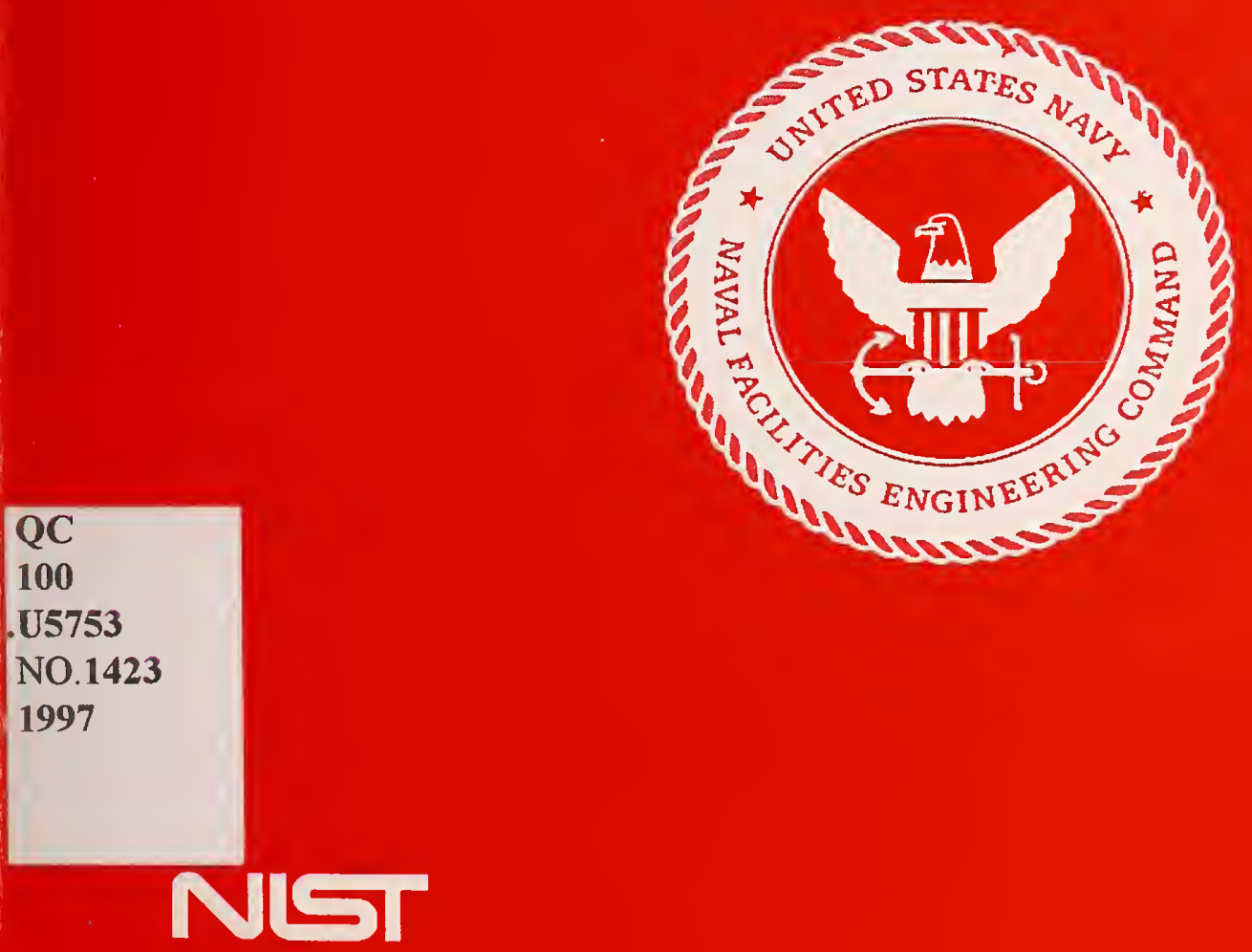

U.S. Department of Commerce Technology Administration National Institute of Standards and Technology
Sponsored by:

U.S. Department of the Navy Naval Facilities Engineering Command Naval Air Systems Command 



\section{ANALYSIS OF High BAY HaNGAR FACILITIES FOR Fire Detector Sensitivity and Placement}

Joseph E. Gott

Darren L. Lowe

Kathy A. Notarianni

William Davis

Building and Fire Research Laboratory

National Institute of Standards and Technology

Gaithersburg, MD 20899

February, 1997

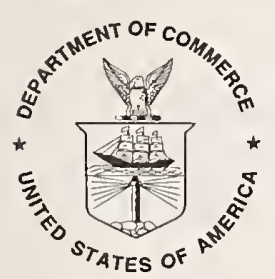

U.S. Department of Commerce

William M. Daley, Secretary

Technology Administration

Mary L. Good, Under Secretary for Technology National Institute of Standards and Technology

Arati Prabhakar, Director
Sponsored by:

U.S. Department of the Navy Naval Facilities Engineering Command Naval Air Systems Command 
National Institute of Standards and Technology

Technical Note 1423

Natl. Inst. Stand. Technol.

Tech. Note 1423

319 pages (February 1997)

CODEN: NTNOEF
U.S. Government Printing Office For sale by the Superintendent of Washington: 1997

Documents

U.S. Government Printing Office

Washington, DC 20402 


\section{EXECUTIVE SUMMARY}

Current guidelines for designing fire protection systems for aircraft hangars were developed with the primary objective of saving the building, and with less consideration given to minimizing damage to the hangar's contents. The high cost of modern aircraft justifies reexamining present fire detection and sprinkler activation methods to determine if new approaches could lead to a quicker response to a smaller fire, with the benefit of substantially reduced damage to aircraft adjacent to the fire source. The Naval Facilities Engineering Command (NAVFAC) established a unique Government/industry partnership to evaluate detector and sprinkler activation in aircraft hangars. The results of this comprehensive program are reported in this document.

Since the establishment of the original guidelines for aircraft fire protection, the use of JP-4 as the primary aviation jet fuel has teen superseded by JP-5 and JP-8, both of which have significantly higher flash points, and composite materials are now commonly integrated into the structures of military aircraft. As a result, both the hazard and risk associated with hangar fires have been modified. So too, fire detection and sprinkler activation methods have continued to evolve. An experimental approach was chosen to determine how the latest generation of fire detectors and sprinkler heads respond to increasing sizes of fires. Actual hangars were used to ensure the impact of the ceiling height and geometry were factored into the behavior of the fire plumes. This was critical because the early studies used to evaluate sprinkler activation were limited to ceiling heights below $10 \mathrm{~m}$.

Thirty-three full-scale experiments were conducted using JP-5 and JP-8 fuels in two Navy high bay aircraft hangars located at the Naval Air Stations in Barber's Point, Hawaii and Keflavik, Iceland. The full-scale test fires produced heat release rates ranging from $100 \mathrm{~kW}$ to $33 \mathrm{MW}$. Over 200 instruments, sprinklers and detectors were used in each full scale experiment to measure the behavior of heat and smoke in high bay areas, and their effect on the response time of fire detection and sprinkler systems. The test matrix also included analyzing the effects of draft curtains, ambient temperature, flat versus curved ceilings, and open versus closed hangar doors.

Analysis of the measurements described in this report yield the following significant findings regarding fire detection in aircraft hangars:

- $\quad$ Experiments with varied spacing of spot-type heat detectors at the ceiling showed that spacing could be increased to $12.2 \mathrm{~m}(40 \mathrm{ft})$ between detectors without any significant reduction in response time.

- The most effective spot-type heat detectors were found to be rate-compensated detectors with a temperature rating approximately equal to that of the automatic sprinklers (i.e., $79^{\circ} \mathrm{C}$ ).

- For a line-type heat detector installed horizontally below a nominally flat hangar roof, the temperatures as indicated by the thermocouples located adjacent to the detector are almost the same as the single temperature indicated by the detector. Thus, line-type detectors could be reliably used in hangars with flat roofs provided set points can be established to initiate an alarm. The set points may be established by using the experimental results of this study and applying computer modeling as necessary to extend the results to conform with the desired geometry. 
- Under a curved hangar roof, the use of line-type heat detectors requires additional study and installation experience to determine spacing and installation requirements.

- $\quad$ Projected beam smoke detectors installed in accordance with their current listing requirements proved ineffective because the dense smoke obscured the optical path, which resulted in the initiation of a trouble alarm. However, if the sensitivity of the projected beam detectors is decreased in the proper manner (which is outside current listing requirements), early and reliable response by these detectors can be obtained. This requires further testing and approval by a certified testing laboratory, as well as investigating the effects that the modified detector settings will have on the initiation of trouble alarms.

- $\quad$ Spot-type smoke detectors, which currently are not used in hangars, were able to detect the fires easily even when installed on the $15 \mathrm{~m}$ and $22 \mathrm{~m}$ high ceilings, indicating their potential in other high ceiling applications. Smoke detector spacings as far as $12.2 \mathrm{~m}(40 \mathrm{ft})$ apart at the tested heights exhibited no significant reduction in response time. The present practice prescribed in NFPA 72 is to reduce detector spacing for ceilings as high as those examined in this study.

- The response of the combination ultraviolet/infrared detectors when set to the current industry requirements previously established for JP-4 was satisfactory in tests using JP-5 and JP-8 jet fuel fires.

- Controller-based optical detectors offer design flexibility that can be exploited to achieve faster response times.

- New test standards need to be developed for optical detectors sensing jet fuel pool fires if damage to aircraft adjacent to the incident aircraft is to be prevented.

The following results apply to sprinkler applications in high bay hangars:

- With proper activation, closed head automatic sprinklers may provide the same level of structural protection as the deluge systems required by NFPA 409 without the problems associated with overhead deluge systems in the event of a false alarm.

- $\quad$ The $79^{\circ} \mathrm{C}\left(175^{\circ} \mathrm{F}\right)$ quick response heads proved to be the only effective sprinklers in high bay hangar applications for the fire sizes studied.

- Draft curtains control the flow of heat and smoke, and increase the number of sprinklers activated as well as decrease the response times. The installation of draft curtains should be considered a part of the fire protection arsenal for all high bay aircraft hangars.

- A comparison of response times for wet-pipe sprinklers versus dry-pipe (or pre-action) sprinklers showed no significant difference for these fast growing fires.

- Quick response sprinklers respond faster and are likely to be more effective in a hangar application. 
The large data base generated by this project warrants additional analysis. However, the application of existing fire models to a number of the experimental fires reveals the following:

- The probabilistic fire correlations and zone models that did not account for the presence of a hot ceiling layer underpredicted the fire centerline temperature. When the model applications were consistent with the physical situation simulated, however, reasonable accuracy in predicting plume centerline temperatures was achieved.

- Unconfined ceiling correlations used to predict sprinkler activation proved unsatisfactory due to the importance of the hot layer on the phenomena. When the presence of the layer was included, the prediction of sprinkler activation improved substantially near the plume centerline, but within the ceiling jet at substantial distances from the plume centerline, the predictions were unsatisfactory.

- The data base assembled with these experiments can be used as a baseline to develop fire protection strategies at other heights. These data can also serve as the starting point for the development, improvement, and validation of fire models and fire correlations in high ceiling spaces.

Navy and DoD criteria have and will continue to change as a result of this project. The National Fire Protection Association's "Standard on Aircraft Hangars," NFPA 409, should be reevaluated based on the data in this report.

In addition to this printed document, a video record of a number of the test fires conducted during this project is available upon request from NAVFAC and NIST. 


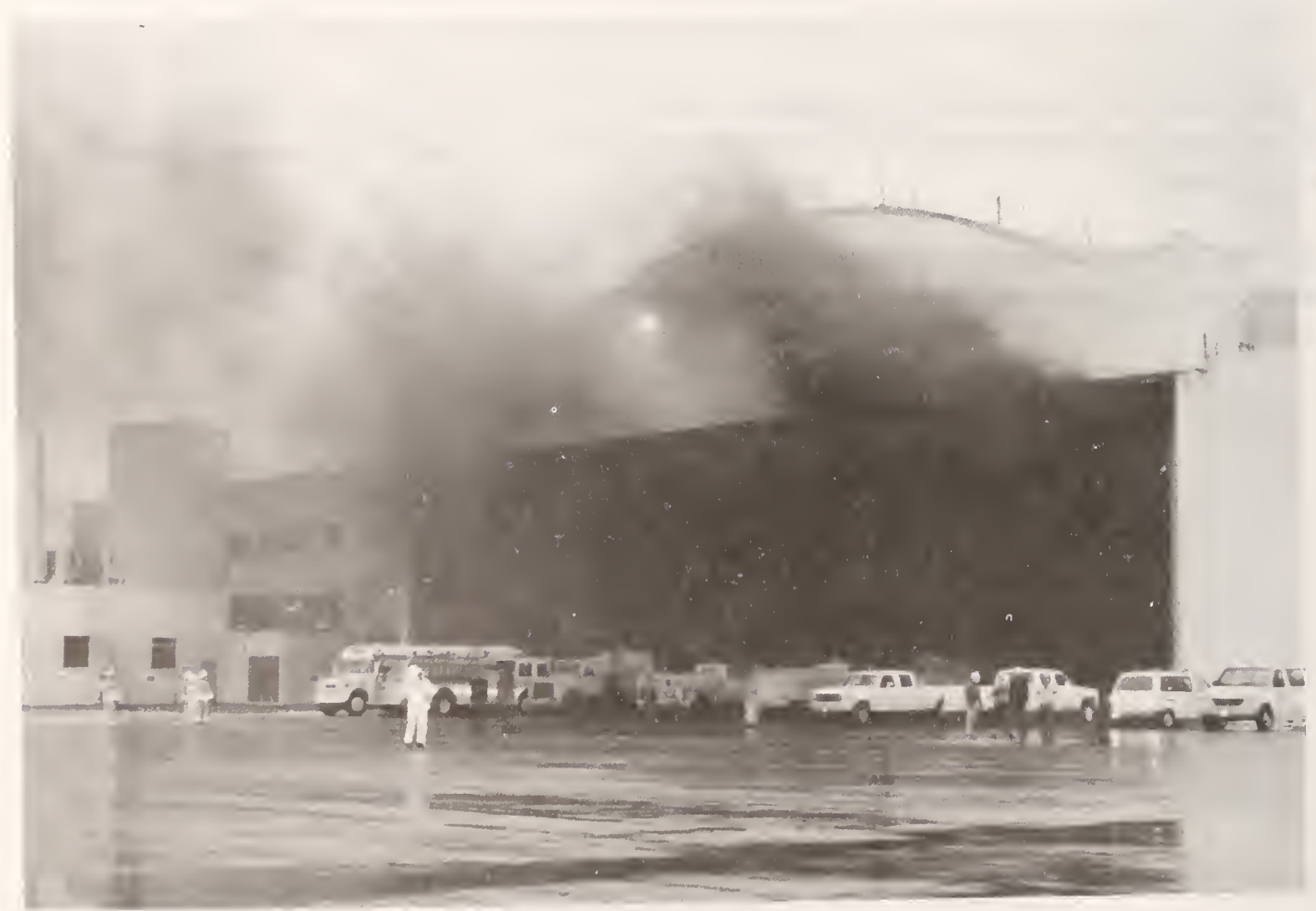

Smoke billowing from aircraft hangar following jet fuel fire test at Naval Air Station, Keflavik, Iceland. 


\section{TABLE OF CONTENTS}

Page

EXECUTIVE SUMMARY iii

ACKNOWLEDGMENTS ix

1 INTRODUCTION 1

2 JET FUEL POOL BURNING RATES

3 WARM CLIMATE EXPERIMENTS - 15 m HISH FACILITY

3.1 Experimental Set-up

3.1.1 Building Specifications of $15 \mathrm{~m}$ High Facility $\ldots \ldots \ldots \ldots \ldots \ldots \ldots \ldots \ldots$

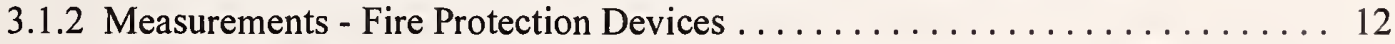

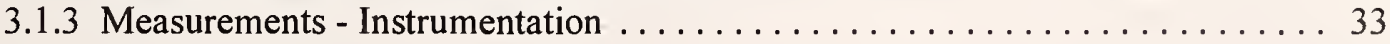

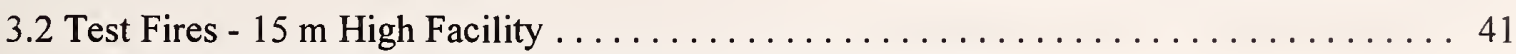

3.2.1 Logic Used to Determine Experimental Fire Sizes. . . . . . . . . . . . . . 43

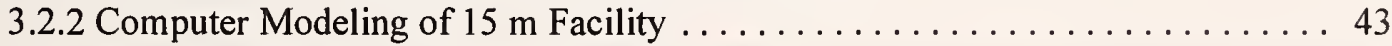

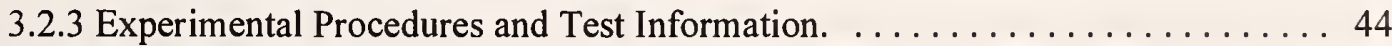

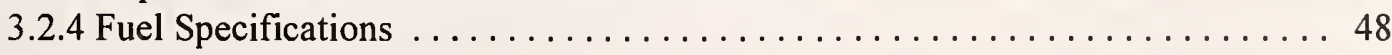

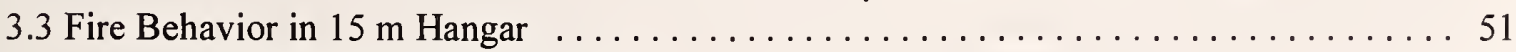

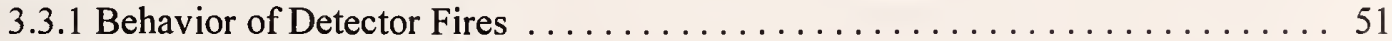

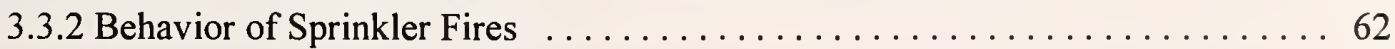

3.4 Response of Detection and Sprinkler Activation Systems to Fires . . . . . . . . 80

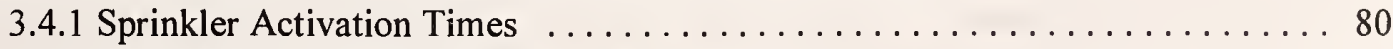

3.4.2 Response of Projected Beam Smoke Detectors . . . . . . . . . . . . . . . 89

3.4.3 Response of Photoelectric Smoke Detectors . . . . . . . . . . . . . . 92

3.4.4 Response of Single Point Heat Detectors . . . . . . . . . . . . . 97

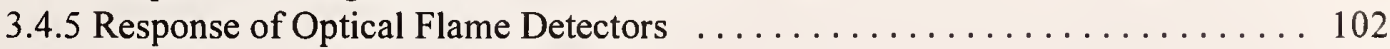

3.4.6 Response of Line-Type Heat Detector . . . . . . . . . . . . 108

4 COLD CLIMATE EXPERIMENTS - 22 m HIGH FACILITY $\ldots \ldots \ldots \ldots \ldots \ldots \ldots \ldots$

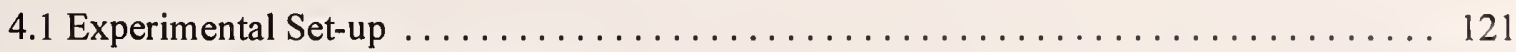

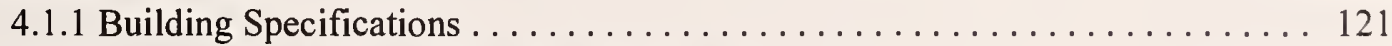

4.1.2 Measurements - Fire Protection Devices . . . . . . . . . . . . . . . 122

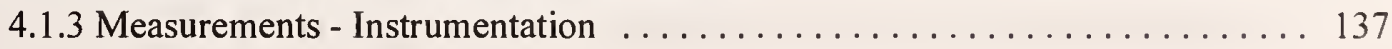


4.2 Test Fires in $22 \mathrm{~m}$ High Facility . . . . . . . . . . . . . . . . . . . . . 144

4.2.1 Rationale for Experimental Fire Sizes . . . . . . . . . . . . . . . . 144

4.2.2 Computer Modeling of $22 \mathrm{~m}$ Facility . . . . . . . . . . . . . . . 145

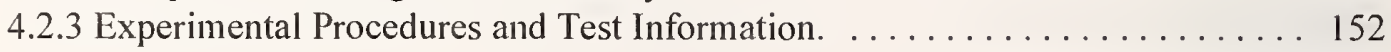

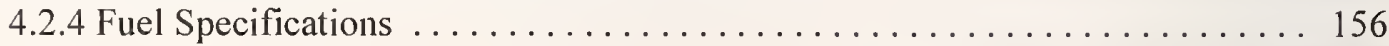

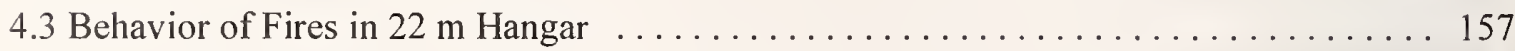

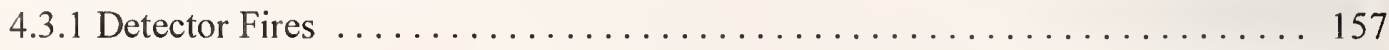

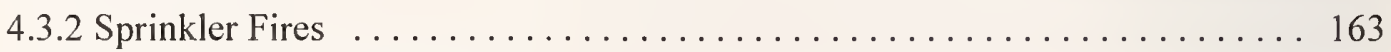

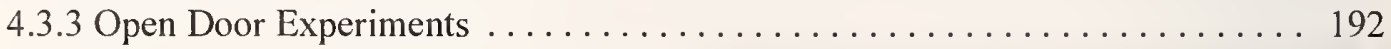

4.4 Response of Detection and Sprinkler Activation Systems to Fires . . . . . . . . 218

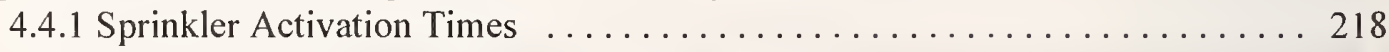

4.4.2 Response of Projected Beam Smoke Detectors . . . . . . . . . . . . 225

4.4.3 Response of Photoelectric Smoke Detectors . . . . . . . . . . . . . 239

4.4 .4 Response of Heat Detectors . . . . . . . . . . . . . . . . . 248

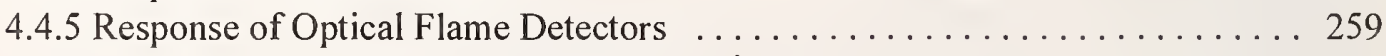

4.4.6 Response of Line-Type Heat Detector . . . . . . . . . . . . . 274

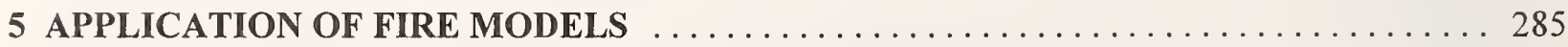

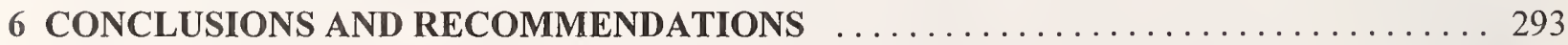

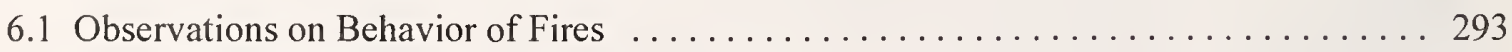

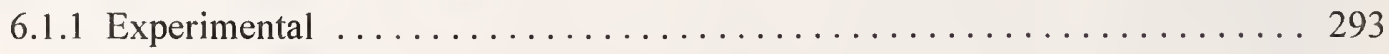

6.1 .2 Numerical Models . . . . . . . . . . . . . . . . . . . . . 294

6.2 Summary of Detection System Performance $\ldots \ldots \ldots \ldots \ldots \ldots \ldots \ldots \ldots \ldots$

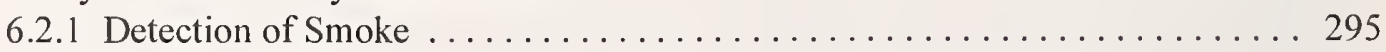

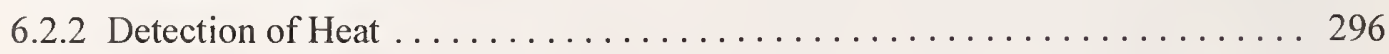

6.2 .3 Detection of Flame Radiation . . . . . . . . . . . . . . . 297

6.3 Summary of Sprinkler Activation Performance . . . . . . . . . . . . . 297

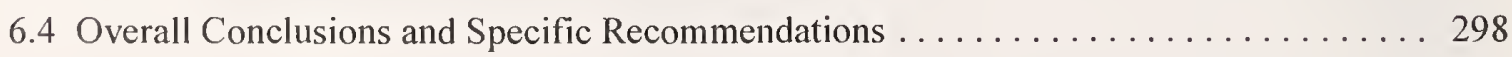

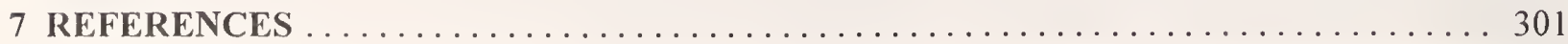

\section{APPENDIX}

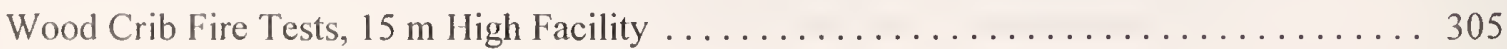




\section{ACKNOWLEDGMENTS}

This project was a unique government and industry partnership. The project team consisted of the Naval Facilities Engineering Command, the Naval Air Systems Command, representatives from the U.S. Air Force, the U.S. Army and the U.S. Marine Corps, private sponsors representing the United States' fire alarm and sprinkler industry, and the National Institute of Standards and Technology. This project would not have been possible without the support from each of these organizations.

We gratefully acknowledge the support of Naval Air Systems Command, especially Mr. John Stebbings, and the following industry sponsors: Simplex Time Recorder Co., The Viking Corporation, Detector Electronics Corporation, Detection Systems, Inc., and Alison Control, Inc. These private industry sponsors not only provided financial assistance, but they also supplied equipment, engineering services, personnel, and technical expertise.

Special thanks go to the Commanding Officer of the Naval Air Station (NAS) at Barbers Point, Hawaii, Captain E. Waller, USN, and the Commanding Officer of the NAS, Keflavik, Iceland, Captain W.R. Blake, Jr., USN, who trusted the research team enough to allow us to burn large fires in their aircraft hangars. We would also like to thank the Public Works Officers and staffs of NAS Barbers Point, Hawaii, and NAS Keflavik, Iceland, especially Commander J.R. Reddish, USN, Lieutenant Commander E. Clarkson, USN. We also gratefully acknowledge the support and cooperation of the Federal Fire Department, Pearl Harbor, Hawaii, and the fire department at the NAS Keflavik, especially Fire Chief $\mathrm{H}$. Stefansson, Deputy Fire Chief A. Eiriksson, Assistant Fire Chief S. Arason, and their staff without whose constant support this project would not have been possible.

The completion of this project required a great deal of time, effort, and support from many fire protection engineers within the Naval Facilities Engineering Command. Special thanks goes to the Atlantic Division, NAVFAC, especially Vince Donnally, Ralph Luca, Phil Bolton, and Ardith Mock; the Pacific Division, NAVFAC, especially Joe Condlin, John Chan, Emily Chun, and Jordan Lau; the Engineering Field Activity, Chesapeake, especially Joe Simone, Diane Pitts, and Tony Militello; the Engineering Field Activity, Northwest, especially Rita Fisher; and the Public Works Center, Washington DC, especially Chris Scheer and Suzette Hartman. Special thanks go to the staff at NAVFAC Headquarters, especially Dave Peterson, Jay Bordwell, and Traci Bangor, whose contributions are too numerous to list. We would like to gratefully acknowledge Dr. Get Moy, Captain K. Gross, USN, Captain E. Rushing, USN, and Mr. Harry Zimmerman at NAVFAC headquarters for their support and commitment to this project.

Assistance from other fire protection engineers at other military branches was also essential to the project. Fred Walker, Mike Davis, and Jim Crawford from the U.S. Air Force, Kevin King from the U.S. Marine Corps, and Bob DiAngelo and Ed Lockwood from the U.S. Army Corps of Engineers were crucial to the planning, engineering and successful execution of this project.

The National Institute of Standards and Technology provided this project with an extensive support staff in addition to the authors. We greatly appreciate the work and technical expertise provided by Dr. William Grosshandler, Mr. Michael Glover, Ms. Anabisdally-Boden Irizarry, and Mr. Scott Laramee.

This report required a significant amount of technical investigation, data reduction and analysis, data 
processing and writing. In addition to the primary authors, this report is a collaboration of the following contributing authors: Chris Scheer, Suzette Hartman, Diane Pitts, Tony Militello, Dave Peterson, Jay Bordwell, Traci Bangor, and Scott Laramee. 


\subsection{Background}

The design of fire protection systems for high bay aircraft hangars poses the same challenges and problems as those encountered in a variety of tall structures including hotel atria and warehouses. Unfortunately, the model building codes and fire codes in the United States offer little or no guidance for the design of fire protection systems for high bay spaces. This is because of a lack of scientific data regarding the behavior of heat and smoke in ceiling heights over $9.1 \mathrm{~m}$. Timely detection of a fire is more difficult in tall structures due to the distance heat and other products of combustion must travel to reach sprinklers and detectors. Stratification may also occur, which poses an additional challenge in selecting the optimal location of detectors.

The Navy and all military services within the U.S. Department of Defense (DoD) are responsible for providing fire protection systems capable of protecting DoD assets around the world. This includes the protection of high value military aircraft which are maintained and repaired in high bay aircraft hangars. These aircraft are an essential element of a strategic military force whose mission is unparalleled by commercial aircraft. The Naval Facilities Engineering Command (NAVFAC) is responsible for the design, construction and maintenance of all shore-based facilities at U.S. Navy and Marine Corps bases worldwide.

For years, NAVFAC has designed fire protection systems for aircraft hangars based on the requirements developed to protect commercial aircraft hangars [1]. However, the scope of NFPA 409 is limited to the protection of the hangar itself, not the aircraft. Current NFPA 409 requirements for Type I aircraft hangars include foam-water deluge sprinkler systems and, in some cases, supplementary underwing foam-water systems as well as hand-held hose systems. These criteria were developed primarily to protect the hangar building from a large spill fire, and are based on a series of tests conducted for the Navy and the Air Force involving fire sizes approximately $9.1 \mathrm{~m} \times 9.1 \mathrm{~m}$.[1] These tests were based on JP-4 fuel which has a flash point of approximately $-8{ }^{\circ} \mathrm{C}$. The military stopped using JP-4 as their primary jet fuel circa 1986, and changed to JP-5 and JP-8 whose flash points are approximately $60{ }^{\circ} \mathrm{C}$ and $38{ }^{\circ} \mathrm{C}$ respectively.

Fire protection design criteria for Navy aircraft hangars have evolved over the years. Many of the existing hangars were built in the World War II era, and their fire protection consists solely of overhead deluge sprinkler systems activated by pneumatic rate-of-rise heat detectors. With the development of aqueous film-forming foam (AFFF), the Navy's design criteria were changed to include overhead AFFF deluge sprinkler systems, a variety of new detection systems, and in many cases, supplementary underwing foam monitor nozzles. In essence, this reflects the current requirements of NFPA 409 for commercial aircraft hangars. However, overhead foam-water deluge systems have caused countless, costly problems in military aircraft hangars.

Both the Navy and Air Force have been plagued with false activations involving foam-water deluge sprinkler systems over aircraft with open cockpits. These false activations have been caused by numerous sources including lightning strikes which introduce transient voltage spikes into the fire alarm system, water hammers in aging underground water distribution systems, accidental releases by maintenance personnel, deliberate acts of vandalism, accidental activation of manual pull stations, failure of pressure relief valves at pumping stations, roof water leakage into overhead heat detection systems, and false activation of fire detection systems. This prompted all branches of DoD to pursue alternative fire protection designs which would provide an equivalent level of protection. 
The first alternative was to utilize closed-head foam-water sprinkler systems at the ceiling, which are now a part of the DoD criteria for hangar protection. The challenge was to design a closed-head sprinkler system which would respond like a deluge system given a spill fire in the hangar. One of the goals of this project was to investigate that design approach, and determine what fire sizes would activate a variety of sprinkler heads and detection systems. Current NFPA requirements for closedhead foam-water sprinkler systems state that the temperature rating of sprinkler heads must be within the range of $121^{\circ} \mathrm{C}$ to $149^{\circ} \mathrm{C}\left(250^{\circ} \mathrm{F}\right.$ to $\left.300^{\circ} \mathrm{F}\right)$ [2]. The research team believed these temperature ratings were too high to have the sprinklers activate in a reasonable time frame, and that lower temperature, quick response heads could function similarly to a deluge system without the false alarm problem. Consequently, a variety of temperature ratings were investigated to improve the overall response time of the closed-head sprinklers.

While it is readily accepted that conventional hangar fire protection systems are not designed to extinguish a three-dimensional fire, fire protection engineers within $\mathrm{DoD}$ believe that properly designed AFFF extinguishing systems are capable of controlling a spill fire and limiting the spread of most fires to the adjacent aircraft.

The second significant alternative was to shift the primary suppression responsibility to the foam-water monitor nozzles, rather than the ceiling-level systems, and then find the quickest and most reliable means of detecting a spill fire. Optical detectors have neither been approved nor tested for JP-5 and JP-8. Their present listings are for JP-4 and only evaluate their response to three fire sizes at arbitrarily determined distances.

The Building Fire and Research Laboratory (BFRL) at the National Institute of Standards and Technology (NIST) has conducted previous experiments and modeling studies of high bay hangars [3]. Those experiments utilized isopropyl alcohol, involved a single fire size, and were conducted with the hangar doors in the closed position. Effective hangar fire protection must consider the possibility of the hangar doors being in the open position because it presents a more challenging fire scenario for detection. The current study investigates the effects of open hangar doors and additional fire configurations on hangar fire detection systems.

Computer fire models could be used to assist in designing the fire protection systems for buildings with high bay ceilings. While the advanced field models may be capable of handling this task, few design engineers have the equipment, the training or the time required to run such complex models. The existing zone models (e.g., CFAST) and special purpose deterministic models (e.g., FPETOOL and DETACT) do not provide reliable predictions for the activation of detectors and automatic sprinklers in buildings with high ceilings [3]. This is due to the fact that most of the existing models were developed based on correlations from fire tests conducted with ceiling heights not exceeding $9.1 \mathrm{~m}$ [4]. Prior to this project, only very limited experimental data had been collected regarding the activation of sprinklers and detectors at ceiling heights over $9.1 \mathrm{~m}$.

\subsection{Scope of Investigation}

A jet fuel spill fire poses a severe threat to military aircraft within high bay hangars. By the time a pool fire grows to the equivalent size of the $9.1 \mathrm{~m}$ by $9.1 \mathrm{~m} \mathrm{JP}-4$ pool fire originally used to test the response of sprinkler systems installed in hangars, collateral damage to adjacent aircraft is almost assured. While it is likely that an aircraft intimate to the ignition source will be lost to a jet fuel fire, the 
goal within DoD is to have a fire protection system capable of protecting other aircraft originally not involved in the fire, as well as to protect the hangar structure itself. This investigation was designed to determine how quickly various sprinklers and detectors would respond to the smoke and heat release rate of fires much smaller than that created by a $9.1 \mathrm{~m}$ by $9.1 \mathrm{~m} \mathrm{JP}-4$ pool.

In addition to fire size, the switch from previously used JP-4 jet fuel to currently used JP-5 and JP-8 reduces the heat release rate, which is likely to extend the time to detection. Higher ceilings also lead to longer times to system activation. As a result, it was important to capture both the fuel type and actual hangar geometry effects in the test plan.

This study consisted of 33 full-scale fire experiments in two Navy high bay aircraft hangars. The movement of smoke and heat as well as the response of detection and suppression devices in high bay hangars under a variety of conditions were measured and analyzed. These data will be used by fire protection engineers in the Navy as well as the other military services to reevaluate fire protection criteria for military aircraft hangars.

Experiments were conducted in two distinctly different climates to understand how smoke movement and detector sensitivity are impacted by ambient temperature. One set of experiments was conducted in a $15 \mathrm{~m}$ high aircraft hangar at the U.S. Naval Air Station in Barbers Point, Hawaii. A second set of experiments was conducted in a $22 \mathrm{~m}$ high aircraft hangar at the U.S. Naval Air Station in Keflavik, Iceland. The $15 \mathrm{~m}$ hangar had a nominally flat roof, while the $22 \mathrm{~m}$ hangar had a curved roof. In addition, a number of laboratory-scale burn tests were conducted to determine the burn rates of JP-4, JP-5 and JP-8 aviation fuels.

The overall objective of these investigations was to provide insight into the behavior of realistic jet fuel fires in aircraft hangars as that behavior impacts the design and operation of various fire protection systems. The specific parameters investigated included the following:

- $\quad$ Burn rates of JP-4, JP-5 and JP-8

- $\quad$ Heat release rates for a variety of a JP-5 and JP-8 pool fires

- $\quad$ Effectiveness of spot-type and line-type heat detectors for high bay hangars

- $\quad$ Spacing of spot-type detectors in high bay hangars

- $\quad$ Approximate minimum fire size threshold for each detector type

- $\quad$ Effect of fuel type on the response of each type of fire detector

- $\quad$ Response distance thresholds of optical detectors to various fire sizes and fuel types

- $\quad$ Effects of temperature, stratification and wind on detector performance

- $\quad$ Overall performance of heat, smoke and projected beam detectors in high bay hangars

- Approximate minimum fire size for sprinkler activation for various sprinkler heads

- $\quad$ Effects of draft curtains on sprinkler and detector response

- $\quad$ Effects of an open-door fire on detector and sprinkler response

- $\quad$ Effects of ceiling configuration on detector and sprinkler response

\subsection{Organization of Report}

Extensive field measurements were conducted at two different facilities. The results of the fire tests conducted in the $15 \mathrm{~m}$ high hangar in Hawaii are reported in Section 3. Section 4 deals with the fire 
tests conducted in the $22 \mathrm{~m}$ high facility in Iceland. Within each of these major sections, the experimental set-up and instrumentation are described, followed by a description of the fires and operational procedures. The corresponding experimental results are then presented in each major section, respectively.

Prior to the field tests, experiments were held in the NIST facility to determine the burning rates of JP4, JP-5 and JP-8. These are presented first, in Section 2. The ability of simple correlations to predict the measured ceiling temperatures and sprinkler activation times is explored briefly in Section 5. The major conclusions and recommendations generated from the project are summarized in Section 6. Additional data on wood crib fires collected during the course of this study but outside the primary focus of the report are found in the Appendix. 


\section{JET FUEL POOL BURNING RATES}

A series of laboratory scale experiments were performed at NIST to determine heat release rates and burning rates as a function of fire size for JP-4, JP-5, and JP-8 jet fuels. These laboratory scale experiments were conducted using a cone calorimeter and the NIST large calorimeter. Results were used to determine appropriate fire sizes for the large scale tests.

These jet fuels were selected because of their widespread use in military aircraft. The fuels were tested and shown to meet Military Specifications MIL-T-5624P for JP-4 and JP-5 [5], and MIL-T-83133D for JP-8 [6]. Table 1 shows these specifications which define heating value, density, and flash point of each fuel.

Table 1. Military Specifications for aviation fuel used in experiments

\begin{tabular}{|c|c|c|c|}
\hline Fuel & $\begin{array}{c}\text { Higher Heating Value } \\
\mathrm{MJ} / \mathrm{kg}\end{array}$ & $\begin{array}{c}\text { Density @ } 15{ }^{\circ} \mathrm{C} \\
\mathrm{kg} / \mathrm{L}\end{array}$ & $\begin{array}{c}\text { Flash Point } \\
{ }^{\circ} \mathrm{C}\end{array}$ \\
\hline JP-4 & 42.8 & $0.751-0.802$ & $-8^{\mathrm{a}}$ \\
\hline JP-5 & 42.6 & $0.788-0.845$ & 60 \\
\hline JP-8 & 42.8 & $0.775-0.840$ & 38 \\
\hline
\end{tabular}

${ }^{\text {a }}$ Flash point as stated in NRL Report 7549 [10]

\subsection{Measurements of Heat Release Rate and Burning Rate}

The heat release rates for each fuel type were determined using oxygen consumption calorimetry techniques. A discussion of the principles of oxygen consumption calorimetry can be found in reference [7]. To summarize the method, all gaseous combustion products from the fire are directed through a duct where mass flow and oxygen concentration are measured as a function of time. Using these measurements, the rate of oxygen consumption is determined. For most fuels, the heat release rate is proportional to the rate of oxygen consumption. A load cell measured mass loss as a function of time. Dividing the rate of mass loss by the pan area yielded burning rates $\left(\mathrm{kg} / \mathrm{m}^{2}-\mathrm{s}\right)$ for each test.

\subsection{Cone Calorimeter Results}

The laboratory scale experiments were comprised of nine tests, three repeat tests for each of the three fuels. A schematic of the Cone Calorimeter apparatus is shown in Figure 1. The ignition source was a small propane torch. As discussed in ASTM E-1354 [8], the heat release rates measured using the Cone Calorimeter have an uncertainty defined by $r=13.3+0.13 q^{\prime \prime}$ max , where $r$ is the error band for tests conducted at the same facility and $q^{\prime \prime}{ }_{\max }$ is the maximum heat release rate per unit area $\left(\mathrm{kW} / \mathrm{m}^{2}\right)$ for all of the tests considered in the sample. The maximum heat release rate used in the above expression was from the test with the highest average heat release rate for each fuel. Table 2 lists the estimated uncertainty and the range of values measured for each fuel. 
Table 2. Cone calorimeter results for jet fuels burning in $0.085 \mathrm{~m}$ diameter pan

\begin{tabular}{|c|c|c|c|}
\hline Fuel & $\begin{array}{c}\text { Number of } \\
\text { Tests }\end{array}$ & $\begin{array}{c}\text { Mean Heat Release Rate } \\
\left(\mathrm{kW} / \mathrm{m}^{2}\right)\end{array}$ & $\begin{array}{c}\text { Burning Rate } \\
\left(\mathrm{g} / \mathrm{m}^{2} / \mathrm{s}\right)\end{array}$ \\
\hline JP-4 & 3 & $395 \pm 67$ & $9.26 \pm 0.34$ \\
\hline JP-5 & 3 & $333 \pm 58$ & $7.01 \pm 0.70$ \\
\hline JP-8 & 3 & $316 \pm 55$ & $6.93 \pm 0.87$ \\
\hline
\end{tabular}

Table 3. Large scale hood calorimeter results for jet fuel fire tests

\begin{tabular}{|c|c|c|c|c|c|}
\hline Fuel & Tests & $\begin{array}{c}\text { Pan Dia. } \\
\mathrm{m}\end{array}$ & $\begin{array}{c}\text { Pan Area } \\
\mathrm{m}^{2}\end{array}$ & $\begin{array}{c}\text { Steady State HRR } \\
\mathrm{kW} \pm 15 \%\end{array}$ & $\begin{array}{c}\text { Burning Rate } \\
\mathrm{kg} / \mathrm{m}^{2} / \mathrm{s}\end{array}$ \\
\hline JP-4 & 3 & 1.0 & 0.79 & 1,900 & $0.094 \pm 0.020$ \\
\hline JP-4 & 1 & 1.2 & 1.13 & 2,500 & $0.066 \pm 0.010$ \\
\hline JP-5 & 2 & 1.0 & 0.79 & 1,400 & $0.070 \pm 0.010$ \\
\hline JP-5 & 2 & 1.2 & 1.13 & 2,000 & $0.060 \pm 0.010$ \\
\hline JP-8 & 3 & 1.0 & 0.79 & 1,500 & $0.086 \pm 0.020$ \\
\hline JP-8 & 2 & 1.2 & 1.13 & 2,200 & $0.060 \pm 0.010$ \\
\hline
\end{tabular}




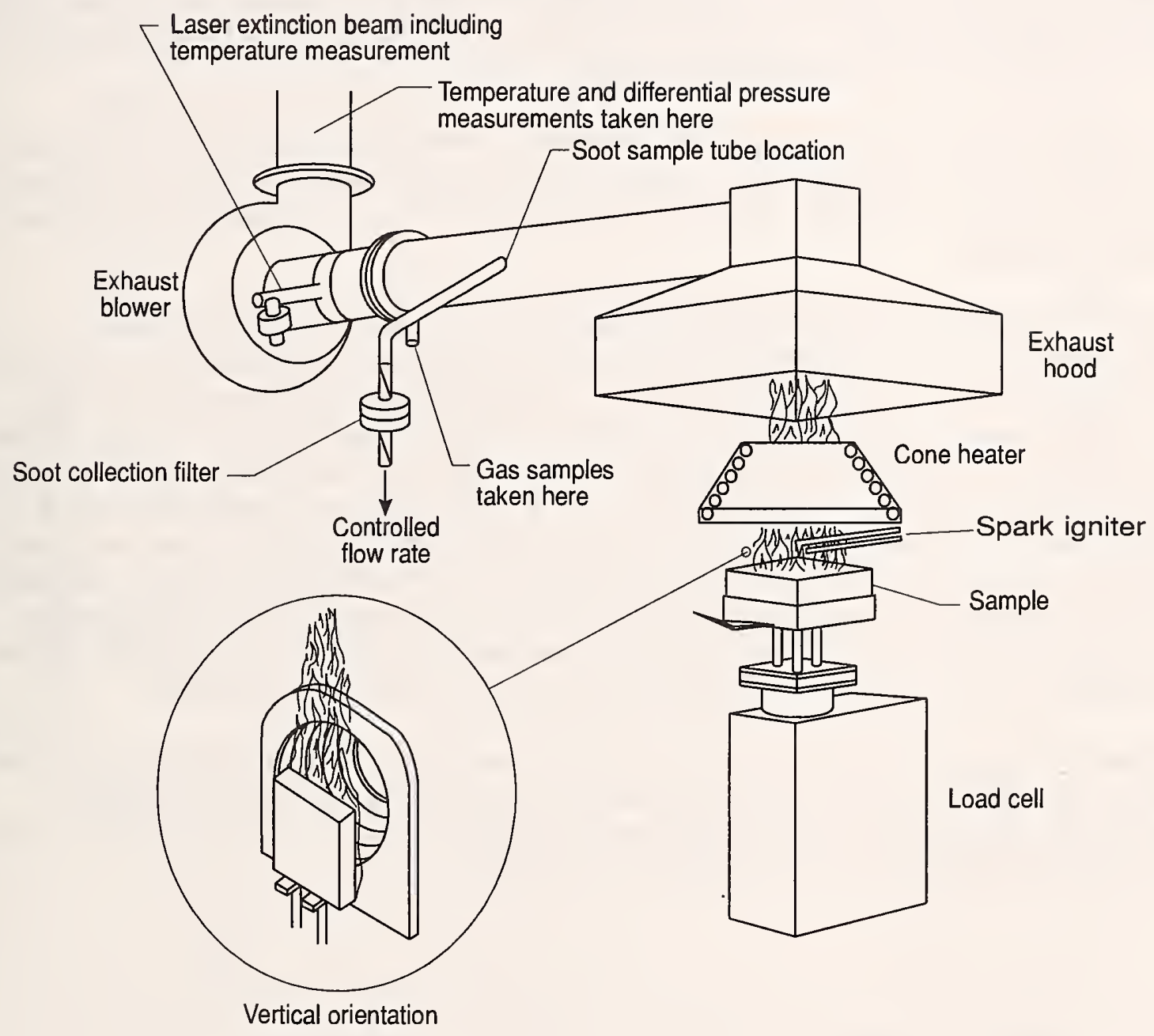

Figure 1. Diagram of cone calorimeter apparatus used for small-scale heat release measurements. 


\subsection{NIST Large Calorimeter Results}

Thirteen fire tests were conducted in the NIST large calorimeter for JP-4, JP-5, and JP-8. Heat release rates as a function of pan size were determined using oxygen consumption calorimetry for a $1.0 \mathrm{~m}(3.3$ $\mathrm{ft})$ diameter and a $1.2 \mathrm{~m}(3.9 \mathrm{ft})$ diameter circular pan. The NIST large calorimeter uses the same principles as for small scale oxygen consumption calorimetry, but the mass flow rate is averaged over nine points across the duct diameter. Also, the oxygen concentration is measured after being collected where the combustion products are considered well mixed. Each fire was ignited using a propane torch with a $6.4 \mathrm{~mm}(0.25 \mathrm{in})$ nozzle made of copper tubing.

The uncertainty associated with the NIST large calorimeter is estimated to be $15 \%$. This estimate is based on a $5 \%$ uncertainty in assuming a constant net heat of combustion for all fuels as discussed in [9], a $5 \%$ measurement uncertainty in pitot tube pressure, and up to $5 \%$ measurement uncertainty in the remaining equipment.

Table 3 shows the heat release rates and burning rates for tests conducted in the NIST large calorimeter. For the two $1.0 \mathrm{~m}$ diameter pan fires of JP-5, the average heat release rate was $1300 \pm$ $100 \mathrm{~kW}$. The average burning rate for JP-5 for the $1.0 \mathrm{~m}$ circular diameter pan was $0.07 \pm 0.01$ $\mathrm{kg} / \mathrm{m}^{2} / \mathrm{s}$. Figüre 2 shows a representative heat release rate curve for each fuel. For a $1.0 \mathrm{~m}$ diameter pan, JP-5 had the lowest heat release rate of the three fuels, with an average heat release rate during steady state burning of $1300 \mathrm{~kW}$ for the test shown. JP-4 had a higher heat release rate, about 1900 $\mathrm{kW}$ during steady state burning for the same pan size. The JP-4 fire also grew to steady state faster than both JP-5 and JP-8, due to its much lower flash point. The JP-8 fuel had an average heat release rate of $1500 \mathrm{~kW}$ during steady state burning, closer to the heat release rate for JP-5. Referring to Table 3, the heat release rates for these two fuels are also similar for the $1.2 \mathrm{~m}$ circular diameter pan, with average heat release rates for JP-5 and JP-8 of $2000 \mathrm{~kW}$ and $2200 \mathrm{~kW}$, respectively.

Heat release rate as a function of pan size is an important parameter needed to determine appropriate fire sizes for the full scale tests. As Figure 3 illustrates, the heat release rate increases with the increase in pan size, increasing from a steady state average heat release rate of $1300 \mathrm{~kW}$ for a $1.0 \mathrm{~m}$ diameter pan to $2000 \mathrm{~kW}$ for a $1.2 \mathrm{~m}$ diameter pan of JP-5 fuel. 


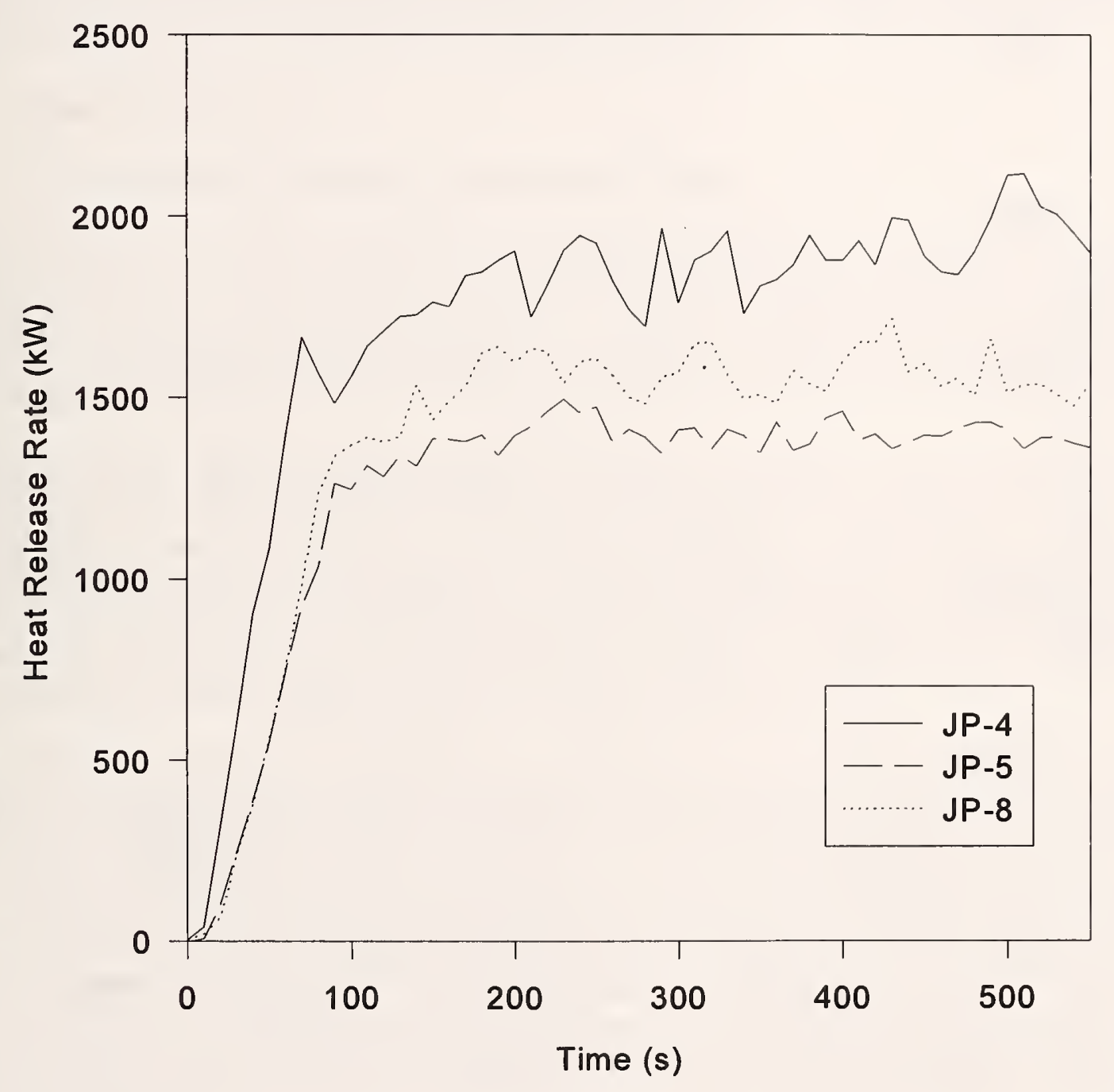

Figure 2. Heat release rate versus time for $1.0 \mathrm{~m}$ diameter pool fires of JP-4, JP-5, and JP-8. 


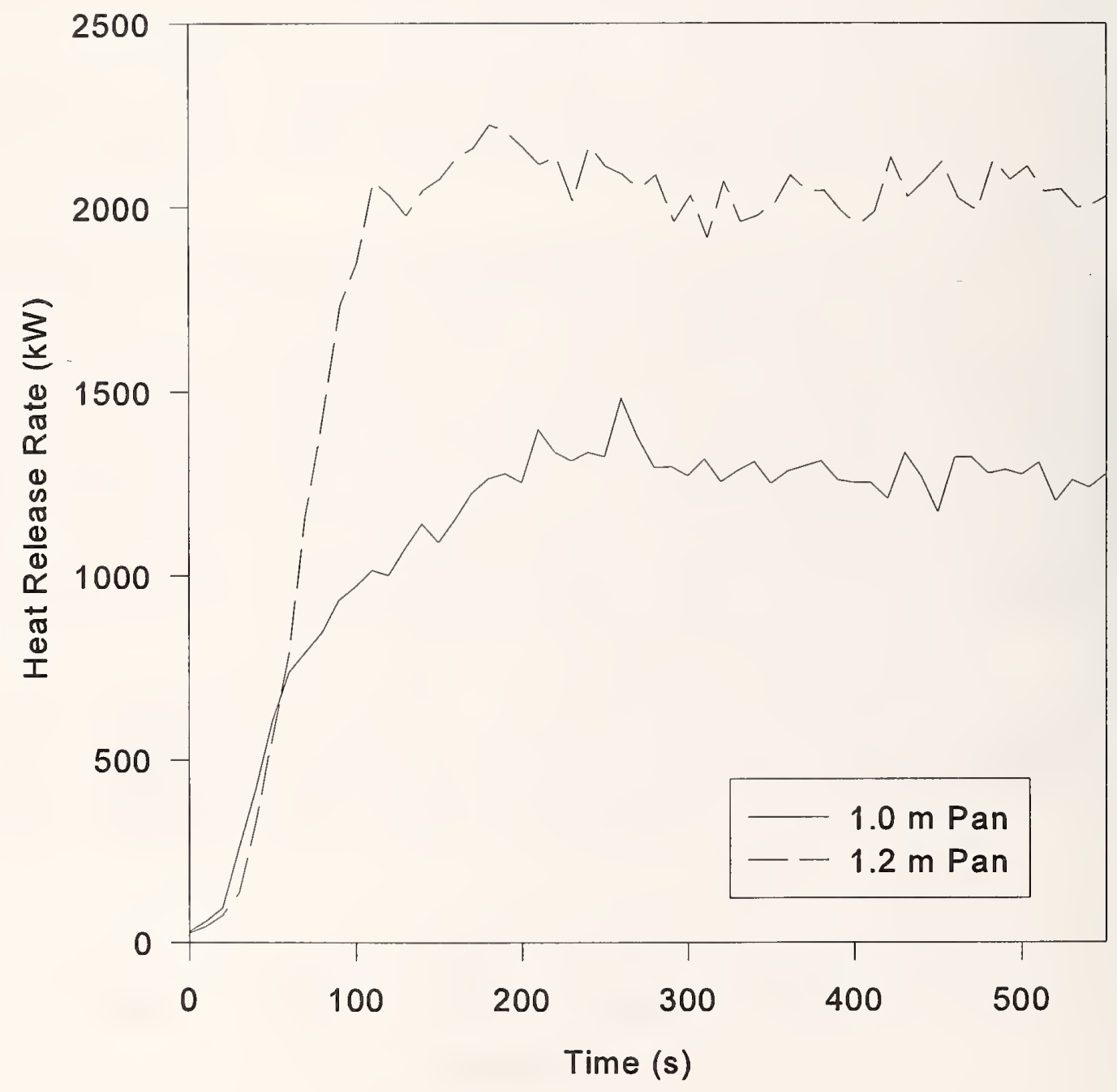

Figure 3. Heat release rate versus time for $1.0 \mathrm{~m}$ and $1.2 \mathrm{~m}$ diameter pool fires using JP-5. 


\section{WARM CLIMATE EXPERIMENTS - 15 m HIGH FACILITY}

The Naval Air Station at Barbers Point, Hawaii, was selected as representative of a warm climate installation, where high normal operating temperatures might be expected to impact the flow of a fire plume and the choice of sprinkler activation temperature. The nominal height of the aircraft hangar in which the full-scale fire tests were conducted is $15 \mathrm{~m}$. The layout of the building is described in the following section. The type of fire protection and suppression devices installed, the instrumentation used to monitor the fire, and the experimental results are presented. In addition, the methodology used to design the fire experiments and analyze the results is provided.

\subsection{Experimental Set-up}

\subsubsection{Building Specifications of $\mathbf{1 5} \mathrm{m}$ High Facility}

The first series of full scale fire experiments was conducted in Hangar 111 at the Naval Air Station in Barbers Point, Hawaii. This hangar was built in 1942 and consists of one large hangar maintenance bay and two adjoining office spaces. A plan view of the hangar bay and fire area are shown in Figure 4. For the purpose of this section, all references to compass direction are made with respect to test north as shown in the Figure 4.

The hangar bay dimensions are approximately $97.8 \mathrm{~m}(321 \mathrm{ft})$ in length and $73.8 \mathrm{~m}(242 \mathrm{ft})$ in width.

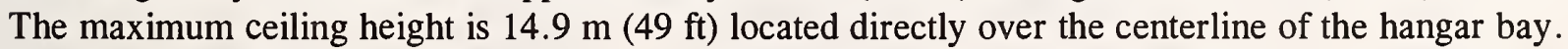
The east and west walls are comprised of concrete masonry construction with numerous unprotected window and door openings into the hangar bay. These walls are two stories in height and provide a non-fire rated separation between the office space and the hangar bay. The north and south ends of the hangar bay consist of metal and glass horizontal sliding hangar doors which are manually operated. This hangar has no existing heating ventilation and air conditioning system.

The roof consists of built-up tar and gravel over a corrugated metal deck. The roof slopes from a

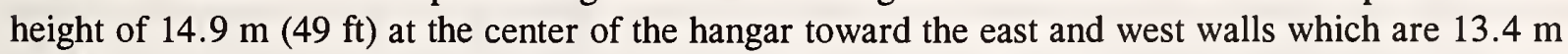
(44 ft) high. The metal deck is directly supported by $0.25 \mathrm{~m}(10 \mathrm{in}) \mathrm{I}$ beams which run the (N-S) width of the hangar and are spaced $4.1 \mathrm{~m}(13.5 \mathrm{ft})$ on center. The I beams are supported by open steel trusses which run perpendicular to the beams (E-W) and are spaced $6.1 \mathrm{~m} \mathrm{(20} \mathrm{ft)} \mathrm{on} \mathrm{center.} \mathrm{These}$ trusses span the full length of the hangar. A picture of the roof assembly is shown in Figure 5. The roof also contains two skylights each of which measures $73.2 \mathrm{~m}(240 \mathrm{ft})$ long, $6.1 \mathrm{~m}(20 \mathrm{ft})$ wide, and $3.7 \mathrm{~m}(12 \mathrm{ft})$ high. The skylights are $36.6 \mathrm{~m} \mathrm{(120} \mathrm{ft)} \mathrm{apart} \mathrm{and} \mathrm{run} \mathrm{parallel} \mathrm{to} \mathrm{the} \mathrm{hangar} \mathrm{doors.}$ Figure 5 shows two elevation views of the hangar and the orientation of the skylights. These skylights have louvered glass openings which are electrically controlled for ventilation but which were closed for all of the experiments.

The hangar bay is fully protected by open-head deluge sprinklers on a pipe scheduled system with a protection area per head of $9.3 \mathrm{~m}^{2}\left(100 \mathrm{ft}^{2}\right)$. The sprinklers are supplied by twelve independent deluge valves which are activated by pneumatic heat actuated devices (HADs) located at the ceiling. The preumatic HADs operate according to a rate-of-rise principle such that when the temperature rise exceeds $7{ }^{\circ} \mathrm{C}$ to $8{ }^{\circ} \mathrm{C}$ per minute, air in the detector expands faster than it can be vented to the atmosphere. At that point, a mechanical diaphragm in the pneumatic tubing converts the pressure to a 
mechanical action which activates a set of alarm contacts. The existing sprinklers and heat detectors were shut off during each of the fire tests.

There are no permanent draft curtains in the hangar. A temporary draft curtain made of fire retardant canvas was constructed and installed for six tests to evaluate the effect of the curtain on the activation times. The space between the top edge of the draft curtain and the metal deck was sealed with fiberglass insulation to prevent smoke leakage beyond the top of the curtain. The draft curtain was installed centered over the fire area as shown in Figure 4. However, the fire, itself was not centered within the hangar. The draft curtain area measured $24.4 \mathrm{~m}(80 \mathrm{ft})$ in length, $18.3 \mathrm{~m}(60 \mathrm{ft})$ in width,

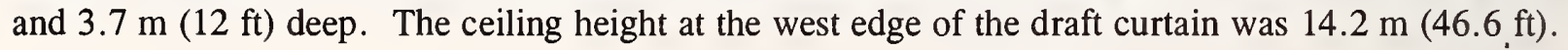

\subsubsection{Measurements - Fire Protection Devices}

A number of conventional fire detection and suppression devices were installed and monitored to determine their actual response characteristics when subjected to the experimental fires. The fire suppression devices were all standard spray upright sprinklers with a variety of temperature ratings, actuation mechanisms, and response time indexes.

The fire detection devices consisted of photoelectric smoke detectors, fixed temperature heat detectors, projected beam smoke detectors, combination ultraviolet/infrared optical flame detectors and line-type heat detectors.

\subsubsection{Sprinkler Installations}

In the $15 \mathrm{~m}$ high facility, nine types of standard spray upright sprinklers with a variety of temperature ratings, fusible elements, and response time indexes were installed and monitored to measure the activation time of each sprinkler head when subject to a range of experimental fires. The piping supplying the sprinkler heads was filled with water to simulate the heat sink associated with a wet-pipe sprinkler configuration. In addition, several sections of blank piping were used within the individual sprinkler trees to simulate a dry-pipe or pre-action sprinkler system. This was done in order to compare the activation times of sprinklers on a wet-pipe system versus a dry-pipe or pre-action system. The fires were designed to determine the threshold fire size for response of each sprinkler type. Each type of sprinkler head listed in Table 4 was selected because of its existing use or potential use in high bay applications.

Two parameters are used to rate sprinkler head sensitivity: activation temperature and response time index (RTI). NFPA 16A [2] and NFPA 409 [17] currently require that the temperature rating of sprinklers in hangars be within the "high" (79 to 107) ${ }^{\circ} \mathrm{C}$ or "extra high" $163{ }^{\circ} \mathrm{C}$ to $191{ }^{\circ} \mathrm{C}$ temperature range as defined by NFPA 13 [18]. Current Navy criteria require the use of sprinklers with a temperature rating of $141^{\circ} \mathrm{C}\left(286^{\circ} \mathrm{F}\right)$ [19]. Ambient air temperatures at the ceiling level of aircraft hangars can exceed $38^{\circ} \mathrm{C}\left(100^{\circ} \mathrm{F}\right)$. Therefore, the lowest temperature sprinkler that could be reasonably installed in an aircraft hangar is a $79{ }^{\circ} \mathrm{C}$ sprinkler which corresponds to the low end of the intermediate temperature range. (NFPA 13, Standard for the Installation of Sprinkler Systems, does not permit the use of ordinary temperature sprinklers (i.e., $57^{\circ} \mathrm{C}$ to $77^{\circ} \mathrm{C}$ ) in buildings where the maximum ceiling temperature exceeds $38^{\circ} \mathrm{C}$.)

Figure 7(a) shows the location of each of the 15 sprinkler trees. Figure 6(b) shows the combination of 
Runway Side

$73.8 \mathrm{~m}$

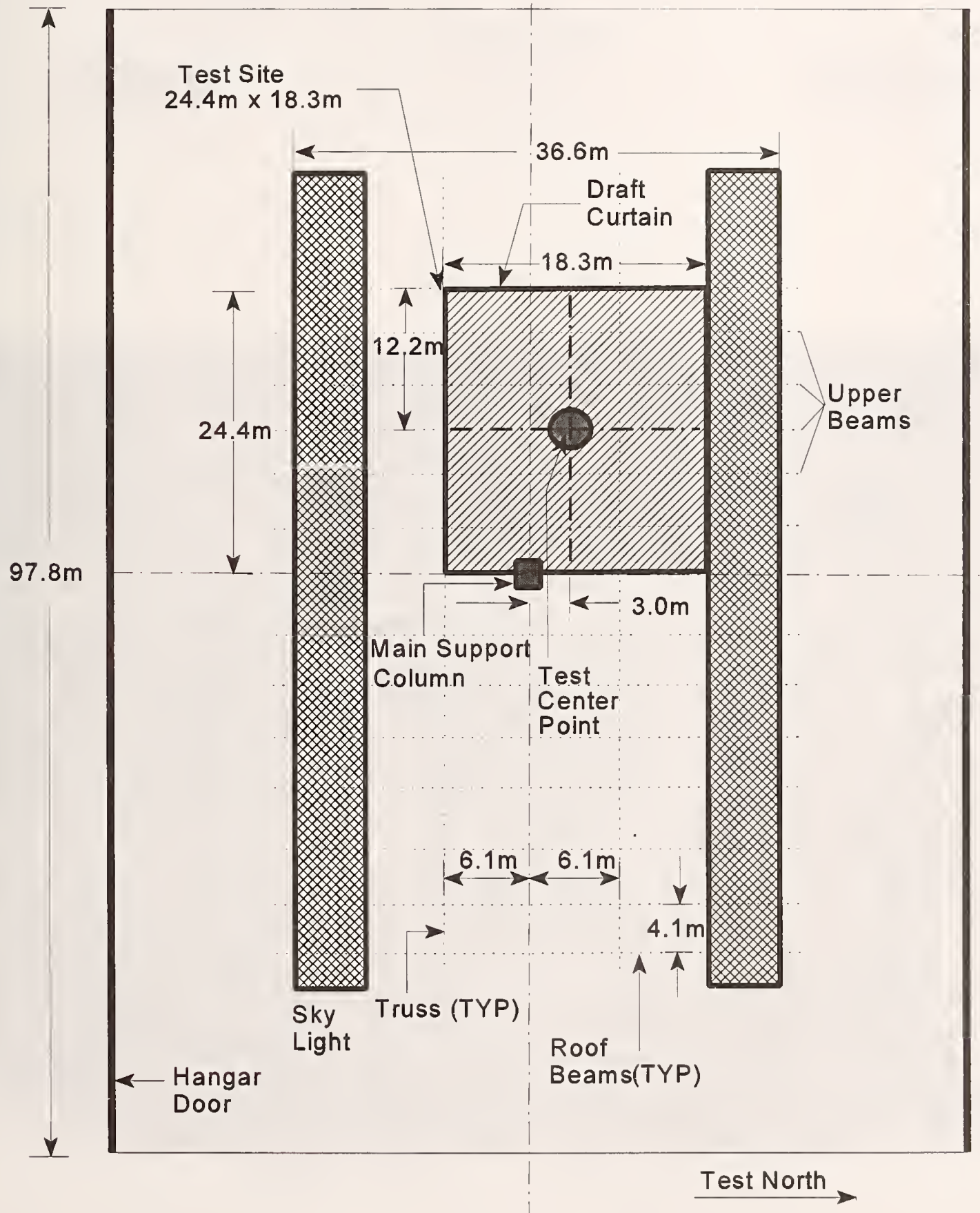

Street Side

Figure 4. Plan view of hangar bay, $15 \mathrm{~m}$ high facility. 


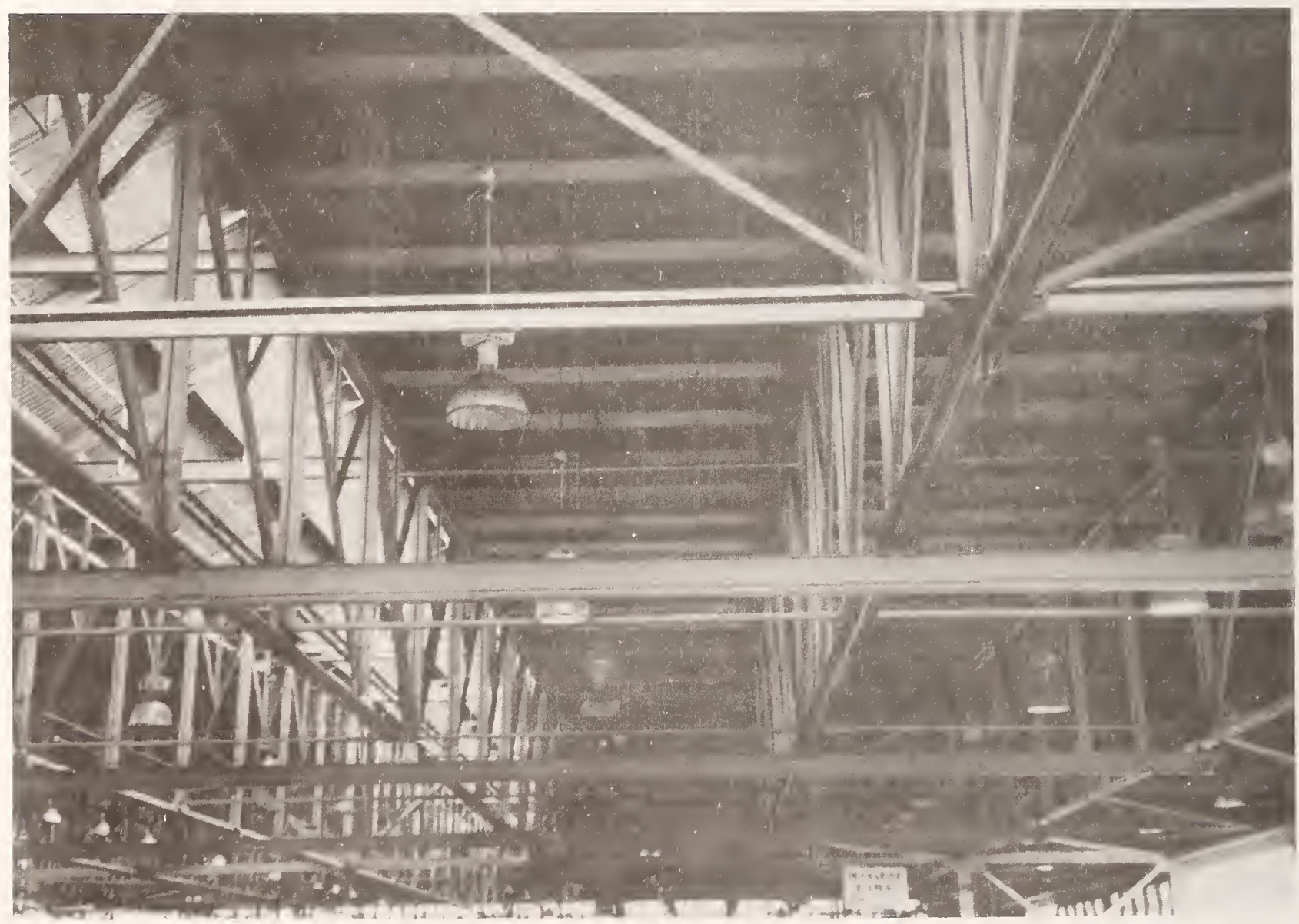

Figure 5. Photograph of ceiling structure, $15 \mathrm{~m}$ high facility. 


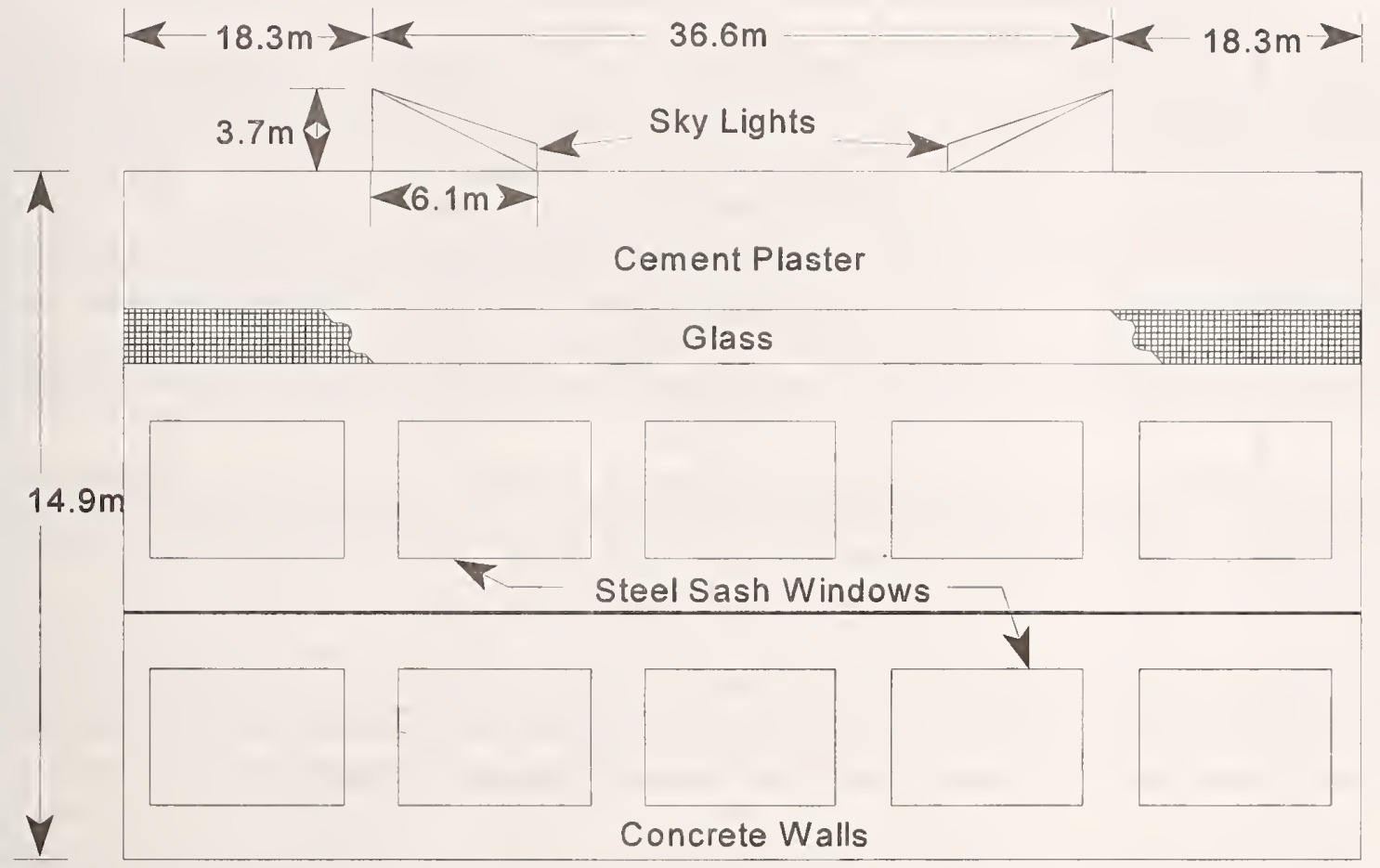

A.

A

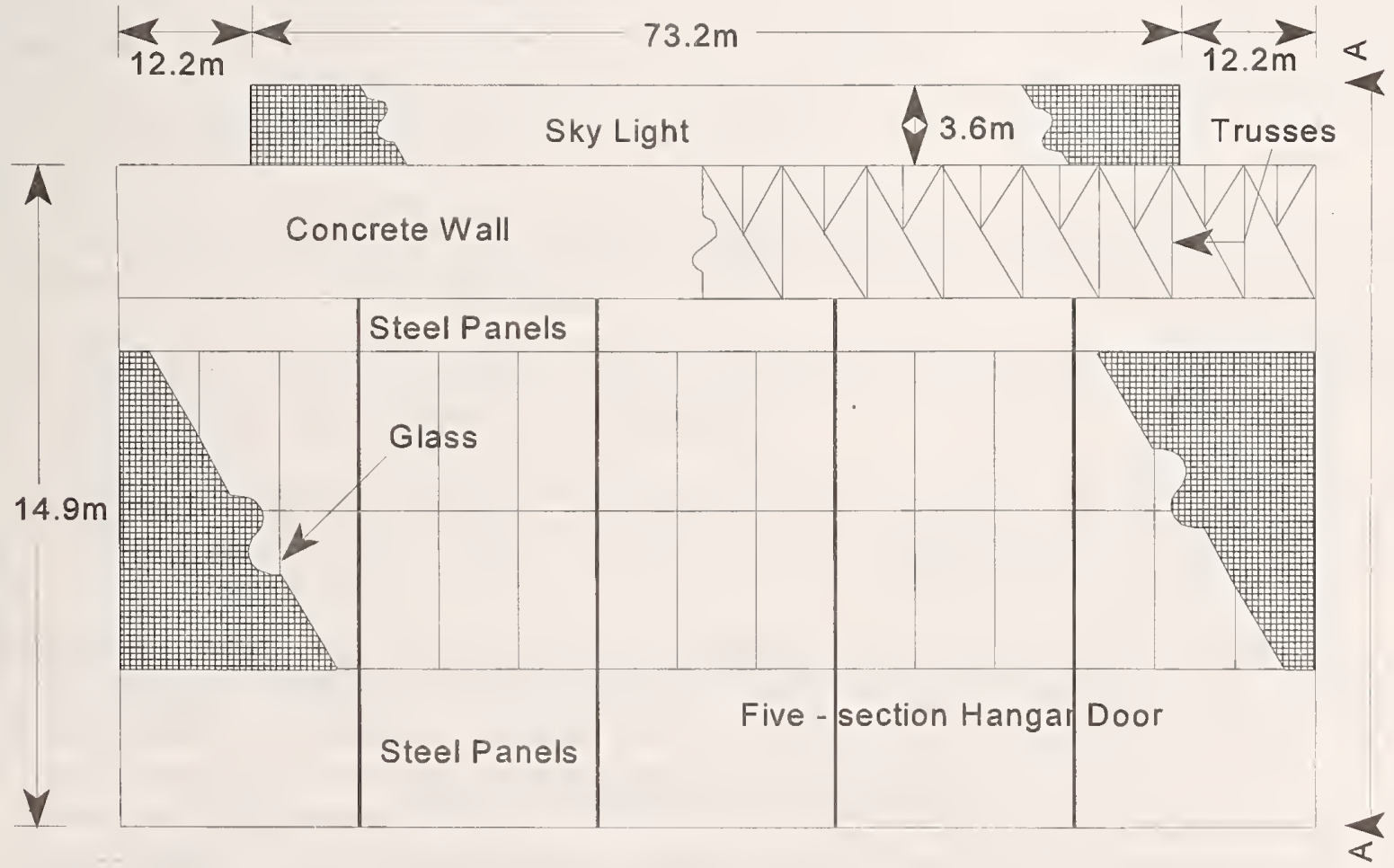

Figure 6. Elevation view of $15 \mathrm{~m}$ high facility. 
Table 4. Sprinkler types installed in $15 \mathrm{~m}$ high test area

\begin{tabular}{|c|c|c|c|c|}
\hline $\begin{array}{c}\text { Activation } \\
\text { Temperature } \\
{ }^{\circ} \mathrm{C}\end{array}$ & $\begin{array}{c}\text { Activation } \\
\text { Temperature } \\
{ }^{\circ} \mathrm{F}\end{array}$ & Description & $\begin{array}{c}\text { Piping } \\
\text { Configuration }\end{array}$ & $\begin{array}{c}\text { Response Time } \\
\text { Index, (RTI) } \\
\mathrm{m} \cdot \mathrm{s}^{\mathrm{s} / 2}\end{array}$ \\
\hline 79 & 175 & Quick Response Bulb & Wet & 35 \\
\hline 79 & 175 & Quick Response Bulb & Dry & 35 \\
\hline 79 & 175 & Standard Response Bulb & Wet & 188 \\
\hline 93 & 200 & Quick Response Bulb & Wet & 35 \\
\hline 141 & 286 & Quick Response Bulb & Wet & 35 \\
\hline 141 & 286 & Quick Response Bulb & Dry & 35 \\
\hline 141 & 286 & Standard Response Bulb & Wet & 188 \\
\hline 141 & 286 & Standard Response Link & Wet & 95 \\
\hline 182 & 360 & Standard Response Bulb & Wet & 188 \\
\hline
\end{tabular}

a NFPA 13 defines Response Time Index (RTI) as a measurable expression of the sensitivity, or responsiveness to temperature change, of the thermal sensing element of a sprinkler.

sprinkler types installed at each location. Each location contained a $141^{\circ} \mathrm{C}$ quick response bulb and $79{ }^{\circ} \mathrm{C}$ quick response bulb. The $141{ }^{\circ} \mathrm{C}$ head satisfies current Navy criteria, and the $79{ }^{\circ} \mathrm{C}$ head would provide the first sprinkler response. In addition, the sprinkler stations within $6.1 \mathrm{~m}$ of the plume also contained a $141{ }^{\circ} \mathrm{C}$ standard response bulb and a $141{ }^{\circ} \mathrm{C}$ standard response link. These provide a point of comparison between standard and quick response sprinklers, and bulb versus link fusible elements. In addition, sprinkler locations within $3.1 \mathrm{~m}$ of the plume also contained a $141{ }^{\circ} \mathrm{C}$ quick response bulb and a $79^{\circ} \mathrm{C}$ quick response bulb piped dry. This provides a point of comparison between similar sprinkler types on a wet-pipe or dry-pipe/pre-action configuration. The sprinkler station located over the center of the plume also contained a $79^{\circ} \mathrm{C}$ standard bulb and $182{ }^{\circ} \mathrm{C}$ standard bulb. The $79^{\circ} \mathrm{C}$ standard bulb provided a comparison with the quick response bulb of the same temperature rating. The $182{ }^{\circ} \mathrm{C}$ head was provided because NFPA 409 requires it for some hangars.

The sprinkler deflectors were installed approximately $300 \mathrm{~mm}$ to $360 \mathrm{~mm}$ below the ceiling deck. NFPA 13 states that under obstructed construction, the sprinkler deflector shall be located $25.4 \mathrm{~mm}$ to $152 \mathrm{~mm}$ (1 in. to $6 \mathrm{in}$.) below the structural members and a maximum distance of $559 \mathrm{~mm}$ (22 in.) below the ceiling/roof deck. Ball valves were installed on each riser nipple to isolate each sprinkler tree in order to prevent head pressure effects from sprinkler assemblies at higher elevations, and to make the filling process more efficient.

Individual sprinkler heads were installed on the sprinkler trees using 1 inch tee fittings. Each sprinkler tree represented the location of a single sprinkler head in a typical hangar installation. Because the response of various sprinklers was being monitored at each sprinkler tree location, the spacing between heads on each tree was limited to $203 \mathrm{~mm}$ ( 8 in). This minimum separation between sprinkler heads was needed to eliminate the risk of wetting adjacent heads after activation, thus affecting activation times. The vent port also allowed any buildup of pressure to escape during the test. Although there was water in the sprinkler supply piping, the control valves were shut off to prevent water from being 
discharged during the experiments.

The sprinkler piping was installed in accordance with NFPA 13 by a local sprinkler contractor. Cross mains, which were hung from support beams parallel to the floor, consisted of $1 \frac{1 / 2}{2}$ inch schedule 40 galvanized pipe with a main drain/fill line attached to a central water supply in the hangar. From these cross mains, riser nipples were installed to supply water to the individual sprinkler trees. A sprinkler tree consisting of numerous sprinkler heads was attached to the top of each riser nipple. The riser nipples were placed at $3 \mathrm{~m}$ intervals originating from the center of the test area as shown in Figure 8 . Consequently, the spacing between sprinkler trees was roughly $3 \mathrm{~m}(9.3 \mathrm{ft})$. The spacing between sprinkler trees was selected to simulate the spacing between sprinklers in a typical hangar installation.

Figure 9 shows a diagram of the typical valve and wiring connections for a sprinkler tree. A union fitting was installed above the ball valve on each riser nipple to facilitate installation and removal of the sprinkler trees. Each sprinkler tree included a vent port to relieve pressure, and purge trapped air from the line.

The time to activation for each sprinkler head was measured and recorded. Figure 9 shows the method used in brief detail. A standard paper clip was inserted between the fusible element and the sprinkler arm. Wires were then attached to the clip and to a central grounding point on the sprinkler tree. All sprinkler heads were monitored on four 16-bit digital I/O cards located inside the data acquisition system. With the sprinkler's fusible element in place, electrical continuity was established, thus appearing as a closed switch or logic " 0 " to the digital $\mathrm{I} / \mathrm{O}$ board. Upon activation, the fusible element would shatter or dislodge and the paper clip would pull away from the sprinkler, thus breaking the circuit. This action was recorded when the logic bit for the sprinkler went to a high or logic " 1 " state. It was important to make sure the clip would pull away completely from the sprinkler; therefore, small weights were used to provide additional load to the clip/wire assembly. The $7 \mathrm{~g}$ weights were placed approximately $150 \mathrm{~mm}$ ( $6 \mathrm{in}$.) behind the clip and the wire leads were fastened so the clip was allowed to swing away and clear from any grounded object in the area.

The data collection rate for the sprinkler activation time measurement was approximately $0.25 \mathrm{~Hz}$. Provided the clip/wire assembly activated freely, the time of activation was measured within $4 \mathrm{~s}$ to $8 \mathrm{~s}$ after actual activation. Each sprinkler head was visually inspected between tests to determine if any activations occurred that were not recorded by the data acquisition system. All sprinkler heads that activated were replaced between tests. Any sprinkler head that did not activate during the previous tests was inspected and cleaned prior to the next test fire.

All sprinkler heads and piping assemblies were supplied and installed by the Viking Corporation on behalf of the automatic sprinkler industry. NIST was responsible for the data collection and the installation of the wiring used to monitor the activation of the sprinkler heads. In cases where the activation of a sprinkler head was not recorded by the data collection system, representatives from Viking Corporation reported any additional sprinkler activations based on visual inspection at the end of each experiment.

\subsubsection{Smoke and Heat Detector Installations}

The instrumentation included photoelectric smoke detectors and electronic heat detectors connected to an addressable fire alarm control panel via signaling line circuits wired in the Style 4 configuration as 


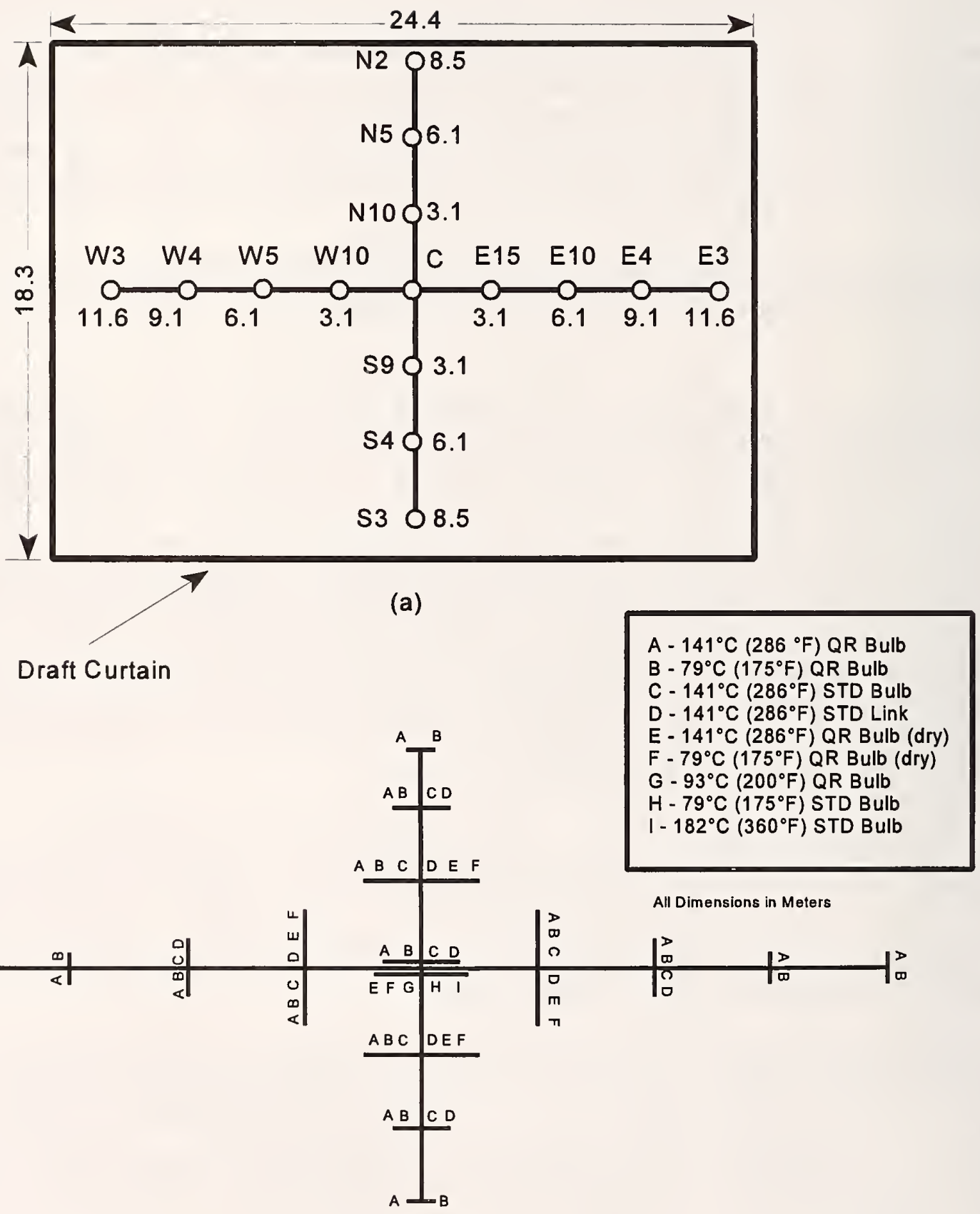

(b)

Figure 7. Individual sprinkler locations within $15 \mathrm{~m}$ high test area. 


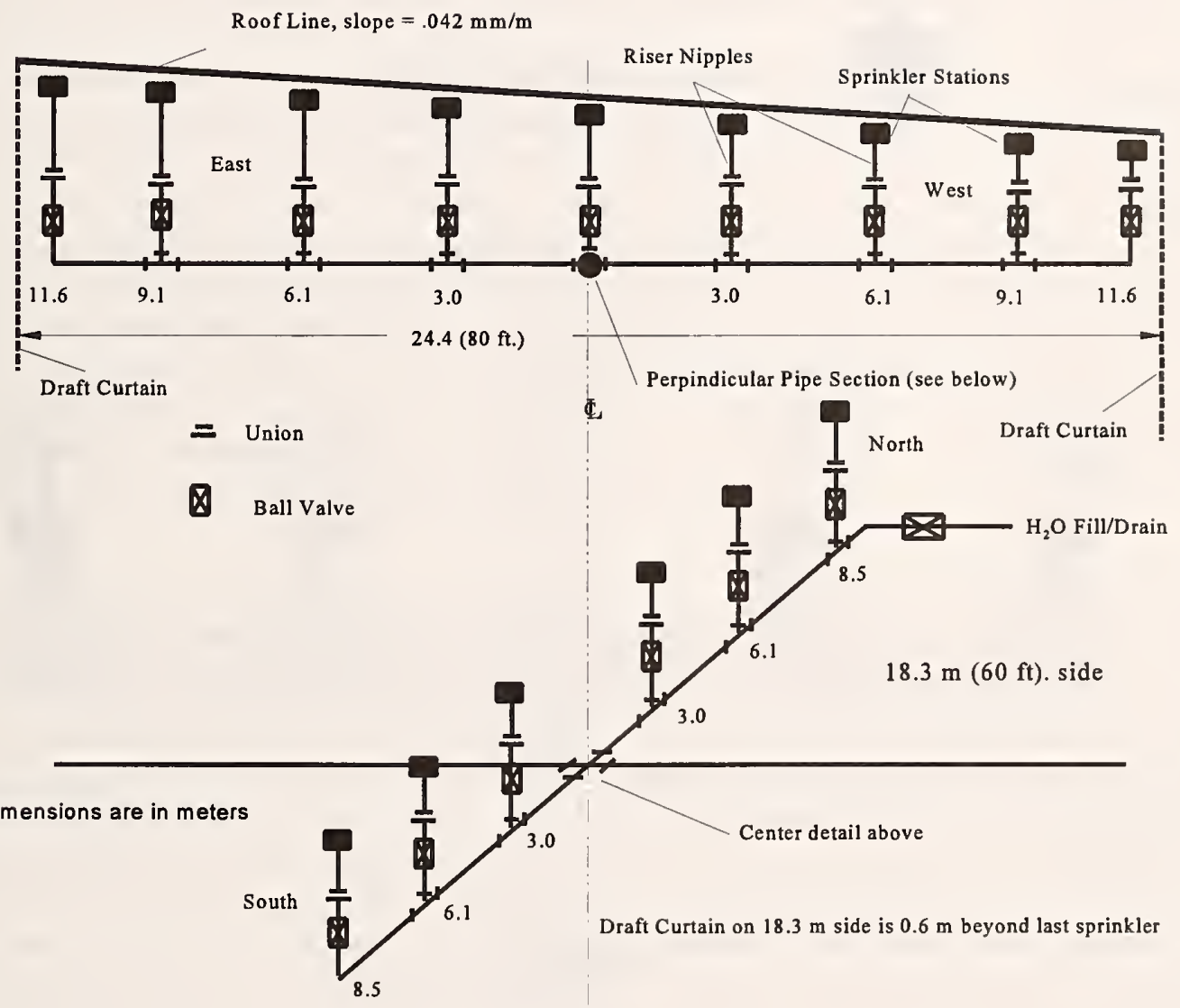

Figure 8. Sprinkler locations within $15 \mathrm{~m}$ facility test area. 


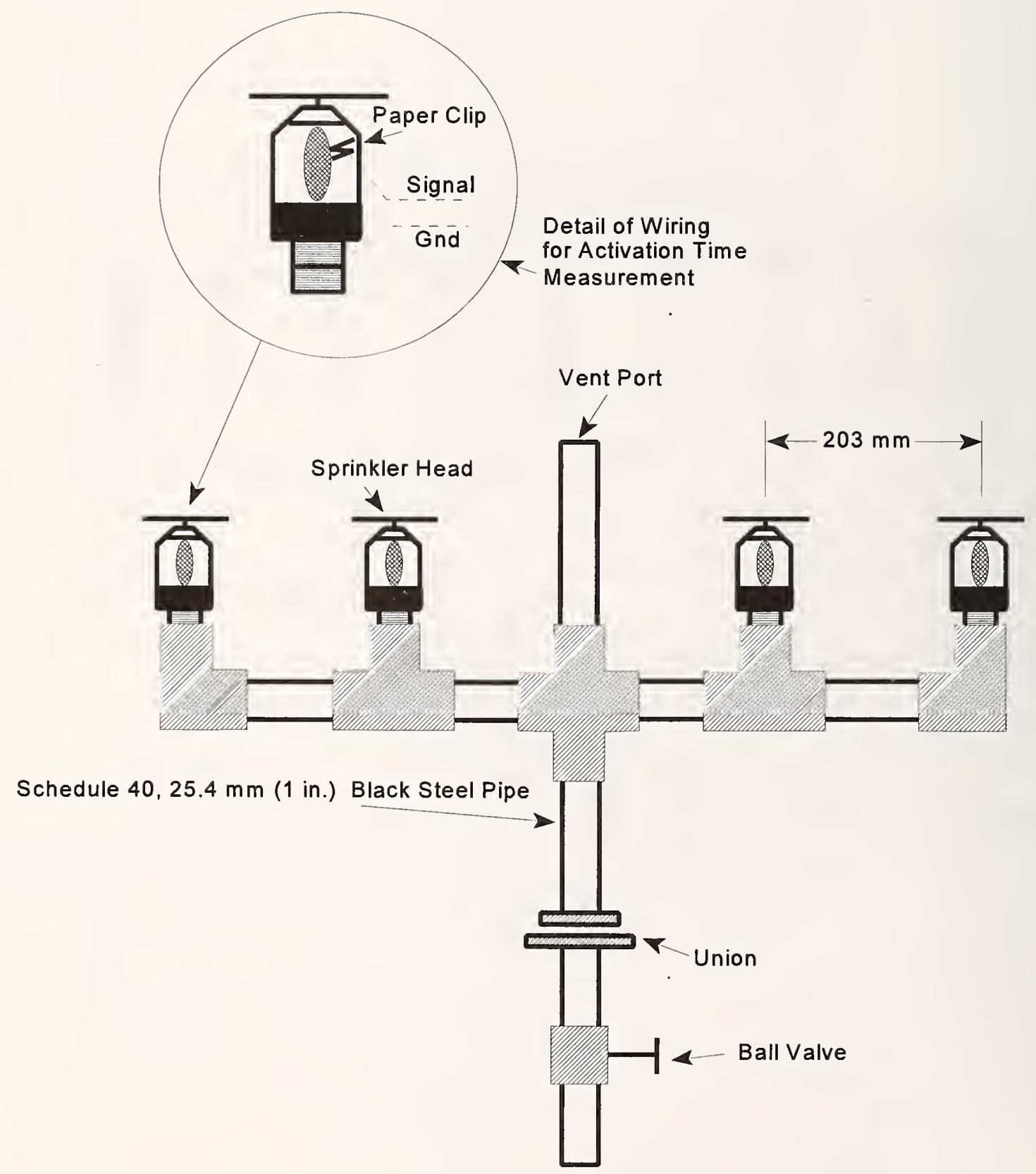

Figure 9. Diagram of typical sprinkler tree with activation time measurement. 
defined in NFPA 72, National Fire Alarm Code [20]. The rate compensation heat detectors were installed because they satisfy the Navy's existing criteria for hangar detection systems at the time these experiments were conducted. Although photoelectric smoke detectors are typically not installed in aircraft hangars, they were installed in these tests to document their response time with respect to heat detectors and projected beam detectors, and to aid in the analysis of possible stratification effects.

The photoelectric smoke detectors were analog addressable spot type detectors which operate according to the light scattering principle. These detectors contain a pulsed LED and silicone photodiode receiver arranged so that light does not fall on the receiver. When smoke particles enter the light path, light strikes the particles and is scattered onto the photosensitive receiver, causing the detector to respond. The detector sends an analog value representative of smoke concentration to the fire alarm control panel. Alarm conditions correspond to a predetermined threshold in the software algorithms. The panel recognizes this threshold value and responds by going into alarm status. The sensitivity setting selected for each smoke detector was $8.2 \%$ per meter $(2.5 \%$ per foot) of smoke obscuration.

The electronic heat detectors were analog addressable spot type detectors which were programmed to operate as fixed temperature heat detectors with an alarm threshold of $57.2^{\circ} \mathrm{C}\left(135^{\circ} \mathrm{F}\right)$. Although this type of detector is also capable of operating as a combination rate-of-rise/fixed temperature detector, each was programmed to operate only as a fixed temperature device. Because this type of detector employs a non-metallic thermistor, it experiences little thermal lag and satisfies the UL 268 requirements for listing as a rate compensation heat detector [21]. A rate compensation detector is a device that responds when the temperature of the surrounding air reaches a predetermined level, regardless of the rate of temperature rise. The sensor sends an analog value (in a digital communications format) to the fire alarm control panel where the software algorithms are applied. When the analog value received from a particular detector corresponds to a predetermined alarm threshold, the fire alarm panel responds by going into alarm status.

There were 18 detector stations each consisting of a smoke detector and a heat detector mounted to a plywood board. The plywood board was suspended from conduit which was clamped to the underside of the I beams supporting the metal roof deck. Given that the ratio of the beam depth to ceiling height was less than 0.1 , and that the ratio of the beam spacing to the ceiling height was less than 0.4 , the detectors were installed at the same elevation as the bottom of the beams which was $0.25 \mathrm{~m}$ (10 in) below the ceiling deck. The location of the detector stations with respect to the fire plume is shown in Figure 10. The heat and smoke detectors at detector station number 14 did not respond during any of the experiments because they could not be mounted at the ceiling level due to the configuration of the skylight. NFPA 72 [20] offers little guidance on the spacing of spot type detection devices in buildings of this height. However, NFPA 72, Table 5-2.7.1.2 indicates that the spacing of heat detectors for ceiling heights up to $9.14 \mathrm{~m}$ (30 ft) should be reduced to $34 \%$ of their listed spacing. Using that as a general guideline, the spacing of detector stations was reduced to $3.0 \mathrm{~m}(10 \mathrm{ft})$. The detectors were only installed along the north/south and east/west axes with respect to the center line of the fire plume. Where a proposed detector location occurred directly at the intersection of the draft curtain and the

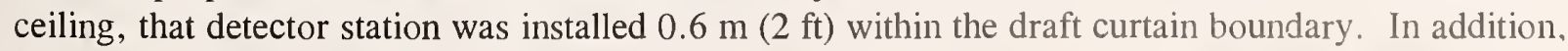

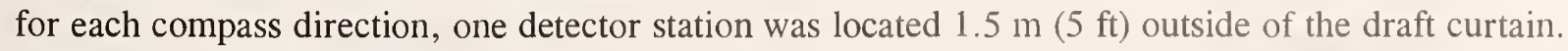
Installation, calibration and test data from the smoke and heat detectors were provided by Simplex Time Recorder Co., on behalf of the detector industry. Data were collected at the addressable fire alarm control panel at a scan rate of approximately $1 \mathrm{~Hz}$. 


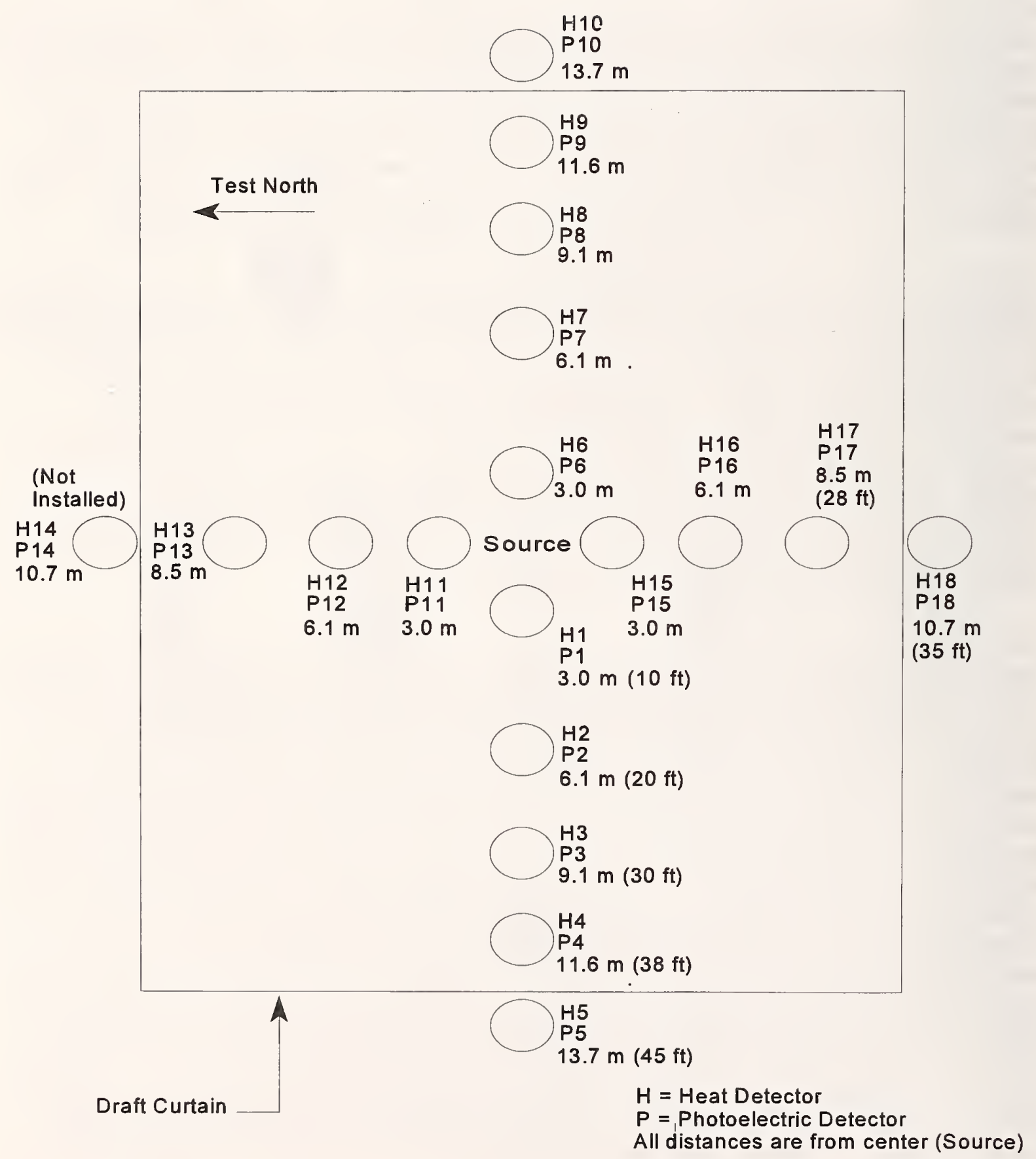

Figure 10. Heat and smoke detector locations, plan view, $15 \mathrm{~m}$ high facility. 


\subsubsection{Projected Beam Smoke Detector Installations}

Projected beam smoke detection systems are photoelectric smoke detectors that consist of separate

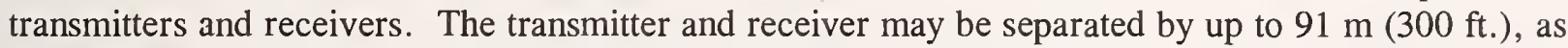
long as they retain linear alignment. The light source in the transmitter produces an invisible infrared beam that is measured by the receiver to determine obscuration caused by smoke. If the beam intensity falls below an alarm threshold and remains there for preset length of time, a fire alarm is initiated. If complete beam blockage occurs, a trouble output is generated rather than a fire alarm. The receiver will wait a preset length of time after the beam is blocked before signaling a trouble. This prevents moving objects (i.e., cranes, lifts, etc.) from causing trouble signals. Gradual loss of signal due to dust/dirt build-up and other long-term effects is automatically compensated for by the receiver up to a point where the signal has been reduced by $50 \%$. When $50 \%$ of the signal is lost, the receiver will indicate a trouble [22].

The sensitivity is set at the receiver. The setting choices are between 2 and 7 representing a $20 \%$ to $70 \%$ decrease in signal strength. As distance increases, less dense smoke is required to obscure the same percentage of signal. UL268 Standard for Safety, "Smoke Detectors For Fire Protective Signaling Systems," specifies that a projected beam smoke detector shall not activate with less than $0.65 \%$ per meter $(0.2 \%$ per foot) obscuration of its light beam [21]. This represents the maximum sensitivity setting (the least amount of smoke that will activate the detector). UL268 also specifies minimum sensitivities as a function of distance (the most amount of smoke that can be present before the detector activates). UL268 states the detector shall activate when the light it transmits through clear air is obscured by smoke by the following amounts:
a. equal to $6.5 \%$ per meter ( $2 \%$ per foot) of length of its light beam for lengths of $6.7 \mathrm{~m} \mathrm{(22}$
$\mathrm{ft}$ ) or less;
b. not more than $36 \%$ total obscuration of its light beam for lengths of $6.7 \mathrm{~m}$ to $13.4 \mathrm{~m} \mathrm{(22 \textrm {ft }}$ to $44 \mathrm{ft}$ ); or
c. equal to $3.3 \%$ per meter ( $1 \%$ per foot) of its light beam for lengths of more than $13.4 \mathrm{~m}$ $(44 \mathrm{ft})$.

The relationship between the percent obscuration per meter $\left(\mathrm{O}_{\mathrm{u}}\right)$, the attenuation of the light beam due to obscuration $\left(\mathrm{T}_{\mathrm{s}} / \mathrm{T}_{\mathrm{c}}\right)$, and the distance between the transmitter and the receiver can be calculated using the following formula:

$$
O_{u}=\left[1-\left(\frac{T_{s}}{T_{r}}\right)^{\frac{1}{d}}\right] \times 100
$$

where: $T_{s}=$ transmission in smoke (signal strength in volts)

$$
\begin{aligned}
& \mathrm{T}_{\mathrm{c}}=\text { transmission in clean air (signal strength in volts) } \\
& \mathrm{d}=\text { distance between transmitter and receiver }(\mathrm{m})
\end{aligned}
$$

Adapted from UL268, Figure 11 compares the distance between transmitter and receiver and smoke densities per unit length. The family of curves is generated by solving for $\mathrm{O}_{\mathrm{u}}$ for a range of detector sensitivities from $20 \%$ to $70 \%$ and separation distances from $10 \mathrm{~m}$ to $100 \mathrm{~m}$. The horizontal lines shown in this figure are the U.L. specified maximum and minimum allowable sensitivity thresholds for this type of detector. For example, at a $40 \%$ sensitivity setting, $\mathrm{T}_{\mathrm{s}} / \mathrm{T}_{\mathrm{c}}=0.6$. Given a separation 


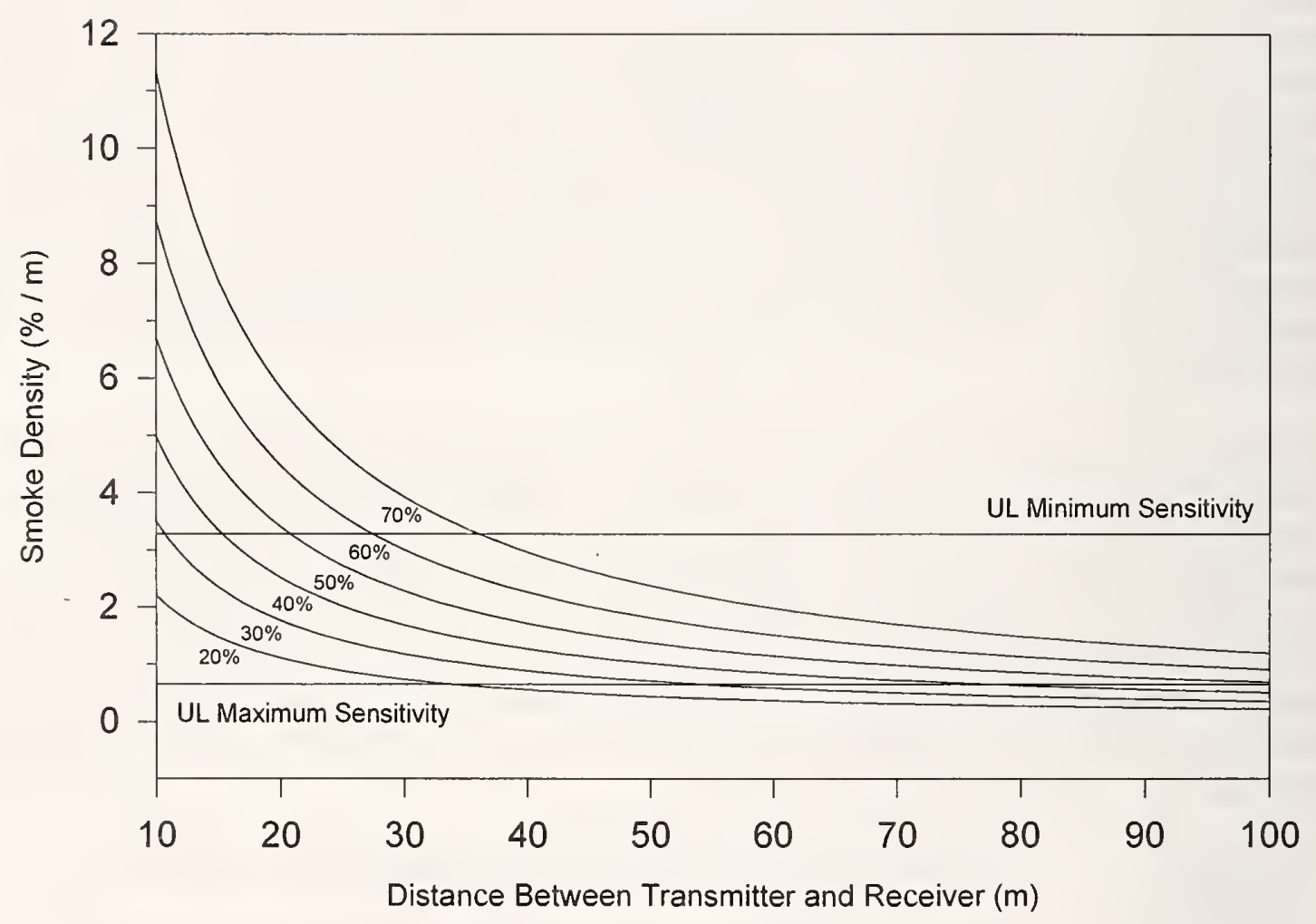

Figure 11. Smoke density as it relates to detector/transmitter separation distance.

distance of $40 \mathrm{~m}$, the resulting smoke density needed to produce an alarm condition is $1.3 \%$ per meter.

One logic feature of the projected beam detectors is a "window." The window is the time the signal must remain below the preset sensitivity level before an alarm is generated. At present the U.L. approved window is 30 seconds (this is based on ordinary combustible fire loads and not jet fuels). This setting requires the detector signal to drop below the preset threshold for 30 seconds without exceeding $90 \%$ signal loss before an alarm can be generated. The window for a trouble alarm is 20 seconds. If the signal loss is greater than $90 \%$ for more than 20 seconds, a trouble condition will be generated. For some of the experiments conducted in the $15 \mathrm{~m}$ facility, the fire alarm window setting was decreased to 5 seconds. This setting was used to determine the difference in response of the optical beam detectors with a shorter window time. However, this window setting is not currently U.L. approved. Sensitivity and window settings for each experiment are specified in Table 5.

Because the slope of the $15 \mathrm{~m}$ high ceiling was not greater than 0.125 , the ceiling was treated as a flat ceiling [20]. The projected beam detectors ran perpendicular to the $0.25 \mathrm{~m}$ (10 in) deep I-beams supporting the roof. These detectors have a listed spacing of $18.3 \mathrm{~m}(60 \mathrm{ft})$. In addition, the 
manufacturer's guidelines recommend a minimum separation distance between transmitter and receiver of $9.1 \mathrm{~m}(30 \mathrm{ft})$.

A total of nine projected beam smoke detectors were installed in the $15 \mathrm{~m}$ facility as shown in Figure 12. Detectors were installed at three elevations, $0.3 \mathrm{~m}(1 \mathrm{ft}), 2.7 \mathrm{~m}(9 \mathrm{ft})$, and $5.8 \mathrm{~m}(19 \mathrm{ft})$ below the ceiling with their beams directed parallel to the ceiling. The $0.3 \mathrm{~m}$ and $2.7 \mathrm{~m}$ elevations were above the bottom of the draft curtain. The $5.8 \mathrm{~m}$ elevation was below the level of the draft curtain which had a depth of $3.7 \mathrm{~m}(12 \mathrm{ft})$. Three detectors were installed at each elevation, and were spaced $7.0 \mathrm{~m}(23 \mathrm{ft})$

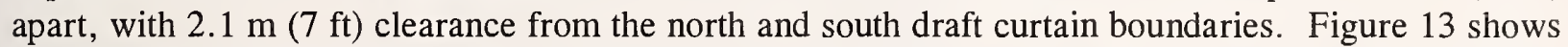
the detector locations within the overall plan view of the hangar. For tests 1 through 8 , the projected beam detectors spanned the length of the draft curtain which was $24.4 \mathrm{~m}(80 \mathrm{ft})$. Because the light beam widens as the distance between the transmitter and receiver is increased, the transmitters and receivers were staggered on adjacent levels so the signals would not interfere with each other. This installation was in accordance with NFPA 72 [20] and the manufacturer's installation requirements [23]. All detectors were wired in a style A configuration as defined in NFPA 72.

For tests 9 through 13, the lower row of beam detectors were relocated. These tests were all conducted without the draft curtain in place. A transmitter (T7) was installed on the far east wall of the aircraft hangar. The three receivers (R7, R8, R9) were relocated to the center of the far west wall of

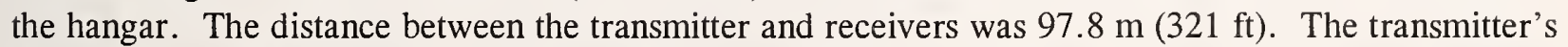
signal (T7) was wide enough at this distance to be received by all three receivers which were mounted adjacent to each other. The transmitter and associated receivers were installed $1.8 \mathrm{~m}(6 \mathrm{ft})$ below the ceiling. The receivers were all set at a sensitivity of $50 \%$; however, the window settings for R7, R8 and $\mathrm{R} 9$ were $30 \mathrm{~s}, 10 \mathrm{~s}$ and $5 \mathrm{~s}$ respectively.

Installation, calibration, and test data were provided to NIST by Detection Systems Inc., on behalf of the smoke detector industry. The detectors were hard-wired to the direct zones on the Simplex fire alarm control panel, and wired in the Class B, Style B format as defined by NFPA 72. Data were collected through the Simplex fire alarm panel at a scan rate of less than $1 \mathrm{~Hz}$. Also, the analog data from each detector were recorded on a data logging system provided by Detection Systems Inc. The scan rate in this case was approximately $1.25 \mathrm{~Hz}$. The lenses of all the detectors were cleaned after test number six. In all other cases, the beam detectors reset themselves [24].

\subsubsection{Combination UV/IR Optical Flame Detectors}

Optical flame detectors are used in aircraft hangars to provide prompt detection of a jet fuel fire which may be located beneath the wing of an aircraft. UV/IR detectors are generally mounted just below the wing height of the smallest aircraft in the hangar. This height usually corresponds to $1.8 \mathrm{~m}$ to $3.7 \mathrm{~m}$ above the floor. Combination UV/IR detectors are the most prominent optical detectors used in aircraft hangars because of their ability to quickly respond to a flaming fire. The ability to avert false alarms give the combination UV/IR detectors an advantage over individual UV and IR optical detectors. For example, individual UV detectors are subject to false alarms from arc welding and lightning.

Individual IR detectors are subject to false alarms from hot body radiation such as a hot engine. In this type of combination detector, both the UV and IR detector heads must independently go into alarm before a fire alarm signal is initiated. However, combination detectors can be blinded. Oil and dirt will blind UV detectors, while ice, water films, and certain vapors blind IR detectors. 
3 WARM Climate - 15 M FACILITY

Table 5. Sensitivity and window settings for projected beam smoke detectors

\begin{tabular}{|c|c|c|c|c|}
\hline Test No. & $\begin{array}{c}\text { Projected } \\
\text { Beam \# }\end{array}$ & $\begin{array}{c}\text { Receiver/ } \\
\text { Transmitter Pair }\end{array}$ & $\begin{array}{l}\text { Sensitivity } \\
\text { (\% signal loss) }\end{array}$ & Window Settings (s) \\
\hline \multirow[t]{9}{*}{$1-4$} & B1 & $\mathrm{R} 1 / \mathrm{T} 1$ & 30 & 30 \\
\hline & B2 & $\mathrm{R} 2 / \mathrm{T} 2$ & 30 & 30 \\
\hline & B3 & $\mathrm{R} 3 / \mathrm{T} 3$ & 30 & 30 \\
\hline & B4 & $\mathrm{R} 4 / \mathrm{T} 4$ & 30 & 30 \\
\hline & B5 & $\mathrm{R} 5 / \mathrm{T} 5$ & 30 & 30 \\
\hline & B6 & $\mathrm{R} 6 / \mathrm{T} 6$ & 30 & 30 \\
\hline & B7 & $\mathrm{R} 7 / \mathrm{T} 7$ & 30 & 30 \\
\hline & B8 & $\mathrm{R} 8 / \mathrm{T} 8$ & 30 & 30 \\
\hline & B9 & R9/T9 & 30 & 30 \\
\hline \multirow[t]{9}{*}{$5-8$} & B1 & $\mathrm{R} 1 / \mathrm{T} 1$ & 30 & 30 \\
\hline & B2 & $\mathrm{R} 2 / \mathrm{T} 2$ & 30 & 30 \\
\hline & B3 & $\mathrm{R} 3 / \mathrm{T} 3$ & 30 & 30 \\
\hline & B4 & $\mathrm{R} 4 / \mathrm{T} 4$ & 20 & 5 \\
\hline & B5 & R5/T5 & 20 & 5 \\
\hline & B6 & R6/T6 & 20 & 5 \\
\hline & B7 & $\mathrm{R} 7 / \mathrm{T} 7$ & 30 & 30 \\
\hline & B8 & $\mathrm{R} 8 / \mathrm{T} 8$ & 30 & 30 \\
\hline & B9 & R9/T9 & 30 & 30 \\
\hline \multirow[t]{9}{*}{$9-13$} & B1 & $\mathrm{R} 1 / \mathrm{T} 1$ & 30 & 30 \\
\hline & B2 & $\mathrm{R} 2 / \mathrm{T} 2$ & 30 & 30 \\
\hline & B3 & $\mathrm{R} 3 / \mathrm{T} 3$ & 30 & 30 \\
\hline & B4 & $\mathrm{R} 4 / \mathrm{T} 4$ & 20 & 5 \\
\hline & B5 & $\mathrm{R} 5 / \mathrm{T} 5$ & 20 & 5 \\
\hline & B6 & R6/T6 & 20 & 5 \\
\hline & B7 & $\mathrm{R} 7 / \mathrm{T} 7$ & 50 & 30 \\
\hline & B8 & $\mathrm{R} 8 / \mathrm{T} 7$ & 50 & 10 \\
\hline & B9 & $\mathrm{R} 9 / \mathrm{T} 7$ & 50 & 5 \\
\hline
\end{tabular}




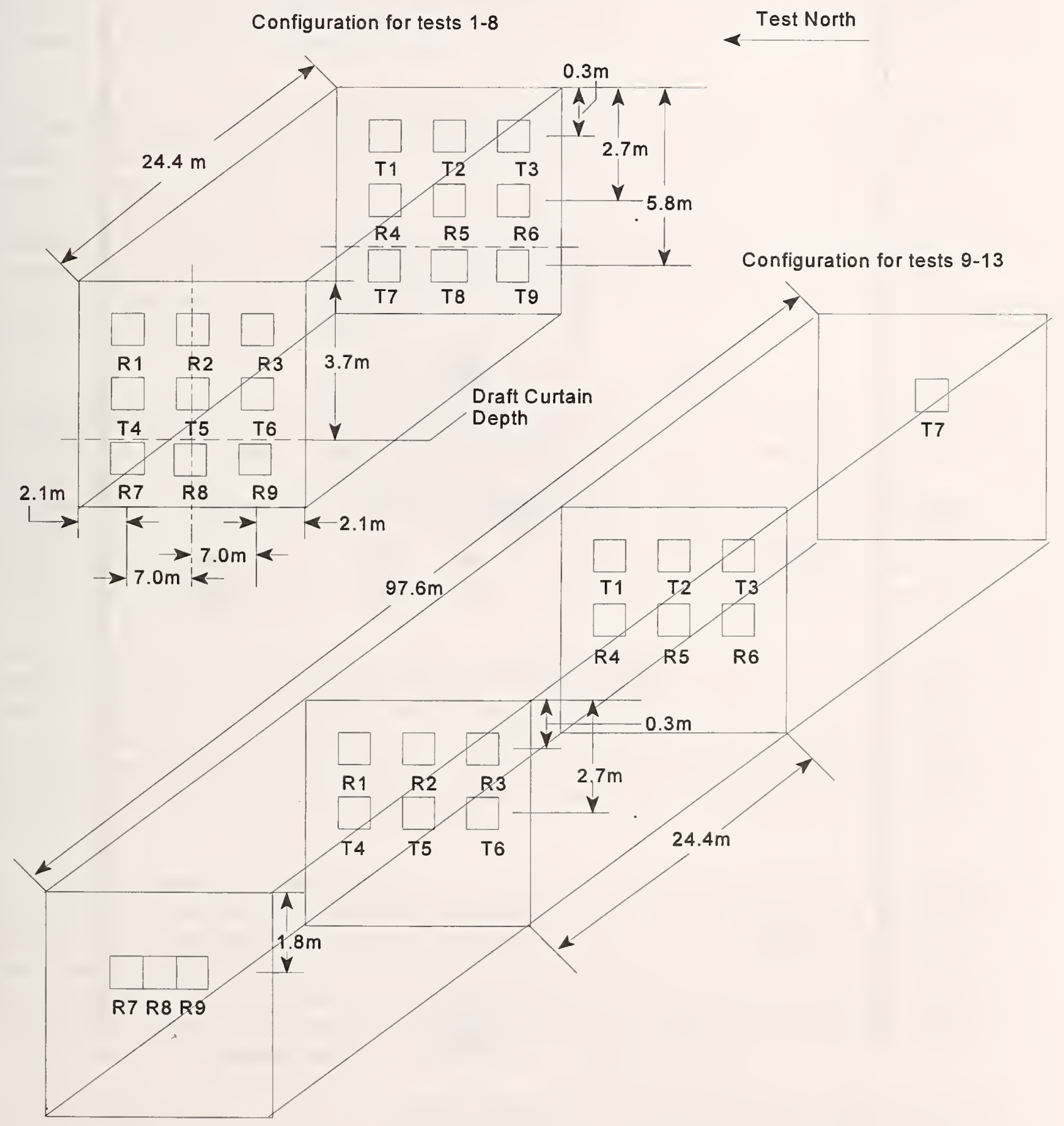

Figure 12. Locations of projected beam smoke detectors, $15 \mathrm{~m}$ high facility. 


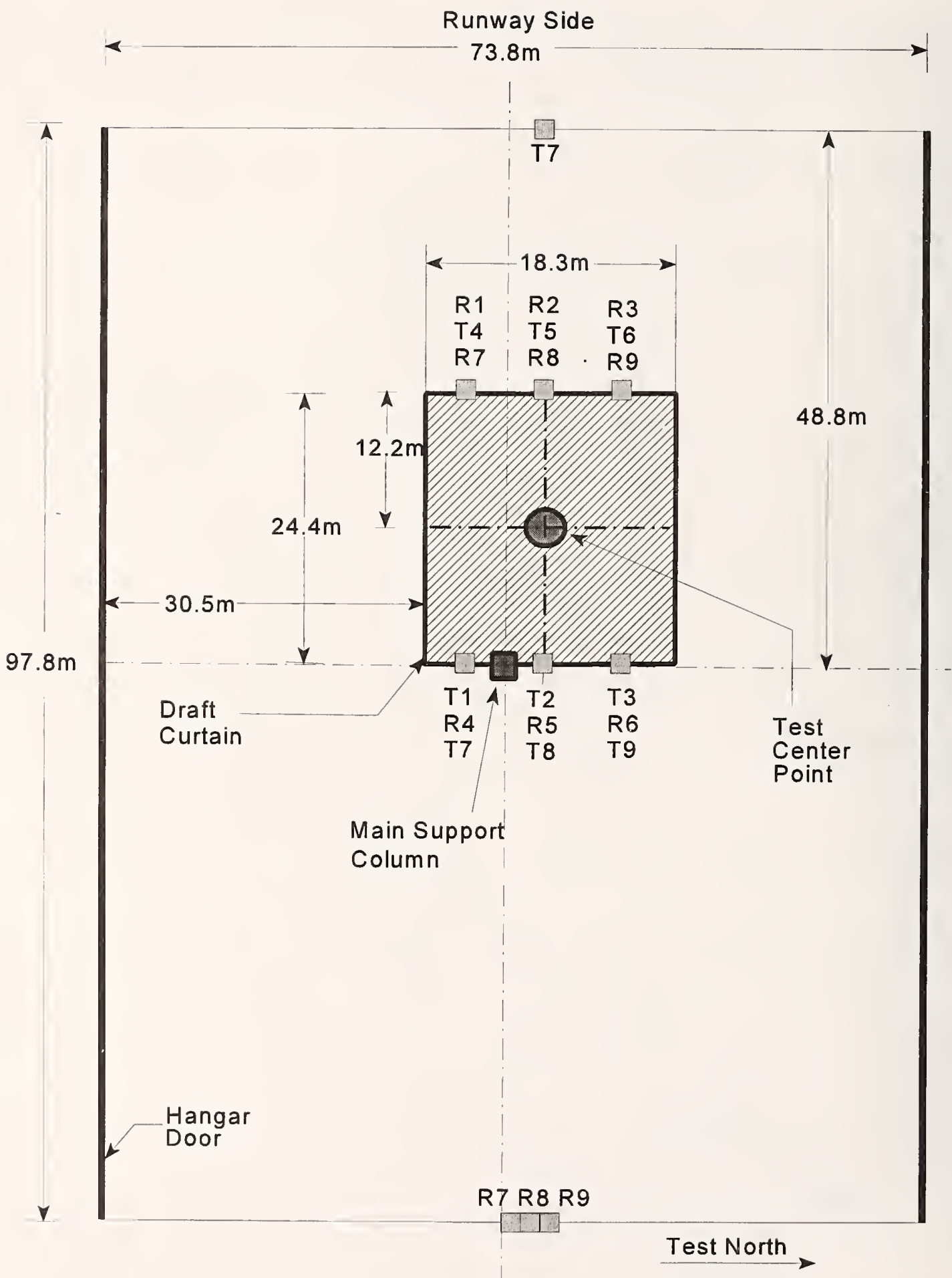

Street Side

Figure 13. Plan view of projected beam smoke detectors, $15 \mathrm{~m}$ high facility. 
The UV portion of the combination detector utilizes an ultraviolet (Geiger-Muller) flame detector tube. The UV sensor responds to high energy radiation with wavelengths from 0.185 to $0.245 \mu \mathrm{m}$. Ultraviolet radiation from the flame strikes the cathode of the gas-filled sensor tube, and a discharge of electrons is initiated towards the anode. The flow of current induced by the radiation creates a charge/discharge action through a series $\mathrm{RC}$ circuit, thus producing electrical pulses at the output. The more intense the incoming radiation, the higher the pulse rate. The tube discharge or pulse rate is measured in counts per second (CPS). The CPS output is compared to a preset alarm threshold, and if exceeded, a UV fire alarm output is initiated.

The IR portion of the detector utilizes a single frequency infrared flame detector. Infrared radiation from the fire is transmitted through optical filters that allow only $4.4 \mu \mathrm{m}$ energy to pass. The filtered infrared radiation is detected by a pyroelectric infrared sensor. The sensor converts the filtered infrared energy to a DC millivolt signal. Modulation or flicker of the DC signal is required in order for further signal processing to occur [25]. Like the UV portion of the detector, the pulse rate is measured in CPS which will produce an IR fire alarm at the controller once the CPS exceeds a preset alarm threshold. To compensate for the quiescent output level of the IR detector, the controller subtracts 1 count from the IR input every $62.5 \mathrm{~ms}$ (i.e., 16 counts per second). The counts are never allowed to be fall to a negative value.

The controller receives the electrical pulses (i.e., counts) from the UV and IR sensors and compares those signals to the preset sensitivity to determine if a fire exists. The controller allows the user to set the thresholds for gate length, counts per gate, and number of consecutive gates required to initiate an alarm. The "gate length" is the increment of time the controller looks at the detector signal to determine if the "counts per gate" requirement is fulfilled. The "counts per gate" are the actual number of electrical pulses received from both the UV and IR sensors within the established gate length. The "number of consecutive gates" is the number of gates which the controller must see the actual counts per gate requirement fulfilled consecutively in order to recognize an alarm threshold.

These combination UV/IR detectors are also available in a unitized configuration. The unitized UV/IR detectors only allow the user to change the response time of the detector between 0.5 seconds and 3 seconds. The choice of settings on the unitized detectors translates to either $0.125 \mathrm{~s}$ gate length, 2 counts per gate and 3 consecutive gates (i.e., roughly $0.5 \mathrm{~s}$ response time); or $0.125 \mathrm{~s}$ gate length, 2 counts per gate and 24 consecutive gates (i.e., $3 \mathrm{~s}$ response time). Controller-based detectors were selected because they allow the user a greater degree of flexibility when setting the sensitivity of the detectors.

Two settings chosen for the experimental fires: $0.25 \mathrm{~s}$ gate length, 2 counts per gate and 3 consecutive gates; and $0.25 \mathrm{~s}$ gate length, 4 counts per gate and 4 consecutive gates. Table 6 shows the controller settings for each experiment. Each UV/IR detector was scanned at a rate of $10 \mathrm{~Hz}$. Although combination detectors were used, the analog CPS data were collected for each UV and IR detector head independently. Consequently, an analysis of the CPS data will show when each UV or IR head individually reached its alarm threshold. These data can also be analyzed to predict the response of unitized-based detectors, or controller-based detectors with different settings.

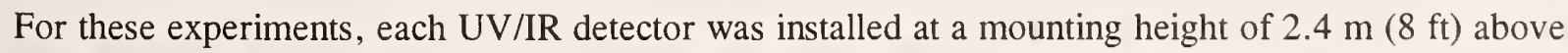
the floor which is a typical mounting height for hangars which house fighter aircraft. The ten UV/IR detectors were mounted on portable stands which were located radially out from the fire. Each 
Table 6. Controller settings of combination UV/IR detectors with respect to test number

\begin{tabular}{|c|c|c|c|c|}
\hline \multirow{2}{*}{ Test Number } & $\begin{array}{c}\text { Description } \\
\text { (Pan Size) }\end{array}$ & \multicolumn{3}{|c|}{ Controller Settings } \\
\cline { 3 - 5 } & $\begin{array}{c}\text { Gate Length } \\
(\mathbf{s})\end{array}$ & $\begin{array}{c}\text { Counts per } \\
\text { Gate }\end{array}$ & $\begin{array}{c}\text { Consecutive } \\
\text { Gates }\end{array}$ \\
\hline 1 & $0.3 \mathrm{~m} \times 0.3 \mathrm{~m}$ & 0.25 & 2 & 3 \\
2 & $0.6 \mathrm{~m} \times 0.6 \mathrm{~m}$ & 0.25 & 2 & 3 \\
3 & $0.9 \mathrm{~m} \times 0.9 \mathrm{~m}$ & 0.25 & 2 & 3 \\
4 & $1.5 \mathrm{~m}$ Diameter & 0.25 & 2 & 3 \\
5 & $2.0 \mathrm{~m}$ Diameter & 0.25 & 2 & 3 \\
$6 \mathrm{~b}$ & $2.5 \mathrm{~m}$ Diameter & 0.25 & 2 & 3 \\
7 & $2.0 \mathrm{~m}$ Diameter & 0.25 & 4 & 4 \\
8 & $2.5 \mathrm{~m}$ Diameter & 0.25 & 4 & 4 \\
11 & $0.3 \mathrm{~m} \times 0.3 \mathrm{~m}$ & 0.25 & 2 & 3 \\
12 & $0.6 \mathrm{~m} \times 0.6 \mathrm{~m}$ & 0.25 & 2 & 3 \\
\hline 13 & $2.0 \mathrm{~m}$ Diameter & 0.25 & 4 & 4 \\
\hline
\end{tabular}

detector was placed to provide a direct line of sight to the fire. Distances from the detectors to the fire were measured along this line of sight as shown in Figure 14 which is an example of the detector layout for the sprinkler fires. The detectors were aimed at the center of the pan using a visible $\mathrm{HeNe}$ laser.

Detector locations varied with the fire pan size; however, for all experiments conducted there were detectors placed at distances of $21.3 \mathrm{~m}, 30.5 \mathrm{~m}$, and $48.8 \mathrm{~m}$ from the fire. All distances were measured along the floor from the detector to the center of the pan. Detector locations for all experiments are given in Table 7. For the sprinkler fires, (i.e., the $1.5 \mathrm{~m}, 2.0 \mathrm{~m}$, and $2.5 \mathrm{~m}$ diameter pans), additional detectors were placed at $6.1 \mathrm{~m}$ intervals from $36.6 \mathrm{~m}$ through $67.1 \mathrm{~m}$ and also at $64.0 \mathrm{~m}$ and $70.1 \mathrm{~m}$. For the detector fires, (i.e., the $0.3 \mathrm{~m} \times 0.3 \mathrm{~m}, 0.6 \mathrm{~m} \times 0.6 \mathrm{~m}$, and $0.9 \mathrm{~m} \times 0.9 \mathrm{~m}$ square pans), the distance the detectors were placed from the fire varied with fire pan size. In all three cases, the maximum distance a detector was placed from the fire was $48.8 \mathrm{~m}$. For the first $0.3 \mathrm{~m} \mathrm{x} 0.3 \mathrm{~m}$ square pan fire (i.e., test 1), additional detectors were placed at $1.52 \mathrm{~m}$ intervals from $9.1 \mathrm{~m}$ through $18.3 \mathrm{~m}$ from the fire. For the first $0.6 \mathrm{~m} \times 0.6 \mathrm{~m}$ and the $0.9 \mathrm{~m} \mathrm{x} 0.9 \mathrm{~m}$ square pan fires (i.e., tests 2 and 3), additional detectors were placed at $1.52 \mathrm{~m}$ intervals from $21.3 \mathrm{~m}$ through $27.4 \mathrm{~m}$, and at $3.0 \mathrm{~m}$ intervals from $30.5 \mathrm{~m}$ through $39.6 \mathrm{~m}$. For the second $0.3 \mathrm{~m} \mathrm{x} 0.3 \mathrm{~m}$ and $0.6 \mathrm{~m} \times 0.6 \mathrm{~m}$ square pan fires (i.e., tests 11 and 12) additional detectors were placed at $3.0 \mathrm{~m}$ intervals from $12.2 \mathrm{~m}$ to $30.5 \mathrm{~m}$ and at $6.1 \mathrm{~m}$ intervals from $30.5 \mathrm{~m}$ to $48.8 \mathrm{~m}$.

Ten controller-based combination ultraviolet/infrared (UV/IR) optical flame detectors were installed 


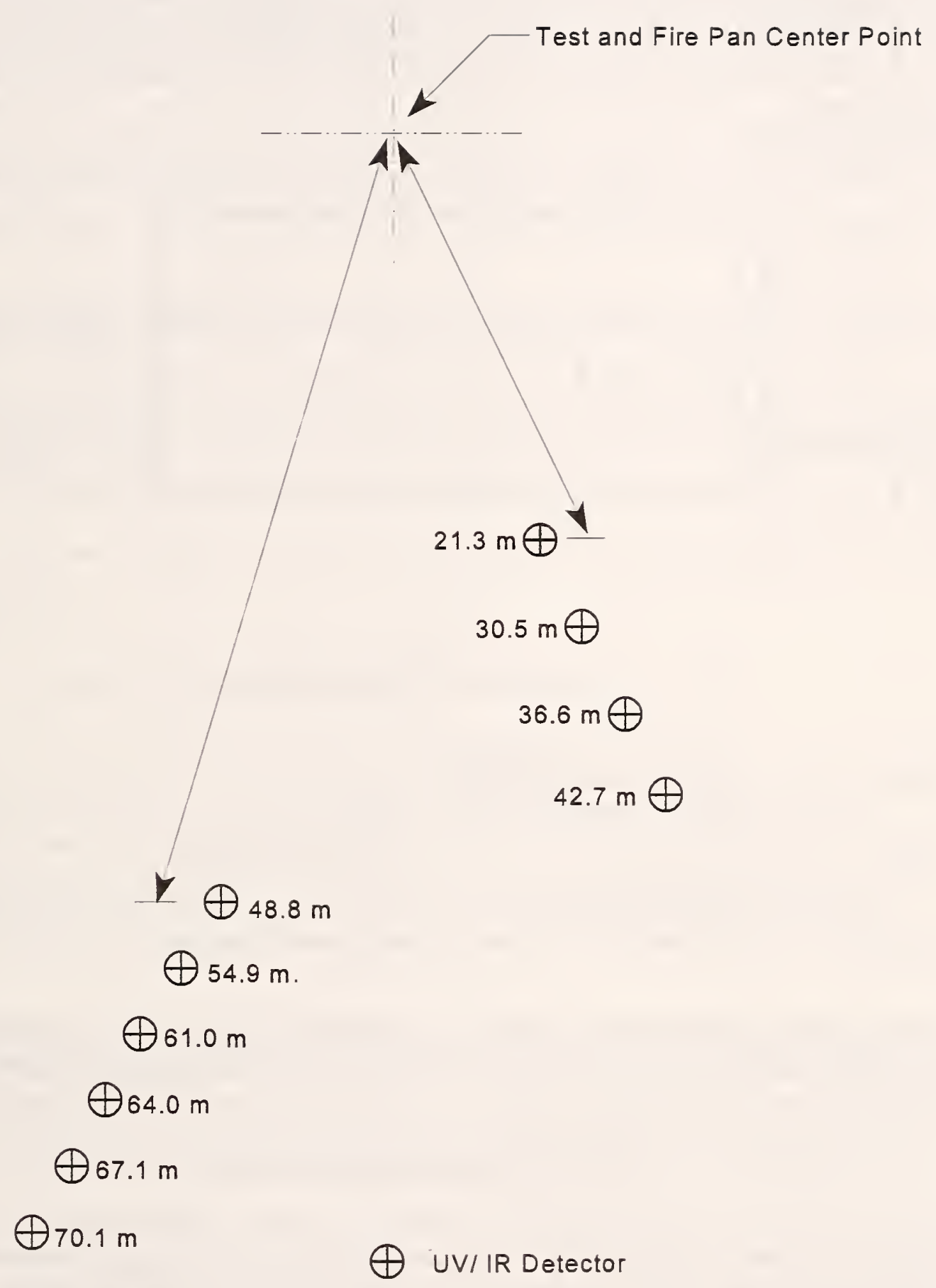

Figure 14. UV/IR detector locations within test area, $15 \mathrm{~m}$ high facility. 
Table 7. Distances of UV/IR detectors (m) from test fires with respect to test number

\begin{tabular}{|c|c|c|c|c|c|c|c|c|c|c|c|}
\hline Test \# & $\begin{array}{c}\text { Pan Size } \\
(\mathbf{m})\end{array}$ & \multicolumn{10}{|c|}{ Detector Number } \\
\hline \multicolumn{2}{|c|}{ Detector Fires } & $\mathbf{1}$ & $\mathbf{2}$ & $\mathbf{3}$ & 4 & $\mathbf{5}$ & $\mathbf{6}$ & $\mathbf{7}$ & $\mathbf{8}$ & $\mathbf{9}$ & $\mathbf{1 0}$ \\
\hline \hline 1 & $0.3 \times 0.3$ & 9.1 & 10.7 & 12.2 & 13.7 & 15.2 & 16.8 & 18.3 & 21.3 & 30.5 & 48.8 \\
2,3 & $0.6 \times 0.6$, & 21.3 & 22.9 & 24.4 & 25.9 & 27.4 & 30.5 & 33.5 & 36.6 & 39.6 & 48.8 \\
& $0.9 \times 0.9$ & & & & & & & & & & \\
11 & $0.3 \times 0.3$ & 12.2 & 15.2 & 18.3 & 21.3 & 24.4 & 27.4 & 30.5 & 36.6 & 42.7 & 48.8 \\
12 & $0.6 \times 0.6$ & 21.3 & 30.5 & 36.6 & 42.7 & 48.8 & 24.4 & 12.2 & 27.4 & 15.2 & 18.3 \\
\hline \multicolumn{2}{|c|}{ Sprinkler Fires } & $\mathbf{1}$ & $\mathbf{2}$ & $\mathbf{3}$ & $\mathbf{4}$ & $\mathbf{5}$ & $\mathbf{6}$ & $\mathbf{7}$ & $\mathbf{8}$ & $\mathbf{9}$ & $\mathbf{1 0}$ \\
\hline \hline $4,5,6 \mathrm{~b}$ & $1.5,2.0$, & 21.3 & 30.5 & 36.6 & 42.7 & 48.8 & 54.9 & 61.0 & 64.0 & 67.1 & 70.1 \\
$7,8,13$ & 2.5 dia. & & & & & & & & & & \\
\hline
\end{tabular}

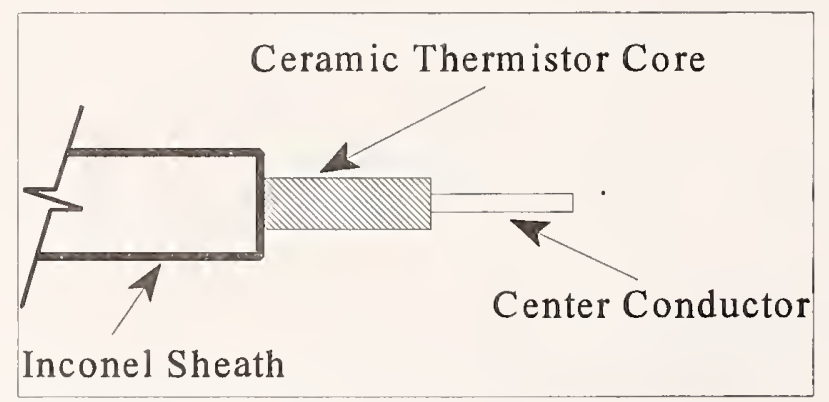

Figure 15. Alison 9090-13 thermal sensor.

and monitored during each experiment. Installation, calibration and test data from the UV/IR detectors were provided by Detector Electronics Corporation on behalf of the optical detector industry.

\subsubsection{Line-Type Heat Detector Installation}

A line type heat detector provided by Alison Control Inc. was used to monitor the perimeter of the draft curtain area in the $15 \mathrm{~m}$ high facility. The Alison 9090-13 continuous linear thermal sensor is small diameter coaxial wire capable of sensing temperature changes along its entire length. The sensor is constructed with a center conductor and an outer Inconel 625 sheath. The center conductor is insulated from the outer sheath by a ceramic thermistor material as shown in Figure 15. The sensor has a diameter of approximately $2.16 \mathrm{~mm}(0.085 \mathrm{in}$.) and therefore has a small mass which allows it rapidly to sense changes in temperature. Its response time index (RTI) is 58 [26] and its operating temperature range extends from $-46^{\circ} \mathrm{C}$ to $1093^{\circ} \mathrm{C}$. Fire detection utilizing this sensor is accomplished 
by measuring the resistance between the center conductor and the outer Inconel sheath. Since the thermistor has a negative coefficient of resistance, electrical resistance between the center wire and the outer sheath decreases exponentially as the surrounding temperature increases. The resistance characteristic of this sensor is equivalent to a parallel resistor network with an infinite number of points.

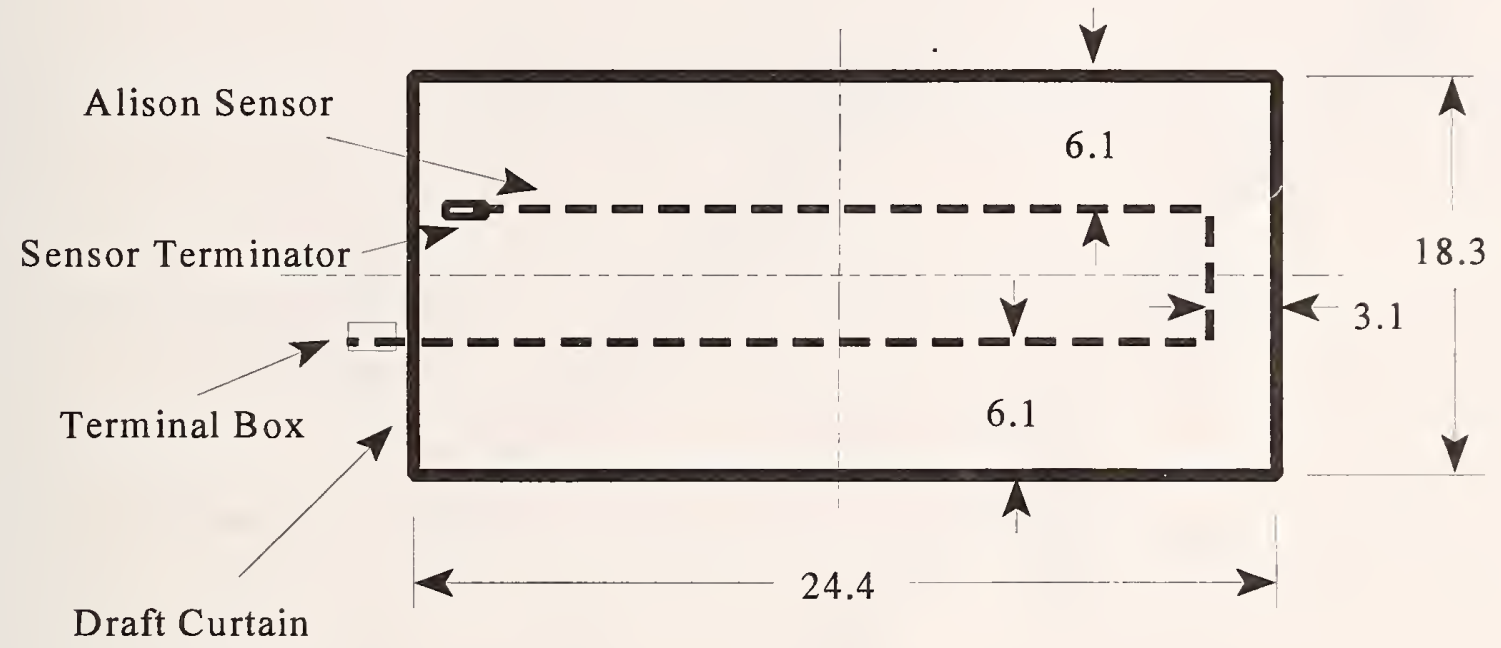

Figure 16. Location of thermal sensor within $15 \mathrm{~m}$ test area.

Based on the fact that NFPA 72 does not specify placement of line type electrical conductivity detectors

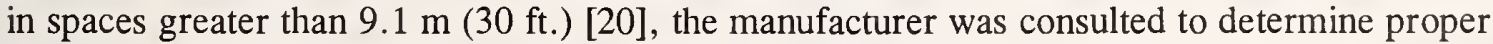
placement. The Alison 9090-13 thermal sensor was installed in a " $U$ " shaped configuration within the

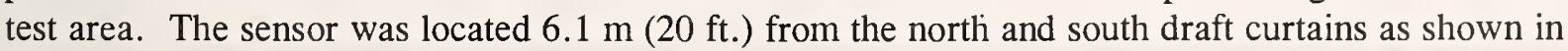

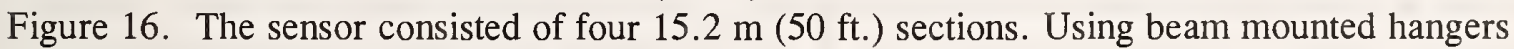
provided by the manufacturer, the sensor was hung approximately $0.3 \mathrm{~m}$ (12 in.) below the structural steel beams.

In order to interface the sensor wire to NIST's data system, the junction box at one end of the sensor cable was connected via instrumentation wire to a control module. The control module provided an output voltage signal relating the temperature of the sensor at any given moment. The control module output voltage was collected at approximately $0.25 \mathrm{~Hz}$. Temperature of the sensor was obtained by applying the manufacturer's response curve similar to Figure 17.

\subsubsection{Measurements - Instrumentation}

NIST installed and monitored 144 transducers during these fire tests. Sixty four measurements were of sprinkler activation time as described above. Other transducers and instrumentation included thermocouples, mass loss of burning fuel, mass flow of the ceiling jet structure, internal and external wind speed and direction, and heat flux radiometers. In addition, video footage was recorded at several locations for visualization and analysis purposes. 


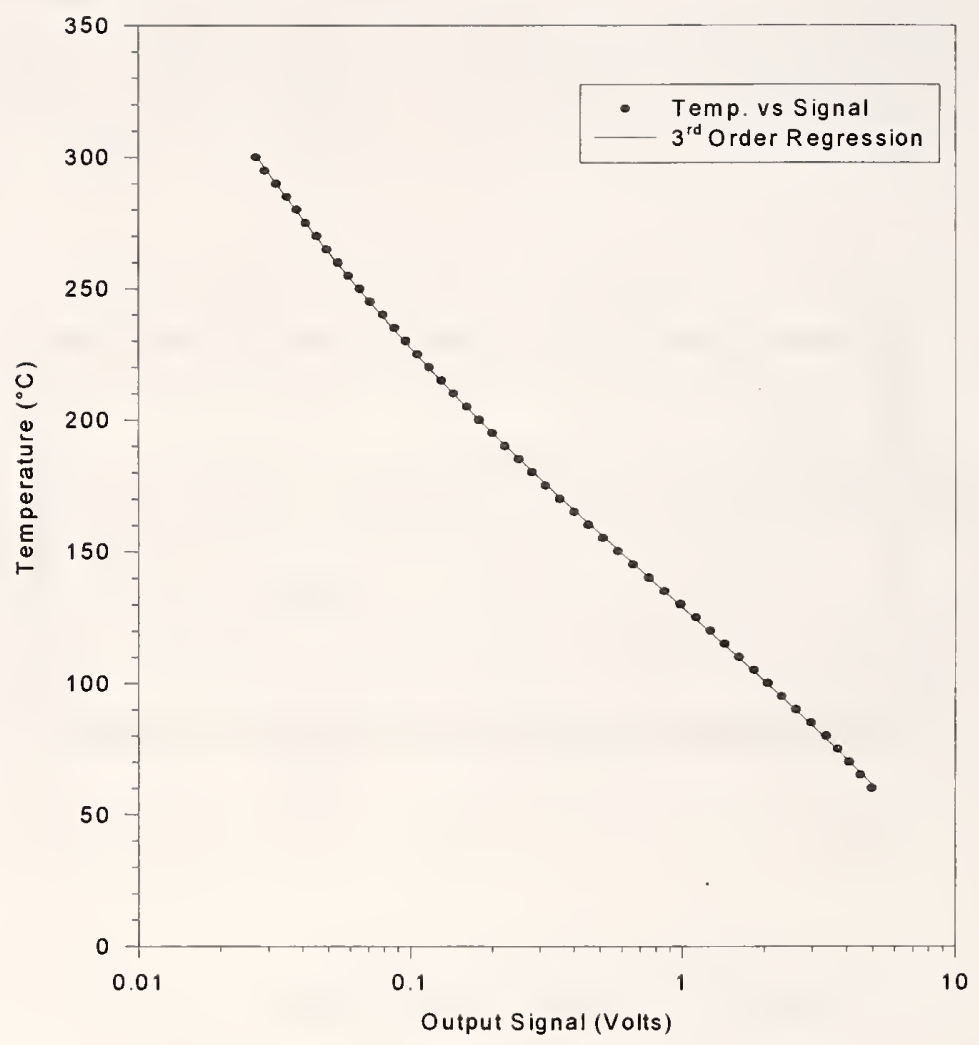

Figure 17. Typical response curve for Alison 9090-13 thermal sensor.

\section{Thermocouples}

Temperatures were measured of the fire plume, air and fuel at 64 locations as shown in Figure 18. Bead-welded, exposed $0.3 \mathrm{~mm}$ diameter wire, type $\mathrm{K}$ thermocouples were used to measure these temperatures.

To measure plume centerline temperatures and plume symmetry, sixteen temperature measurements were taken over the fire plume. An array of five thermocouples was placed at $0.31 \mathrm{~m}$ below the ceiling, one in the center over the fire pan, and one $1.5 \mathrm{~m}$ radially out from the center in each of the four directions. Nine thermocouples were installed $3.0 \mathrm{~m}$ below the ceiling in a cross pattern, one along the centerline, and two radially out from the center in each direction, at $0.91 \mathrm{~m}$, and $2.1 \mathrm{~m}$. These aided in determining which direction the plume was leaning. Two additional thermocouples were installed at $1.5 \mathrm{~m}$ and $6.1 \mathrm{~m}$ below the ceiling along the centerline.

To measure ceiling jet temperature, thermocouples were placed in all four directions, $0.31 \mathrm{~m}$ below the ceiling at $1.5 \mathrm{~m}, 3.0 \mathrm{~m}, 6.1 \mathrm{~m}, 9.1 \mathrm{~m}$, and $11.6 \mathrm{~m}$ radially out from the center to the east and west, and at $3.0 \mathrm{~m}, 6.1 \mathrm{~m}, 8.5 \mathrm{~m}$ radially out from the center to the north and south. Also, in each of the four directions, at $6.1 \mathrm{~m}$ radially out from the center, additional thermocouples were placed vertically down from the ceiling to measure the temperature of the ceiling jet as a function of depth below the ceiling. These were placed at $0.15 \mathrm{~m}, 0.46 \mathrm{~m}, 0.61 \mathrm{~m}$, and $0.76 \mathrm{~m}$ below the ceiling. This information 


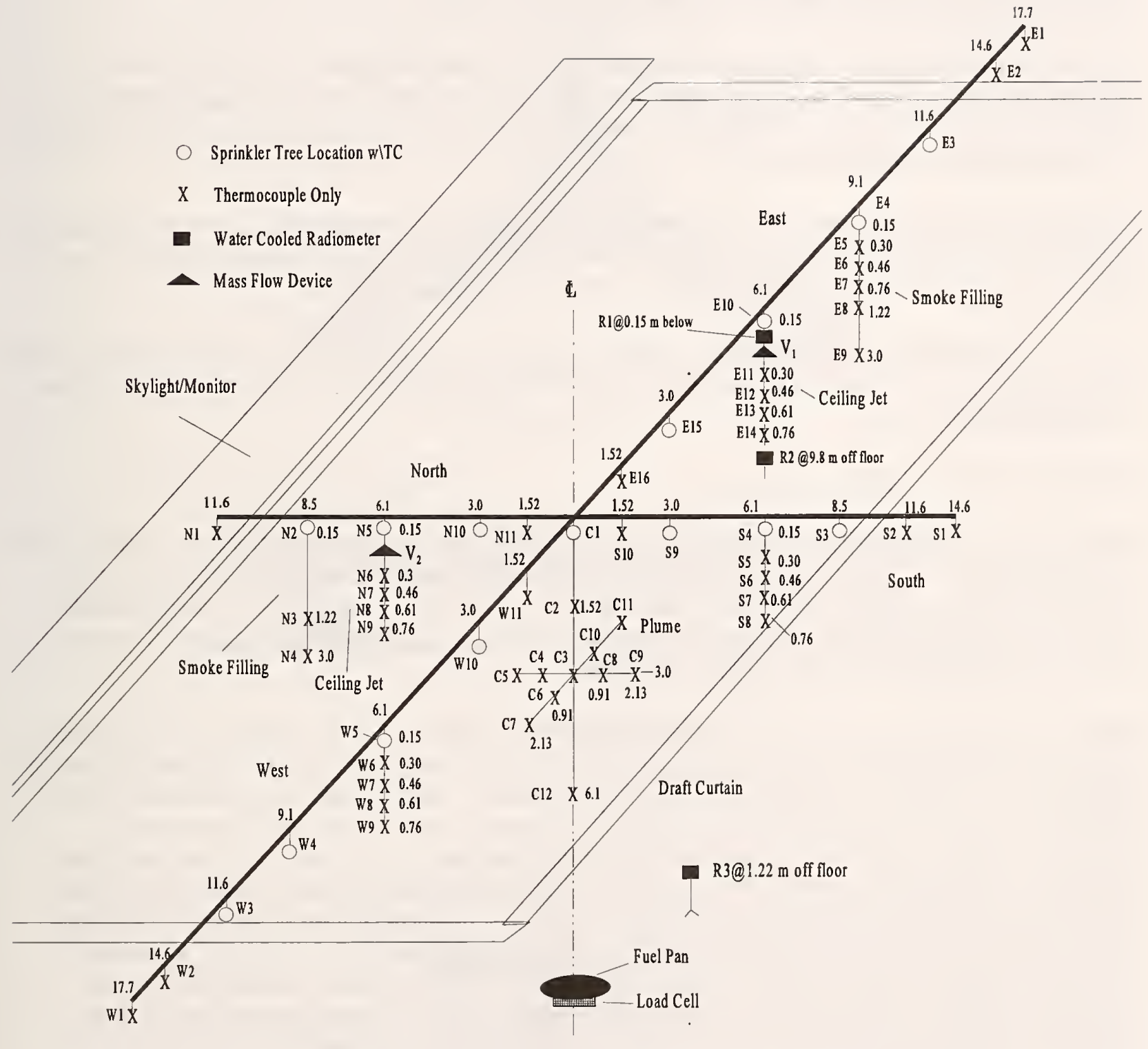

All Dimensions in Meters

Figure 18. Instrumentation locations in $15 \mathrm{~m}$ high facility. 
is useful for fire model verification and for refinement of detector placement strategies.

To track the build-up of fire products within the draft curtained area, thermocouples were placed at $8.5 \mathrm{~m}$ north, and $9.1 \mathrm{~m}$ east of the centerline. Thermocouples were installed from $0.15 \mathrm{~m}$ to $3.0 \mathrm{~m}$ below the ceiling. Assuming that the smoke and heat flow together, the thermocouple readings can indicate the initial arrival of smoke to the thermocouple location.

To track the flow of fire products into the adjacent draft curtained areas, thermocouples were installed outside of the draft curtained area in all four directions. Thermocouples were installed to the north $11.6 \mathrm{~m}$ from the centerline (inside the skylight), to the south $11.6 \mathrm{~m}$ and $14.6 \mathrm{~m}$ from centerline, and to the east and west $14.6 \mathrm{~m}$ and $17.7 \mathrm{~m}$ from the centerline.

To measure the temperature at time of activation of smoke and heat detectors, a thermocouple was placed at each sprinkler tree/smoke detector station. These data provides information useful in model verification and prediction of activation of fire protection devices.

To provide critical safety temperatures, a thermocouple was placed on the main structural steel beam directly over the fire. Two thermocouples were placed within the fire pan (to monitor fuel depth and pan temperature).

\section{Mass Loss of Burning Fuel}

Measurement of the mass loss rate of the burning fuel was essential for determining heat release values for each test fire. This measurement also provided information on the time required for the fire to reach steady state condition. Heat release rates were estimated for all experimental fires for which mass loss data were collected. The heat release rate $(\mathrm{kW})$ was calculated by multiplying the mass loss rate by the known heat of combustion for each fuel.

Since a load measuring platform had to accommodate pan sizes from $0.3 \mathrm{~m}$ square to $2.5 \mathrm{~m}$ diameter round, it was necessary to build two separate platforms for this test series. Figure 18 describes the load platforms. The smaller load platform used one $227 \mathrm{~kg}$ (500 lb.) strain gauge type precision load cell, produced by GSE Inc. Measurements and Controls*. Coupled with a strain gauge power supply/ indicator, a voltage output directly proportional to total mass $(\mathrm{kg})$ was produced. For the three point load platform, three $454 \mathrm{~kg}(1000 \mathrm{lb}$.) strain gauges were connected in parallel to the power supply/ indicator. This configuration provided a $1361 \mathrm{~kg}(3000 \mathrm{lb}$.), in terms of total mass, capacity for the load platform. The power supply/indicator device supplied a stable $10 \mathrm{VDC}\left(0.005 \% /{ }^{\circ} \mathrm{C}\right.$ stability $)$ excitation voltage to the $350 \Omega$ strain gauges. Depending on the gain factor programmed into the indicator circuitry, standard units were displayed continuously and an analog output ranging from \pm 10 VDC was measured and logged through the data acquisition system. In addition the power supply/ indicator unit contained circuitry for calibration span adjustment and zero.

* Certain trade names and company products are mentioned in the text or identified in an illustration in order to specify adequately the experimental procedure and equipment used. In no case does such identification imply recommendation or endorsement by the National Institute of Standards and Technology, nor does it imply that the products are necessarily the best available for the purpose. 


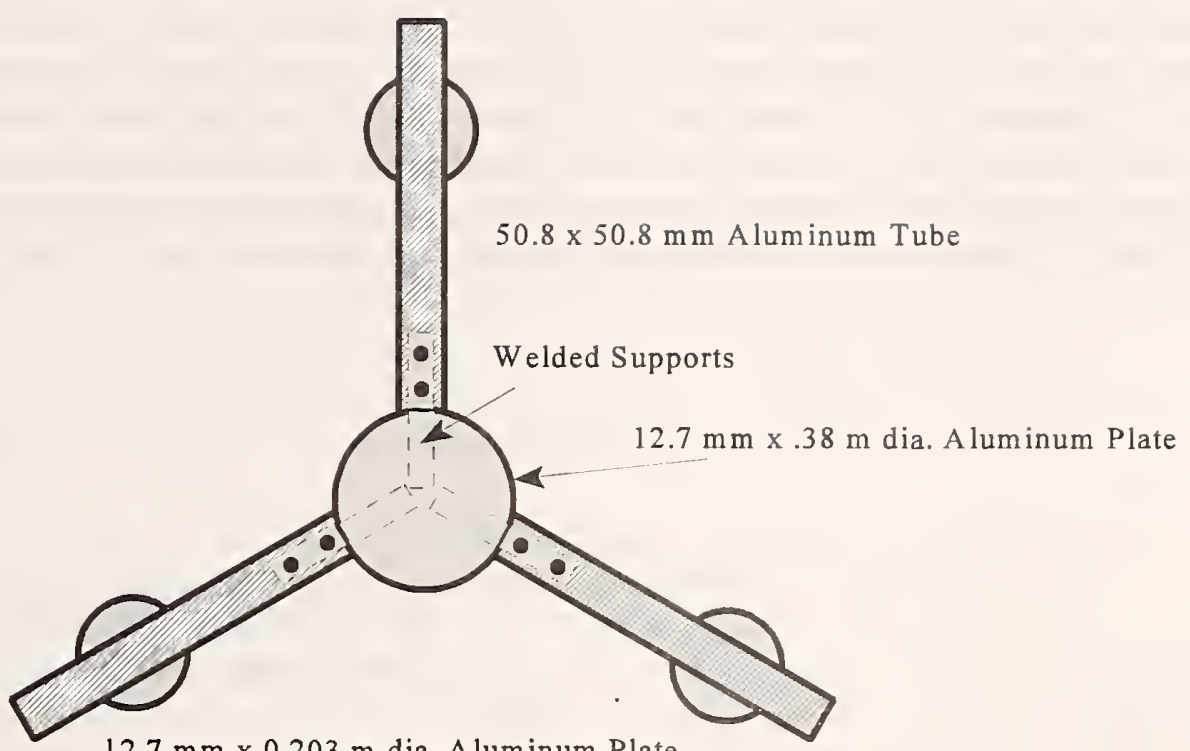

$12.7 \mathrm{~mm} \times 0.203 \mathrm{~m}$ dia. Aluminum Plate

Welded Supports

$12.7 \mathrm{~mm}$ Calcium Silicate Board

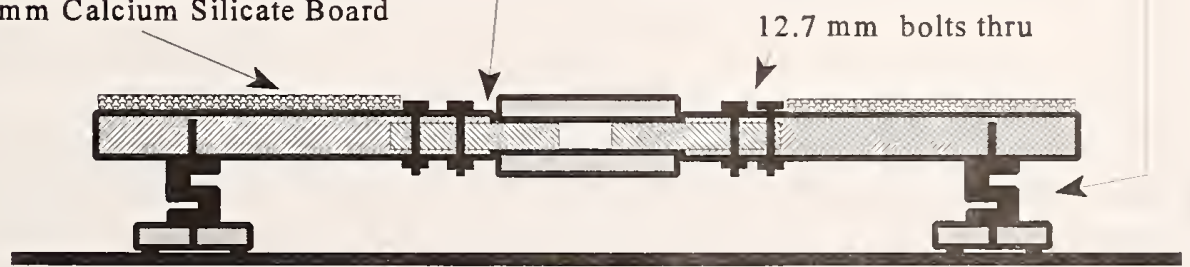

Three Point Load Platform

$12.7 \mathrm{~mm}$ Calcium Silicate Board

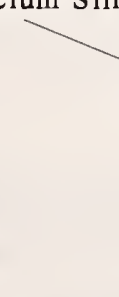

$12.7 \mathrm{~mm}$ thick Aluminum Plate

Single Point Load Platform
Model 5353, $227 \mathrm{~kg}$

(500 1b.) Strain Gauge

Figure 19. Single and three point load platform schematic. 
Calibrations were performed on both load platforms prior to fire testing. The single strain gauge load platform was calibrated using a $18000 \mathrm{~kg}$ (40 $000 \mathrm{lb}$.) hydraulic testing machine. Approximately ten points from (0 to 227) $\mathrm{kg}$ were recorded, along with the corresponding voltage output. For the three point load platform a $1.5 \mathrm{~m}$ round pan, of a known volume, was filled with water to several depths and the corresponding voltage was recorded. By calculating the mass of water for each volume, a calibration constant was obtained for several points. In addition, an experiment was performed using a small electric pump to discharge the water, thus simulating the mass loss characteristics of a pan of

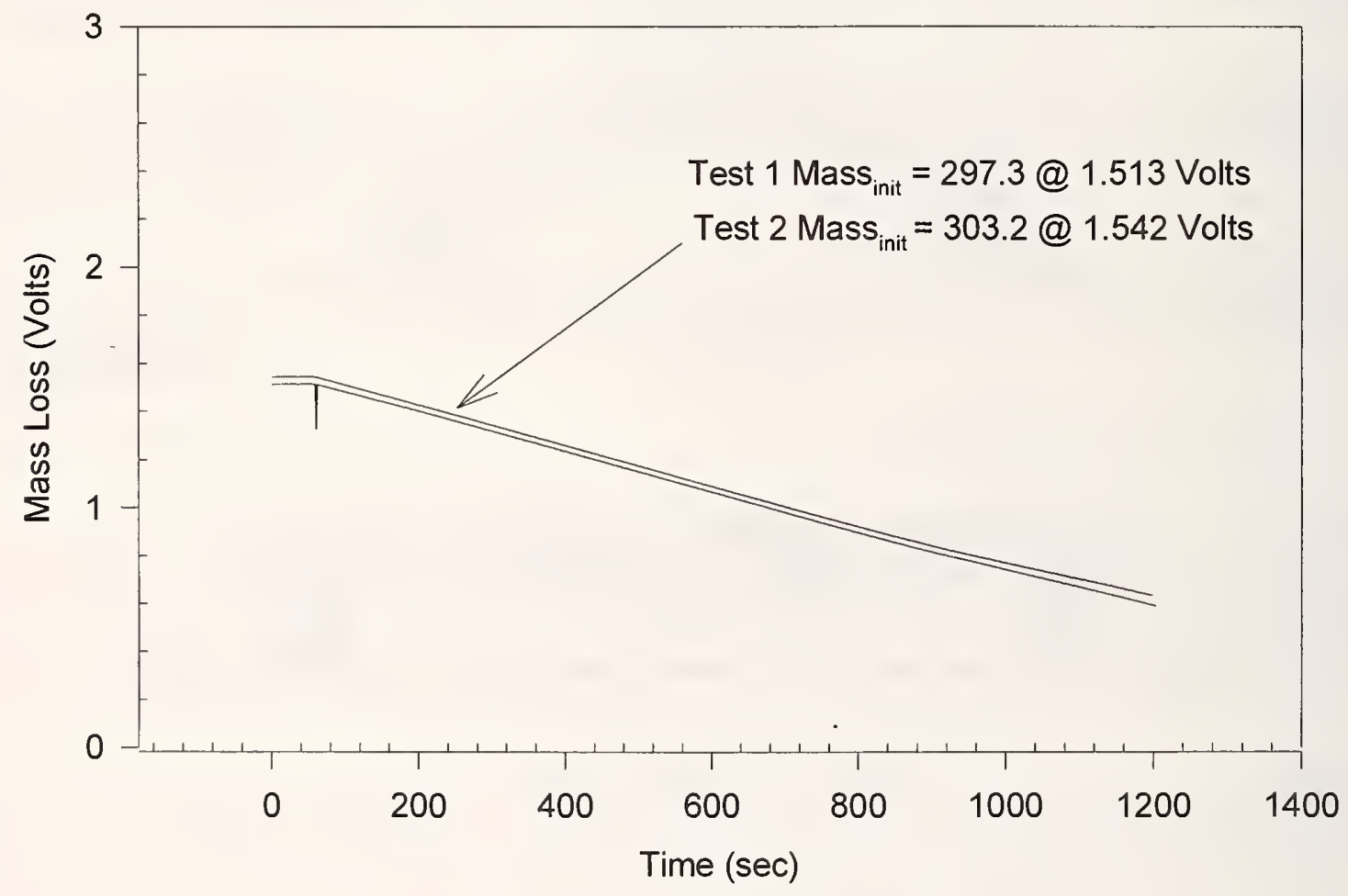

Figure 20. Results from sample mass loss simulation experiment.

burning fuel. Two similar runs are shown in Figure 20. Each strain gauge was thermally protected using a ceramic blanket wrapped loosely around the gauge and the load platform frame was protected using $12.7 \mathrm{~mm}(0.5 \mathrm{in}$.) calcium silicate board. The uncertainty of the mass measurement for the load platforms is a function of the uncertainty of the strain gauges, power supply indicator, and the data collection system. The manufacturers of the strain gauges indicate a non-repeatability of $\leq 0.01 \%$ with a temperature effect rating on output of $\pm 0.002 \% /{ }^{\circ} \mathrm{C}$ and a stability of excitation voltage of $0.005 \% /{ }^{\circ} \mathrm{C}$. For the power supply/indicator, the manufacturer reports an accuracy with respect to temperature of $0.005 \% /{ }^{\circ} \mathrm{C}$. Overall, excluding the uncertainty of the data collection system (discussed in following section), the uncertainty of this measurement depends on the temperature stability of the individual components, primarily. With this in mind, a conservative estimate of $\pm 0.5 \mathrm{~kg}$ variation can 
be assumed.

\section{Ceiling Jet Velocity Transducers}

Ceiling jet velocity measurements were made using two Sierra Steel-Trak Industrial Insertion Mass Flow Meters (series 640). Locations of these mass flow meters are indicated in Figure 18. $\mathrm{V}_{1}$ in the

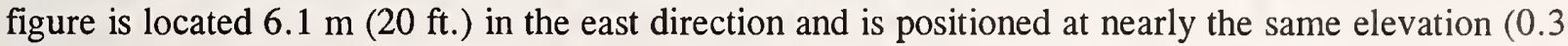
$\mathrm{m}$ below ceiling deck) as the thermal element of the sprinkler at station E10. $\mathrm{V}_{2}$ is located at $6.1 \mathrm{~m}$ in the north direction and at a similar elevation. The rationale for choosing these locations was to investigate the mass flow of the ceiling jet in the vicinity of a sprinkler. From this measurement, information about the convective cooling of the sprinkler's thermal element could be realized.

The transducer contains two sensors; a velocity sensor and a temperature sensor that automatically correct for temperature changes. Both sensors are reference-grade platinum RTD's wound on a ceramic mandrels. Internal circuitry heats the velocity sensor above ambient with respect to the temperature sensor and measures the cooling effect of the gas flow. Since the heat is carried away by the gas, the heated sensor directly measures gas mass velocity, $\rho \mathrm{V}$, referenced to standard conditions of $21.1^{\circ} \mathrm{C}\left(70^{\circ} \mathrm{F}\right)$ and atmospheric pressure. Electronically, an output voltage signal (0 to 5)VDC is produced which is proportional to the total gas mass velocity. "The usable range for these transducers is up to $0.5 \mathrm{~m} / \mathrm{s}(100 \mathrm{ft} / \mathrm{min})$ at standard conditions.

\section{Wind Speed and Direction Meters}

Wind speed and direction were measured inside and outside the hangar during the experiments. The objective of this measurement was primarily to observe the effects of wind currents occurring during an open door experiment. Four wind speed/direction meters were used. One meter was mounted on the roof of the hangar to observe ambient wind conditions. This measurement was augmented by the weather station at NAS Barbers Point which provided updated weather data collected at various points near the hangar. The other three meters were placed in a straight line, approximately $3.0 \mathrm{~m} \mathrm{(10} \mathrm{ft.)}$ above the floor, generally upwind from the fuel pan (open door case). The distance from the center of the fuel pan to the wind speed/direction meters varied. Table 8 lists the distances with respect to test number.

Table 8. Distance from wind speed meters to center of fuel pan.

\begin{tabular}{|c|c|c|c|}
\hline & \multicolumn{3}{|c|}{ Distance From Center of Fuel Pan to Wind Meter $(\mathrm{m})$} \\
Test Number & 1 & 2 & 3 \\
1 & $25.9(85 \mathrm{ft})$. & $15.2(50 \mathrm{ft})$. & $6.1(20 \mathrm{ft})$. \\
4 & $25.9(85 \mathrm{ft})$. & $18.3(60 \mathrm{ft})$. & $11.3(37 \mathrm{ft})$. \\
9 & $25.9(85 \mathrm{ft})$. & $18.3(60 \mathrm{ft})$. & $10.7(35 \mathrm{ft})$. \\
\hline
\end{tabular}

The wind speed meters use a 3-cup anemometer to produce a time varying pulse where the frequency of the pulse is proportional to the wind velocity. For example, $1 \mathrm{pps}$ equals $0.45 \mathrm{~m} / \mathrm{s}(1 \mathrm{mph})$. Since 
the data system could not capture signals of this frequency, a frequency to voltage converter was constructed which produced a voltage proportional to wind speed. Using the manufacturer's calibration constant for the meter, a calibration curve was established by using a constant speed fan and a calibrated strobe light configuration. The wind direction was indicated by the change of resistance measured across a center tapped, single-turn potentiometer located inside the turret of the wind direction vane. With a constant voltage applied to the potentiometer, the potential at the center tap varied with change in direction. The "north" direction was established by orienting the meter so that the voltage output was near zero. Typically, the DC voltage range for a complete $360^{\circ}$ turn of the vane was from $0 \mathrm{~V}$ to $9 \mathrm{~V}$ which corresponds to a change of $26 \mathrm{mV} /$ degree. Ten angular degrees were subtracted during each revolution due to account for the "dead band" of the potentiometer.

The primary degree of uncertainty for the wind speed/direction meters originates in the conversion of frequency to voltage for wind speed. Since the conversion is accomplished by utilizing an RC charge pump method, there is considerable ripple effects at the lower frequencies. Ripple, caused by the charge/discharge action of a capacitor in the circuit, yields a variance of nearly $10 \%$ in the $0.95 \mathrm{~m} / \mathrm{s}$ to $6.7 \mathrm{~m} / \mathrm{s}$ wind speed range. According to the manufacturer, wind speed, using a pulse counting measurement, can be measured to within $\pm 0.15 \mathrm{~m} / \mathrm{s}$. Wind direction can accurately be measured to within $\pm 2^{\circ}$. Mechanical wear and friction can also cause measurement errors. For example, the cup anemometer must overcome a friction force associated with the internal bushing. Therefore, a threshold velocity [typically $0.95 \mathrm{~m} / \mathrm{s}(2.1 \mathrm{mph})$ ] prevents the meter from reading small air currents that may develop during a test.

\section{Heat Flux Radiometers}

Three water cooled, Gardon type heat flux transducers were used to measure total heat flux from the test fires. Figure 18 indicates the location of the gauges. Two transducers (R1 and R2) were mounted at $6.1 \mathrm{~m}$ east and $0.15 \mathrm{~m}$ below the ceiling and $9.8 \mathrm{~m}$ off the floor, respectively. The third transducer (R3) was placed $1.22 \mathrm{~m}$ off the floor but at several different distances away from the fire.

The Gardon type transducer absorbs heat flux in a thin metallic circular foil at the surface and then heat is transferred radially out to an integral heat sink which remains at a temperature below that of the sensor surface. The difference in temperature is taken between the center and edge of the foil. This temperature difference between the points along the path of the heat flow from the sensor to the heat sink is proportional to the heat being transferred, and, therefore proportional to the heat being absorbed. The transducer uses a thermocouple which generates a thermoelectric circuit providing a self-generated EMF between the two output leads directly proportional to the heat transfer rate.

The nominal measurement range of the transducers was 0 to $50 \mathrm{~kW} / \mathrm{m}^{2}$ with a maximum operating temperature of $204{ }^{\circ} \mathrm{C}\left(400^{\circ} \mathrm{F}\right)$. The output voltage provided by the sensor was up to $10 \mathrm{mV}$ with over-range capability of $150 \%\left(+15 \mathrm{~kW} / \mathrm{m}^{2}\right)$. Other characteristics include maximum nonlinearity of $\pm 2 \%$ full range, less than $0.05 \mathrm{~s}$ response time, measurement uncertainty of $\pm 3 \%(0.3 \mathrm{mV})$, and sensor absorptance of 0.92 from $0.6 \mu \mathrm{m}$ to $15.0 \mu \mathrm{m}$.

Cooling water for these transducers was provided by the water main used for filling the sprinkler trees. Plastic hose (9.5 mm O.D.) was used to supply the transducers and provide a drain line which was piped to a central drain in the hangar. 


\section{Data Acquisition System}

The data acquisition system used to collect fire test data in the $15 \mathrm{~m}$ high facility was the Hewlett Packard 75000 series B Data Acquisition/Control Unit (HP 1301A Mainframe). This unit uses an industry standard IEEE-488.2 command structure; complimented by the HPVEE graphical user interface. The programming, logging, and analysis was done on an IBM compatible computer operating under a 486-dx2 microprocessor, at a speed of $66 \mathrm{MHZ}$.

Analog and digital input signals were captured via various interface cards mounted within the instrument rack of the $75000 \mathrm{~B}$. The entire system was protected with a $450 \mathrm{kV}$ uninterruptable power supply (UPS) and surge protector. In the event of a power failure, the system would remain on battery power for $5 \mathrm{~min}$ to $7 \mathrm{~min}$. Figure 21 describes the general components incorporated into the data acquisition system The HP 1301A contains an internal 51/2-digit multi meter (HP E1326B) which measures the input voltage signals and then provides ASCII type data to the computer for storage and manipulation. The multi-meter is capable of resolving $120 \mathrm{nV}$ in the $0.125 \mathrm{~V}$ range, and as stated by Hewlett Packard, the accuracy over 90 days is $0.01 \%$. The input modules consisted of four 16 -channel type $\mathrm{K}$ thermocouple modules, two 32-bit digital input modules, and one 16-channel analog voltage module.

Programming each component of the data acquisition system was accomplished using the HPVEE graphical user interface (GUI). Real-time displays, channel conversions, and analysis functions were all part of the GUI. These features were quite useful in observing temperatures at various locations, mass loss with respect to time, and important safety factors during the fire tests.

\section{Other Measurements and Information}

In addition to measurements described above, video footage of each test fire was taken. In all cases, High resolution $8 \mathrm{~mm}$ video cameras were located in three specific areas with respect to the test fire. Camera 1 was approximately $13.4 \mathrm{~m}$ ( $44 \mathrm{ft}$.) from the center of the test fire, looking in the direction of the north wall. This angle provided a view of the fire pan, hangar door, windows, and other large objects from which visible flame height could be estimated. Cameras 2 and 3 were located in the eastern and north western sector of the hangar bay, respectively. The locations of cameras 1 and 2 complimented one another by supplying information on time to full pan involvement, flame propagation across fuel pan, flame structure, and symmetry of the plume. Camera 3 focused on the top of the hangar to observe smoke filling rates and relative obscuration.

Weather data, measured at several locations in the vicinity of the hangar, was provided by the weather station at NAS Barbers Point. Temperature, relative humidity, wind speed/direction, dew-point, barometric pressure, and precipitation amounts, were reported hourly.

\subsection{Test Fires, $15 \mathrm{~m}$ High Facility}

Thirteen fire experiments were conducted in the $15 \mathrm{~m}$ high facility. Eleven of these were pool fires burning JP-5 jet fuel. The jet fuel fires ranged in size from $0.09 \mathrm{~m}^{2}\left(1 \mathrm{ft}^{2}\right)$ to $4.9 \mathrm{~m}^{2}\left(52.8 \mathrm{ft}^{2}\right)$. The following sections include the rationale for each fire size, computer modeling of the facility based on 


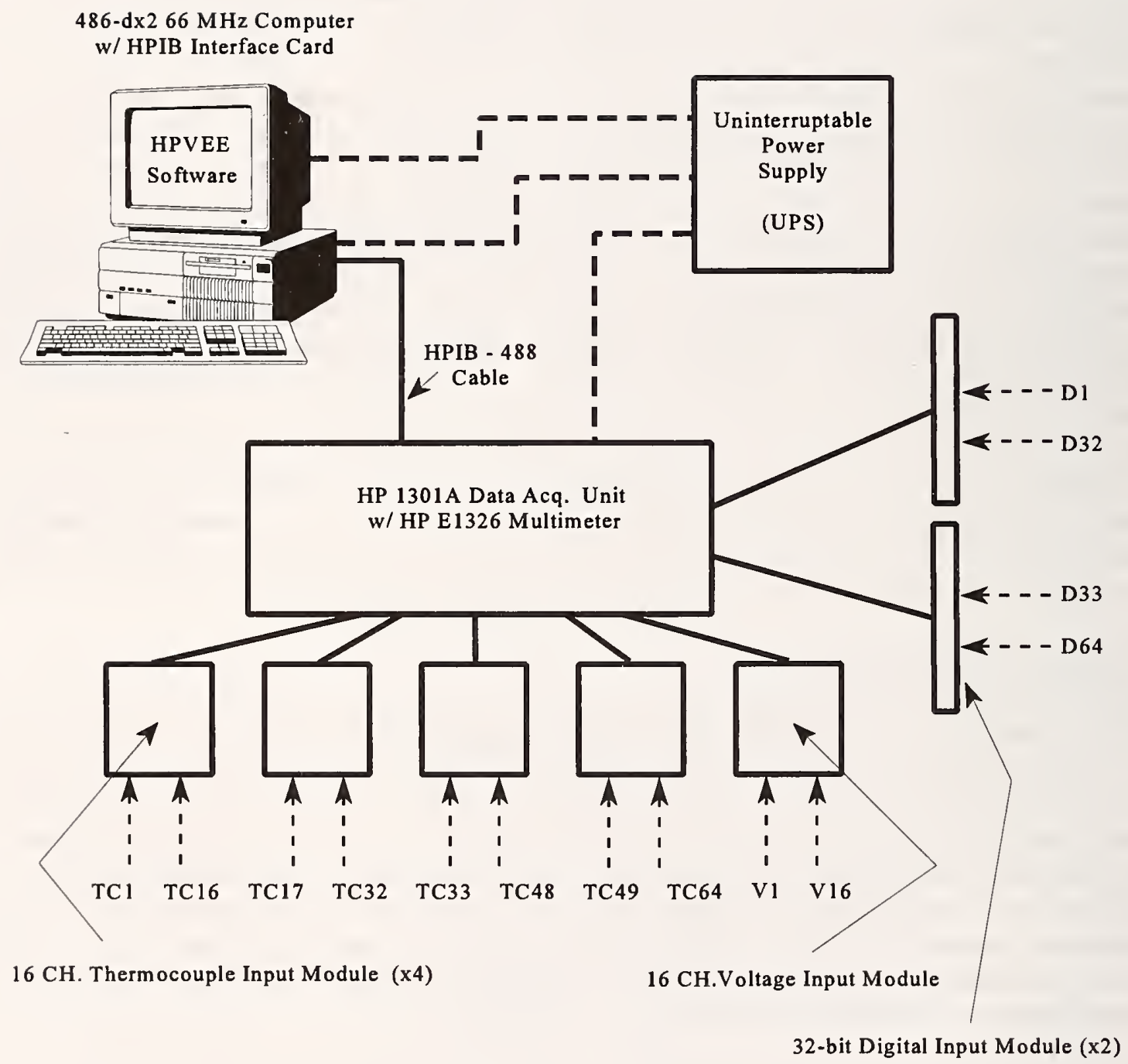

Figure 21. Diagram of data acquisition system components. 
anticipated heat sources, test procedures, summary of all experiments, and fuel specifications.

Two wood crib fire tests, $0.6 \mathrm{~m} \times 0.6 \mathrm{~m} \times 0.6 \mathrm{~m}$ and $0.6 \mathrm{~m} \times 0.6 \mathrm{~m} \times 1.2 \mathrm{~m}$, were also conducted. These were to simulate an ordinary combustibles fire in a high bay space. The wood crib fires are discussed in the Appendix.

\subsubsection{Logic Used to Determine Experimental Fire Sizes}

A combination of plume theory, three-dimensional computational fluid dynamic modeling, and engineering judgement were used to determine the heat release rates and associated pan sizes to meet the experimental objectives. Each of the experiments can be grouped into one of two categories, referred to as "detector fires" and "sprinkler fires." Detector fires were designed to determine an approximate minimum fire size for detection ability for the various types of heat, smoke, and flame detectors. Detector fires were small square pan fires of three different sizes; $0.3 \mathrm{~m} \mathrm{x} 0.3 \mathrm{~m} \mathrm{(1 \textrm {ft } \mathrm { x } 1}$ $\mathrm{ft}), 0.6 \mathrm{~m} \times 0.6 \mathrm{~m}(2 \mathrm{ft} \times 2 \mathrm{ft})$, and $0.9 \mathrm{~m} \times 0.9 \mathrm{~m}(3 \mathrm{ft} \times 3 \mathrm{ft})$. Square pan fires were chosen since the $0.3 \mathrm{~m} \times 0.3 \mathrm{~m}$ and the $0.6 \mathrm{~m} \times 0.6 \mathrm{~m}$ fires are industry standards for testing of the UV/IR detectors.

The sprinkler fires were larger round pan fires designed to determine the approximate fire size for activation of the various types of automatic sprinklers. Sprinkler fires were designed to meet three objectives:

- To demonstrate a large fire that would come close to but not activate any of the installed test sprinklers. The first sprinkler fire was a $1.5 \mathrm{~m}$ diameter circular pan fire with an estimated heat release rate of $4.5 \mathrm{MW}$

- To demonstrate a fire large enough to activate the $79^{\circ} \mathrm{C}\left(175^{\circ} \mathrm{F}\right)$ sprinklers within the fire plume) The second sprinkler fire was a $2.0 \mathrm{~m}$ diameter pan fire with an estimated heat release rate of $8.6 \mathrm{MW}$.

- To demonstrate a fire that would activate the $79^{\circ} \mathrm{C}\left(175^{\circ} \mathrm{F}\right)$ sprinklers inside and outside the fire plume and possibly the $141{ }^{\circ} \mathrm{C}\left(286^{\circ} \mathrm{F}\right)$ within the fire plume. The third sprinkler test was a $2.5 \mathrm{~m}$ diameter pan fire with an estimated heat release rate of $12.6 \mathrm{MW}$.

Draft curtains were fabricated and installed in the $15 \mathrm{~m}$ facility. to enclose an area $24.4 \mathrm{~m} \times 18.3 \mathrm{~m}$ ( 80 $\mathrm{ft} x 60 \mathrm{ft})$. The draft curtain was $3.7 \mathrm{~m}(12 \mathrm{ft})$ deep. Most of the experiments were repeated without the draft curtain to determine the effects of the draft curtain.

\subsubsection{Computer Modeling of $15 \mathrm{~m}$ Facility}

Computer modeling was used extensively as a design tool to predict the effects of fire size on ceiling temperature, smoke movement, and sprinkler activation. Use of computer models to aid in the design of the hangar experiments was based on some successful results obtained modeling test fires in a $30 \mathrm{~m}$ (100 ft) hangar.[3] The initial modeling effort was directed toward the establishment of fire sizes that would just activate the $79{ }^{\circ} \mathrm{C}$ and $141^{\circ} \mathrm{C}$ sprinklers based on the expected ambient temperatures at the hangar site. Draft curtains were assumed to be absent for this analysis.

Initially, the zone fire models LAVENT [27] and DETACT-QS [28] were used to establish target fire 
sizes. The computational fluid dynamics model, HARWELL-FLOW3D [29], was then used to refine the target fire sizes and investigate the impact of the ceiling geometry on sprinkler activation. The CFD model allowed for the calculation of temperatures and sprinkler activation times within the plume region. Neither zone model contained physical models which are valid for sprinkler activation inside the plume.

Modeling parameters for the CFD model used here are reported in reference [3]. Three target fire sizes were selected to test sprinkler activation. The first fire size was $4.5 \mathrm{MW}$ which was not expected to activate any sprinklers. The second fire size of $8.1 \mathrm{MW}$ was expected to produce ceiling temperatures sufficient to activate the $79^{\circ} \mathrm{C}$ heads within $2.5 \mathrm{~m}$ of plume center but none of the $120^{\circ} \mathrm{C}$ heads. The final fire size of $12.6 \mathrm{MW}$ was expected to activate a $141^{\circ} \mathrm{C}$ head at plume center but none of the other $141{ }^{\circ} \mathrm{C}$ heads. The $79{ }^{\circ} \mathrm{C}$ heads were predicted to activate out to about $5.5 \mathrm{~m}$ from plume center for this fire.

The impact of the 5 degree ceiling slope on smoke movement (assumed to travel with the heat) was investigated using the CFD model. The effect of the 5 degree slope was found to exhibit only a small enhancement of smoke flow down slope. Figure 22 shows the predicted temperature distribution at $30 \mathrm{~s}$ after ignition. The long rectangular slice extending out to the left in the figure represents a horizontal plane at the bottom of the monitor window. Since the ceiling slopes five degrees down toward the left of the figure, the plane showing the location of the hot gas stops when the ceiling slope intersects the height of the plane. The ceiling is flat in the up-down direction in the figure. The fire is located at the upper left hand corner of the figure with the contours representing different temperatures. As can be seen from the figure, there is substantially more flow of heat in the flat direction then in the sloped direction.

Simulations using the $8.6 \mathrm{MW}$ fire size and draft curtains fis a $18 \mathrm{~m} \mathrm{x} 24 \mathrm{~m}$ area were done using LAVENT and the CFD model in order to predict the temperature structure of the ceiling jet. The fire was assumed to grow quadratically in time and to reach full involvement in $10 \mathrm{~s}$. The two model calculations were compared $90 \mathrm{~s}$ after the start of the fire. The calculated ceiling jet temperature profile, using the CFD model, predicted a nearly flat temperature profile $6 \mathrm{~m}$ from plume center while the temperature profile derived from LAVENT predicted a substantial fall-off in temperature with distance beneath the ceiling. Based on the calculations, thermocouple trees were designed to monitor temperatures with a $0.15 \mathrm{~m}$ resolution covering a distance of $0.76 \mathrm{~m}$ beneath the roof in order to measure the temperature profile of the ceiling jet.

Modeling the impact of draft curtains versus no draft curtains was also done using the CFD model. Initially draft curtains $5.5 \mathrm{~m}$ deep were investigated for spaces with areas of $18 \mathrm{~m} \mathrm{x} 24 \mathrm{~m}$ and $24 \mathrm{~m} \mathrm{x}$ $24 \mathrm{~m}$. Only small differences in ceiling temperatures were obtained with the different draft curtain configurations. It was found that the presence of draft curtains slightly increased the temperature within the curtained region and produced a more uniform temperature distribution within the curtained region. Based on the modeling results, it was decided to use the $18 \mathrm{~m} \mathrm{x} 24 \mathrm{~m}$ draft curtain configuration. The curtain depth used for the experiment was decreased to $3.6 \mathrm{~m}$ based on present fire code regulations.

\subsubsection{Experimental Procedures and Test Information}

A test procedure was developed to coordinate the many tasks required to conduct each full scale experiment. These tasks were supervised by the project leader according to the following procedures. 


\section{Hawaii Hangar}

Temperature $30 \mathrm{~s}$

$8.1 \mathrm{MW}$ Fire

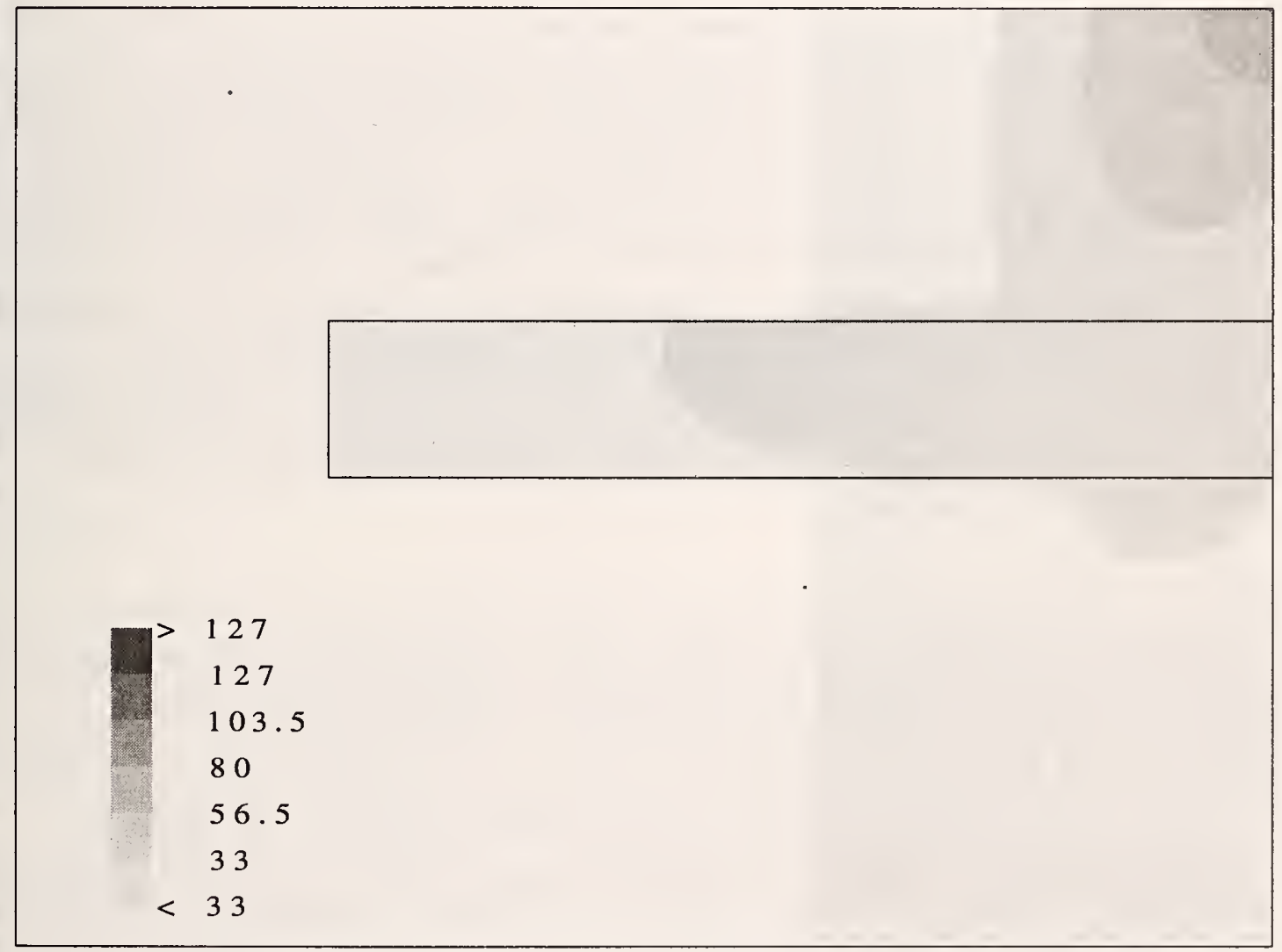

Figure 22. Top view of $15 \mathrm{~m}$ high facility as viewed in horizontal plane near ceiling. The fire is located in upper right corner. Temperature representation stops when horizontal plane intersects ceiling. The monitor window located on roof is represented by rectangle which extends beyond the intersection of plane and roof. 


\section{Equipment Check}

Instrumentation and fire protection devices were inspected before each experiment. Thermocouple and sprinkler connections were electronically checked to ensure no open circuits. Initially, thermocouples were tested with a small heat source to ensure temperature response and switch-like sprinkler connections were inspected to verify operation. Each data channel was checked for proper measurement and response. Channels or measurement points with incorrect or intermittent operations were repaired. The data system was readied for the upcoming experiment. Power supplies and controllers for wind speed transducers, the linear heat sensor, the load platform, and mass flow transducers were examined for proper operation. Water supplies for the three water-cooled radiometers were inspected for proper flow. Video cameras used to record the test were positioned. The camera designed to aid in flame height measurements was placed at a known distance from the fuel pan with a backdrop of elevation markings at $0.6 \mathrm{~m}$ intervals from the floor.

Projected beam detectors were inspected for proper alignment and operation. A nominal output voltage of four volts from each detector confirmed operation. A lower output meant the detector's lens was dirty or the unit was defective. Lenses were manually cleaned after nearly all experiments. Smoke and heat detectors were inspected to confirm acceptable operation and the central fire alarm panel provided a measure of percent-of-alarm for each detector. Generally, a value greater than $1 \%$ to $2 \%$ suggested that the detector needed to be cleaned or replaced. To speed these changes, detectors were installed onto mounting plates so they could be easily removed. Upon completion of the larger fire tests, most detectors were replaced. UV/IR detectors were located at pre-determined distances from the fire pan. A small hand held source, used as a calibration, was directed at each detector and necessary adjustments were made. The temperature of the water contained in the sprinkler piping was measured. If the temperature of the water was higher than ambient, the water was drained and the piping refilled. At this point a portable motor generator system was started to provide backup power for all data systems, power supplies and controllers.

\section{Set Fuel Pan}

The next major step in the procedure was to position the load platform and appropriate fuel pan. It was critical that these elements were centered so that measurements concerning plume symmetry, temperature and smoke movement could be referenced to a consistent central location. The pan was then leveled on the load platform and the weight of the empty pan was measured using the load cell controller. An LED indicator on the controller provided a continuous display of the weight in appropriate engineering units. Depending on the pan size (i.e., $1.5 \mathrm{~m}, 2.0 \mathrm{~m}$, and $2.5 \mathrm{~m}$ round pans), a larger load platform was used. For the later experiments conducted without the load platform which was destroyed during test 6 , fuel pans were placed on a circular arrangement of concrete blocks $0.3 \mathrm{~m}$ (1 ft) high. For the wood crib experiments a separate platform configuration and ignition sequence was used. All information on wood crib fires is documented in the Appendix.

The fuel (JP-5) was transported into the hangar via a small fuel truck. All activities concerning fuel transport were supervised by fire fighting personnel to safeguard the operation. Fuel was pumped from the fuel truck into calibrated buckets to measure the volume. Once measured, the fuel was carefully poured from the buckets into the pan. This method of volume measurement has an estimated uncertainty of $\pm 0.47 \ell(0.5$ quarts), based on the error in reading the fuel volume from the buckets, and any spillage occurring during fuel transfer. Another weight measurement was recorded for initial 
weight of fuel in the pan. Once again, a check on the stability and center position of the pan was made.

At this point a final check of all instrumentation was made. The floor based radiometer was positioned at a predetermined distance from the pan. Each UV/IR detector was positioned and aimed at the fire pan using a small visible laser mounted on the side of the detector.

\section{Building Check}

The positions of main hangar and side maintenance doors throughout the hangar were confirmed. One experiment conducted required hangar doors to be partially open. However, for the other tests all doors were closed. Other openings such as skylights and ventilation fan louvers were closed and secured. The base fire personnel were notified to stand ready. For the larger fire tests, a charged hose line containing AFFF was brought into the hangar in case an emergency shutdown was necessary. Fire fighting personnel were provided protective suits and breathing gear.

\section{Countdown Sequence}

Once all instrumentation, fuel pan, and building checks were completed a countdown sequence was initiated. The project leader notified all participants to enable their data systems and record necessary ambient conditions. Personnel who operated hangar doors for post-test smoke evacuation were told to stand ready. Video cameras began recording. The data system used to measure temperatures, sprinkler activation, and other fire parameters began recording background information.

The fuel in the pan was ignited using either a propane or acetylene torch. Ignition time was defined by sustained burning of the fuel when the torch flame was removed. A member of the test crew signaled ignition. At this point, the ignition time was noted and the remaining data recording systems were begun. A stopwatch was started at the time of ignition.

\section{During Tests}

Visual observations of plume symmetry, smoke filling, smoke movement throughout hangar, and burning characteristics, including flame spread rate across the pan, were noted along with the elapsed time. Photographs of important events which occurred during the experiment were taken. Throughout the experiment, safety temperatures (i.e., steel beam and fuel pan) were monitored to ensure that structural integrity of the hangar was not at risk. Also, smoke depth above the floor was monitored. If any of these conditions surpassed established risk protocol or other serious conditions arose, the project leader would terminate the experiment and take appropriate action to evacuate the building and begin suppression procedures. The tests continued for nominally ten minutes or until temperatures near the ceiling reached equilibrium.

\section{Suppression and Smoke Evacuation}

Upon completion of the experiment, the project leader signaled the suppression crew to begin the extinguishment process. The suppression crew consisted of base fire personnel and team members with fire fighting experience all equipped with required safety gear. $\mathrm{CO}_{2}$ type extinguishers were used to suppress the smaller fires. For the larger fires, a combination of $\mathrm{CO}_{2}$ extinguishers and a suppression lid mounted on long handles was used. As the lid was lowered over the pan, $\mathrm{CO}_{2}$ was applied to the 
flame, thus inerting the space underneath the lid. This method proved very efficient in not only suppressing the fire but protecting the load platform electronics and without spilling large amounts of fuel. One emergency shutdown was performed because the burning pan tilted and spilled fuel on the floor creating a potential hazard. In this case, the hose line filled with foam was employed and as a result the load platform was destroyed and an extensive clean-up of the area was necessary.

In all cases, once the fire was suppressed, hangar doors and skylights were opened to evacuate the smoke. During this time, all nonessential personnel were evacuated from the building. Members of the fire fighting crew remained near the extinguished pan to ensure complete suppression and prevent potential re-ignition of the fuel.

\section{Data Reduction and Fuel Removal}

Once the smoke had been evacuated, participants reentered the building and returned to their stations. Data systems were reset and files were transferred to backup media. Results were printed and graphed for analysis. The residual fuel in the pan was removed once the temperature of the fuel decreased well below its flash point. Small hand pumps were used to transfer the residual fuel into the calibrated containers for material volume measurement. The fuel was then discarded into sealable steel drums and removed from the building. The base hazard materials team performed all fuel transfers and cleanup.

\section{Discuss Results with Participants}

The final process was to discuss the results from the previous experiment. Interesting events and unusual behavior of instrumentation were also discussed. Participants evaluated instrumentation damage and/or changes required for the next experiment. The project leader was responsible for evaluating all results and planning the next experiment accordingly.

\section{Test Information}

Thirteen experiments were conducted in the $15 \mathrm{~m}$ high facility. Using the above procedures for each experiment, Table 9 contains a summary of important information relevant to each experiment, including the date and time the experiment was conducted, pan size, fuel type, ignition time, and test duration.

\subsubsection{Fuel Specifications}

All experiments conducted in the $15 \mathrm{~m}$ facility utilized JP-5 jet fuel. The base fuels department conducts certain standard tests on each batch of fuel delivered to the base. The fuel properties for the JP-5 utilized in these experiments as reported by the fuels department laboratory at Barbers Point Naval Air Station are listed in Table 10. These values were in the acceptable range as required by the military specification for JP-5 [5]. 
Table 9. Test information for each experiment conducted in $15 \mathrm{~m}$ high facility

\begin{tabular}{|c|c|c|c|c|c|c|}
\hline $\begin{array}{c}\text { Test } \\
\text { Number }\end{array}$ & Date & Time & Pan Size & Fuel Type & $\begin{array}{l}\text { Ign. } \\
\text { Time } \\
\text { (s) }\end{array}$ & $\begin{array}{c}\text { Test } \\
\text { Duration } \\
\text { (s) }\end{array}$ \\
\hline 1 & $2 / 17 / 95$ & $14: 13$ & $0.3 \mathrm{~m} \times 0.3 \mathrm{~m}$ & JP - 5 & 370 & 977 \\
\hline 2 & 2/17/95 & $17: 10$ & $0.6 \mathrm{~m} \times 0.6 \mathrm{~m}$ & JP -5 & 256 & 727 \\
\hline 3 & $2 / 17 / 95$ & $19: 30$ & $0.9 \mathrm{~m} \mathrm{x} 0.9 \mathrm{~m}$ & JP -5 & 144 & 673 \\
\hline 4 & $2 / 18 / 95$ & $10: 59$ & $1.5 \mathrm{~m}$ Diameter & JP -5 & 209 & 578 \\
\hline 5 & $2 / 18 / 95$ & $15: 04$ & $2.0 \mathrm{~m}$ Diameter & JP- 5 & 291 & 537 \\
\hline $6 b^{a}$ & $2 / 18 / 95$ & $22: 05$ & $2.5 \mathrm{~m}$ Diameter & JP - 5 & 90 & 563 \\
\hline $7^{\mathrm{b}}$ & $2 / 19 / 95$ & $15: 03$ & $2.0 \mathrm{~m}$ Diameter & JP - 5 & 93 & 744 \\
\hline 8 & $2 / 19 / 95$ & $18: 48$ & $2.5 \mathrm{~m}$ Diameter & JP - 5 & 617 & 517 \\
\hline $9^{c}$ & $2 / 20 / 95$ & $11: 28$ & $0.6 \mathrm{~m}$ (cube) & Wood Crib & 40 & 275 \\
\hline $10^{c}$ & $2 / 20 / 95$ & $11: 58$ & $0.6 \mathrm{~m} \times 0.6 \mathrm{~m} \times 1.2 \mathrm{~m}$ & Wood Crib & 226 & 615 \\
\hline 11 & $2 / 20 / 95$ & $12: 53$ & $0.3 \mathrm{~m} \mathrm{x} 0.3 \mathrm{~m}$ & $\mathrm{JP}-5$ & 161 & 681 \\
\hline 12 & $2 / 20 / 95$ & $13: 40$ & $0.6 \mathrm{~m} \times 0.6 \mathrm{~m}$ & $J P-5$ & 37 & 735 \\
\hline $13^{\mathrm{d}}$ & $2 / 20 / 95$ & $16: 30$ & $2.0 \mathrm{~m}$ Diameter ${ }^{\mathrm{d}}$ & JP - 5 & 150 & 155 \\
\hline
\end{tabular}

a Test 6 a was aborted.

${ }^{\mathrm{b}}$ The draft curtain was removed for tests 7-13.

${ }^{\mathrm{c}}$ All data for wood crib fires (tests 9 and 10) is available in Appendix [ ].

${ }^{\mathrm{d}}$ Test conducted with both hangar doors partially open as described in section 6.3.1. 
Table 10. Fuel specifications for $15 \mathrm{~m}$ high facility experimental fires

\begin{tabular}{|c|c|}
\hline Parameter & Specification \\
\hline Fuel Sample & JP-5 \\
Date Taken & $2 / 17 / 95$ \\
API Gravity @ $15^{\circ} \mathrm{C}$ & 40.9 \\
Specific Gravity & 0.8074 \\
Density $\left(\mathrm{kg} / \mathrm{m}^{3}\right)$ & 807.1 \\
Flash Point $\left({ }^{\circ} \mathrm{C}\right)$ & 60.0 \\
\hline
\end{tabular}




\subsection{Fire Behavior in $15 \mathrm{~m}$ Hangar}

Table 9 is a list of all the fires set in the $15 \mathrm{~m}$ hangar at Barbers Point. The JP-5 pools smaller than 1.0 $\mathrm{m}$ are classified "detector fires" because they were designed to check the response characteristics of various fire detection schemes. The behavior of these fires is described in the following section. Fires larger than $1.0 \mathrm{~m}$ are classified as "sprinkler fires." These were chosen to challenge different sprinkler activation designs, and are discussed in section 3.3.2. The two wood crib fires were used to investigate the response of the detection systems to a Class A fire; these are outside the focus of this report but are included in the Appendix for completeness.

\subsubsection{Behavior of Detector Fires}

There were five detector fires conducted in the $15 \mathrm{~m}$ high facility, three with the draft curtain in place and two without the draft curtain. All the detector fires were conducted on the single point load platform and used JP-5 aviation fuel. Fires were all positioned at the test center point as described in Figure 4. Detector fires were ignited at one corner of the fire test pan. The $0.3 \mathrm{~m} \mathrm{x} 0.3 \mathrm{~m}$ fires were ignited with a propane torch and the $0.6 \mathrm{~m} \mathrm{x} 0.6 \mathrm{~m}$ and the $0.9 \mathrm{~m} \times 0.9 \mathrm{~m}$ fires were ignited with an acetylene torch. The ambient fuel temperatures ranged from $27{ }^{\circ} \mathrm{C}$ to $31{ }^{\circ} \mathrm{C}$. It took over $60 \mathrm{~s}$ to achieve sustained combustion with the propane torch and between 5 and 10 seconds to achieve sustained combustion with the acetylene torch. Table 11 provides the test information for each detector fire conducted. Information in the table includes pan size, ambient temperatures, time for the fire to spread across and fully involve the fire pan, and steady state flame heights as measured from the video. All detector fires were allowed to burn at least ten minutes.

Table 11. Information on detector fires conducted in $15 \mathrm{~m}$ high facility

\begin{tabular}{|c|c|c|c|c|}
\hline Test Number & $\begin{array}{c}\text { Pan Size } \\
\mathrm{m}\end{array}$ & $\begin{array}{c}\text { Ambient } \\
\text { Temperature } \\
{ }^{\circ} \mathrm{C}\end{array}$ & $\begin{array}{c}\text { Full Pan } \\
\text { Involvement } \\
\mathrm{s}\end{array}$ & $\begin{array}{c}\text { Steady State } \\
\text { Flame Height } \\
\mathrm{m}\end{array}$ \\
\hline 1 & $0.3 \times 0.3$ & 27 & $<5$ & 0.9 \\
\hline 2 & $0.6 \times 0.6$ & 28 & 10 & 2.3 \\
\hline 3 & $0.9 \times 0.9$ & 27 & 20 & 3.7 \\
\hline 11 & $0.3 \times 0.3$ & 31 & $<5$ & 0.9 \\
\hline 12 & $0.6 \times 0.6$ & 31 & 10 & 2.3 \\
\hline
\end{tabular}

\section{Plume Symmetry}

The spatial location of the plume near the ceiling was determined using both the regular array of thermocouples located $0.15 \mathrm{~m}$ beneath the ceiling at radial positions of $1.5 \mathrm{~m}$ and $3.0 \mathrm{~m}$ in the experimental $\mathrm{N}, \mathrm{S}, \mathrm{E}$, and $\mathrm{W}$ directions from the geometric center of the fire and the array of thermocouples located $3.0 \mathrm{~m}$ beneath the ceiling at radial positions of $0.0 \mathrm{~m}, 0.9 \mathrm{~m}$ and $2.1 \mathrm{~m}$ in the $\mathrm{N}$, $\mathrm{S}, \mathrm{E}$, and $\mathrm{W}$ directions from the geometric center as previously described. The initial position of the 
plume near the ceiling was determined using the arrival time of the hot gas at each thermocouple, while later plume positions were deduced from comparing the relative temperature of symmetric pairs of thermocouples for the thermocouple array at the ceiling and $3.0 \mathrm{~m}$ beneath the ceiling. An idealized plume has its highest temperature on its center line with mixing of the entrained ambient air causing the temperature distribution to decrease radially outward. The largest uncertainties in the determination of plume center occur due to thermal irregularities in the plume and to the fact that thermocouples were measured sequentially. The time between adjacent thermocouple readings was normally less than $1.5 \mathrm{~s}$.

Videos of the fire taken using cameras looking north and east were also used to determine the lean of the flame and lower plume. While the location of the smoke plume at the ceiling was either not available or difficult to determine owing to poor visibility at the ceiling, the lean of the flame and lower plume provide some confirmation of plume lean as determined by the thermocouples at or near the ceiling. The flame leans are determined based on the position of the tip of the continuous part of the flame compared to the location of the edge of the pan. This measurement should be regarded as an estimate with an accuracy equal to about $25 \%$ of the pan edge or diameter.

Two $0.3 \mathrm{~m} \times 0.3 \mathrm{~m}$ tests were conducted, one with and one without draft curtains. These tests produced temperature increases at the ceiling of only $0.5^{\circ} \mathrm{C}$ and $3{ }^{\circ} \mathrm{C}$ respectively. For the curtained test, comparison of the thermocouples $\mathrm{C} 5, \mathrm{C} 7, \mathrm{C} 9$, and $\mathrm{C} 11$ reveal that the plume leaned toward the north for the first $280 \mathrm{~s}$ of the test, then leaned south for the next $250 \mathrm{~s}$ and then was centered for the rest of the test. In the E-W plane, the plume initially had a slight east lean for the first $150 \mathrm{~s}$, was centered for the next $150 \mathrm{~s}$, and then leaned west for the remainder of the test. The video observations indicated an early SE lean for the flame which was estimated to be about $0.2 \mathrm{~m}$ to both the east and south directions. The lean to the east persisted till at least 210 's into the test but the lean to the south disappeared about $150 \mathrm{~s}$ into the test. For the uncurtained test, thermocouple S7 consistently yielded temperatures higher than any of the other thermocouples in the array located $3.0 \mathrm{~m}$ below the ceiling, implying that the plume was centered about $2.0 \mathrm{~m}$ south of geometric center. Video observations suggest the fire was fairly well centered in the $\mathrm{N}-\mathrm{S}$ direction till after the first beam detector activated, at which time the fire exhibited a slight lean to the north. In the E-W direction, the fire exhibited a fairly consistent lean of about $0.3 \mathrm{~m}$ towards the east throughout the test.

Two $0.6 \mathrm{~m} \times 0.6 \mathrm{~m}$ tests were conducted, one with and one without draft curtains. For the test with the draft curtains, a significant shift of the plume center to experimental east was observed early in the fire as thermocouples E15 and E16 produced higher readings than thermocouples W10 and W11, with thermocouple E15 reading higher than thermocouple $\mathrm{Cl}$ which was located at the geometrical center of the fire. This suggested that the plume center was located at least $1.5 \mathrm{~m}$ south of fire center. There was an early indication of a shift in plume center to experimental south but this shift was much smaller than the shift to the east. Video observations showed that the flame was centered at the beginning of the test but by $70 \mathrm{~s}$ had begun to lean to the west by $0.2 \mathrm{~m}$. At $120 \mathrm{~s}$, the flame again became centered and remained that way until about $240 \mathrm{~s}$ into the test when it began to lean to the $\mathrm{N}-\mathrm{W}$. At about $300 \mathrm{~s}$ into the test, the N-W lean reached a maximum of about $0.3 \mathrm{~m}$ in both the north and west directions and then moved to the west at $360 \mathrm{~s}$ and then to the north at $420 \mathrm{~s}$. The north lean maximized at $0.4 \mathrm{~m}$ at $450 \mathrm{~s}$ with an additional $0.2 \mathrm{~m}$ lean to the west. The plume center for the test conducted without a draft curtain shows a substantial shift to the south-west with both thermocouples $\mathrm{C} 6$ and $\mathrm{C} 8$ recording temperatures higher than thermocouple $\mathrm{C} 3$ located at the geometric center of the fire. Estimated plume center location was about $1.0 \mathrm{~m}$ to the south and almost the same distance to the west. Video 
observations of the flame displayed an initial lean of $0.2 \mathrm{~m}$ to the west at the beginning of the test. At about 25 seconds into the test, the flame became centered and then at $120 \mathrm{~s}$, returned to the $0.2 \mathrm{~m} \mathrm{~S}-\mathrm{E}$ lean. At about $180 \mathrm{~s}$ the flame centered in both the E-W and N-S directions and then at $210 \mathrm{~s}$ it returned to a lean of $0.2 \mathrm{~m}$ to the south.

The plume for the $0.9 \mathrm{~m} \times 0.9 \mathrm{~m}$ test indicated a plume center that was located about $0.5 \mathrm{~m}$ to the north and just slightly off center to the west. The displacement to the north was estimated by comparing thermocouples $\mathrm{C} 3$ and $\mathrm{C} 4$ located at the center and $1.0 \mathrm{~m}$ to the north respectively. These thermocouples recorded almost identical temperatures indicating that the plume center was located about midway between the two thermocouples. The video records for this test indicated that in the N-S direction the flame started out centered but was leaning $0.2 \mathrm{~m}$ north by $90 \mathrm{~s}$ into the test. The flame remained in a northward orientation but swayed from being almost centered to leaning as much as 0.4 $\mathrm{m}$ to the north. In the E-W direction, the flame started out leaning $0.2 \mathrm{~m}$ to the west, centered at $25 \mathrm{~s}$, and then by $120 \mathrm{~s}$ was leaning $0.1 \mathrm{~m}$ to the west. This westward lean reached $0.2 \mathrm{~m}$ by $150 \mathrm{~s}$ when the flame began moving back toward the center. For flame remained centered till about $360 \mathrm{~s}$ when it again moved to about $0.1 \mathrm{~m}$ to the west.

\section{Temperature}

Thermocouples at the ceiling of the $15 \mathrm{~m}$ high facility were evaluated to determine the temperature rise above ambient temperature for all detector fires. This information can be used to compare how temperature varies with fire sizes and to validate temperature predictions of various models.

Table 12 shows the maximum temperature in the center region of the test area and the corresponding rise above ambient temperature. The maximum temperature rise was determined by evaluating thermocouples located $0.15 \mathrm{~m}$ below the ceiling deck and within a $3.0 \mathrm{~m}$ radius of the fire centerline. Thermocouples used were the following: center (C1), $1.5 \mathrm{~m}$ north/south/east/west (N11, S10, E16, $\mathrm{W} 11$ ), and $3.0 \mathrm{~m}$ north/south/east/west (N10, S9, E15, W10). The temperatures reported are based on analyzing the temperature range over the time interval where the fire's mass loss rate appeared steady and choosing a value equal to ninety percent of the range. Since the temperatures throughout this range were increasing, the maximum value generally occurred late in the test. By evaluating the central region of temperatures for each test, the effect of plume lean on center temperature is somewhat minimized.

Maximum temperature with respect to time for the thermocouples within a $3.0 \mathrm{~m}$ radius from center at $0.15 \mathrm{~m}$ below the ceiling are presented in Figures 23 and 24. Figure 23 shows the detector fires conducted with the draft curtain (tests $1,2,3$ ) and the Figure 24 shows the detector fires conducted without the draft curtains (tests 11,12 ). In this central region temperatures are similar in magnitude for both the draft curtained and non-curtained cases.

Table 13 indicates maximum temperatures at specific locations with respect to the draft curtain. All entries are for thermocouples located $0.3 \mathrm{~m}$ below ceiling deck. For example, temperatures at $8.5 \mathrm{~m}$ north and south are located just inside the draft curtain as is the temperatures at $11.6 \mathrm{~m}$ east and west. This position in the north and south direction is located outside the draft curtain. Thermocouples at $14.6 \mathrm{~m}$ east and west are located outside the draft curtain. Omitted entries in the table are locations where temperature measurements were not made or are duplicates of other measurements. 
Table 12. Temperature rise above ambient for detector fires

\begin{tabular}{|c|c|c|c|c|c|}
\hline \multicolumn{3}{|c|}{ Test Information } & \multicolumn{3}{c|}{ Temperature Parameters } \\
\hline $\begin{array}{c}\text { Test } \\
\text { Number }\end{array}$ & $\begin{array}{c}\text { Pan Size } \\
\mathrm{m}\end{array}$ & $\begin{array}{c}\text { HRR } \\
\mathrm{MW}\end{array}$ & $\begin{array}{c}\text { Maximum } \\
\text { Temperature } \\
{ }^{\circ} \mathrm{C}\end{array}$ & $\begin{array}{c}\text { Ambient } \\
\text { Temperature, } \\
{ }^{\circ} \mathrm{C}\end{array}$ & $\begin{array}{c}\text { Rise Above } \mathrm{T}_{\text {amb }} \\
{ }^{\circ} \mathrm{C}\end{array}$ \\
\hline 1 & $0.3 \times 0.3$ & 0.1 & 31 & 27 & 4 \\
\hline 2 & $0.6 \times 0.6$ & 0.5 & 44 & 28 & 16 \\
\hline 3 & $0.9 \times 0.9$ & 1.9 & 56 & 27 & 29 \\
\hline $11^{\mathrm{b}}$ & $0.3 \times 0.3$ & 0.1 & 34 & 31 & 3 \\
\hline $12^{\mathrm{b}}$ & $0.6 \times 0.6$ & $\mathrm{n} / \mathrm{a}$ & 44 & 31 & 13 \\
\hline
\end{tabular}

${ }^{a}$ Maximum temperature found by evaluating thermocouples at center, $1.5 \mathrm{~m}, 3.0 \mathrm{~m}$ (NSEW), $0.15 \mathrm{~m}$ below deck

b Tests conducted without draft curtains

\section{Hot Gas Flow}

The impact of the draft curtain on hot gas flow can be seen from the data presented in Table 14. The filling time for the draft curtain was determined by comparing temperatures measured with the thermocouple tree located at $9.1 \mathrm{~m}$ east of fire center to the tree $3.0 \mathrm{~m}$ inside the edge of the draft curtain. Based on the times required for the thermocouple located $3.0 \mathrm{~m}$ below the ceiling to record a temperature rise, the draft curtain filled in $100 \mathrm{~s}$ and $67 \mathrm{~s}$ for $0.6 \mathrm{~m} \mathrm{x} 0.6 \mathrm{~m}$ pan and the $0.9 \mathrm{~m} \mathrm{x} 0.9 \mathrm{~m}$ pan, respectively.

The times for the hot gas to reach the $6.1 \mathrm{~m}$ position and the edge of the draft curtain are essentially the same for all fire tests. The reason for this is that each fire pan was only ignited at one corner. For the early timing measurements, the fire size depends on how much of each pan has become fully involved and not on pan size. Since the ignition method was approximately the same for each pan size, the flame spread and hence the fire size will be the same for each pan size early in the test. Variations in the timing will occur due to uncertainties in the fire start time, the initial fuel temperature, and in the initial amount of area ignited by the torch.

With the draft curtain in place, the transport time of the hot gas to the ceiling was approximately $18 \mathrm{~s}$ for the $0.3 \mathrm{~m} \mathrm{x} 0.3 \mathrm{~m}$ pan fire, $8 \mathrm{~s}$ for the $0.6 \mathrm{~m} \mathrm{x} 0.6 \mathrm{~m}$ pan, and $13 \mathrm{~s}$ for the $0.9 \mathrm{~m} \mathrm{x} 0.9 \mathrm{~m}$ pan. Arrival of heat at the ceiling was indicated by a temperature rise on one of the thermocouples $0.3 \mathrm{~m}$ below the ceiling over the test center point or at $1.5 \mathrm{~m}$ radially out from test center. Without the draft curtain in place, transport time to the ceiling was $24 \mathrm{~s}$ for the $0.6 \mathrm{~m} \mathrm{x} 0.6 \mathrm{~m}$ fire. Transport time was not measurable for the $0.3 \mathrm{~m} \mathrm{x} 0.3 \mathrm{~m}$ fire without the draft curtain due to the very slight temperature rise at the ceiling. Major uncertainties in determining the transport time of hot gas to the ceiling include; accurate determination of the starting time for the fire, initial plume lean, and the coarseness of the measurement interval which varied between $3 \mathrm{~s}$ to $4 \mathrm{~s}$.

A comparison of the time for the draft curtain to fill with the time for the hot gas to reach a thermocouple outside the draft curtain can be used to determine if the draft curtain fills before spilling into the adjacent area. For these comparisons, the ceiling thermocouple at $14.6 \mathrm{~m}$ east is used to determine spillage time outside the draft curtain while the thermocouple at $9.1 \mathrm{~m}$ east, $3.0 \mathrm{~m}$ below the ceiling, is used for draft curtain filling. The reason for using only the east thermocouples is to attempt 


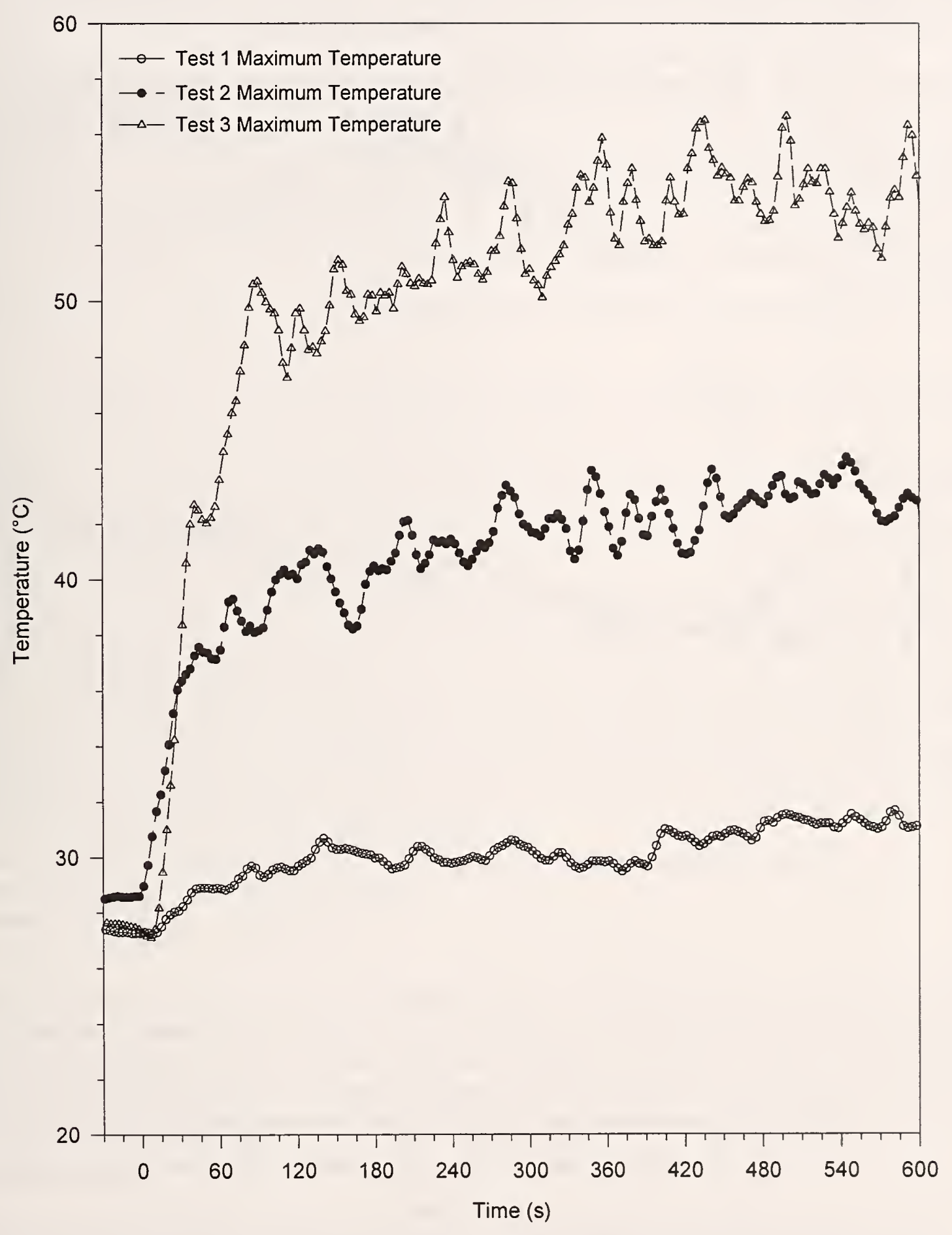

Figure 23. Maximum temperatures for detector fires conducted with draft curtains. 


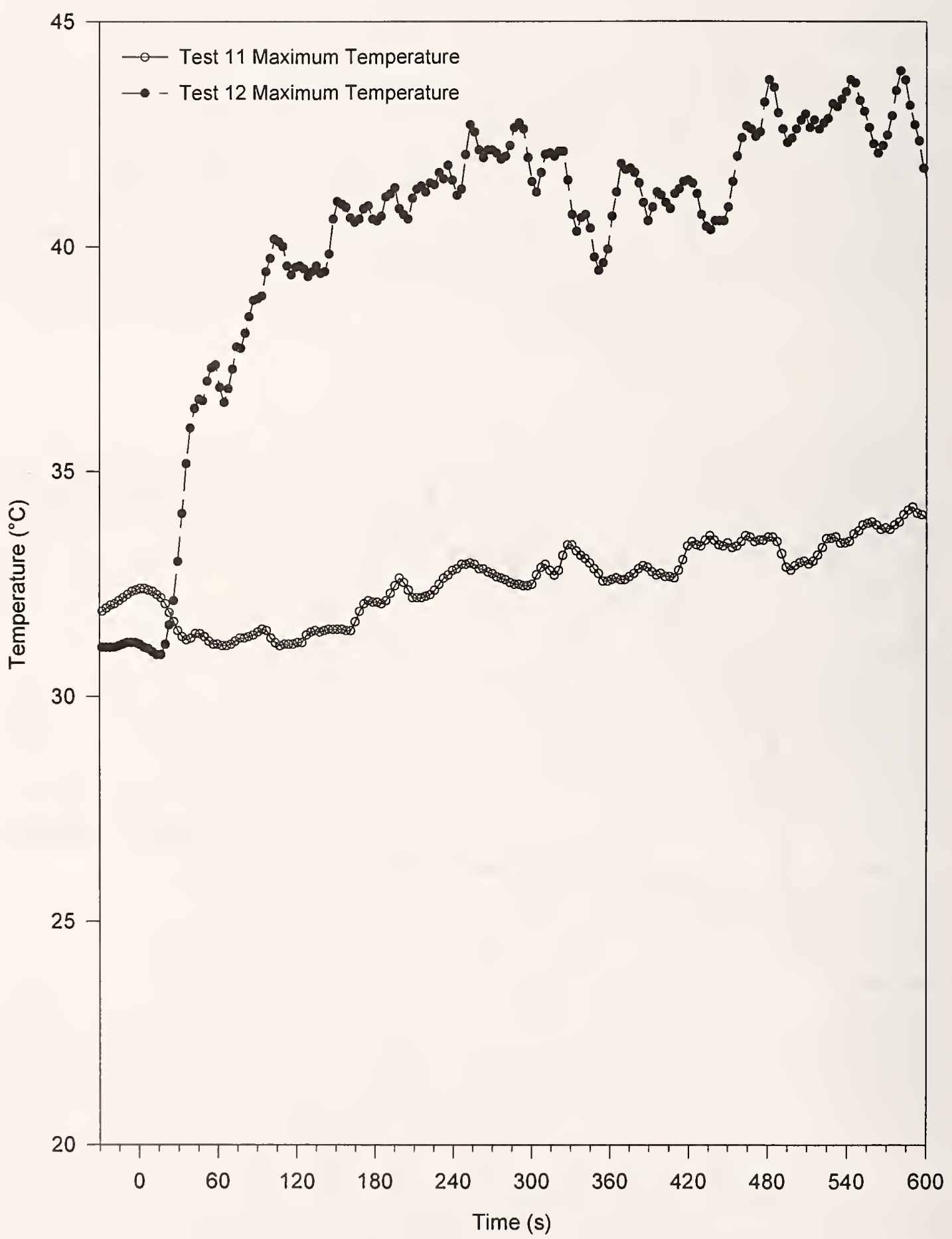

Figure 24. Maximum temperatures for detector fires conducted without draft curtains. 
Table 13. Maximum temperature rise at various locations

\begin{tabular}{|c|c|c|c|c|c|c|c|}
\hline \multicolumn{3}{|c|}{ Test Information } & \multicolumn{5}{|c|}{ Maximum Temperature Rise Above $\mathrm{T}_{\text {amb }}\left({ }^{\circ} \mathrm{C}\right)$} \\
\hline $\begin{array}{c}\text { Test } \\
\text { Number }\end{array}$ & $\begin{array}{c}\text { Pan Size } \\
\text { m }\end{array}$ & $\begin{array}{l}\mathrm{T}_{\text {amb }} \\
{ }^{\circ} \mathrm{C}\end{array}$ & Location & $6.1 \mathrm{~m}$ & $8.5 \mathrm{~m}^{\mathrm{a}}$ & $11.6 \mathrm{~m}^{\mathrm{b}}$ & $14.6 \mathrm{~m}^{\mathrm{c}}$ \\
\hline \multirow{4}{*}{$\begin{array}{c}1 \\
w / \\
\text { Draft } \\
\text { Curtain }\end{array}$} & \multirow[t]{4}{*}{$0.3 \times 0.3$} & \multirow[t]{4}{*}{27} & north & 1. & 1 & 0 & -- \\
\hline & & & south & 4 & 3 & 1 & -- \\
\hline & & & east & 2 & - & 2 & 1 \\
\hline & & & west & 3 & -- & 2 & 1 \\
\hline \multirow{4}{*}{$\begin{array}{c}11 \\
\text { w/o } \\
\text { Draft } \\
\text { Curtain }\end{array}$} & \multirow[t]{4}{*}{$0.3 \times 0.3$} & \multirow[t]{4}{*}{31} & north & 1 & 2 & 2 & - \\
\hline & & & south & 2 & 1 & 1 & -- \\
\hline & & & east & 1 & - & 1 & 1 \\
\hline & & & west & 0 & -- & 1 & 1 \\
\hline \multirow{4}{*}{$\begin{array}{c}2 \\
\text { w/ } \\
\text { Draft } \\
\text { Curtain }\end{array}$} & \multirow[t]{4}{*}{$0.6 \times 0.6$} & \multirow[t]{4}{*}{28} & north & 13 & 10 & 4 & -- \\
\hline & & & south & 14 & 10 & 3 & -- \\
\hline & & & east & 9 & - & 9 & 5 \\
\hline & & & west & 9 & -- & 9 & 4 \\
\hline \multirow{4}{*}{$\begin{array}{c}12 \\
\text { w/o } \\
\text { Draft } \\
\text { Curtain }\end{array}$} & \multirow[t]{4}{*}{$0.6 \times 0.6$} & \multirow[t]{4}{*}{31} & north & 8 & 6 & 5 & -- \\
\hline & & & south & 9 & 6 & 6 & -- \\
\hline & & & east & 8 & - & 4 & 4 \\
\hline & & & west & 5 & -- & 4 & 3 \\
\hline \multirow{4}{*}{$\begin{array}{c}3 \\
\text { w/ } \\
\text { Draft } \\
\text { Curtain }\end{array}$} & \multirow[t]{4}{*}{$0.9 \times 0.9$} & \multirow[t]{4}{*}{27} & north & 24 & 20 & 9 & - \\
\hline & & & south & 21 & 18 & 7 & -- \\
\hline & & & east & 21 & - & 18 & 11 \\
\hline & & & west & 16 & -- & 17 & 8 \\
\hline
\end{tabular}

${ }^{a}$ Located near inside edge of north and south draft curtains

${ }^{b}$ Located near inside edge of east and west draft curtains, outside DC in north and south direction

${ }^{c}$ Located outside draft curtain in east/west direction

-- Temperature not measured at this location

to minimize the impact of plume lean on the comparisons. The difference in time between the hot gas flow registering a temperature rise outside the draft curtain and the time to fill the draft curtain are $11 \mathrm{~s}$ and $6 \mathrm{~s}$ respectively for the $0.6 \mathrm{~m} \times 0.6 \mathrm{~m}$ and $0.9 \mathrm{~m} \times 0.9 \mathrm{~m}$ pans. Since the hot gas flowing over the bottom of the draft curtain must rise to the ceiling and flow radially outward an additional $2.4 \mathrm{~m}$, the data suggests that the hot gas flows under the draft curtain prior to filling the draft curtain.

\section{Ceiling Jet Velocities}

Ceiling jet velocities were determined using two hot wire anemometers as described earlier. The anemometers were located $6.1 \mathrm{~m}$ to the east and north of fire center and $0.15 \mathrm{~m}$ below the ceiling. 
Table 14. Hot gas flow results (s) for experiments conducted with draft curtain

\begin{tabular}{|c|c|c|c|c|}
\hline $\begin{array}{c}\text { Draft Curtain } \\
\text { Test } \\
\text { Pan Size, } \mathrm{m}\end{array}$ & $\begin{array}{c}\text { Curtain Filling } \\
\text { Time }\end{array}$ & $\begin{array}{c}\text { Time to } 11.6 \mathrm{~m} \\
\text { East }\end{array}$ & $\begin{array}{c}\text { Time to } 14.6 \mathrm{~m} \\
\text { East }\end{array}$ & $\begin{array}{c}\text { Time from } \\
6.1 \mathrm{~m} \text { to } 11.6 \mathrm{~m} \\
\text { East }\end{array}$ \\
\hline $0.6 \times 0.6$ & 100 & 43 & 89 & 13 \\
\hline $0.9 \times 0.9$ & 67 & 38 & 61 & 12 \\
\hline 1.5 diameter & 50 & 38 & 57 & 14 \\
\hline 2.0 diameter & 38 & 42 & 48 & 17 \\
\hline 2.5 diameter & 32 & 29 & 39 & 9 \\
\hline
\end{tabular}

Table 15. Maximum ceiling jet velocity and radiation measurements

\begin{tabular}{|c|c|c|c|c|c|}
\hline $\begin{array}{c}\text { Test } \\
\text { Pan Size, } \mathrm{m}\end{array}$ & $\begin{array}{c}\text { CJ east } \\
\mathrm{m} / \mathrm{s} \pm 0.1\end{array}$ & $\begin{array}{c}\text { CJ north } \\
\mathrm{m} / \mathrm{s} \pm 0.1\end{array}$ & $\begin{array}{c}\text { Rad. } 1 \\
\mathrm{~kW} / \mathrm{m}^{2} \pm 0.25\end{array}$ & $\begin{array}{c}\text { Rad. } 2 \\
\mathrm{~kW} / \mathrm{m}^{2} \pm 0.25\end{array}$ & $\begin{array}{c}\text { Rad. } 3 \\
\mathrm{~kW} / \mathrm{m}^{2} \pm 0.25\end{array}$ \\
\hline $0.3 \times 0.3^{\mathrm{a}}$ & $\mathrm{n} / \mathrm{a}$ & $\mathrm{n} / \mathrm{a}$ & $\mathrm{n} / \mathrm{a}$ & $\mathrm{n} / \mathrm{a}$ & $\mathrm{n} / \mathrm{a}$ \\
\hline $0.3 \times 0.3$ & 0.1 & 0.2 & 0 & 0 & 0 \\
\hline $0.6 \times 0.6^{\mathrm{a}}$ & 0.7 & 0.4 & 0 & 0 & 0 \\
\hline $0.6 \times 0.6$ & 0.4 & 0.2 & 0 & 0 & 0 \\
\hline $0.9 \times 0.9^{\mathrm{a}}$ & 0.9 & 0.7 & 0 & 0 & 0 \\
\hline 1.5 dia. $^{2}$ & 0.4 & 1.3 & 2.6 & 0.89 & 0.91 \\
\hline 2.0 dia. $^{\mathrm{a}}$ & 0.5 & 1.0 & 5.4 & 0.59 & 1.5 \\
\hline 2.0 dia. $^{\mathrm{a}}$ & 0.7 & 1.6 & 4.7 & 0.67 & 1.2 \\
\hline 2.5 dia. $^{\mathrm{a}}$ & $\mathrm{n} / \mathrm{a}$ & $\mathrm{n} / \mathrm{a}$ & 6.8 & 1.19 & 2.4 \\
\hline 2.5 dia. & $\mathrm{n} / \mathrm{a}$ & $\mathrm{n} / \mathrm{a}$ & $\mathrm{n} / \mathrm{a}$ & $\mathrm{n} / \mathrm{a}$ & $\mathrm{n} / \mathrm{a}$ \\
\hline
\end{tabular}

${ }^{a}$ Draft curtain experiment

Measurement of maximum ceiling jet velocities in all experiments are presented in Table 15 . The anemometers were oriented such that only the component of the velocity parallel to the ceiling would be measured. The anemometers were limited to a maximum temperature of $120^{\circ} \mathrm{C}$. Temperatures in excess of this amount would cause a low or zero velocity reading.

Maximum velocity readings for the $0.3 \mathrm{~m} \mathrm{x} 0.3 \mathrm{~m}$ test without a draft curtain were $0.1 \mathrm{~m} / \mathrm{s}$ east and $0.2 \mathrm{~m} / \mathrm{s}$ north. The $0.3 \mathrm{~m} \times 0.3 \mathrm{~m}$ test with a draft curtain did not have velocity measurements due to an instrument failure. Maximum velocity readings for the $0.6 \mathrm{~m} \times 0.6 \mathrm{~m}$ tests were $0.7 \mathrm{~m} / \mathrm{s}$ to the east 
and $0.4 \mathrm{~m} / \mathrm{s}$ to the north for the draft curtain test and $0.4 \mathrm{~m} / \mathrm{s}$ to the east and $0.2 \mathrm{~m} / \mathrm{s}$ to the north for the test without the draft curtain. Based on the plume symmetry observations, both measurements were made outside the plume region. The $0.9 \mathrm{~m} \times 0.9 \mathrm{~m}$ test gave velocity readings of $0.9 \mathrm{~m} / \mathrm{s}$ east and 0.7 $\mathrm{m} / \mathrm{s}$ north. The plume leaned to the north and west for this test but the north readings did not indicate the anemometer was in the plume.

\section{Heat Flux Measurements}

Total heat flux (primarily radiation) was measured at three positions using water-cooled Gardon type heat flux transducers. Each transducer was aimed directly at the fire center. The first transducer was placed approximately $5 \mathrm{~m}$ east of fire center and was located $1.22 \mathrm{~m}$ above the floor. The second transducer was located $9.8 \mathrm{~m}$ above the floor and $6.1 \mathrm{~m}$ east of fire center while the third was located $0.15 \mathrm{~m}$ below the ceiling and $6.1 \mathrm{~m}$ east of fire center. Heat flux results are shown in Table 15 . None of the flux meters recorded measurable signals from the detector fires.

\section{Heat Release Rate}

Two methods were used to determine the heat release rate for the detector fires. The first method employed direct measurement of the mass loss rate of the fuel. The heat release rate was then determined by multiplying the measured mass loss rate by the heat of combustion of the fuel. For those tests where the mass loss rate was not measured due to instrumentation failures, an approximate measure of the mass loss rate was made by determining the volume of fuel burned during the test and using the density of the fuel to calculate the average mass loss over the duration of the test. Since the final volume measurement for the fuel was not made until the fuel had cooled down below the flash point, the final volume measurement would include any losses due to fuel vaporization and extinguishment losses during fire suppression. In all cases, suppression was performed with a lid supplemented by $\mathrm{CO}_{2}$ fire extinguishers at the pan edges. This technique was used to minimize residual fuel losses and protect the load platform electronics. Direct measurement of the mass loss rate using a load cell was performed for the $0.6 \mathrm{~m} \mathrm{x} 0.6 \mathrm{~m}, 0.9 \mathrm{~m} \mathrm{x} 0.9 \mathrm{~m}, 1.5 \mathrm{~m}$ diameter, and $2.0 \mathrm{~m}$ diameter pans for the fire tests conducted with draft curtains. The mass loss rate for all the other tests were calculated from the fuel volume consumed by the fire.

Where load cell data were available, a linear curve fit was used to determine burning rate after an approximate steady state condition was reached. Figure 25 shows an example of the steady state analysis of the mass loss data. For the fire tests where the consumed volume method was used, the volume of fuel consumed was divided by the total test time in order to obtain an average mass loss rate. The estimated steady state heat release rates for the draft curtained fires are $0.1 \mathrm{MW}$ for the $0.3 \mathrm{~m} \mathrm{x}$ $0.3 \mathrm{~m}$ pan, $0.5 \mathrm{MW}$ for the $0.6 \mathrm{~m} \times 0.6 \mathrm{~m}$ pan, and $1.9 \mathrm{MW}$ for the $0.9 \mathrm{~m} \mathrm{x} 0.9 \mathrm{~m}$ pan. Additional data including the mass loss rate for all tests are shown in Table 16. Omitted entries in the table indicate load platform malfunction and incomplete volume measurements of residual fuel. Each experiment was run for a minimum of ten minutes. The burning rate increased during the early part of the fire until steady state burning was reached. Temperature profiles in the plume, similar to those shown in the previous figures, were analyzed to determine a consistent time range where the temperature increases were of a uniform nature. Factors such as plume lean and burning off the side of the pan were considered. The values for steady state time are show in Table 16. The time required to reach steady state varied with pan size, with the larger pans generally requiring more time to achieve steady state. 

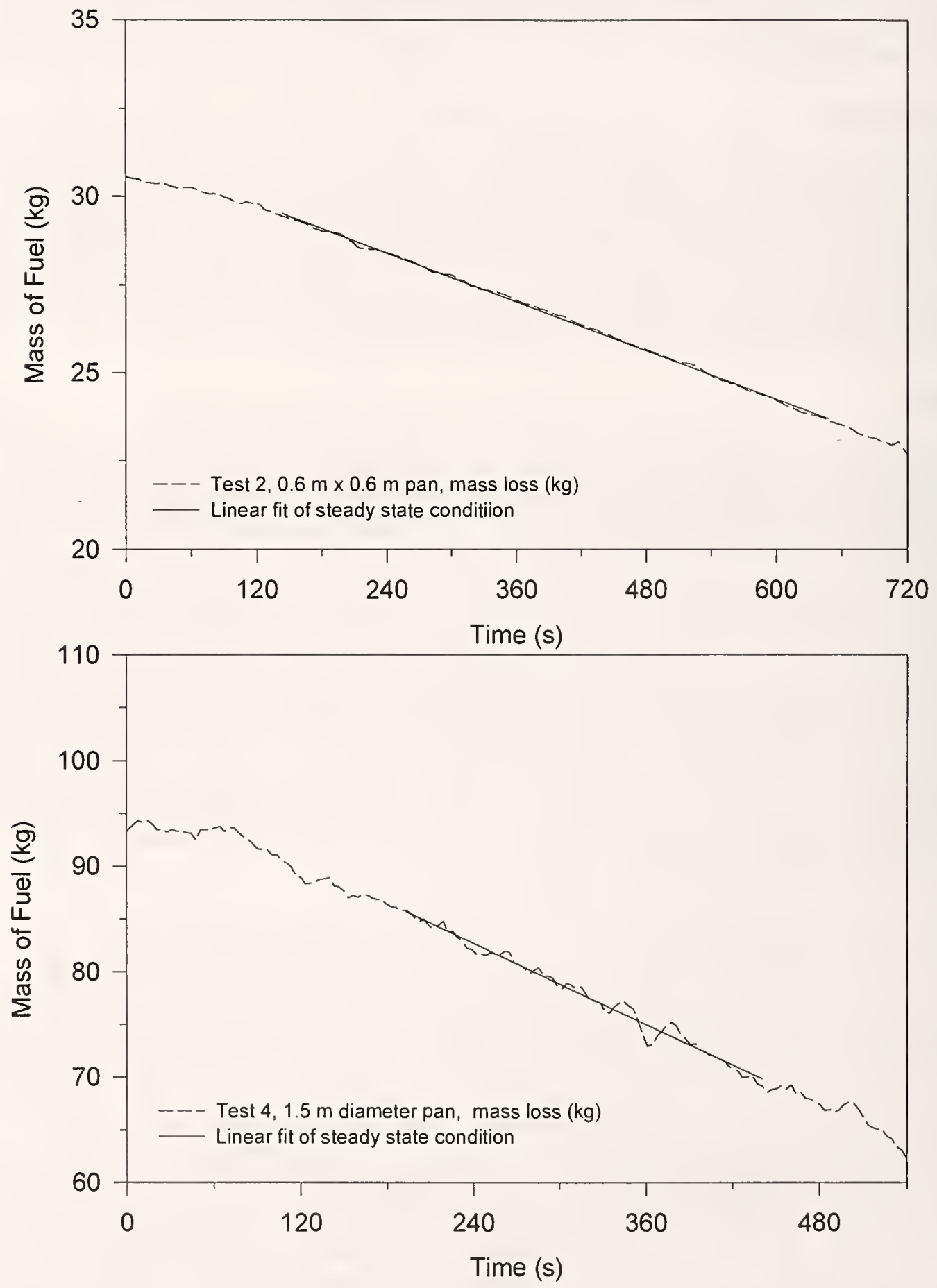

Figure 25. Examples of mass loss curves and linear fit of steady state region. 


\begin{tabular}{|c|c|c|c|c|c|c|c|c|c|c|c|c|c|}
\hline 岁 & 墭 & 命 & $\widehat{N}$ & $\frac{n}{6}$ & $\infty$ & $\tilde{n}_{n}^{n}$ & $\hat{\circ}$ & 寺 & $\frac{n}{n}$ & $\infty$ & $\stackrel{n}{n}$ & $\approx$ & \\
\hline 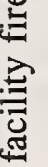 & 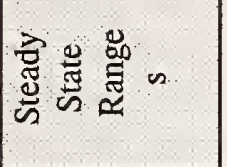 & 용 & 용요 & $\begin{array}{l}1 \\
0 \\
0\end{array}$ & 용 & \begin{tabular}{ll}
1 & 0 \\
$\stackrel{2}{0}$ & 8 \\
\hdashline
\end{tabular} & 운은 & $\stackrel{1}{\infty} \stackrel{\infty}{\infty}$ & 官 & 1 & 용 & $\stackrel{1}{1} 8$ & \\
\hline a & 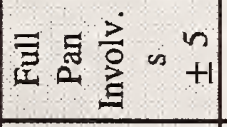 & in & 으 & 이 & in & $\tilde{m}$ & 웅 & $\approx$ & 웅 & in & 으 & $\tilde{m}$ & \\
\hline 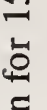 & 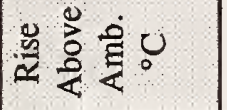 & $\nabla$ & 10 & શิ & $\mathscr{t}$ & $\infty$ & త్ & $F$ & $\tilde{\Xi}$ & $m$ & 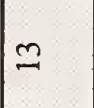 & 8 & \\
\hline 。롤 & है है & $\hat{\sim}$ & $\stackrel{\infty}{\sim}$ & ㄱ & $\approx$ & $\hat{\sim}$ & $\approx$ & లి & নิ & $\bar{m}$ & $\vec{m}$ & $\stackrel{\infty}{\sim}$ & \\
\hline$\frac{4}{3}$ & 氙 & $\vec{m}$ & $\forall$ & 吕 & $\approx$ & $\stackrel{n}{=}$ & 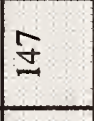 & 음 & $\approx$ & से & 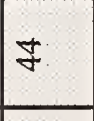 & ล́ & \\
\hline t & 절 & $\stackrel{\pi}{a}$ & $\tilde{0}$ & $\stackrel{9}{-}$ & $\begin{array}{l}\infty \\
i \\
i\end{array}$ & $\bigcup_{0}^{\infty}$ & $\frac{\pi}{a}$ & $\frac{\pi}{a}$ & $\stackrel{5}{2}$ & $\stackrel{a}{a}$ & $\stackrel{a}{a}$ & $\stackrel{\tilde{z}}{a}$ & \\
\hline $\begin{array}{l}\text { สี } \\
\text { ฝี }\end{array}$ & $\frac{2}{2}=\dot{0}$ & $\ddot{0}$ & $\dddot{n}$ & 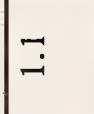 & $\vec{m}$ & $\frac{\pi}{\pi}$ & $\therefore$ & $\begin{array}{l}0 \\
i\end{array}$ & $\frac{\pi}{\pi}$ & $\ddot{0}$ & $\frac{\pi}{a}$ & $\frac{\pi}{a}$ & \\
\hline E & E & $\stackrel{3}{a}$ & $\begin{array}{l}\vec{\sim} \\
\tilde{\sigma} \\
\dot{0}\end{array}$ & $\begin{array}{l}n \\
\tilde{n} \\
0 \\
0\end{array}$ & $\begin{array}{l}\hat{\sigma} \\
\tilde{O} \\
0\end{array}$ & $\begin{array}{l}8 \\
8 \\
0 \\
0\end{array}$ & $\frac{\pi}{a}$ & $\stackrel{\pi}{a}$ & $\stackrel{\pi}{2}$ & $\stackrel{\pi}{a}$ & $\frac{\pi}{a}$ & $\stackrel{\pi}{a}$ & $\begin{array}{l}\text { 亏ే } \\
\tilde{0} \\
0\end{array}$ \\
\hline 胥 & 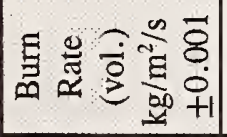 & 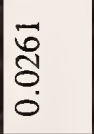 & 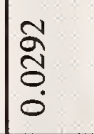 & 怘 & $\begin{array}{l}+ \\
0 \\
0 \\
0\end{array}$ & $\stackrel{\pi}{a}$ & $\mid \begin{array}{l}n \\
0 \\
0 \\
0 \\
0\end{array}$ & $\stackrel{m}{\frac{m}{\sigma}}$ & $\stackrel{\pi}{a}$ & 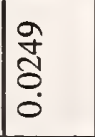 & $\tilde{a}$ & $\frac{\pi}{a}$ & 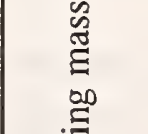 \\
\hline 焉 & 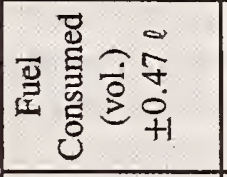 & $\mid \begin{array}{l}\infty \\
i\end{array}$ & $\tilde{a}$ & $\infty$ & $\stackrel{\square}{n}$ & $\stackrel{\pi}{a}$ & aे & $\stackrel{0}{\varrho}$ & $\frac{\pi}{a}$ & 9 & $\stackrel{\pi}{a}$ & $\stackrel{\check{a}}{a}$ & 芯 \\
\hline$\frac{\pi}{2}$ & 造 & mे & $\begin{array}{l}\infty \\
\infty \\
0\end{array}$ & $\stackrel{\sigma}{\sigma}$ & $\stackrel{n}{-}$ & $\begin{array}{l}8 \\
8 \\
i\end{array}$ & in & $\stackrel{8}{i}$ & 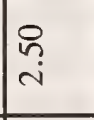 & 节 & $\stackrel{\infty}{\infty}$ & $\begin{array}{l}8 \\
i\end{array}$ & 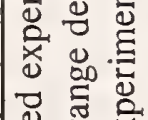 \\
\hline 9 & 焉芯 & 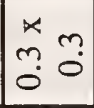 & $\begin{array}{ll}x & 0 \\
0 & 0 \\
0 & 0 \\
0 & 0\end{array}$ & $\begin{array}{ll}x & 9 \\
a & 0 \\
0 & 0\end{array}$ & $\because$ ฮ. & $\stackrel{0}{i}: \stackrel{g}{z}$ & 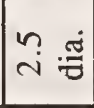 & 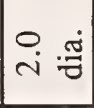 & 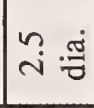 & $\mid \begin{array}{l}x \\
m \\
0 \\
0\end{array}$ & $\mid \begin{array}{ll}x & 0 \\
0 & 0 \\
0 & 0\end{array}$ & 욤 & 㡙 \\
\hline & $\vec{\omega}$ & 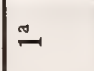 & テ̃ & $\ddot{m}$ & $\stackrel{g}{\forall}$ & in & ${ }^{\circ} 0$ & $r$ & $\infty$ & $=$ & $\cong$ & $\ddot{m}$ & 矛 \\
\hline
\end{tabular}




\subsubsection{Behavior of Sprinkler Fires}

There were six sprinkler fires conducted in the $15 \mathrm{~m}$ high facility, three with and three without the draft curtain in place. One experiment with no draft curtain was conducted with the hangar doors open.

All the sprinkler fires were conducted with the fuel pan on the three point load platform. Fires were all positioned with the pan center over the test center point as shown in Figure 22. Sprinkler fires were ignited at a single point along the pan edge with an acetylene torch. The ambient fuel temperature was between $25^{\circ} \mathrm{C}$ and $30^{\circ} \mathrm{C}$. It took between $6 \mathrm{~s}$ and $10 \mathrm{~s}$ to achieve sustained combustion. Table 17 provides the test information for each sprinkler fire conducted: Information in the table includes pan size, ambient temperatures, time for the fire to spread across and fully involve the fire pan, and steady state flame heights. Flame height information was obtained through visual accounts and video footage.

Table 17. Information on sprinkler fires

\begin{tabular}{|c|c|c|c|c|}
\hline Test Number & $\begin{array}{c}\text { Pan Size } \\
\text { Diameter } \\
\mathrm{m}\end{array}$ & $\begin{array}{c}\text { Ambient } \\
\text { Temperature } \\
{ }^{\circ} \mathrm{C}\end{array}$ & $\begin{array}{c}\text { Full Pan } \\
\text { Involvement } \\
\mathrm{s}, \pm 5\end{array}$ & $\begin{array}{c}\text { Steady State } \\
\text { Flame Height } \\
\mathrm{m}, \pm 0.2\end{array}$ \\
\hline $4^{\mathrm{a}}$ & 1.5 & 27 & 30 & 7.0 \\
\hline $5^{\mathrm{a}}$ & 2.0 & 27 & 35 & 8.2 \\
\hline $6 \mathrm{~b}^{\mathrm{a}}$ & 2.5 & 25 & 40 & 9.8 \\
\hline 7 & 2.0 & 30 & 35 & 8.2 \\
\hline 8 & 2.5 & 29 & 40 & 9.8 \\
\hline $13^{\mathrm{b}}$ & 2.0 & 28 & 35 & $--^{\mathrm{c}}$ \\
\hline
\end{tabular}

${ }^{a}$ Draft curtained experiment

${ }^{b}$ Open door experiment

${ }^{\mathrm{C}}$ Flame height information not available due to significant flame lean.

\section{Plume Symmetry}

The fire plume for the $1.5 \mathrm{~m}$ diameter fire with draft curtain exhibited a SE lean early in the test with the plume center position estimated to be approximately $1 \mathrm{~m}$ from geometric center. This estimation is based on the high temperature readings registered by thermocouples $\mathrm{C} 8$ and $\mathrm{C} 10$ which were located $3.0 \mathrm{~m}$ below the ceiling and $0.9 \mathrm{~m}$ from center in the south and east direction respectively. The southward lean seemed to disappear from about $60 \mathrm{~s}$ to $210 \mathrm{~s}$ and then resumed the southward lean for the rest of the test. The eastward plume lean continued throughout the test based on the W10 and E15 thermocouples but the lean did begin to disappear starting about $360 \mathrm{~s}$ into the test. Video footage observations of the flame indicate that the flame leaned to the south early in the test in response to asymmetric ignition of the fuel in the pan. The flame centered in the N-S direction in the period between $60 \mathrm{~s}$ and $210 \mathrm{~s}$ but did start to lean to the east $90 \mathrm{~s}$ into the test with the flame tip reaching $0.75 \mathrm{~m}$ by $120 \mathrm{~s}$. This eastward lean persisted for the rest of the test. At about $240 \mathrm{~s}$, the fire started 
to spawn small fire whirl structures off the side of the pan.

The fire plume for the $2.0 \mathrm{~m}$ diameter fire with draft curtain exhibited a SE lean during the first $6 \mathrm{~s}$ of the test which quickly changed $13 \mathrm{~s}$ into the test to a south lean with the plume center located about $1.0 \mathrm{~m}$ south of geometric center. At $55 \mathrm{~s}$ into the test, the plume changed to an eastward lean moving as much as $2.0 \mathrm{~m}$ from geometric center. It should be noted that this fire plume produced sufficient rotation to generate a fire whirl which would account for the strong lean and the sharp gradients in plume temperature. About $200 \mathrm{~s}$ into the test, the peak temperatures recorded by the thermocouple array located $3.0 \mathrm{~m}$ beneath the ceiling decreased substantially. During the next $100 \mathrm{~s}$ period, the plume tended to lean either about $1.0 \mathrm{~m}$ to the south or $1.0 \mathrm{~m}$ to the west. At $310 \mathrm{~s}$ into the test, the high peak temperatures reappeared with the plume exhibiting about a $1.0 \mathrm{~m}$ lean to the south or west.

Video observations of the flame showed an initial lean to the east which quickly centered by $40 \mathrm{~s}$ into the test. The flame becomes very much eastward oriented by 90 seconds into the test with $0.5 \mathrm{~m}$ and $0.75 \mathrm{~m}$ leans occurring at about $90 \mathrm{~s}$ and $120 \mathrm{~s}$ into the test respectively. A slight lean of $0.5 \mathrm{~m}$ to the north developed at $120 \mathrm{~s}$. At $150 \mathrm{~s}$ into the test, a large fire whirl was generated which substantially lowered the flame height over the rest of the pan. By $210 \mathrm{~s}$, the fire whirl disappeared with the flame leaning strongly to the west maximizing at about $240 \mathrm{~s}$ into the test. A fire whirl developed about $290 \mathrm{~s}$ into the test which strengthened significantly at $300 \mathrm{~s}$ and then subsided $60 \mathrm{~s}$ later.

The fire plume for the $2.5 \mathrm{~m}$ diameter fire with draft curtain exhibited an initial plume lean in the SW direction with the plume center estimated to be as much as $2.0 \mathrm{~m}$ to the south and about $1.0 \mathrm{~m}$ to the west. This lean to the SW became more centered at about $70 \mathrm{~s}$ into the test with the plume center located less than $0.5 \mathrm{~m}$ to the SW. For the remainder of the test, the plume tended to lean in the SW direction, being more south than west for the time periods between $140 \mathrm{~s}$ to $160 \mathrm{~s}$ and $250 \mathrm{~s}$ to $340 \mathrm{~s}$ with the plume center being more west of south for the other time periods. Typical flame leans ranged from $0.5 \mathrm{~m}$ to $1.0 \mathrm{~m}$ in the above directions.

Video observations of the flame indicated an initial SW lean which disappeared about $60 \mathrm{~s}$ into the test. At about $120 \mathrm{~s}$ into the test, fuel spilled out of the SW side of the pan, causing additional burning in this area. The flame leaned to the west in response to the spill, with the flame tip leaning $0.8 \mathrm{~m}$ at about $180 \mathrm{~s}$. At about $240 \mathrm{~s}$, a south spill occurred causing the flame to lean south $0.6 \mathrm{~m}$ off center for the next $120 \mathrm{~s}$.

The fire plume for the $2.0 \mathrm{~m}$ diameter fire without draft curtain exhibited an initial plume lean to the SW with the plume center located about $1.0 \mathrm{~m}$ to the west and somewhat less than that to the south. The plume center maintained this position throughout the test with the exception of a westward migration to about $2.0 \mathrm{~m}$ between $500 \mathrm{~s}$ and $550 \mathrm{~s}$ into the test. The temperature curves for this test indicate three strong temperature pulsations with peaks at about $140 \mathrm{~s}, 350 \mathrm{~s}$, and $590 \mathrm{~s}$ into the test.

Video observations of this test showed the fire plume initially centered in the pan, but at about $60 \mathrm{~s}$ the flame leans to the SW with the tip about $0.5 \mathrm{~m}$ off geometric center in both directions. The southern lean reached $1.2 \mathrm{~m}$ at $120 \mathrm{~s}$ while the westward lean remained at about $0.5 \mathrm{~m}$. At $170 \mathrm{~s}$, a minor fuel spill to the west produces a strong westward lean while the flame centers in the N-S plane. At $330 \mathrm{~s}$, small fire whirls are spawned to the west and south with the flame exhibiting a $0.8 \mathrm{~m}$ lean to the west which increases to $2.0 \mathrm{~m}$ at $410 \mathrm{~s}$. 
The fire plume for the $2.5 \mathrm{~m}$ diameter fire without draft curtain was initially centered at the start of the test but moved to a SE lean at about $30 \mathrm{~s}$ into the test. The plume center moved about $0.5 \mathrm{~m}$ to the east for the first $100 \mathrm{~s}$ and then moved westward to about $0.5 \mathrm{~m}$ west of center at about $200 \mathrm{~s}$ into the test. The plume centered in the east - west direction about $400 \mathrm{~s}$ into the test. The plume leaned initially to the south about $0.5 \mathrm{~m}$ off center from about $30 \mathrm{~s}$ to about $100 \mathrm{~s}$ into the test. The plume then leaned north for the next $150 \mathrm{~s}$ and then centered itself in the north - south direction for the rest of the test.

Video observations of this test showed that the initial pan ignition on the south side of the pan spread west faster than it spread east. The flame for this test remained fairly well centered with only a slight lean to the south in the first minute and then a slight lean to the north from $120 \mathrm{~s}$ to $240 \mathrm{~s}$ into the test. The flame tip leaned only $0.2 \mathrm{~m}$ in each case.

With the draft curtain in place, the initial transport time of the hot gas to the ceiling was approximately $11 \mathrm{~s}$ for the $1.5 \mathrm{~m}$ diameter pan fire, $15 \mathrm{~s}$ for the $2.0 \mathrm{~m}$ diameter pan, and $7 \mathrm{~s}$ for the $2.5 \mathrm{~m}$ diameter pan. Arrival of the hot gas at the ceiling was indicated by a temperature rise on one of the thermocouples $0.3 \mathrm{~m}$ below the ceiling over the test center point or $1.5 \mathrm{~m}$ radially out from test center. Without the draft curtain in place, transport time to the ceiling was $11 \mathrm{~s}$ for the $2.0 \mathrm{~m}$ diameter pan. Transport time was not measurable for the $2.5 \mathrm{~m}$ diameter pan test because of an equipment failure. Uncertainties in determining the transport time of hot gas to the ceiling include determination of the starting time for the fire, initial plume lean, and the coarseness of the measurement interval which varied between $3 \mathrm{~s}$ and $4 \mathrm{~s}$.

\section{Temperature}

Thermocouples at the ceiling of the $15 \mathrm{~m}$ high facility were evaluated to determine the temperature rise above ambient for all sprinkler fires. This information can be used to compare how temperature varies with fire sizes for a fixed ceiling height and to validate temperature modeling. Table 18 shows the maximum temperature rise in the center region of the test area and the corresponding rise above ambient temperature. The maximum temperature rise was determined by evaluating thermocouples located $0.15 \mathrm{~m}$ below the ceiling deck and within a $3.0 \mathrm{~m}$ radius of the fire centerline. Thermocouples used were as follows: center (C1); $1.5 \mathrm{~m}$ north/south/east/west (N11, S10, E16, W11); and $3.0 \mathrm{~m}$ north/south/east/west (N10, S9, E15, W10). The temperature values reported are based on analyzing the temperature range over the time interval where the fire's mass loss rate appeared steady and choosing a value equal to ninety percent of the range. The temperatures throughout this range were generally increasing, reaching a maximum value about half way through the test. For those experiments where mass loss measurement was not available (i.e., tests $6 \mathrm{~b}, 7,8,13$ ), the steady state time range was found by evaluating the mid portion of the maximum temperature profile. The steady state time range in these cases was defined by a steadily increasing temperature without significant high or low fluctuations. Also, by considering the temperatures within the $3.0 \mathrm{~m}$ radius of plume center for each test, the effect of plume lean on center temperature was somewhat minimized.

To further illustrate, the maximum temperatures as a function of time for the thermocouples within a $3.0 \mathrm{~m}$ radius from center and $0.15 \mathrm{~m}$ below the ceiling are presented in Figures 26 and 27 . Figure 26 shows the sprinkler fires conducted with the draft curtain (tests 4, 5, 6b) and Figure 27 shows the sprinkler fires conducted without the draft curtains (tests 7, 8). In Figure 26, test 5 shows unusual burning characteristics. The drop in maximum temperature between $180 \mathrm{~s}$ and $300 \mathrm{~s}$ was coincident with observed fire whirls in the plume. 
Table 18. Temperature rise above ambient for sprinkler fires

\begin{tabular}{|c|c|c|c|c|}
\hline \multicolumn{2}{|c|}{ Test Information } & \multicolumn{3}{|c|}{ Temperature Parameters $\left( \pm 2{ }^{\circ} \mathrm{C}\right)$} \\
\hline $\begin{array}{c}\text { Test } \\
\text { Number }\end{array}$ & $\begin{array}{c}\text { Pan Size } \\
\mathrm{m}\end{array}$ & $\begin{array}{c}\text { Maximum } \\
\text { Temperature } \\
{ }^{\circ} \mathrm{C}\end{array}$ & $\begin{array}{c}\text { Ambient } \\
\text { Temperature, } \mathrm{T}_{\text {amb }}{ }^{\circ} \mathrm{C}\end{array}$ & $\begin{array}{c}\text { Rise Above } \mathrm{T}_{\text {amb }} \\
{ }^{\circ} \mathrm{C}\end{array}$ \\
\hline $4^{\mathrm{b}}$ & 1.5 dia. & 75 & 27 & 47 \\
\hline $5^{\mathrm{b}}$ & 2.0 dia. & 115 & 27 & 88 \\
\hline $6 \mathrm{~b}^{\mathrm{b}}$ & 2.5 dia. & 147 & 25 & 122 \\
\hline 7 & 2.0 dia. & 101 & 30 & 71 \\
\hline 8 & 2.5 dia. & 152 & 29 & 123 \\
\hline $13^{\mathrm{c}}$ & 2.0 dia. & 60 & 28 & 69 \\
\hline
\end{tabular}

${ }^{a}$ Maximum temperature found by evaluating thermocouples at center, $1.5 \mathrm{~m}, 3.0 \mathrm{~m}$ (NSEW)

${ }^{b}$ Draft curtained experiment

${ }^{\mathrm{c}}$ Open door experiment

Table 19 indicates maximum temperatures at specific locations with respect to the draft curtain. For example, temperatures at $8.5 \mathrm{~m}$ north and south are located just inside the draft curtain as is the temperatures at $11.6 \mathrm{~m}$ east and west. This position in the north and south direction is located outside the draft curtain. Thermocouples at $14.6 \mathrm{~m}$ east and west are located outside the draft curtain. Omitted entries in the table are locations where temperature measurements were not made or are duplicates of other measurements.

\section{Hot gas flow}

The impact of the draft curtain on hot gas flow can be seen from the data presented in Table 14. The filling time for the draft curtain was determined by using the thermocouple tree located at $9.1 \mathrm{~m}$ east of fire center and $3.0 \mathrm{~m}$ inside the edge of the draft curtain. Based on the times required for the thermocouple located at $3.0 \mathrm{~m}$ below the ceiling to record a $3{ }^{\circ} \mathrm{C}$ temperature rise, the draft curtain filled in $50 \mathrm{~s}, 38 \mathrm{~s}$, and $32 \mathrm{~s}$ respectively for fire sizes ranging from the $1.5 \mathrm{~m}$ diameter pan to the 2.5 $\mathrm{m}$ diameter pan. Figure 28 shows the hot gas flow during the $1.5 \mathrm{~m}$ diameter fire experiment. Since the $2.0 \mathrm{~m}$ and $2.5 \mathrm{~m}$ diameter pans required $35 \mathrm{~s}$ and $40 \mathrm{~s}$ for the fire to fully involve the pan surface, respectively, the $2.0 \mathrm{~m}$ pan had just reached full involvement and the flames on the surface of the 2.5 $\mathrm{m}$ pan were still spreading when the draft curtain filled. The times for the hot gas to reach the $6.1 \mathrm{~m}$ position and the edge of the draft curtain are essentially the same for all fire tests. The reason for this is that each fire pan was only ignited at one corner. For the early timing measurements, the fire size depends on how much of each pan has become fully involved and not on pan size. Since the ignition method was approximately the same for each pan size, the flame spread and hence the fire size was the same for each pan size early in the test. Variations in the timing occurred due to uncertainties in the fire start time, the initial fuel temperature, and in the initial amount of surface area ignited by the acetylene torch.

A comparison of the time for the draft curtain area to fill with the time for the hot gas to reach a thermocouple outside the draft curtain can be used to determine if the draft curtain filled and then spilled into the adjacent space. Likewise, these comparisons can be used to determine if the hot gas flows down and around the draft curtain prior to the draft curtain area filling. For these comparisons, 


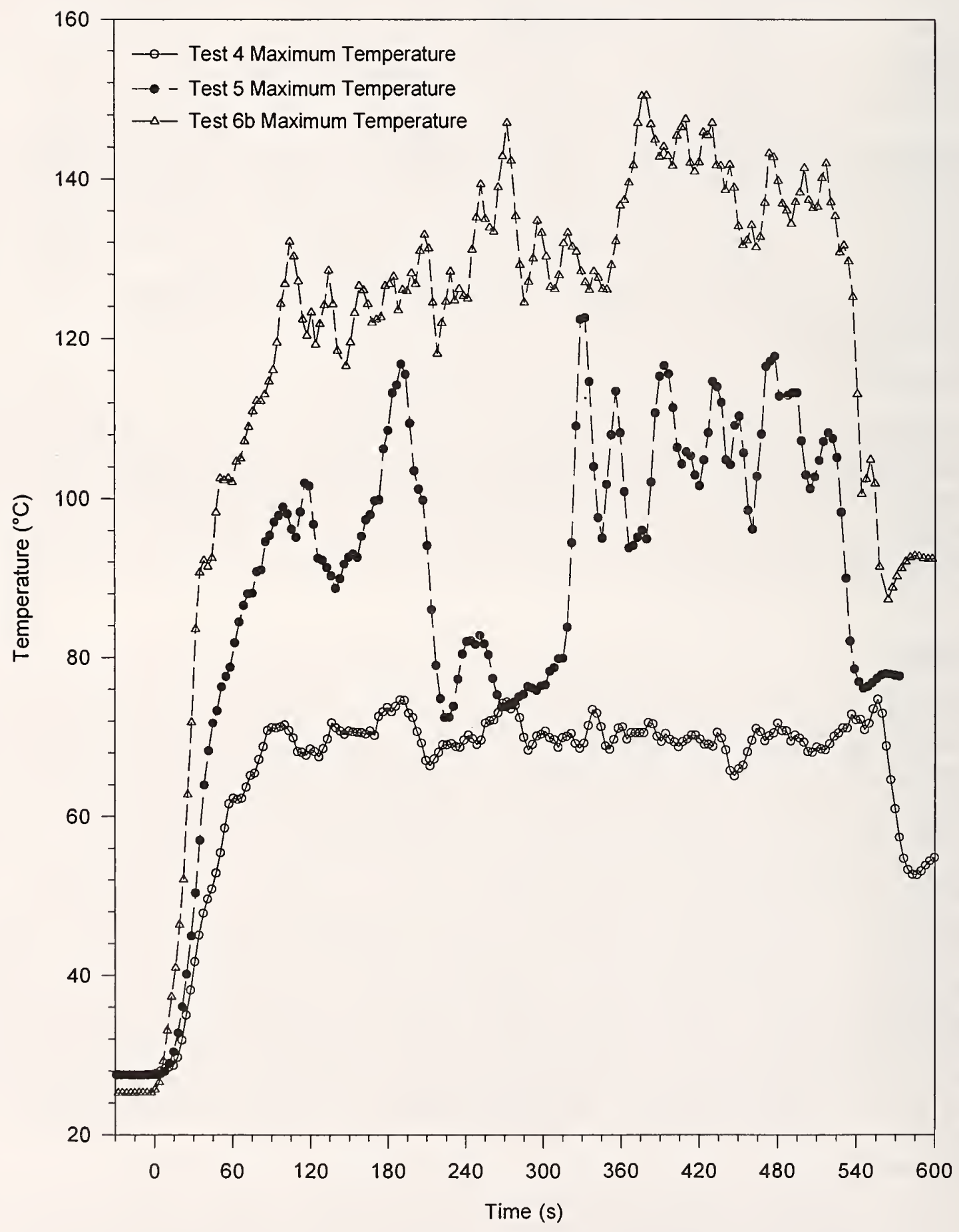

Figure 26. Maximum temperature profiles for sprinkler fires conducted with draft curtains. 


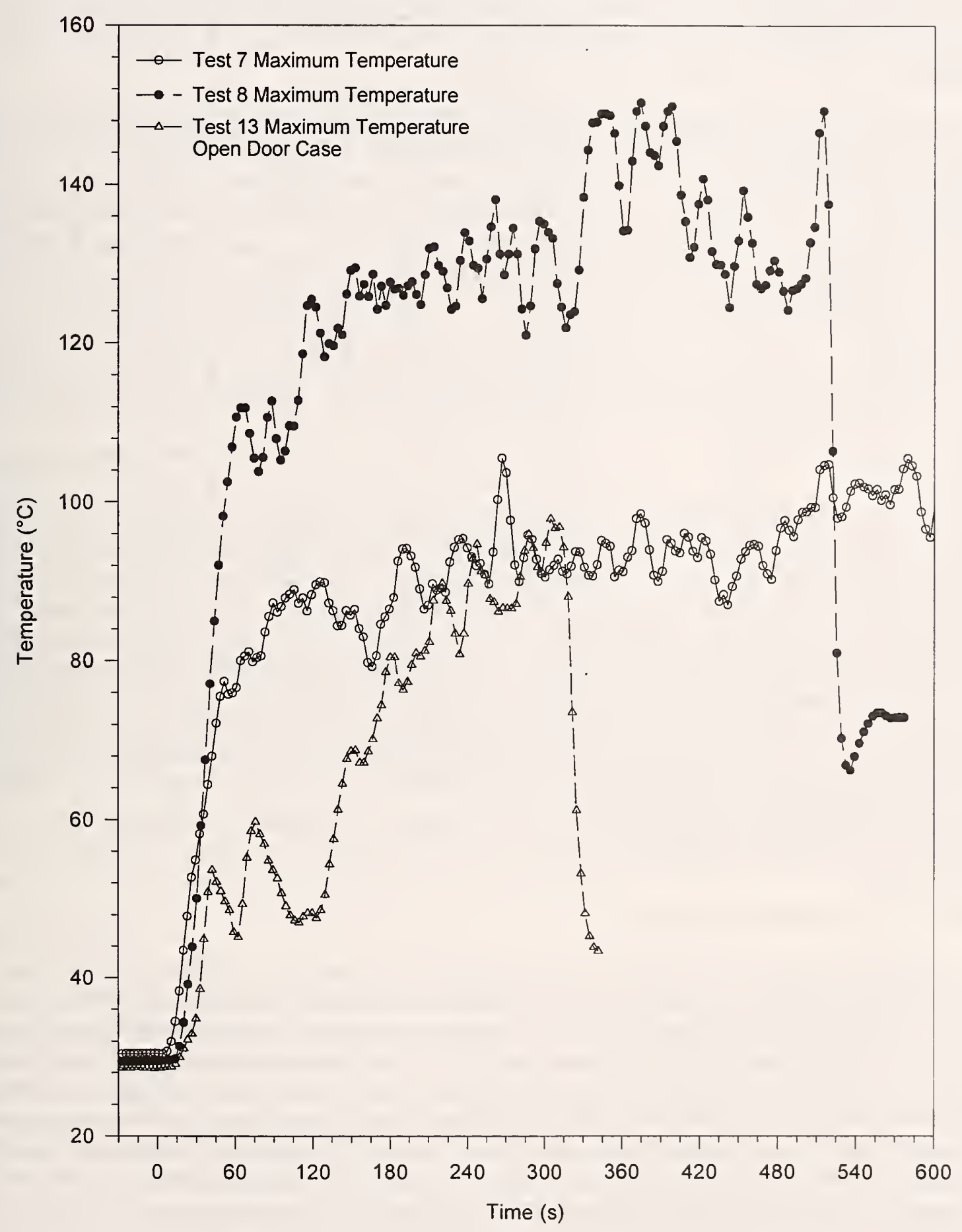

Figure 27. Maximum temperature profiles for sprinkler fires conducted without draft curtains. 
Table 19. Maximum temperature rise at various locations

\begin{tabular}{|c|c|c|c|c|c|c|c|}
\hline \multicolumn{3}{|c|}{ Test Information } & \multicolumn{5}{|c|}{ Maximum Temperature Rise Above $\mathrm{T}_{\text {amb }}\left( \pm 2.0^{\circ} \mathrm{C}\right)$} \\
\hline $\begin{array}{c}\text { Test } \\
\text { Number }\end{array}$ & $\begin{array}{c}\text { Pan Size } \\
\mathrm{m}\end{array}$ & $\begin{array}{l}\mathrm{T}_{\mathrm{amb}} \\
{ }^{\circ} \mathrm{C}\end{array}$ & Location & $6.1 \mathrm{~m}$ & $8.5 \mathrm{~m}^{\mathrm{a}}$ & $11.6 \mathrm{~m}^{\mathrm{b}}$ & $14.6 \mathrm{~m}^{\mathrm{c}}$ \\
\hline \multirow{4}{*}{$\begin{array}{c}4 \\
\text { w/ } \\
\text { Draft } \\
\text { Curtain }\end{array}$} & \multirow{4}{*}{$\begin{array}{c}1.5 \\
\text { Diameter }\end{array}$} & \multirow[t]{4}{*}{27} & north & 29 & 31 & 18 & - \\
\hline & & & south & 40 & 35 & 15 & -- \\
\hline & & & east & 36 & - & 29 & 22 \\
\hline & & & west & 26 & -- & 29 & 16 \\
\hline \multirow{4}{*}{$\begin{array}{c}5 \\
\text { w/ } \\
\text { Draft } \\
\text { Curtain }\end{array}$} & \multirow{4}{*}{$\begin{array}{c}2.0 \\
\text { Diameter }\end{array}$} & \multirow[t]{4}{*}{27} & north & 68 & 60 & 34 & - \\
\hline & & & south & 64 & 60 & 34 & -- \\
\hline & & & east & 68 & -- & 56 & 40 \\
\hline & & & west & 60 & -- & 56 & 36 \\
\hline \multirow{4}{*}{$\begin{array}{c}7 \\
\text { w/o } \\
\text { Draft } \\
\text { Curtain }\end{array}$} & \multirow{4}{*}{$\begin{array}{c}2.0 \\
\text { Diameter }\end{array}$} & \multirow[t]{4}{*}{30} & north & 68 & 60 & 34 & - \\
\hline & & & south & 64 & 60 & 34 & -- \\
\hline & & & east & 43 & - & 34. & 30 \\
\hline & & & west & 43 & -- & $n / a^{d}$ & 30 \\
\hline \multirow{4}{*}{$\begin{array}{c}6 b \\
w / \\
\text { Draft } \\
\text { Curtain }\end{array}$} & \multirow{4}{*}{$\begin{array}{c}2.5 \\
\text { Diameter }\end{array}$} & \multirow[t]{4}{*}{25} & north & 99 & 83 & 74 & - \\
\hline & & & south & 95 & 83 & 39 & -- \\
\hline & & & east & 85 & - & 73 & 51 \\
\hline & & & west & 74 & -- & 69 & 41 \\
\hline \multirow{4}{*}{$\begin{array}{c}8 \\
\text { w/o } \\
\text { Draft } \\
\text { Curtain }\end{array}$} & \multirow{4}{*}{$\begin{array}{c}2.5 \\
\text { Diameter }\end{array}$} & \multirow[t]{4}{*}{29} & north & 74 & 60 & 46 & - \\
\hline & & & south & 77 & 62 & 54 & -- \\
\hline & & & east & 64 & - & 48 & 44 \\
\hline & & & west & 56 & -- & 46 & 40 \\
\hline
\end{tabular}

${ }^{a}$ Located near inside edge of north and south draft curtains

${ }^{b}$ Located near inside edge of east and west draft curtains, outside DC in north and south direction

${ }^{c}$ Located outside draft curtain in east/west direction

${ }^{d}$ Faulty reading

-- Temperature not measured at this location

the ceiling thermocouple at $14.6 \mathrm{~m}$ east is used to determine spillage time outside the draft curtain, while the thermocouple at $9.1 \mathrm{~m}$ east, $3.0 \mathrm{~m}$ below the ceiling, is used for draft curtain filling. The reason for using only the east thermocouples is to attempt to minimize the impact of plume lean on the comparisons. The difference in time between the hot gas flow registering a temperature rise outside the draft curtain and the time to fill the draft curtain are $-7 \mathrm{~s},-10 \mathrm{~s}$, and $-7 \mathrm{~s}$ respectively for pan sizes ranging from the $1.5 \mathrm{~m}$ diameter pan to the $2.5 \mathrm{~m}$ diameter pan. Since the hot gas flowing over the bottom of the draft curtain must rise to the ceiling and flow radially outward an additional $2.4 \mathrm{~m}$, the data suggest that the hot gas flows under the draft curtain prior to filling the draft curtain area. Visual observations of the smoke flowing under the draft curtain confirm this assumption.

\section{Ceiling Jet Velocity}

Ceiling jet velocities were determined using two hot wire anemometers located $6.1 \mathrm{~m}$ to the east and 
north of fire center and $0.15 \mathrm{~m}$ below the ceiling. The anemometers were oriented such that only the component of velocity parallel to the ceiling would be measured. The anemometers were limited to temperatures below $120^{\circ} \mathrm{C}$. Maximum ceiling jet velocities for the $1.5 \mathrm{~m}$ diameter test were $0.4 \mathrm{~m} / \mathrm{s}$ east (transducer $\mathrm{V}_{1}$ ) and $1.3 \mathrm{~m} / \mathrm{s}$ north (transducer $\mathrm{V}_{2}$ ). The measurements of ceiling jet velocity for these larger fires are shown in Table 15. The fire plume in this test exhibited a strong eastward lean which may account for the low reading by the anemometer in the east. If the anemometer is in the plume, the strongest velocity component would be perpendicular to the ceiling and would not be measured by the anemometer. The $2.0 \mathrm{~m}$ diameter fire with a draft curtain resulted in velocities of 0.5 $\mathrm{m} / \mathrm{s}$ and $1.0 \mathrm{~m} / \mathrm{s}$ to the east and north respectively. This test produced a tornado-type plume. The north anemometer showed four distinct peaks in velocity during this test which could have been due to movement of the plume. The $2.0 \mathrm{~m}$ diameter fire without draft curtain resulted in maximum velocities of $0.7 \mathrm{~m} / \mathrm{s}$ east and $1.6 \mathrm{~m} / \mathrm{s}$ north. Anemometer measurements for both of the $2.5 \mathrm{~m}$ diameter fires were not available due to instrumentation failures. Figure 29 shows sample plots of measured ceiling jet velocity. The $2.0 \mathrm{~m}$ diameter experiments (i.e., test 5) with the draft curtain and the experiment without the draft curtain (i.e., test 7) are compared. In the upper graph of the figure, ceiling jet velocities at $6.1 \mathrm{~m}$ east are shown. The lower graph shows the measured velocities at $6.1 \mathrm{~m}$ north.

\section{Heat Flux Measurements}

Total heat flux was measured at three positions; the first was $5 \mathrm{~m}$ east of fire center and $1.22 \mathrm{~m}$ above the floor. The second and third transducers were located $6.1 \mathrm{~m}$ east and placed $9.8 \mathrm{~m}$ above the floor and $0.15 \mathrm{~m}$ below the ceiling. Maximum average fluxes for the $1.5 \mathrm{~m}, 2.0 \mathrm{~m}$ and the two $2.5 \mathrm{~m}$ tests are presented in Table 15. Heat fluxes recorded by the third gauge near the ceiling and by the second gauge located near the beams are higher than would be expected from a simple inverse square law correlation using a point source near the pan center. Since the sensor near the ceiling is immersed in the hot smoke layer, convective heating of the sensor may produce heat fluxes higher than expected from radiation alone. (These total heat flux gauges were calibrated with radiative heat flux only.) This effect is evident when the second radiometer, located at $9.8 \mathrm{~m}$ above the floor is compared with the third radiometer located at the ceiling. In each test, the flux gauge at the ceiling yields a higher reading indicating that convective heating may have a significant contribution. For these pan fires, the flame height is substantial. Hence, the heat flux gauges near the ceiling are closer to the flames than the geometrical distance between the radiometer and the pan center.

\section{Heat Release Rate}

The same two methods were used to determine the heat release rate for the sprinkler fires as with the detector fires. Direct measurement of the mass loss rate using a load cell was performed for the $1.5 \mathrm{~m}$ diameter and $2.0 \mathrm{~m}$ diameter pans for the fire tests conducted with draft curtains. The mass loss rate for all the other tests were calculated from the fuel volume consumed by the fire. Where load cell data were available, a linear curve fit was used to determine burning rate after an approximate steady state condition was reached. For the fire tests where the volume method was used, the volume of fuel lost was divide by the total test time in order to obtain an average mass loss rate. The estimated steady state heat release rates for the draft curtained fires areas follows: $2.8 \mathrm{MW}$ for the $1.5 \mathrm{~m}$ diameter pan, 6.8 MW for the $2.0 \mathrm{~m}$ diameter pan with draft curtain, 5.6 MW for the $2.0 \mathrm{~m}$ diameter pan without draft curtain, and 7.7 MW for the $2.5 \mathrm{~m}$ pan. Two different heat release rates are provided for the 2.0 $\mathrm{m}$ diameter pan fires as the fire with the draft curtain produced a tornado-like plume while the pan fire without the draft curtain produced a normal plume. (The $7.7 \mathrm{MW}$ heat release rate for test 8 was 

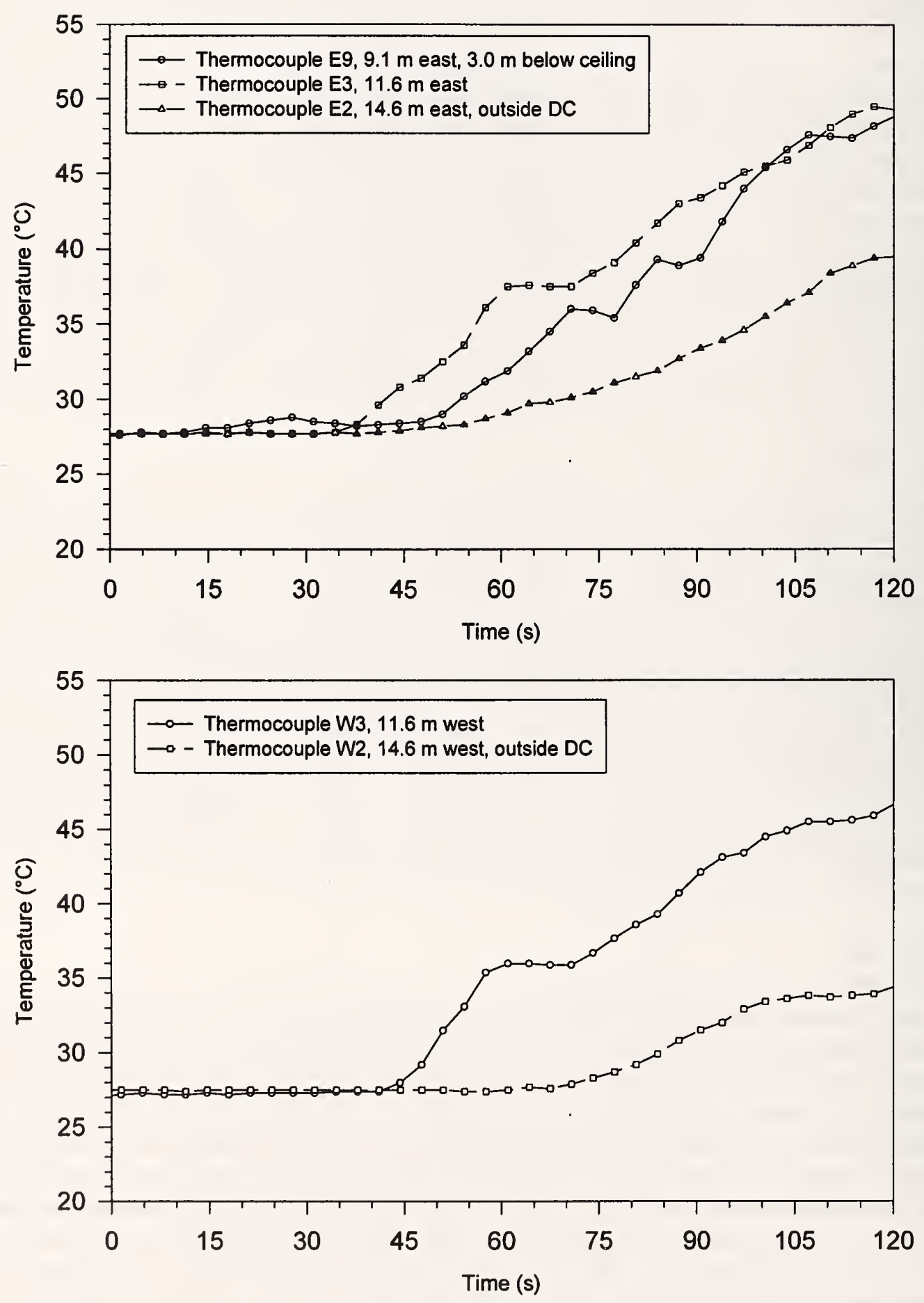

Figure 28. Hot gas flow results for $1.5 \mathrm{~m}$ diameter test with draft curtains. 

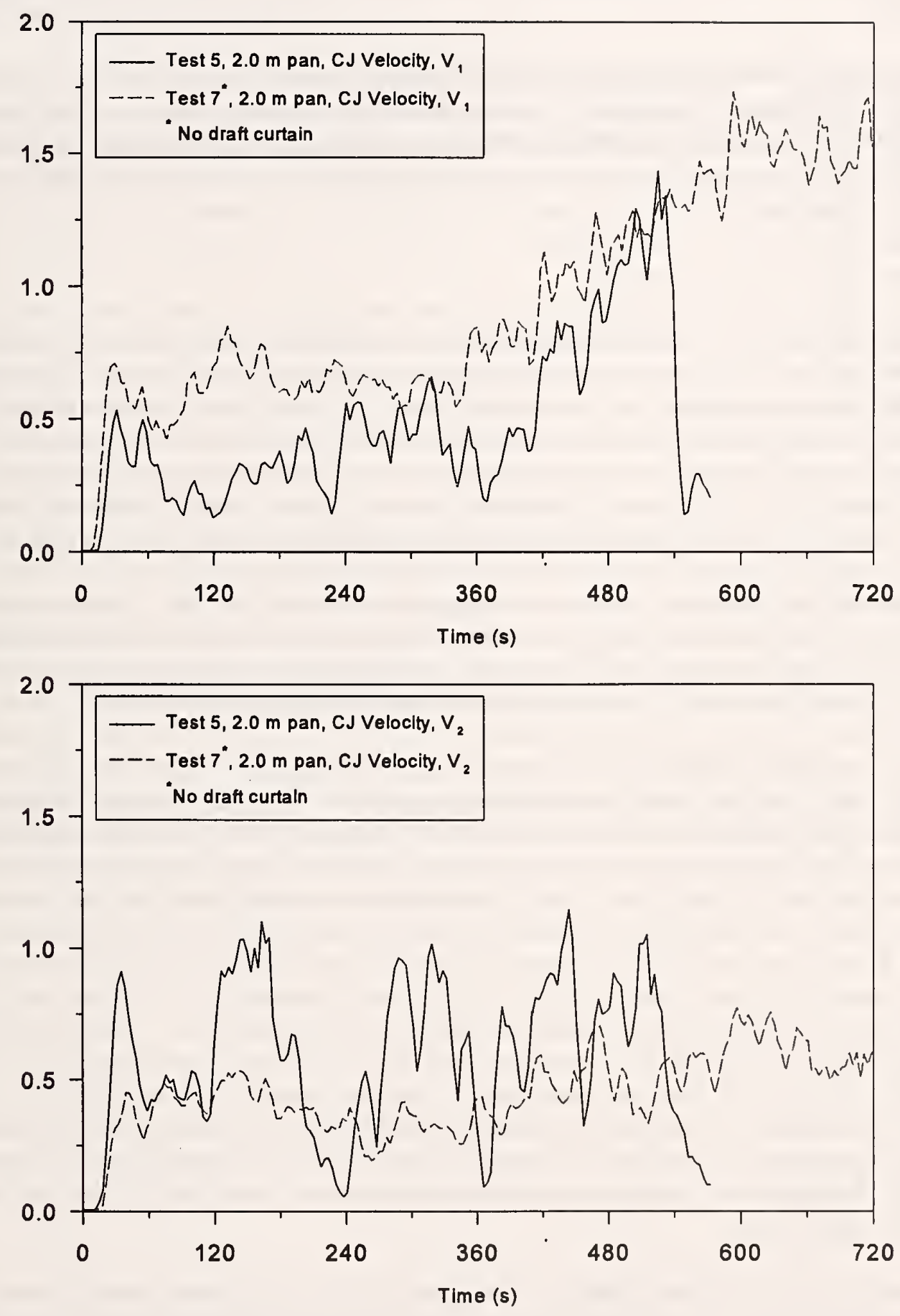

Figure 29. Ceiling jet velocities measured $6.1 \mathrm{~m}$ north and east of fire center for $2.0 \mathrm{~m}$ diameter experiments. 
inferred to be the same as the heat released from test $6 \mathrm{~b}$ based on the similar temperatures measured in the two fire plumes.) Additional data including the mass loss rate for each test and test durations are shown in Table 16. Also, the measured mass loss including steady state linear fit is shown graphically in Figure 25.

The burning rate increased during the early part of the fire until steady state burning was reached. Tests conducted without the load platform utilized temperature profiles, similar to those shown in the previous figures, to determine a steady state time range. The values for steady state time are show in the Table 16. The time required to reach steady state varied with pan size with the larger pans requiring more time to achieve steady state.

\section{Effect of Open Door on Behavior of Fire}

A single open door test was conducted using the $2.0 \mathrm{~m}$ diameter pan and JP-5 fuel in order to study the effects of wind on the fire and the detection of the fire by the ceiling mounted smoke and heat detectors and the UV/IR detectors mounted on stands on the floor. The hangar doors on the NW, SW, NE, and SE sides relative to the hangar were opened distances of $14.3 \mathrm{~m}, 14.5 \mathrm{~m}, 8.5 \mathrm{~m}$, and $8.4 \mathrm{~m}$, respectively, in order to present a nearly symmetric opening. Immovable doors of width $9.9 \mathrm{~m}$, located on either side of the $\mathrm{N}-\mathrm{S}$ center line through the fire, provided wind blockages along the center line as shown in Figure 30. Wind speed and direction meters were located $10.4 \mathrm{~m}, 18.3 \mathrm{~m}$, and 25.9 $\mathrm{m}(\mathrm{W} 1, \mathrm{~W} 2$, and $\mathrm{W} 3)$ from the fire pan center along the center line north of the fire. The anemometers were all located $3.0 \mathrm{~m}$ above the hangar floor. A total heat flux gauge to monitor radiation from the flame was located $5.1 \mathrm{~m}$ from the fire center in the west direction and was at a height of $0.9 \mathrm{~m}$ above the floor. UV/IR detectors were positioned in a line at $21 \mathrm{~m}, 30 \mathrm{~m}, 37 \mathrm{~m}$, $43 \mathrm{~m}, 49 \mathrm{~m}, 55 \mathrm{~m}, 61 \mathrm{~m}, 64 \mathrm{~m}, 67 \mathrm{~m}$, and $70 \mathrm{~m}$ from the fire in the NE direction.

At the start of the test, the wind was very light with only anemometer, W1, measuring a wind speed of $2.3 \mathrm{~m} / \mathrm{s}$. The wind speed increased rapidly during the first $30 \mathrm{~s}$ of the test reaching maximum values of $8.0 \mathrm{~m} / \mathrm{s}$ for W1 with speeds of $3.5 \mathrm{~m} / \mathrm{s}$ recorded for W2 and nearly $8.0 \mathrm{~m} / \mathrm{s}$ for W 3 as shown in Figure 31. The wind direction for all three measurements was about $30^{\circ}$ west of north. This wind direction remained constant over the entire test. Video observations of the flame during this time show initial flame lean slightly to the south but by the time of maximum wind speed, the flame was estimated to be leaning $60^{\circ}$ to the south with only a slight eastward lean. The wind then decreased over the next $20 \mathrm{~s}$ to $30 \mathrm{~s}$ with speeds dropping to nearly $4.0 \mathrm{~m} / \mathrm{s}$. Video footage indicated that the plume straightened significantly with the southward lean reducing to about $15^{\circ}$ during this time. A second wind gust then occurred at about $70 \mathrm{~s}$ which produced wind speeds of about $8.0 \mathrm{~m} / \mathrm{s}$ as measured by W1. The flame was estimated to lean $80^{\circ}$ to the south during this period and also had a lean of about $45^{\circ}$ to the east. Comparison with a correlation of flame lean versus wind speed by the American Gas Association [11] showed good agreement (i.e., within $3 \%$ ) with the observed leans. According to the correlation, a wind speed of $8.0 \mathrm{~m} / \mathrm{s}$ would be expected to produce about an $81^{\circ}$ flame lean. The doors were closed at about $110 \mathrm{~s}$ into the test.

A comparison of pairs of thermocouples at $6.1 \mathrm{~m}$ in the N-S and E-W planes show the expected asymmetry in temperatures with the high temperatures in the south and east directions correlating with the wind gusts as shown in Figure 32. Temperatures at the ceiling in the south and east directions are fairly constant from plume center to $8.5 \mathrm{~m}$ from the fire center and do not reach values required to activate any of the sprinkler heads. The radiometer measured a peak flux of about $6.3 \mathrm{~kW} / \mathrm{m}^{2}$ during 
the time between the wind gusts when the flame was nearly vertical, as shown in Figure 33 . Assuming a heat release rate equivalent to what was measured for the closed door $2.0 \mathrm{~m}$ test (i.e., $6.4 \mathrm{MW}$ ) and assuming a radiative fraction equal to 0.3 , a flux level of $5.8 \mathrm{~W} / \mathrm{m}^{2}$ would be expected from a point source. Mass loss rate was not available.

The time of activation of the smoke detectors reflect the observed wind direction. The first detectors to activate were the south detectors. The detectors in this direction responded out to $11.6 \mathrm{~m}$ within the first $34 \mathrm{~s}$ of the test. Only after the first wind gust had subsided, the north detectors at $3.0 \mathrm{~m}$ and $6.1 \mathrm{~m}$ activated within $47 \mathrm{~s}$ from the start of the test. Activation of the smoke detectors in the east and west direction remain fairly symmetric. The detectors in the east direction at $3.0 \mathrm{~m}$ and $6.1 \mathrm{~m}$ both activated at $39 \mathrm{~s}$ while the west detectors at $3.0 \mathrm{~m}$ and $6.1 \mathrm{~m}$ activated at $38 \mathrm{~s}$ and $42 \mathrm{~s}$ respectively.

The UV/IR detectors were gated to provide count rates every $0.1 \mathrm{~s}$ during the fire. Figure 34 shows the UV (upper graph) and IR (lower graph) count rate as a function of time. The detector shown in the figure is located $21.3 \mathrm{~m}$ from the pan. There are two substantial decreases in UV emission shown in these figures, one at about $55 \mathrm{~s}$ and the other at about $80 \mathrm{~s}$ into the test. The fire was estimated to start at about $12 \mathrm{~s}$ from time zero in these figures based on the increase of the infrared signals reducing the $55 \mathrm{~s}$ and $80 \mathrm{~s}$ times to $43 \mathrm{~s}$ and $68 \mathrm{~s}$ respectively. The IR detector also shows similar, but smaller drops in signal during these periods. A comparison of IR and UV count rate versus detector distance reveals that both count rates decay as the inverse square of the distance from the fire center.

The temperature measured at $9.1 \mathrm{~m}$ above pan center can be used to determine when the flame leans as a function of time. When the temperature recorded by this thermocouple is high, the flame is more upright. Lower temperatures suggest a flame which is strongly leaning due to the wind. Figure 35 provides this temperature profile which implies that the flame is showing substantial lean during the periods between $35 \mathrm{~s}$ and $45 \mathrm{~s}$ and again at $70 \mathrm{~s}$ to $80 \mathrm{~s}$ which correlates with the decrease in UV signal. Note that these times are corrected from the figure for the $12 \mathrm{~s}$ delay in fire start. If the bulk of the UV emission were being produced by the upper portion of the flame, the fact that the flame leans away from the detectors during this time would explain the decrease in UV emission. Another explanation could be that with the flame leaning, there is more soot to absorb the UV emission, thus causing lower net UV flux directed toward the detectors. 


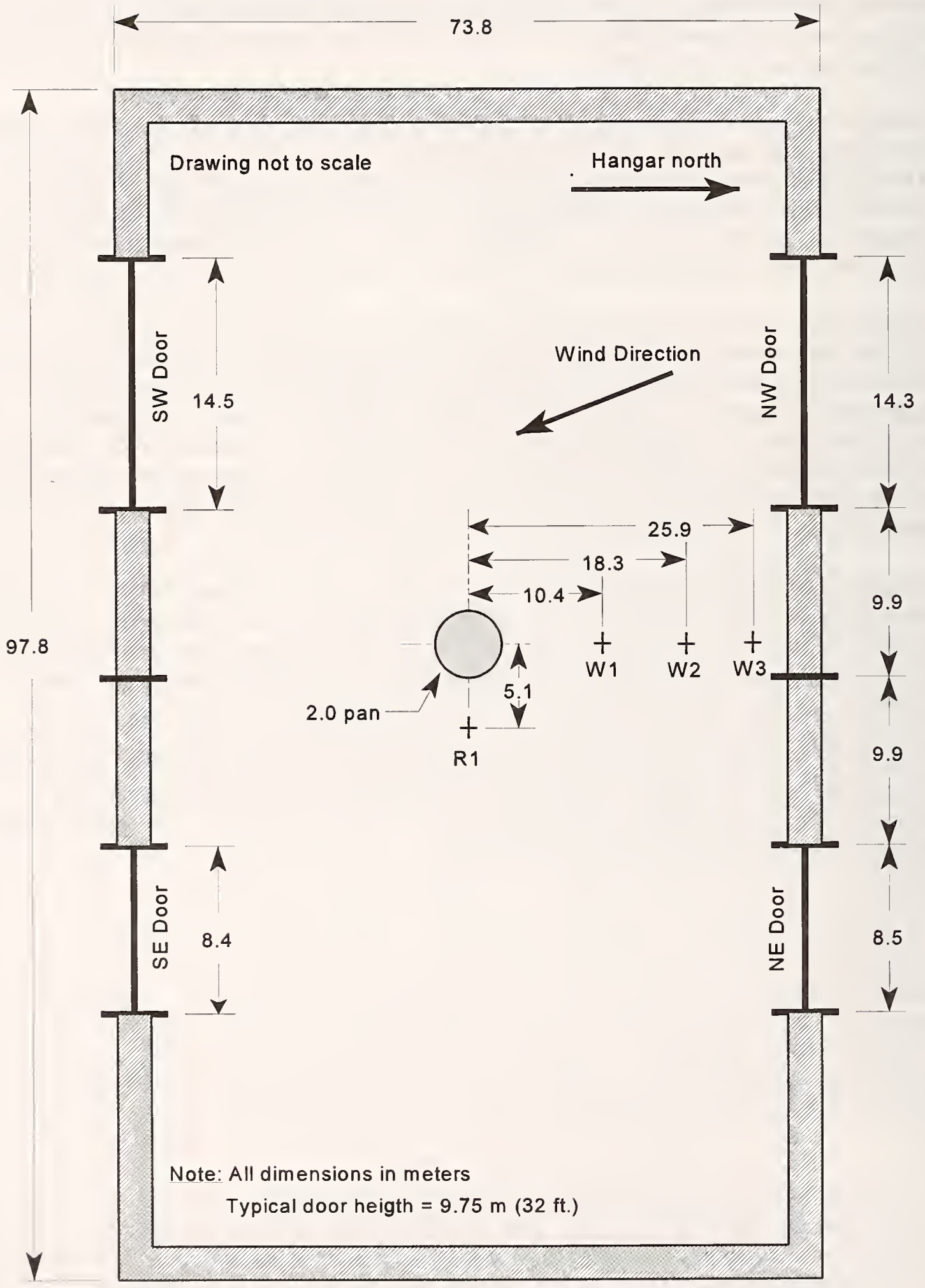

Figure 30. Layout for $2.0 \mathrm{~m}$ open door fire test in $15 \mathrm{~m}$ high facility. 


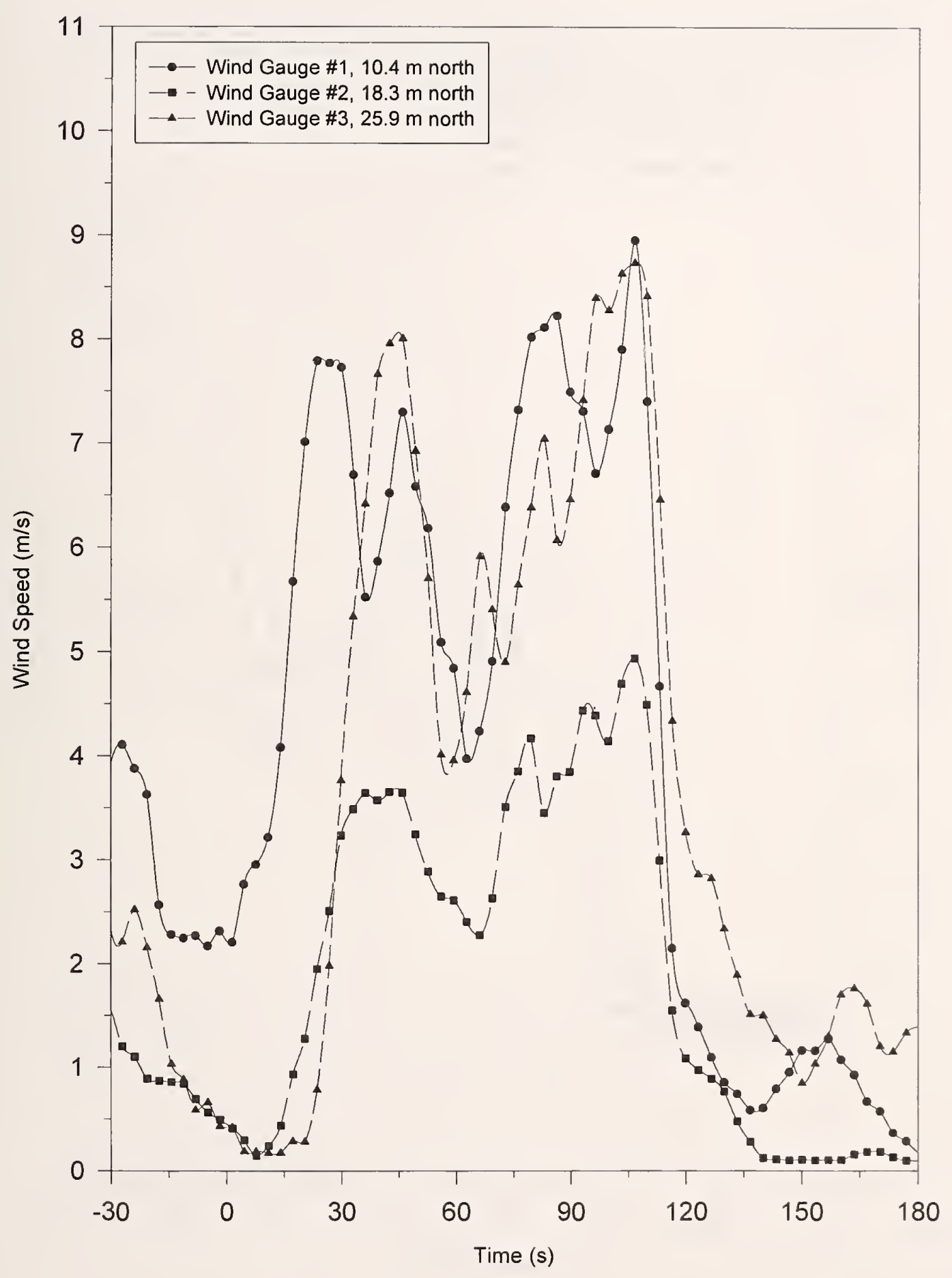

Figure 31. Wind speed measurements for $2.0 \mathrm{~m}$ open door fire test. 


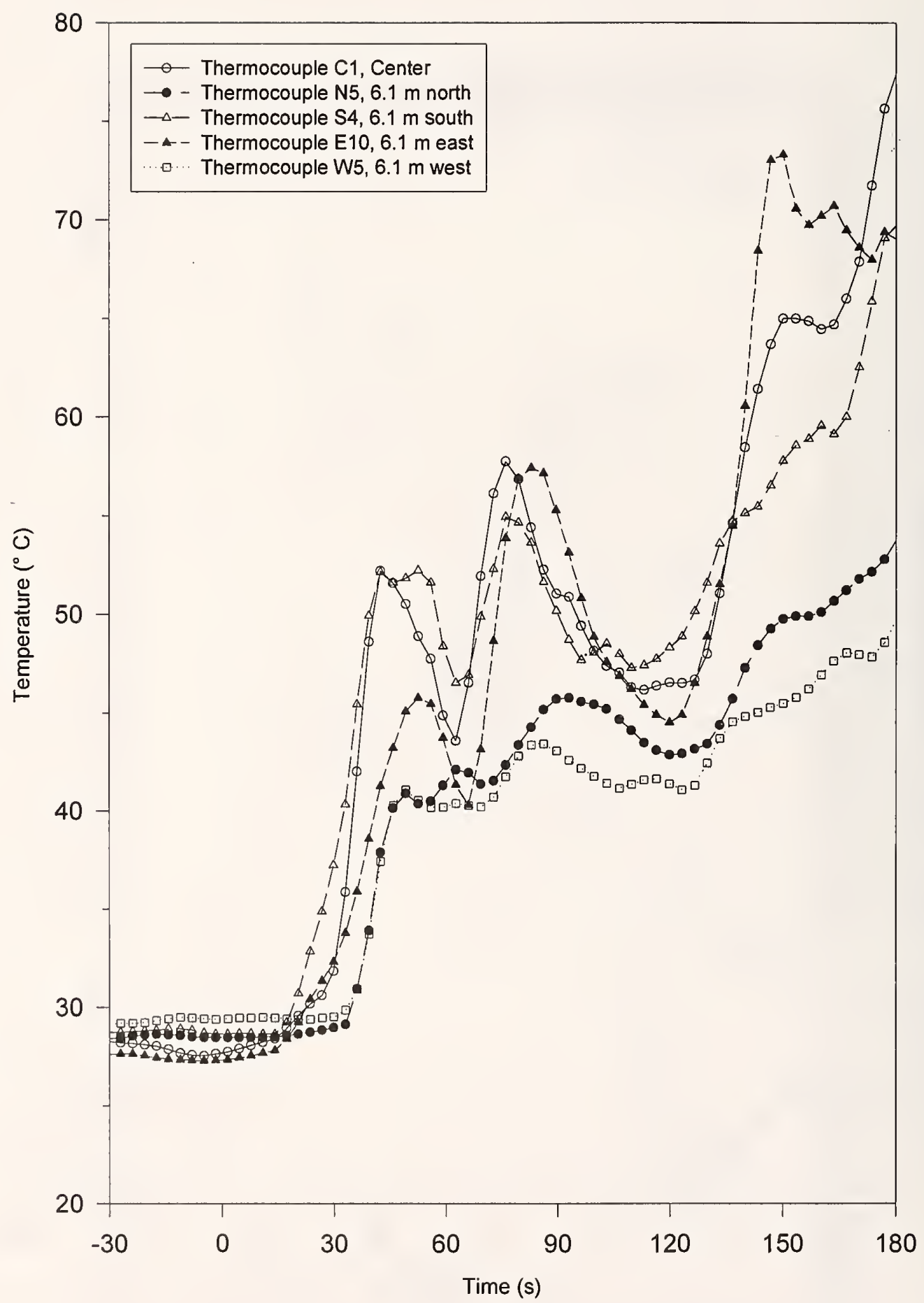

Figure 32. Temperature measurements for $2.0 \mathrm{~m}$ open door fire test. 


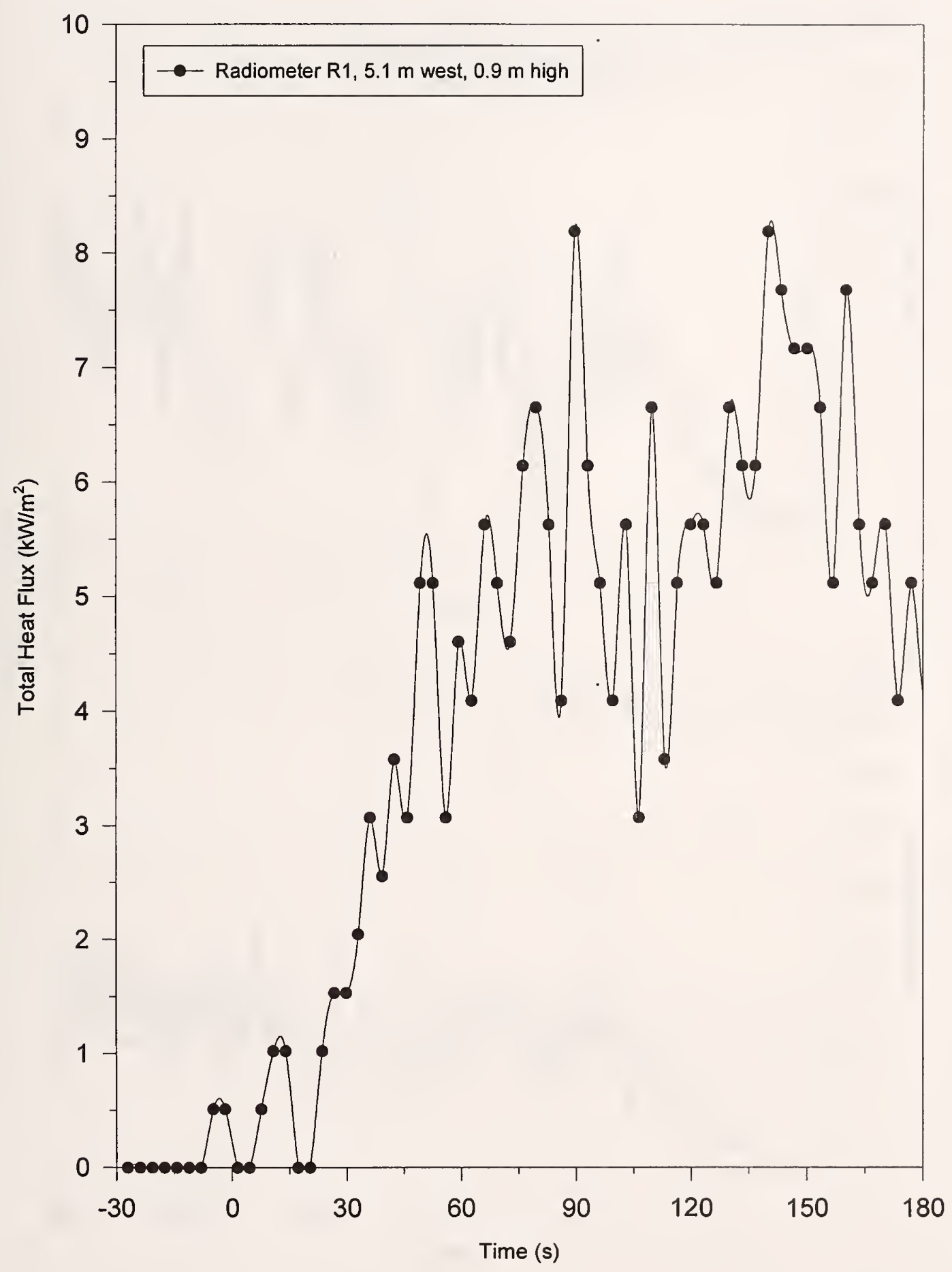

Figure 33. Total heat flux measurement for $2.0 \mathrm{~m}$ open door fire test. 

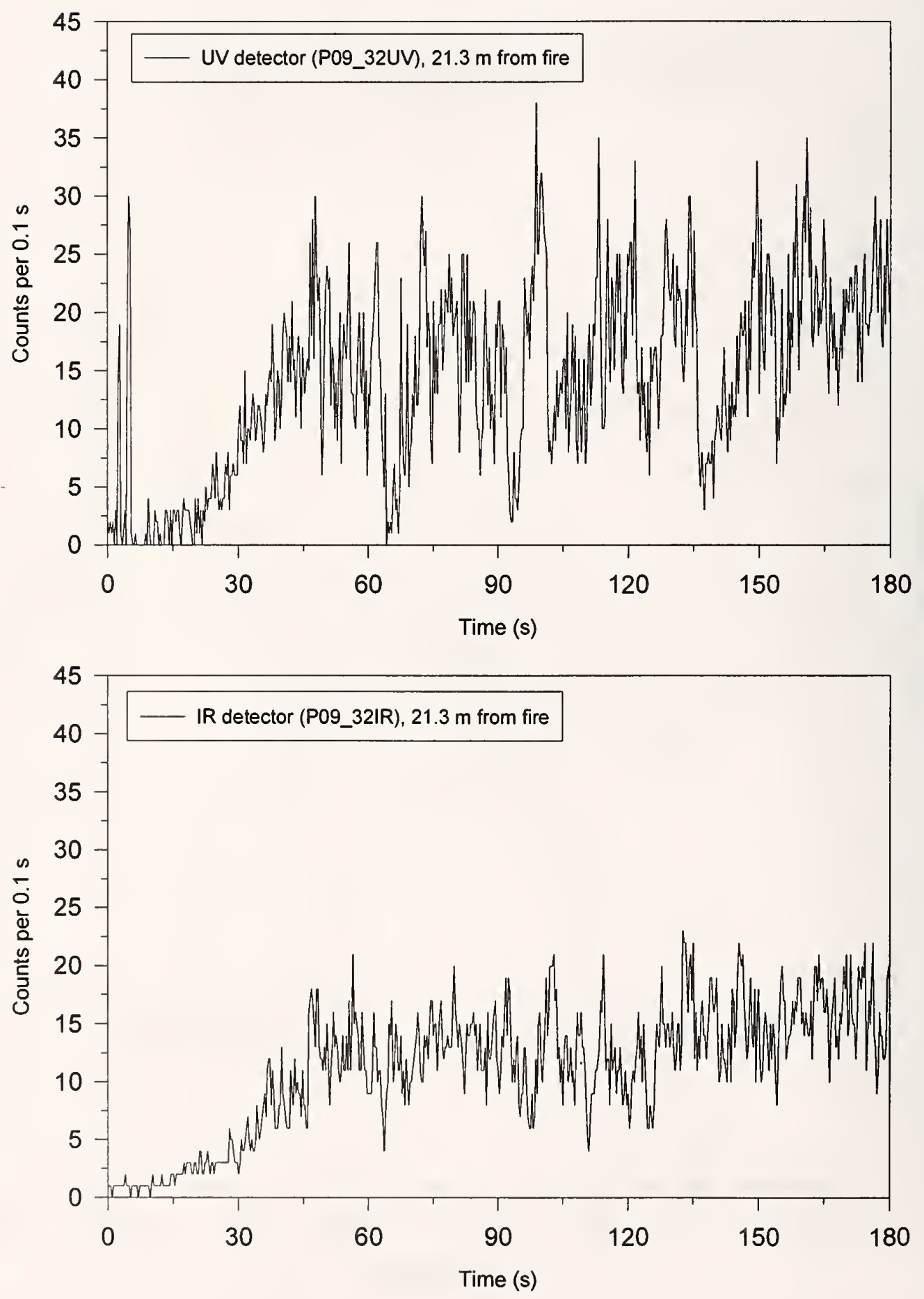

Figure 34. UV and IR emission counts for detector at $21.3 \mathrm{~m}$ during open door fire test. 


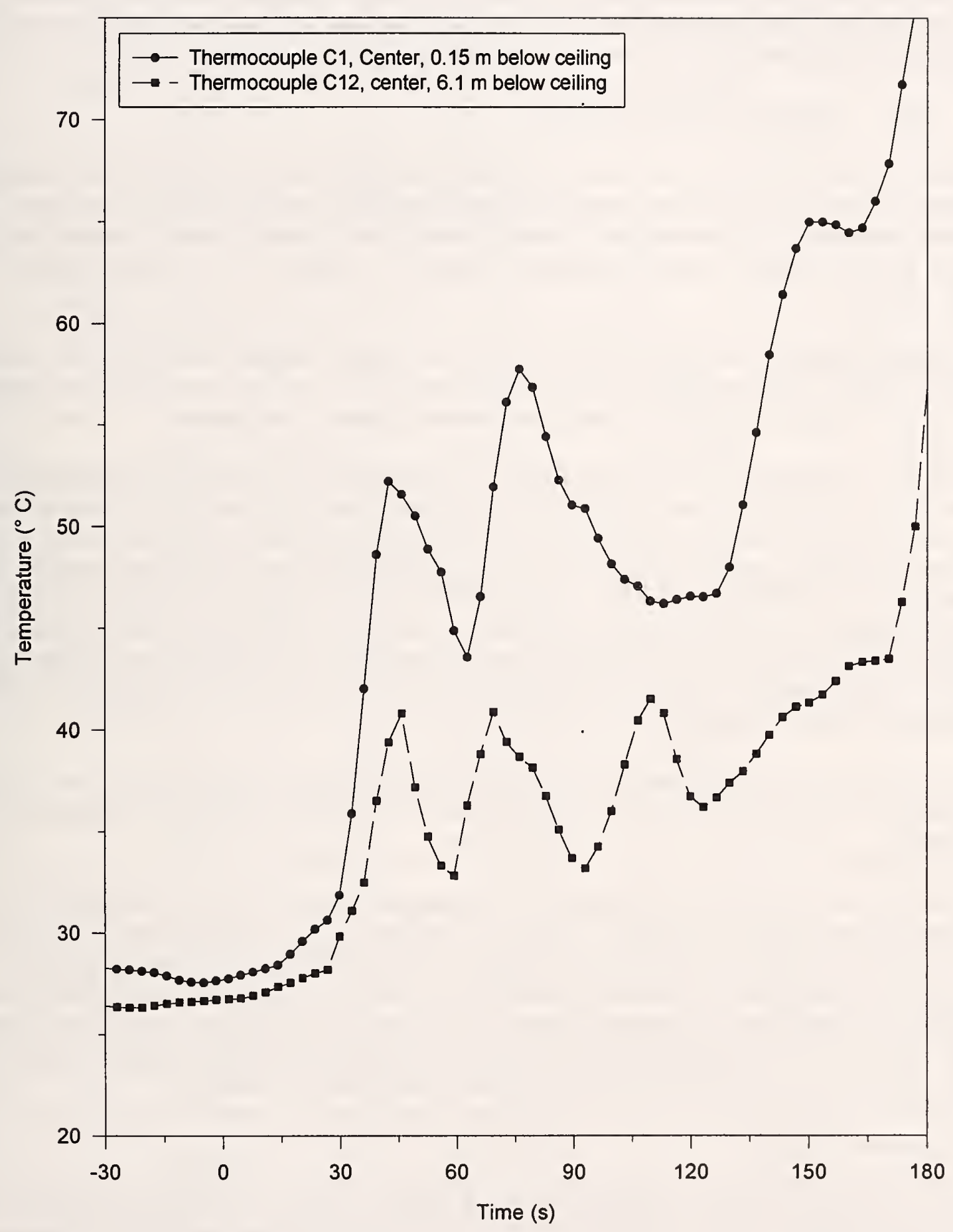

Figure 35. Temperatures along plume center for $2.0 \mathrm{~m}$ diameter pan open door fire test. 


\subsection{Response of Detection and Sprinkler Activation Systems to Fires}

The numerous detection systems and sprinkler heads that were installed during the fires described in the previous two sections were greatly affected by the fire size and conditions under which the tests were run. In section 3.4, the activation times of the sprinklers and the response of the specific detection schemes to the heat, smoke, and radiation produced by the fires are described.

\subsubsection{Sprinkler Activation Times}

The spacing and installation of the automatic sprinklers installed in the $15 \mathrm{~m}$ facility were previously described, Figure 7. The sprinkler response analysis includes the number and type of sprinklers activated, response times, effect of draft curtains, threshold fire sizes for sprinkler response, effects of thermal element, and the conductive heat transfer effects of wẹt-pipe versus dry-pipe sprinkler configurations.

No sprinkler heads activated during tests $1,2,3,11$ or 12 , where the heat release rate was below 2 MW and the pool size was under $1 \mathrm{~m}$ (i.e., the "detector fires"). Test 4 , which was the $1.5 \mathrm{~m}$ diameter pan fire with a heat release rate of $2.8 \mathrm{MW}$, also did not activate any sprinklers.

Tests $5,6 \mathrm{~b}, 7$ and 8 did activate sprinklers in the $15 \mathrm{~m}$ hangar. Table 20 shows the response times of all the sprinklers which activated in these four experiments. The $2.0 \mathrm{~m}$ diameter pan fires with heating rates ranging from approximately $5.6 \mathrm{MW}$ to $6.8 \mathrm{MW}$, were the smallest size fires to activate any automatic sprinklers. The $2.5 \mathrm{~m}$ diameter pan fires (tests $6 \mathrm{~b}$ and 8 ), which produced estimated heat release rates of $7.7 \mathrm{MW}$ also activated a number of $79^{\circ} \mathrm{C}$ to $93^{\circ} \mathrm{C}$ automatic sprinklers. None of the $141^{\circ} \mathrm{C}$ sprinklers activated in any of the full-scale tests in the $15 \mathrm{~m}$ facility. It should be noted that the maximum ceiling temperatures for test $6 \mathrm{~b}$ and test 8 exceeded $141{ }^{\circ} \mathrm{C}$; hence, the only reason the sprinklers did not activate for these tests was that they were not located in the high temperature gas for a long enough period of time.

Test 13 was also a $2.0 \mathrm{~m}$ diameter pan fire, but was conducted with the hangars doors open. Due to the severe plume lean this test was terminated at $150 \mathrm{~s}$. No sprinklers activated prior to the test termination.

Analysis of Table 20 shows that for test 5 , only one sprinkler activated in the center plume region, compared to four sprinkler activations in test 7 . One possible cause for this is that test 5 exhibited a fire whirl type phenomenon where the swirling flame moved back and forth across the surface of the fuel, causing temperature fluctuations at the ceiling. The whirl phenomena also caused the high temperatures at the ceiling to be more localized in space than for a normal plume. A second cause is the time history of the ceiling temperature. Between $190 \mathrm{~s}$ and $330 \mathrm{~s}$, when there were no whirls, the ceiling temperature dropped below $80^{\circ} \mathrm{C}$, which would delay link activation.

\section{Effects of Draft Curtains}

There are three aspects which can be examined to determine the effects of the draft curtain with respect to sprinkler response. They are: number of sprinklers activated, response times and the distance from plume centerline at which sprinkler activation occurred. In this analysis, only similar fire sizes can be compared. Thus, test 5 ( $2.0 \mathrm{~m}$ diameter pan with the draft curtain in place) is compared to test 7 
Table 20. Sprinkler activation times, seconds. $\mathrm{n}=$ no activation, $*=$ no sprinklers installed

\begin{tabular}{|c|c|c|c|c|c|c|c|c|c|c|c|}
\hline \multirow{2}{*}{$\begin{array}{c}\text { Test } \\
\#\end{array}$} & \multirow{2}{*}{\multicolumn{2}{|c|}{ Sprinkler Location }} & \multicolumn{9}{|c|}{ Sprinkler Type (see Figure 7) } \\
\hline & & & A & B & $\mathrm{C}$ & $\mathrm{D}$ & $\mathrm{E}$ & $\mathrm{F}$ & G & $\mathrm{H}$ & I \\
\hline \multirow{6}{*}{$\begin{array}{c}\# 5 \\
2 \mathrm{~m} \\
6.7 \\
\mathrm{MW}\end{array}$} & \multicolumn{2}{|l|}{ center } & $\mathrm{n}$ & $\mathrm{n}$ & $\mathrm{n}$ & $\mathrm{n}$ & $\mathrm{n}$ & 182 & $\mathrm{n}$ & $\mathrm{n}$ & $\mathrm{n}$ \\
\hline & $3.1 \mathrm{~m}$ radius & $\begin{array}{l}\mathrm{N}, \mathrm{S} \\
\mathrm{E}, \mathrm{W}\end{array}$ & $\begin{array}{l}\mathrm{n}, \mathrm{n} \\
\mathrm{n}, \mathrm{n}\end{array}$ & $\begin{array}{c}192,196 \\
\mathrm{n}, \mathrm{n}\end{array}$ & $\begin{array}{l}\mathrm{n}, \mathrm{n} \\
\mathrm{n}, \mathrm{n}\end{array}$ & $\begin{array}{l}\mathrm{n}, \mathrm{n} \\
\mathrm{n}, \mathrm{n}\end{array}$ & $\begin{array}{l}\mathrm{n}, \mathrm{n} \\
\mathrm{n}, \mathrm{n}\end{array}$ & $\begin{array}{c}199,206 \\
138, \mathrm{n}\end{array}$ & $*$ & $*$ & * \\
\hline & $6.1 \mathrm{~m}$ radius & $\begin{array}{l}\mathrm{N}, \mathrm{S}, \\
\mathrm{E}, \mathrm{W}\end{array}$ & $\begin{array}{l}\mathrm{n}, \mathrm{n} \\
\mathrm{n}, \mathrm{n}\end{array}$ & $\begin{array}{c}395, \mathrm{n} \\
199, \mathrm{n}\end{array}$ & $\begin{array}{l}\mathrm{n}, \mathrm{n} \\
\mathrm{n}, \mathrm{n}\end{array}$ & $\begin{array}{l}\mathrm{n}, \mathrm{n} \\
\mathrm{n}, \mathrm{n}\end{array}$ & * & $*$ & $*$ & $*$ & * \\
\hline & $8.5 \mathrm{~m} \mathrm{rad}$. & $\mathrm{N}, \mathrm{S}$ & $\mathrm{n}, \mathrm{n}$ & $\mathrm{n}, \mathrm{n}$ & $*$ & $*$ & * & $*$ & * & $*$ & * \\
\hline & $9.1 \mathrm{~m} \mathrm{rad}$. & $\mathrm{E}, \mathrm{W}$ & $\mathrm{n}, \mathrm{n}$ & $\mathrm{n}, \mathrm{n}$ & $*$ & * & $*$ & $*$ & $*$ & $*$ & * \\
\hline & $11.6 \mathrm{~m} \mathrm{rad}$. & $\mathrm{E}, \mathrm{W}$ & $\mathrm{n}, \mathrm{n}$ & $\mathrm{n}, \mathrm{n}$ & $*$ & $*$ & * & * & $*$ & $*$ & * \\
\hline \multirow{6}{*}{$\begin{array}{c}\# 6 \mathrm{~b} \\
2.5 \mathrm{~m} \\
7.7 \\
\text { MW }\end{array}$} & \multicolumn{2}{|l|}{ center } & $\mathrm{n}$ & 78 & $\mathrm{n}$ & $\mathrm{n}$ & $\mathrm{n}$ & 91 & 94 & 321 & $\mathrm{n}$ \\
\hline & $3.1 \mathrm{~m}$ radius & $\begin{array}{l}\mathrm{N}, \mathrm{S}, \\
\mathrm{E}, \mathrm{W}\end{array}$ & $\begin{array}{l}\mathrm{n}, \mathrm{n} \\
\mathrm{n}, \mathrm{n}\end{array}$ & $\begin{array}{c}n, 88 \\
147,104\end{array}$ & $\begin{array}{l}\mathrm{n}, \mathrm{n} \\
\mathrm{n}, \mathrm{n}\end{array}$ & $\begin{array}{l}\mathrm{n}, \mathrm{n} \\
\mathrm{n}, \mathrm{n}\end{array}$ & $\begin{array}{l}\mathrm{n}, \mathrm{n} \\
\mathrm{n}, \mathrm{n}\end{array}$ & $\begin{array}{l}107,100 \\
137,100\end{array}$ & $*$ & * & * \\
\hline & $6.1 \mathrm{~m}$ radius & $\begin{array}{l}\mathrm{N}, \mathrm{S}, \\
\mathrm{E}, \mathrm{W}\end{array}$ & $\begin{array}{l}\mathrm{n}, \mathrm{n} \\
\mathrm{n}, \mathrm{n}\end{array}$ & $\begin{array}{l}144,140 \\
251,207\end{array}$ & $\begin{array}{l}\mathrm{n}, \mathrm{n} \\
\mathrm{n}, \mathrm{n}\end{array}$ & $\begin{array}{l}\mathrm{n}, \mathrm{n} \\
\mathrm{n}, \mathrm{n}\end{array}$ & $*$ & * & $*$ & $*$ & * \\
\hline & $8.5 \mathrm{~m}$ radius & $\mathrm{N}, \mathrm{S}$, & $\mathrm{n}, \mathrm{n}$ & 295,247 & * & $*$ & $*$ & * & * & * & * \\
\hline & $9.1 \mathrm{~m}$ radius & E,W & $\mathrm{n}, \mathrm{n}$ & $\mathrm{n}, 439$ & $*$ & $*$ & $*$ & * & $*$ & $*$ & * \\
\hline & $11.6 \mathrm{~m} \mathrm{rad}$. & E,W & $\mathrm{n}, \mathrm{n}$ & $\mathrm{n}, \mathrm{n}$ & $*$ & $*$ & * & $*$ & $*$ & $*$ & * \\
\hline \multirow{6}{*}{$\begin{array}{c}\# 7 \\
2 \mathrm{~m} \\
5.6 \\
\mathrm{MW}\end{array}$} & \multicolumn{2}{|l|}{ center } & $\mathrm{n}$ & 481 & $\mathrm{n}$ & $\mathrm{n}$ & $\mathrm{n}$ & 313 & 582 & 528 & n \\
\hline & $3.1 \mathrm{~m}$ radius & $\begin{array}{l}\mathrm{N}, \mathrm{S}, \\
\mathrm{E}, \mathrm{W}\end{array}$ & $\begin{array}{l}\mathrm{n}, \mathrm{n} \\
\mathrm{n}, \mathrm{n}\end{array}$ & $\begin{array}{l}585, \mathrm{n} \\
\mathrm{n}, 403\end{array}$ & $\begin{array}{l}\mathrm{n}, \mathrm{n} \\
\mathrm{n}, \mathrm{n}\end{array}$ & $\begin{array}{l}\mathrm{n}, \mathrm{n} \\
\mathrm{n}, \mathrm{n}\end{array}$ & $\begin{array}{l}\mathrm{n}, \mathrm{n} \\
\mathrm{n}, \mathrm{n}\end{array}$ & $\begin{array}{l}545, \mathrm{n} \\
\mathrm{n}, 383\end{array}$ & $*$ & $*$ & * \\
\hline & $6.1 \mathrm{~m}$ radius & $\begin{array}{l}\mathrm{N}, \mathrm{S}, \\
\mathrm{E}, \mathrm{W}\end{array}$ & $\begin{array}{l}\mathrm{n}, \mathrm{n} \\
\mathrm{n}, \mathrm{n}\end{array}$ & $\begin{array}{l}\mathrm{n}, \mathrm{n} \\
\mathrm{n}, \mathrm{n}\end{array}$ & $\begin{array}{l}\mathrm{n}, \mathrm{n} \\
\mathrm{n}, \mathrm{n}\end{array}$ & $\begin{array}{l}\mathrm{n}, \mathrm{n} \\
\mathrm{n}, \mathrm{n}\end{array}$ & $*$ & $*$ & $*$ & $*$ & * \\
\hline & $8.5 \mathrm{~m}$ radius & $\mathrm{N}, \mathrm{S}$ & $\mathrm{n}, \mathrm{n}$ & $\mathrm{n}, \mathrm{n}$ & $*$ & * & * & * & $*$ & $*$ & * \\
\hline & $9.1 \mathrm{~m}$ radius & E,W & $\mathrm{n}, \mathrm{n}$ & $\mathrm{n}, \mathrm{n}$ & $*$ & * & $*$ & $*$ & $*$ & $*$ & * \\
\hline & $11.6 \mathrm{~m} \mathrm{rad}$. & $\mathrm{E}, \mathrm{W}$ & $\mathrm{n}, \mathrm{n}$ & $\mathrm{n}, \mathrm{n}$ & $*$ & * & $*$ & $*$ & $*$ & * & * \\
\hline \multirow{6}{*}{$\begin{array}{c}\# 8 \\
2.5 \mathrm{~m}\end{array}$} & \multicolumn{2}{|c|}{ center } & n & 311 & $\mathrm{n}$ & $\mathrm{n}$ & $\mathrm{n}$ & 311 & 342 & $\mathrm{n}$ & n \\
\hline & $3.1 \mathrm{~m}$ radius & $\begin{array}{l}\mathrm{N}, \mathrm{S}, \\
\mathrm{E}, \mathrm{W}\end{array}$ & $\begin{array}{l}\mathrm{n}, \mathrm{n} \\
\mathrm{n}, \mathrm{n}\end{array}$ & $\begin{array}{l}366,366 \\
359,403\end{array}$ & $\begin{array}{l}\mathrm{n}, \mathrm{n} \\
\mathrm{n}, \mathrm{n}\end{array}$ & $\begin{array}{l}\mathrm{n}, \mathrm{n} \\
\mathrm{n}, \mathrm{n}\end{array}$ & $\begin{array}{l}\mathrm{n}, \mathrm{n} \\
\mathrm{n}, \mathrm{n}\end{array}$ & $\begin{array}{l}379,389 \\
338,379\end{array}$ & $*$ & $*$ & * \\
\hline & $6.1 \mathrm{~m}$ radius & $\begin{array}{l}\mathrm{N}, \mathrm{S}, \\
\mathrm{E}, \mathrm{W}\end{array}$ & $\begin{array}{l}\mathrm{n}, \mathrm{n} \\
\mathrm{n}, \mathrm{n}\end{array}$ & $\begin{array}{c}467, \mathrm{n} \\
\mathrm{n}, \mathrm{n}\end{array}$ & $\begin{array}{l}\mathrm{n}, \mathrm{n} \\
\mathrm{n}, \mathrm{n}\end{array}$ & $\begin{array}{l}\mathrm{n}, \mathrm{n} \\
\mathrm{n}, \mathrm{n}\end{array}$ & $*$ & $*$ & $*$ & $*$ & * \\
\hline & $8.5 \mathrm{~m}$ radius & $\mathrm{N}, \mathrm{S}$ & $\mathrm{n}, \mathrm{n}$ & $\mathrm{n}, \mathrm{n}$ & * & $*$ & $*$ & $*$ & $*$ & $*$ & * \\
\hline & $9.1 \mathrm{~m}$ radius & $\mathrm{E}, \mathrm{W}$ & $\mathrm{n}, \mathrm{n}$ & $\mathrm{n}, \mathrm{n}$ & $*$ & $*$ & $*$ & $*$ & * & $*$ & * \\
\hline & $11.6 \mathrm{~m} \mathrm{rad}$. & $\mathrm{E}, \mathrm{W}$ & $\mathrm{n}, \mathrm{n}$ & $\mathrm{n}, \mathrm{n}$ & * & $*$ & $*$ & $*$ & $*$ & $*$ & * \\
\hline
\end{tabular}


( $2.0 \mathrm{~m}$ diameter pan without the draft curtain). Similarly, test $6 \mathrm{~b}(2.5 \mathrm{~m}$ diameter pan with the draft curtain in place) is compared to test 8 ( $2.5 \mathrm{~m}$ diameter pan without the draft curtain). In both tests 5 and 7 , eight of the 65 sprinklers activated. In this comparison, although the number of sprinklers activated was the same, the response times were significantly different. In test 5 , the first sprinkler activation occurred in $138 \mathrm{~s}$ compared to $313 \mathrm{~s}$ for the first sprinkler activation in test 7 . A comparison of Figure 36 with Figure 37 shows a much faster sprinkler response time with the draft curtain in place. The faster activation for test 5 may have been caused by the fire whirl which produced higher temperatures than in test 7 .

These figures show the ability of the draft curtain to confine the heat released by the fires and limit its spread across the ceiling. Without the draft curtain, the heated gases spread across the ceiling and were cooled below the sprinklers' activation temperatures.

The effects of the draft curtain were also clearly evident in the larger, $2.5 \mathrm{~m}$ diameter pan fires. In test $6 \mathrm{~b}, 18$ sprinklers activated compared to 12 sprinklers in test 8 . This shows that $50 \%$ more sprinklers activated with the draft curtain in place. Comparing Figure 38 with Figure 39 shows much faster sprinkler response times with the draft curtain in place. In test $6 \mathrm{~b}$, the first sprinkler activated in $78 \mathrm{~s}$ compared to $311 \mathrm{~s}$ in test 8 . Further analysis also shows with the draft curtain in place a significant increase in the number of sprinkler activations outside the plume. For these tests, both plumes were normal and the peak plume temperatures were similar. The measured differences in sprinkler activation were probably due to the presence of the draft curtains. In a typical military aircraft hangar, these heads would provide possible cooling of adjacent aircraft.

\section{Effects of Ceiling Configuration}

The ceiling is comprised of $0.25 \mathrm{~m}$ (10 inch) I-beams which run north to south across the width of the hangar, spaced $4.1 \mathrm{~m}(13.5 \mathrm{ft})$ on center. The sprinkler deflectors were installed approximately $0.30 \mathrm{~m}$ to $0.36 \mathrm{~m}$ below the ceiling deck which placed the deflectors below the I-beam obstructions.

To examine whether the I-beam configuration affected sprinkler response times, it is important to compare the response times of the sprinklers along the north/south axis to those along the east/west axis to determine if the I-beams channeled the heat. An analysis of Table 20 indicates that the ceiling configuration had no perceivable effect on the sprinkler response times.

\section{Effects of Fire Size}

The experimental fires were designed to determine the threshold fire sizes needed to activate a variety of sprinklers, with the primary focus on the $79^{\circ} \mathrm{C}$ and $141{ }^{\circ} \mathrm{C}$ heads. The threshold fire size needed to activate the $79^{\circ} \mathrm{C}$ sprinklers in the $15 \mathrm{~m}$ hangar was the $2.0 \mathrm{~m}$ diameter pan fire which produced a heat release rate of approximately $6.8 \mathrm{MW}$. The $2.5 \mathrm{~m}$ diameter pan fire which produced a heat release rate of approximately $7.7 \mathrm{MW}$ was the largest fire conducted in the $15 \mathrm{~m}$ hangar. Ceiling temperatures in the $7.7 \mathrm{MW}$ fires did reach the activation temperature of the $141^{\circ} \mathrm{C}$ sprinklers, but were not maintained at that temperature long enough to cause sprinkler activation. Figures 40 and 41 show the effects of fire size on ceiling temperature and sprinkler response in the $15 \mathrm{~m}$ hangar. Fire size affected both the number of sprinklers that activated as well as the response times. Since the draft curtain has a profound impact on the response times of the sprinklers, studying the effects of fire size is accomplished by comparing test 5 to test $6 \mathrm{~b}$, and test 7 to test 8 . 


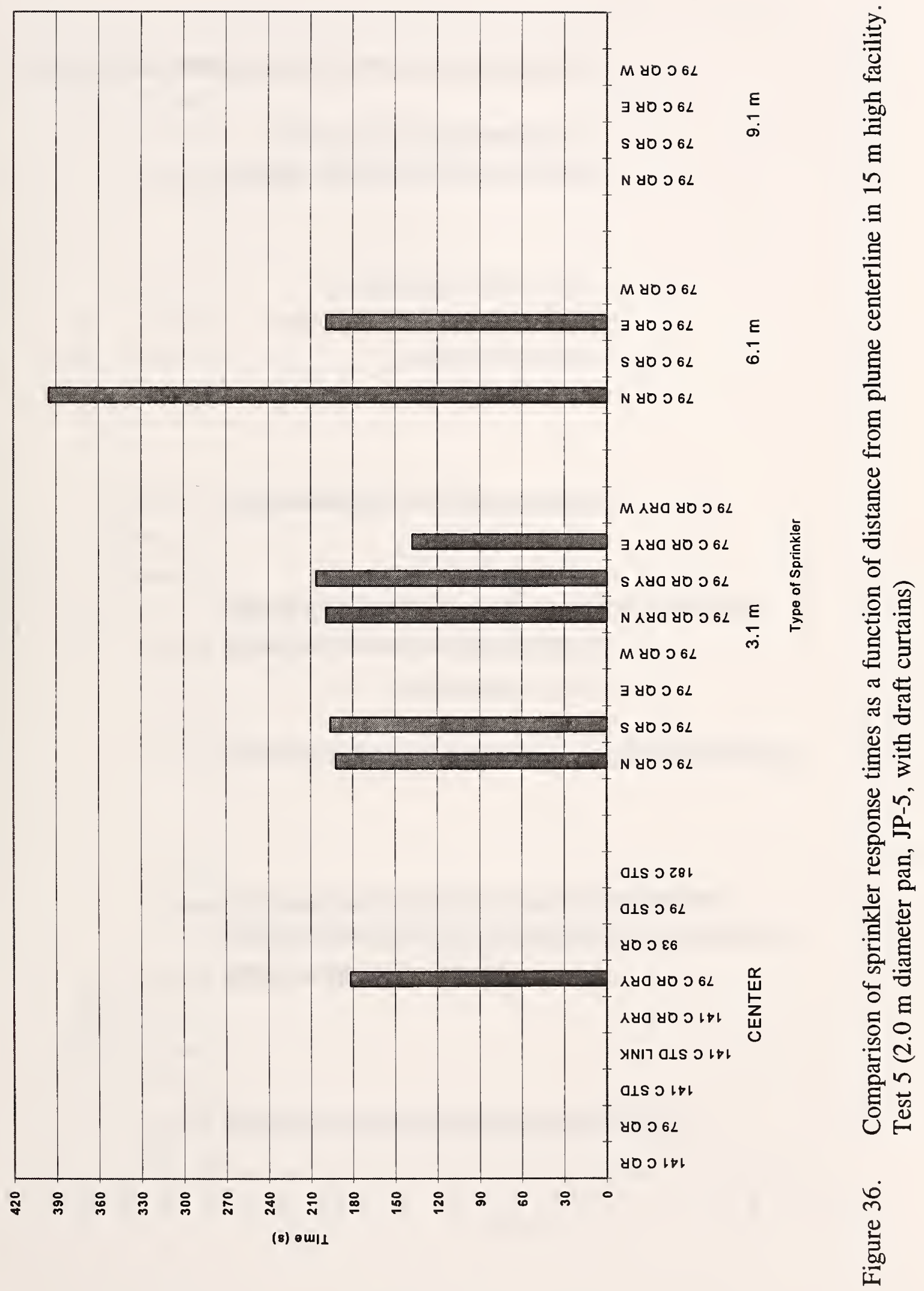




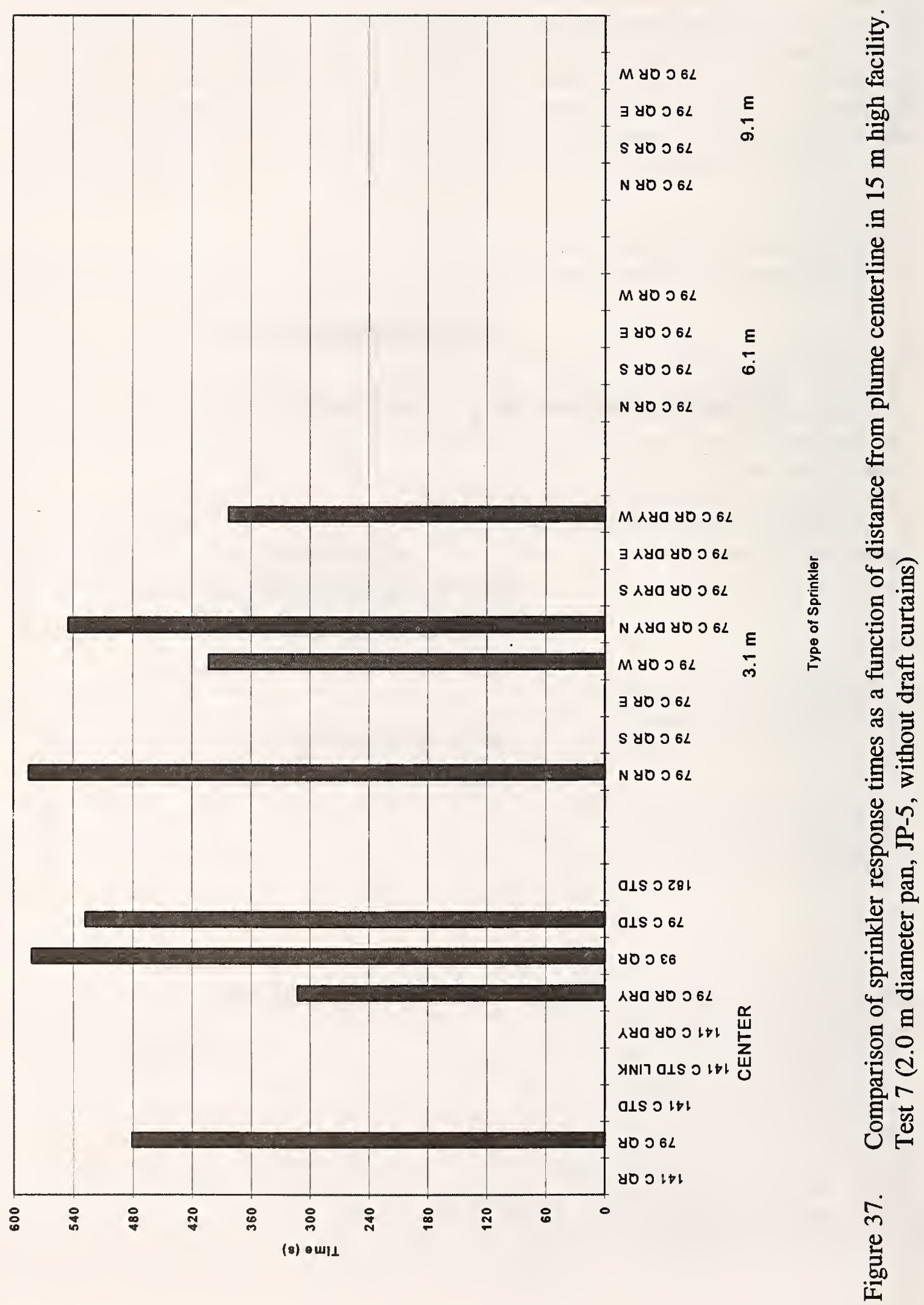




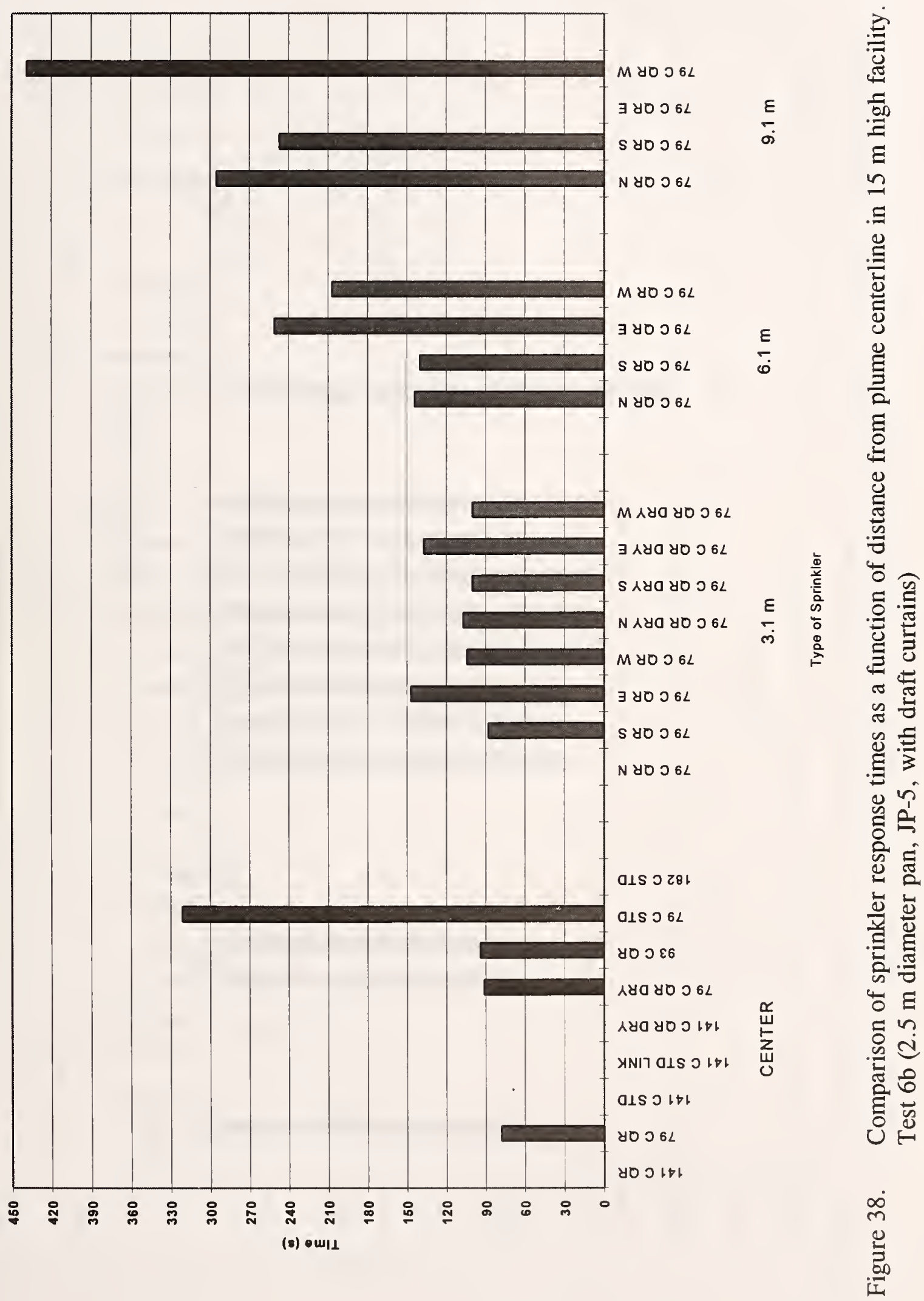




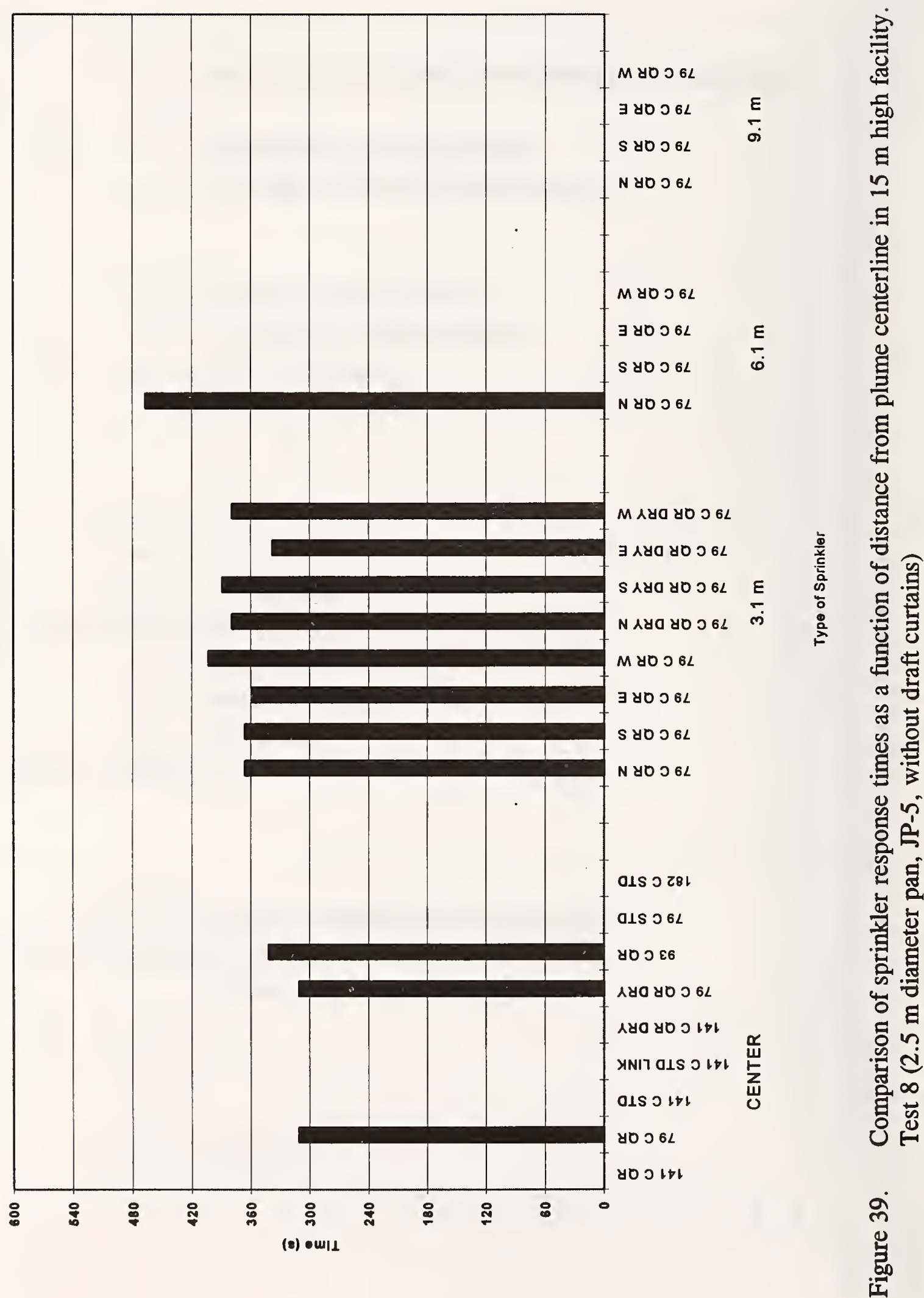




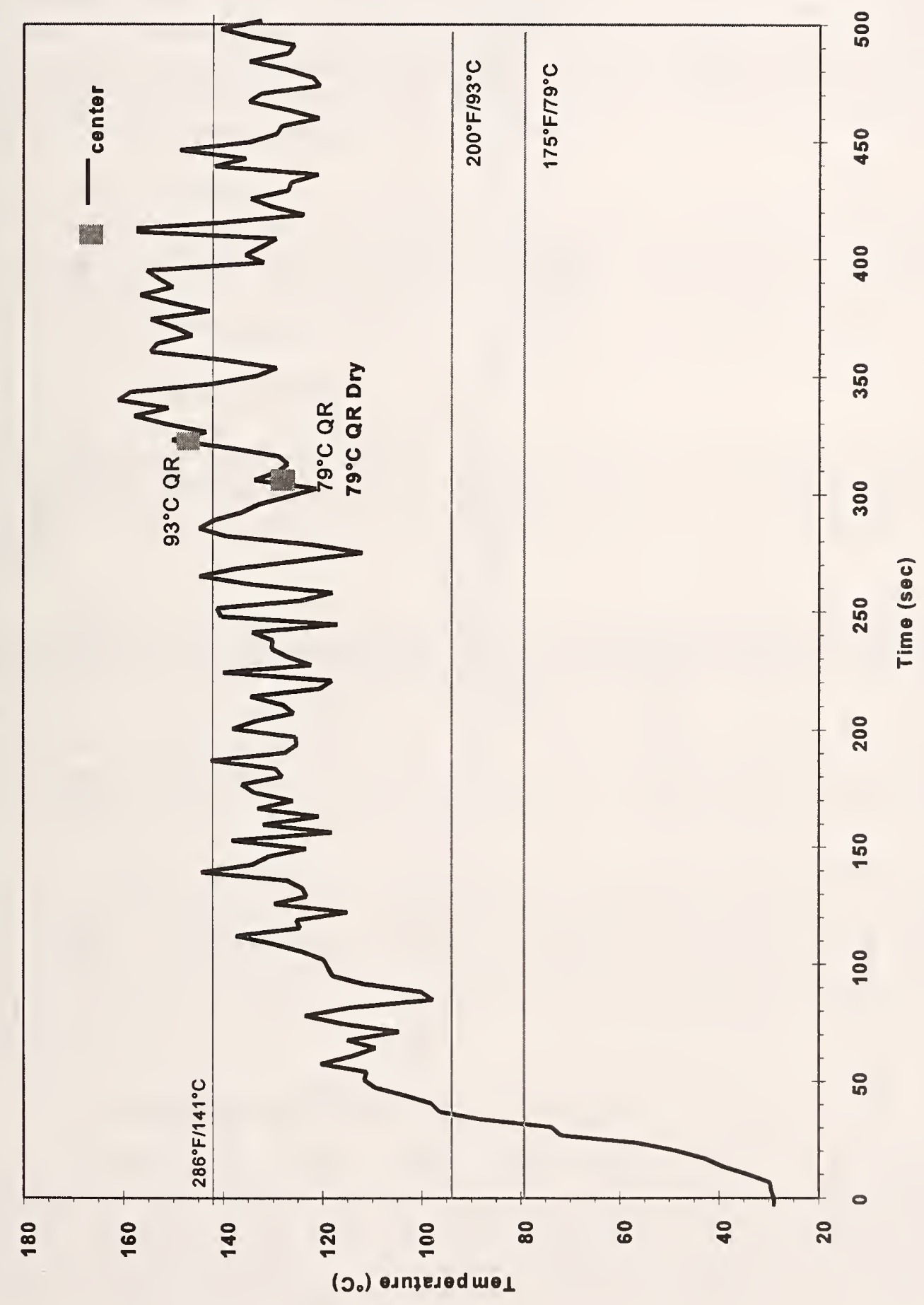




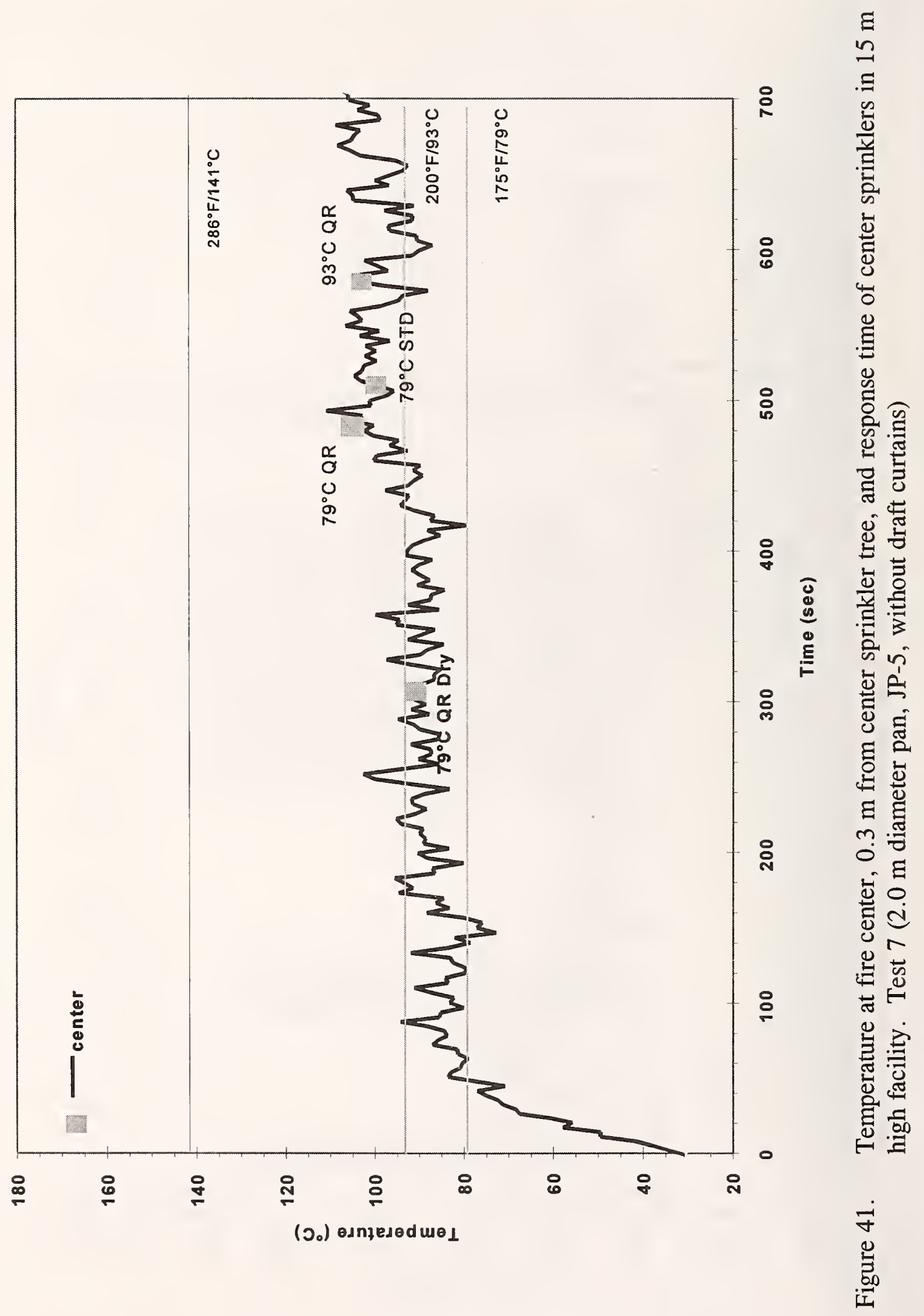




\section{Effects of Thermal Element}

Two factors were analyzed with respect to the thermal element of the automatic sprinklers. The first was the temperature rating of the sprinkler heads used (i.e., $79^{\circ} \mathrm{C}, 93^{\circ} \mathrm{C}, 141^{\circ} \mathrm{C}$, and $182^{\circ} \mathrm{C}$ ). The second was the response time index (RTI), which for this analysis focused on quick response versus standard response heads. The $79{ }^{\circ} \mathrm{C}$ heads responded faster than the $93{ }^{\circ} \mathrm{C}$ heads as expected; no $141^{\circ} \mathrm{C}$ or $182^{\circ} \mathrm{C}$ heads activated. In general, the lower RTI heads responded more often than the standards, however, the limited number of comparisons between sprinklers with the same temperatu :e ratings but different RTIs are insufficient to quantify how much more quickly the quick response sprinkler head would normally operate.

For the examination of the effects of the RTI, the response of the $79^{\circ} \mathrm{C}$ standard response sprinkler was compared to that of the $79{ }^{\circ} \mathrm{C}$ quick response sprinkler. Again, the limited data in the $15 \mathrm{~m}$ experiments make it difficult to draw any definite conclusions. However, analysis of test $6 \mathrm{~b}$ shows that the $79{ }^{\circ} \mathrm{C}$ quick response sprinkler at plume center responded in $78 \mathrm{~s}$ compared to $321 \mathrm{~s}$ for the $79{ }^{\circ} \mathrm{C}$ standard response head at the same location. This issue is also readdressed in section 4 .

\section{Effects of Wet- vs. Dry-Pipe Sprinklers}

In order to determine the conductive heat transfer effects of wet-pipe versus dry-pipe sprinklers, the average response times of similar sprinklers were examined. Table 21 shows the average response times for the $79{ }^{\circ} \mathrm{C} \mathrm{QR}$ (wet) and the $79{ }^{\circ} \mathrm{C} \mathrm{QR}$ (dry) sprinklers located $3.1 \mathrm{~m}$ from the plume centerline.

Table 21. Average response times (s) of wet-pipe and dry-pipe sprinkler configurations

\begin{tabular}{|c|c|c|c|}
\hline Test Number & $\mathbf{7 9}^{\circ} \mathbf{C}$ QR-Wet (s) & $\mathbf{7 9}^{\circ} \mathbf{C}$ QR-Dry (s) & \% Difference \\
\hline 5 & 194 & 181 & 6.7 \\
\hline $6 \mathrm{~b}$ & 113 & 111 & 1.7 \\
\hline 7 & 495 & 464 & 6.3 \\
\hline 8 & 374 & 371 & 0.8 \\
\hline
\end{tabular}

As shown in the above table, the wet-pipe versus dry-pipe configuration used in these experiments had no significant effect on the response time of the automatic sprinkler heads. However, any dry-pipe or pre-action sprinkler system will incur an additional time delay in delivering water from the alarm check valve assembly to a fused sprinkler head. A few seconds faster activation of automatic sprinkler heads in a dry-pipe or pre-action configuration will be overshadowed by the time delay (e.g., up to $60 \mathrm{~s}$ ) at the alarm valve.

\subsubsection{Response of Projected Beam Smoke Detectors}

Fire tests conducted in the $15 \mathrm{~m}$ high facility provided information relative to the response of projected beam smoke detectors as a function of location, sensitivity settings, window settings, and spacing. The projectẹd beam detectors were installed parallel to the ceiling at three different elevations. (Refer to Table 5 and Figure 12.) Discussion of their behavior during the test program is divided between the "detector fire" (less than $2 \mathrm{MW}$ ) and the "sprinkler fire" experiments (greater than $2 \mathrm{MW}$ ). 
Fires less than $2 M W$ (tests $1-3,11,12$ )

Small ( $<2 \mathrm{MW}$ ) test fires were used to determine the response characteristics of the projected beam smoke detectors. The detector response times for these smaller fires are listed in Table 22. Detectors were set for an alarm sensitivity of $30 \%$ signal loss, with an alarm window setting of $30 \mathrm{~s}$, unless otherwise noted.

Table 22. Response times (s) of projected beam detectors for test fires less than $2 \mathrm{MW}$

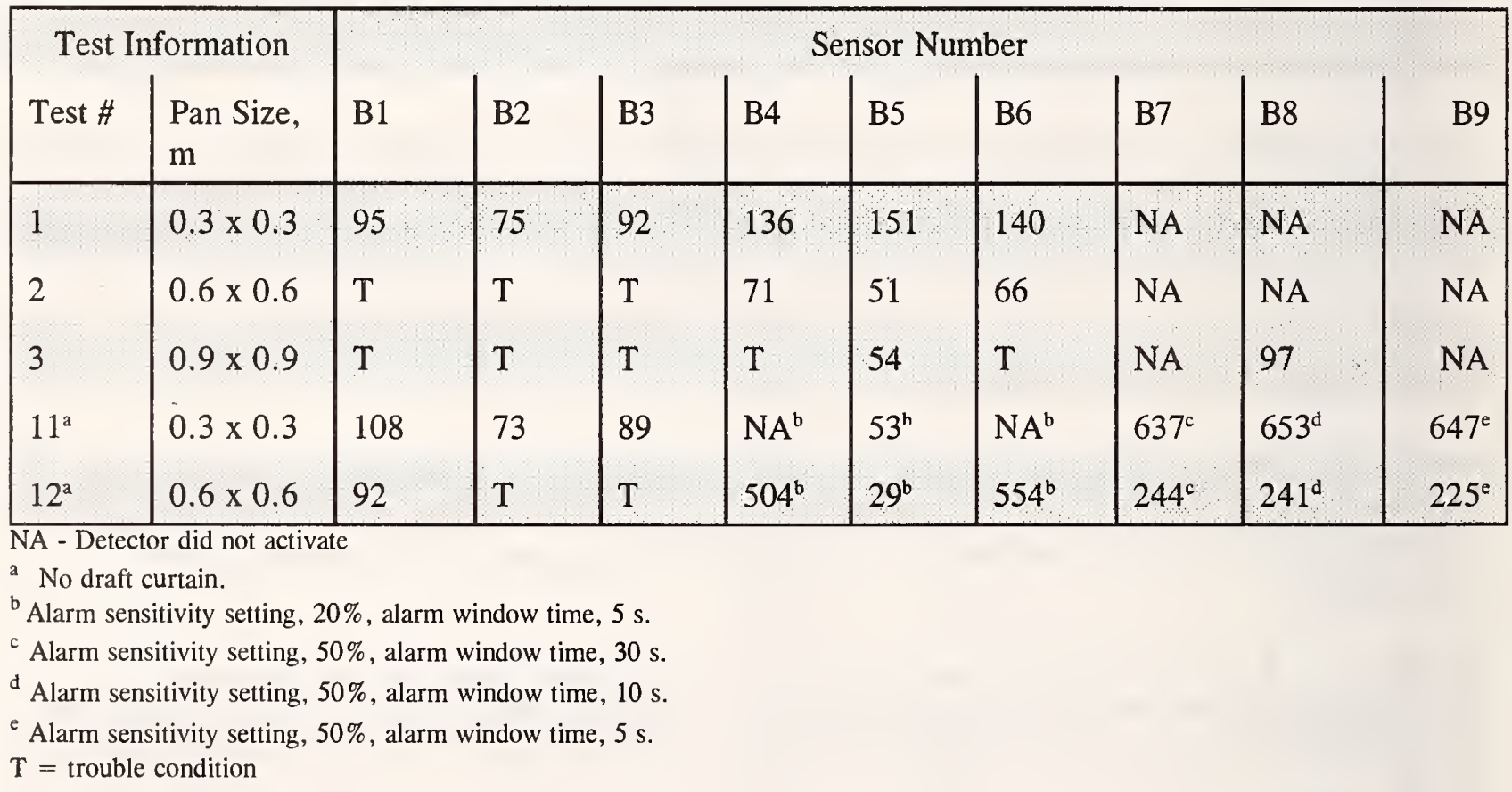

For the $0.3 \mathrm{~m} \times 0.3 \mathrm{~m}$ pan fire with the draft curtain, the three detectors at the highest elevation $(0.3 \mathrm{~m}$ below the ceiling) responded within $95 \mathrm{~s}$. In the same test, the three detectors located $2.7 \mathrm{~m}$ below the ceiling alarmed between $136 \mathrm{~s}$ and $151 \mathrm{~s}$. The detectors located $5.8 \mathrm{~m}$ below the ceiling did not activate. Note, the detectors located $5.8 \mathrm{~m}$ below the ceiling were below the bottom edge of the draft curtain which had a depth of $3.7 \mathrm{~m}$. For the $0.6 \mathrm{~m} \mathrm{x} 0.6 \mathrm{~m}$ pan fire with the draft curtain, the three detectors at the highest elevation went into trouble. A thick layer of smoke quickly developed which caused nearly complete obscuration of transmitter beam, thus producing a trouble condition. The three detectors located $2.7 \mathrm{~m}$ below the ceiling alarmed between $51 \mathrm{~s}$ and $71 \mathrm{~s}$. The detectors located $5.8 \mathrm{~m}$ below the ceiling did not activate. While the smoke was not entirely confined by the draft curtain, the ceiling volume of the hangar outside the draft curtain prevented the smoke layer from dropping to $5.8 \mathrm{~m}$ where those detectors would activated.

For the $0.9 \mathrm{~m} \times 0.9 \mathrm{~m}$ pan fire with the draft curtain, the three detectors at the highest elevation went into trouble. Of the three detectors located $2.7 \mathrm{~m}$ below the ceiling, only the detector over the center of the plume alarmed, while the two detectors $7.0 \mathrm{~m}$ off center went into trouble. Of the three detectors located $5.8 \mathrm{~m}$ below the ceiling, only the detector over the center of the plume alarmed, while the two detectors $7.0 \mathrm{~m}$ off center did not activate. 
The $0.3 \mathrm{~m} \mathrm{x} 0.3 \mathrm{~m}$ and $0.6 \mathrm{~m} \times 0.6 \mathrm{~m}$ pan fires were repeated without the draft curtain to determine the effect of the draft curtain on the smoke layer development and the response characteristics of the detectors for the $0.3 \mathrm{~m} \mathrm{x} 0.3 \mathrm{~m}$ pan fires. Comparing the operation with and without draft curtains showed no significant difference in response time for the detectors at the highest elevation. These detectors were near the ceiling (i.e., $0.3 \mathrm{~m}$ below), and smoke filling at this level was independent of the draft curtain. However, for the three detectors located $2.7 \mathrm{~m}$ below the ceiling, only the detector over the center of the plume alarmed without the draft curtain in place. The center detector, B5, went into alarm after $53 \mathrm{~s}$. The two detectors located $7.0 \mathrm{~m}$ off center never activated, even though their sensitivity and alarm window settings were adjusted to provide faster response. This clearly shows that without the draft curtains, the smoke progressed along the ceiling and did not bank down enough to activate these outer detectors.

Also, for the comparison of the $0.6 \mathrm{~m} \mathrm{x} 0.6 \mathrm{~m}$ fire with and without the draft curtain, no significant difference in response time was observed for the detectors at the highest elevation. Of the three detectors located $2.7 \mathrm{~m}$ below the ceiling, the detector located over the center of the plume alarmed in $29 \mathrm{~s}$. However, the two detectors located $7.0 \mathrm{~m}$ off center showed a significant delay in response time even though their sensitivity was increased. This again demonstrates the effect of the draft curtain. Note, for the $0.3 \mathrm{~m} \mathrm{x} 0.3 \mathrm{~m}$ and $0.6 \mathrm{~m} \times 0.6 \mathrm{~m}$ pan fires without the draft curtain, detectors B7, B8 and $\mathrm{B} 9$ were relocated as described earlier.

Fires greater than $2 M W$ (tests $4-8,13$ )

For the JP-5 fuel fires with heat outputs greater than $2 \mathrm{MW}$, results from projected beam smoke detectors are presented in Table 23. For all tests the detectors at the highest elevation all went into a trouble state. This is attributed to the rapid development of high density smoke within the draft curtained area. Consistent with current installation practices [21], the alarm window for these detectors was set at $30 \mathrm{~s}$. . Analysis of the actual detector signal shows that these detectors could have produced alarm conditions if they were adjusted to be less sensitive, yet faster to respond.

Detectors located $2.7 \mathrm{~m}$ below the ceiling consistently alarmed within a range of $22 \mathrm{~s}$ to $200 \mathrm{~s}$. The only exception was in test 4 where these detectors sensed a trouble condition. Once again, the detector's sensitivity setting was $20 \%$ and alarm window was set at 30 s for test 4 . Subsequently, the alarm window was decreased to $5 \mathrm{~s}$ and the sensitivity was increased from $30 \%$ to a $20 \%$ signal loss threshold. The response times in the Table 23 indicate consistent activation for this set of detectors.

In most cases, detector $\mathrm{B} 5$, located along the centerline $2.7 \mathrm{~m}$ below the ceiling, went into alarm nearly $30 \mathrm{~s}$ before the fuel pan was fully involved with flame. (Time to full involvement of the fuel pan was extracted from video tape footage and observations made during the tests.) The detectors located $5.8 \mathrm{~m}$ below the ceiling ( $2.1 \mathrm{~m}$ below the draft curtain) responded somewhat inconsistently. For the $1.5 \mathrm{~m}$ diameter pan fire with the draft curtain, the center detector alarmed in $143 \mathrm{~s}$. A trouble condition occurred for the $2.0 \mathrm{~m}$ and $2.5 \mathrm{~m}$ diameter pan fires. Without the draft curtain, this detector alarmed in $646 \mathrm{~s}$ for the $2.0 \mathrm{~m}$ diameter and then reported a trouble condition for the $2.5 \mathrm{~m}$ diameter pan fire. The two outer detectors, located $7.0 \mathrm{~m}$ off center responded sporadically. Since the smoke plume leaned significantly in some cases, detectors in the direction the plume was leaning generally responded faster.

From the data, it can be seen that with draft curtains, the detectors located at $2.7 \mathrm{~m}$ below the ceiling responded faster than those in similar fires without draft curtains. The exception in this case is the 
center detector at $2.7 \mathrm{~m}$ below the ceiling. This detector showed no significant change throughout the series. However, the two detectors located $7.0 \mathrm{~m}$ off center alarmed much faster with the draft curtain. For example, in test 5 ( $2.0 \mathrm{~m}$ dia. pan, w/ draft curtains), detector B4 went into alarm at $39 \mathrm{~s}$, whereas in test 7 (2.0 m dia. pan, w/o draft curtains) the same detector alarmed in $152 \mathrm{~s}$. Similarly, in comparing tests $6 \mathrm{~b}$ and 8 , detectors $\mathrm{B} 4$ and B6 went into alarm at $32 \mathrm{~s}$ and $31 \mathrm{~s}$, but for the latter test they did not alarm until $175 \mathrm{~s}$ and $200 \mathrm{~s}$ respectively.

Table 23. Projected beam detector response times (s) for test fires greater than $2 \mathrm{MW}$

\begin{tabular}{|c|c|c|c|c|c|c|c|c|c|c|}
\hline \multicolumn{2}{|c|}{ Test Information } & \multicolumn{10}{|c|}{ Sensor Number } \\
\cline { 3 - 11 } Test \# & $\begin{array}{c}\text { Pan Size } \\
(\mathrm{m})\end{array}$ & $\mathrm{B} 1$ & $\mathrm{~B} 2$ & $\mathrm{~B} 3$ & $\mathrm{~B} 4$ & $\mathrm{~B} 5$ & $\mathrm{~B} 6$ & $\mathrm{~B} 7$ & $\mathrm{~B} 8$ & $\mathrm{~B} 9$ \\
4 & 1.5 dia. & $\mathrm{T}$ & $\mathrm{T}$ & $\mathrm{T}$ & $\mathrm{T}$ & $\mathrm{T}$ & $\mathrm{T}$ & $\mathrm{NA}$ & 143 & 448 \\
5 & 2.0 dia. & $\mathrm{T}$ & $\mathrm{T}$ & $\mathrm{T}$ & $39^{\mathrm{b}}$ & $25^{\mathrm{b}}$ & $39^{\mathrm{b}}$ & 88 & $\mathrm{~T}$ & 308 \\
$6 \mathrm{~b}$ & 2.5 dia. & $\mathrm{T}$ & $\mathrm{T}$ & $\mathrm{T}$ & $32^{\mathrm{b}}$ & $22^{\mathrm{b}}$ & $31^{\mathrm{b}}$ & 84 & $\mathrm{~T}$ & 566 \\
\hline $7^{\mathrm{a}}$ & 2.0 dia. & $\mathrm{T}$ & $\mathrm{T}$ & $\mathrm{T}$ & $152^{\mathrm{b}}$ & $22^{\mathrm{b}}$ & $46^{\mathrm{b}}$ & 521 & 646 & 552 \\
$8^{\mathrm{a}}$ & 2.5 dia. & $\mathrm{T}$ & $\mathrm{T}$ & $\mathrm{T}$ & $175^{\mathrm{b}}$ & $24^{\mathrm{b}}$ & $200^{\mathrm{b}}$ & 530 & $\mathrm{~T}$ & $\mathrm{NA}$ \\
$13^{\mathrm{a}^{*}}$ & 2.0 dia. & $\mathrm{T}$ & $\mathrm{T}$ & $\mathrm{T}$ & $47^{\mathrm{b}}$ & $39^{\mathrm{b}}$ & $27^{\mathrm{b}}$ & $\mathrm{T}^{\mathrm{c}}$ & $55^{\mathrm{d}}$ & $50^{\mathrm{c}}$ \\
\hline
\end{tabular}

NA - Detector did not activate

- Open door test

${ }^{\text {a }}$ No draft curtain

${ }^{\mathrm{b}}$ Alarm sensitivity setting, $20 \%$, alarm window time, $5 \mathrm{~s}$.

' Alarm sensitivity setting, $50 \%$, alarm window time, $30 \mathrm{~s}$.

'Alarm sensitivity setting, $50 \%$, alarm window time, $10 \mathrm{~s}$.

${ }^{e}$ Alarm sensitivity setting, $50 \%$, alarm window time, $5 \mathrm{~s}$.

$\mathrm{T}=$ trouble condition

Figure 42 shows the response of these detectors for all cases with and without draft curtains. It can be seen from the figure that the tests without the draft curtain resulted in detector responses, in most cases, much longer than the cases with the draft curtain. Since the draft curtain contains the accumulating smoke within a defined area, the response time of the outer two detectors (B4, B6) is similar to the center detector. However, in the cases without draft curtain, only the center detector responded with reasonable certainty.

During the open door test case (test 13), all three detectors responded quickly (i.e., B4 - 47 s, B5 $39 \mathrm{~s}, \mathrm{~B} 6-27 \mathrm{~s})$. It was observed however, during the open door test, that the flame leaned substantially and provided a large volume of plume smoke near the ceiling which enhanced the activation of beam detectors as compared to experiments with no wind and the plume upright.

\subsubsection{Response of Photoelectric Smoke Detectors}

Photoelectric smoke detectors normally have not been installed in aircraft hangars. However, these experiments included photoelectric smoke detectors to help determine their response in general high 


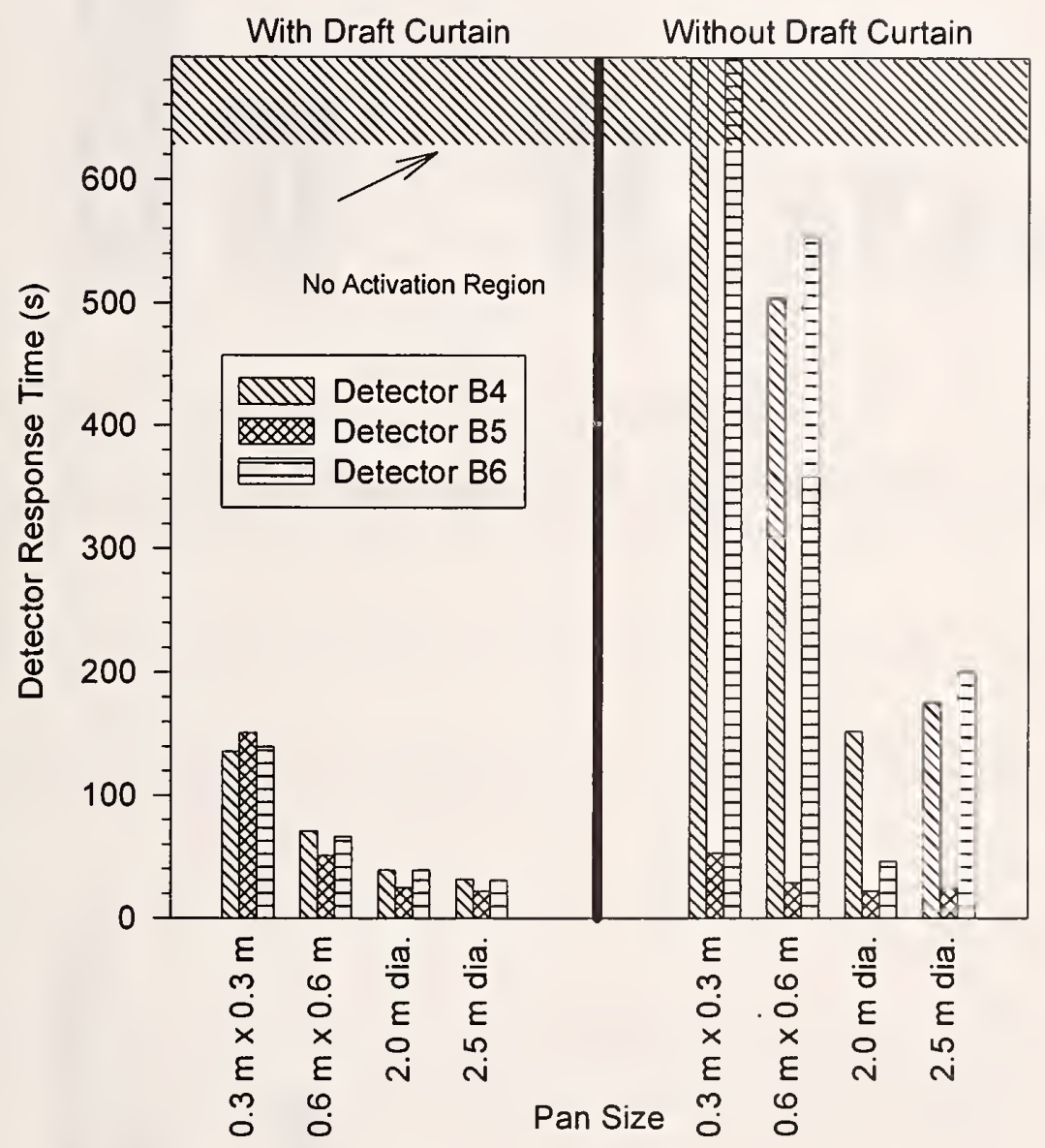

Figure 42. Projected beam detector response for test cases with and without draft curtains, $2.7 \mathrm{~m}$ below ceiling. 


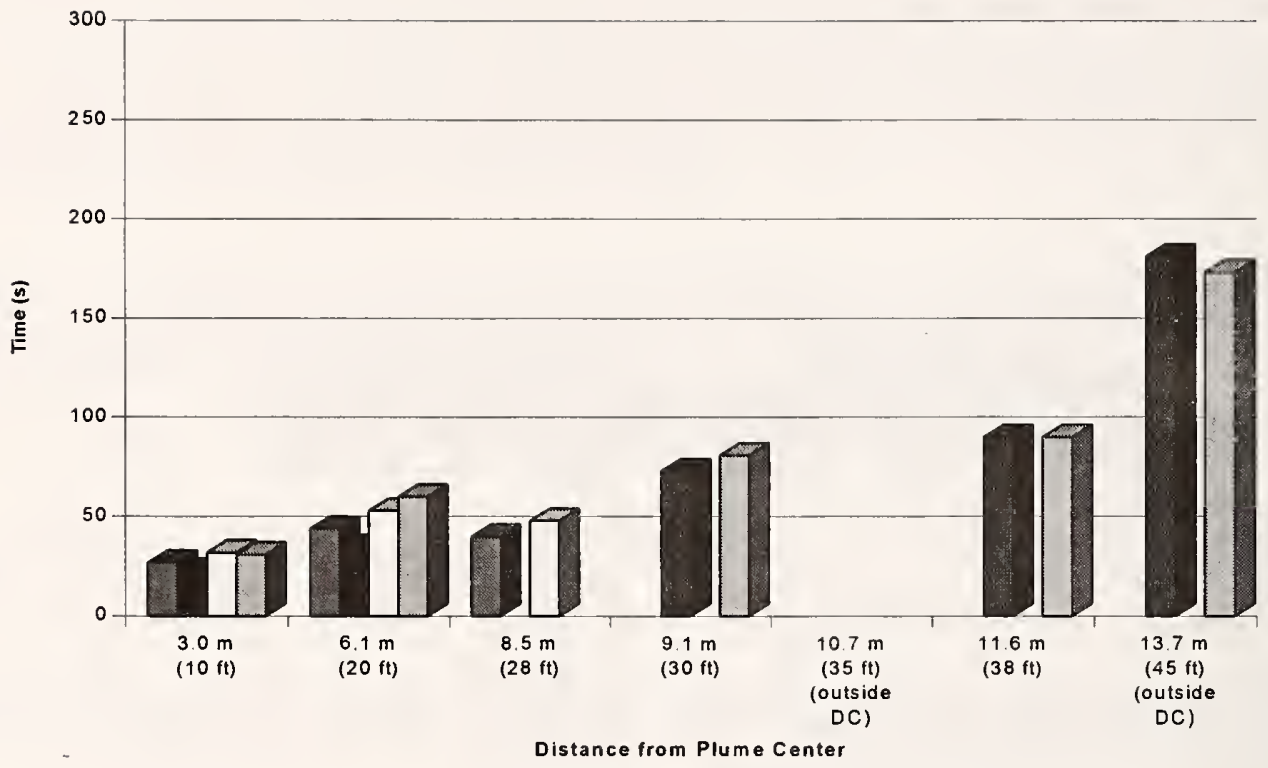

Figure 43. Photoelectric smoke detector response, 0.5 MW fire with draft curtain.

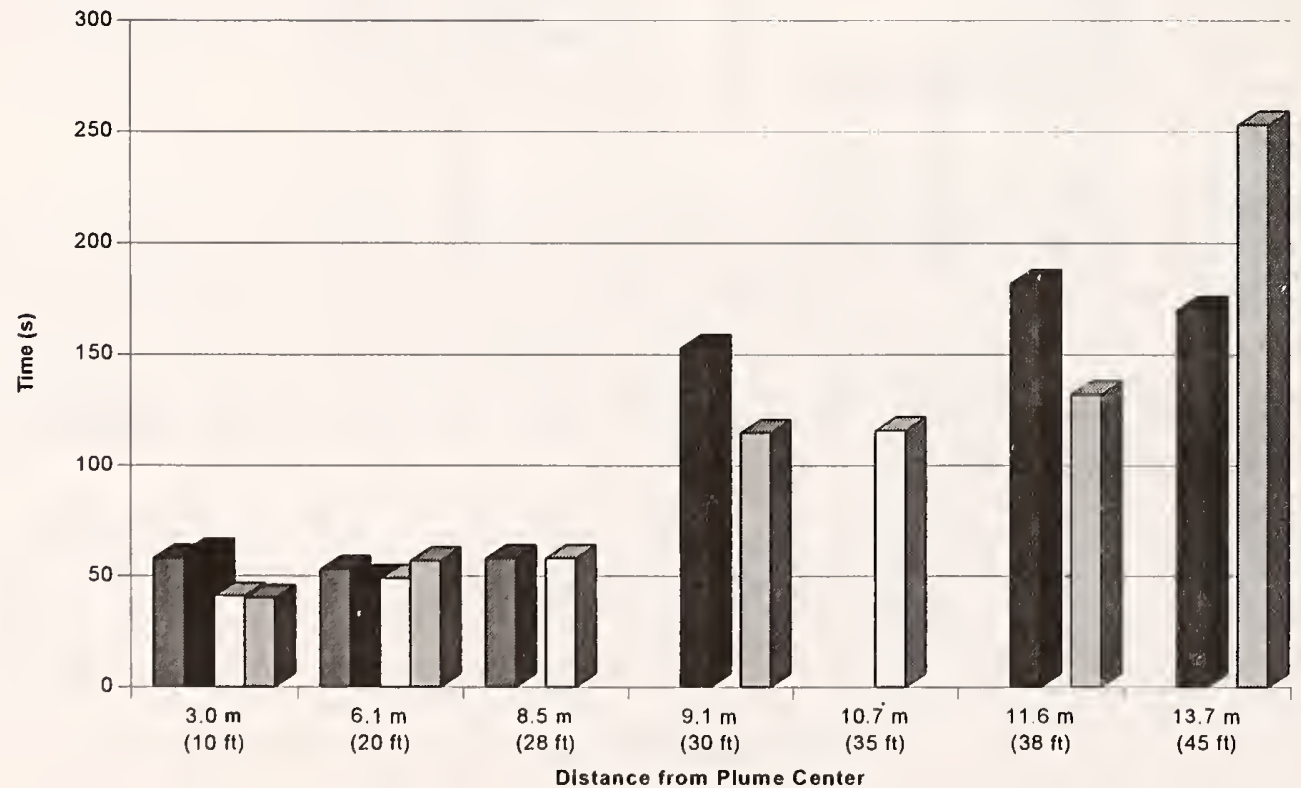

Figure 44. Photoelectric smoke detector response, $0.5 \mathrm{MW}$ fire w/o draft curtain. 
3 WARM CLIMATE - 15 M FACILITY

Table 24. Photoelectric smoke detector response times (s) for fires less than $2 \mathrm{MW}$

\begin{tabular}{|c|c|c|c|c|c|c|c|}
\hline Location & $\begin{array}{l}3.0 \mathrm{~m} \\
(10 \mathrm{ft})\end{array}$ & $\begin{array}{l}6.1 \mathrm{~m} \\
(20 \mathrm{ft})\end{array}$ & $\begin{array}{l}8.5 \mathrm{~m} \\
(28 \mathrm{ft})\end{array}$ & $\begin{array}{l}9.1 \mathrm{~m} \\
(30 \mathrm{ft})\end{array}$ & $\begin{array}{c}10.7 \mathrm{~m} \\
\text { (35 ft) } \\
\text { (outside DC) }\end{array}$ & $\frac{11.6 \mathrm{~m}}{(38 \mathrm{ft})}$ & $\begin{array}{c}13.7 \mathrm{~m} \\
\begin{array}{c}(45 \mathrm{ft}) \\
\text { (outside DC) }\end{array}\end{array}$ \\
\hline \multicolumn{8}{|c|}{ Test $1-0.3 \mathrm{~m} \times 0.3 \mathrm{~m}$ pan, JP- 5 , With Draft Curtain } \\
\hline North & $\bullet$ & $\diamond$ & $\bullet$ & - & - & - & - \\
\hline East & $\diamond$ & $\diamond$ & - & $\diamond$ & - & $\diamond$ & $\diamond$ \\
\hline South & $\bullet$ & $\bullet$ & 753 & - & $\bullet$ & - & - \\
\hline West & 382 & $\bullet$ & - & $\diamond$ & - & $\diamond$ & $\bullet$ \\
\hline \multicolumn{8}{|c|}{ Test $2-0.6 \mathrm{~m} \times 0.6 \mathrm{~m}$ pan, JP-5, With Draft Curtain } \\
\hline North & 27 & 44 & 40 & - & - & - & - \\
\hline East & 23 & 35 & - & 73 & - & 90 & 181 \\
\hline South & 32 & 53 & 48 & - & $\diamond$ & - & - \\
\hline West & 31 & 60 & - & 81 & $=$ & 90 & 173 \\
\hline \multicolumn{8}{|c|}{ Test $3-0.9 \mathrm{~m} \times 0.9 \mathrm{~m}$ pan, JP-5, With Draft Curtain } \\
\hline North & 33 & 33 & 37 & - & - & - & - \\
\hline East & 33 & 37 & - & 53 & - & 57 & 103 \\
\hline South & 41 & 41 & 41 & - & 137 & - & - \\
\hline West & 32 & 36 & - & 49 & - & 70 & 91 \\
\hline \multicolumn{8}{|c|}{ Test $11-0.3 \mathrm{~m} \times 0.3 \mathrm{~m}$ pan, JP-5, Without Draft Curtain } \\
\hline North & $\bullet$ & $\bullet$ & $\bullet$ & - & - & - & - \\
\hline East & $\diamond$ & $\diamond$ & - & $\diamond$ & - & $\bullet$ & $\bullet$ \\
\hline South & $\bullet$ & 596 & 604 & - & $\bullet$ & - & - \\
\hline West & 504 & $\bullet$ & - & $\bullet$ & - & $\bullet$ & $\bullet$ \\
\hline \multicolumn{8}{|c|}{ Test $12-0.6 \mathrm{~m} \times 0.6 \mathrm{~m}$ pan, JP-5, Without Draft Curtain } \\
\hline North & 58 & 53 & 58 & - & - & - & - \\
\hline East & 61 & 49 & - & 153 & - & 182 & 170 \\
\hline South & 41 & 49 & 58 & - & 116 & - & - \\
\hline West & 40 & 57 & - & 115 & - & 132 & 253 \\
\hline
\end{tabular}

detector did not activate

-no detector installed 
bay applications. This may be useful in evaluating detector response and spacing in other high bay occupancies. The location of photoelectric smoke detectors in the $15 \mathrm{~m}$ high facility is described earlier and shown in Figure 10.

The spacing of detectors beyond $6.1 \mathrm{~m}$ from the source of the fire was slightly different along the north/south axis than the east/west axis due to the location of the draft curtain. The detectors located $8.5 \mathrm{~m}$ and $10.7 \mathrm{~m}$ from the source were only installed along the north and south axes. The detectors located $9.1 \mathrm{~m}, 11.6 \mathrm{~m}$ and $13.7 \mathrm{~m}$ from the source were only installed along the east and west axes. These distances were selected in order to achieve the most uniform spacing from the edges of the draft curtain.

Fires less than $2 M W$ (tests 1-3,11,12)

The response times of the photoelectric smoke detectors for fire sizes less than $2 \mathrm{MW}$ are shown in Table 24. For the $0.6 \mathrm{~m} \mathrm{x} 0.6 \mathrm{~m}$ pan fires, a comparison of the response times of the detectors at 8.5 $\mathrm{m}$ to those at $9.1 \mathrm{~m}$ from the source shows that the ceiling configuration (i.e., the direction of the beams with respect to air flow) was a factor. The detectors at $9.1 \mathrm{~m}$ were perpendicular to the smoke movement across the roof beams while the detectors at $8.5 \mathrm{~m}$ were parallel to the smoke movement along the beams. The activation of the detectors at $9.1 \mathrm{~m}$ occurred approximately $1-1 / 2$ to $2-1 / 2$ times later than the detectors at $8.5 \mathrm{~m}$. This effect was not evident for any of the larger fires.

Tests 1 and 11 were conducted using the $0.3 \mathrm{~m} \times 0.3 \mathrm{~m}$ pans; neither produced sufficient smoke to activate any of the photoelectric smoke detectors prior to $382 \mathrm{~s}$. Tests 2 and 12 were conducted using the $0.6 \mathrm{~m} \mathrm{x} 0.6 \mathrm{~m}$ pans $(0.45 \mathrm{MW}$ fire). In test 2 , which was conducted with a draft curtain in place, 12 of the 14 detectors within the draft curtain activated sooner than the same detectors in test 12 which was conducted without the draft curtain. This can be seen graphically by comparing Figures 43 and 44. Similarly, the detectors located $9.1 \mathrm{~m}(30 \mathrm{ft})$ from the source in test 2 activated within $81 \mathrm{~s}$, however, the response time of the same detectors in test 12 ranged from $115 \mathrm{~s}$ to $153 \mathrm{~s}$. This shows that the draft curtain has a definite effect on detector response time for a fire of this size.

The photoelectric smoke detectors installed in these experiments have a smooth ceiling listed spacing of $9.1 \mathrm{~m}$ ( $30 \mathrm{ft}$ ). Analysis of the detector spacing for both $0.6 \mathrm{~m} \mathrm{x} 0.6 \mathrm{~m}$ pan fires shows that all the

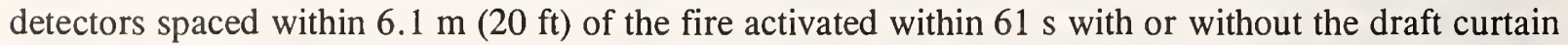
in place. This indicates that a detector spacing of $12.2 \mathrm{~m}(40 \mathrm{ft})$ would be acceptable for detecting a $0.6 \mathrm{~m} \mathrm{x} 0.6 \mathrm{~m} \mathrm{JP}-5$ fire in a $15 \mathrm{~m}$ high hangar. This is contrary to the current practice of reducing detector spacing for high bay areas.

Test 3 was conducted using the $0.9 \mathrm{~m} \times 0.9 \mathrm{~m}$ pan with the draft curtain in place. All detectors within $9.1 \mathrm{~m}(30 \mathrm{ft})$ of the source activated within $53 \mathrm{~s}$. The ceiling configuration did not have a significant effect on the activation of detectors for this size fire. The activation of detectors outside the draft curtain occurred approximately 1-1/2 to 3 times longer than the detectors within the draft curtain. The spacing of detectors showed no significant difference in the response times of the detectors located 9.1 $\mathrm{m}(30 \mathrm{ft})$ from the source compared to those spaced $3.0 \mathrm{~m}(10 \mathrm{ft})$ and $6.1 \mathrm{~m}(20 \mathrm{ft})$ from the source. Again, this is contrary to the present practice of reducing detector spacing in high bay areas. 
The response times of the photoelectric detectors for fire sizes greater than $2 \mathrm{MW}$ are shown in Table 25. For these larger tests, the draft curtain did not have a significant effect on the activation time of the photoelectric detectors. For example, although the detectors outside the draft curtain in test 5 took longer to activate than the same detectors without a draft curtain in test 7 the actual response time of all the smoke detectors was within $79 \mathrm{~s}$ for test 5 and $50 \mathrm{~s}$ for test 7 . An analysis of the spacing of the detectors shows no significant difference in the response time of detectors spaced $9.1 \mathrm{~m}(30 \mathrm{ft})$ from the

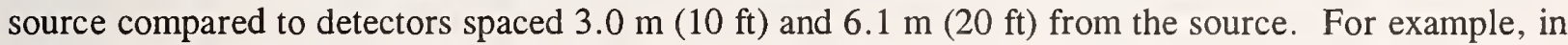
test $6 \mathrm{~b}$, the detector located $9.1 \mathrm{~m}$ east of the source activated in $31 \mathrm{~s}$ while the detector located $3.0 \mathrm{~m}$ east activated in $27 \mathrm{~s}$. In addition, the ceiling/beam configuration had little or no effect on the response time of the detectors. For example, in test 8 , the detector located $9.1 \mathrm{~m}$ east (where the smoke flow was perpendicular to the roof beams) activated in $38 \mathrm{~s}$, while the detector located $8.5 \mathrm{~m}$ north (where the smoke flow was parallel to the roof beams) activated in $34 \mathrm{~s}$.

\subsubsection{Response of Single Point Heat Detectors}

The point heat detectors tested in the $15 \mathrm{~m}$ high facility were those listed as rate-compensation, fixedtemperature detectors with an alarm threshold of $57.2^{\circ} \mathrm{C}\left(135^{\circ} \mathrm{F}\right)$. This alarm threshold would not normally be suitable for a high bay hangar application with relatively high ambient temperatures. This alarm threshold was chosen as the lowest possible alarm threshold for a hangar application. The spacing of detectors beyond $6.1 \mathrm{~m}$ from the source of the fire was slightly different along the north/south axis than the east/west axis due to the location of the draft curtain.

For fire sizes less than $2 \mathrm{MW}$, none of the $57.2^{\circ} \mathrm{C}$ heat detectors responded, while for fire sizes greater than $2 \mathrm{MW}$ the $57.2^{\circ} \mathrm{C}$ heat detectors did activate. In addition, some of these experiments also activated $79.4^{\circ} \mathrm{C}$ automatic sprinklers. In every case where an automatic sprinkler activated, it was preceded by the activation of a $57.2{ }^{\circ} \mathrm{C}$ heat detector.

Test 4 , which was a $1.5 \mathrm{~m}$ diameter pan fire with a heat release rate of $2.8 \mathrm{MW}$ was the smallest fire size to activate any $57.2{ }^{\circ} \mathrm{C}$ heat detector in the $15 \mathrm{~m}$ high facility. The first heat detector responded $96 \mathrm{~s}$ after ignition. That detector was located $3.0 \mathrm{~m}$ east of the fire's centerline, and its activation corresponded to the plume lean. The overall detector response time ranged from $96 \mathrm{~s}$ to $551 \mathrm{~s}$. Only 10 of the 17 heat detectors activated during this experiment, and none of the detectors outside the draft curtain activated. This fire size appeared to represent the lower threshold with respect to heat detector activation in the $15 \mathrm{~m}$ high facility.

Test 13 was conducted with the doors open. Due to the severe plume lean this test was terminated at $150 \mathrm{~s}$. No heat detectors activated prior to test termination. This result is consistent with the thermocouple measurements which indicated temperatures below $57^{\circ} \mathrm{C}$ for most of the time during the test.

The response times of the heat detectors for all fire sizes greater than $2 \mathrm{MW}$ are shown in Table 26.

\section{Effects of Detector Spacing}

In test 5 , the average response time of the detectors located $3.0 \mathrm{~m}$ from fire center was $79 \mathrm{~s}$, compared 
Table 25. Photoelectric smoke detector response times (s) for fires greater than $2 \mathrm{MW}$

\begin{tabular}{|c|c|c|c|c|c|c|c|}
\hline Location & $\begin{array}{l}3.0 \mathrm{~m} \\
(10 \mathrm{ft})\end{array}$ & $\begin{array}{l}6.1 \mathrm{~m} \\
(20 \mathrm{ft})\end{array}$ & $\begin{array}{l}8.5 \mathrm{~m} \\
(28 \mathrm{ft})\end{array}$ & $\begin{array}{l}9.1 \mathrm{~m} \\
(30 \mathrm{ft})\end{array}$ & $\frac{10.7 \mathrm{~m}}{(35 \mathrm{ft})}$ & $\frac{11.6 \mathrm{~m}}{(38 \mathrm{ft})}$ & $\frac{13.7 \mathrm{~m}}{(45 \mathrm{ft})}$ \\
\hline \multicolumn{8}{|c|}{ Test $4-1.5 \mathrm{~m}$ diameter pan, JP-5, With Draft Curtain } \\
\hline \multirow[t]{2}{*}{ North } & 25 & 30 & 38 & - & - & & \\
\hline & 17 & 22 & - & 29 & - & 38 & 67 \\
\hline South & 26 & 26 & 30 & - & 75 & - & - \\
\hline West & 21 & 29 & - & 38 & - & 46 & 58 \\
\hline \multicolumn{8}{|c|}{ Test $5-2.0 \mathrm{~m}$ diameter pan, JP-5. With Draft Curtain } \\
\hline North & 33 & 33 & 42 & - & - & - & - \\
\hline East & 29 & 37 & - & 42 & - & 50 & 71. \\
\hline South & 25 & 42 & 37 & - & 79 & - & - \\
\hline West & 29 & 29 & - & 41 & - & 45 & 54 \\
\hline \multicolumn{8}{|c|}{ Test $6 \mathrm{~b}-2.5 \mathrm{~m}$ diameter pan, JP-5, With Draft Curtain } \\
\hline North & 27 & 27 & 31 & - & - & - & - \\
\hline East & 27 & 31 & - & 31 & - & $\diamond$ & $\diamond$ \\
\hline South & 18 & 23 & 27 & - & $\diamond$ & - & - \\
\hline West & 38 & 42 & - & 46 & - & 51 & 55 \\
\hline \multicolumn{8}{|c|}{ Test $7-2.0 \mathrm{~m}$ diameter pan, JP-5, Without Draft Curtain } \\
\hline North & 30 & 30 & 33 & - & - & - & - \\
\hline East & 29 & 37 & - & 42 & - & 46 & 50 \\
\hline South & 25 & 30 & 34 & - & 38 & - & - \\
\hline West & 21 & 29 & - & 37 & - & 37 & 41 \\
\hline \multicolumn{8}{|c|}{ Test $8-2.5 \mathrm{~m}$ diameter pan, JP-5, Without Draft Curtain } \\
\hline North & 26 & 29 & 34 & - & - & - & $\longrightarrow$ \\
\hline East & 25 & 34 & - & 38 & - & 42 & 46 \\
\hline South & 26 & 29 & 29 & - & 42 & - & - \\
\hline West & 25 & 33 & - & 37 & - & 41 & 50 \\
\hline \multicolumn{8}{|c|}{ Test $13-2.0 \mathrm{~m}$ diameter pan, JP-5, Without Draft Curtain, Open Door } \\
\hline North & 47 & 47 & 51 & - & - & - & - \\
\hline East & 39 & 39 & - & 51 & - & 56 & 56 \\
\hline South & 26 & 30 & 30 & - & 34 & - & - \\
\hline West & 38 & 42 & - & 46 & - & 51 & 55 \\
\hline
\end{tabular}


to $94 \mathrm{~s}$ for the detectors located $6.1 \mathrm{~m}$ from fire center. In test $6 \mathrm{~b}$, the average response time of the detectors located $3.0 \mathrm{~m}$ from fire center was $60 \mathrm{~s}$, compared to $57 \mathrm{~s}$ for the detectors located $6.1 \mathrm{~m}$ from fire center. In test 7 , the average response time of the detectors located $3.0 \mathrm{~m}$ from fire center was $103 \mathrm{~s}$, compared to $111 \mathrm{~s}$ for the detectors located $6.1 \mathrm{~m}$ from fire center. In test 8 , the average response time of the detectors located $3.0 \mathrm{~m}$ from fire center was $53 \mathrm{~s}$, compared to $65 \mathrm{~s}$ for the detectors located $6.1 \mathrm{~m}$ from fire center.

Analysis of the $57^{\circ} \mathrm{C}$ heat detectors in the $15 \mathrm{~m}$ hangar indicates no significant difference in the average response times for the detectors installed $6.1 \mathrm{~m}$ from the fire as compared to those installed $3.0 \mathrm{~m}$ from fire center. Detectors installed $3.0 \mathrm{~m}$ and $6.1 \mathrm{~m}$ from fire center actually represent a spacing of $6.0 \mathrm{~m}$ and $12.2 \mathrm{~m}$ between detectors. Consequently, in the $15 \mathrm{~m}$ hangar, the response of these heat detectors to a jet fuel spill fire shows that the detectors could be installed at a spacing of 12.2 $\mathrm{m}(40 \mathrm{ft})$ without adversely affecting response times.

\section{Effects of Draft Curtains}

Figures 45 and 46 graphically represent the response times of the $57{ }^{\circ} \mathrm{C}$ heat detectors in tests $6 \mathrm{~b}$ and 8 respectively. As shown in Figure 45, the average response time for the detectors located $9.1 \mathrm{~m}$ from the fire was $51 \mathrm{~s}$ with the draft curtain in place. By comparison, Figure 46 shows the average response time for the detectors $9.1 \mathrm{~m}$ from the fire to be $111 \mathrm{~s}$ without the draft curtain. Further analysis of the detectors located $11.6 \mathrm{~m}$ from the fire shows an average response time of $79 \mathrm{~s}$ with the draft curtain in place compared to $182 \mathrm{~s}$ without the draft curtain.

Figures 45 and 46 also illustrate the ability of the draft curtains to confine the heat and limit its spread across the ceiling. To illustrate this point, note that in Figure 45 the detectors outside the draft curtain (at $13.7 \mathrm{~m}$ from the fire) had an average response time of $384 \mathrm{~s}$. By comparison, the same detectors in Figure 46 (without the draft curtains) had an average response time of only $207 \mathrm{~s}$.

With the draft curtain in place, the detectors inside the draft curtain activated sooner than the same detectors with the draft curtain removed. The detectors installed beyond the limits of the draft curtain activated sooner when the draft curtain was removed.

\section{Effects of Ceiling Configuration}

The I-beams which directly support the roof run along the north/south axis. Consequently, the heat detectors installed along the north/south axis were run parallel to these beams, while the detectors installed along the east/west axis were perpendicular to them. An analysis of Table 26 indicates no systematic variations due to the orientation of the I-beams. 
Table 26. $\quad 57.2{ }^{\circ} \mathrm{C}$ Heat detector response times (s) in $15 \mathrm{~m}$ high facility

\begin{tabular}{|c|c|c|c|c|c|c|c|}
\hline Location & $\begin{array}{l}3.0 \mathrm{~m} \\
(10 \mathrm{ft})\end{array}$ & $\begin{array}{l}6.1 \mathrm{~m} \\
(20 \mathrm{ft})\end{array}$ & $\begin{array}{l}8.5 \mathrm{~m} \\
(28 \mathrm{ft})\end{array}$ & $\begin{array}{l}9.1 \mathrm{~m} \\
(30 \mathrm{ft})\end{array}$ & $\begin{array}{c}10.7 \mathrm{~m} \\
(35 \mathrm{ft}) \\
\text { (outside DC) }\end{array}$ & $\begin{array}{c}11.6 \mathrm{~m} \\
(38 \mathrm{ft})\end{array}$ & $\begin{array}{c}13.7 \mathrm{~m} \\
(48 \mathrm{ft}) \\
\text { (outside DC) }\end{array}$ \\
\hline \multicolumn{8}{|c|}{ Test 4 - $1.5 \mathrm{~m}$ diameter pan, $2.8 \mathrm{MW}$ fire, with draft curtain } \\
\hline North & 463 & 526 & $\bullet$ & - & - & - & - \\
\hline East & 96 & 184 & - & 551 & - & $\bullet$ & $\bullet$ \\
\hline South & 197 & 247 & 397 & - & $\bullet$ & - & - \\
\hline West & 217 & 521 & - & $\bullet$ & - & $\bullet$ & $\bullet$ \\
\hline \multicolumn{8}{|c|}{ Test $5-2.0 \mathrm{~m}$ diameter pan, $6.8 \mathrm{MW}$ fire with draft curtain } \\
\hline North & 92 & 96 & 154 & - & - & - & - \\
\hline East & 71 & 88 & - & 121 & - & 144 & 371 \\
\hline South & 80 & 92 & 113 & - & $\bullet$ & - & - \\
\hline West & 71 & 100 & - & 175 & - & 196 & 375 \\
\hline \multicolumn{8}{|c|}{ Test $6 \mathrm{~b}-2.5 \mathrm{~m}$ diameter pan, $7.7 \mathrm{MW}$ fire with draft curtain } \\
\hline North & 65 & 65 & 69 & - & - & - & - \\
\hline East & 69 & 27 & - & 69 & - & 85 & 365 \\
\hline South & 19 & 65 & 65 & - & 377 & - & - \\
\hline West & 85 & 69 & - & 32 & - & 73 & 402 \\
\hline \multicolumn{8}{|c|}{ Test $7-2.0 \mathrm{~m}$ diameter pan, $5.6 \mathrm{MW}$ fire without draft curtain } \\
\hline North & 188 & 92 & 200 & - & - & - & - \\
\hline East & 75 & 138 & - & 274 & - & 580 & 584 \\
\hline South & 84 & 101 & 138 & - & 201 & - & - \\
\hline West & 63 & 113 & - & 167 & - & 303 & 589 \\
\hline \multicolumn{8}{|c|}{ Test $8-2.5 \mathrm{~m}$ diameter pan, $7.7 \mathrm{MW}$ fire without draft curtain } \\
\hline North & 59 & 59 & 105 & - & - & - & - \\
\hline East & 51 & 59 & - & 96 & - & 201 & 201 \\
\hline South & 51 & 67 & 92 & - & 151 & - & - \\
\hline West & 51 & 75 & - & 125 & - & 163 & 213 \\
\hline \multicolumn{8}{|c|}{ Test $13-2.0 \mathrm{~m}$ diameter pan, open door fire without draft curtain } \\
\hline North & $\bullet$ & $\bullet$ & $\bullet$ & - & - & - & - \\
\hline East & $\bullet$ & $\diamond$ & - & $\bullet$ & - & $\bullet$ & $\bullet$ \\
\hline South & $\bullet$ & $\diamond$ & $\bullet$ & - & $\bullet$ & - & - \\
\hline West & $\bullet$ & $\bullet$ & - & $\bullet$ & - & $\bullet$ & $\bullet$ \\
\hline
\end{tabular}

detector did not activate

- no detector installed at this location 


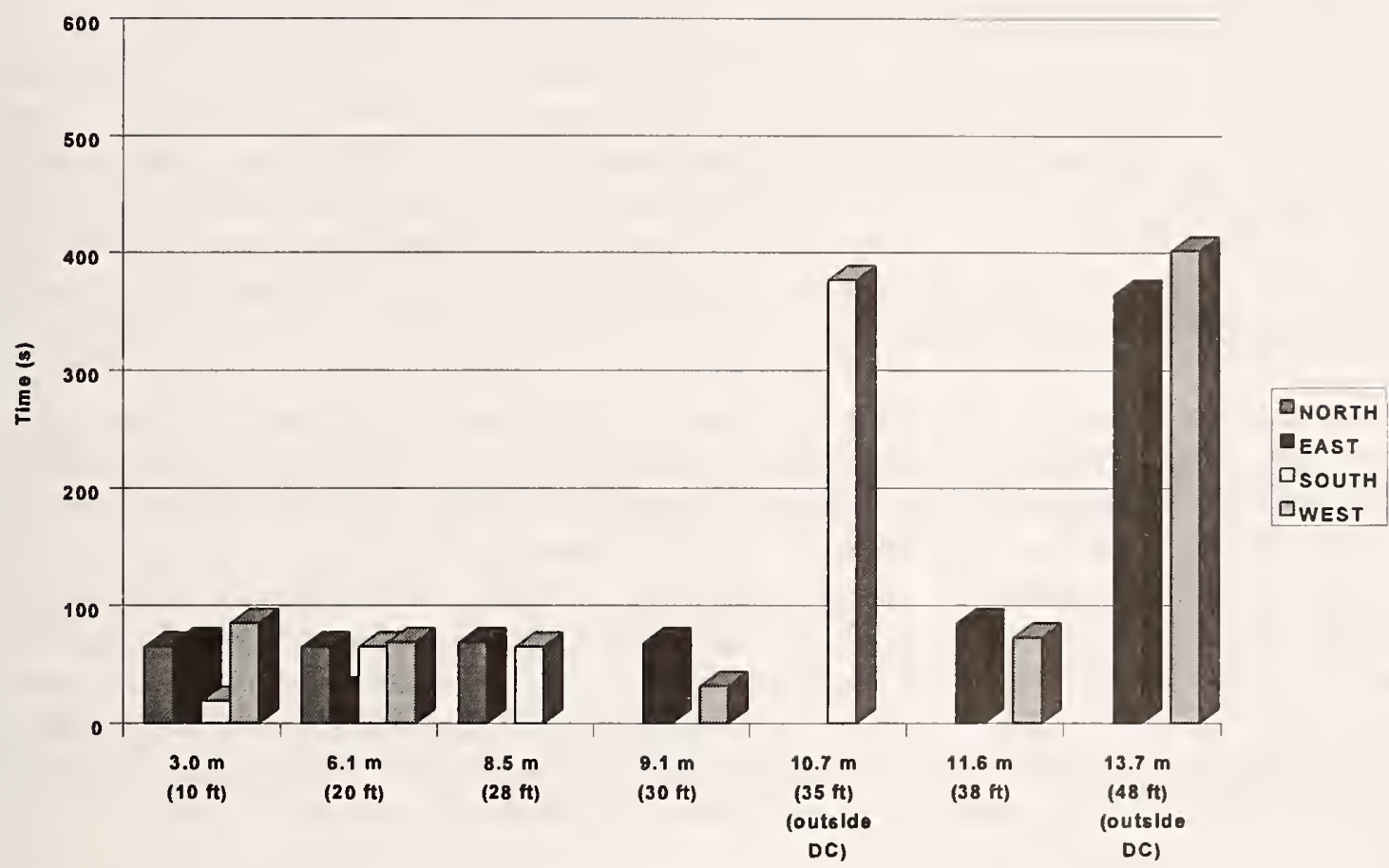

Distance from Plume Center

Figure 45. Response of $57{ }^{\circ} \mathrm{C}$ heat detectors to $7.7 \mathrm{MW}$ fire conducted in $15 \mathrm{~m}$ high facility with draft curtains.

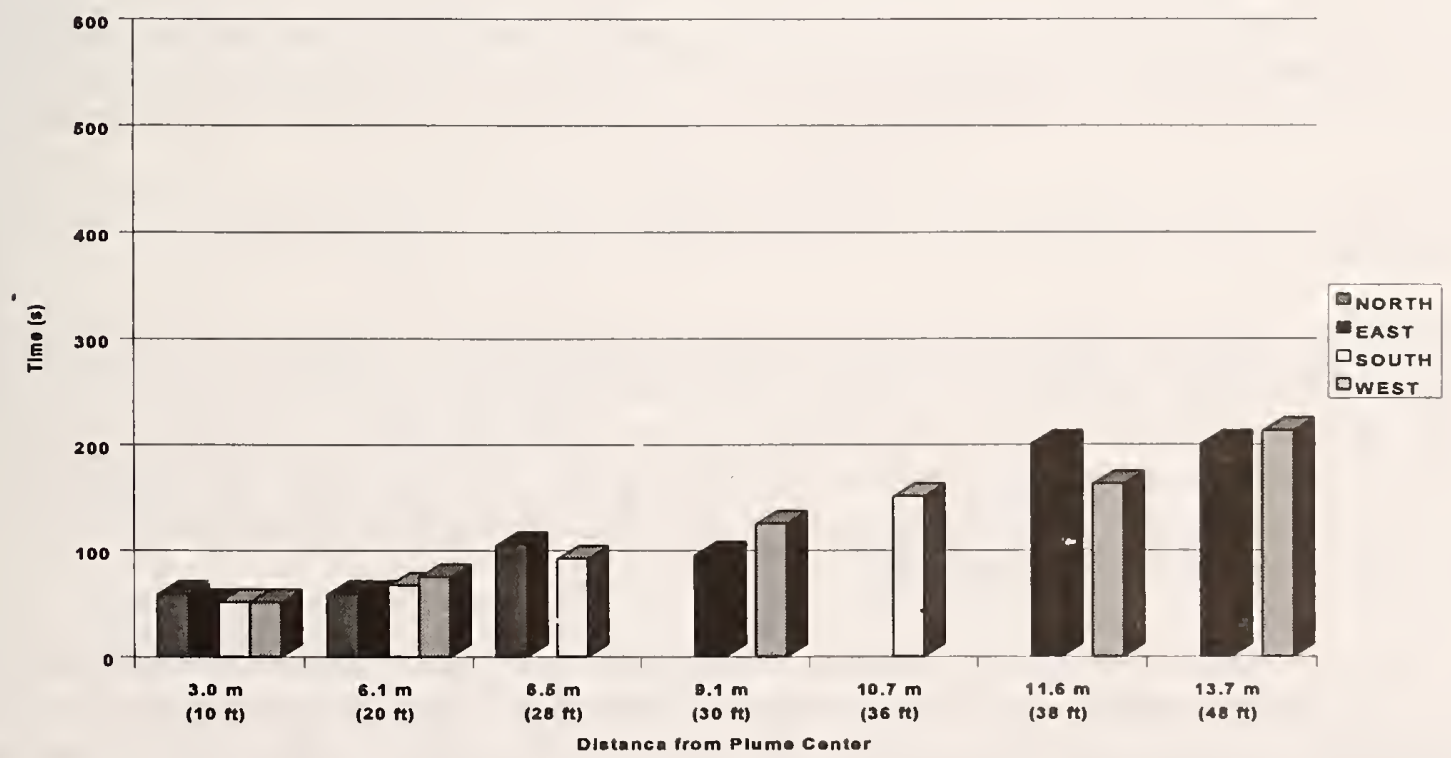

Figure 46. Response of $57{ }^{\circ} \mathrm{C}$ heat detectors to $7.7 \mathrm{MW}$ fire conducted in $15 \mathrm{~m}$ high facility without draft curtains. 


\subsubsection{Response of Optical Flame Detectors}

The settings, configuration and mounting height of the combination UV/IR optical detectors were discussed earlier, with the exact location of the detectors shown in Figure 14. The effects of ceiling height and draft curtains were not evaluated for these detectors since UV/IR detectors respond to the flame and not smoke or heat. The physical dimensions of the $15 \mathrm{~m}$ hangar permitted detectors to be located a maximum distance of $70.1 \mathrm{~m}$ from the fire center. The optical flame detectors were evaluated for each fire size. The fire experiments were designed to evaluate the response thresholds to the detector fires and to the sprinkler fires.

There are three significant facts regarding the controller settings and the physical location of the detectors that warrant further discussion. First, because the experiments included a variety of fire sizes, detectors were positioned in five different configurations. Second, the UV/IR controller settings were varied for the $2.0 \mathrm{~m}$ and $2.5 \mathrm{~m}$ diameter pan fires. These controller settings are shown in Table 6 . The main effect of changing the controller settings was to increase or decrease the detector's range. The controller setting of $0.25 \mathrm{~s}$ gate length, 2 counts per gate, and 3 consecutive gates $(0.25 / 2 / 3)$ requires a minimal signal strength of 6 counts occurring in $0.75 \mathrm{~s}$ to reach alarm state. This equates to a count per second (CPS) rate of $8 \mathrm{CPS}$ for $1 \mathrm{~s}$ from both the UV and IR portions of the detector. The controller setting of $0.25 \mathrm{~s}$ gate length, 4 counts per gate, and 4 consecutive gates $(0.25 / 4 / 4)$ requires a signal strength of $16 \mathrm{CPS}$ for $1 \mathrm{~s}$ to reach alarm state. This equates to a rate of $16 \mathrm{CPS}$ for $1 \mathrm{~s}$ from both the UV and IR portions of the detector.

The third factor involves the manner in which the optical flame detectors were aimed during these tests. All experiments were conducted with the optical flame detectors positioned such that each detector had a direct line of sight to the fire source. This effectively means that the fuel pan was directly in the center of each detector's cone of vision which would yield the detector's optimum response.

Consequently, the test results here represent the best case response scenario for the optical detectors. Fires that occur within the detector's cone of vision, but not directly along the centerline axis will have slower response times and shorter threshold response distances. The response characteristics will decrease proportionally as the viewing angle increases towards the maximum listed viewing angle of the detector.

\section{General Analysis}

The raw CPS data files compiled by Detector Electronics Corporation were examined for response time from three distinct events: ignition, full pan involvement, and steady state burning. The application of these three response time milestones for each detector yields a representation of threshold response distances to a variety of fire sizes and at various stages during each fire. The data is presented in this format to aid design engineers in determining when and at what distance these optical detectors will respond to a growing fire in an aircraft hangar.

For the purpose of analyzing this data, ignition is defined as the time that self-sustained combustion was achieved. Full pan involvement was determined by visual observation, and was considered to be the time at which the flame front completely covered the fuel surface. The time to steady state burning was calculated using the mass loss measurements recorded by the load cell. Where load cell data was not available, a conservative estimate of the time to steady state burning was made based on similar size fires, and by analyzing the steady state infrared signature recorded by the optical detectors. 
Table 27. Optical detector response time after ignition for all $15 \mathrm{~m}$ high facility tests

\begin{tabular}{|c|c|c|c|c|c|c|c|c|c|c|c|c|c|}
\hline PAN SIZE (m) & FACILITY & HRR (MW) & TEST & & DETE & CTOR I & DISTAI & NCE FH & ROM S & OURCI & $\mathrm{E}$ CEN & TER (m & \\
\hline $.3 \times .3$ & $15 \mathrm{~m}$ & $0.1^{\wedge}$ & 1 & 9.1 & 10.7 & 12.2 & 13.7 & 15.2 & 16.8 & 18.3 & 21.3 & 30.5 & 48.8 \\
\hline Controller: & $.25 / 2 / 3$ & Response Time & e (s) & $\mathrm{N} / \mathrm{A}^{\mathrm{a}}$ & $N / A^{a}$ & $\mathrm{~N} / \mathrm{A}^{\mathrm{a}}$ & $\mathrm{N} / \mathrm{A}^{\mathrm{a}}$ & $\mathrm{N} / \mathrm{A}^{\mathrm{a}}$ & $\mathrm{N} / \mathrm{A}^{\mathrm{a}}$ & $\mathrm{N} / \mathrm{A}^{\mathrm{a}}$ & $\mathrm{N} / \mathrm{A}^{\mathrm{a}}$ & $\mathrm{N} / \mathrm{A}^{\mathrm{a}}$ & $N / A^{a}$ \\
\hline FULL PAN: & $5 \mathrm{~s}$ & ST STATE: & $120 \mathrm{~s}$ & & & & & & & & & & \\
\hline $.3 \times .3$ & $15 \mathrm{~m}$ & $0.1^{\wedge}$ & 11 & 12.2 & 15.2 & 18.3 & 21.3 & 24.4 & 27.4 & 30.5 & 36.6 & 42.7 & 48.8 \\
\hline Controller: & $.25 / 2 / 3$ & Response Time & e (s) & 9.1 & 25.0 & NR & NR & NR & NR & NR & NR & NR & NR \\
\hline FULL PAN: & $5 \mathrm{~s}$ & ST STATE: & $150 \mathrm{~s}$ & & & & & & & & & & \\
\hline $.6 \times .6$ & $15 \mathrm{~m}$ & 0.5 & 2 & 21.3 & 22.9 & 24.4 & 25.9 & 27.4 & 30.5 & 33.5 & 36.6 & 39.6 & 48.8 \\
\hline Controller: & $.25 / 2 / 3$ & Response Time & e (s) & 5.5 & 10.4 & 10.4 & 11.7 & 21.5 & 18.8 & 20.8 & 20.8 & 67.2 & NR \\
\hline FULL PAN: & $10 \mathrm{~s}$ & ST STATE: & $150 \mathrm{~s}$ & & & & & & & & & & \\
\hline $.6 \times .6$ & $15 \mathrm{~m}$ & $\mathrm{n} / \mathrm{a}$ & 12 & 12.2 & 15.2 & 18.3 & 21.3 & 24.4 & 27.4 & 30.5 & 36.6 & 42.7 & 48.8 \\
\hline Controller: & $.25 / 2 / 3$ & Response Time & e (s) & 1.5 & 16.1 & 25.6 & 28.6 & 28.5 & 28.6 & NR & NR & NR & NR \\
\hline FULL PAN: & $10 \mathrm{~s}$ & ST STATE: & $150 \mathrm{~s}$ & & & & & & & & & & \\
\hline $.9 \times .9$ & $15 \mathrm{~m}$ & 1.9 & 3 & 21.3 & 22.9 & 24.4 & 25.9 & 27.4 & 30.5 & 33.5 & 36.6 & 39.6 & 48.8 \\
\hline Controller: & $.25 / 2 / 3$ & Response Time & e (s) & 18.5 & 18.2 & 29.2 & 22.7 & 21.5 & 30.8 & 25.5 & 33.0 & 44.5 & 47.0 \\
\hline FULL PAN: & $20 s$ & ST STATE: & $150 \mathrm{~s}$ & & & & & & & & & & \\
\hline 1.5 Dia & $15 \mathrm{~m}$ & 2.8 & 4 & 21.3 & 30.5 & 36.6 & 42.7 & 48.8 & 54.9 & 61.0 & 64.0 & 67.1 & 70.1 \\
\hline Controller: & $.25 / 2 / 3$ & Response Time & e (s) & 24.4 & 33.0 & 34.0 & 36.1 & 39.8 & 47.9 & 72.5 & 58.2 & 72.6 & 93.1 \\
\hline FULL PAN: & $30 \mathrm{~s}$ & ST STATE: & $180 \mathrm{~s}$ & & & & & & & & & & \\
\hline 2.0 Dia & $15 \mathrm{~m}$ & 6.8 & 5 & 21.3 & 30.5 & 36.6 & 42.7 & 48.8 & 54.9 & 61.0 & 64.0 & 67.1 & 70.1 \\
\hline Controller: & $.25 / 2 / 3$ & Response Time & e (s) & 17.3 & 23.6 & 24.8 & 30.6 & 33.6 & 45.2 & 43.4 & 41.7 & 61.6 & 69.9 \\
\hline FULL PAN: & $35 \mathrm{~s}$ & ST STATE: & $120 \mathrm{~s}$ & & & & & & & & & & \\
\hline 2.0 Dia & $15 \mathrm{~m}$ & $5.6^{\wedge}$ & 7 & 21.3 & 30.5 & 36.6 & 42.7 & 48.8 & 54.9 & 61.0 & 64.0 & 67.1 & 70.1 \\
\hline Controller: & $.25 / 4 / 4$ & Response Time & e (s) & 17.6 & 20.6 & 26.4 & 31.4 & 34.8 & 51.4 & NR & 61.4 & NR & NR \\
\hline FULL PAN: & $35 \mathrm{~s}$ & ST STATE: & $180 \mathrm{~s}$ & & & & & & & & & & \\
\hline 2.0 Dia & $15 \mathrm{~m}$ & $\mathrm{n} / \mathrm{a}$ & 13 & 21.3 & 30.5 & 36.6 & 42.7 & 48.8 & 54.9 & 61.0 & 64.0 & 67.1 & 70.1 \\
\hline Controller: & $.25 / 4 / 4$ & Response Time & e (s) & $N / A^{h}$ & $\mathrm{~N} / \mathrm{A}^{\mathrm{b}}$ & $N / A^{b}$ & $N / A^{b}$ & $\mathrm{~N} / \mathrm{A}^{\mathrm{b}}$ & $N / A^{b}$ & $\mathrm{~N} / \mathrm{A}^{\mathrm{h}}$ & $\mathrm{N} / \mathrm{A}^{\mathrm{b}}$ & $\mathrm{N} / \mathrm{A}^{\mathrm{h}}$ & $\mathrm{N} / \mathrm{A}^{\mathrm{b}}$ \\
\hline FULL PAN: & $35 \mathrm{~s}$ & ST STATE: & $180 \mathrm{~s}$ & OPEN & DOOF & TEST & & & & & & & \\
\hline $2.5 \mathrm{Dia}$ & $15 \mathrm{~m}$ & $7.7^{\wedge}$ & $6 \mathrm{~b}$ & 21.3 & 30.5 & 36.6 & 42.7 & 48.8 & 54.9 & 61.0 & 64.0 & 67.1 & 70.1 \\
\hline Controller: & $.25 / 2 / 3$ & Response Time & e (s) & 12.7 & 18.1 & 20.8 & 30.4 & 33.6 & 34.6 & 40.1 & 38.7 & 41.3 & 45.5 \\
\hline FULL PAN: & $40 \mathrm{~s}$ & ST STATE: & $150 \mathrm{~s}$ & & & & & & & & & & \\
\hline $2.5 \mathrm{Dia}$ & $15 \mathrm{~m}$ & $\mathrm{n} / \mathrm{a}$ & 8 & 21.3 & 30.5 & 36.6 & 42.7 & 48.8 & 54.9 & 61.0 & 64.0 & 67.1 & 70.1 \\
\hline Controller: & $.25 / 4 / 4$ & Response Time & e (s) & 13.3 & 23.6 & 28.7 & 35.7 & 37.4 & 39.7 & 46.7 & NR & NR & NR \\
\hline FULL PAN: & $40 \mathrm{~s}$ & ST STATE: & $150 \mathrm{~s}$ & & & & & & & & & & \\
\hline
\end{tabular}

a - No optical flame detector responses were recorded during test \#1.

b - No valid data for optical flame detector responses from ignition were obtained from Test \#13.

NR - No response from detector.

^ - Estimated HRR used.

NOTE: 1. Response times are measured in reference to elapsed time from "time zero" for ignition response or from a controller reset for full pan and steady state responses

2. Full Pan and Steady State times are the time to reach that respective state and are measured in reference to "time

zero". 
Table 28. Optical detector response time after full-pan involvement for all $15 \mathrm{~m}$ tests \begin{tabular}{|l|l|l|l}
\hline PAN SIZE $(\mathrm{m})$ & FACILITY & HRR (MW) & TEST NO. DETECTOR DISTANCE FROM SOURCE CENTER (m)
\end{tabular}

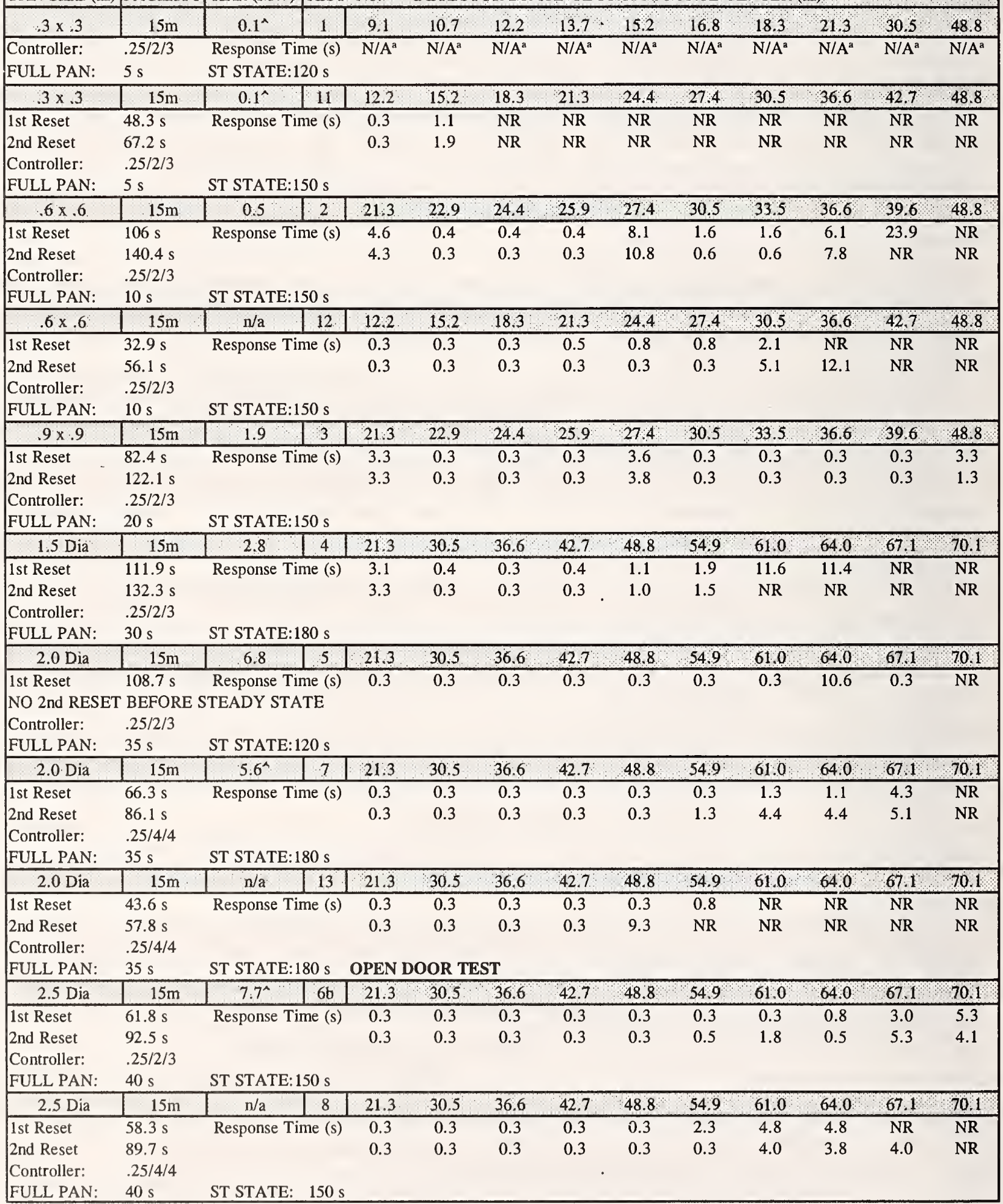

a - No optical flame detector responses were recorded during test \#1.

NR - No response from detector. A - Estimated HRR used. 
Table 29. Optical detector response times after steady-steady burn rate for all $15 \mathrm{~m}$ tests \begin{tabular}{|l|l|l|l|l|}
\hline PAN SIZE (m) & FACILITY & HRR (MW) & TEST No. & DETECTOR DISTANCE FROM SOURCE CENTER (m) \\
\hline
\end{tabular}

\begin{tabular}{|c|c|c|c|c|c|c|c|c|c|c|c|c|c|}
\hline $3 \times .3$ & $15 \mathrm{~m}$ & $0.1^{\wedge}$ & 1 & 9.1 & 10.7 & 12.2 & 13.7 & 15.2 & 16.8 & 18.3 & 21.3 & 30.5 & 48.8 \\
\hline Controller: & $.25 / 2 / 3$ & Response Tim & ne (s) & $N / A^{a}$ & $\mathrm{~N} / \mathrm{A}^{\mathrm{a}}$ & N/A ${ }^{a}$ & $\mathrm{~N} / \mathrm{A}^{\mathrm{a}}$ & $\mathrm{N} / \mathrm{A}^{\mathrm{a}}$ & N/A ${ }^{a}$ & $\mathrm{~N} / \mathrm{A}^{\mathrm{a}}$ & $\mathrm{N} / \mathrm{A}^{\mathrm{a}}$ & $\mathrm{N} / \mathrm{A}^{\mathrm{a}}$ & $\mathrm{N} / \mathrm{A}^{\mathrm{a}}$ \\
\hline FULL PAN: & $5 \mathrm{~s}$ & ST STATE: & $120 \mathrm{~s}$ & & & & & & & & & & \\
\hline $.3 \times 3$ & $15 \mathrm{~m}$ & $0.1^{\wedge}$ & 11 & 12.2 & 15.2 & 18.3 & 21.3 & 24.4 & 27.4 & 30.5 & 36.6 & 42.7 & 48.8 \\
\hline 1st Reset & $48.3 \mathrm{~s}$ & Response Tim & ne (s) & 0.3 & 1.1 & NR & NR & NR & NR & NR & NR & NR & NR \\
\hline 2nd Reset & $67.2 \mathrm{~s}$ & & & 0.3 & 1.9 & NR & NR & NR & NR & NR & NR & NR & NR \\
\hline Controller: & $.25 / 2 / 3$ & & & & & & & & & & & & \\
\hline FULL PAN: & $5 \mathrm{~s}$ & ST STATE: & $150 \mathrm{~s}$ & & & & & & & & & & \\
\hline $.6 \times .6$ & $15 \mathrm{~m}$ & 0.5 & 2 & 21.3 & 22.9 & 24.4 & 25.9 & 27.4 & 30.5 & 33.5 & 36.6 & 39.6 & 48.8 \\
\hline 1st Reset & $164.9 \mathrm{~s}$ & Response Tim & ne (s) & 3.5 & 0.3 & 0.3 & 0.3 & 5.3 & 0.3 & 1.0 & 0.3 & NR & NR \\
\hline 2nd Reset & $189.4 \mathrm{~s}$ & & & 3.6 & 0.3 & 0.3 & 0.3 & 5.1 & 0.3 & 0.6 & 0.6 & 24.8 & NR \\
\hline Controller: & $.25 / 2 / 3$ & & & & & & & & & & & & \\
\hline FULL PAN: & $10 s$ & ST STATE: & $150 \mathrm{~s}$ & & & & & & & & & & \\
\hline $.6 \times .6$ & $15 \mathrm{~m}$ & $\mathrm{n} / \mathrm{a}$ & 12 & 12.2 & 15.2 & 18.3 & 21.3 & 24.4 & 27.4 & 30.5 & 36.6 & 42.7 & 48.8 \\
\hline 1st Reset & $162.8 \mathrm{~s}$ & Response Tim & ne (s) & 0.3 & 0.3 & 0.3 & 0.3 & 0.3 & 0.3 & 0.3 & 9.6 & NR & NR \\
\hline 2nd Reset & $182.9 \mathrm{~s}$ & & & 0.3 & 0.3 & 0.3 & 0.3 & 0.3 & 0.3 & 1.4 & NR & NR & NR \\
\hline Controller: & $.25 / 2 / 3$ & & & & & & & & & & & & \\
\hline FULL PAN: & $10 \mathrm{~s}$ & ST STATE: & $150 \mathrm{~s}$ & & & & & & & & & & \\
\hline $9 \times .9$ & $15 \mathrm{~m}$ & 1.9 & 3 & 213 & $22: 9$ & 24.4 & 25.9 & 27.4 & 30.5 & 33.5 & 36.6 & 39.6 & 48.8 \\
\hline 1st Reset & $151.7 \mathrm{~s}$ & Response Tim & ne (s) & 3.3 & 0.3 & 0.3 & 0.3 & 4.1 & 0.3 & 0.3 & 0.3 & 1.6 & 1.6 \\
\hline 2nd Reset & $166.9 \mathrm{~s}$ & & & 3.6 & 0.3 & 0.3 & 0.3 & 4.1 & 0.3 & 0.3 & 0.8 & 0.8 & 4.8 \\
\hline Controller: & $.25 / 2 / 3$ & & & & & & & & & & & & \\
\hline FULL PAN: & $20 \mathrm{~s}$ & ST STATE: & $150 \mathrm{~s}$ & & & & & & & & & & \\
\hline $1.5 \mathrm{Dia}$ & $15 \mathrm{~m}$ & 2.8 & 4 & $21: 3$ & 30.5 & 36.6 & .42 .7 & 48.8 & 54.9 & 61.0 & 64.0 & 67.1 & 70.1 \\
\hline 1st Reset & $192 \mathrm{~s}$ & Response Tim & ne (s) & 3.1 & 0.3 & 0.3 & 0.3 & 0.3 & 4.6 & 14.9 & 10.9 & NR & NR \\
\hline 2nd Reset & $222.1 \mathrm{~s}$ & & & 3.1 & 0.3 & 0.3 & 0.3 & 0.3 & 2.1 & 2.4 & 13.1 & 2.3 & NR \\
\hline Controller: & $.25 / 2 / 3$ & & & & & & & & & & & & \\
\hline FULL PAN: & $30 \mathrm{~s}$ & ST STATE: & $180 \mathrm{~s}$ & & & & & & & & & & \\
\hline $2.0 \mathrm{Dia}$ & $15 \mathrm{~m}$ & 6.8 & 5 & 21.3 & 30.5 & 36.6 & 42.7 & 48.8 & 54.9 & 61.0 & 64.0 & 67.1 & 70.1 \\
\hline 1st Reset & $129.7 \mathrm{~s}$ & Response Tim & ne (s) & 3.1 & 0.3 & 0.3 & 0.3 & 0.3 & 0.8 & 3.9 & 10.9 & 3.3 & NR \\
\hline 2nd Reset & $159.7 \mathrm{~s}$ & & & 3.0 & 0.3 & 0.3 & 0.3 & 0.3 & 0.3 & 0.8 & 10.8 & 0.8 & 0.8 \\
\hline Controller: & $.25 / 2 / 3$ & & & & & & & & & & & & \\
\hline FULL PAN: & $35 \mathrm{~s}$ & ST STATE: & $120 \mathrm{~s}$ & & & & & & & & & & \\
\hline $2.0 \mathrm{Dia}$ & $15 \mathrm{~m}$ & $5.6^{\wedge}$ & 7 & 21.3 & 30.5 & 36.6 & 42.7 & 48.8 & 54.9 & 61.0 & 64.0 & 67.1 & 70.1 \\
\hline 1st Reset & $189.3 \mathrm{~s}$ & Response Tim & ne (s) & 0.3 & 0.3 & 0.3 & 0.3 & 0.3 & 0.3 & 0.3 & 0.8 & 5.0 & NR \\
\hline 2nd Reset & $211.5 \mathrm{~s}$ & & & 0.3 & 0.3 & 0.3 & 0.3 & 0.3 & 0.3 & NR & 0.3 & NR & NR \\
\hline Controller: & $.25 / 4 / 4$ & & & & & & & & & & & & \\
\hline FULL PAN: & $35 \mathrm{~s}$ & ST STATE: & $180 \mathrm{~s}$ & & & & & & & & & & \\
\hline 2.5 Dia. & $15 \mathrm{~m}$ & $77^{\wedge}$ & $6 b$ & 21.3 & 30.5 & 36.6 & 42.7 & 48.8 & 54.9 & 61.0 & 64.0 & 67.1 & 70.1 \\
\hline 1st Reset & $159 \mathrm{~s}$ & Response Tim & ne (s) & 0.3 & 0.3 & 0.3 & 0.3 & 0.3 & 1.1 & 0.8 & 1.1 & 2.8 & 5.9 \\
\hline 2nd Reset & $179.1 \mathrm{~s}$ & & & 0.3 & 0.3 & 0.3 & 0.3 & 0.3 & 0.3 & 0.8 & 0.3 & 3.1 & 3.9 \\
\hline Controller: & $.25 / 2 / 3$ & & & & & & & & & & & & \\
\hline FULL PAN: & $40 \mathrm{~s}$ & ST STATE: & $150 \mathrm{~s}$ & & & & & & & & & & \\
\hline $2.5 \mathrm{Dia}$ & $15 \mathrm{~m}$ & $\mathrm{n} / \mathrm{a}$ & 8 & 21.3 & 30.5 & 36.6 & 42.7 & 48.8 & 54.9 & 61.0 & 64.0 & 67.1 & 70.1 \\
\hline 1st Reset & $171.5 \mathrm{~s}$ & Response Tim & ne (s) & 0.3 & 0.3 & 0.3 & 0.3 & 0.3 & 2.5 & 11.3 & 11.3 & 11.3 & NR \\
\hline 2nd Reset & $195.7 \mathrm{~s}$ & & & 0.3 & 0.3 & 0.3 & 0.3 & 0.3 & 1.2 & 4.8 & 4.8 & NR & NR \\
\hline Controller: & $.25 / 4 / 4$ & & & & & & & & & & & & \\
\hline FULL PAN: & $40 \mathrm{~s}$ & ST STATE: & $150 \mathrm{~s}$ & & & & & & & & & & \\
\hline
\end{tabular}

a - No optical flame detector responses were recorded during test $\# 1$.

NR - No response from detector. ^ - Estimated HRR used. 
Table 27 shows the response times from ignition, along with pan size, heat release rate (HRR), controller settings, time to full pan involvement from ignition, and time to steady state burning from ignition.

During each experiment all of the UV/IR detectors were repeatedly reset at various times during the test. The purpose of these resets was to obtain response time data at various stages of the fire (i.e., from ignition, full pan involvement from ignition, and steady state burning from ignition). Table 28 shows the response time corresponding to the first two manual resets after full pan involvement. Times associated with each reset represent elapsed time from ignition. Table 28 also shows pan size, HRR, controller settings, time to full pan involvement from ignition, and time to steady state burning from ignition. In most cases the manual resets occurred after most or all detectors had responded, or changes had stopped occurring. The average time between resets ranged from $10 \mathrm{~s}$ to $30 \mathrm{~s}$. The minimum response time from reset for any detector was $0.3 \mathrm{~s}$, corresponding to the time it takes to actually reset the controller. The number of resets analyzed after achieving full pan involvement and steady state burning reflects the lowest common denominator (i.e., number of resets) for the vast majority of experiments. In most cases, response time results for full pan and steady state conditions were taken from the first two manual resets that occurred after these conditions were reached.

The response times from manual reset after steady state burning are listed in Table 29. Table 29 also shows pan size, HRR, controller settings, time to full pan involvement from ignition, time to steady state burning from ignition. As with the response times from full pan involvement, the response time of each detector was determined from a manual reset occurring during the period of steady state burning.

\section{Threshold Response Distances at Selected Response Times}

Threshold response distances from ignition, full pan involvement and steady state burning were examined at response times of $5 \mathrm{~s}, 10 \mathrm{~s}, 20 \mathrm{~s}, 30 \mathrm{~s}$, and $45 \mathrm{~s}$. Table 30 shows the threshold response distances of the optical detectors for each fire size as a function of these selected response times. For example, if the threshold response distance from ignition for the $2.8 \mathrm{MW}$ fire in test 4 is shown as $30.5 \mathrm{~m}$ at $20 \mathrm{~s}$, that means that $30.5 \mathrm{~m}$ was the maximum distance at which an optical detector responded within $20 \mathrm{~s}$ for that fire test. These times were selected to indicate the maximum effective response "distance" at which the detectors responded within a number of response time intervals.

Within DoD, the existing testing and approval criteria for optical flame detectors have been primarily based on two sets of acceptance criteria. First, the Navy and Air Force design specifications require an optical detector to respond to a $3 \mathrm{~m} \times 3 \mathrm{~m}$ steady state JP-4 fire within $5 \mathrm{~s}$. Factory Mutual requires an optical detector to respond to a $1.5 \mathrm{~m} \times 1.5 \mathrm{~m}$ steady state JP-4 fire within $10 \mathrm{~s}$. Based on those requirements, the actual voluntary tests standards which the industry has developed over the years identify the following response distance thresholds shown in Table 31.

Previous studies by the Factory Mutual Engineering Corporation indicate that the skin of aircraft fuselages will fail after $45 \mathrm{~s}$ of spill fire exposure. [30] Unfortunately, those data do not represent the decreased resistance to fire of today's typical composite material (i.e., stealth aircraft). Nevertheless, $45 \mathrm{~s}$ was the maximum response time used in determining threshold response distances. Further studies on the effect of fire exposure on aircraft skin will help determine acceptable response times of optical 
Table 30. Threshold response distances $(\mathrm{m})$ of optical detectors as a function of selected response times for $15 \mathrm{~m}$ high facility tests

\begin{tabular}{|c|c|c|c|c|c|c|c|}
\hline \multicolumn{3}{|c|}{ Test and Optical Detector Set-up Information } & \multicolumn{5}{|c|}{ Distance (m) from Ignition at Selected Times } \\
\hline TEST NO. & HRR(PAN SIZE) & CONTROLLER & $5 s$ & $10 \mathrm{~s}$ & $20 \mathrm{~s}$ & $30 \mathrm{~s}$ & $45 \mathrm{~s}$ \\
\hline TEST 1 & $0.1 \mathrm{MW}(.3 \mathrm{~m} \mathrm{X} .3 \mathrm{~m})$ & $.25 / 2 / 3$ & $\mathrm{~N} / \mathrm{A}^{\mathrm{a}}$ & $\mathrm{N} / \mathrm{A}^{\mathrm{a}}$ & $\mathrm{N} / \mathrm{A}^{\mathrm{a}}$ & $\mathrm{N} / \mathrm{A}^{\mathrm{a}}$ & $N / A^{a}$ \\
\hline TEST 11 & $0.1 \mathrm{MW}(.3 \mathrm{~m} \mathrm{X} .3 \mathrm{~m})$ & $.25 / 2 / 3$ & NR & 12.2 & 12.2 & 15.2 & 15.2 \\
\hline TEST 2 & $0.5 \mathrm{MW}(.6 \mathrm{~m} \mathrm{x} .6 \mathrm{~m})$ & $.25 / 2 / 3$ & NR & 21.3 & 25.9 & 36.6 & 36.6 \\
\hline TEST 12 & $\mathrm{~N} / \mathrm{A}^{\mathrm{c}} \mathrm{MW}(.6 \mathrm{~m} \times .6 \mathrm{~m})$ & $.25 / 2 / 3$ & 12.2 & 12.2 & 15.2 & 27.4 & 27.4 \\
\hline TEST 3 & $1.9 \mathrm{MW}(.9 \mathrm{~m} \times .9 \mathrm{~m})$ & $.25 / 2 / 3$ & NR & NR & 22.9 & 27.4 & 39.6 \\
\hline TEST 4 & $2.8 \mathrm{MW}(1.5 \mathrm{~m} \mathrm{dia})$ & $.25 / 2 / 3$ & NR & NR & 30.5 & 21.3 & 48.8 \\
\hline TEST 5 & $6.8 \mathrm{MW}(2.0 \mathrm{~m} \mathrm{dia})$ & $.25 / 2 / 3$ & NR & NR & 21.3 & 36.6 & 48.8 \\
\hline TEST 7 & $5.6 \mathrm{MW}(2.0 \mathrm{~m} \mathrm{dia})$ & $.25 / 4 / 4$ & NR & NR & 21.3 & 36.6 & 48.8 \\
\hline TEST $13^{b}$ & N/Ac MW (2.0 m dia) & $.25 / 4 / 4$ & $N / A^{b}$ & $\mathrm{~N} / \mathrm{A}^{\mathrm{b}}$ & $\mathrm{N} / \mathrm{A}^{\mathrm{b}}$ & $N / A^{b}$ & $N / A^{b}$ \\
\hline TEST $6 \mathrm{~B}$ & $7.7 \mathrm{MW}(2.5 \mathrm{~m} \mathrm{dia})$ & $.25 / 2 / 3$ & NR & NR & 30.5 & 36.6 & 67.1 \\
\hline TEST 8 & $\mathrm{~N} / \mathrm{A}^{\mathrm{c}}(2.5 \mathrm{~m} \mathrm{dia})$ & $.25 / 4 / 4$ & NR & NR & 21.3 & 36.6 & 54.9 \\
\hline \multicolumn{3}{|c|}{ Test and Optical Detector Set-up Information } & \multicolumn{5}{|c|}{ Distance $(\mathrm{m})$ from Full Pan Involvement at Selected Times } \\
\hline TEST NO. & HRR(PAN SIZE) & CONTROLLER & $5 \mathrm{~s}$ & $10 \mathrm{~s}$ & $20 \mathrm{~s}$ & $30 \mathrm{~s}$ & $45 \mathrm{~s}$ \\
\hline TEST 1 & $0.1 \mathrm{MW}(.3 \mathrm{~m} \mathrm{X} .3 \mathrm{~m})$ & $.25 / 2 / 3$ & $N / A^{a}$ & $N / A^{a}$ & $N / A^{a}$ & $N / A^{a}$ & $\mathrm{~N} / \mathrm{A}^{\mathrm{a}}$ \\
\hline TEST 11 & $0.1 \mathrm{MW}(.3 \mathrm{~m} \mathrm{X} .3 \mathrm{~m})$ & $.25 / 2 / 3$ & 15.2 & 15.2 & 15.2 & 15.2 & 15.2 \\
\hline TEST 2 & $0.5 \mathrm{MW}(.6 \mathrm{~m} \mathrm{x} .6 \mathrm{~m})$ & $.25 / 2 / 3$ & 25.9 & 25.9 & 36.6 & 36.6 & 36.6 \\
\hline TEST 12 & $\mathrm{~N} / \mathrm{A}^{\mathrm{c}} \mathrm{MW}(.6 \mathrm{~m} \mathrm{x} .6 \mathrm{~m})$ & $.25 / 2 / 3$ & 27.4 & 30.5 & 30.5 & 30.5 & 30.5 \\
\hline TEST 3 & $1.9 \mathrm{MW}(.9 \mathrm{~m} \mathrm{x} .9 \mathrm{~m})$ & $.25 / 2 / 3$ & 48.5 & 48.8 & 48.8 & 48.8 & 48.8 \\
\hline TEST 4 & $2.8 \mathrm{MW}(1.5 \mathrm{~m} \mathrm{dia})$ & $.25 / 2 / 3$ & 54.9 & 54.9 & 54.9 & 54.9 & 54.9 \\
\hline TEST 5 & $6.8 \mathrm{MW}(2.0 \mathrm{~m} \mathrm{dia})$ & $.25 / 2 / 3$ & 61 & 61 & 67.1 & 67.1 & 67.1 \\
\hline TEST 7 & $5.6 \mathrm{MW}(2.0 \mathrm{~m} \mathrm{dia})$ & $.25 / 4 / 4$ & 64 & 67.1 & 67.1 & 67.1 & 67.1 \\
\hline TEST $13^{b}$ & $\mathrm{~N} / \mathrm{A}^{\mathrm{c}} \mathrm{MW}(2.0 \mathrm{~m} \mathrm{dia})$ & $.25 / 4 / 4$ & 42.7 & 48.8 & 48.8 & 48.8 & 48.8 \\
\hline TEST $6 \mathrm{~B}$ & $7.7 \mathrm{MW}(2.5 \mathrm{~m} \mathrm{dia})$ & $.25 / 2 / 3$ & 64 & 70.1 & 70.1 & 70.1 & 70.1 \\
\hline TEST 8 & $\mathrm{~N} / \mathrm{A}^{\mathrm{c}}(2.5 \mathrm{~m} \mathrm{dia})$ & $.25 / 4 / 4$ & 64 & 64 & 64 & 64 & 64 \\
\hline \multicolumn{3}{|c|}{ Test and Optical Detector Set-up Information } & \multicolumn{5}{|c|}{ Distance $(\mathrm{m})$ from Steady State at Selected Times } \\
\hline TEST NO. & HRR(PAN SIZE) & CONTROLLER & $5 \mathrm{~s}$ & $10 \mathrm{~s}$ & $20 \mathrm{~s}$ & $30 \mathrm{~s}$ & $45 s$ \\
\hline TEST 1 & $0.1 \mathrm{MW}(.3 \mathrm{~m} \mathrm{X} .3 \mathrm{~m})$ & $.25 / 2 / 3$ & $\mathrm{~N} / \mathrm{A}^{\mathrm{a}}$ & $\mathrm{N} / \mathrm{A}^{\mathrm{a}}$ & N/A ${ }^{a}$ & $\mathrm{~N} / \mathrm{A}^{\mathrm{a}}$ & $N / A^{a}$ \\
\hline TEST 11 & $0.1 \mathrm{MW}(.3 \mathrm{~m} \mathrm{X} .3 \mathrm{~m})$ & $.25 / 2 / 3$ & 15.2 & 15.2 & 15.2 & 15.2 & 15.2 \\
\hline TEST 2 & $0.5 \mathrm{MW}(.6 \mathrm{~m} \mathrm{x} .6 \mathrm{~m})$ & $.25 / 2 / 3$ & 25.9 & 36.6 & 36.6 & 36.6 & 36.6 \\
\hline TEST 12 & $\mathrm{~N} / \mathrm{A}^{\mathrm{c}} \mathrm{MW}(.6 \mathrm{~m} \times .6 \mathrm{~m})$ & $.25 / 2 / 3$ & 30.5 & 30.5 & 30.5 & 30.5 & 30.5 \\
\hline TEST 3 & $1.9 \mathrm{MW}(.9 \mathrm{~m} \mathrm{x} .9 \mathrm{~m})$ & $.25 / 2 / 3$ & 48.8 & 48.8 & 48.8 & 48.8 & 48.8 \\
\hline TEST 4 & $2.8 \mathrm{MW}(1.5 \mathrm{~m} \mathrm{dia})$ & $.25 / 2 / 3$ & 54.9 & 54.9 & 64 & 64 & 64 \\
\hline TEST 5 & $6.8 \mathrm{MW}(2.0 \mathrm{~m} \mathrm{dia})$ & $.25 / 2 / 3$ & 61 & 61 & 67.1 & 67.1 & 67.1 \\
\hline TEST 7 & $5.6 \mathrm{MW}(2.0 \mathrm{~m} \mathrm{dia})$ & $.25 / 4 / 4$ & 54.9 & 54.9 & 54.9 & 54.9 & 54.9 \\
\hline TEST $13^{b}$ & $\mathrm{~N} / \mathrm{A}^{\mathrm{c}} \mathrm{MW}(2.0 \mathrm{~m} \mathrm{dia})$ & $.25 / 4 / 4$ & $N / A^{b}$ & $N / A^{b}$ & $N / A^{b}$ & $N / A^{b}$ & $N / A^{b}$ \\
\hline TEST 6B & $7.7 \mathrm{MW}(2.5 \mathrm{~m} \mathrm{dia})$ & $.25 / 2 / 3$ & 67.1 & 70.1 & 70.1 & 70.1 & 70.1 \\
\hline TEST 8 & $\mathrm{~N}^{\prime} \mathrm{A}^{\mathrm{c}}(2.5 \mathrm{~m} \mathrm{dia})$ & $.25 / 4 / 4$ & 54.9 & 54.9 & 64 & 64 & 64 \\
\hline
\end{tabular}


detectors. An additional element which must be considered in determining the acceptable response time is the time required to achieve foam coverage of the designated floor areas after the fire has been detected.

The controller settings of combination UV/IR detector were varied from test to test. Variations of controller setting for similar sized fires was limited in these tests, with the result that the impact of setting on threshold response distances at selected times was not conclusively determined. The effect of the varied controller settings on threshold response distances at selected times are examined further in section 4 dealing with the $22 \mathrm{~m}$ hangar fires.

\section{Maximum Response Distances}

The maximum response distances for the optical flame detectors in the $15 \mathrm{~m}$ facility were determined to be the maximum distance at which a detector responded without respect to the selected response times. Since detector response was measured at three key fire events, the time at which the maximum response distance was reached is represented for each stage of fire growth. The maximum response distances are presented in Table 32 and graphically illustrated in Figure 47. The effects of different controller sensitivity settings on the maximum response distance were studied for the $2.0 \mathrm{~m}$ and $2.5 \mathrm{~m}$ diameter pan fires. The experiments with controller settings of $0.25 / 2 / 3$ had a greater maximum response distance than those with settings of $0.25 / 4 / 4$ (Figure 48 ).

\section{Predicted Response of Unitized UV/IR Optical Flame Detectors.}

The researchers from Detector Electronics Corporation were asked to take the actual raw counts per second data acquired from the each experiment and mathematically predict the responses of the unitized optical flame detectors. This was done in order to compare them to the responses of the controller based detectors. This analysis was performed for responses from ignition during a select time interval. Table 33 lists the predicted response times for each detector placement. In addition, the unitized maximum predicted response distances are shorter than the controller based detectors in nearly all cases. The predicted response times from ignition for the unitized detector were considerably longer in most cases.

\subsubsection{Response of Line-Type Heat Detector}

The line-type heat detector used in these test provided continuous measurement of temperature as a function of fire size. The specifications, theory of operation, and location can be found earlier in section 3. The data from the sensor was compared to thermocouples N10, S9 and W4 which correspond to $3.0 \mathrm{~m}$ north, $3.0 \mathrm{~m}$ south and $9.1 \mathrm{~m}$ west respectively. The readings from these three thermocouples were averaged to provide an estimate of temperature near the sensor. Figure 49 shows temperature profiles of the thermocouples used and the resulting average, along with the response of the linear heat detector for a $2.0 \mathrm{~m}$ diameter test fire. Figure 50 shows these comparisons for tests $1-5$ (with draft curtain) and Figure 51 for tests 7,9,11-13 (without draft curtain). Results for tests $6 \mathrm{~b}$ and 8 are not available due to a malfunction of the sensor's power supply during these tests. 
Table 31. Voluntary industry standards which identify response distance thresholds for UV/IR optical detectors

\begin{tabular}{|c|c|}
\hline Fire Size & Response Distance Threshold \\
\hline $0.3 \mathrm{~m} \times 0.3 \mathrm{~m}(1 \mathrm{ft} \times 1 \mathrm{ft})$ & $15.3 \mathrm{~m}(50 \mathrm{ft})$ \\
\hline $0.6 \mathrm{~m} \times 0.6 \mathrm{~m}(2 \mathrm{ft} \times 2 \mathrm{ft})$ & $30.5 \mathrm{~m}(100 \mathrm{ft})$ \\
\hline $3.0 \mathrm{~m} \times 3.0 \mathrm{~m}(10 \mathrm{ft} \times 10 \mathrm{ft})$ & $45.7 \mathrm{~m}(150 \mathrm{ft})$ \\
\hline
\end{tabular}

Table 32. Optical detector response times at maximum distance from fire source for tests conducted in $15 \mathrm{~m}$ high facility

\begin{tabular}{|c|c|c|c|c|c|c|c|}
\hline \multicolumn{2}{|c|}{ Test Information } & \multirow{2}{*}{$\begin{array}{l}\text { Controller } \\
\text { Setting }\end{array}$} & \multirow{2}{*}{$\begin{array}{l}\text { Threshold } \\
\text { Detector } \\
\text { Distance (m) }\end{array}$} & \multirow{2}{*}{$\begin{array}{c}\text { Maximum } \\
\text { Detector } \\
\text { Placement }(\mathrm{m})\end{array}$} & \multicolumn{3}{|c|}{ Response Time (s) From: } \\
\hline Test No. & HRR(Pan Size) & & & & Ignition & $\begin{array}{c}\text { Full-Pan } \\
\text { Involvement }\end{array}$ & $\begin{array}{c}\text { Steady } \\
\text { State }\end{array}$ \\
\hline TEST 1 & $0.1 \mathrm{MW}(.3 \mathrm{~m} \mathrm{X} .3 \mathrm{~m})$ & $.25 / 2 / 3$ & $\mathrm{~N} / \mathrm{A}^{\mathrm{a}}$ & $\mathrm{N} / \mathrm{A}^{\mathrm{a}}$ & $\mathrm{N} / \mathrm{A}^{\mathrm{a}}$ & $\mathrm{N} / \mathrm{A}^{\mathrm{a}}$ & $\mathrm{N} / \mathrm{A}^{\mathrm{a}}$ \\
\hline TEST 11 & $0.1 \mathrm{MW}(.3 \mathrm{~m} \mathrm{X} .3 \mathrm{~m})$ & $.25 / 2 / 3$ & 15.2 & 48.8 & 25 & 1.9 & 1.9 \\
\hline TEST 2 & $0.5 \mathrm{MW}(.6 \mathrm{~m} \mathrm{x} .6 \mathrm{~m})$ & $.25 / 2 / 3$ & 36.6 & 48.8 & 20.8 & 7.8 & 0.6 \\
\hline TEST 12 & $\mathrm{~N} / \mathrm{A}^{\mathrm{c}} \mathrm{MW}(.6 \mathrm{~m} \mathrm{x} .6 \mathrm{~m})$ & $.25 / 2 / 3$ & 27.4 & 48.8 & 28.6 & 0.8 & 0.3 \\
\hline TEST 3 & $1.9 \mathrm{MW}(.9 \mathrm{~m} \mathrm{x} .9 \mathrm{~m})$ & $.25 / 2 / 3$ & 48.8 & 48.8 & 47 & 3.3 & 4.8 \\
\hline TEST 4 & $2.8 \mathrm{MW}(1.5 \mathrm{~m} \mathrm{dia})$ & $.25 / 2 / 3$ & 54.9 & 70.1 & 47.9 & 1.9 & 4.6 \\
\hline TEST 5 & $6.8 \mathrm{MW}(2.0 \mathrm{~m} \mathrm{dia})$ & $.25 / 2 / 3$ & 67.1 & 70.1 & 61.6 & 0.3 & 3.3 \\
\hline TEST 7 & $5.6 \mathrm{MW}(2.0 \mathrm{~m} \mathrm{dia})$ & $.25 / 4 / 4$ & 54.9 & 70.1 & 51.4 & 1.3 & 0.3 \\
\hline TEST 13 & $\mathrm{~N} / \mathrm{A}^{\mathrm{c}} \mathrm{MW}(2.0 \mathrm{~m} \mathrm{dia})$ & $.25 / 4 / 4$ & 48.8 & 70.1 & $\mathrm{~N} / \mathrm{A}^{\mathrm{b}}$ & 9.3 & $\mathrm{~N} / \mathrm{A}^{\mathrm{b}}$ \\
\hline TEST 6B & $7.7 \mathrm{MW}(2.5 \mathrm{~m} \mathrm{dia})$ & $.25 / 2 / 3$ & 70.1 & 70.1 & 45.5 & 5.9 & 5.3 \\
\hline TEST 8 & $\mathrm{~N} / \mathrm{A}^{\mathrm{c}}(2.5 \mathrm{~m} \mathrm{dia})$ & $.25 / 4 / 4$ & 64 & 70.1 & NR & 11.3 & 4.8 \\
\hline
\end{tabular}

NR - No detector response

a - No optical flame detector responses were recorded during test \#1.

Note: Test \#13 is open door test.

$\mathrm{b}$ - No valid data for optical flame detector responses from ignition and steady state were obtained from

Test \#13.

c - HRR data not available 


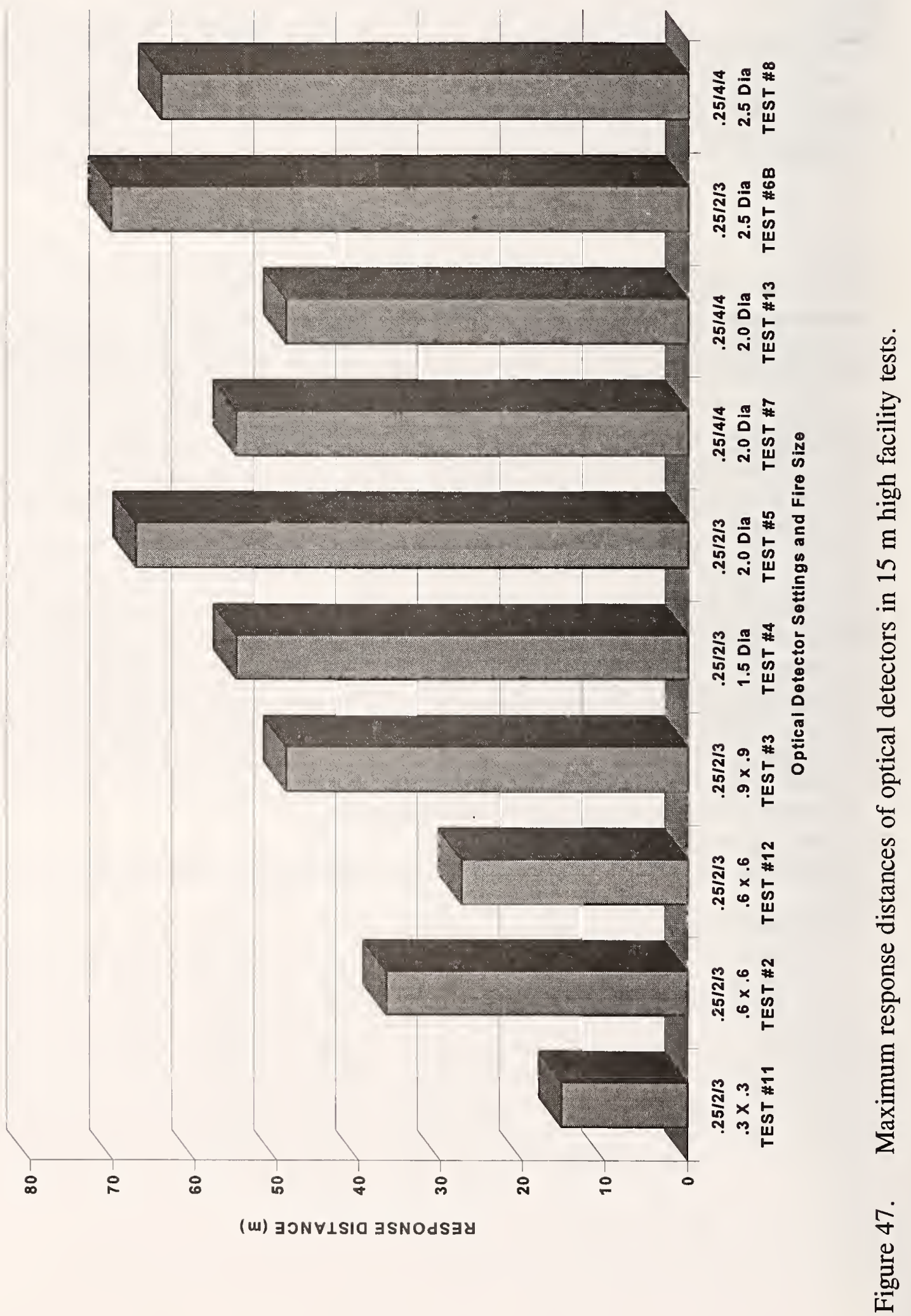




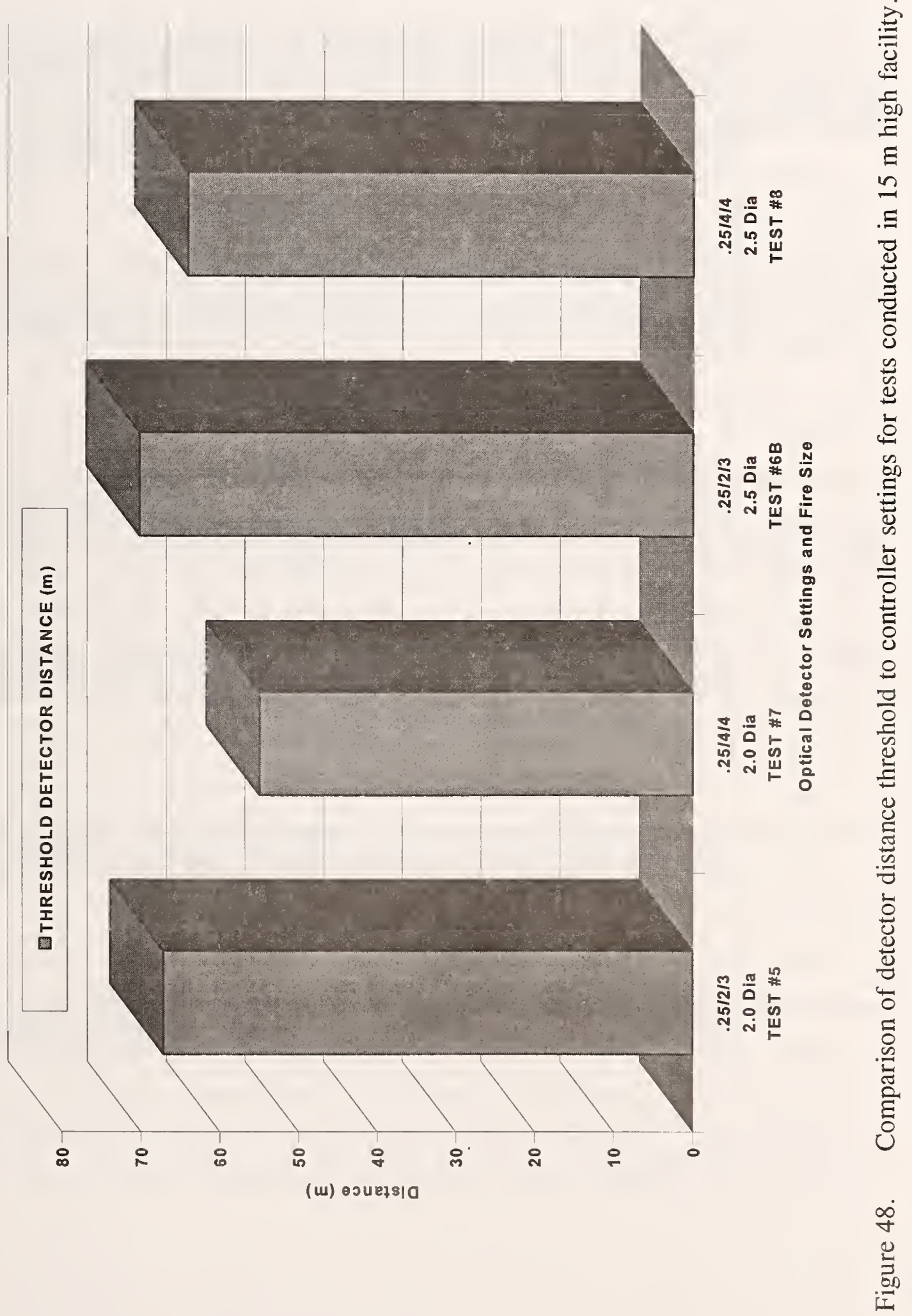


Table 33. Predicted response times for unitized UV/IR optical detectors

\begin{tabular}{|c|c|c|c|c|c|c|c|c|c|c|c|}
\hline \multirow{2}{*}{$\begin{array}{c}\text { Test \#1 } \\
0.3 \mathrm{~m} \times 0.3 \mathrm{~m} \\
0.1 \mathrm{MW}\end{array}$} & Localon & $9 \cdot 1 / 1$ & $10.7 \mathrm{~m}$ & $12.2 \mathrm{~m}$ & $137 \mathrm{~m}$ & $15.2 n$ & 168 8n: & $18 \% \mathrm{~m}$ & $21,3 \mathrm{~m}$ & 30.5n & $48.8 \pi$ \\
\hline & \multicolumn{11}{|c|}{ No Response Times were Recorded for Test 1} \\
\hline \multirow{3}{*}{$\begin{array}{c}\text { Test \#11 } \\
0.3 \mathrm{~m} \mathrm{x} 0.3 \mathrm{~m}\end{array}$} & Location & $122 m$ & $15.2 m$ & $18.3 \mathrm{~m}$ & $213 \mathrm{~m}$ & $24+11$ & 27. 4.m & $30.5 \mathrm{~m}$ & $66.6 \mathrm{~m}$ & $42,11 \%$ & $48.8 \pi$ \\
\hline & $0.25 / 2 / 3^{\mathrm{a}}$ & 9.1 & 25.0 & NR & NR & NR & NR & NR & NR & NR & NR \\
\hline & Unitize $3 \mathrm{~s}$ & NR & NR & NR & NR & NR & NR & NR & NR & NR & NR \\
\hline $0.1 \mathrm{MW}$ & Unitize $0.5 \mathrm{~s}$ & 42.6 & NR & NR & NR & NR & NR & NR & NR & NR & NR \\
\hline \multirow{4}{*}{$\begin{array}{l}\text { Test \#2 } \\
5 \mathrm{~m} \times 0.6 \mathrm{~m} \\
0.5 \mathrm{MW}\end{array}$} & location & $2 \%$ Hin & 22.90 \% & $24.1 \mathrm{~m}$ & $25 \%$ m & $27.11 \%$ & $30,5 m$ & 33.5 & $36.6 \mathrm{~m}$ & $42,11 \%$ & 48.8 \\
\hline & $0.25 / 2 / 3^{\mathrm{a}}$ & 5.5 & 10.4 & 10.4 & 11.7 & 21.5 & 18.8 & 20.8 & 20.8 & 67.2 & NR \\
\hline & Unitize $3 \mathrm{~s}$ & 20.9 & 21.0 & 21.0 & 68.3 & 23.2 & NR & NR & NR & NR & NR \\
\hline & Unitize $0.5 \mathrm{~s}$ & 11.9 & 15.6 & 18.5 & 20.7 & 20.7 & 66.5 & NR & NR & NR & NR \\
\hline \multirow{4}{*}{$\begin{array}{c}\text { Test \#12 } \\
0.6 \mathrm{~m} \times 0.6 \mathrm{~m} \\
{[\quad]}\end{array}$} & Location & $122 m$ & 152 m & $18.3 \mathrm{~m}$ & $21.3 n$ & $244 m$ & 27.4 n & $30.9 m$ & $36.61 \%$ & 42.11 & 48.8 . \\
\hline & $0.25 / 2 / 3^{\mathrm{a}}$ & 1.5 & 16.1 & 25.6 & 28.6 & 28.5 & 28.6 & NR & NR & NR & NR \\
\hline & Unitize $3 \mathrm{~s}$ & 30.8 & 30.9 & 50.7 & 54.2 & NR & NR & NR & NR & NR & NR \\
\hline & Unitize $0.5 \mathrm{~s}$ & 17.7 & 28.4 & 28.6 & 36.1 & 34.7 & 53.2 & NR & 52.0 & NR & NR \\
\hline \multirow{4}{*}{$\begin{array}{l}\text { Test \#3 } \\
9 \mathrm{~m} \times 0.9 \mathrm{~m} \\
1.9 \mathrm{MW}\end{array}$} & 1 0 ocalon & $21 / 1 n$ & $22.91 \%$ & 24.4 m & $25,9 \mathrm{~m}$ & 27. n & $80.5 m$ & 39.51 & $36.6 m$ & $4271 \%$ & 48.87 \\
\hline & $0.25 / 2 / 3^{\mathrm{a}}$ & 18.5 & 18.2 & 29.2 & 22.7 & 21.5 & 30.8 & 35.5 & 33.0 & 44.5 & 47.0 \\
\hline & Unitize $3 \mathrm{~s}$ & 34.1 & 34.7 & 34.9 & 35.2 & 34.7 & 47.9 & NR & NR & NR & NR \\
\hline & Unitize $0.5 \mathrm{~s}$ & 25.2 & 25.7 & 25.5 & 32.4 & 25.5 & 45.4 & 45.1 & 47.2 & NR & NR \\
\hline \multirow{4}{*}{$\begin{array}{c}\text { Test \#4 } \\
1.5 \mathrm{~m} \mathrm{Diam.} \\
2.8 \mathrm{MW}\end{array}$} & Locator & $213 \mathrm{~m}$ & $30.5 n$ & $86.6 m$ & 42.11 & $48.8 n$ & $54.91 \%$ & $610 \mathrm{~m}$ & $6400 \%$ & 67.111 & 10 17n \\
\hline & $0.25 / 2 / 3^{\mathrm{a}}$ & 24.4 & 33.0 & 34.0 & 36.1 & 39.8 & 47.9 & 72.5 & 58.2 & 72.6 & 93.1 \\
\hline & Unitize $3 \mathrm{~s}$ & 35.3 & 41.6 & NR & NR & NR & NR & NR & NR & NR & NR \\
\hline & Unitize $0.5 \mathrm{~s}$ & 26.6 & 35.7 & 39.8 & 48.0 & NR & NR & NR & NR & NR & NR \\
\hline \multirow{4}{*}{ Test 5} & Kocaton & $283 m$ & $30.6 n^{\circ}$ & $36.6 n$ & $4271 \%$ & $48.8 \mathrm{~m}$ & $549 \mathrm{~m}$ & $60 \mathrm{~m}$ & $640 \mathrm{~m}$ & 6710 & 10.111 \\
\hline & $0.25 / 2 / 3^{a}$ & 17.3 & 23.6 & 24.8 & 30.6 & 33.6 & 45.2 & 43.4 & 41.7 & 61.6 & 69.9 \\
\hline & Unitize $3 \mathrm{~s}$ & 25.9 & 40.8 & 41.5 & 60.3 & 93.2 & NR & NR & NR & NR & NR \\
\hline & Unitize $0.5 \mathrm{~s}$ & 19.4 & 31.4 & 33.4 & 39.4 & 43.3 & 85.1 & 91.7 & NR & NR & NR \\
\hline
\end{tabular}




\begin{tabular}{|c|c|c|c|c|c|c|c|c|c|c|c|}
\hline \multirow{4}{*}{$\begin{array}{c}2.0 \mathrm{~m} \text { Diam. } \\
5.6 \mathrm{MW}\end{array}$} & Location & 21.31 & $30 \%$ m & $366 \mathrm{~m}$ & $427 \mathrm{~m}$ & $48.8 \mathrm{~m}$ & 54,911 & $610 \mathrm{~m}$ & $640 \mathrm{~m}$ & $67 / \mathrm{m}$ & $70.1 \mathrm{~m}$ \\
\hline & $.25 / 4 / 4^{\mathrm{a}}$ & 17.6 & 20.6 & 26.4 & 31.4 & 34.8 & 51.4 & NR & 61.4 & NR & NR \\
\hline & Unitize $3 \mathrm{~s}$ & 19.9 & 31.3 & 32.4 & 34.0 & NR & NR & NR & NR & NR & NR \\
\hline & Unitize $0.5 \mathrm{~s}$ & 17.4 & 20.6 & 29.9 & 31.5 & 37.9 & 53.3 & NR & 54.2 & NR & NR \\
\hline \multirow{4}{*}{$\begin{array}{c}\text { Test \#13 } \\
2.0 \mathrm{~m} \text { Diam. }\end{array}$} & Cocalton & 21.317 & $80.5,11$ & $36.6 n$ & 42711 & $488 \mathrm{~m}$ & 54.911 & $61.0 \mathrm{~m}$ & $64.0 \mathrm{~m}$ & $671 \mathrm{~m}$ & $70.1 \mathrm{~m}$ \\
\hline & $.25 / 4 / 4^{a}$ & \multicolumn{10}{|c|}{ This Test Had No Valid Start Data } \\
\hline & Unitize $3 \mathrm{~s}$ & 14.9 & 26.6 & 31.0 & NR & NR & NR & NR & NR & NR & NR \\
\hline & Unitize $0.5 \mathrm{~s}$ & 10.2 & 18.7 & 18.7 & 28.7 & 28.7 & 61.0 & 61.3 & NR & NR & NR \\
\hline \multirow{4}{*}{$\begin{array}{c}\text { Test \#6b } \\
2.5 \mathrm{~m} \text { Diam. } \\
7.7 \mathrm{MW}\end{array}$} & 1.ocation & 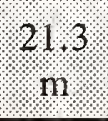 & .30 .5 & 66.6 & (12.7. & $4^{48.8}$ & n & 61.0 & 640 & 67 m & .70 .1 \\
\hline & $.25 / 2 / 3^{\mathrm{a}}$ & 12.7 & 18.1 & 20.8 & 30.4 & 33.6 & 34.6 & 40.1 & 38.7 & 41.3 & 45.5 \\
\hline & Unitize $3 \mathrm{~s}$ & 23.0 & 38.8 & 40.3 & 46.6 & NR & NR & NR & NR & NR & NR \\
\hline & $\begin{array}{c}\text { Unitize } \\
0.5 \mathrm{~s}\end{array}$ & 20.5 & 31.4 & 34.5 & 38.1 & 40.3 & 44.8 & 45.1 & 45.1 & NR & NR \\
\hline \multirow{4}{*}{$\begin{array}{l}\text { Test \#8 } \\
2.5 \mathrm{~m} \\
\text { Diam. }\end{array}$} & Location & 21.311 & 30.50 & $36,61 \%$ & 42.71 & $48.8 \mathrm{~m}$ & 54.91 & $61.0 \mathrm{~m}$ & $64.0 \mathrm{~m}$ & 6711 & 70.117 \\
\hline & $.25 / 4 / 4^{a}$ & 13.3 & 23.6 & 28.7 & 35.7 & 37.4 & 39.7 & 46.7 & NR & NR & NR \\
\hline & Unitize $3 \mathrm{~s}$ & 23.0 & 31.5 & 38.6 & 47.8 & 56.3 & NR & NR & NR & NR & NR \\
\hline & Unitize $0.5 \mathrm{~s}$ & 14.6 & 23.4 & 29.4 & 35.8 & 37.3 & 39.8 & 55.0 & NR & NR & NR \\
\hline
\end{tabular}

NR - No Response

a - Controller Based Detector Settings 
Table 34. Test conditions and response parameters for the line type heat detector used in $15 \mathrm{~m}$ high facility

\begin{tabular}{|c|c|c|c|c|c|c|}
\hline Test & $\begin{array}{c}\text { Pan Size } \\
\mathrm{m}\end{array}$ & $\begin{array}{c}\text { Fire Size } \\
\text { MW } \\
\pm 0.1\end{array}$ & $\begin{array}{c}\text { Max. Center } \\
\text { Thermocouple } \\
\text { Temperature } \\
{ }^{\circ} \mathrm{C}, \pm 2.0\end{array}$ & $\begin{array}{c}\text { Max. } \\
\text { Sensor } \\
\text { Reading } \\
{ }^{\circ} \mathrm{C}, \pm 3.0\end{array}$ & $\begin{array}{c}\text { Time to } \\
57^{\circ} \mathrm{C}(135 \\
\left.{ }^{\circ} \mathrm{F}\right) \\
\mathrm{s}, \pm 4\end{array}$ & $\begin{array}{c}\text { Time to } \\
79^{\circ} \mathrm{C} \\
\left(175{ }^{\circ} \mathrm{F}\right) \\
\mathrm{s}, \pm 4\end{array}$ \\
\hline 1 & $0.3 \times 0.3$ & .1 & 30 & 30 & $--^{\mathrm{a}}$ & $--^{\mathrm{a}}$ \\
\hline 2 & $0.6 \times 0.6$ & .5 & 43 & 41 & $--^{\mathrm{a}}$ & $-\mathrm{-}^{\mathrm{a}}$ \\
\hline 3 & $0.9 \times 0.9$ & 1.9 & 56 & 53 & $--^{\mathrm{a}}$ & $--^{\mathrm{a}}$ \\
\hline 4 & 1.5 dia. & 2.8 & 71 & 69 & 113 & $--^{\mathrm{a}}$ \\
\hline 5 & 2.0 dia. & 6.8 & 112 & 107 & 69 & 113 \\
\hline $6 \mathrm{~b}$ & 2.5 dia. & 7.7 & 150 & $\mathrm{n} / \mathrm{a}^{\mathrm{b}}$ & $\mathrm{n} / \mathrm{a}^{\mathrm{b}}$ & $\mathrm{n} / \mathrm{a}^{\mathrm{b}}$ \\
\hline 7 & 2.0 dia. & 6.8 & 105 & 89 & 71 & 364 \\
\hline 8 & 2.5 dia. & $\mathrm{n} / \mathrm{a}^{\mathrm{c}}$ & 157 & $\mathrm{n} / \mathrm{a}^{\mathrm{b}}$ & $\mathrm{n} / \mathrm{a}^{\mathrm{b}}$ & $\mathrm{n} / \mathrm{a}^{\mathrm{b}}$ \\
\hline 11 & $0.3 \times 0.3$ & .1 & 34 & 31 & $--^{\mathrm{a}}$ & $--^{\mathrm{a}}$ \\
\hline 12 & $0.6 \times 0.6$ & $\mathrm{n} / \mathrm{a}^{\mathrm{c}}$ & 44 & 36 & $-\mathrm{a}^{\mathrm{a}}$ & $-\mathbf{- a}^{\mathrm{a}}$ \\
\hline $13^{\mathrm{d}}$ & 2.0 dia. & $\mathrm{n} / \mathrm{a}^{\mathrm{c}}$ & 65 & 74 & 153 & $--^{\mathrm{a}}$ \\
\hline
\end{tabular}

${ }^{a}$ Did not reach temperature threshold specified.

b Not measured due to equipment malfunction.

${ }^{c}$ Heat release rate value not available.

${ }^{\mathrm{d}}$ Open door test. 


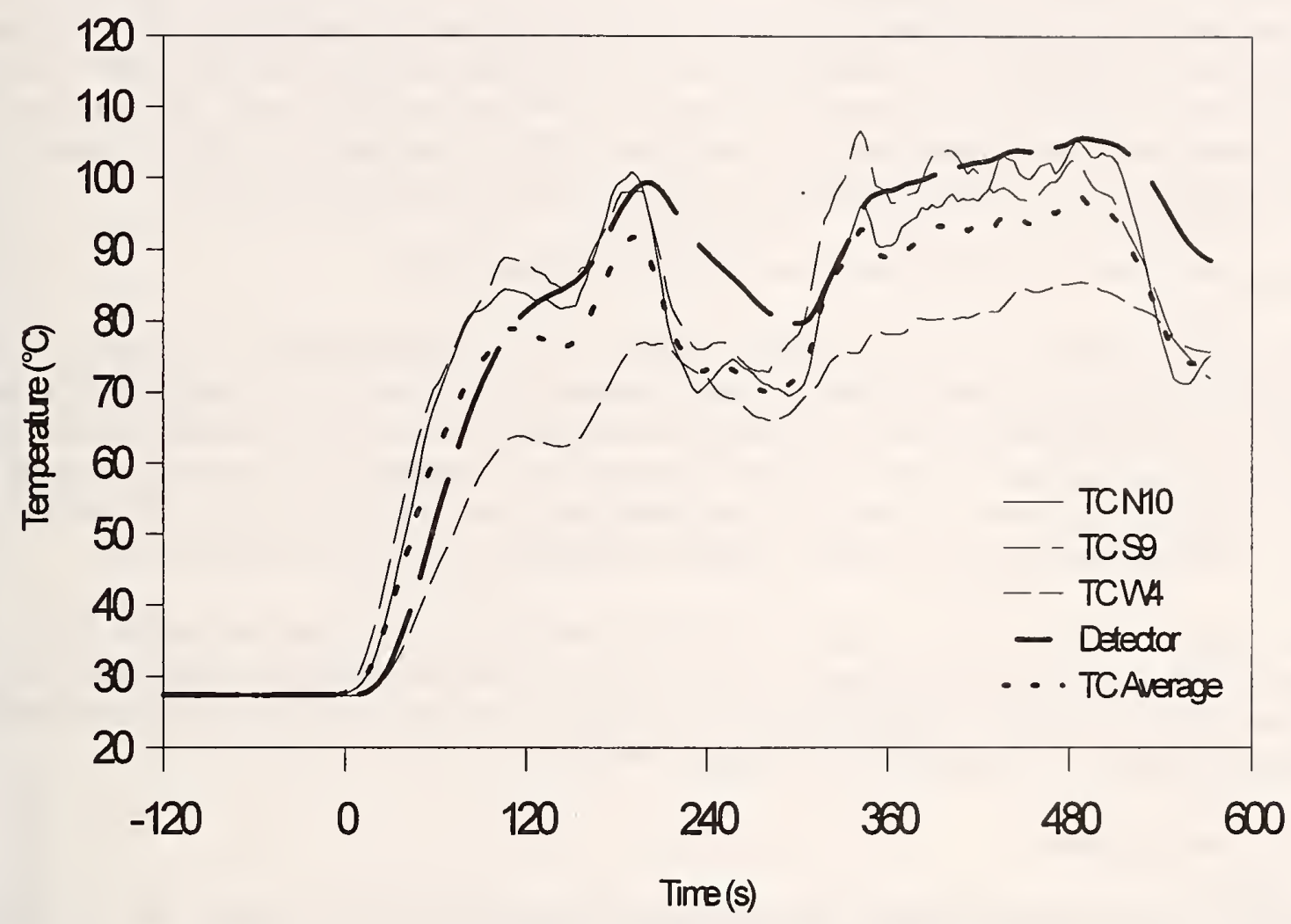

Figure 49. Temperature comparisons for thermocouples near linear heat detector for $2.0 \mathrm{~m}$ diameter test fire (test 5).

\section{Comparison of Line-Type Heat Detector and Spot-Type Detector Response Times}

Table 34 lists the fire sizes, maximum temperature at the center, maximum temperature of the linear heat sensor, and the time the sensor takes to reach $57^{\circ} \mathrm{C}\left(135^{\circ} \mathrm{F}\right)$ and $79^{\circ} \mathrm{C}\left(175^{\circ} \mathrm{F}\right)$. It is important to know the time necessary to reach these temperature thresholds so that a comparison to spot-type heat detectors and intermediate temperature range sprinklers can be made.

Table 34 shows that for the smaller fires that are less than $2 \mathrm{MW}$ the sensor never surpassed the threshold of $57{ }^{\circ} \mathrm{C}$. This threshold corresponds to the alarm point of the spot-type heat detectors used. However, in the tests with fires greater than $2 \mathrm{MW}$, the temperature exceeded $57^{\circ} \mathrm{C}$ between $69 \mathrm{~s}$ and $153 \mathrm{~s}$.

The first experiment where the temperature exceeded the $57{ }^{\circ} \mathrm{C}$ threshold was test 4 . Spot-type heat detectors at $3.0 \mathrm{~m}$ and $6.1 \mathrm{~m}$ east of center responded at $97 \mathrm{~s}$ and $184 \mathrm{~s}$ respectively. This is compared 
to the linear heat sensor which reached the $57^{\circ} \mathrm{C}$ level at $113 \mathrm{~s}$. The heat detectors that were directly above the sensor wire, at $3.0 \mathrm{~m}$ south and north, went into alarm at $197 \mathrm{~s}$ and $364 \mathrm{~s}$. The linear heat sensor in test 5 reached the $57^{\circ} \mathrm{C}$ threshold at $69 \mathrm{~s}$. Spot-type heat detectors located within a $6.1 \mathrm{~m}$ radial distance from the center, alarmed at $71 \mathrm{~s}$ to $100 \mathrm{~s}$. Without the draft curtain, the linear heat sensor reached the spot-type heat detector's alarm level in $89 \mathrm{~s}$. Once again, the spot-type heat detectors within the $6.1 \mathrm{~m}$ radius responded in a similar manner between $63 \mathrm{~s}$ and $138 \mathrm{~s}$.

\section{Comparison of Line-Type Heat Detector and Sprinkler Response Times}

The linear heat detector is also compared to the response of automatic sprinklers. In a iypical application, the linear heat detector may be used to activate a pre-action valve to supply water to the sprinklers. It is important to know if the detector can trip the valve before any sprinklers are activated. Table 34 indicates the time necessary to reach the activation temperature of the intermediate range sprinklers used in these tests. In test 5 , the linear heat sensor reached the $79^{\circ} \mathrm{C}\left(175^{\circ} \mathrm{F}\right)$ mark in $113 \mathrm{~s}$. The first quick response sprinkler, located at the center, did not activate until $179 \mathrm{~s}$.

In test 7 a $79{ }^{\circ} \mathrm{C}$ quick response sprinkler (C6) located above at the pan center activated at $312 \mathrm{~s}$. The linear heat sensor, located approximately $3.1 \mathrm{~m}$ out from the test centerline, did not reach the $79{ }^{\circ} \mathrm{C}$ level until nearly $50 \mathrm{~s}$ later. These results for tests 5 and 7, comparing linear heat detector response to sprinkler activation, are represented graphically in Figure 52.

\section{Effect of Draft Curtains}

The effect of the draft curtain can also be seen from the sensor data. For the smaller fires the effect is minor, but for fires greater than $2 \mathrm{MW}$ the draft curtain contains and concentrates the heat. Figure 52 compares tests 5 and 7 and illustrates this point. It can be seen that with the same size fire, the linear heat sensor in test 7 takes nearly $250 \mathrm{~s}$ longer to reach the $79^{\circ} \mathrm{C}$ level than in test 5 . 


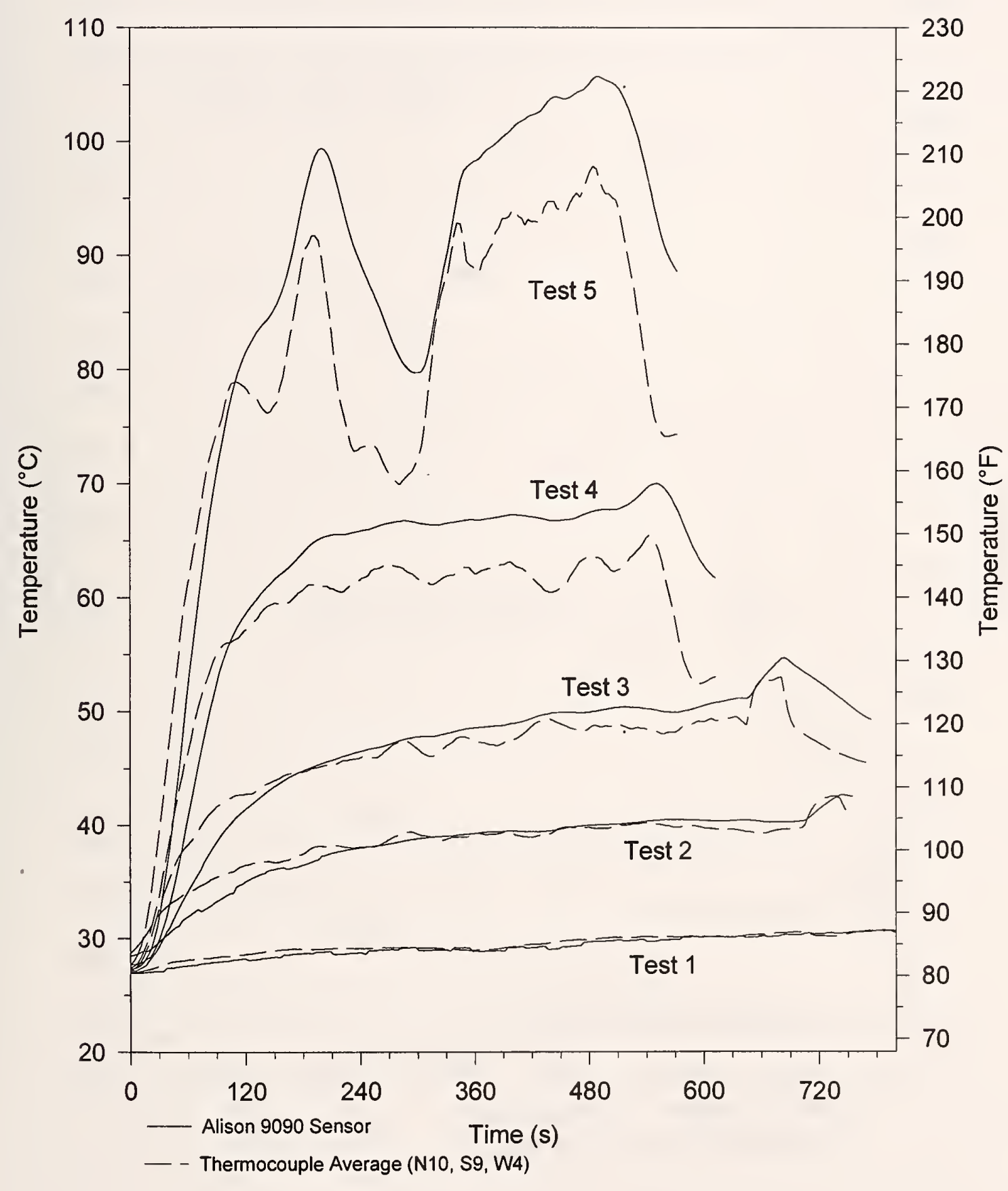

Figure 50. Line-type detector response for $15 \mathrm{~m}$ facility tests with draft curtains. 


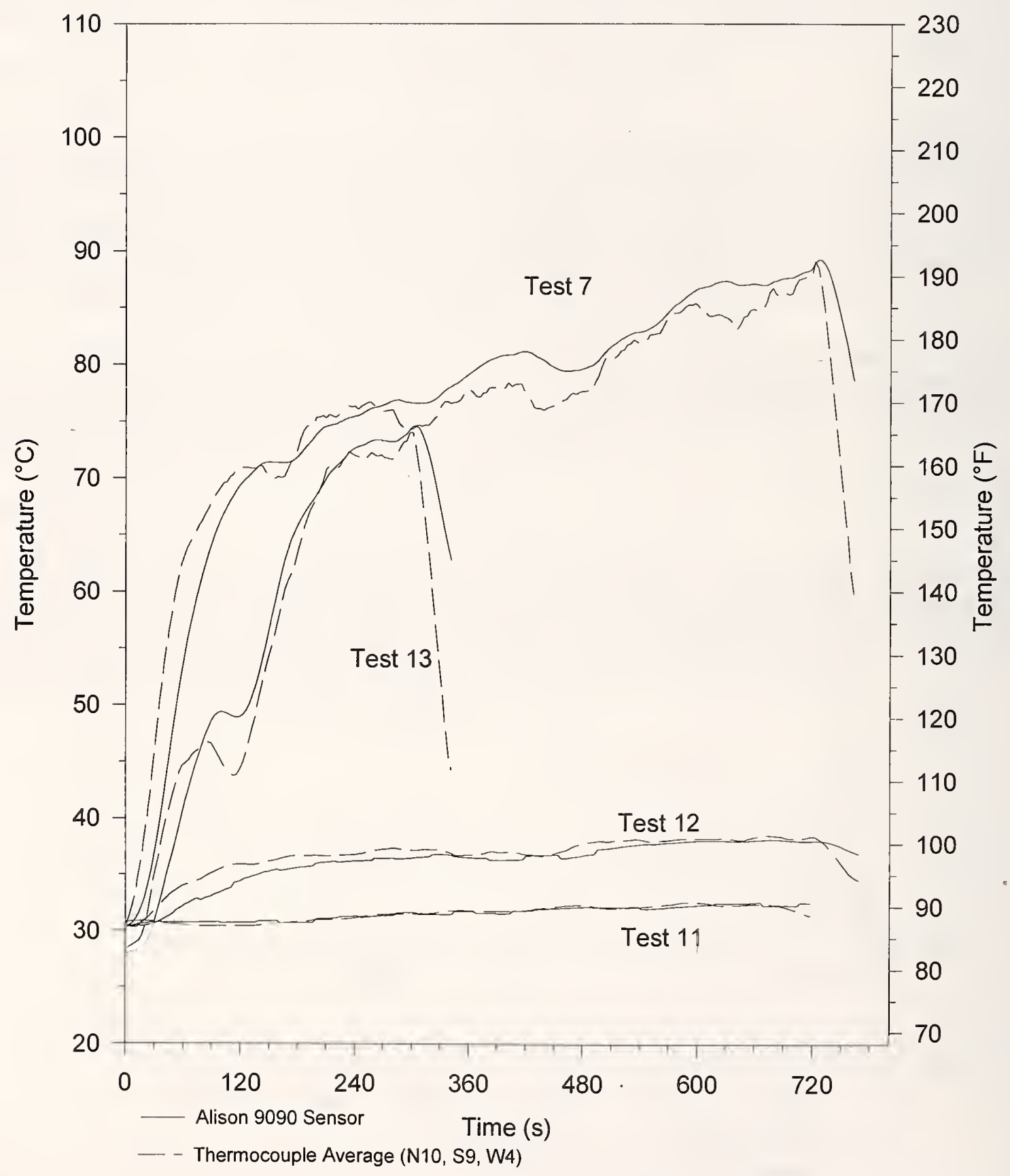

Figure 51. Line-type detector response for $15 \mathrm{~m}$ facility tests without draft curtains. 


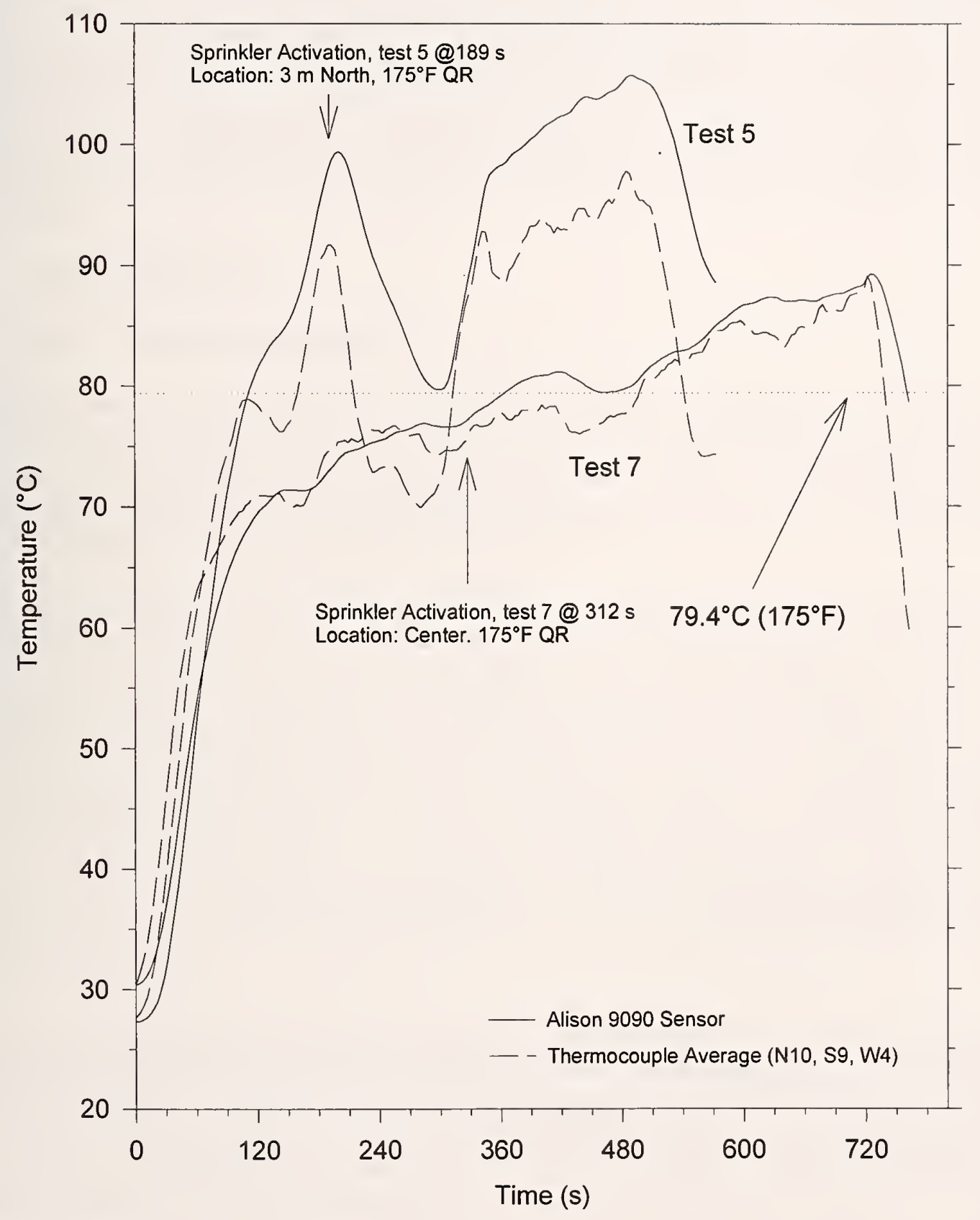

Figure 52. Line-type detector response for $2.0 \mathrm{~m}$ diameter pan fire (tests $5 \& 7$ ). 



\section{COLD CLIMATE EXPERIMENTS - 22 m HIGH FACILITY}

The behavior of a fire plume and the response of detection devices in a cold building may not be replicated well by the experiments held in the warm hangar in Hawaii. The Naval Air Station in Keflavik, Iceland, was chosen to conduct a second full-scale test program to check the significance of ambient temperature on the performance of the fire protection systems. This second series also permitted an evaluation of building geometry effects. Most significant are the increased ceiling height ( $22 \mathrm{~m}$ vs. $15 \mathrm{mi}$ ) and ceiling shape (barrel-shaped vs. flat) in the Iceland hangar. The building specifications, the installation of sprinkler heads and fire detection systems, the instruments used to monitor the fire behavior, and the results of $22 \mathrm{JP}-5$ and JP- 8 pool fire experiments are presented in this section.

\subsection{Experimental Set-up}

\subsubsection{Building Specifications}

The second series of full scale fire experiments were conducted in Hangar 831 at the Naval Air Station in Keflavik, Iceland. This building was built in 1957 and consists of one large hangar maintenance bay as well as adjoining industrial shops, offices and classrooms. A plan view of the hangar bay and fire area are shown in Figure 53. For the purpose of this section, all references to compass direction are made with respect to test north as shown in Figure 53.

The hangar bay dimensions are approximately $73.8 \mathrm{~m}(242 \mathrm{ft})$ in length and $45.7 \mathrm{~m}(150 \mathrm{ft})$ in width. The hangar roof is a curved (i.e., barrel-shaped) design with a ceiling height ranging from $12.2 \mathrm{~m} \mathrm{(40}$

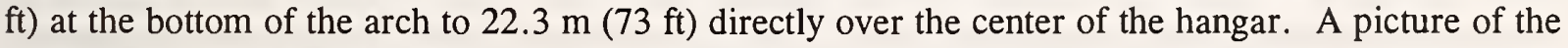
roof assembly is shown in Figure 54. The primary roof support consists of a series of steel trusses which form arches spanning the width of the hangar bay, running parallel to the hangar doors. These primary trusses are approximately $1.0 \mathrm{~m}(3.3 \mathrm{ft})$ deep and are spaced $7.4 \mathrm{~m}(24.3 \mathrm{ft})$ on center. The primary trusses are interconnected with a series of secondary trusses which are perpendicular to them and run the length of the hangar bay. The secondary trusses are spaced at intervals ranging from $5.8 \mathrm{~m}$ to $6.4 \mathrm{~m}$ ( $19 \mathrm{ft}$ to $21 \mathrm{ft}$ ) on center. The metal deck roof is directly attached to a series of steel beams which sit on top of the primary and secondary trusses. These steel beams are perpendicular to the

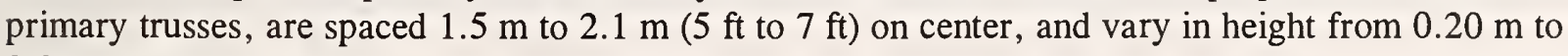
$0.30 \mathrm{~m}$ (8 in to $12 \mathrm{in})$.

The roof is insulated via a suspended tile ceiling which is supported by a conventional suspended tile ceiling grid located at the same elevation as the bottom of the steel beams (i.e., $0.20 \mathrm{~m}$ to $0.30 \mathrm{~m}$ below the metal deck). The individual ceiling tiles in the center bay (test) and the adjacent bay (south) were removed prior to testing. Corrugated steel draft curtains subdivide the ceiling into five equal bays approximately $14.8 \mathrm{~m}(48.6 \mathrm{ft})$ in width and $45.7 \mathrm{~m}(150 \mathrm{ft})$ in length. The draft curtains extend down

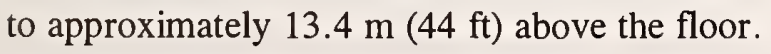

The east and west walls are a combination of concrete masonry units and gypsum board construction with numerous unprotected window and door openings into the hangar bay. The north and south ends of the hangar bay consist of metal and glass horizontal sliding hangar doors which are electrically 
operated. Figure 55 shows an elevation view of the hangar. Heat is furnished via geothermal hot water unit heaters with electric fan units.

The hangar bay is fully protected by open-head deluge sprinklers on a pipe scheduled system with a protection area per head of $7.8 \mathrm{~m}^{2}\left(84 \mathrm{ft}^{2}\right)$ The sprinklers are supplied by seven independent deluge valves which are activated by pneumatic heat actuated devices located at the ceiling. The existing sprinklers and heat detectors were shut off during each of the fire tests.

\subsubsection{Measurements - Fire Protection Devices}

A number of conventional fire detection and suppression devices were installed and monitored to determine their actual response characteristics when subject to the experimental fires. The fire suppression devices were all standard spray upright sprinklers with a variety of temperature ratings, actuation mechanisms, and response time indexes.

The fire detection devices consisted of photoelectric smoke detectors, fixed temperature heat detectors, projected beam smoke detectors, combination ultraviolet/infrared optical flame detectors and line-type heat detectors.

\subsubsection{Sprinkler Installations}

In the $22 \mathrm{~m}$ high facility, nine types of standard spray upright sprinklers with a variety of temperature ratings, fusible elements, and response time indexes were installed and monitored to measure the activation time of each sprinkler head when subject to a range of experimental fires. The sprinklers were configured in a similar manner to the $15 \mathrm{~m}$ high facility.

The fires were designed to determine the threshold fire size for response of each sprinkler type. Each type of sprinkler head was selected because of its existing use or potential use in high bay applications. NFPA 16A [2] and NFPA 409 [17] currently require that the temperature rating of sprinklers in hangars be within the high $\left(79^{\circ} \mathrm{C}\right.$ to $\left.107^{\circ} \mathrm{C}\right)$ or extra high $\left(163^{\circ} \mathrm{C}\right.$ to $\left.191{ }^{\circ} \mathrm{C}\right)$ temperature range as defined by NFPA 13 [18]. Current Navy criteria requires the use of sprinklers with a temperature rating of $141{ }^{\circ} \mathrm{C}$ [19]. Since ambient air temperatures at the ceiling level of aircraft hangars can exceed $38^{\circ} \mathrm{C}\left(100^{\circ} \mathrm{F}\right)$, the lowest temperature sprinkler that could be reasonably installed in an aircraft hangar is a $79^{\circ} \mathrm{C}$ sprinkler which corresponds to the low end of the intermediate temperature range. The nine types of sprinkler heads installed are shown in Table 35.

Figure 56 shows the location of each of the 15 sprinkler trees. Included in the figure are the combinations of sprinkler types installed at each location. Each location contained a $141^{\circ} \mathrm{C}$ quick response bulb and $79^{\circ} \mathrm{C}$ quick response bulb. The $141^{\circ} \mathrm{C}$ head satisfies current Navy criteria and the $79^{\circ} \mathrm{C}$ head would provide the first sprinkler response. In addition, the sprinkler stations within $6.1 \mathrm{~m}$ of the plume also contained a $141^{\circ} \mathrm{C}$ standard response bulb and a $141{ }^{\circ} \mathrm{C}$ standard response link to provide a point of comparison. Also, located within $3.1 \mathrm{~m}$ of the plume center, were a $141^{\circ} \mathrm{C}$ quick response bulb and a $79^{\circ} \mathrm{C}$ quick response bulb in a dry-pipe configuration. The sprinkler station located at the plume center contained a $79{ }^{\circ} \mathrm{C}$ standard bulb and a $182{ }^{\circ} \mathrm{C}$ standard bulb. The $182{ }^{\circ} \mathrm{C}$ head was provided because NFPA 409 requires it for some hangars. All sprinkler heads and piping assemblies used for the full scale tests were supplied by Viking Corporation. The sprinkler stations were again located at the ceiling above the center of the fire test area and spaced at $3.1 \mathrm{~m} \mathrm{(10} \mathrm{ft)}$ 
Table 35. Specifications for automatic sprinklers installed in $22 \mathrm{~m}$ high test facility

\begin{tabular}{|c|c|c|c|c|}
\hline $\begin{array}{c}\text { Activation } \\
\text { Temperature } \\
{ }^{\circ} \mathrm{C}\end{array}$ & $\begin{array}{c}\text { Activation } \\
\text { Temperature } \\
{ }^{\circ} \mathrm{F}\end{array}$ & Description & $\begin{array}{c}\text { Response Time } \\
\text { Index (RTI) } \\
\mathrm{m} \cdot \mathrm{s}^{1 / 2}\end{array}$ & $\begin{array}{c}\text { Piping } \\
\text { Configuration }\end{array}$ \\
\hline 141 & 286 & Quick Response Bulb & 35 & wet \\
\hline 79 & 175 & Quick Response Bulb & 35 & wet \\
\hline 141 & 286 & Standard Response Bulb & 188 & wet \\
\hline 141 & 286 & Standard Response Link & 95 & wet \\
\hline 141 & 286 & Quick Response Bulb & 35 & dry \\
\hline 79 & 175 & Quick Response Bulb & 35 & dry \\
\hline 93 & 200 & Quick Response Bulb & 35 & wet \\
\hline 79 & 175 & Standard Response Bulb & 188 & wet \\
\hline 182 & 360 & Standard Response Bulb & 188 & wet \\
\hline
\end{tabular}

intervals in four perpendicular directions, to simulate the spacing between sprinklers in a typical hangar installation. Since the roof was curved in the north and south directions relative to the hangar, the piping was installed parallel to the curved portion to allow the sprinkler heads at each station to be a similar distance from the ceiling. Once again, a licensed sprinkler contractor installed the water mains and riser nipples conforming to NFPA 13 specifications. The sprinkler main for the curved section of the ceiling was fabricated using $3.1 \mathrm{~m}(10 \mathrm{ft})$ sections of Schedule $40,38.1 \mathrm{~mm}$ (1.5 in) pipe coupled with two $90^{\circ}$ elbows and a tee. The $90^{\circ}$ elbows would allow each section of the branch main to be parallel with the curved roof. The east and west cross main were installed in a normal fashion. Valves and fill/drain lines were installed on each end of the branch that ran in the north and south direction. Filling and draining the branch and cross mains was performed from the floor of the hangar. Similar to the $15 \mathrm{~m}$ high facility, sprinklers were mounted at $0.20 \mathrm{~m}(8 \mathrm{in}$.) intervals on cross trees, with a valve and union installed for purging air and filling the lines with water.

The sprinkler deflectors were installed between $0.30 \mathrm{~m}$ to $0.61 \mathrm{~m}$ below the ceiling deck as indicated in Table 36. NFPA 13 also states that under obstructed construction, the sprinkler deflector shall be located $0.25 \mathrm{~m}$ to $0.15 \mathrm{~m}$ ( 1 in. to 6 in.) below the structural members and a maximum distance of 0.56 $\mathrm{m}$ (22 in.) below the ceiling/roof deck [18]. Ball valves were installed on each riser nipple to isolate each sprinkler tree in order to prevent head pressure effects from sprinkler assemblies at higher elevations, and to make the filling process more efficient. Each sprinkler tree included a vent port to relieve pressure, and purge trapped air from the line.

The time to activation for each sprinkler head was measured and recorded. The data collection rate for the sprinkler activation time measurement was approximately $0.25 \mathrm{~Hz}$. Provided the clip/wire assembly activated freely, the time of activation was measured within $4 \mathrm{~s}$ to $8 \mathrm{~s}$ after actual activation. Each sprinkler head was visually inspected between tests to determine if any activations occurred that were not recorded by the data acquisition system. All sprinkler heads that activated were replaced between tests. Any sprinkler head that did not activate during the previous tests was inspected and 
Table 36 Automatic sprinkler deflector location and distance below ceiling as installed in $22 \mathrm{~m}$ high test facility

\begin{tabular}{|c|c|c|}
\hline $\begin{array}{c}\text { Sprinkler Station Number } \\
\text { (as shown in Figure 56) }\end{array}$ & $\begin{array}{c}\text { Location, Relative to } \\
\text { Plume Center }\end{array}$ & $\begin{array}{c}\text { Deflector Distance From Ceiling } \\
\mathrm{m}\end{array}$ \\
\hline C & Center & 0.61 \\
N1 & $3.0 \mathrm{~m}$ North & 0.36 \\
N2 & $6.1 \mathrm{~m}$ North & 0.43 \\
S1 & $3.0 \mathrm{~m}$ South & 0.38 \\
S2 & $6.1 \mathrm{~m}$ South & 0.30 \\
W1 & $3.0 \mathrm{~m}$ West & 0.56 \\
W2 & $6.1 \mathrm{~m}$ West & 0.46 \\
W3 & $9.1 \mathrm{~m}$ West & 0.56 \\
W4 & $12.2 \mathrm{~m}$ West & 0.56 \\
W5 & $15.2 \mathrm{~m}$ West & 0.56 \\
E1 & $3.0 \mathrm{~m}$ East & 0.61 \\
E2 & $6.1 \mathrm{~m}$ East & 0.61 \\
E3 & $9.1 \mathrm{~m}$ East & 0.61 \\
E4 & $12.2 \mathrm{~m}$ East & 0.46 \\
E5 & $15.2 \mathrm{~m}$ East & 0.61 \\
\hline
\end{tabular}




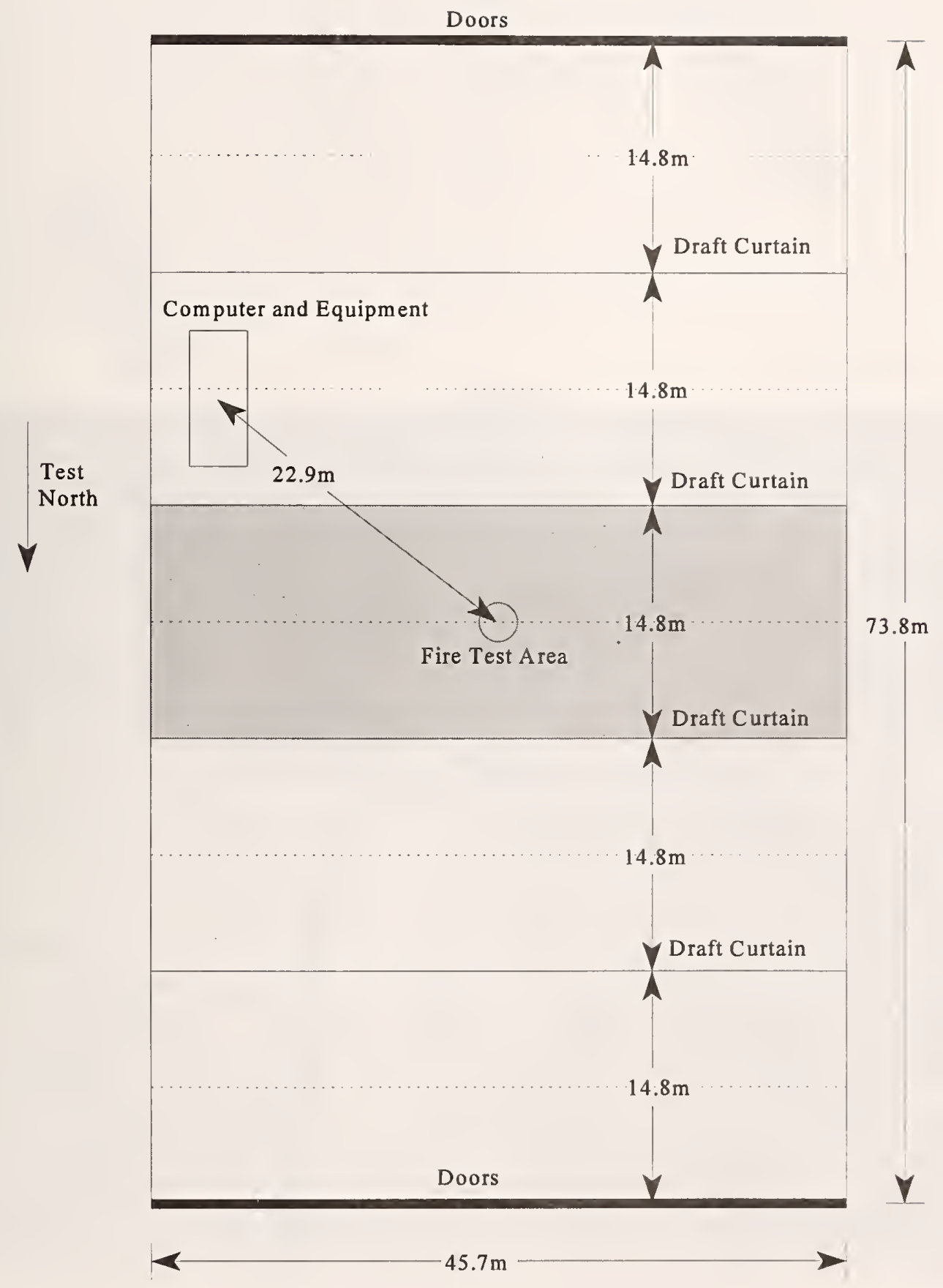

Figure 53. Plan view of hangar bay, $22 \mathrm{~m}$ high facility. 


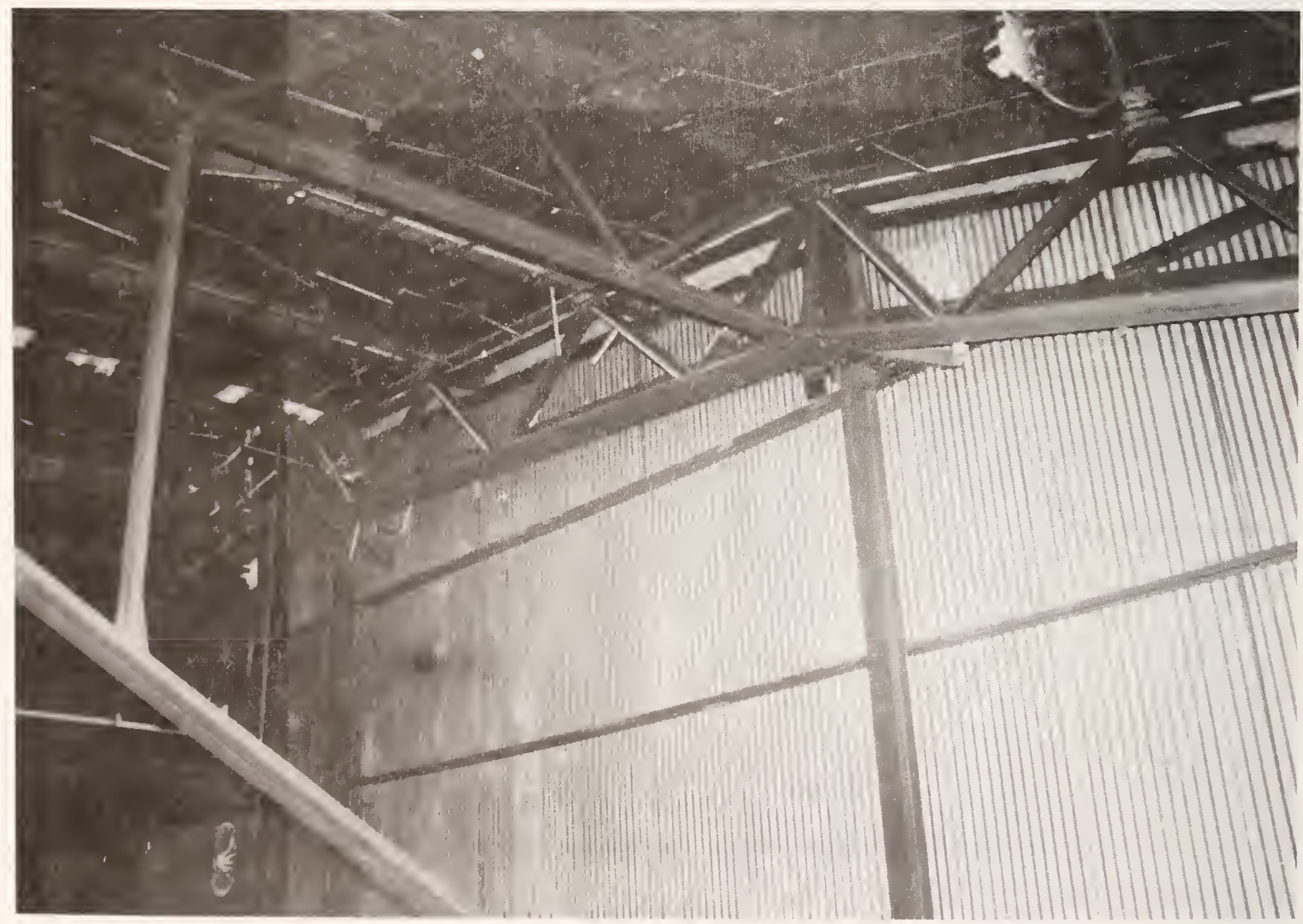

Figure 54. Photograph of ceiling structure, $22 \mathrm{~m}$ high facility. 

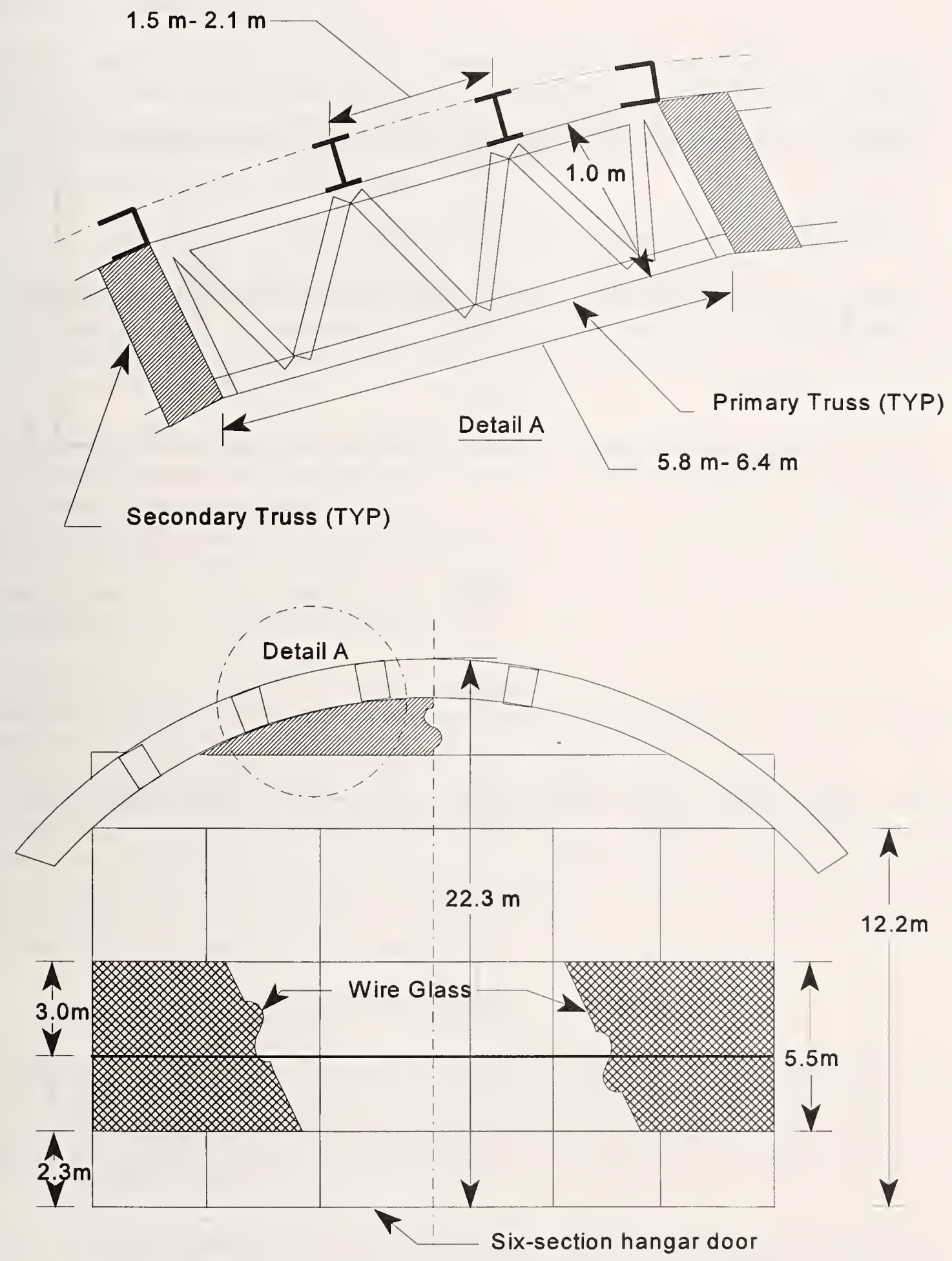

Figure 55. Detail of truss structure and elevation view of $22 \mathrm{~m}$ high facility. 

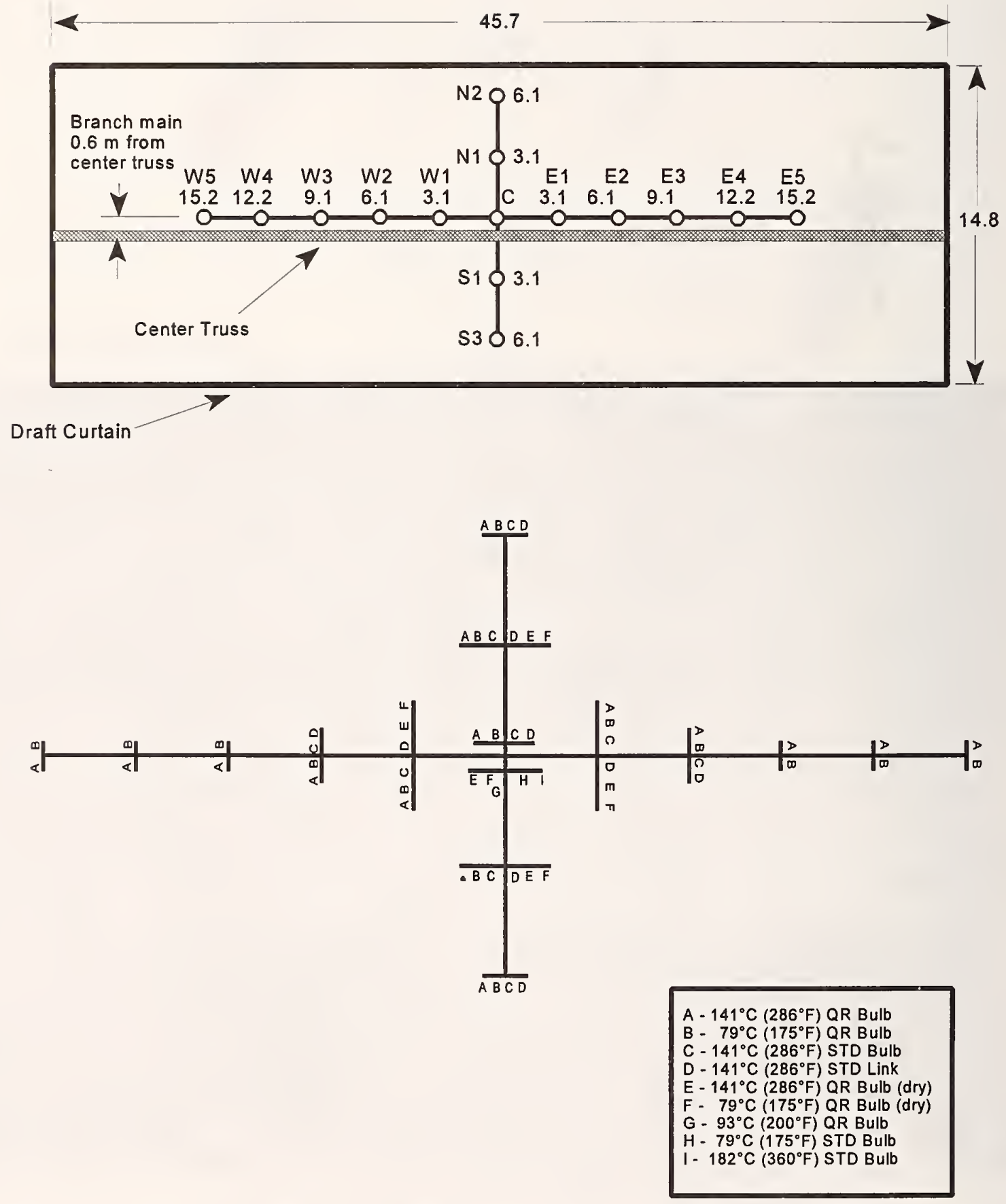

All Dimensions in Meters

Figure 56. Individual sprinkler locations within test area, $22 \mathrm{~m}$ high facility. 
cleaned prior to the next test fire.

All sprinkler heads and piping assemblies were supplied and installed by the Viking Corporation on behalf of the automatic sprinkler industry. NIST was responsible for the data collection and the installation of the wiring used to monitor the activation of the sprinkler heads. In cases where the activation of a sprinkler head was not recorded by the data collection system, representatives from Viking Corporation reported any activations to NIST.

\subsubsection{Smoke and Heat Detector Installations}

The instrumentation used in these experiments included photoelectric smoke detectors and two types of electronic heat detectors. The photoelectric smoke detectors and analog addressable heat detectors were the same type of detectors used in the $15 \mathrm{~m}$ experiments. The rationale for their spacing and use, as well as their wiring configuration and operating principles were defined in section 3 .

The instrumentation for the $22 \mathrm{~m}$ high test facility included conventional hard-wired heat detectors connected to the signaling line circuit through signaling line circuit interface devices. These detectors use a thermistor-type sensing element with an alarm threshold of $93.3^{\circ} \mathrm{C}\left(200^{\circ} \mathrm{F}\right)$. This detector type employs a comparator circuit which compares the resistance in the thermistor to a reference resistor. When the difference between the thermistor and the reference resistor reaches a predetermined level, the detector goes into alarm and sends an alarm signal to the fire alarm control panel [J03]. Data were collected through the Simplex fire alarm control panel at a scan rate of $0.1 \mathrm{~s}$.

There were 18 detector stations each consisting of a smoke detector, two heat detectors and one signaling line interface device mounted to two plywood boards. The plywood boards were attached to the suspended acoustical tile ceiling grid which was the same approximate elevation as the sprinkler deflectors. This distance ranged from $0.3 \mathrm{~m}$ (12 in) to $0.6 \mathrm{~m}$ (24 in) below the ceiling deck. The acoustic ceiling tiles themselves were removed. The location of the detector stations with respect to the fire plume center is shown in Figure 57. The detectors were only installed along the north/south and east/west axes with respect to the center line of the fire plume. In addition, one detector station was located outside of the north and south draft curtains at a distance of $9.14 \mathrm{~m} \mathrm{(30} \mathrm{ft)} \mathrm{from} \mathrm{plume} \mathrm{center.}$ Installation, calibration and test data from the smoke and heat detectors were provided by Simplex Time Recorder Co., on behalf of the detector industry.

\subsubsection{Projected Beam Smoke Detector Installations}

The operating principle, sensitivity settings, and control features of the projected beam smoke detectors were described previously. Based on the beam detector performance in the $15 \mathrm{~m}$ high facility experiments, the window settings for the beam detectors in the $22 \mathrm{~m}$ hangar were all set at 5 seconds. Sensitivity was either $20 \%$ or $30 \%$ as shown in Table 37 . These settings remained constant for each of the experiments.

Because the $22 \mathrm{~m}$ high facility has a domed ceiling whose slope exceeds 0.125 , it is classified as a sloping-peaked typed ceiling as defined in NFPA 72. The concept for smoke detector placement and spacing in buildings with sloped ceilings is derived from the location and spacing criteria developed for heat detectors. NFPA 72 offers little guidance on the orientation of projected beam smoke detectors

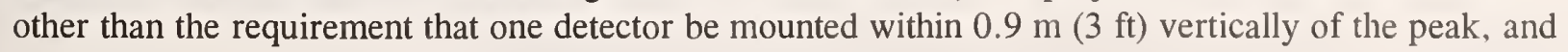




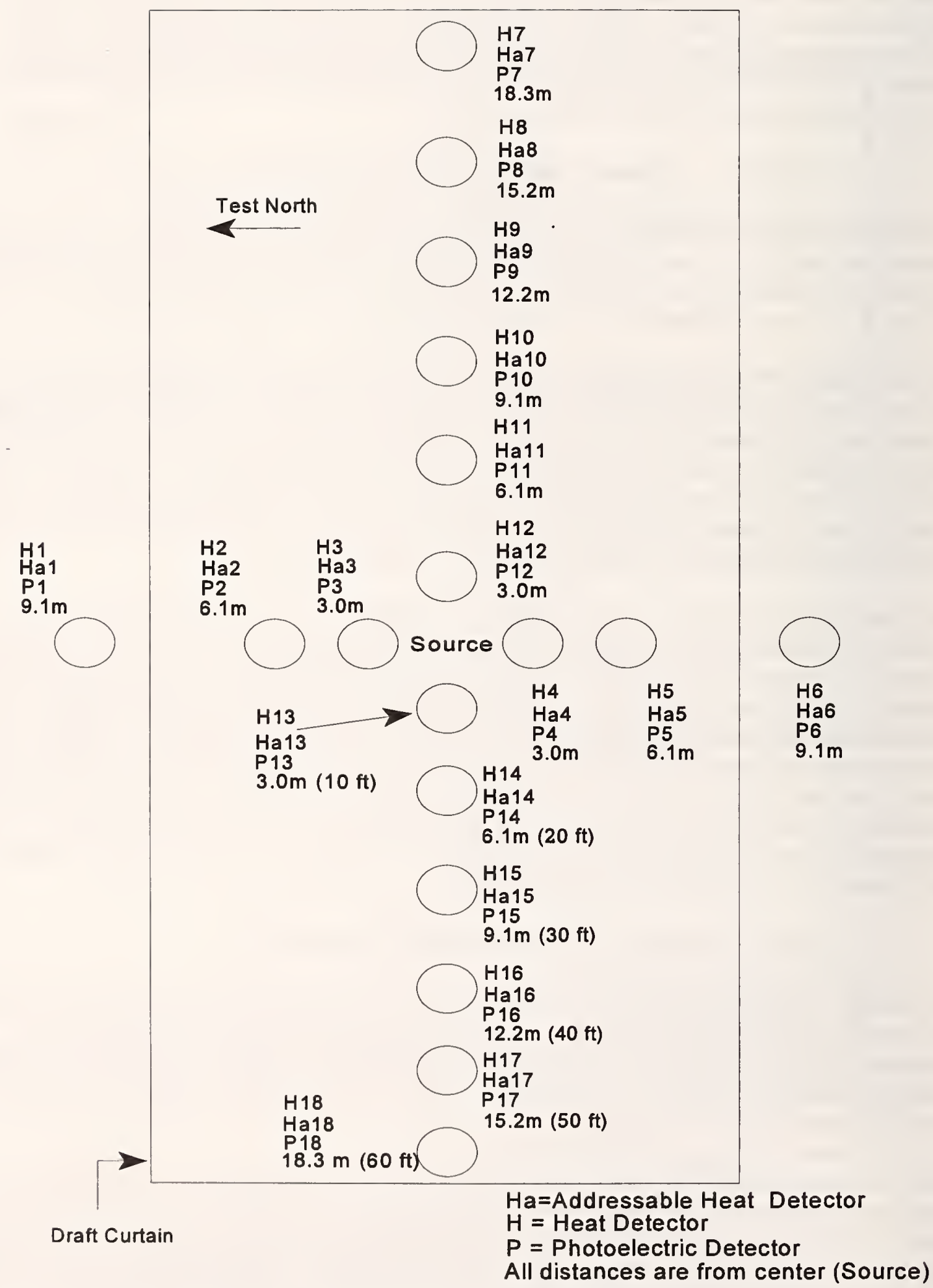

Figure 57. Plan view of smoke and heat detectors, $22 \mathrm{~m}$ high facility. 
that adjacent detectors be installed within their listed spacing. Due to obstructions in the ceiling created by the steel trusses, a detector could not be located within $0.9 \mathrm{~m}$ of the top of the arch. Instead, this

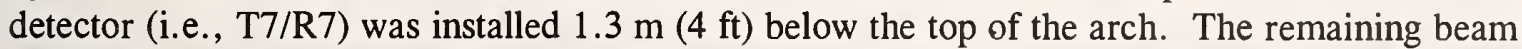
detectors were installed with their beams running parallel to the draft curtains in order to achieve a greater separation distance between the transmitters and receivers.

A total of seven projected beam smoke detectors were installed in the $22 \mathrm{~m}$ facility as shown in Figure 59. Detectors were installed at four elevations, $1.3 \mathrm{~m}(4.3 \mathrm{ft}), 1.9 \mathrm{~m}(6.2 \mathrm{ft}), 4.2 \mathrm{~m}(13.8 \mathrm{ft})$, and $10.9 \mathrm{~m}(35.8 \mathrm{ft})$ below the peak of the arched ceiling. One detector (T7/R7) was mounted at the $1.3 \mathrm{~m}$ elevation with its beam aimed perpendicular to the draft curtains. The distance between this transmitter and receiver was $13.6 \mathrm{~m}(44.6 \mathrm{ft})$.

Two detectors were mounted at each of the other three elevations with their beams aimed parallel to the draft curtains. The distance between the transmitters and receivers were $18.8 \mathrm{~m}(61.7 \mathrm{ft})$ at the $1.9 \mathrm{~m}$

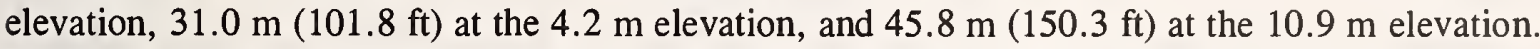
These six detectors were each spaced $2.1 \mathrm{~m}$ from the edge of the draft curtain, and $10.6 \mathrm{~m}$ apart.

Installation, calibration, and test data were provided to NIST by Detection Systems Inc., on behalf of the smoke detector industry. The detectors were hard-wired to the direct zones on the Simplex fire alarm control panel, and wired in the Class B, Style B configuration as defined by NFPA 72. In addition, the auxiliary alarm contacts on each detector were also connected to the data acquisition system which Detection Systems Inc. provided. Data were collected through the Simplex fire alarm control panel at a scan rate of $0.1 \mathrm{~s}$.

\subsubsection{Combination UV/IR Optical Flame Detectors}

Ten controller-based combination ultraviolet/infrared (UV/IR) optical flame detectors were installed and monitored during each experiment. A description of these detectors including general theory of operation can be found in section 3. The ten UV/IR detectors were mounted on portable stands which were located radially out from the fire. Each UV/IR detector was installed at a mounting height of 2.4 $\mathrm{m}(8 \mathrm{ft})$ above the floor. The detectors were placed to provide a direct line of sight to the fire. Distances from the detectors to the fire were measured along this line of sight as shown in Figure 59, which is an example of the detector layout for the two larger detector fires and the sprinkler fires.

Detector locations varied with the fire pan size; however, for all 22 tests conducted there were detectors placed at distances of $21.3 \mathrm{~m}, 30.5 \mathrm{~m}$, and $45.7 \mathrm{~m}$ from the fire. The distance from the center of the pan to the furthest wall was $45.7 \mathrm{~m}$. Locations for each detector for all 22 tests are shown in Table 38. All distances were measured along the floor from the detector to the center of the pan. For the $0.3 \mathrm{~m} \mathrm{x} 0.3 \mathrm{~m}$ square pan fires, additional detectors were placed at $1.52 \mathrm{~m}$ intervals from $9.1 \mathrm{~m}$ to $18.3 \mathrm{~m}$. For the $0.6 \mathrm{~m} \mathrm{x} 0.6 \mathrm{~m}$ square pan fires, additional detectors were placed at $1.52 \mathrm{~m}$ intervals from $22.9 \mathrm{~m}$ to $27.4 \mathrm{~m}$, and at $3.05 \mathrm{~m}$ intervals from $33.5 \mathrm{~m}$ to $39.6 \mathrm{~m}$. For the sprinkler fires (i.e., the $2.0 \mathrm{~m}$ and $2.5 \mathrm{~m}$ diameter pans and the $3.0 \mathrm{~m} \mathrm{x} 3.0 \mathrm{~m}, 4.6 \mathrm{~m} \mathrm{x} 4.6 \mathrm{~m}$ square pan fires), additional detectors were placed at $1.52 \mathrm{~m}$ intervals from $24.4 \mathrm{~m}$ through $27.4 \mathrm{~m}$ and at $3.05 \mathrm{~m}$ intervals from $33.5 \mathrm{~m}$ to $42.7 \mathrm{~m}$. The two sensitivity settings chosen for the experimental fires were $0.25 \mathrm{~s}$ gate length, 2 counts per gate and 3 consecutive gates; and $0.25 \mathrm{~s}$ gate length, 4 counts per gate and 4 consecutive gates (Table 39). Each UV/IR detector was scanned at a rate of $10 \mathrm{~Hz}$. 
Table 37. Sensitivity and window settings for projected beam smoke detectors installed in $22 \mathrm{~m}$ high facility

\begin{tabular}{|c|c|c|c|}
\hline $\begin{array}{c}\text { Projected } \\
\text { Beam } \\
\text { Number }\end{array}$ & Receiver/Transmitter Pair & $\begin{array}{c}\text { Sensitivity } \\
\text { \% signal loss }\end{array}$ & $\begin{array}{c}\text { Window Settings }^{*} \\
\text { s }\end{array}$ \\
\hline B1 & R1/T1 & 20 & 5 \\
B2 & R2/T2 & 20 & 5 \\
B3 & R3/T3 & 30 & 5 \\
B4 & R4/T4 & 30 & 5 \\
B5 & R5/T5 & 30 & 5 \\
B6 & R6/T6 & 30 & 5 \\
B7 & R7/T7 & 20 & 5 \\
\hline
\end{tabular}

* Sensitivity and window settings remained the same for all experiments. 


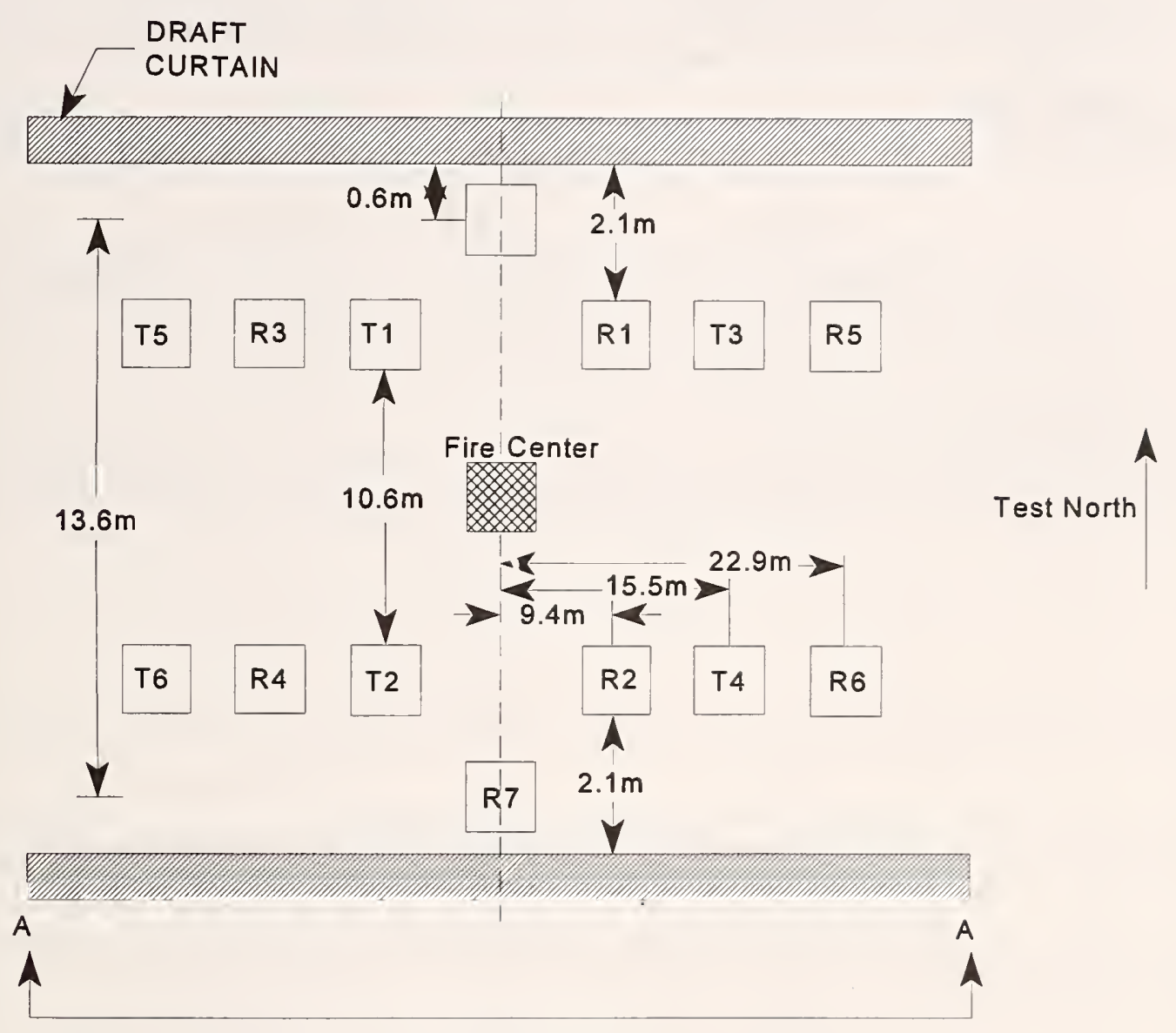

PLAN VIEW (a)

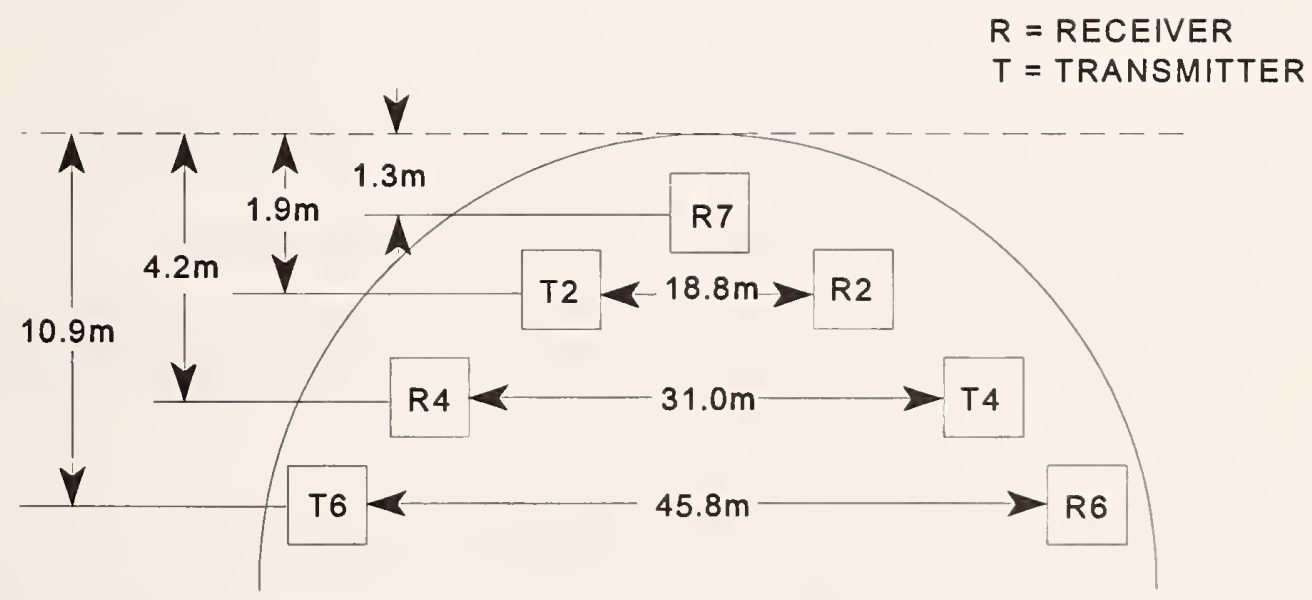

A

A

ELEVATION (b)

Figure 58. Plan and elevation views of projected beam detector locations, $22 \mathrm{~m}$ high facility. 
Table 38. Distances of UVIR detectors (m) from fire center in $22 \mathrm{~m}$ high facility

\begin{tabular}{|c|c|c|c|c|c|c|c|c|c|c|}
\hline Pan Size (m) & \multicolumn{10}{|c|}{ Detector Number } \\
\hline Detector Fires & $\mathbf{1}$ & $\mathbf{2}$ & $\mathbf{3}$ & $\mathbf{4}$ & $\mathbf{5}$ & $\mathbf{6}$ & $\mathbf{7}$ & $\mathbf{8}$ & $\mathbf{9}$ & $\mathbf{1 0}$ \\
\hline \hline $0.3 \times 0.3$ & 9.1 & 10.7 & 12.2 & 13.7 & 15.2 & 16.8 & 18.3 & 21.3 & 30.5 & 45.7 \\
$0.6 \times 0.6$ & 22.9 & 24.4 & 25.9 & 27.4 & 33.5 & 36.6 & 39.6 & 21.3 & 30.5 & 45.7 \\
$0.9 \times 0.9$, & 42.7 & 24.4 & 25.9 & 27.4 & 33.5 & 36.6 & 39.6 & 21.3 & 30.5 & 45.7 \\
$1.2 \times 1.2$ & & & & & & & & & & \\
\hline Sprinkler Fires & $\mathbf{1}$ & $\mathbf{2}$ & $\mathbf{3}$ & $\mathbf{4}$ & $\mathbf{5}$ & $\mathbf{6}$ & $\mathbf{7}$ & $\mathbf{8}$ & $\mathbf{9}$ & $\mathbf{1 0}$ \\
\hline \hline $\begin{array}{c}2.0,2.5 \text { dia. } \\
3.0 \times 3.0,4.6 \times 4.6\end{array}$ & 42.7 & 24.4 & 25.9 & 27.4 & 33.5 & 36.6 & 39.6 & 21.3 & 30.5 & 45.7 \\
\hline
\end{tabular}


Table 39. Controller settings for UV/IR detectors used in $22 \mathrm{~m}$ high facility

\begin{tabular}{|c|c|c|c|c|}
\hline \multirow[t]{2}{*}{ Test Number } & \multirow{2}{*}{$\begin{array}{l}\text { Description } \\
\text { (Pan Size) }\end{array}$} & \multicolumn{3}{|c|}{ Controller Settings } \\
\hline & & Gate Length (s) & Counts per Gate & $\begin{array}{c}\text { Consecutive } \\
\text { Gates }\end{array}$ \\
\hline 1 & $0.3 \mathrm{~m} \times 0.3 \mathrm{~m}$ & 0.25 & 2 & 3 \\
\hline 2 & $0.3 \mathrm{~m} \times 0.3 \mathrm{~m}$ & 0.25 & 2 & 3 \\
\hline 3 & $0.6 \mathrm{~m} \times 0.6 \mathrm{~m}$ & 0.25 & 2 & 3 \\
\hline 4 & $0.6 \mathrm{~m} \times 0.6 \mathrm{~m}$ & 0.25 & 2 & 3 \\
\hline 5 & $0.9 \mathrm{~m} \times 0.9 \mathrm{~m}$ & 0.25 & 2 & 3 \\
\hline 6 & $0.9 \mathrm{~m} \times 0.9 \mathrm{~m}$ & 0.25 & 4 & 4 \\
\hline 7 & $1.2 \mathrm{mx} 1.2 \mathrm{~m}$ & 0.25 & 4 & 4 \\
\hline $8^{a}$ & $1.2 \mathrm{~m} \mathrm{x} 1.2 \mathrm{~m}$ & 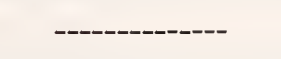 & --------- & ------ \\
\hline 9 & $0.3 \mathrm{~m} \times 0.3 \mathrm{~m}$ & 0.25 & 4 & 4 \\
\hline 10 & $0.6 \mathrm{~m} \mathrm{x} 0.6 \mathrm{~m}$ & 0.25 & 2 & 3 \\
\hline 11 & $0.6 \mathrm{~m} \times 0.6 \mathrm{~m}$ & 0.25 & 2 & 3 \\
\hline 12 & $0.9 \mathrm{~m} \times 0.9 \mathrm{~m}$ & 0.25 & 2 & 3 \\
\hline 13 & $1.2 \mathrm{~m} \mathrm{x} 1.2 \mathrm{~m}$ & 0.25 & 4 & 4 \\
\hline 14 & $2.5 \mathrm{~m} \mathrm{Diameter}$ & 0.25 & 4 & 4 \\
\hline 15 & $3.0 \mathrm{~m} \times 3.0 \mathrm{~m}$ & 0.25 & 4 & 4 \\
\hline 16 & $2.5 \mathrm{~m}$ Diameter & 0.25 & 4 & 4 \\
\hline 17 & $3.0 \mathrm{~m} \times 3.0 \mathrm{~m}$ & 0.25 & 4 & 4 \\
\hline 18 & $2.0 \mathrm{~m}$ Diameter & 0.25 & 4 & 4 \\
\hline 19 & $2.5 \mathrm{~m}$ Diameter & 0.25 & 4 & 4 \\
\hline 20 & $3.0 \mathrm{~m} \times 3.0 \mathrm{~m}$ & 0.25 & 4 & 4 \\
\hline 21 & $4.6 \mathrm{~m} \mathrm{x} 4.6 \mathrm{~m}$ & 0.25 & 4 & 4 \\
\hline 22 & $4.6 \mathrm{~m} \mathrm{x} 4.6 \mathrm{~m}$ & 0.25 & 4 & 4 \\
\hline
\end{tabular}

${ }^{a}$ UV/IR data was not collected for test 8 . 


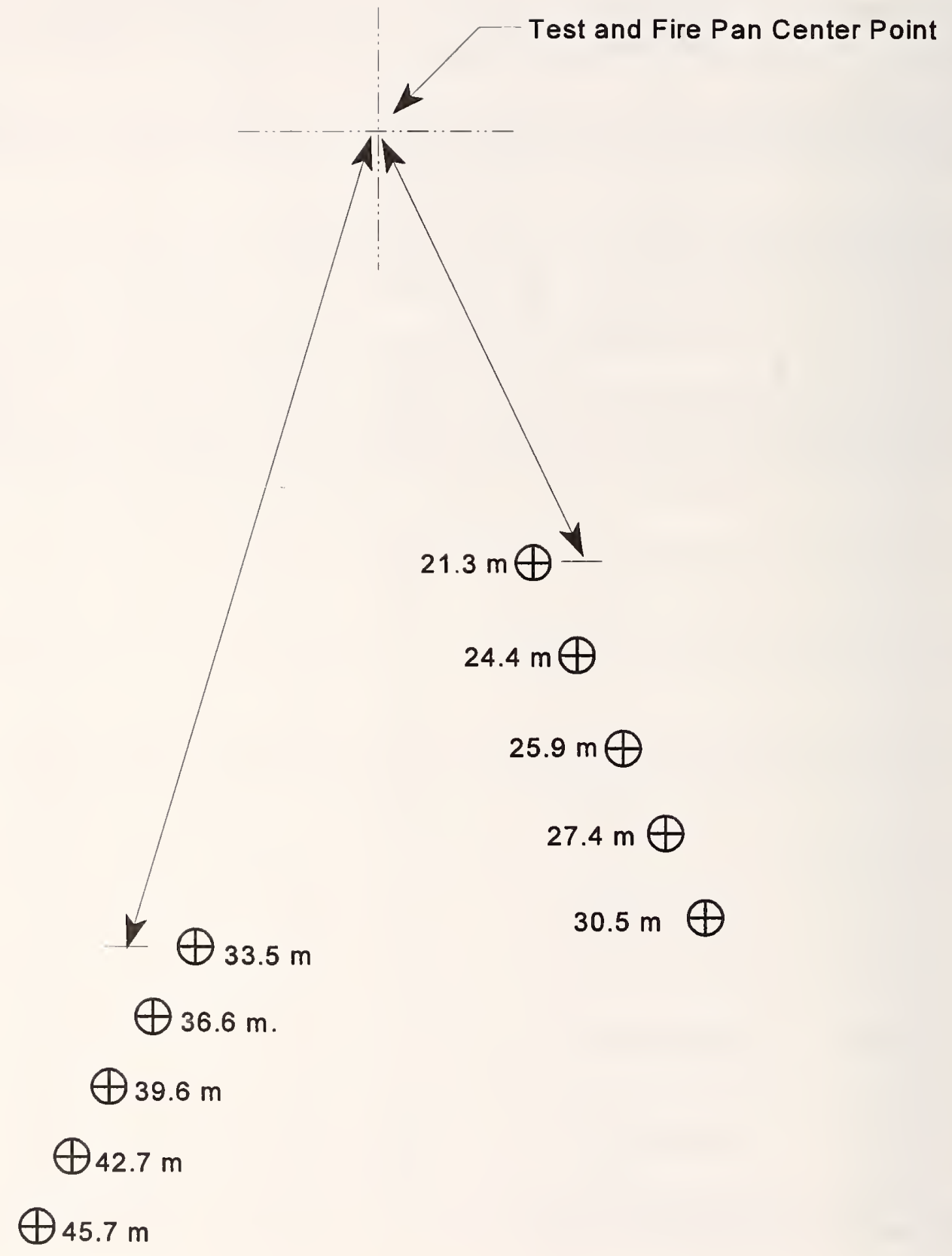

$\bigoplus \quad$ UVIIR Detector

Figure 59. UV/IR detector locations within test area, $22 \mathrm{~m}$ high facility. 


\subsubsection{Line-Type Heat Detector Installation}

A line type heat detector provided by Alison Control Inc. was used to monitor the perimeter of the draft curtain area in the $22 \mathrm{~m}$ high facility. The Alison 9090-13 as described in section 3 was used. Based on the fact that NFPA 72 does not specify placement of line type electrical conductivity detectors

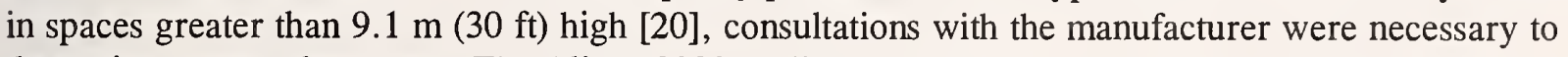
determine proper placement. The Alison 9090-13 linear heat detector, as shown in Figure 60 was located within the test area $0.3 \mathrm{~m}(1 \mathrm{ft})$ from the north and south draft curtains, along the center truss, and approximately $4.3 \mathrm{~m}(14 \mathrm{ft})$ from the east and west walls of the hangar bay. The sensor consisted of ten $15.2 \mathrm{~m}(50 \mathrm{ft})$ sections connected using in-line, sealed connectors. The sensor was hung approximately $0.3 \mathrm{~m}$ below the structural steel beams. Special beam mounted hangers were provided by the manufacturer to support the sensor.

Using the customized control box supplied by the manufacturer, an analog voltage output was recorded of the temperature of the sensor at any given moment.

\subsubsection{Measurements - Instrumentation}

NIST installed and monitored 144 transducers during these fire tests. Sixty four measurements were of sprinkler activation time, as described in section 3. Other transducers and instrumentation included

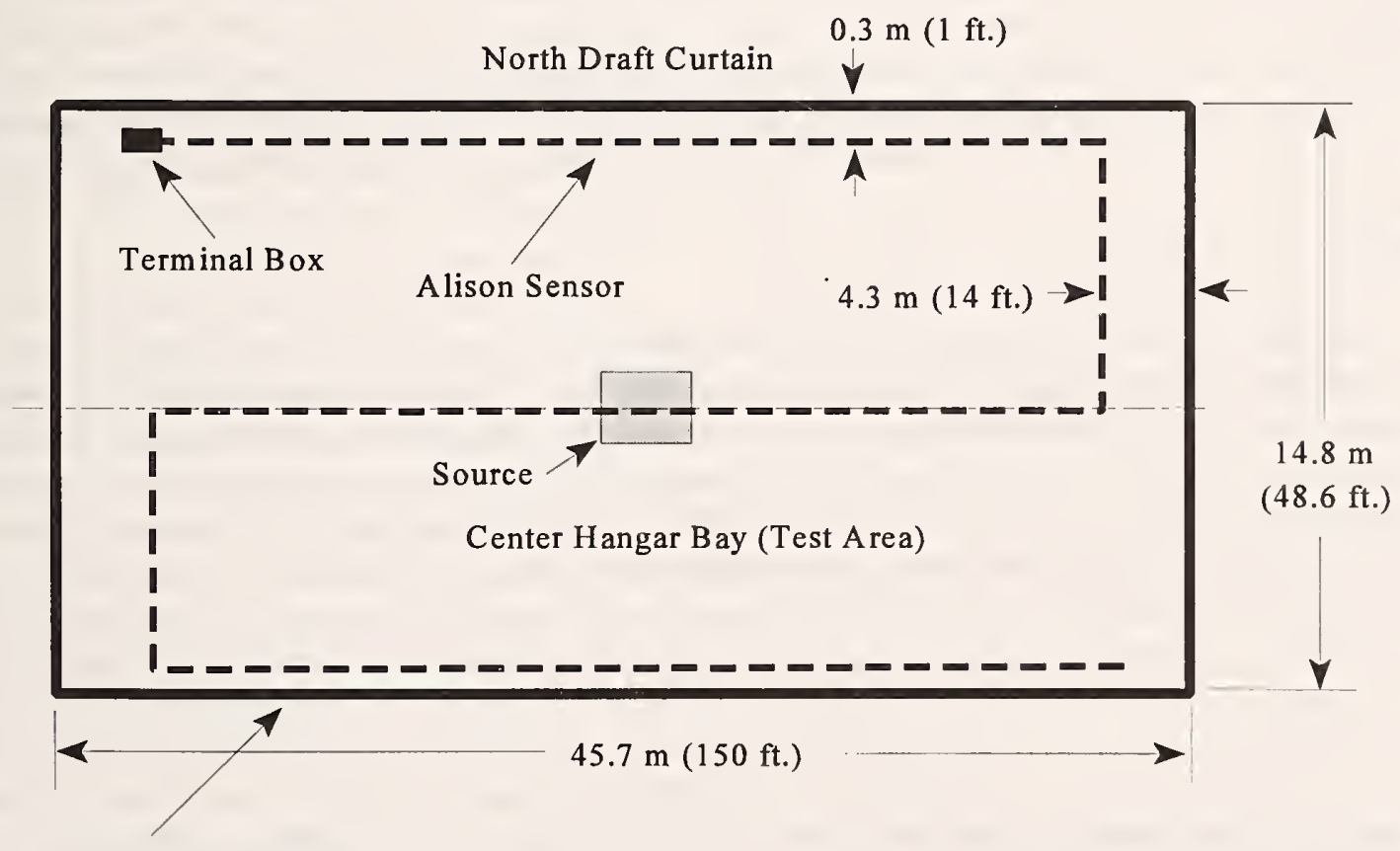

South Draft Curtain

Figure 60. Linear heat detector location diagram, $22 \mathrm{~m}$ high facility. 
thermocouples, mass loss of burning fuel, mass flow of the ceiling jet structure, internal and external wind speed and direction, and heat flux radiometers. In addition, video recordings were made at several locations for visualization and analysis purposes.

\section{Temperatures}

Sixty four thermocouples were installed in the $22 \mathrm{~m}$ facility in order to measure hot gas, air and fuel temperatures. Figure 63 shows the thermocouple layout. Type K thermocouples were used to measure these temperatures. Temperature measurements for the $22 \mathrm{~m}$ high facility varied somewhat from that of the $15 \mathrm{~m}$ high facility described in section 3 . The measurements differed in that temperature was measured for the first series of experiments (shown in lower dotted box in Figure 61) and ceiling jet profile temperatures were measured for the repeat tests. All other locations were measured for all tests. These configurations allowed NIST to collect more complete information about these phenomena. Described below are the general locations of thermocouples and rationale for their placement.

To measure plume centerline temperatures, thirteen temperature measurements were taken over the fire plume. An array of five thermocouples was placed at $0.31 \mathrm{~m}$ below the ceiling, one in the center over the fire pan, and one $3.0 \mathrm{~m}$ radially out from the center in each of the four directions. Along the centerline, four thermocouples were installed at $1.5 \mathrm{~m}, 3.0 \mathrm{~m}, 4.6 \mathrm{~m}$, and $6.1 \mathrm{~m}$ below the ceiling. Similar measurements were made at $3.0 \mathrm{~m}$ in the east direction at the same elevation as the centerline thermocouples. These provided some measure of direction the plume was leaning.

To measure the ceiling jet temperature, thermocouples were placed along the curved portion of the ceiling in the east direction at $9.1 \mathrm{~m}, 12.2 \mathrm{~m}$, and $15.2 \mathrm{~m}$ (shown in upper dotted box in Figure 61). At these locations thermocouples were placed vertically down from the ceiling to measure the temperature of the ceiling jet as a function of depth below the ceiling. Thermocouples were placed at $0.15 \mathrm{~m}, 0.46 \mathrm{~m}, 0.61 \mathrm{~m}, 0.76 \mathrm{~m}$, and $0.91 \mathrm{~m}$ below the ceiling. This information is useful for fire model verification, detector placement strategies, and comparison to data collected in $15 \mathrm{~m}$ high facility.

To track heat and smoke filling the draft curtained area, thermocouples were placed along the curved portion of the ceiling in the east direction at $3.0 \mathrm{~m}, 6.1 \mathrm{~m}, 9.1 \mathrm{~m}$, and $12.2 \mathrm{~m}$ from the centerline. Assuming that the smoke and heat flow together, the thermocouple readings can indicate the initial arrival of smoke to the thermocouple location. Also, in the south direction, along the flat portion of the ceiling, temperatures were measured at $3.0 \mathrm{~m}, 4.6 \mathrm{~m}, 6.1 \mathrm{~m}$, and $6.7 \mathrm{~m}$ (shown in lower dotted box in Figure 61). The distance below the ceiling deck for these smoke filling measurements was based on elevation of the thermocouples along the centerline. The goal was to establish a plane of temperature measurements in two directions, at different distances form the ceiling. Thermocouples were installed from $0.30 \mathrm{~m}$ to $6.1 \mathrm{~m}$ below the ceiling (at centerline). The distance to the "temperature planes" from the hangar floor (used as a flat reference) were approximately $22.0 \mathrm{~m}, 20.8 \mathrm{~m}, 19.3 \mathrm{~m}$, $17.7 \mathrm{~m}$, and $16.2 \mathrm{~m}$. Also, prior computer simulations had suggested that the deep draft curtains used in this facility would cause a circulation pattern to form in the draft curtained area instead of a uniform smoke layer slowly filling the volume.

To track the flow of heat and smoke into the adjacent draft curtained areas, thermocouples were installed outside of the draft curtained area in the south direction. Thermocouples were placed in the adjacent bay at $7.9 \mathrm{~m}, 12.2 \mathrm{~m}$, and $21.6 \mathrm{~m}$ from the centerline and $0.3 \mathrm{~m}$ and $6.1 \mathrm{~m}$ below the ceiling. 
As before, computer simulations suggest that the hot gases within the adjacent bay would tend to progress along the ceiling and down the far curtain. The measurements in the adjacent bay would therefore be used to compare actual results with those provided through the computer simulations.

To measure the temperature at time of activation of smoke and heat detectors, a thermocouple was placed at each sprinkler tree/smoke detector station. These data provide information useful in model verification and prediction of activation of fire protection devices.

To provide critical safety temperatures, a thermocouple was placed on the main structural steel beam directly over the fire. Two thermocouples were placed within the fire pan to monitor fuel depth and pan temperature.

\section{Mass Loss of Burning Fuel}

Measurement of the mass loss rate of the burning fuel was essential for determining approximate heat release values for each test fire. This measurement also provided information on the time required for the fire to reach steady state burning. Heat release rates were estimated for nearly all test fires provided mass loss data were available. Using the mass loss rate $(\mathrm{kg} / \mathrm{s})$ multiplied by the known heat of combustion, $\mathrm{H}_{\mathrm{c}}$, for each fuel $(\mathrm{kJ} / \mathrm{kg})$ results in heat release rate $(\mathrm{kW})$.

Since a load measuring platform had to accommodate small and large pan sizes, it was necessary to build two load platforms for this test series. Figures 62 and 64 describe the load platforms. The smaller three-point load platform used three $227 \mathrm{~kg}(500 \mathrm{lb})$ strain gauge type precision load cells, provided by GSE Inc. Measurements and Controls. Coupled with a strain gauge power supply/ indicator, a voltage output of $0 \mathrm{Vdc}$ to $5 \mathrm{Vdc}$, directly proportional to total mass $(\mathrm{kg})$ was recorded. For the larger four-point load platform, four $454 \mathrm{~kg}(1000 \mathrm{lb})$ strain gauges were used. This configuration provided a total mass capacity of $1814 \mathrm{~kg}(4000 \mathrm{lb})$.

Calibrations were performed on the strain gauges prior to fire testing. The three $227 \mathrm{~kg}$ gauges were anchored to a small cylindrical plate and subjected to a vertical load. Using a hydraulic load testing machine at NIST, approximately ten points from $0 \mathrm{~kg}$ to $227 \mathrm{~kg}$ were recorded, along with the corresponding voltage output. The four $454 \mathrm{~kg}(1000 \mathrm{lb})$ gauges used on the larger load platform were anchored to a small square plate and similarly calibrated. On-site load calibrations were made using $18.1 \mathrm{~kg}(40 \mathrm{lb})$ water containers placed on the load platform. These containers were filled with water and weighed independently using a calibrated lab balance. The weight of each container when filled was $18.5 \pm 0.23 \mathrm{~kg}(40.7 \pm 0.5 \mathrm{lb})$. Each strain gauge and associated wiring was thermally protected using a ceramic blanket wrapped loosely around the gauge and the load platform frame was protected using $12.7 \mathrm{~mm}(0.5 \mathrm{in}$.) calcium silicate board.

\section{Ceiling Jet Velocity Transducers}

Ceiling jet velocity measurements were made using two Sierra Steel-Trak Industrial Insertion Mass Flow Meters (series 640). Detailed information on the operating principles of this transducer is given in section 3. Locations of these mass flow meters are shown in Figure 61. $V_{1}$ in the figure is located $6.1 \mathrm{~m}(20 \mathrm{ft})$ in the east direction and is positioned at nearly the same elevation $(0.3 \mathrm{~m}$ below ceiling deck) as the thermal element of the sprinkler at station E2. $\mathrm{V}_{2}$ is located at $12.2 \mathrm{~m}(40 \mathrm{ft})$ in the east direction and also $0.3 \mathrm{~m}$ below the ceiling deck in the vicinity of sprinkler station $\mathrm{E} 4$. 


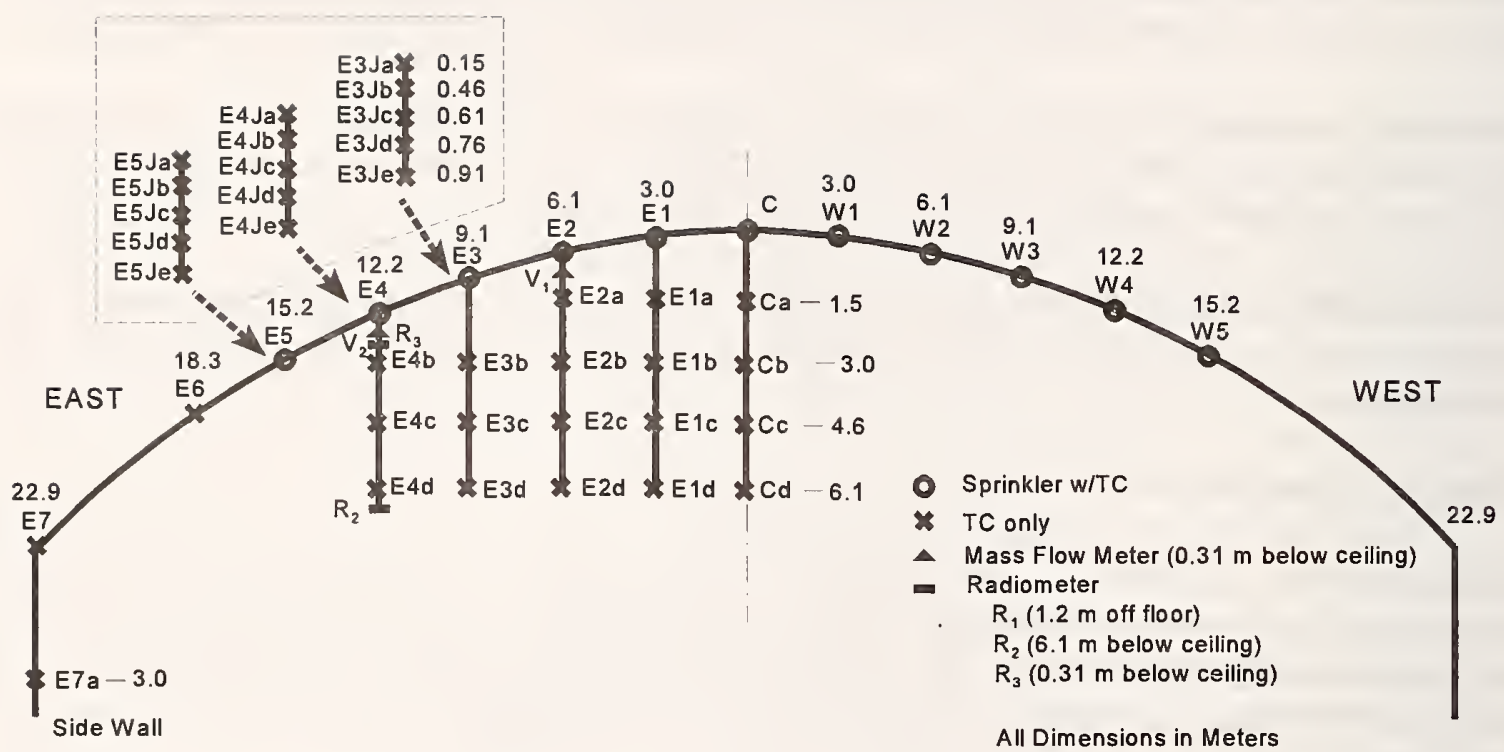

SOUTH

NORTH

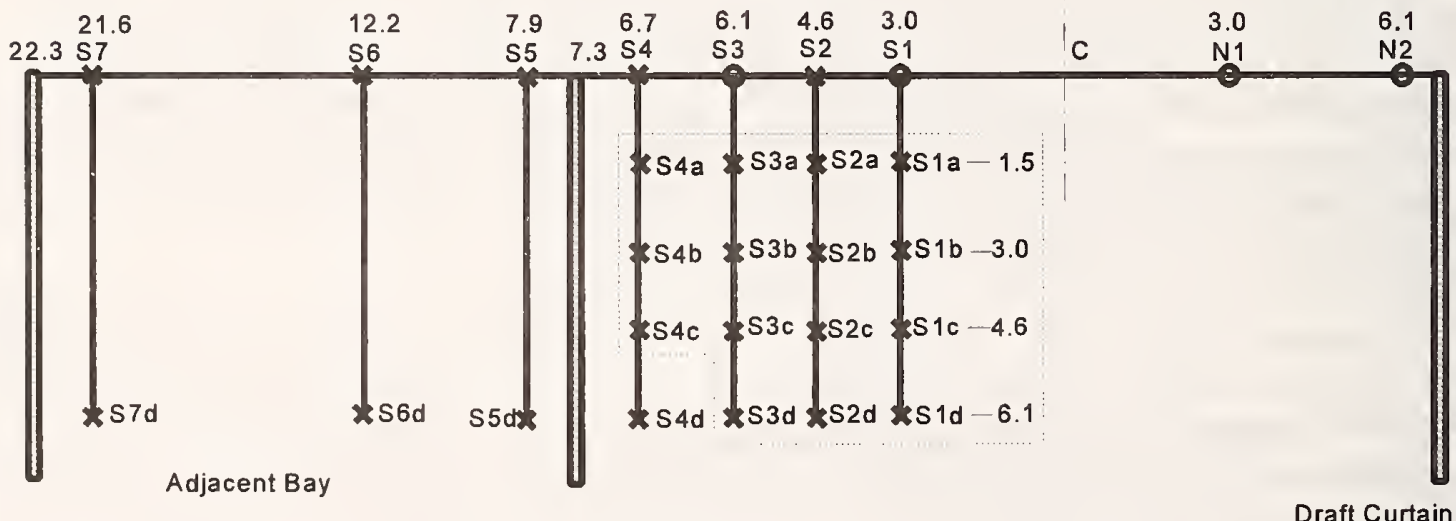

Figure 61. Instrumentation locations in $22 \mathrm{~m}$ high facility. 


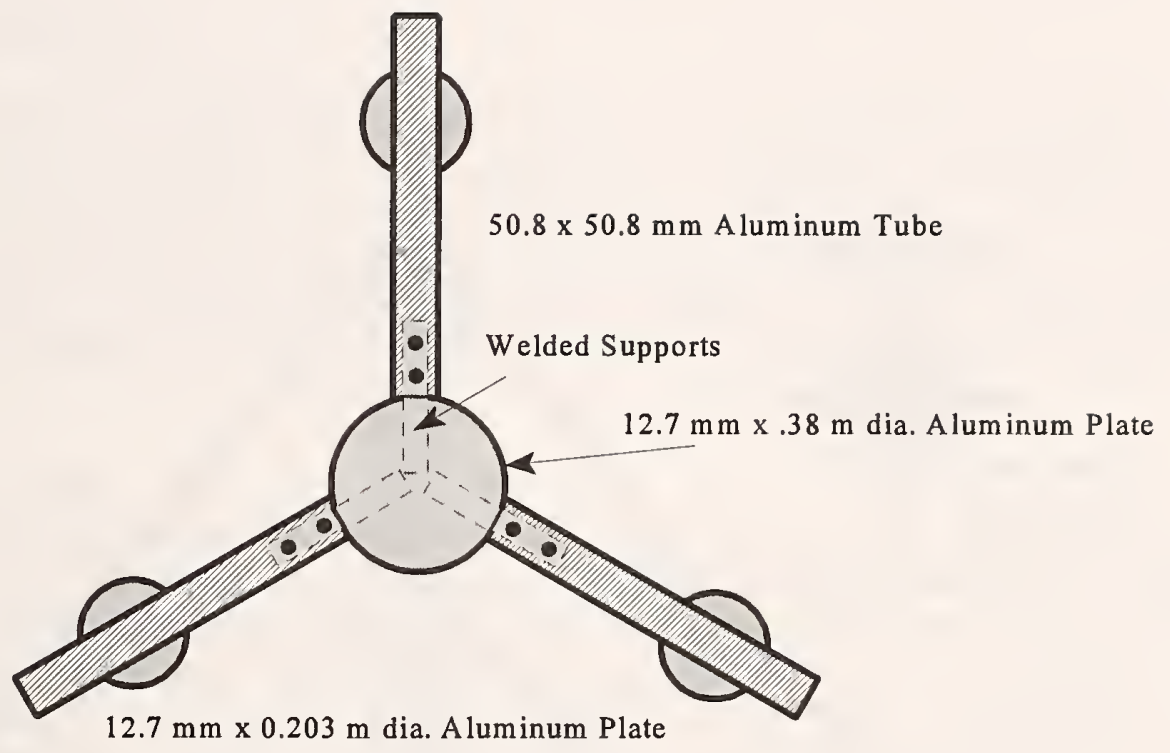

$12.7 \mathrm{~mm}$ Calcium Silicate Board

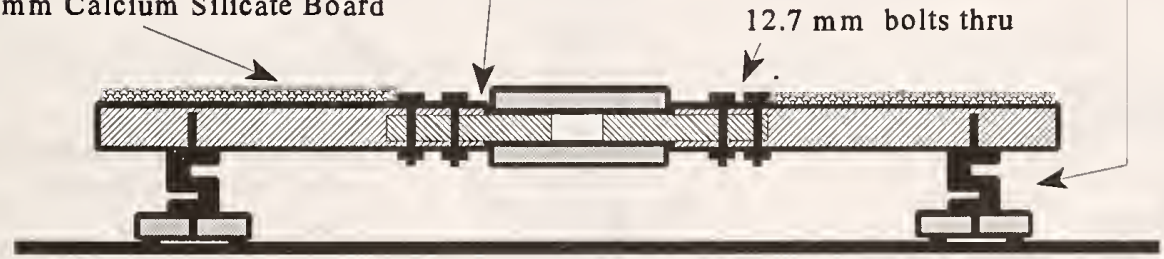

Figure 62. Three-point load platform used to measure mass loss in $22 \mathrm{~m}$ high facility experimental fires. 


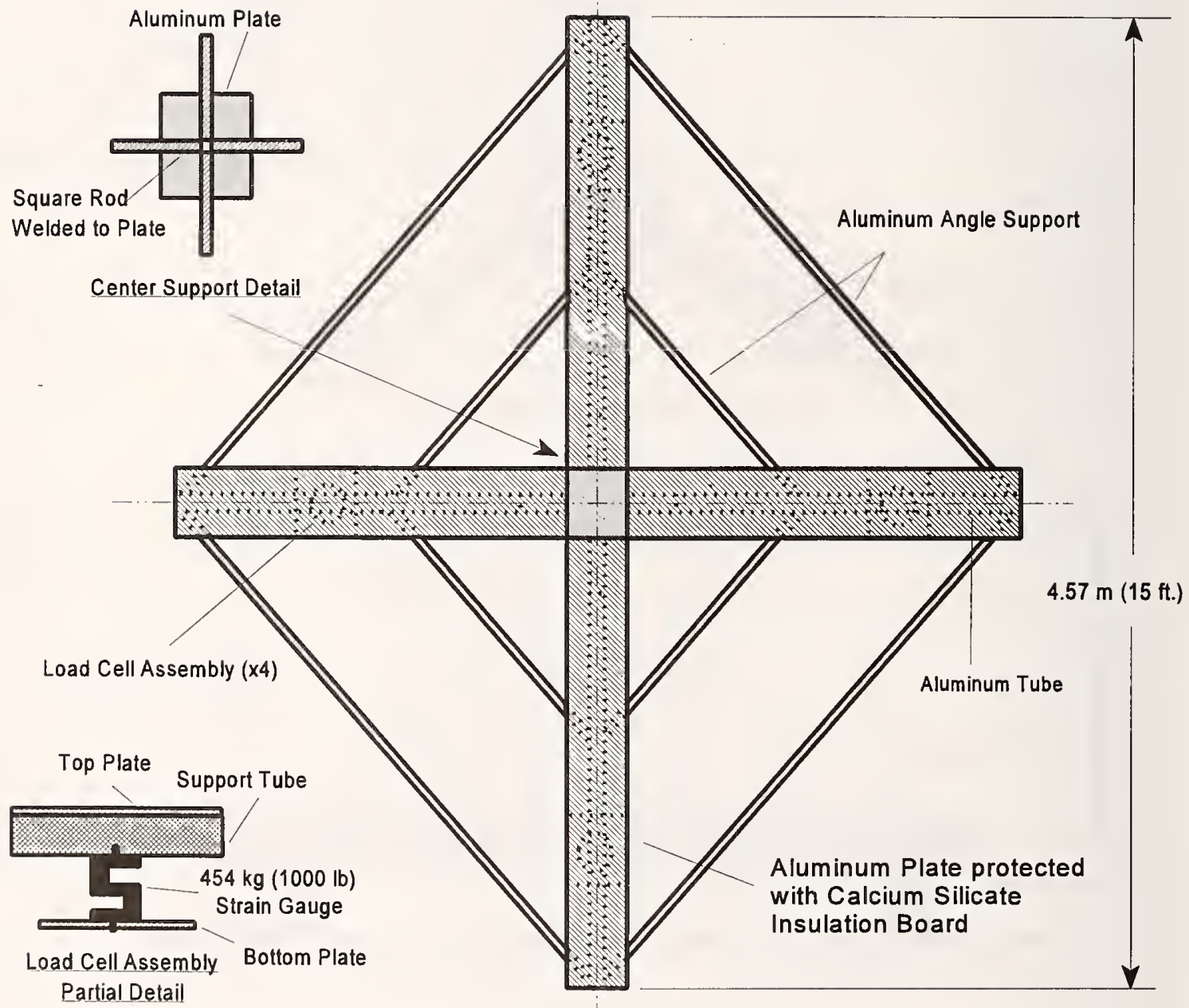

Figure 63. Four-point load platform used to measure mass loss of larger pan fires conducted in $22 \mathrm{~m}$ high facility. 
An output voltage signal $0 \mathrm{Vdc}$ to $5 \mathrm{Vdc}$ is produced which is proportional to the total mass flow. The usable range for these transducers is 0 standard $\mathrm{m} / \mathrm{s}$ to 0.5 standard $\mathrm{m} / \mathrm{s}(0 \mathrm{ft} / \mathrm{min}$ to $100 \mathrm{ft} / \mathrm{min})$.

\section{Wind Speed and Direction Meters}

Wind speed and direction were measured inside and outside the hangar during the experiments. Four wind speed/direction meters were used in the following manner. One meter was mounted on the roof at the south end of the hangar to observe ambient wind conditions. The other three meters were placed within the hangar at various locations depending on the fire test size. Figure 66 describes the location of each sensor. The four wind speed/direction sensors were calibrated at NIST in a standard wind tunnel. Additional information and theory of operation on these sensors can be found in section 3 .

\section{Heat Flux Meters}

Three water cooled, Gardon type heat flux transducers were used to measure total heat flux from the test fires. Figure 61 indicates the location of the gauges. Two transducers, R2 and R3 were mounted at $12.2 \mathrm{~m}$ from the test center in the east direction. Depending on the fire pan size, R1 was positioned at various distances away from the pan. Transducer R3 was mounted $0.3 \mathrm{~m}$ below the ceiling and transducer R2 was mounted $6.1 \mathrm{~m}$ below the ceiling. The third transducer, R1, was positioned $1.63 \mathrm{~m}$ off the floor for the first 4 tests, and at $1.07 \mathrm{~m}$ for rest of the test series. Cooling water for these transducers was provided by the water supply used for filling the sprinkler trees. Plastic hose $(9.5 \mathrm{~mm}$ O.D.) was used to supply the transducers and provided a drain line which was piped to a central drain in the hangar. Section 3 describes the operating principle of these transducers.

\section{Data Acquisition System}

The data acquisition system used to collect fire test data in the $22 \mathrm{~m}$ high facility was the same system used in the previous test series. Additional information and a block diagram of the system can be found in section 3. The overall system scan rate for all 144 channels varied between $3.5 \mathrm{~s}$ and $4.5 \mathrm{~s}$ depending on the graphical display requirement for each test.

\section{Other Measurements and Information}

In addition to measurements described above, video footage of each test fire was taken. In all cases, high resolution $8 \mathrm{~mm}$ cameras were located in two specific areas with respect to the test fire. Camera 1

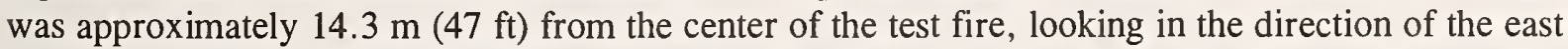
wall of the hangar. Height markings were placed on the east wall at equal intervals, to provide a visual flame height measurement. Camera 2 was located in the northeast corner of the test area to provide footage of smoke filling rates and relative obscuration. Camera 3 was portable so as to capture important events during the tests. The locations of cameras 1 and 2 complimented one another by also supplying information on time to full pan involvement, flame propagation across fuel pan, flame structure, and symmetry of the plume.

Weather data, measured at several locations near the hangar, were provided by the weather station at NAS Keflavik. Temperature, relative humidity, wind speed/direction, dew point, barometric pressure, and precipitation amounts were all reported hourly. In addition, relative humidity was measured inside the hangar prior to each test. 


\subsection{Test Fires in $22 \mathrm{~m}$ High Facility}

Twenty-two fire experiments were conducted in the $22 \mathrm{~m}$ high facility. The majority of these fires involved JP-5, and the remainder burned JP-8. The jet fuel fires ranged in size from $0.06 \mathrm{~m}^{2}\left(1 \mathrm{ft}^{2}\right)$ to $20.9 \mathrm{~m}^{2}\left(225 \mathrm{ft}^{2}\right)$. The following sections include the rationale for each fire size, computer modeling of the facility based on anticipated heat sources, test procedures, summary of all experiments, and fuel specifications for JP-5 and JP-8.

\subsubsection{Rationale for Experimental Fire Sizes}

A combination of plume theory, three-dimensional computational fluid dynamics modeling, and engineering judgement were used to determine the heat release rates and associated pan sizes to meet the experimental objectives. Each of the experiments can be grouped into one of two categories, one referred to as "detector fires" and the other "sprinkler fires." Detector fires were designed to determine the approximate minimum fire size for detectability for the various types of heat, smoke, and flame detectors installed. Detector fires were small square pan fires of four different sizes: $0.3 \mathrm{~m} \mathrm{x} 0.3$ $\mathrm{m}(1 \mathrm{ft} \times 1 \mathrm{ft}), 0.6 \mathrm{~m} \times 0.6 \mathrm{~m}(2 \mathrm{ft} \times 2 \mathrm{ft}), 0.9 \mathrm{~m} \times 0.9 \mathrm{~m}(3 \mathrm{ft} \times 3 \mathrm{ft})$, and $1.2 \mathrm{~m} \times 1.2 \mathrm{~m}(4 \mathrm{ft} \times 4 \mathrm{ft})$. The detector fire sizes were chosen to correlate with those conducted in the $15 \mathrm{~m}$ high facility in order to determine the effect of the higher ceiling on the maximum ceiling temperature and the response of the various detectors. The larger $1.2 \mathrm{~m} \times 1.2 \mathrm{~m}$ detector fire was added due to the higher ceiling height.

The sprinkler fires were a combination of round pan fires and large square pan fires. Sprinkler fires were designed to determine the approximate fire size for activation of the various types of automatic sprinklers. An ambient temperature of $7{ }^{\circ} \mathrm{C}\left(45^{\circ} \mathrm{F}\right)$ was assumed for calculation purposes. Sprinkler fires were designed to meet four objectives:

- To demonstrate a large fire that would come close to but not activate any of the installed test sprinklers. The first sprinkler fire was a $2.0 \mathrm{~m}$ diameter circular pan fire with an estimated heat release rate of approximately $8 \mathrm{MW}$.

- To demonstrate a fire large enough to activate the $79^{\circ} \mathrm{C}\left(175^{\circ} \mathrm{F}\right)$ sprinklers within the fire plume. The second sprinkler fire was a $2.5 \mathrm{~m}$ diameter pan fire with an estimated heat release rate of approximately $13 \mathrm{MW}$.

- To demonstrate a fire that would activate the $79^{\circ} \mathrm{C}\left(175^{\circ} \mathrm{F}\right)$ sprinklers inside and outside the fire plume and the $141{ }^{\circ} \mathrm{C}\left(286^{\circ} \mathrm{F}\right)$ within the fire plume. The third sprinkler test was a $3.0 \mathrm{~m}$ x $3.0 \mathrm{~m}(10 \mathrm{ft} \times 10 \mathrm{ft})$ square pan fire with an estimated heat release rate of $20 \mathrm{MW}$.

- To demonstrate a fire that would activate the $141^{\circ} \mathrm{C}\left(286^{\circ} \mathrm{F}\right)$ sprinklers inside and outside the

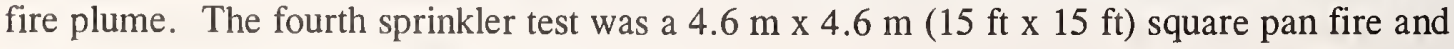
with an estimated heat release rate of $45 \mathrm{MW}$.

The fire experiments were conducted in the center draft curtained area, which measures $14.8 \mathrm{~m}$ $(48.5 \mathrm{ft})$ in width by $45.7 \mathrm{~m}(150 \mathrm{ft})$ in length. Some of the key fires were repeated with JP- 8 . Laboratory scale experiments discussed in section 2 showed similar heat release rates for JP- 5 and JP-8. 


\subsubsection{Computer Modeling of $22 \mathrm{~m}$ Facility}

Computer modeling for the $22 \mathrm{~m}$ high facility was focused toward predicting the impact that the curved ceiling and large draft curtains would have on smoke and heat flow. The draft curtains had depths of $8.7 \mathrm{~m}(28.5 \mathrm{ft})$ which should substantially inhibit the flow of heat outside of the curtained area. Predictions were also made concerning the fire size required to activate a $141{ }^{\circ} \mathrm{C}\left(286{ }^{\circ} \mathrm{F}\right)$ sprinkler heads at the ceiling. Finally, the effect that wind blowing in the open side of the hangar would have on the fire and heat flow was investigated.

The CFD model, HARWELL FLOW3D was used to investigate the hot gas flow since this hangar had a curved roof and the available zone models only allowed for flat roof situations. Initially, the hangar was modeled without draft curtains in order to separate the draft curtain effects on the hot gas flow from that of the curved roof. The results of these calculations revealed that the flow of heat in the direction of the curved ceiling would be slowed by the curved ceiling. Including the draft curtains into the calculation provided a major change in the hot gas flow patterns. The draft curtains were deep enough to completely contain the heat early in the fire. Figure 65 shows the temperature patterns within the draft curtains for a $32 \mathrm{MW}$ fire at $60 \mathrm{~s}$ into the simulated fire. The flow moves along the ceiling, down the draft curtain, and turns back toward the fire plume. As the hot gas flows beneath the draft curtain, it flows up the other side and is trapped by the adjacent draft curtain as shown in Figure 65. Inside the second draft curtained volume, filling of the far side should occur prior to filling the side adjacent to the first draft curtain. Based on these calculations, two sets of thermocouples were designed to investigate these flow patterns.

To investigate ceiling temperatures versus fire size, calculations using 32 and $40 \mathrm{MW}$ fires at an ambient temperature of $7{ }^{\circ} \mathrm{C}\left(45^{\circ} \mathrm{F}\right)$ predicted maximum ceiling temperatures at plume center of $201{ }^{\circ} \mathrm{C}\left(394^{\circ} \mathrm{F}\right)$ and $243^{\circ} \mathrm{C}\left(469^{\circ} \mathrm{F}\right) 60 \mathrm{~s}$ into the simulated fire. The simulated fire was designed to reach its maximum heat release rate during the first $10 \mathrm{~s}$. Both fire sizes were predicted to activate all the $141{ }^{\circ} \mathrm{C}\left(286^{\circ} \mathrm{F}\right)$ sprinkler heads enclosed by the draft curtains in the direction perpendicular to the curved ceiling. In the direction parallel of the curved ceiling, activation of all $141{ }^{\circ} \mathrm{C}$ heads should

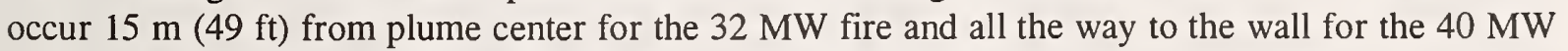
fire. Either fire size should meet the goal to activate the high temperature sprinkler heads both inside and out of the plume region regardless of the range of ambient temperatures expected for these experiments.

The effect of wind blowing in one hangar door was investigated for a $32 \mathrm{MW}$ fire. It was assumed that the hangar door was fully opened and that there was a small leak at the bottom wall on the hangar side opposite the door. The wind was assumed to be blowing perpendicular to the door and have a constant vertical velocity profile. Figures 66 and 67 show the results of the calculations for flow velocity and local gas temperatures with a wind speed of $8.9 \mathrm{~m} / \mathrm{s}(20 \mathrm{mph})$. Figures 68 and 69 show the results of the calculations for flow velocity and local gas temperatures with a wind speed of $17.8 \mathrm{~m} / \mathrm{s}(40 \mathrm{mph})$. In both cases, the wind is deflected down by the door opening and by the time it reaches the center of the hangar, the strongest velocity component is near the floor. The $8.9 \mathrm{~m} / \mathrm{s}$ wind will produce some flame lean and show preferential smoke filling of the draft curtain area centered under the fire and the one immediately behind the fire opposite the open door. As the wind speed increases to $17.8 \mathrm{~m} / \mathrm{s}$, the fire should exhibit a significant flame lean with insignificant amounts of smoke filling draft curtain areas on the door side of the flame. The available venting area in the side of the hangar opposite the open door should have a significant impact on the amount of flame lean and hot gas flow. 


\section{Iceland Hangar}

$32 \mathrm{MW}$ Fire, $60 \mathrm{~s}$

Temperature, Deg. C

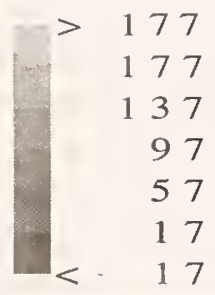

Figure 65. Side view of the $22 \mathrm{~m}$ high facility in a plane through the fire center. The draft curtains are represented by two vertical lines extending from the ceiling to just below the side roof level. The $32 \mathrm{MW}$ fire is located on the hangar floor at the right side of the figure. 
If the hangar is more open on the opposite side than is assumed in these calculations, the slow down of the wind velocity will lessen and the wind impact on the fire and plume will be enhanced.

Two different thermocouple configurations were used for test fires in the $22 \mathrm{~m}$ hangar. The goals of the first configuration were to measure the ceiling jet flow along the curved portion (i.e., east - west) of the hangar roof, to measure the temperature at the smoke detectors and sprinkler heads, and to measure the rate of smoke filling in the hangar. Computer simulations had indicated that the rate of hot gas flow along the curved roof of the hangar would be slowed compared to the rate of hot gas flow in the direction of constant ceiling height (i.e., north - south). In order to test this prediction and also measure the overall hot gas filling rate of the hangar, thermocouples were located $0.15 \mathrm{~m} \mathrm{(} 6$ in.) beneath the ceiling at fire center and at $3.0 \mathrm{~m}, 6.1 \mathrm{~m}, 9.1 \mathrm{~m}, 12.2 \mathrm{~m}, 15.2 \mathrm{~m}$, and $23 \mathrm{~m}(0 \mathrm{ft}, 10 \mathrm{ft}$, $20 \mathrm{ft}, 30 \mathrm{ft}, 40 \mathrm{ft}, 50 \mathrm{ft}, 60 \mathrm{ft}$, and $75 \mathrm{ft}$ ) along the curved ceiling in both the east and west directions from the fire center. In addition, a thermocouple was mounted at $23 \mathrm{~m}$ (75 ft.) from fire center and 6.1 $\mathrm{m}$ beneath the ceiling in the east direction. In addition, thermocouples were located $0.15 \mathrm{~m}$ beneath the ceiling at $3.0 \mathrm{~m}, 4.6 \mathrm{~m}, 6.1 \mathrm{~m}$, and $6.7 \mathrm{~m}$ in the south direction and at $3.0 \mathrm{~m}$ and $6.1 \mathrm{~m}$ in the north direction. This set of thermocouples would be used to measure the time of arrival of the hot gases at each location.

A set of thermocouple trees was designed to measure the vertical temperature profile of the ceiling jet along the curved section of the ceiling. Here, thermocouple trees located at distances of $0.15 \mathrm{~m}, 0.30$ $\mathrm{m}, 0.46 \mathrm{~m}, 0.76 \mathrm{~m}$, and $0.91 \mathrm{~m}$ below the ceiling at $9.1 \mathrm{~m}, 12.2 \mathrm{~m}$ and $15.2 \mathrm{~m}$ distances along the curved ceiling toward the east direction. The thermocouples would be used to measure the temperature profile of the ceiling jet at three locations outside the plume. The vertical spacing of the thermocouples in these trees were increased over the distances monitored for the $15 \mathrm{~m}$ high facility based on the results obtained from the $15 \mathrm{~m}$ high bay facility experiments and the larger fires designed for these experiments.

The second thermocouple configuration was designed to examine the hot gas movement within the draft curtained area as a function of depth beneath the ceiling. Computer simulations had suggested that the deep draft curtains used in this facility would cause a circulation pattern to be set up in the draft curtained area instead of a uniform hot gas layer slowly filling the curtained volume. Secondly, computer simulations suggested that these draft curtains would be deep enough to contain the hot gases for some time with hot gas flow into the adjacent curtained regions occurring later in the fire. When hot gas flow did spill into the adjacent curtained areas, it would tend to drop down the side of the curtain, move along the ceiling and then back down the far curtain, leaving the middle of the curtained area void of hot gas for an additional period of time.

In order to test these predictions, the thermocouples used to measure the vertical temperature profile of the ceiling jet were replaced by four thermocouple trees in the south direction with thermocouples at depths beneath the ceiling of $0.15 \mathrm{~m}, 1.5 \mathrm{~m}, 3.0 \mathrm{~m}, 4.6 \mathrm{~m}$, and $6.1 \mathrm{~m}$ and distances from the plume center of $3.0 \mathrm{~m}, 4.6 \mathrm{~m}, 6.1 \mathrm{~m}$, and $6.7 \mathrm{~m}$. In addition, four thermocouple trees in the east direction were replaced with thermocouples at depths beneath the ceiling peak of $0.15 \mathrm{~m}, 1.5 \mathrm{~m}, 3.0 \mathrm{~m}, 4.6 \mathrm{~m}$, and $6.1 \mathrm{~m}$. Utilizing a second tree at plume center with the same thermocouple configuration, two measurement planes were used to track the time needed for the hot gases to fill the draft curtain volume. In the adjacent draft curtain to the south, three thermocouple trees were located at distances of $7.9 \mathrm{~m}, 12.2 \mathrm{~m}$, and $22.6 \mathrm{~m}$ from the fire center. Each tree had thermocouples located at depths of $0.15 \mathrm{~m}$ and $6.1 \mathrm{~m}$ from the ceiling. 
Iceland Hangar

$32 \mathrm{MW}$ Fire, $8.9 \mathrm{~m} / \mathrm{s}$ Wind

Long Arrows Represent $8.9 \mathrm{~m} / \mathrm{s}$ Wind Speed

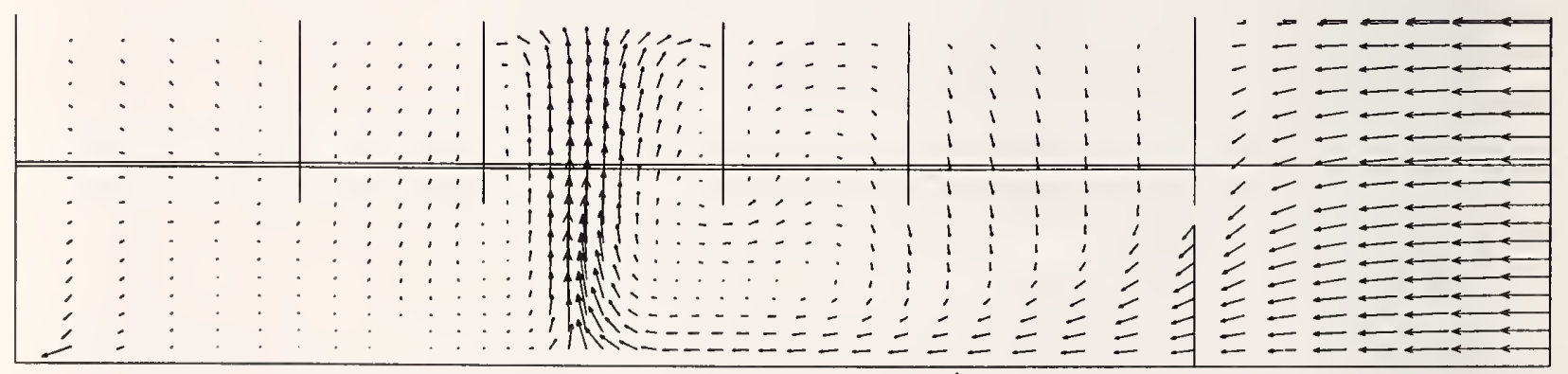

Figure 66. Side view of $22 \mathrm{~m}$ high facility in plane through the fire center. Rectangle at far right represents region outside of hangar with door and wall represented by vertical lines on side of rectangle. Draft curtains are represented by vertical lines extending from ceiling to just below pair of horizontal lines near middle of figure. Arrows: direction and magnitude of velocity. $32 \mathrm{MW}$ fire located on hangar floor centered between second and third draft curtains from hangar door. Wind speed $8.9 \mathrm{~m} / \mathrm{s}(20 \mathrm{mph})$. 
Iceland Hangar

$32 \mathrm{MW}$ Fire, $8.9 \mathrm{~m} / \mathrm{s}$ Wind

Temperature Deg. C
$\rightarrow 127.0$
127.0
99.5
72.0
42.5
$<17.0$

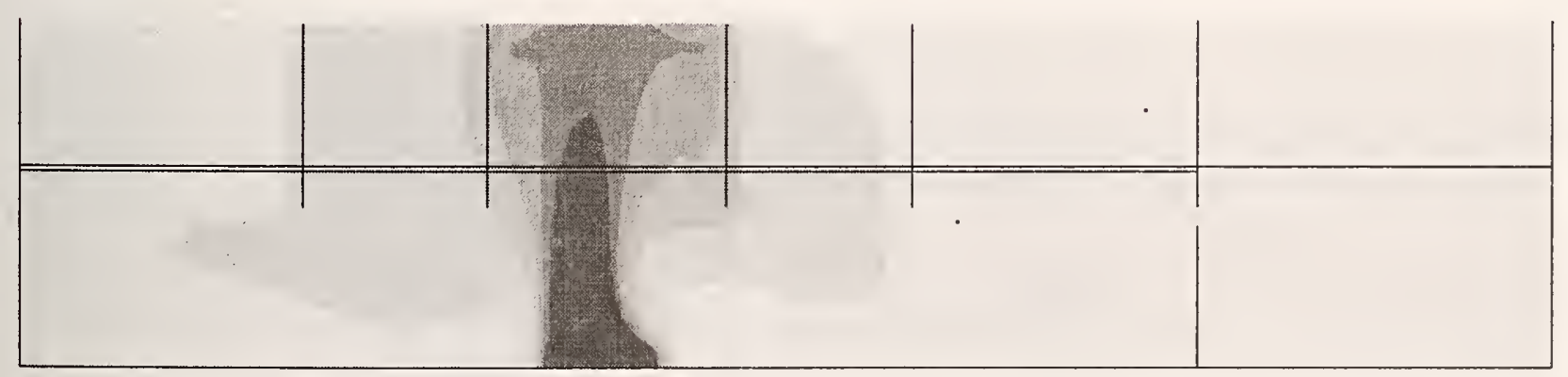

Figure 67. Contours represent local gas temperatures from the $32 \mathrm{MW}$ fire and with a wind speed of $8.9 \mathrm{~m} / \mathrm{s}$. 


\section{Iceland Hangar}

$32 \mathrm{MW}$ Fire, $17.8 \mathrm{~m} / \mathrm{s}$ Wind

Long Arrows Represent $17.8 \mathrm{~m} / \mathrm{s}$ Wind Speed

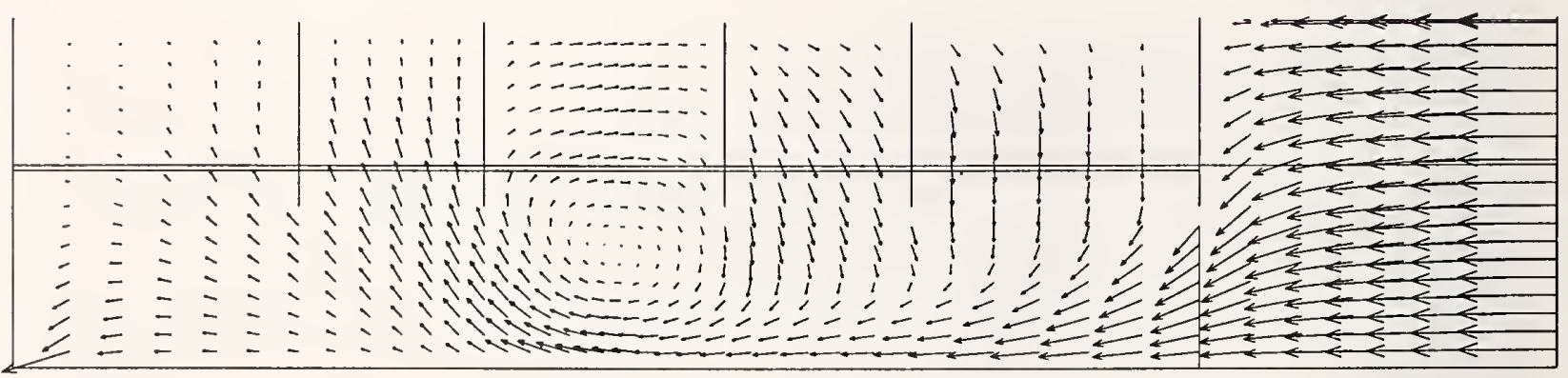

Figure 68. Similar modeling configuration of $22 \mathrm{~m}$ facility as described in Figure 66. Wind speed is $17.8 \mathrm{~m} / \mathrm{s}(40 \mathrm{mph})$. 


\section{Iceland Hangar}

$32 \mathrm{MW}$ Fire, $17.8 \mathrm{~m} / \mathrm{s}$ Wind

\section{Temperature Deg. C}

$$
\begin{array}{r}
>\quad 127.0 \\
127.0 \\
99.5 \\
72.0 \\
44.5 \\
<\quad 17.0
\end{array}
$$

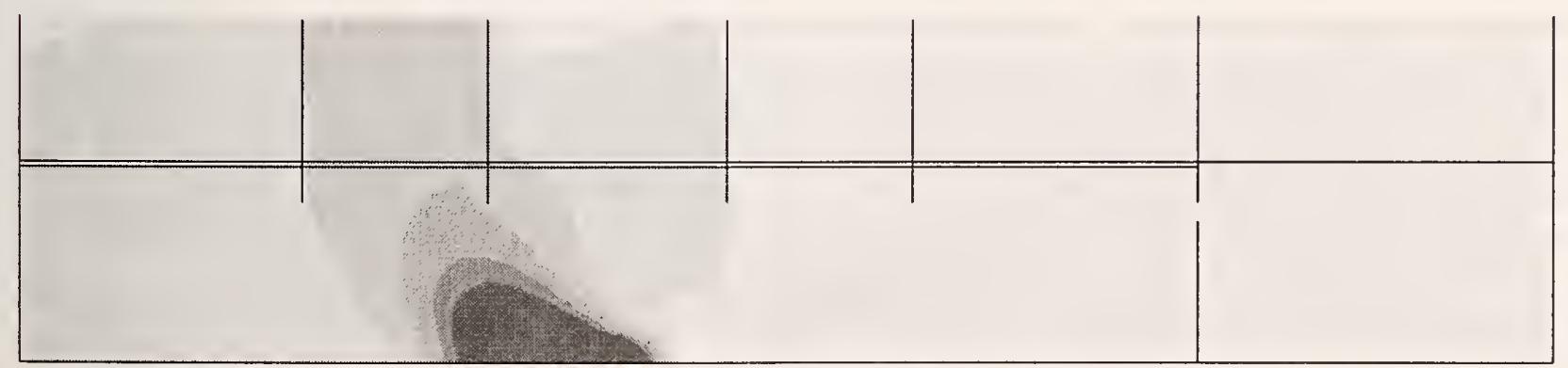

Figure 69. Similar modeling configuration of $22 \mathrm{~m}$ facility as described in Figure 67. Contours represent local gas temperatures from $32 \mathrm{MW}$ fire, wind speed of $17.8 \mathrm{~m} / \mathrm{s}$. 
The two sets of four thermocouple trees in the east and south directions plus the center thermocouple tree formed planes which allowed the hot gas filling within the draft curtains to be monitored. The three thermocouple trees in the adjacent draft curtain will be used to analyze the time to spill over and the flow pattern with this draft curtained volume.

\subsubsection{Experimental Procedures and Test Information}

A test procedure was developed to ease the many tasks required to conduct each full scale experiment. These tasks were supervised by the project leader according to the following procedures.

\section{Equipment Check}

Instrumentation and fire protection devices were inspected before each experiment. Thermocouple and sprinkler connections were electronically checked to ensure no open circuits. Initially, thermocouples were tested with a small heat source to ensure temperature response and switch-like sprinkler connections were inspected to verify operation. Each data channel was checked for proper measurement and response. Channels or measurement points with incorrect or intermittent operations were repaired. The data system was readied for the upcoming experiment. Power supplies and controllers for wind speed transducers, linear heat sensor, load platform, and mass flow transducers were examined for proper operation. Water supplies for the three water-cooled radiometers were inspected for proper flow. Video cameras used to capture test footage were positioned. The camera designed to aid in flame height measurements was placed at a known distance from the fuel pan with a backdrop of elevation markings at $1.5 \mathrm{~m}(5 \mathrm{ft})$ intervals starting at the floor.

Projected beam detectors were inspected for proper alignment and operation. A nominal output voltage of four volts from each detector confirmed operation. A lower output meant the detector's lens was dirty or the unit was defective. Lenses were manually cleaned after nearly all experiments. Smoke and heat detectors were inspected to confirm acceptable operation and the central fire alarm panel provided a measure of percent-of-alarm for each detector. Generally, a value greater than $1 \%$ to $2 \%$ suggested that the detector needed to be cleaned or replaced. To speed these changes, detectors were installed onto mounting plates so they could be easily removed. Upon completion of the larger fire tests, most detectors were replaced. UV/IR detectors were located at pre-determined distances from the fire pan. A small hand held source, used as a calibration, was directed at each detector and necessary adjustments were made. The temperature of the water contained in the sprinkler piping was measured. If the temperature of the water was higher than ambient, the water was drained and the piping refilled.

\section{Set Fuel Pan}

The next major step in the procedure was to position the load platform and appropriate fuel pan. It was critical that these elements were centered so that measurements concerning plume symmetry, temperature and hot gas movement could be referenced to a central consistent location. The pan was then leveled on the load platform and the weight of the empty pan was measured using the load cell controller. An LED indicator on the controller provided a continuous display of the weight in appropriate engineering units. Depending on the pan size (i.e., $2.5 \mathrm{~m}$ diameter and $3.0 \mathrm{~m} \times 3.0 \mathrm{~m}$ pans), a larger four-point load platform was used. For the smaller experiments a three-point load platform was used. For the largest fire tests, the $4.6 \mathrm{~m} \mathrm{x} 4.6 \mathrm{~m}$ pan was placed directly on the floor. 
The load platform was not used in these experiments because of stability problems and flexing of the steel pan.

The fuels (JP-5, JP-8), which were stored in steel drums were transported into the hangar via a fork lift. Fuel was pumped from the fuel truck into calibrated buckets to measure the volume. Once measured, the fuel was carefully poured from the buckets into the pan. This method of volume measurement has an estimated uncertainty of $\pm 0.47 \ell(0.5$ quarts), based on the error in reading the fuel volume from the buckets, and any spillage occurring during fuel transfer. As an added precaution, all activities concerning fuel transport was supervised by fire fighting personnel to safeguard the operation.

For the larger full scale tests, fuel was pumped directly from $208 \ell(55 \mathrm{gal})$ drums into the pan. The initial and residual volumes were measured using a calibrated measuring stick, basing volume on an increment of depth and assuming a constant cross sectional area of the barrel. The estimated uncertainty for this measurement was $\pm 3.8 \ell(1 \mathrm{gal})$, based on the flexing of the drum when fuel was added. This flexing created different cross sectional areas of the drum at different depths, reducing the accuracy of these volume measurements. Since several drums of fuel were required for larger tests, the uncertainty stated should be included for each full drum of fuel. Another weight measurement was recorded for initial weight of fuel in the pan. Once again, a check on the stability and center position of the pan was made.

At this point a final check of all instrumentation was made. The floor based radiometer was positioned at a predetermined distance from the pan. Each UV/IR detector was located at a measured position and aimed at the fire pan using a small visible laser mounted on the side of the detector.

\section{Building Check}

The next step in the procedure was to confirm the position of hangar and side maintenance doors throughout the hangar. Two experiments conducted required hangar doors to be partially open, however, for the majority of the tests all doors were closed. Other openings such as office doors and ventilation fan louvers were closed and secured. The base fire personnel were notified to stand ready. For the larger fire tests, a charged hose line containing AFFF was brought into the hangar in case an emergency shutdown was necessary. Fire fighting personnel were provided protective suits and breathing gear.

\section{Countdown Sequence}

Once all instrumentation, fuel pan and building checks were completed a countdown sequence was started. The project leader notified all participants to enable their data systems and record necessary ambient conditions. Personnel who operated hangar doors for post-test smoke evacuation were told to stand ready. Video cameras began recording. The data system used to measure temperatures, sprinkler activation, and other fire parameters began recording background information.

The fuel in the pan was ignited using an acetylene torch. Ignition time was defined by sustained burning of the fuel when the torch flame was removed. A member of the test crew signaled ignition. At this point, all data systems began recording or indicated ignition time within their data files. A stopwatch was started at the time of ignition. 


\section{During Tests}

Visual observations of plume symmetry, smoke filling, smoke movement throughout the hangar, and burning characteristics, including flame spread rate across the pan, were noted along with the elapsed time. Photographs of important events which occurred during the experiment were taken and documented. Throughout the experiment, safety temperatures (i.e., steel beam and fuel pan) were monitored to ensure that structural integrity was not at risk. Also, smoke depth above the floor was monitored. If any of these conditions surpassed established risk protocol or other serious conditions arose, the project leader would terminate the experiment and take appropriate action to evacuate the building and begin suppression procedures. If everything ran smoothly, the test continued for nominally ten minutes or until temperatures near the ceiling reached equilibrium.

\section{Suppression and Smoke Evacuation}

Upon completion of the experiment, the project leader signaled the suppression crew to begin extinguishment process. The suppression crew consisted of base fire personnel and team members with fire fighting experience all equipped with required safety gear. $\mathrm{CO}_{2}$ type extinguishers were used to suppress the smaller fires. For the larger fires, a combination of $\mathrm{CO}_{2}$ extinguishers and a suppression lid mounted on long handles was used. As the lid was lowered over the pan, $\mathrm{CO}_{2}$ was applied to the flame, thus inerting the space underneath the lid. This method proved very efficient in not only suppressing the fire but protecting the load platform electronics and without spilling large amounts of fuel. For the larger fires, a $4.9 \mathrm{~m} \mathrm{x} 4.9 \mathrm{~m}$ suppression lid was used. This lid was suspended from a boom connected to large fork truck, which was used to transport the lid and hoist it over the burning pan. Once the lid was placed over the pan, a small port on the side of the lid was carefully opened and $\mathrm{CO}_{2}$ was injected to suppress the fire. This method worked extremely well.

Once the fire was suppressed, personnel opened hangar doors to evacuate the smoke. During this time, all nonessential personnel were evacuated from the building until the smoke abated. Members of the fire fighting crew remained near the extinguished pan to ensure complete suppression and prevent potential re-ignition of the fuel.

\section{Data Reduction and Fuel Removal}

Once the smoke had been evacuated, participants reentered the building and returned to their stations. Data systems were reset and files were transferred to backup media. Results were printed and graphed for analysis. The residual fuel in the pan was removed once the temperature of the fuel decreased well below its flash point. Small hand pumps were used to transfer the residual fuel into the calibrated containers for final volume measurement. The fuel was then discarded into sealable steel drums and removed from the building. The base hazard materials team performed all fuel transfers and clean-up.

\section{Discuss Results with Participants}

The final process was to discuss the results from the previous experiment. Interesting events and unusual behavior of instrumentation was also discussed. Participants evaluated instrumentation damage and or changes required for the next experiment. The project leader was responsible for evaluating all results and planning the next experiment accordingly. 
Table 40. Test information for each experiment conducted in $22 \mathrm{~m}$ high facility

\begin{tabular}{|c|c|c|c|c|c|c|c|}
\hline $\begin{array}{c}\text { Test } \\
\text { Number }\end{array}$ & Date & Time & Pan Size & $\begin{array}{l}\text { Fuel } \\
\text { Type }\end{array}$ & $\begin{array}{l}\text { Amb. } \\
\text { Temp. } \\
\left({ }^{\circ} \mathrm{C}\right)\end{array}$ & $\begin{array}{l}\text { Ign. } \\
\text { Time } \\
\text { (s) }\end{array}$ & $\begin{array}{c}\text { Test } \\
\text { Duration } \\
\text { (s) }\end{array}$ \\
\hline 1 & $5 / 4 / 95$ & $08: 24$ & $0.3 \mathrm{~m} \mathrm{x} 0.3 \mathrm{~m}$ & JP-5 & 10 & 43 & 674 \\
\hline 2 & $5 / 4 / 95$ & $09: 25$ & $0.3 \mathrm{~m} \mathrm{x} 0.3 \mathrm{~m}$ & JP-5 & 10 & 86 & 693 \\
\hline 3 & $5 / 4 / 95$ & $10: 52$ & $0.6 \mathrm{~m} \mathrm{x} 0.6 \mathrm{~m}$ & JP-5 & 11 & 66 & 638 \\
\hline 4 & $5 / 4 / 95$ & $11: 49$ & $0.6 \mathrm{~m} \mathrm{x} 0.6 \mathrm{~m}$ & JP-5 & 14 & 75 & 620 \\
\hline 5 & $5 / 4 / 95$ & $13: 35$ & $0.9 \mathrm{~m} \times 0.9 \mathrm{~m}$ & JP-5 & 17 & 207 & 621 \\
\hline 6 & $5 / 4 / 95$ & $14: 51$ & $0.9 \mathrm{~m} \times 0.9 \mathrm{~m}$ & JP-5 & 16 & 246 & 619 \\
\hline 7 & $5 / 4 / 95$ & $16: 18$ & $1.2 \mathrm{mx} 1.2 \mathrm{~m}$ & JP-5 & 16 & 87 & 609 \\
\hline 8 & $5 / 4 / 95$ & $17: 49$ & $1.2 \mathrm{~m} \times 1.2 \mathrm{~m}$ & JP-5 & $\mathrm{n} / \mathrm{a}$ & 87 & 623 \\
\hline 9 & $5 / 5 / 95$ & 08:09 & $0.3 \mathrm{~m} \times 0.3 \mathrm{~m}$ & JP-8 & 9 & 71 & 610 \\
\hline 10 & $5 / 5 / 95$ & 09:08 & $0.6 \mathrm{~m} \times 0.6 \mathrm{~m}$ & JP-8 & 9 & 129 & 618 \\
\hline 11 & $5 / 5 / 95$ & 09:58 & $0.6 \mathrm{~m} \times 0.6 \mathrm{~m}$ & JP-8 & 9 & 91 & 613 \\
\hline 12 & $5 / 5 / 95$ & $11: 08$ & $0.9 \mathrm{~m} \times 0.9 \mathrm{~m}$ & JP-8 & 9 & 31 & 621 \\
\hline 13 & $5 / 5 / 95$ & $12: 26$ & $1.2 \mathrm{mx} 1.2 \mathrm{~m}$ & JP-8 & 11 & 39 & 629 \\
\hline 14 & $5 / 6 / 95$ & $09: 58$ & $2.5 \mathrm{~m}$ Diameter & JP-5 & 12 & 639 & 641 \\
\hline 15 & $5 / 6 / 95$ & $13: 33$ & $3.0 \mathrm{~m} \times 3.0 \mathrm{~m}$ & JP-5 & 12 & 205 & 659 \\
\hline $16^{2}$ & $5 / 6 / 95$ & $19: 30$ & $2.5 \mathrm{~m}$ Diameter & JP-5 & 8 & 291 & 383 \\
\hline 17 & $5 / 6 / 95$ & $21: 42$ & $3.0 \mathrm{~m} \times 3.0 \mathrm{~m}$ & JP-8 & 11 & 51 & 668 \\
\hline $18^{b}$ & $5 / 8 / 95$ & $10: 36$ & $2.0 \mathrm{~m}$ Diameter & JP-5 & 10 & 127 & 679 \\
\hline $19^{b, c}$ & $5 / 8 / 95$ & $12: 57$ & $2.5 \mathrm{~m}$ Diameter & JP-5 & 13 & 71 & 380 \\
\hline $20^{b}$ & $5 / 8 / 95$ & $17: 00$ & $3.0 \mathrm{~m} \times 3.0 \mathrm{~m}$ & JP-5 & 14 & 457 & 665 \\
\hline 21 & $5 / 9 / 95$ & $13: 12$ & $4.6 \mathrm{~m} \mathrm{x} 4.6 \mathrm{~m}$ & JP-5 & 14 & 211 & 294 \\
\hline $22^{\mathrm{d}}$ & $5 / 9 / 95$ & $18: 15$ & $4.6 \mathrm{~m} \times 4.6 \mathrm{~m}$ & JP-5 & 16 & 64 & 424 \\
\hline
\end{tabular}

${ }^{a}$ Test conducted with two hangar doors open.

${ }^{\mathrm{b}}$ Ceiling jet thermocouple configuration

${ }^{c}$ Test conducted with one hangar door open.

${ }^{\mathrm{d}}$ Simulated spill test 
Twenty-two experiments were conducted in the $22 \mathrm{~m}$ high facility, using the above procedures for each experiment. Table 40 contains a summary of information for each experiment. The date and time along with pan size, fuel type, ignition time, and test duration are included.

\subsubsection{Fuel Specifications}

All experiments conducted in the $22 \mathrm{~m}$ high facility utilized JP- 5 and JP- 8 jet fuel. The JP- 5 fuel for the full scale tests was taken from on-base reserves. The JP-8 fuel was delivered to Keflavik Naval Air Station from the United States Air Force. The base fuels department conducts certain standard tests on each batch of fuel delivered to the base. The fuel properties for the JP- 5 and JP- 8 used in these experiments as reported by the fuels department laboratory at Keflavik Naval Air Station are listed in Table 41. These values were within acceptable range as defined in the military specification for JP-5 [5] and JP-8 [6].

Table 41. Fuel properties of JP-5 and JP-8 used in experiments

\begin{tabular}{|c|c|c|c|c|c|c|}
\hline \multicolumn{7}{|c|}{ Fuel Samples, 22 m High Facility } \\
\hline $\begin{array}{c}\text { Reference } \\
\text { No. }\end{array}$ & $95-047$ & $95-048$ & $95-049$ & $95-050$ & $95-041$ & $95-042$ \\
$\begin{array}{c}\text { Fuel } \\
\text { Sample }\end{array}$ & JP-5 & JP-5 & JP-5 & JP-5 & JP-8 & JP-8 \\
Date Taken & $3 / 8 / 95$ & $5 / 9 / 95$ & $5 / 4 / 95$ & $5 / 6 / 95$ & $4 / 28 / 95$ & $4 / 28 / 95$ \\
API & 41.6 & 41.5 & 41.5 & 41.6 & 43.7 & 43.6 \\
$\begin{array}{c}\text { Gravity @ } \\
15{ }^{\circ} \mathrm{C}\end{array}$ & 0.8174 & 0.8179 & 0.8179 & 0.8174 & 0.8076 & 0.8081 \\
$\begin{array}{c}\text { Specific } \\
\text { Gravity } \\
\text { Density } \\
\left.\text { (kg/m }{ }^{3}\right)\end{array}$ & 817.1 & 817.5 & 817.5 & 817.1 & 807.3 & 807.7 \\
$\begin{array}{c}\text { Flash Point } \\
\left({ }^{\circ} \mathrm{C}\right)\end{array}$ & 62.8 & 63.3 & 63.3 & 62.8 & 45.6 & 47.8 \\
\hline
\end{tabular}




\subsection{Behavior of Fires in $22 \mathrm{~m}$ High Hangar}

There were twenty-two full-scale fire experiments performed in the Iceland hangar. As with the Hawaii tests, these experiments were broken into detector fires (less than $2.8 \mathrm{MW}$ ) and sprinkler fires (greater than $2.8 \mathrm{MW}$ ). The behavior of these fires is described in the following sections.

\subsubsection{Detector Fires}

There were thirteen detector fires conducted in the $22 \mathrm{~m}$ high facility, eight fires using JP-5 aviation fuel and five fires using JP- 8 aviation fuel. All of the detector fires were conducted using square pans supported by the three point load cell described earlier. The detector fires were ignited at one corner of the fire test pan using an acetylene torch. The ambient fuel temperatures ranged from $9{ }^{\circ} \mathrm{C}$ to $17^{\circ} \mathrm{C}$. The time required for the fire to involve the full pan is presented in Table 42. Included in Table 42 are the observed flame heights. These measurements were obtained through video analysis.

\section{Plume Symmetry}

The spacial location of the plume near the ceiling was determined using the regular array of thermocouples located $0.3 \mathrm{~m}$ beneath the ceiling at radial positions of $0.0 \mathrm{~m}, 3.0 \mathrm{~m}$, and $6.1 \mathrm{~m}$ in the experimental N, S, E, and W directions from the geometric center of the fire. The initial position of the plume near the ceiling was determined using the arrival time of the hot gas at each thermocouple while later plume positions were deduced by comparing the relative temperature of symmetric pairs of thermocouples in the N-S or E-W directions. An idealized plume should possess its highest temperature on its center line with mixing of the entrained ambient air causing the temperature distribution to decrease radially outward. The largest uncertainties in the determination of plume center would occur due to thermal irregularities in the plume and to the lack of simultaneity in the thermocouple measurements. Pairs of thermocouples were typically separated by no more than 10 data channels such that the lack of simultaneity was considerably less than the recording cycle of approximately $3.1 \mathrm{~s}$. For the $0.3 \mathrm{~m} \mathrm{x} 0.3 \mathrm{~m}$ pan fires, the low values of temperature at the ceiling make the determination of plume location difficult.

Videos of the fire taken using cameras looking east and southwest were used to determine the lean of the flame and lower plume. While the location of the smoke plume at the ceiling was either not available or difficult to determine owing to poor visibility at the ceiling, the lean of the flame and lower plume could provide verification of the positions determined by the thermocouples at the ceiling. The flame leans are determined based on the position of the tip of the continuous part of the flame compared to the location of the edge of the fire pan. The amount of the lean is given in meters from fire center. 'When the term 'slight lean' is used, the flame lean is less than $0.15 \mathrm{~m}$. Measurements of flame lean should be regarded as an estimate with an accuracy equal to about 0.25 of the pan diameter.

Two $0.3 \mathrm{~m} \mathrm{x} 0.3 \mathrm{~m}$ test were conducted using JP-5 (tests 1 and 2). Video observations of test 1 indicated that the flame exhibited a northeast lean of $0.15 \mathrm{~m}$ at about $40 \mathrm{~s}$ into the test. At $100 \mathrm{~s}$, the flame leaned about $0.15 \mathrm{~m}$ to the southeast and then to the south at about $140 \mathrm{~s}$. At $170 \mathrm{~s}$, fuel was observed to be burning off the southeast corner of the pan. Small amounts of fuel were observed to be burning off the south or southeast side of the pan up to $400 \mathrm{~s}$ into the test. The flame exhibited a northwest lean of about $0.3 \mathrm{~m}$ at $200 \mathrm{~s}$, centered itself at $240 \mathrm{~s}$, and then leaned $0.15 \mathrm{~m}$ to the southeast at $360 \mathrm{~s}$. At $410 \mathrm{~s}$, the flame again leaned $0.15 \mathrm{~m}$ to the northwest and then centered at $460 \mathrm{~s}$. 
Thermocouple measurements at the ceiling suggest that the plume exhibited a slight lean to the south between $80 \mathrm{~s}$ to $200 \mathrm{~s}$ into the test. This lean increased to about $3 \mathrm{~m}$ between $200 \mathrm{~s}$ to $500 \mathrm{~s}$. The increased lean coincided with observed burning of the fuel off the south side of the pan.

Video observations of test 2 indicate that the flame was initially centered but exhibited a $0.15 \mathrm{~m}$ lean to the northwest at about $25 \mathrm{~s}$ into the test. The flame centered $90 \mathrm{~s}$ into the test and then leaned $0.15 \mathrm{~m}$ to $0.3 \mathrm{~m}$ to the south or southeast for the next $300 \mathrm{~s}$. There was some burning of fuel off the south side of the pan at about $100 \mathrm{~s}$ into the test and on the east side of the pan at about $500 \mathrm{~s}$ into the test. Thermocouple measurements at the ceiling suggested that the plume was centered. The signals reflected the high turbulence levels in the plume, making the precise assessment of center position difficult.

Two $0.6 \mathrm{~m} \times 0.6 \mathrm{~m}$ tests were conducted using JP-5 (test 3 and 4). Video observations of test 3 showed that the flame leaned to the north or northwest from $20 \mathrm{~s}$ to about $430 \mathrm{~s}$. The average flame lean was about $0.15 \mathrm{~m}$ but at $70 \mathrm{~s}$, the lean appeared to increase to about $0.6 \mathrm{~m}$. During the period of maximum flame lean, there appeared to be some fuel burning off the north side of the pan. The flame was centered after $430 \mathrm{~s}$.

Thermocouple measurements at the ceiling showed about a $1.5 \mathrm{~m}$ plume lean to the north between $40 \mathrm{~s}$ and $170 \mathrm{~s}$. There was also a slight lean to the east between $100 \mathrm{~s}$ and $140 \mathrm{~s}$. Between $180 \mathrm{~s}$ and $450 \mathrm{~s}$, the plume was centered in the north - south directions and only leaned slightly to the west between $200 \mathrm{~s}$ and $280 \mathrm{~s}$ and again between $320 \mathrm{~s}$ and $500 \mathrm{~s}$. The plume also exhibited a slight southward lean between $460 \mathrm{~s}$ and $500 \mathrm{~s}$.

The flame lean for test 4 was consistently to the north or northwest with the lean typically only $0.15 \mathrm{~m}$. At $300 \mathrm{~s}$ into the test, some fuel was observed burning off the northeast corner of the pan and the lean increased to $0.3 \mathrm{~m}$ in the northwest for the next $90 \mathrm{~s}$. At $580 \mathrm{~s}$ into the test, burning off the north side of the pan occurred with the plume leaning as much as $0.6 \mathrm{~m}$ to the northwest. Thermocouple measurements at the ceiling indicated only a slight lean in the north and east direction. Plume lean to the east occurred between $40 \mathrm{~s}$ and $300 \mathrm{~s}$ and again between $410 \mathrm{~s}$ and $500 \mathrm{~s}$. Plume lean to the north occurred between $60 \mathrm{~s}$ and $120 \mathrm{~s}$ and again between $260 \mathrm{~s}$ and $390 \mathrm{~s}$.

Two $0.9 \mathrm{~m} \times 0.9 \mathrm{~m}$ tests were conducted using JP-5 (Test 5 and 6). For test 5, there was an initial flame lean of $0.15 \mathrm{~m}$ to the north with observed burning of fuel off the northwest side of the pan. The north lean of the flame increased to $0.3 \mathrm{~m}$ at $110 \mathrm{~s}$ and then increased to $0.6 \mathrm{~m}$ and changed directions to the northwest at $160 \mathrm{~s}$. At $120 \mathrm{~s}$, additional fuel burning off the north side of the pan was observed but the flame was essentially centered. At $200 \mathrm{~s}$, the plume started to rotate and produce a fire whirl. Additional burning of fuel off the northeast corner occurred at $230 \mathrm{~s}$ but this burning only produced a $0.15 \mathrm{~m}$ flame lean to the north. By $240 \mathrm{~s}$ the plume became centered and the fire whirl dissipated. At $345 \mathrm{~s}$ into the test, additional fuel burning again occurred on the south side of the pan with the flame leaning $0.3 \mathrm{~m}$ to the southeast. At $400 \mathrm{~s}$, a fire whirl developed to the south with additional burning of fuel off the south side of the pan. At $520 \mathrm{~s}$, the flame centered and the fire whirl dissipated.

Thermocouple measurements at the ceiling show that the plume leaned about $1.5 \mathrm{~m}$ to the south between $10 \mathrm{~s}$ and $30 \mathrm{~s}$. At $80 \mathrm{~s}$, the plume leaned to the north by as much as $3.0 \mathrm{~m}$. The $3.0 \mathrm{~m}$ lean to the north reoccurred between $350 \mathrm{~s}$ and $460 \mathrm{~s}$. In the east-west directions, the plume was initially centered but then leaned to the east by as much as $3.0 \mathrm{~m}$ between $35 \mathrm{~s}$ and $70 \mathrm{~s}$. The plume became 
upright between $80 \mathrm{~s}$ and $130 \mathrm{~s}$ and then leaned eastward about $1.5 \mathrm{~m}$ between $140 \mathrm{~s}$ and $330 \mathrm{~s}$.

The flame for test 6 exhibited a $0.15 \mathrm{~m}$ lean to the northwest between $30 \mathrm{~s}$ and $55 \mathrm{~s}$ and again between $280 \mathrm{~s}$ and $350 \mathrm{~s}$. At $420 \mathrm{~s}$, a northwest lean occurred which reached a maximum of $0.45 \mathrm{~m}$ at about $450 \mathrm{~s}$. Thermocouple measurements at the ceiling indicated only a slight lean to the south between $30 \mathrm{~s}$ and $50 \mathrm{~s}$. Between $70 \mathrm{~s}$ and $260 \mathrm{~s}$ and again between $290 \mathrm{~s}$ and $320 \mathrm{~s}$, the plume leaned slightly to the north. In the east - west direction, the plume exhibited a slight lean to the west between $30 \mathrm{~s}$ and $40 \mathrm{~s}$ and again between $120 \mathrm{~s}$ and $140 \mathrm{~s}$. It exhibited a slight lean to the east between $60 \mathrm{~s}$ and $90 \mathrm{~s}$ and again between $160 \mathrm{~s}$ and $350 \mathrm{~s}$.

Two $1.2 \mathrm{~m} \mathrm{x} 1.2 \mathrm{~m}$ tests were conducted using JP-5 (tests 7 and 8 ). For test 7 , the flame exhibited a lean of $0.15 \mathrm{~m}$ to the southeast between $20 \mathrm{~s}$ and $110 \mathrm{~s}$. At $215 \mathrm{~s}$, the flame began to lean to the northwest, reaching a maximum lean of $0.8 \mathrm{~m}$ to the northwest at about $220 \mathrm{~s}$. At this time there was burning of fuel off the north side of the pan. At $300 \mathrm{~s}$, the flame became upright and remained that way until $335 \mathrm{~s}$ when the flame leaned $0.6 \mathrm{~m}$ to the north. The northward lean increased to about $0.9 \mathrm{~m}$ to the north west at $400 \mathrm{~s}$. During this period, there was burning of fuel off the north side of the pan. From $480 \mathrm{~s}$ to $600 \mathrm{~s}$, the flame was upright. Thermocouple measurements at the ceiling indicated that the plume exhibited only a slight lean to the north between $20 \mathrm{~s}$ and $90 \mathrm{~s}$. In the east west direction, the plume leaned slightly to the west between $100 \mathrm{~s}$ and $150 \mathrm{~s}$ and again between $220 \mathrm{~s}$ and $250 \mathrm{~s}$. The plume leaned slightly to the east between $160 \mathrm{~s}$ and $210 \mathrm{~s}$ and again between $410 \mathrm{~s}$ and $500 \mathrm{~s}$.

For test 8, the flame exhibited a slight north lean at $90 \mathrm{~s}$ which increased to $0.4 \mathrm{~m}$ to the northwest by $100 \mathrm{~s}$. At $130 \mathrm{~s}$, the flame became upright and with the exception of a $0.15 \mathrm{~m}$ lean to the northwest between $180 \mathrm{~s}$ and $420 \mathrm{~s}$ and again between $560 \mathrm{~s}$ and $580 \mathrm{~s}$ was upright through the rest of the test period. Thermocouple measurements were not available for this test due to an equipment malfunction.

The JP-8 tests were conducted on a day when strong winds in excess of $48 \mathrm{~km} / \mathrm{h}$ (30 mph) were observed. The impact of the wind on the hangar test fires was to produce consistently large plume leans even though the building doors were closed during the tests. The wind blew consistently from the south which resulted in observed plume leans in the north direction. Test 9 was a $0.3 \mathrm{mx} 0.3 \mathrm{~m}$ JP-8 pan fire. The flame leaned $0.8 \mathrm{~m}$ to the north for the entire test. Fuel burned off the north side of the pan starting at $200 \mathrm{~s}$ into the test and continued to for the next $200 \mathrm{~s}$. Smoke was observed filling the north half of the curtained area first. Thermocouple measurements at the ceiling for this test indicated that the plume was centered for the first $250 \mathrm{~s}$ of the test and then leaned slightly to the north for the test duration.

Test 10 was a $0.6 \mathrm{~m} \times 0.6 \mathrm{~m} \mathrm{JP}-8$ pan fire. The flame leaned $0.5 \mathrm{~m}$ to the north at the start of the test. The flame lean increased to $0.9 \mathrm{~m}$ north by $50 \mathrm{~s}$ and was accompanied by burning off the north side of the pan. The strong north lean continued throughout the rest of the test with occasional episodes of burning off the north side of the pan. Thermocouple measurements at the ceiling indicated a north lean of $1.5 \mathrm{~m}$ between $40 \mathrm{~s}$ and $60 \mathrm{~s}$. This lean decreased in the north direction between $60 \mathrm{~s}$ and $100 \mathrm{~s}$ and then increased to a lean of $1.5 \mathrm{~m}$ to $3.0 \mathrm{~m}$ to the north between $100 \mathrm{~s}$ and $500 \mathrm{~s}$. The greatest north lean occurred between $220 \mathrm{~s}$ and $260 \mathrm{~s}$. There was also a slight eastward plume lean between $40 \mathrm{~s}$ and $370 \mathrm{~s}$.

Test 11 was a repeated $0.6 \mathrm{~m} \mathrm{x} 0.6 \mathrm{~m} \mathrm{JP}-8$ pan fire. The flames started with a slight north lean which 
increased to a lean of $0.8 \mathrm{~m}$ to the north by $50 \mathrm{~s}$. At $70 \mathrm{~s}$, burning was observed off the north side of the pan which persisted till about $250 \mathrm{~s}$. The flame consistently leaned $0.8 \mathrm{~m}$ to the north throughout the rest of the test. Thermocouple measurements at the ceiling indicated that the plume was centered for the first $300 \mathrm{~s}$ and then developed a slight east lean. Between $340 \mathrm{~s}$ and $370 \mathrm{~s}$ the plume was upright and then leaned slightly to the east between $370 \mathrm{~s}$ and $440 \mathrm{~s}$. The plume then remained upright throughout the rest of the test.

Test 12 was a $0.9 \mathrm{~m} \mathrm{x} 0.9 \mathrm{~m} \mathrm{JP}-8$ pan fire. The flame leaned slightly north at the start of the fire and increased its lean to $0.8 \mathrm{~m}$ north at $80 \mathrm{~s}$ when burning off the north side of the pan was observed. At $90 \mathrm{~s}$, a small fire whirl was observed to form at the northwest corner of the pan and lasted for about $20 \mathrm{~s}$. The $0.8 \mathrm{~m}$ lean to the north persisted for the remainder of the experiment. Thermocouple measurements at the ceiling indicated that the plume leaned between $3 \mathrm{~m}$ and $5 \mathrm{~m}$ to the north over the duration of the experiment. The plume also leaned slightly to the east between $400 \mathrm{~s}$ and $500 \mathrm{~s}$.

Test 13 was a $1.2 \mathrm{~m} \times 1.2 \mathrm{~m} \mathrm{JP}-8$ pan fire. The flame leaned $0.3 \mathrm{~m}$ to the north at the start of the fire. This lean increased to $0.9 \mathrm{~m}$ to the north at about $100 \mathrm{~s}$ into the fire and remained between $0.6 \mathrm{~m}$ and $0.9 \mathrm{~m}$ to the north for the duration of the fire. Burning off the north side of the pan produced a small fire whirl approximately $70 \mathrm{~s}$ into the test. By $160 \mathrm{~s}$, the fire whirl disappeared but there was still substantial burning of fuel off the north side of the pan. Thermocouple measurements at the ceiling indicated that the plume leaned $3 \mathrm{~m}$ and $5 \mathrm{~m}$ to the north between $20 \mathrm{~s}$ and $410 \mathrm{~s}$ with the north lean reducing to $3 \mathrm{~m}$ between $410 \mathrm{~s}$ and $500 \mathrm{~s}$. The plume was upright in the east-west direction for the entire test.

\section{Temperature}

The ambient temperature for each of the thirteen detector fires is listed in Table 43. Ambient temperatures for these tests ranged between $9{ }^{\circ} \mathrm{C}$ and $16^{\circ} \mathrm{C}$. Also listed in the table is the temperature rise above ambient recorded by thermocouples located $0.3 \mathrm{~m}$ beneath the ceiling and radially at fire center and at $3.0 \mathrm{~m}$ to the north, south, east, and west of fire center (C, N1, S1, E1, and W1). The temperature values reported are based on analyzing the temperature range over the time interval where the fire's mass loss rate appeared steady and choosing the value equal to ninety percent of the range. In general, the ceiling temperature increases with time, hence the temperature values reported in the table will typically be realized late in the test period. The temperatures reported in the table will not be useful in determining plume symmetry with respect to the fire center, since the ninety percent temperature values at each thermocouple could occur at different times as the plume center moves around the ceiling. Also listed are the heat release rates and pan size for each fire.

\section{Heat Flow}

The impact of the draft curtain on smoke flow can be studied by comparing the time required for the combustion products to produce a $3.0^{\circ} \mathrm{C}$ temperature rise at thermocouples E7 and S7.

Thermocouple E7 was located $22.9 \mathrm{~m}(75 \mathrm{ft})$ from the geometric center of the fire $0.3 \mathrm{~m}(1.0 \mathrm{ft})$ beneath the ceiling along the curved portion of the ceiling. Thermocouple S7 was located $21.6 \mathrm{~m} \mathrm{(71}$ $\mathrm{ft}$ ) from the geometric center of the fire and $0.3 \mathrm{~m}$ beneath the ceiling in the adjacent draft curtain bay just before the second draft curtain. Since both thermocouples were located approximately the same radial distance from the fire, time differences in the arrival of the hot gas would give an indication of how effective the draft curtain was in containing heat and smoke. Figure 41 shows a comparison of the 
time required to produce a $3{ }^{\circ} \mathrm{C}$ temperature rise at thermocouples $\mathrm{E} 7$ and $\mathrm{S} 7$ as a function of heat release rate (HRR) for the JP-5 pan fires. The detector fires, with heat release rates less than $3 \mathrm{MW}$, produced substantial time differences in the two directions with the hot gas arriving at least $100 \mathrm{~s}$ earlier in the direction parallel to the draft curtain. The $0.3 \mathrm{~m}$ by $0.3 \mathrm{~m}$ pan fires were not included in the figure because the temperature increases were insignificant at these large distances from the fire.

The JP-8 pan fires show a similar trend with the largest detector fire showing a $70 \mathrm{~s}$ difference in the two directions. The hot gas flow for the JP-8 detector fires was impacted by strong winds blowing outside the hangar as mentioned in the plume symmetry section. The ability of the draft curtains to contain the heat and smoke was only slightly modified by the induced air currents in the building.

Hot gas flow within the first draft curtain can be studied by using the set of 20 thermocouples located at radial distances south from fire center of $3.0 \mathrm{~m}, 4.6 \mathrm{~m}, 6.1 \mathrm{~m}$, and $6.7 \mathrm{~m}$ and at distances beneath the ceiling of $0.3 \mathrm{~m}, 1.5 \mathrm{~m}, 3.0 \mathrm{~m}, 4.6 \mathrm{~m}$, and $6.1 \mathrm{~m}$. The hot gas would be expected to flow radially outward from plume center as a ceiling jet, be deflected downward by the draft curtain, lose buoyancy and be drawn back toward the plume as shown in Figure 71. The effect of this circulation pattern would be to create a low temperature volume in a central region between the plume and the draft curtain. The temperature data from test 7 , a $1.2 \mathrm{~m} \mathrm{x} 1.2 \mathrm{~m}$ pan fire, provides an excellent example of this flow. Table 44 presents the time necessary to reach a $3{ }^{\circ} \mathrm{C}$ temperature rise for each thermocouple in the thermocouple array.

From the table it can be seen that thermocouple S3a, S2b, S3b, S2c, and S2d require the most time to reach $3{ }^{\circ} \mathrm{C}$. This is consistent with the flow pattern shown in Figure 71. Other fire tests show similar temperature profiles, but the feature is most easily visualized using the smaller tests as the large tests tend to quickly fill the draft curtain and cut off the flow of ambient air to the draft curtained region.

The flow of hot gas along the curved portion of the ceiling can be analyzed by comparing the $3{ }^{\circ} \mathrm{C}$ temperature rise times for thermocouples E1, E3, E5, and E7 at radial distances from fire center of 3.0 $\mathrm{m}, 9.1 \mathrm{~m}, 15.2 \mathrm{~m}$, and $22.9 \mathrm{~m}$ as shown in Table 45. For the detector fires (less than $3 \mathrm{MW}$ ), it took from $20 \mathrm{~s}$ to $44 \mathrm{~s}$ for the hot gas to move from thermocouple E1 to thermocouple E5. From thermocouple E5 to thermocouple E7 it took from $28 \mathrm{~s}$ to $80 \mathrm{~s}$ for the hot gas to cover this distance. The increased time for the hot gas to move between E5 and E7 indicates a substantial decrease in ceiling jet velocity.

\section{Ceiling Jet Velocities}

Ceiling jet velocities were measured using mass flow meters positioned at $6.1 \mathrm{~m}$ and $12.2 \mathrm{~m}(20 \mathrm{ft}$ and $40 \mathrm{ft}$ ) from fire center along the curved roof in the east direction. The mass flow meters were located $0.3 \mathrm{~m}$ beneath the ceiling. For the JP- 5 tests, the $0.3 \mathrm{~m} \mathrm{x} 0.3 \mathrm{~m}$ pan fires yielded a ceiling jet velocity of about $0.25 \mathrm{~m} / \mathrm{s}$ at $6.1 \mathrm{~m}$ for both tests. The highest ceiling jet velocities were recorded for test 5 , a $0.9 \mathrm{~m} \mathrm{x} 0.9 \mathrm{~m}$ pan fire where the velocities early in the test reached speeds of about $1.4 \mathrm{~m} / \mathrm{s}$. Figure 72 presents the time history of these measurements for this $0.9 \mathrm{~m} \mathrm{x} 0.9 \mathrm{~m}$ test fire. Typical ceiling jet velocities for the three larger fires ranged from $0.6 \mathrm{~m} / \mathrm{s}$ to $1.0 \mathrm{~m} / \mathrm{s}$ with little evidence of dependence on fire size. With the exception of the smallest JP-5 test, measured ceiling jet velocity tended to be larger early in the test. This is probably due to the formation of the layer with the subsequent loss of buoyancy by the plume gases penetrating the layer. With the exception of $0.3 \mathrm{~m} \mathrm{x} 0.3 \mathrm{~m}$ pan fires, the ceiling jet velocities $12.2 \mathrm{~m}$ from fire center for all the JP- 5 detector fires ranged between $0.2 \mathrm{~m} / \mathrm{s}$ and 
$0.4 \mathrm{~m} / \mathrm{s}$ independent of fire size. The $0.3 \mathrm{~m} \mathrm{x} 0.3 \mathrm{~m}$ pan fire produced a ceiling jet velocity of $0.1 \mathrm{~m} / \mathrm{s}$ at $12.2 \mathrm{~m}$ east of fire center.

The JP-8 detector fires tended to exhibit higher ceiling jet velocities than the JP-5 test with the ceiling jet velocities at $6.1 \mathrm{~m}$ from fire center ranging between $0.75 \mathrm{~m} / \mathrm{s}$ and $1.2 \mathrm{~m} / \mathrm{s}$ for the three larger tests. The ceiling jet velocity for these tests stayed relatively constant during the entire test and did not exhibit the decrease in velocity with time observed for the JP-5 tests. The $0.3 \mathrm{~m} \mathrm{x} 0.3 \mathrm{~m} \mathrm{JP}-8$ test exhibited ceiling jet velocities at $6.1 \mathrm{~m}$ of about twice the ceiling jet velocities for the JP-5 fires. At $12.2 \mathrm{~m}$ from fire center, the larger three JP-8 fires yielded ceiling jet velocities in the range from $0.25 \mathrm{~m} / \mathrm{s}$ to 0.5 $\mathrm{m} / \mathrm{s}$ which again was somewhat higher than the JP-5 fires. It should be noted that the JP-8 fire plumes were affected by windy conditions outside the hangar. These windy conditions are likely to be responsible for the differences observed in the ceiling jet velocities between the JP-5 and JP- 8 tests.

In all cases, the measured ceiling jet velocities are substantially smaller than theory would predict using Alpert's correlations for a flat ceiling [31]. For the present experiments, the smoke flow at the ceiling is obstructed by beams and trusses. The primary obstruction to the smoke flow is a series of ceiling beams of width from $0.2 \mathrm{~m}$ to $0.3 \mathrm{~m}$. These beams run perpendicularly to the flow direction measured by the flow meters and are spaced every $1.5 \mathrm{~m}$ to $2.1 \mathrm{~m}$ on center. A series of trusses also running perpendicular to the flow are positioned on top of the beams and are spaced at intervals ranging from $5.8 \mathrm{~m}$ to $6.4 \mathrm{~m}$ on center. Since the flow meters were positioned $0.3 \mathrm{~m}$ below the ceiling, the presence of the ceiling beams of an equivalent width would be expected to reduce the flow velocities at these elevations compared to the expected flow velocities from smooth ceiling calculations. A second factor which may play a role in reducing the flow velocity is the ceiling curvature. The fire was centered over the highest part of the hangar ceiling. Smoke flow along the curved part of the ceiling would be required to follow a downward sloping path and therefore be slowed by the buoyant forces of the fire.

\section{Heat Flux Measurements}

Heat flux was measured using three flux meters which are described in section 3. Due to the small magnitude of the transducer output signal, the data collection system could only resolve a reading of approximately $0.25 \mathrm{~kW} / \mathrm{m}^{2}$; hence, only the flux meter $\mathrm{R} 1$ registered non-zero flux measurements for the detector fires. Table 46 lists the average radiative flux by $\mathrm{R} 1$ as a function of detector position from the center of the pan during steady-state burning.

For test numbers 1,2 , and 9 the heat flux was below the measurable threshold of $\mathrm{R} 1$. Plotting the heat flux measurements from the JP-5 tests $(5-7)$ and the JP-8 tests $(10$ - 13) where the detector positions were kept approximately constant, the flux appears to be comparable for both fuels. This comparison is shown in Figure 73. Based on the average values of these measurements, it appears the intensity of heat flux increases linearly with heat release rate. Figure 74 shows the measured thermal radiation with respect to time for the $0.9 \mathrm{~m} \times 0.9 \mathrm{~m}$ and $1.2 \mathrm{~m} \times 1.2 \mathrm{~m}$ pan fires using JP-5 fuel. Figure 75 shows the measurements for each detector fire using JP-8 with the exception of test 9 . The heat flux radiometers mounted at two positions near the ceiling did not indicate measurable levels of heat flux for these detector fires.

\section{Heat Release Rate}

Heat release information for the 13 detector fires was calculated using time dependent mass loss data 
provided by the load platform. In addition, measurements of initial and final fuel volume were made. This method of volume measurement has an estimated uncertainty of $\pm 0.47 \ell$ ( \pm 0.5 quarts), based on the error in reading the fuel volume from the buckets, and any spillage occurring during fuel transfer.

The amount of fuel consumed by the fire was determined using both the load platform (direct mass loss rate) method and volume consumed method. The heat release rate was then determined by multiplying the measured mass loss of fuel by the heat of combustion of the fuel. Using the volume of fuel consumed method, an estimate of heat release rate was made by calculating the average mass loss, using the density of the fuel multiplied by the measured volume, over the duration of the test. This method of determining heat release rate included the volume consumed over the entire test. Since the final volume was not measured until the residual fuel in the pan cooled to below its flash point, the total volume of fuel consumed would include any losses due to fuel vaporization and minimal losses during the extinguishment process. Table 47 shows calculated heat release rates using both methods of mass loss measurement, burning rates, and steady state time interval.

The mass loss rate using the load platform method is provided for all thirteen detector fires with the exception of test 8 , which is not available due to equipment malfunction. For each test, a linear curve fit was used to determine burning rate after an approximate steady state condition was reached. The steady state condition was defined as the region on the mass loss curve where the slope was consistently decreasing without major fluctuations.

There were difficulties in determining the steady state heat release rate values for several of the detector experiments. These problems are attributed to fluctuations in the mass loss curves during the early stages of the experiment. Fluctuations were caused by instrumental anomalies, non-uniform burning, and burning outside of the pan in some cases. An effort was made to adapt high-order polynomial curve fits that were representative of the time dependant mass loss rate. However, heat release rates calculated from the derivative of these polynomials were very sensitive to small changes in slope and showed poor agreement with the steady state heat release values.

To simplify the process, a steady state region was determined and the linear fit extended to the limits of the steady state interval. It is important to realize that by changing the steady state interval, changes may occur in the resultant heat release value. The uncertainty of the calculated heat release rates was determined by evaluating upper and lower limits obtained by using curve fits during various portions of the mass loss curve. Figure 76 shows the measured mass loss for test 7 and test $13(1.2 \mathrm{~m} \mathrm{x} 1.2 \mathrm{~m}$ pans), the region where steady state was determined, and a linear curve fit of the steady state region.

The burning rate increased during the early part of the fire until a steady state condition was reached. The time required to reach this condition varied with pan size with the larger pans generally requiring more time to reach steady state. Figures 77 and 78 show the mass loss curves for the $0.6 \mathrm{~m} \times 0.6 \mathrm{~m}$ and $0.9 \mathrm{~m} \times 0.9 \mathrm{~m}$ test fires using JP- 5 and JP- 8 fuels.

\subsubsection{Sprinkler Fires}

There were eight sprinkler fires conducted in the $22 \mathrm{~m}$ high facility, seven fires using JP- 5 aviation fuel and one fire using JP-8 fuel. Two of the JP-5 fires were open door fires. All except one of the sprinkler fires used the four point load cell. The $4.6 \mathrm{~m} \times 4.6 \mathrm{~m}$ square pan was not rigid enough to be 
Table 42. Time to full-pan involvement and observed flame heights for detector fires

\begin{tabular}{|c|c|c|c|c|c|c|}
\hline $\begin{array}{c}\text { Test } \\
\text { Number }\end{array}$ & $\begin{array}{c}\text { Fuel } \\
\text { Type }\end{array}$ & $\begin{array}{c}\text { Pan Size } \\
\mathrm{m}\end{array}$ & $\begin{array}{c}\text { Time to Full } \\
\text { Involvement } \\
\mathrm{s}\end{array}$ & $\begin{array}{c}\text { Flame } \\
\text { Height } \\
\mathrm{m}\end{array}$ & $\begin{array}{c}\text { Steady State Heat } \\
\text { Release Rate } \\
\mathrm{MW}\end{array}$ & $\begin{array}{c}\text { Steady State } \\
\text { Range } \\
\mathrm{s}\end{array}$ \\
\hline 1 & $\mathrm{JP}-5$ & $0.3 \times 0.3$ & 2 & 0.9 & 0.1 & $120-600$ \\
\hline 2 & $\mathrm{JP}-5$ & $0.3 \times 0.3$ & 2 & 0.9 & 0.1 & $150-600$ \\
\hline 3 & $\mathrm{JP}-5$ & $0.6 \times 0.6$ & 15 & 2.0 & 0.9 & $120-360$ \\
\hline 4 & $\mathrm{JP}-5$ & $0.6 \times 0.6$ & 15 & 1.8 & 0.8 & $125-420$ \\
\hline 5 & $\mathrm{JP}-5$ & $0.9 \times 0.9$ & 20 & 2.6 & 1.7 & $90-330$ \\
\hline 6 & $\mathrm{JP}-5$ & $0.9 \times 0.9$ & 20 & 2.5 & 1.4 & $120-420$ \\
\hline 7 & $\mathrm{JP}-5$ & $1.2 \times 1.2$ & 30 & 3.5 & 2.8 & $150-420$ \\
\hline 8 & $\mathrm{JP}-5$ & $1.2 \times 1.2$ & 30 & 3.3 & $\mathrm{n} / \mathrm{a}^{\mathrm{b}}$ & $\mathrm{n} / \mathrm{a}^{\mathrm{b}}$ \\
\hline 9 & $\mathrm{JP}-8$ & $0.3 \times 0.3$ & 2 & $0.7^{\mathrm{a}}$ & 0.2 & $120-450$ \\
\hline 10 & $\mathrm{JP}-8$ & $0.6 \times 0.6$ & 15 & $1.4^{\mathrm{a}}$ & 0.6 & $120-510$ \\
\hline 11 & $\mathrm{JP}-8$ & $0.6 \times 0.6$ & 15 & $1.3^{\mathrm{a}}$ & 0.8 & $120-450$ \\
\hline 12 & $\mathrm{JP}-8$ & $0.9 \times 0.9$ & 20 & $2.0^{\mathrm{a}}$ & 1.6 & $180-420$ \\
\hline 13 & $\mathrm{JP}-8$ & $1.2 \times 1.2$ & 30 & $2.4^{\mathrm{a}}$ & 2.7 & $120-420$ \\
\hline
\end{tabular}

a Significant plume and flame lean

b Data not available due to equipment malfunction 
Table 43. Temperature data for $22 \mathrm{~m}$ high facility detector fire tests

\begin{tabular}{|c|c|c|c|c|c|c|c|c|c|c|}
\hline $\begin{array}{c}\text { Test } \\
\text { Number }\end{array}$ & $\begin{array}{c}\text { Pan Size } \\
\mathrm{m}\end{array}$ & $\mathrm{T}_{\text {amb }}$ & $\begin{array}{c}\text { Steady State } \\
\text { Heat Release } \\
\text { Rate, MW }\end{array}$ & $\mathrm{C}$ & $\mathrm{N} 1$ & $\mathrm{~S} 1$ & $\mathrm{~W} 1$ & $\mathrm{E} 1$ & $\begin{array}{c}\text { Max. } \\
\text { Value }\end{array}$ & $\begin{array}{c}\text { Rise } \\
\text { Above } \\
\mathrm{T}_{\text {amb }}\end{array}$ \\
\hline Test 1 & $0.3 \times 0.3$ & 10 & 0.1 & 13 & 12 & 13 & 13 & 13 & 13 & 3 \\
\hline Test 2 & $0.3 \times 0.3$ & 10 & 0.1 & 13 & 13 & 13 & 13 & 13 & 13 & 3 \\
\hline Test 3 & $0.6 \times 0.6$ & 11 & 0.9 & 20 & 20 & 19 & 20 & 19 & 20 & 9 \\
\hline Test 4 & $0.6 \times 0.6$ & 14 & 0.8 & 22 & 21 & 21 & 21 & 21 & 22 & 8 \\
\hline Test 5 & $0.9 \times 0.9$ & 17 & 1.7 & 29 & 30 & 29 & 29 & 30 & 30 & 13 \\
\hline Test 6 & $0.9 \times 0.9$ & 16 & 1.4 & 33 & 32 & 33 & 32 & 32 & 33 & 17 \\
\hline Test 7 & $1.2 \times 1.2$ & 16 & 2.8 & 47 & 46 & 45 & 45 & 45 & 47 & 31 \\
\hline Test $8^{\mathrm{a}}$ & $1.2 \times 1.2$ & $\mathrm{n} / \mathrm{a}$ & $\mathrm{n} / \mathrm{a}$ & $\mathrm{n} / \mathrm{a}$ & $\mathrm{n} / \mathrm{a}$ & $\mathrm{n} / \mathrm{a}$ & $\mathrm{n} / \mathrm{a}$ & $\mathrm{n} / \mathrm{a}$ & $\mathrm{n} / \mathrm{a}$ & $\mathrm{n} / \mathrm{a}$ \\
\hline Test $9^{\mathrm{b}}$ & $0.3 \times 0.3$ & 9 & 0.2 & 11 & 11 & 11 & 11 & 11 & 11 & 2 \\
\hline Test $10^{\mathrm{b}}$ & $0.6 \times 0.6$ & 9 & 0.6 & 17 & 18 & 17 & 18 & 18 & 18 & 9 \\
\hline Test $11^{\mathrm{b}}$ & $0.6 \times 0.6$ & 9 & 0.8 & 17 & 18 & 16 & 17 & 17 & 18 & 9 \\
\hline Test $12^{\mathrm{b}}$ & $0.9 \times 0.9$ & 9 & 1.6 & 26 & 27 & 24 & 25 & 26 & 27 & 18 \\
\hline Test $13^{\mathrm{b}}$ & $1.2 \times 1.2$ & 11 & 2.7 & 36 & 38 & 34 & 36 & 36 & 38 & 27 \\
\hline
\end{tabular}

${ }^{a}$ Data for test 8 not available due to equipment malfunction

${ }^{b}$ JP-8 aviation fuel used

Table 44. Time for hot gas to fill draft curtain volume based upon $3{ }^{\circ} \mathrm{C}$ temperature rise for south array of thermocouples for test 7 (1.2 $\mathrm{m} \times 1.2 \mathrm{~m}, \mathrm{JP}-5$ fuel, $2.8 \mathrm{MW}$ HRR)

\begin{tabular}{|c|c|c|c|c|}
\hline \multirow{2}{*}{$\begin{array}{c}\text { Depth Below } \\
\text { Ceiling }\end{array}$} & \multicolumn{4}{|c|}{ Radial Distance From Center } \\
\cline { 2 - 5 } & south $3.0 \mathrm{~m}$ & south $4.6 \mathrm{~m}$ & south $6.1 \mathrm{~m}$ & south $6.7 \mathrm{~m}$ \\
\hline $0.3 \mathrm{~m}$ & $26 \mathrm{~s}$ & $26 \mathrm{~s}$ & $34 \mathrm{~s}$ & $34 \mathrm{~s}$ \\
\hline $1.5 \mathrm{~m}$ & $26 \mathrm{~s}$ & $34 \mathrm{~s}$ & $42 \mathrm{~s}$ & $34 \mathrm{~s}$ \\
\hline $3.0 \mathrm{~m}$ & $34 \mathrm{~s}$ & $58 \mathrm{~s}$ & $58 \mathrm{~s}$ & $34 \mathrm{~s}$ \\
\hline $4.6 \mathrm{~m}$ & $38 \mathrm{~s}$ & $46 \mathrm{~s}$ & $34 \mathrm{~s}$ & $34 \mathrm{~s}$ \\
\hline $6.1 \mathrm{~m}$ & $34 \mathrm{~s}$ & $58 \mathrm{~s}$ & $46 \mathrm{~s}$ & $46 \mathrm{~s}$ \\
\hline
\end{tabular}


Table 45. Hot gas transport times along east direction of ceiling

\begin{tabular}{|c|c|c|c|c|c|c|}
\hline Test Number & \multirow{2}{*}{$\begin{array}{c}\text { Pan Size } \\
\mathrm{m}\end{array}$} & $\begin{array}{c}\text { HRR } \\
\text { MW }\end{array}$ & \multicolumn{4}{|c|}{ Transport Times (s) } \\
\cline { 4 - 7 } & & $\mathrm{E} 1$ & $\mathrm{E} 3$ & $\mathrm{E} 5$ & $\mathrm{E} 7$ \\
\hline Test 3 & $0.6 \times 0.6$ & 0.9 & 53.6 & 93.3 & 97.3 & 177.5 \\
\hline Test 4 & $0.6 \times 0.6$ & 0.8 & 77.4 & 101.2 & 101.2 & 196.5 \\
\hline Test 5 & $0.9 \times 0.9$ & 1.7 & 33.7 & 56 & 56 & 83.3 \\
\hline Test 6 & $0.9 \times 0.9$ & 1.4 & 34.3 & 61.5 & 61.5 & 120.5 \\
\hline Test 7 & $1.2 \times 1.2$ & 2.8 & 26 & 42.1 & 54.2 & 82.4 \\
\hline Test $10^{\mathrm{a}}$ & $0.6 \times 0.6$ & 0.6 & 42.4 & 91.6 & 112.2 & 218.8 \\
\hline Test $11^{\mathrm{a}}$ & $0.6 \times 0.6$ & 0.8 & 54.3 & 102.6 & 102.6 & 187.8 \\
\hline Test $12^{\mathrm{a}}$ & $0.9 \times 0.9$ & 1.6 & 34.5 & 42.6 & 66.8 & 103.2 \\
\hline Test $13^{\mathrm{a}}$ & $1.2 \times 1.2$ & 2.7 & 26.6 & 38.6 & 54.7 & 90.9 \\
\hline
\end{tabular}

${ }^{a}$ JP-8 aviation fuel used

Table 46. Heat flux measurements for detector fires

\begin{tabular}{|c|c|c|c|c|c|c|}
\hline $\begin{array}{c}\text { Test } \\
\text { Number }\end{array}$ & $\begin{array}{c}\text { Pan Size } \\
\mathrm{m}\end{array}$ & Fuel & $\begin{array}{c}\text { Heat Release } \\
\text { Rate } \\
\mathrm{MW}( \pm 0.1)\end{array}$ & \multicolumn{2}{|c|}{$\begin{array}{c}\text { Location with Respect to Pan } \\
\text { Center, } \mathrm{m}( \pm 0.1)\end{array}$} & $\begin{array}{c}\text { Radiative Flux, } \\
\text { Ristance }\end{array}$ \\
\hline 3 & $0.6 \times 0.6$ & $\mathrm{JP}-5$ & 0.9 & 4.4 & 1.6 & 1.0 \\
\hline 4 & $0.6 \times 0.6$ & $\mathrm{JP}-5$ & 0.8 & 7.6 & 1.6 & 0.25 \\
\hline 5 & $0.9 \times 0.9$ & $\mathrm{JP}-5$ & 1.7 & 3.7 & 1.1 & 3.5 \\
\hline 6 & $0.9 \times 0.9$ & $\mathrm{JP}-5$ & 1.4 & 3.7 & 1.1 & 3.0 \\
\hline 7 & $1.2 \times 1.2$ & JP-5 & 2.8 & 3.7 & 1.1 & 4.5 \\
\hline 10 & $0.6 \times 0.6$ & JP-8 & 0.6 & 3.8 & 1.1 & 1.5 \\
\hline 11 & $0.6 \times 0.6$ & JP-8 & 0.8 & 3.8 & 1.1 & 1.5 \\
\hline 12 & $0.9 \times 0.9$ & JP-8 & 1.6 & 3.8 & 1.1 & 3.5 \\
\hline 13 & $1.2 \times 1.2$ & JP-8 & 2.7 & 3.8 & 1.1 & 5.5 \\
\hline
\end{tabular}


Table 47. Heat release information for detector fires in $22 \mathrm{~m}$ high facility

\begin{tabular}{|c|c|c|c|c|c|c|c|c|c|}
\hline $\begin{array}{l}\text { Test } \\
\text { Number }\end{array}$ & $\begin{array}{c}\text { Pan Size } \\
\mathrm{m}\end{array}$ & Fuel & $\begin{array}{c}\text { Eff. } \\
\text { Pan Dia: } \\
\text { m }\end{array}$ & $\begin{array}{c}\text { Res. } \\
\text { Volume } \\
\ell \\
\pm 0.47\end{array}$ & $\begin{array}{c}\text { Burn Rate } \\
\text { (vol.) } \\
\mathrm{kg} / \mathrm{m}^{2} \mathrm{~s} \\
\pm 0.001\end{array}$ & $\begin{array}{l}\text { Burn Rate } \\
\text { (load) } \\
\mathrm{kg} / \mathrm{m}^{2} \mathrm{~s} \\
\pm 0.001\end{array}$ & $\begin{array}{l}\text { HRR } \\
\text { (vol.) } \\
\text { MW } \\
\pm 0.1\end{array}$ & $\begin{array}{l}\text { HRR } \\
\text { (load) } \\
\text { MW } \\
\pm 0.1\end{array}$ & $\begin{array}{c}\text { SS Range } \\
\mathrm{s}\end{array}$ \\
\hline 1 & $0.3 \times 0.3$ & JP-5 & 0.34 & 3.1 & 0.0409 & 0.0233 & 0.2 & 0.1 & $110-607$ \\
\hline 2 & $0.3 \times 0.3$ & JP-5 & 0.34 & 3.3 & 0.0429 & 0.0199 & 0.2 & 0.1 & $150-600$ \\
\hline 3 & $0.6 \times 0.6$ & JP-5 & 0.68 & 7.6 & 0.0266 & 0.0601 & 0.4 & 0.9 & $120-360$ \\
\hline 4 & $0.6 \times 0.6$ & JP-5 & 0.68 & 9.5 & 0.0342 & 0.0496 & 0.5 & 0.8 & $125-420$ \\
\hline 5 & $0.9 \times 0.9$ & JP-5 & 1.02 & 22.7 & 0.0364 & 0.0486 & 1.3 & 1.7 & $90-330$ \\
\hline 6 & $0.9 \times 0.9$ & JP-5 & 1.02 & 22.7 & 0.0366 & 0.0400 & 1.3 & 1.4 & $120-420$ \\
\hline 7 & $1.2 \times 1.2$ & JP-5 & 1.35 & 48.3 & 0.0444 & 0.0454 & 2.8 & 2.8 & $150-420$ \\
\hline 8 & $1.2 \times 1.2$ & JP-5 & 1.35 & 45.4 & 0.0409 & $\mathrm{n} / \mathrm{a}^{\mathrm{a}}$ & 2.5 & $\mathrm{n} / \mathrm{a}^{\mathrm{a}}$ & $\mathrm{n} / \mathrm{a}^{\mathrm{a}}$ \\
\hline 9 & $0.3 \times 0.3$ & JP-8 & 0.34 & 1.9 & 0.0278 & 0.0461 & 0.1 & 0.2 & $120-450$ \\
\hline 10 & $0.6 \times 0.6$ & JP-8 & 0.68 & 10.4 & 0.0378 & 0.0386 & 0.6 & 0.6 & $120-510$ \\
\hline 11 & $0.6 \times 0.6$ & JP-8 & 0.68 & 10.4 & 0.0381 & 0.0499 & 0.6 & 0.8 & $120-450$ \\
\hline 12 & $0.9 \times 0.9$ & JP-8 & 1.02 & 27.4 & 0.044 & 0.0465 & 1.5 & 1.6 & $180-420$ \\
\hline 13 & $1.2 \times 1.2$ & JP-8 & 1.35 & 49.2 & 0.0438 & 0.0429 & 2.7 & 2.7 & $120-420$ \\
\hline
\end{tabular}

a Data not available due to equipment malfunction

Table 48. Time to full-pan involvement and observed flame heights for sprinkler fires

\begin{tabular}{|c|c|c|c|c|c|c|}
\hline $\begin{array}{c}\text { Test } \\
\text { Number }\end{array}$ & $\begin{array}{c}\text { Fuel } \\
\text { Type }\end{array}$ & $\begin{array}{c}\text { Pan Size } \\
\mathrm{m}\end{array}$ & $\begin{array}{c}\text { Time to Full } \\
\text { Involvement } \\
\mathrm{s}( \pm 5)\end{array}$ & $\begin{array}{c}\text { Flame } \\
\text { Height } \\
\mathrm{m}\end{array}$ & $\begin{array}{c}\text { Steady State Heat } \\
\text { Release Rate } \\
\text { MW }\end{array}$ & $\begin{array}{c}\text { Steady State } \\
\text { Range } \\
\mathrm{s}\end{array}$ \\
\hline $14^{\mathrm{a}}$ & JP-5 & $2.5 \mathrm{dia}$ & 50 & $5.1 \pm 0.5$ & 7.9 & $120-420$ \\
\hline 15 & JP-5 & $3.0 \times 3.0$ & 65 & $6.1 \pm 0.5$ & 15.7 & $330-600$ \\
\hline $16^{\mathrm{c}}$ & JP-5 & 2.5 dia. & 50 & $5.0 \pm 0.5$ & 7 & $180-270$ \\
\hline 17 & JP-8 & $3.0 \times 3.0$ & 50 & $6.0 \pm 0.5$ & 14.3 & $270-540$ \\
\hline 18 & JP-5 & 2.0 dia. & 40 & $4.5 \pm 0.5$ & 4.9 & $180-420$ \\
\hline $19^{\text {bc }}$ & JP-5 & 2.5 dia & 50 & $4.7 \pm 0.5$ & 9.1 & $120-420$ \\
\hline 20 & JP-5 & $3.0 \times 3.0$ & 65 & $6.1 \pm 0.5$ & 14.6 & $240-540$ \\
\hline 21 & JP-5 & $4.6 \times 4.6$ & 80 & $10 \pm 1$ & $33^{\mathrm{d}}$ & $\mathrm{n} / \mathrm{a}$ \\
\hline
\end{tabular}

Both hangar doors open fully

b North hangar door open fully

c Significant plume and flame lean

d Heat release rate extrapolated from previous test data 


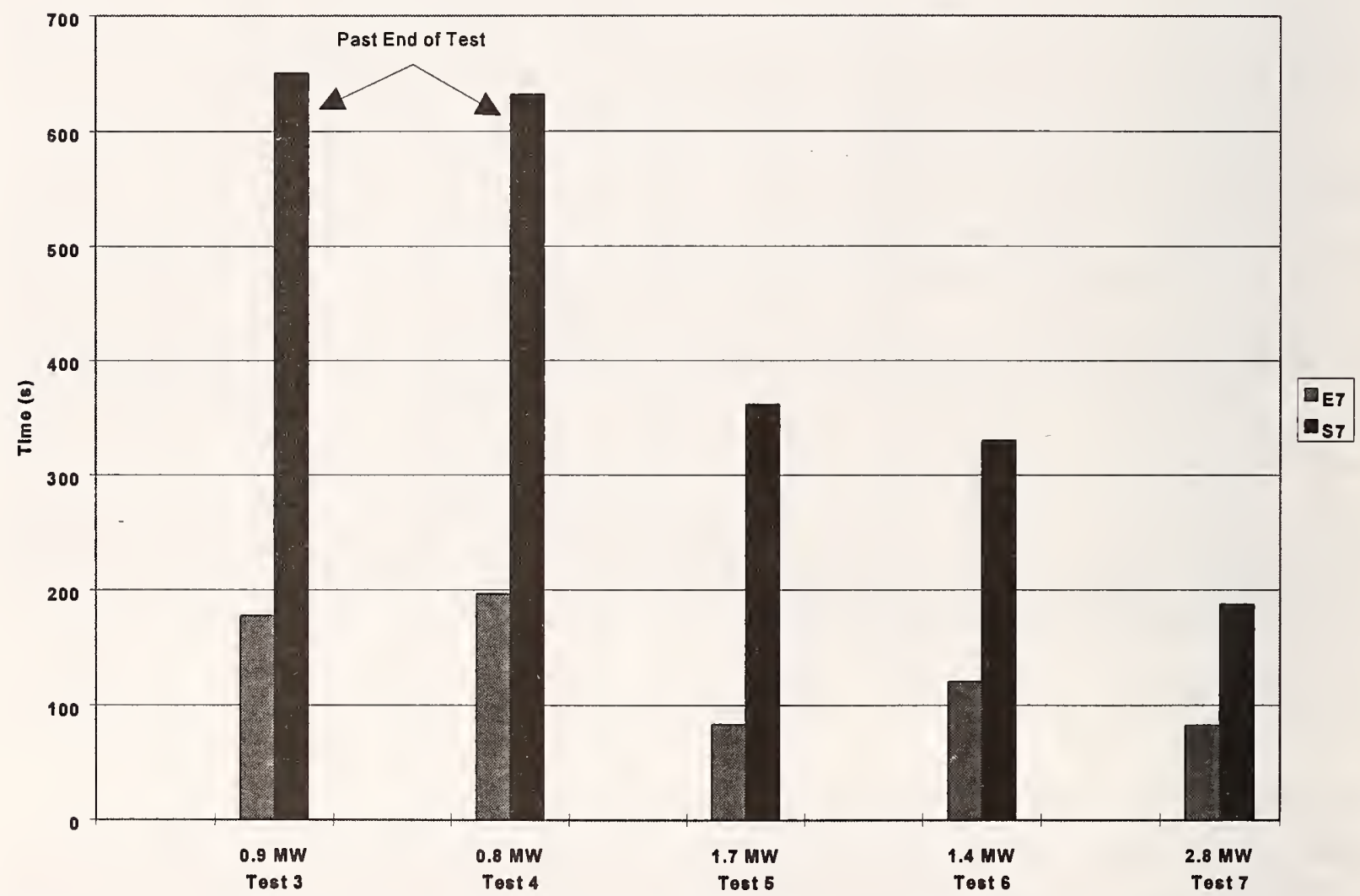

Figure 70. Comparison of smoke fill times for thermocouples E7 (22.9 m east) and S7 (21.6 $\mathrm{m}$ south) for detector fires. 


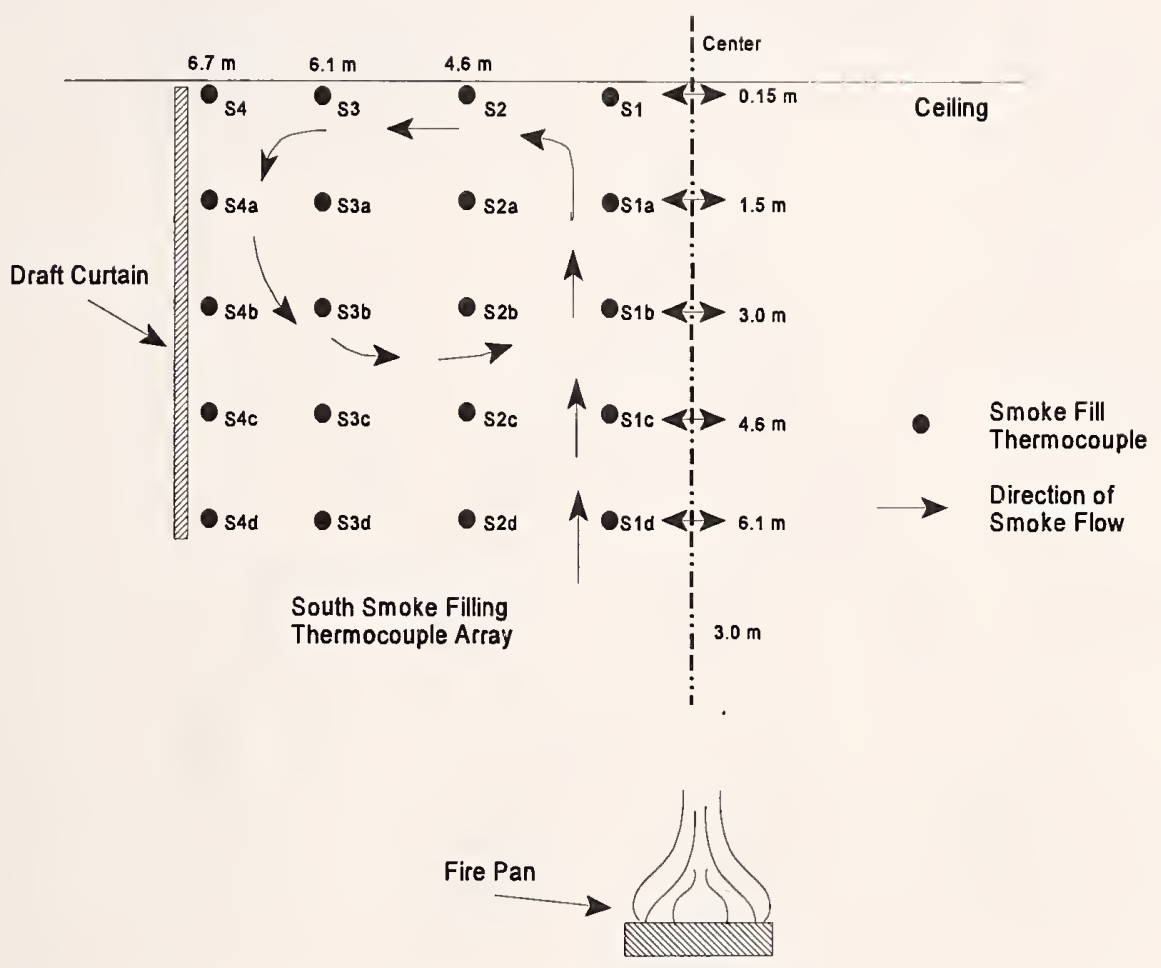

Figure 71. Diagram of typical early stage hot gas flow in $22 \mathrm{~m}$ high facility. 


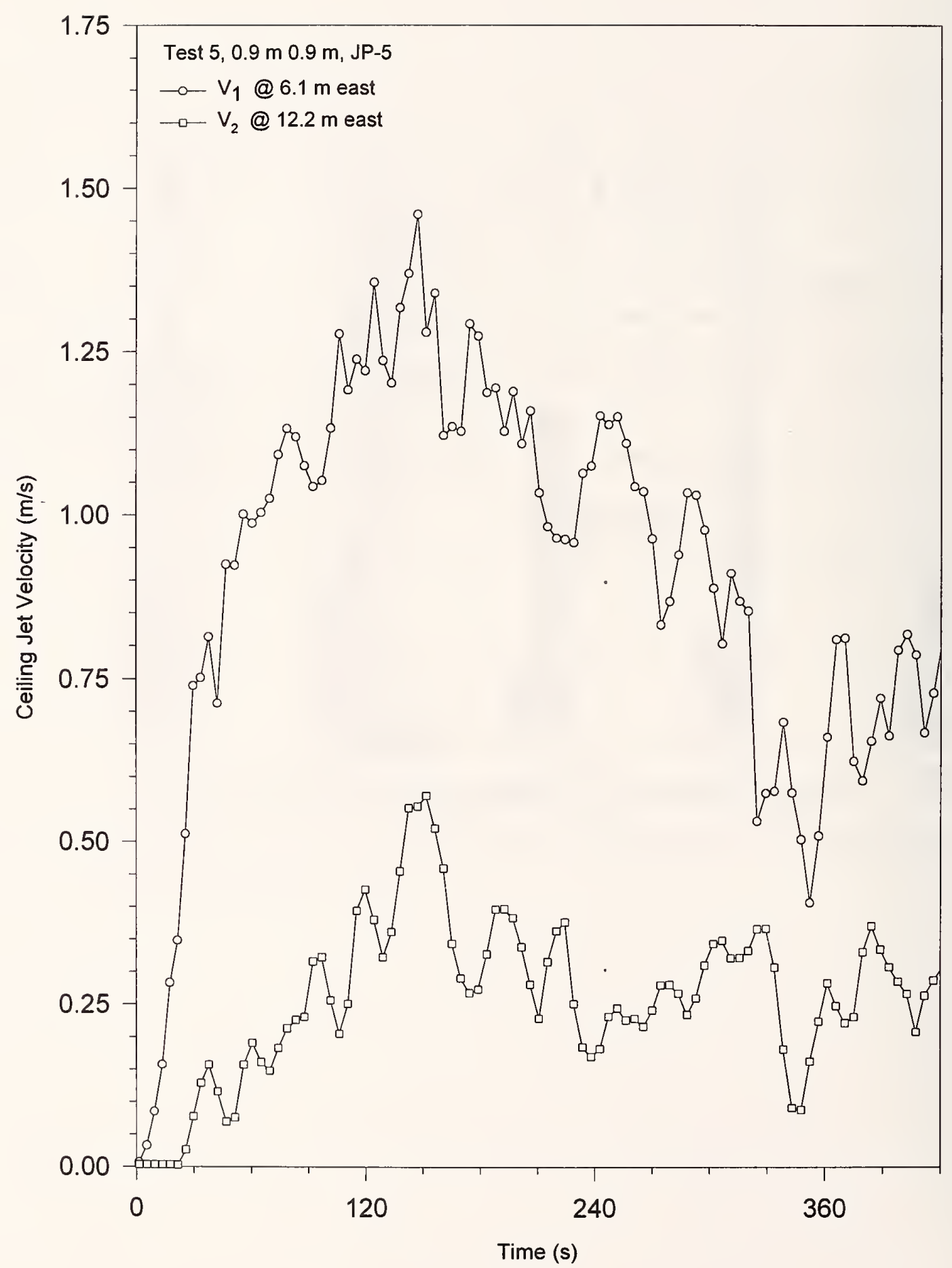

Figure 72. Measured ceiling jet velocities for test 5, conducted in $22 \mathrm{~m}$ high facility. 


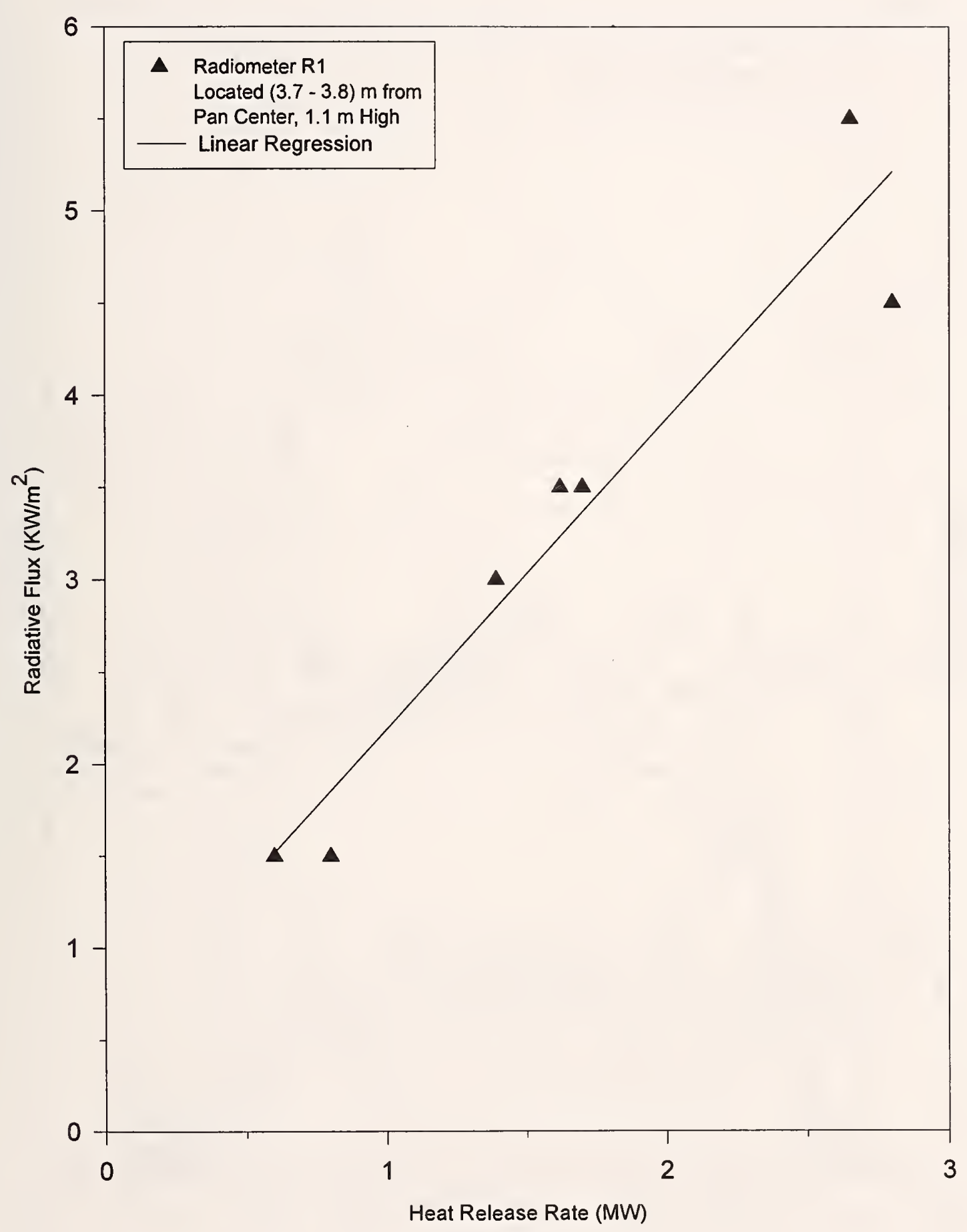

Figure 73. Average radiative flux values for detector fires using JP-5 and JP-8. 


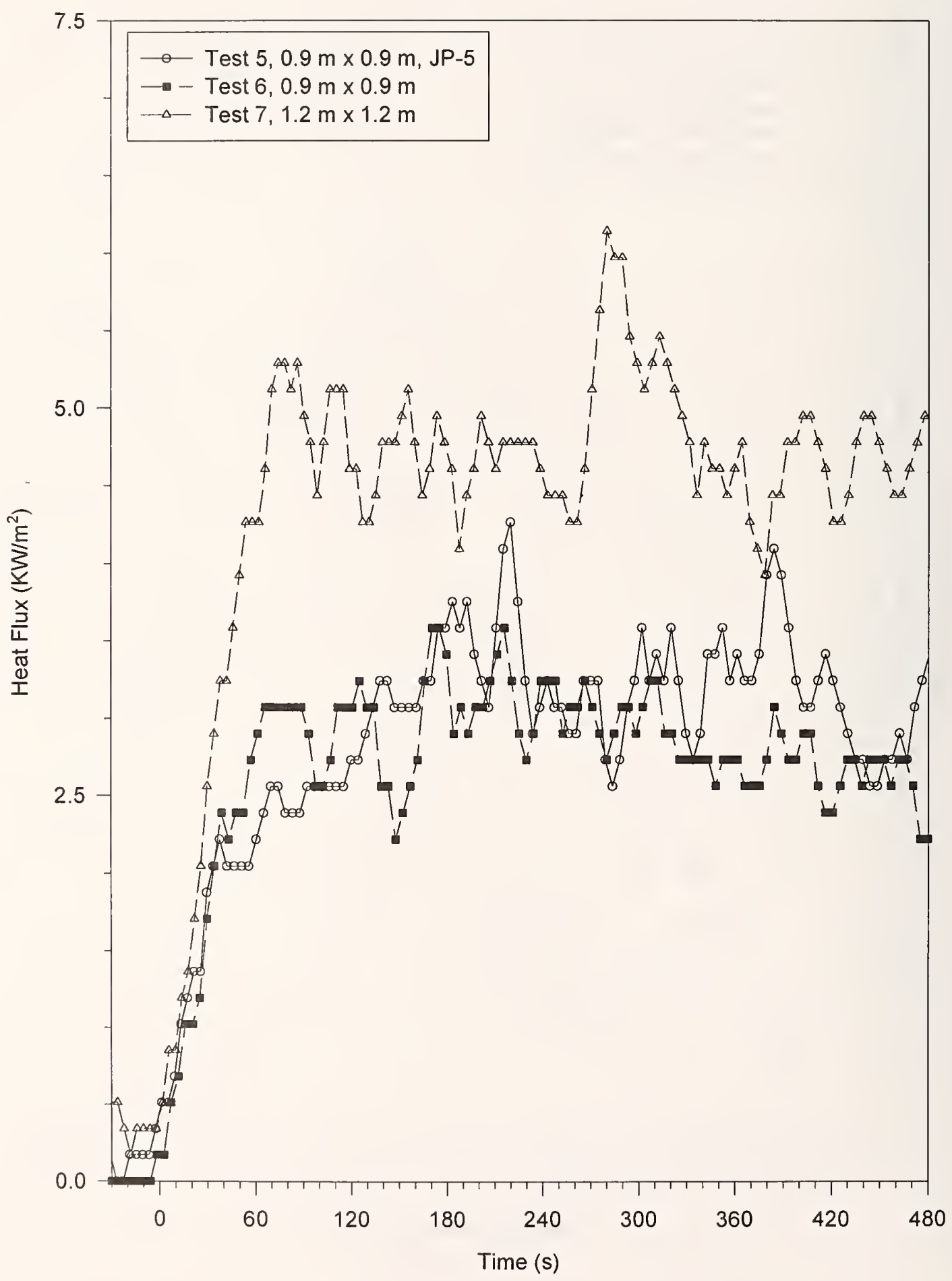

Figure 74. Heat flux measurements for detector fires using JP-5 fuel. 


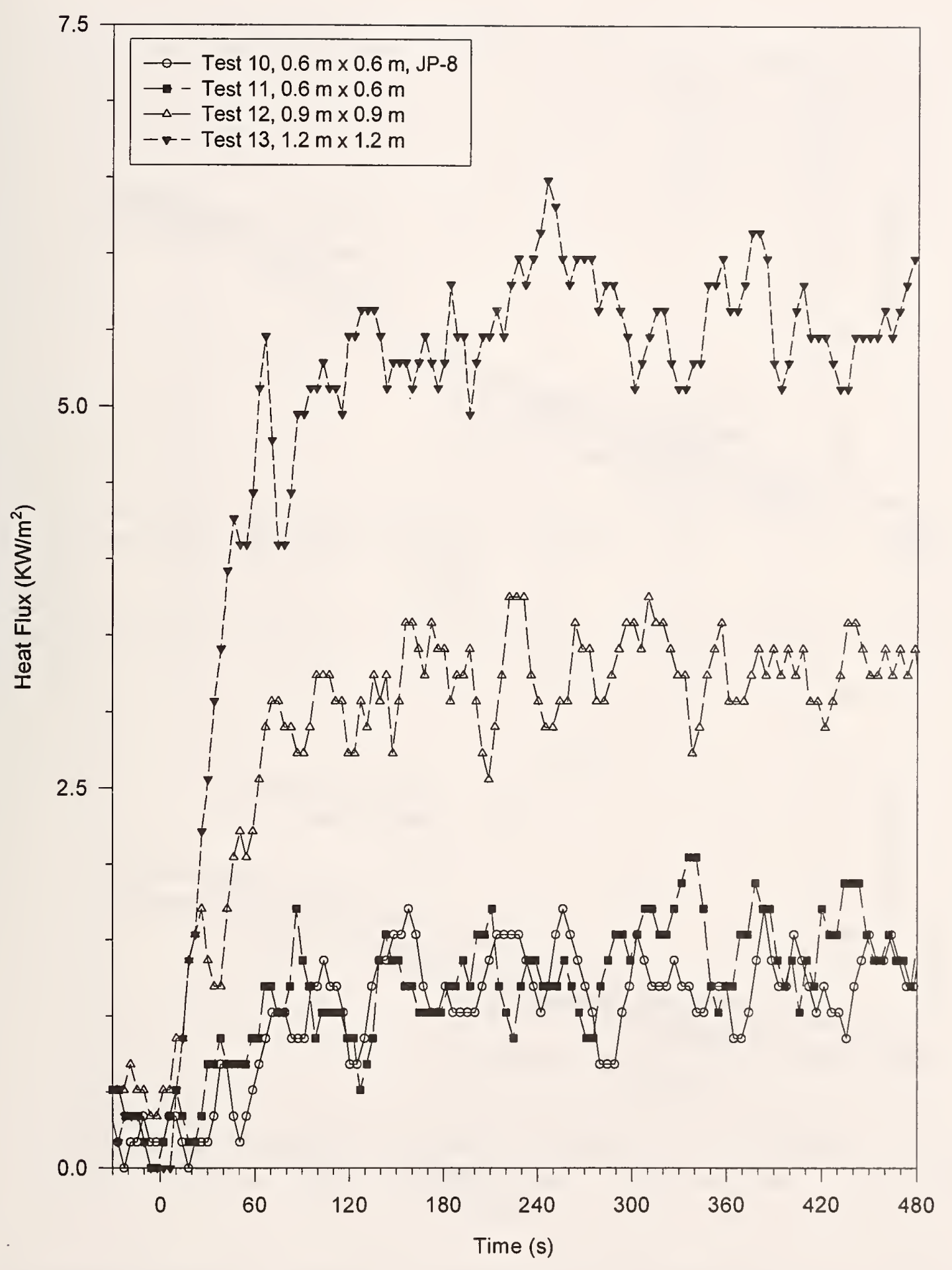

Figure 75. Heat flux measurements for detector fires using JP-8 fuel. 


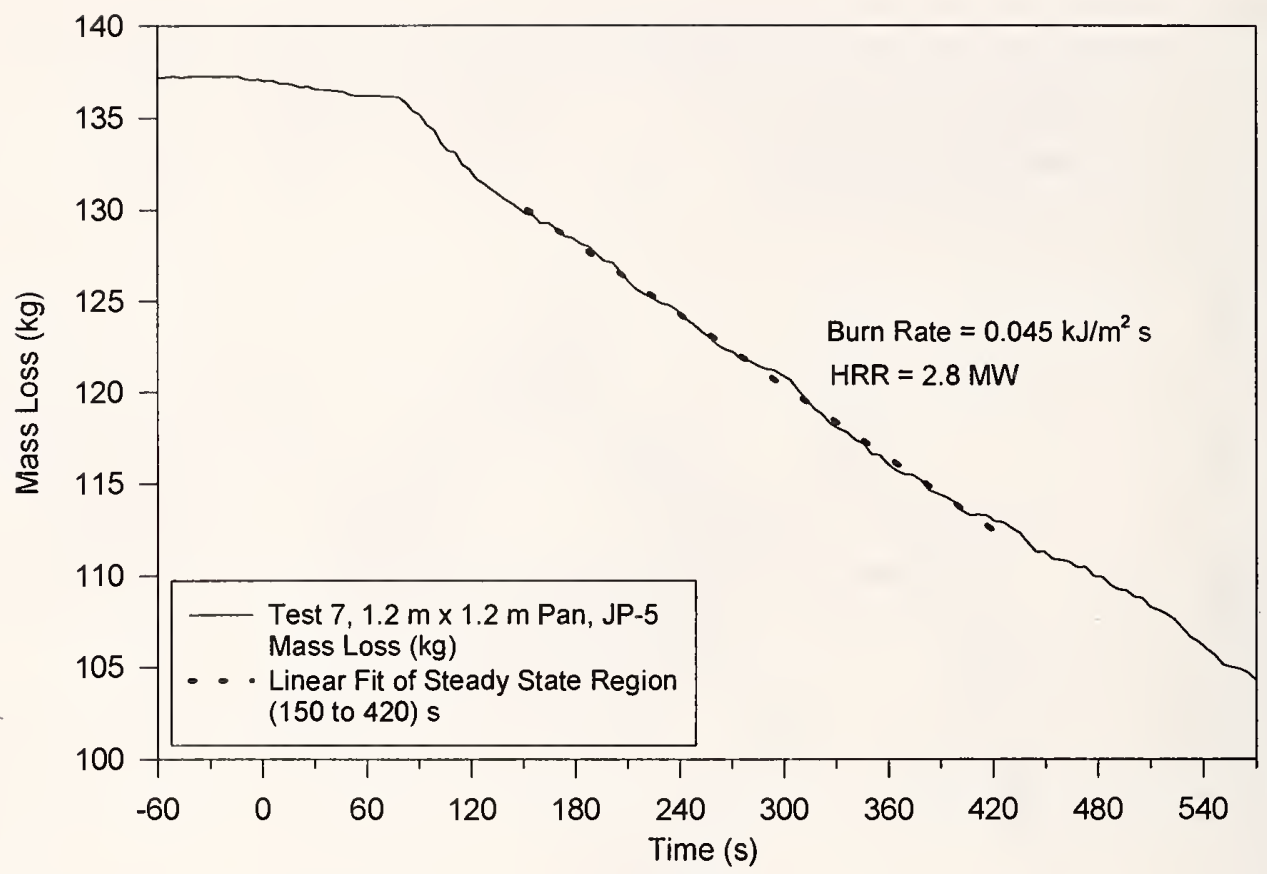

(A)

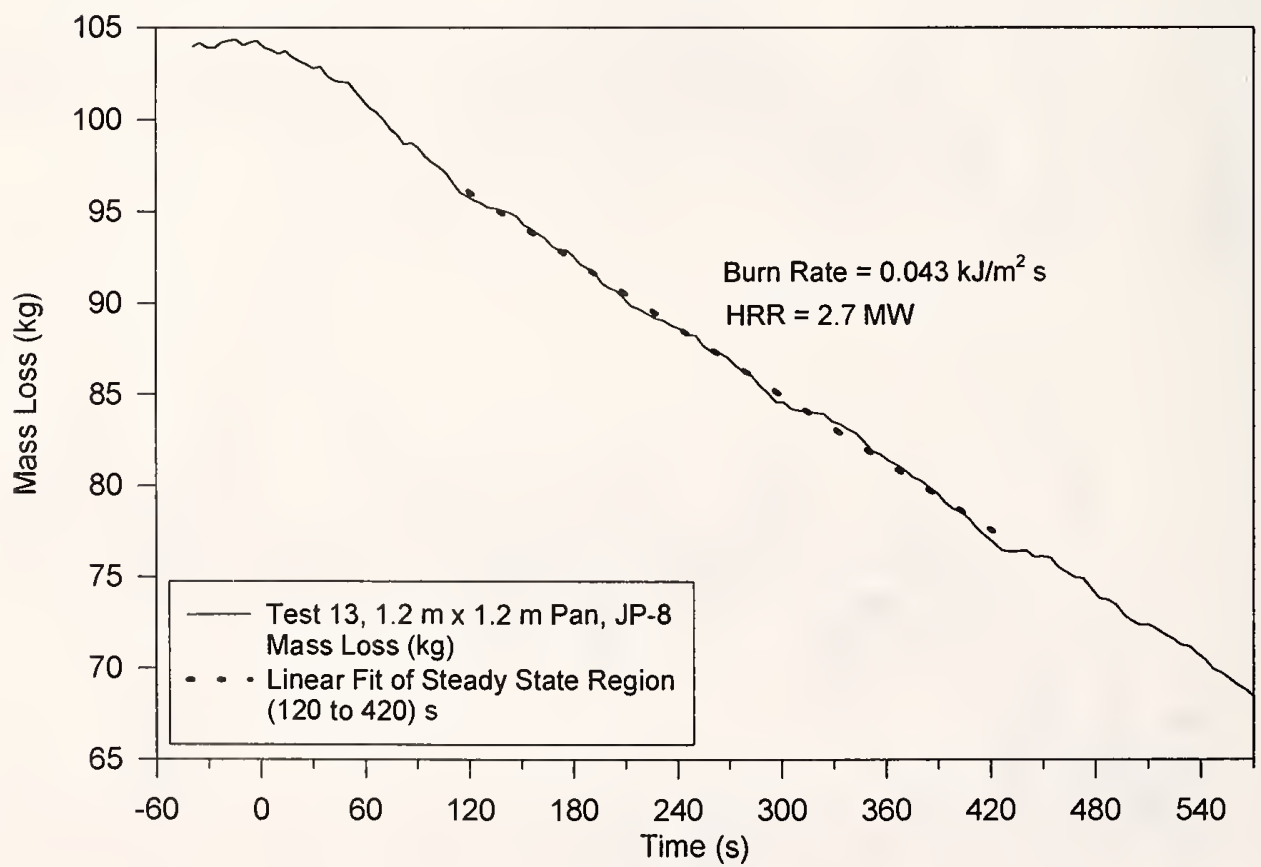

(B)

Figure 76. Mass loss and linear curve fit for test 7 (A). Mass loss and linear curve fit for test 13 (B). 


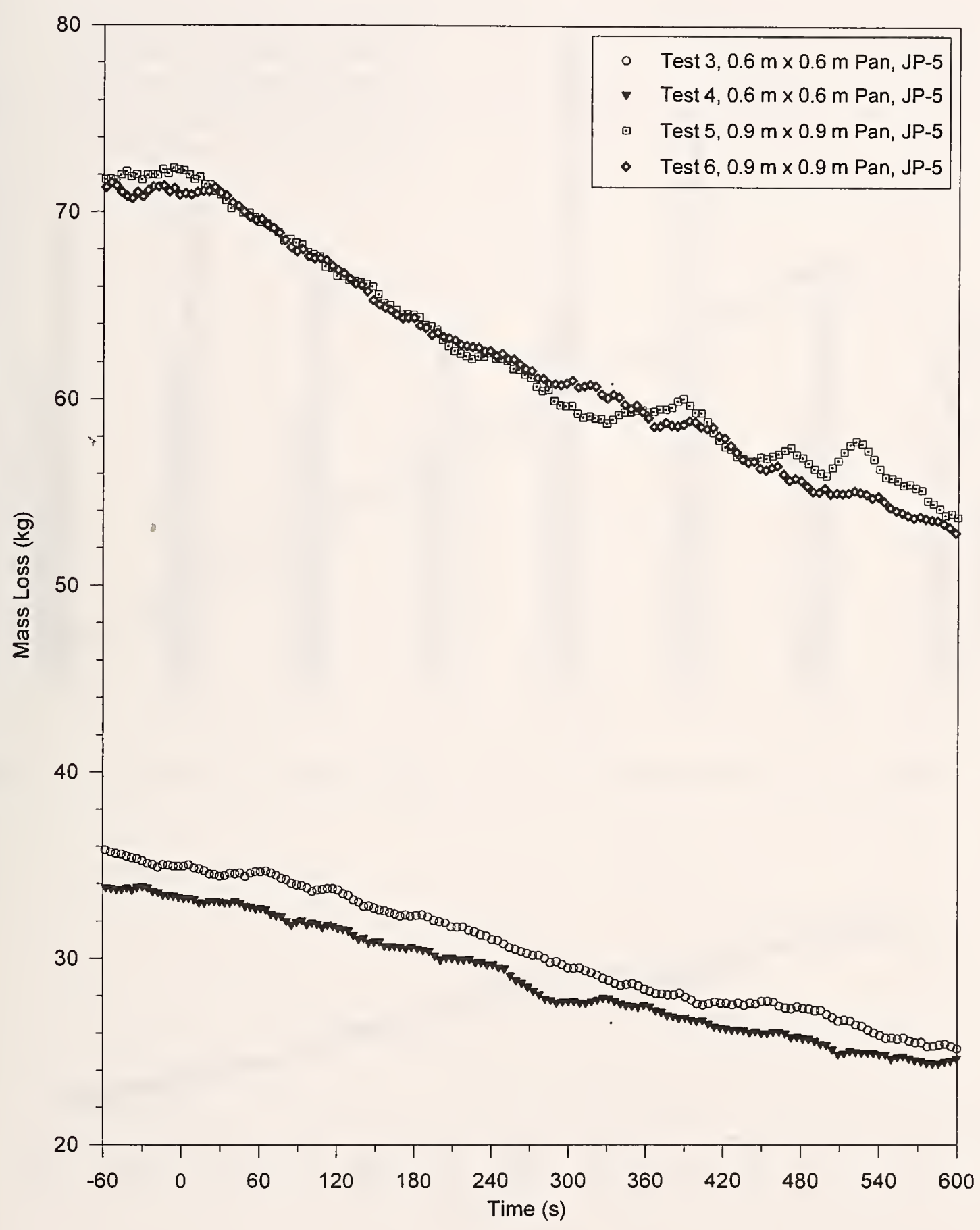

Figure 77. Mass loss curves for $0.6 \mathrm{~m} \times 0.6 \mathrm{~m}$ and $0.9 \mathrm{~m} \times 0.9 \mathrm{~m}$ test fires using JP- 5 fuel. 


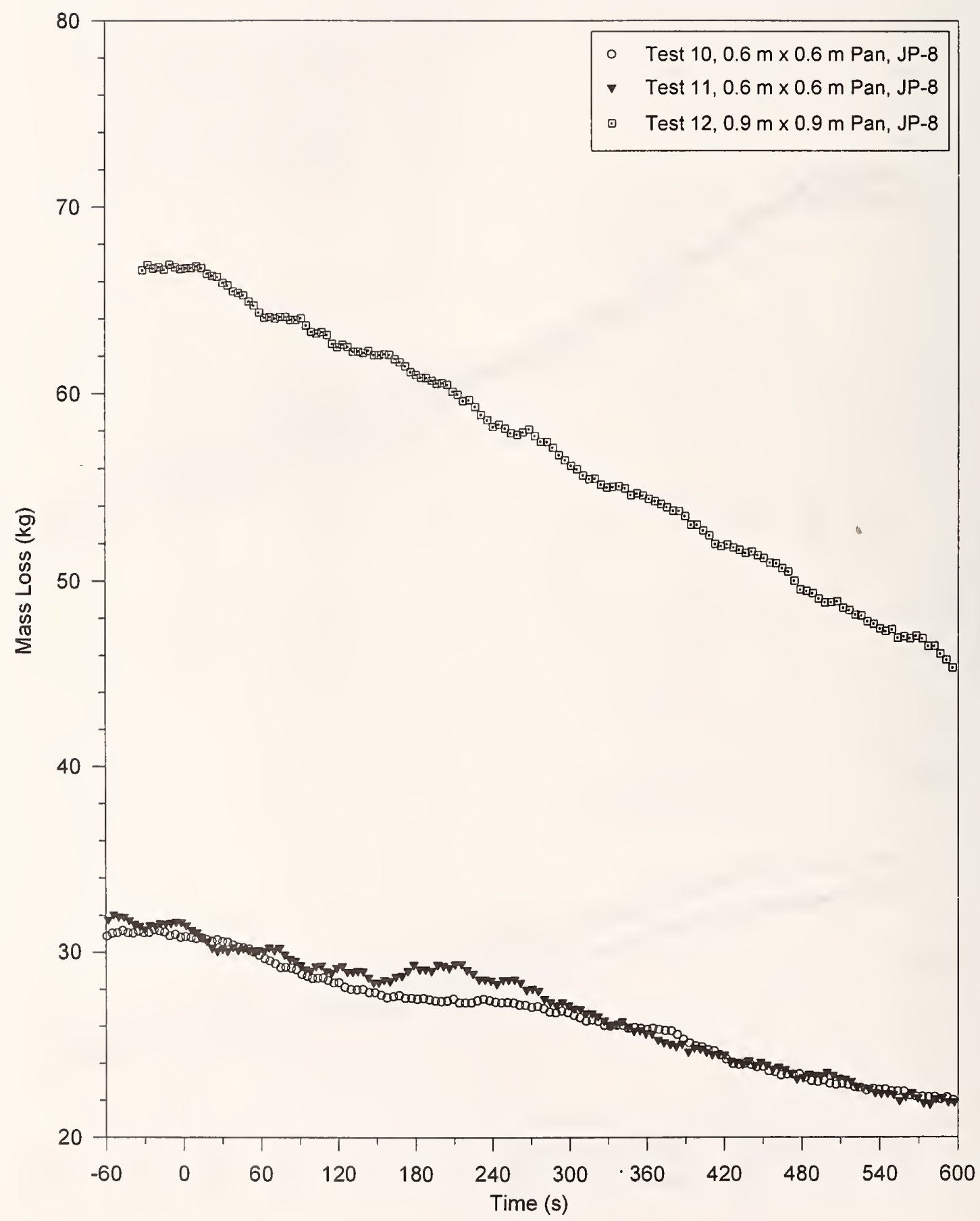

Figure 78. Mass loss curves for $0.6 \mathrm{~m} \times 0.6 \mathrm{~m}$ and $0.9 \mathrm{~m} \times 0.9 \mathrm{~m}$ test fires using JP-8 fuel. 


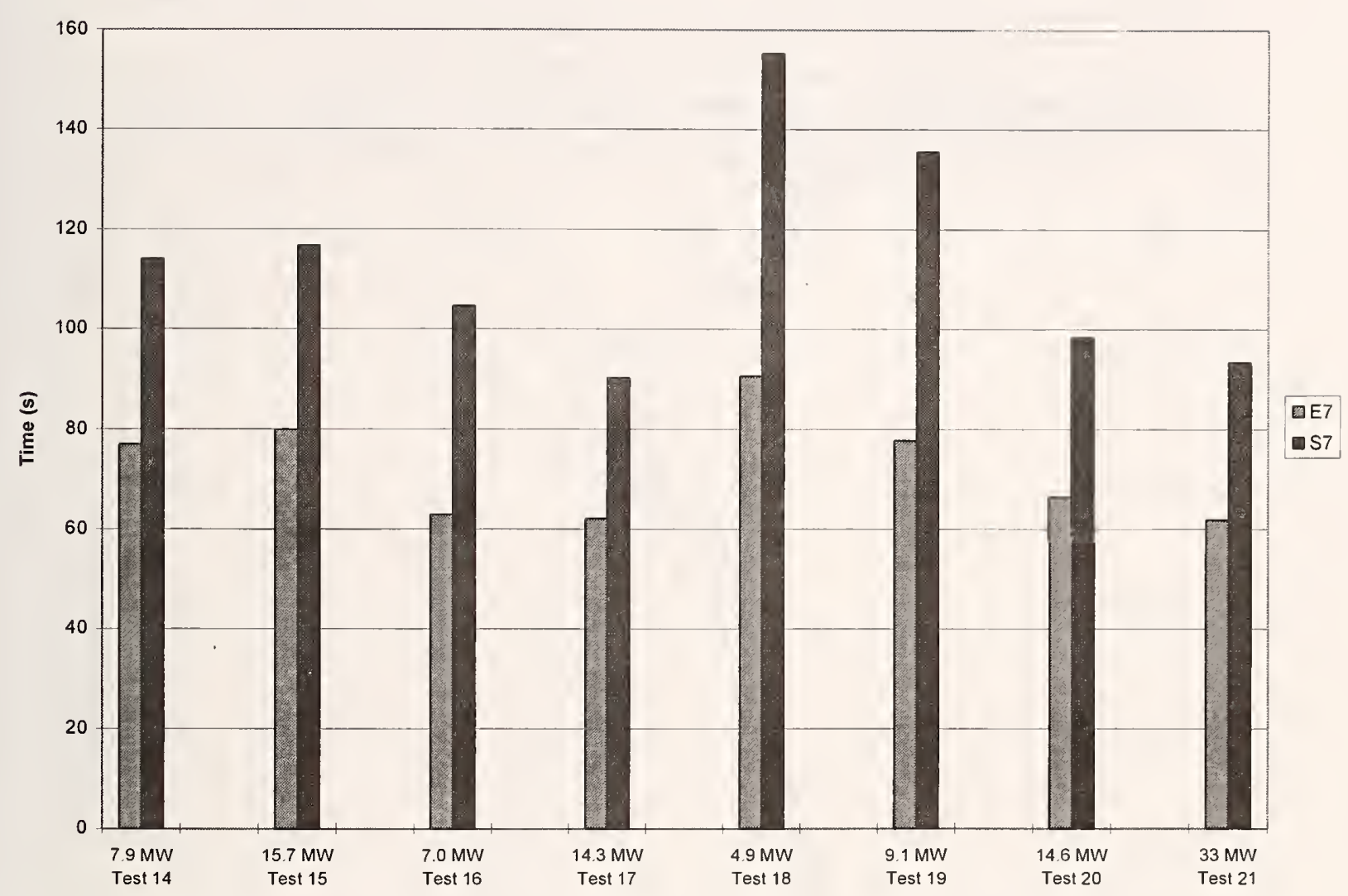

Figure 79. Comparison of hot gas fill times at E7 (22.9 m east) and S7 (21.6 m south). 


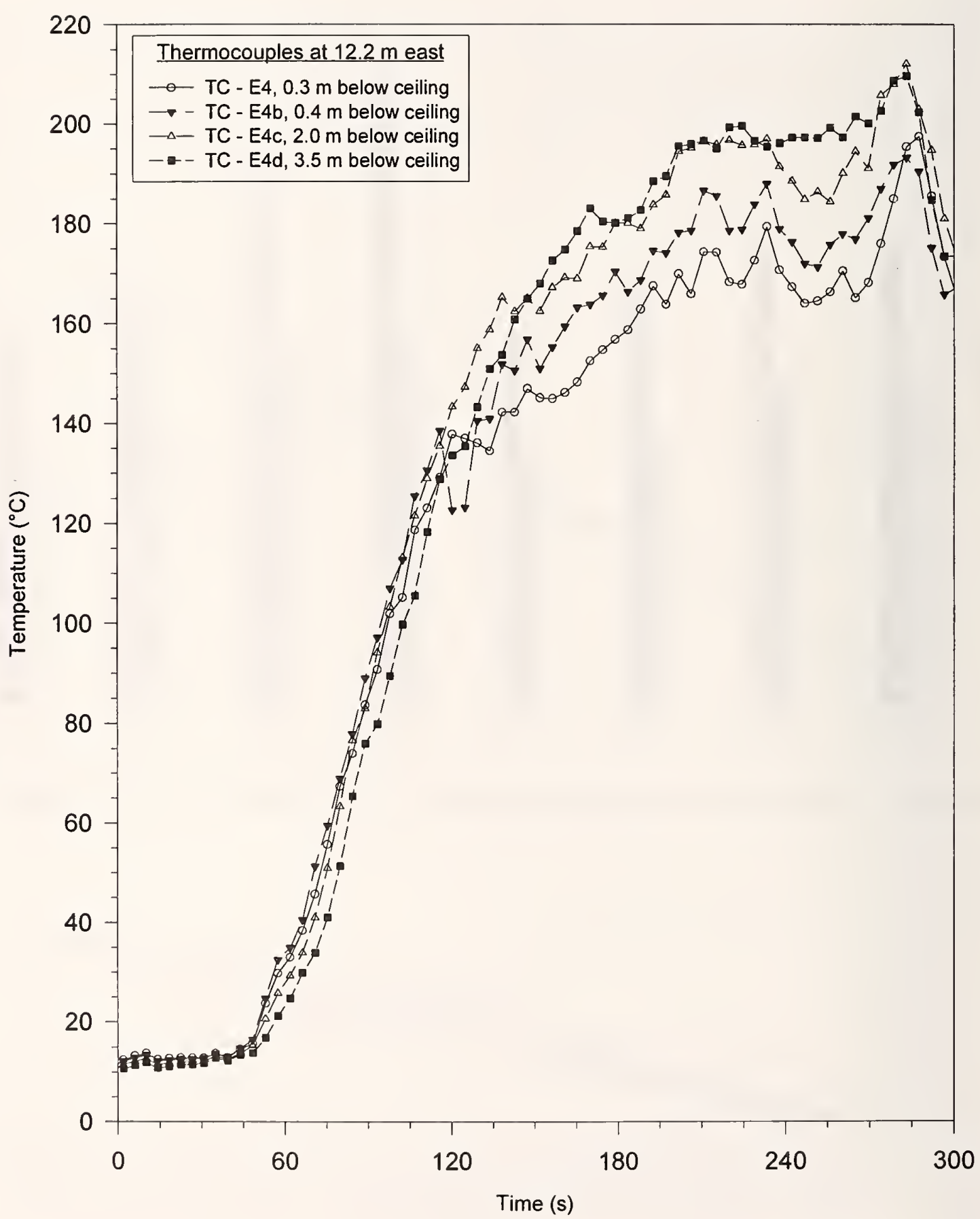

Figure 80. Temperature profiles of heat flow near ceiling for $4.6 \mathrm{~m} \times 4.6 \mathrm{~m}$ pan test using thermocouples located $12.2 \mathrm{~m}$ east of fire center. 


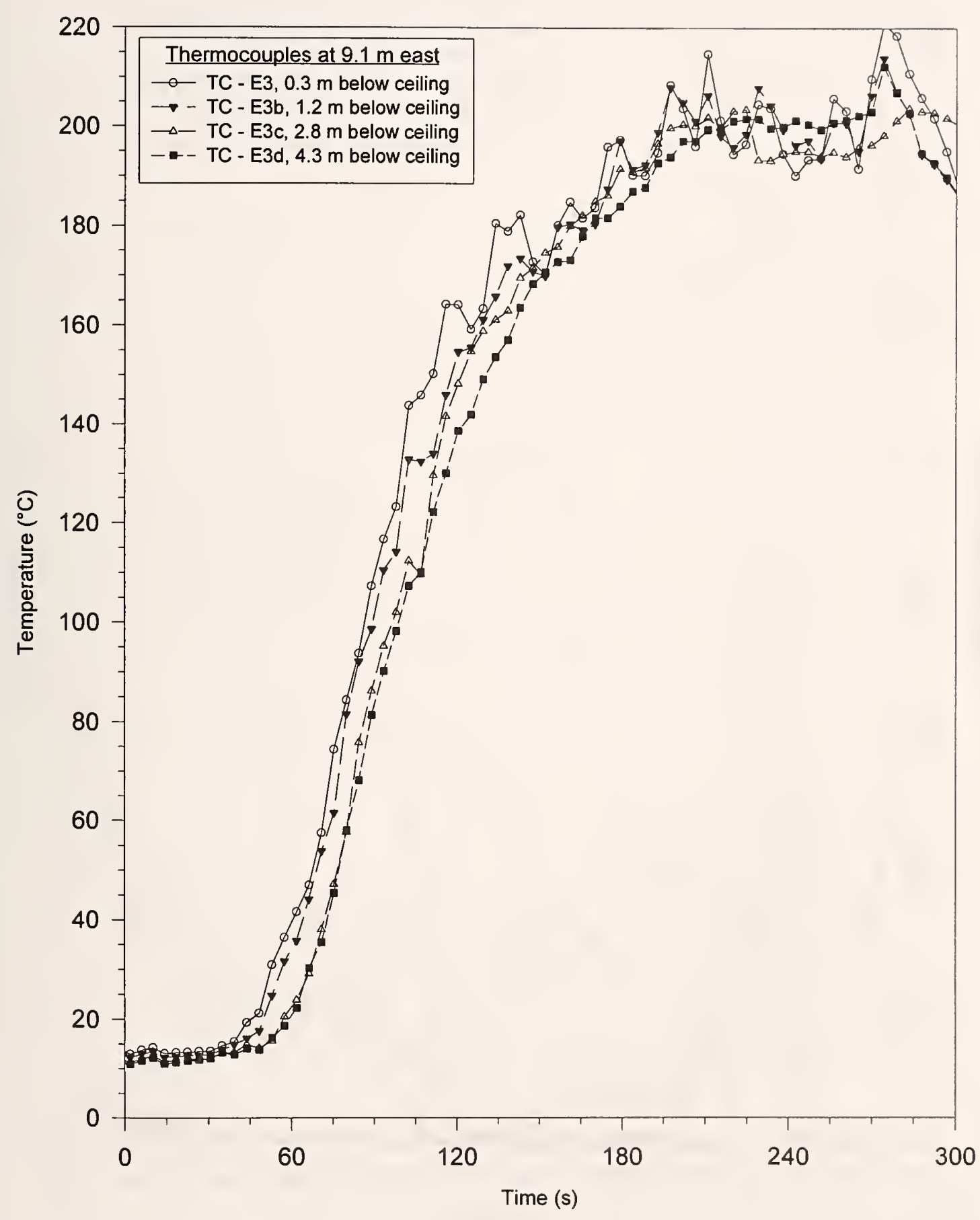

Figure 81. Temperature profiles at $9.1 \mathrm{~m}$ east of fire center for $4.6 \mathrm{~m} \times 4.6 \mathrm{~m}$ test fire. 


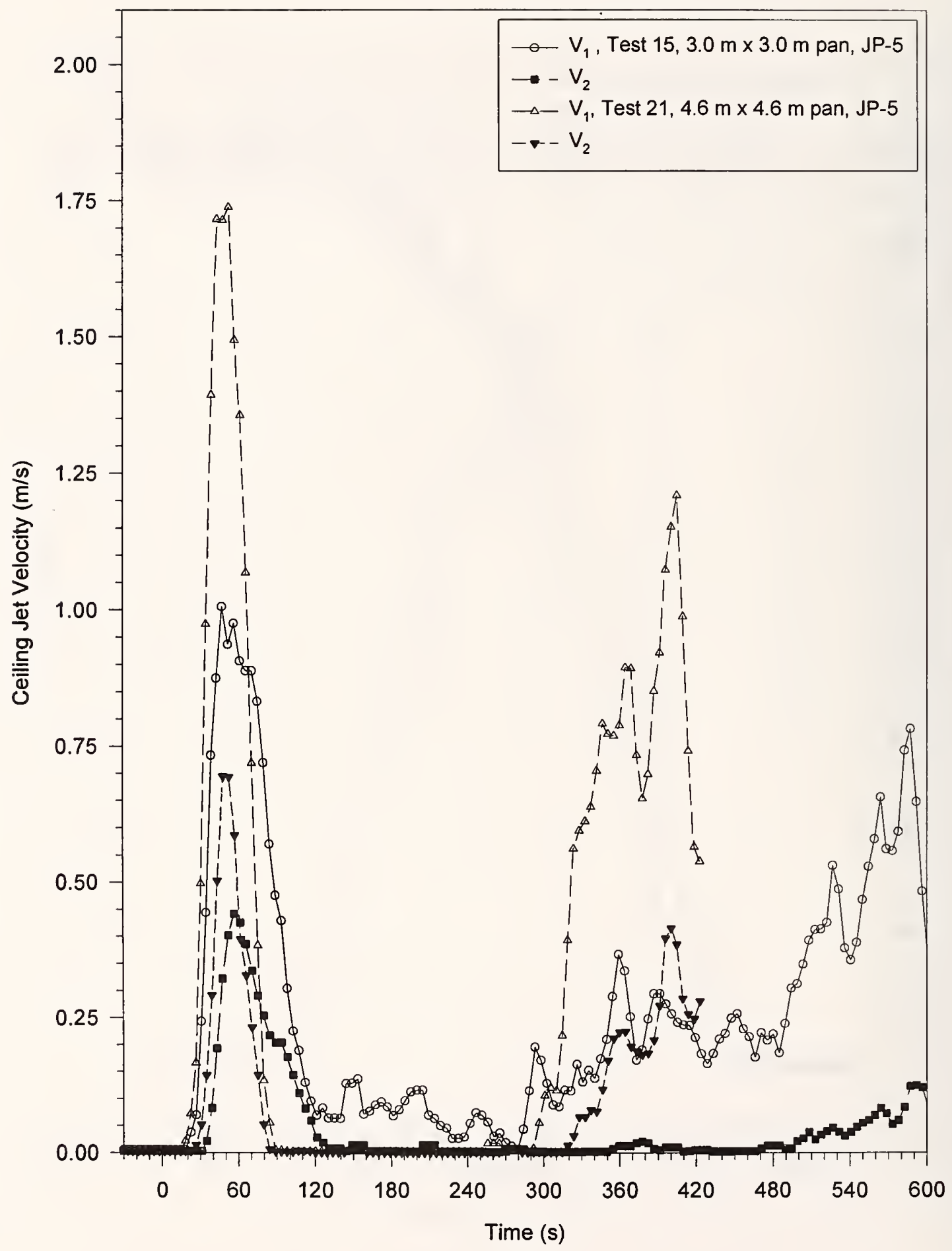

Figure 82. Measured ceiling jet velocities for $3.0 \mathrm{~m} \times 3.0 \mathrm{~m}$ and $4.6 \mathrm{~m} \times 4.6 \mathrm{~m}$ test fires. 


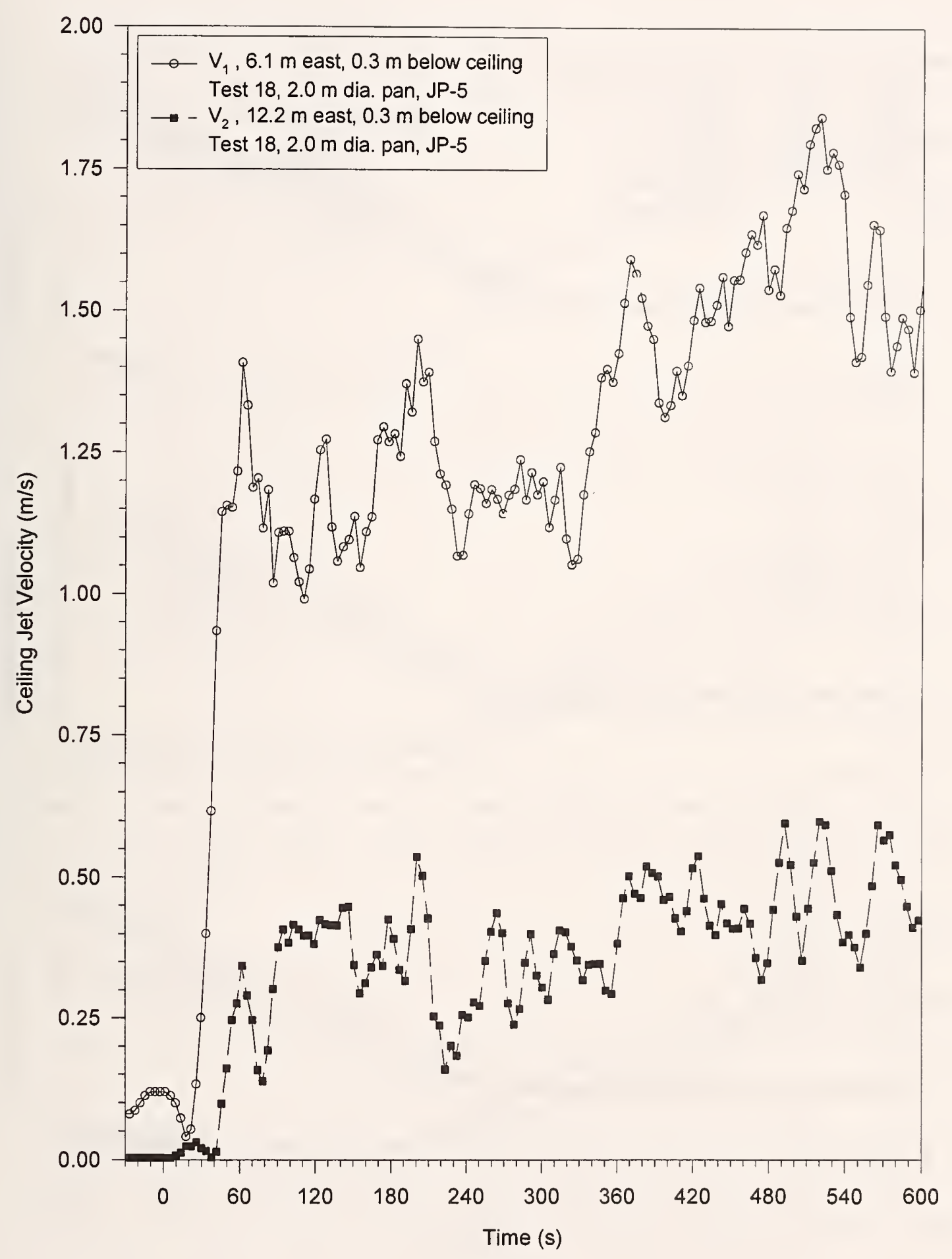

Figure 83. - Measured ceiling jet velocities for $2.0 \mathrm{~m}$ diameter test fire. 

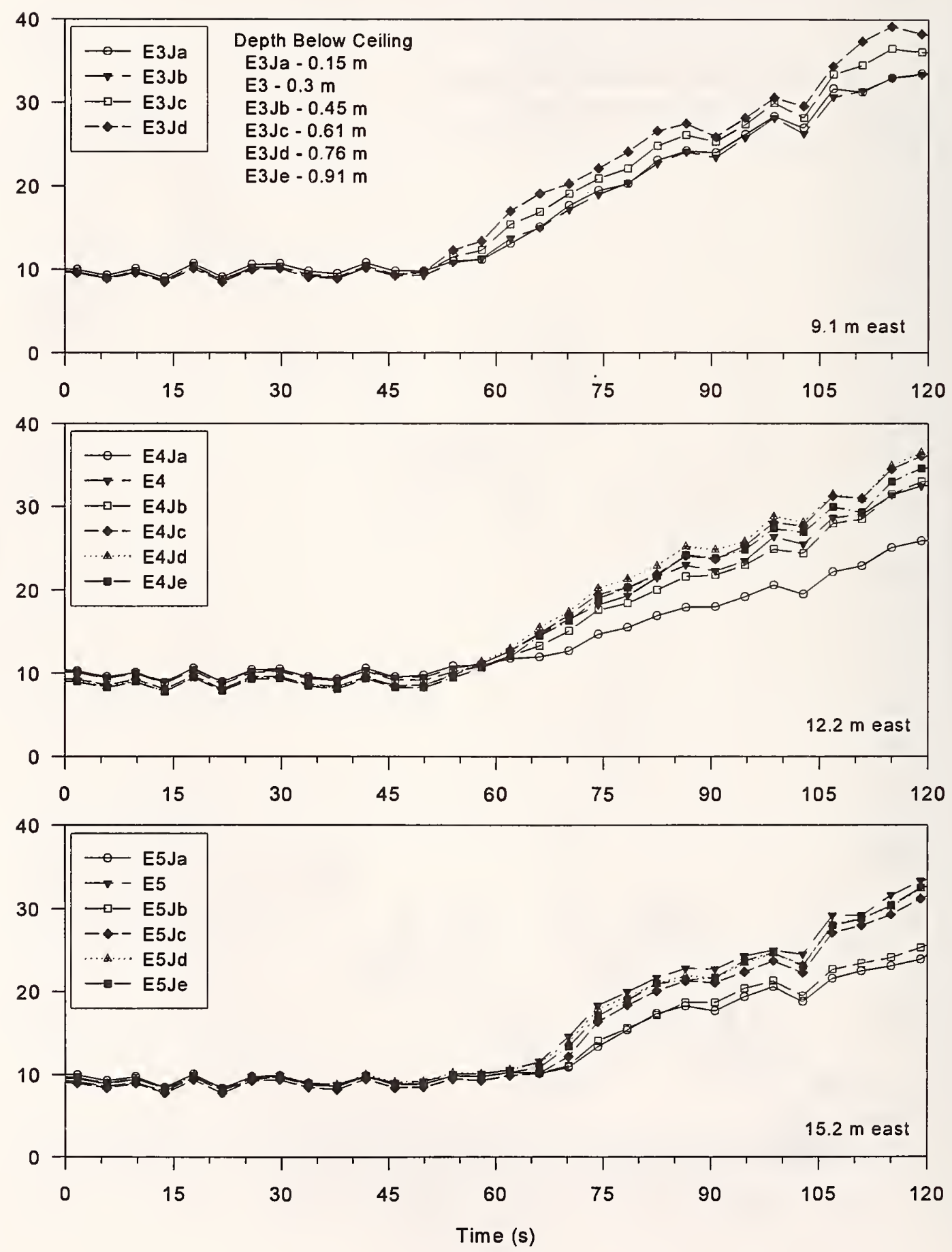

Figure 84. Temperature profiles of ceiling jet region for $2.0 \mathrm{~m}$ diameter test fire (test 18 ). 

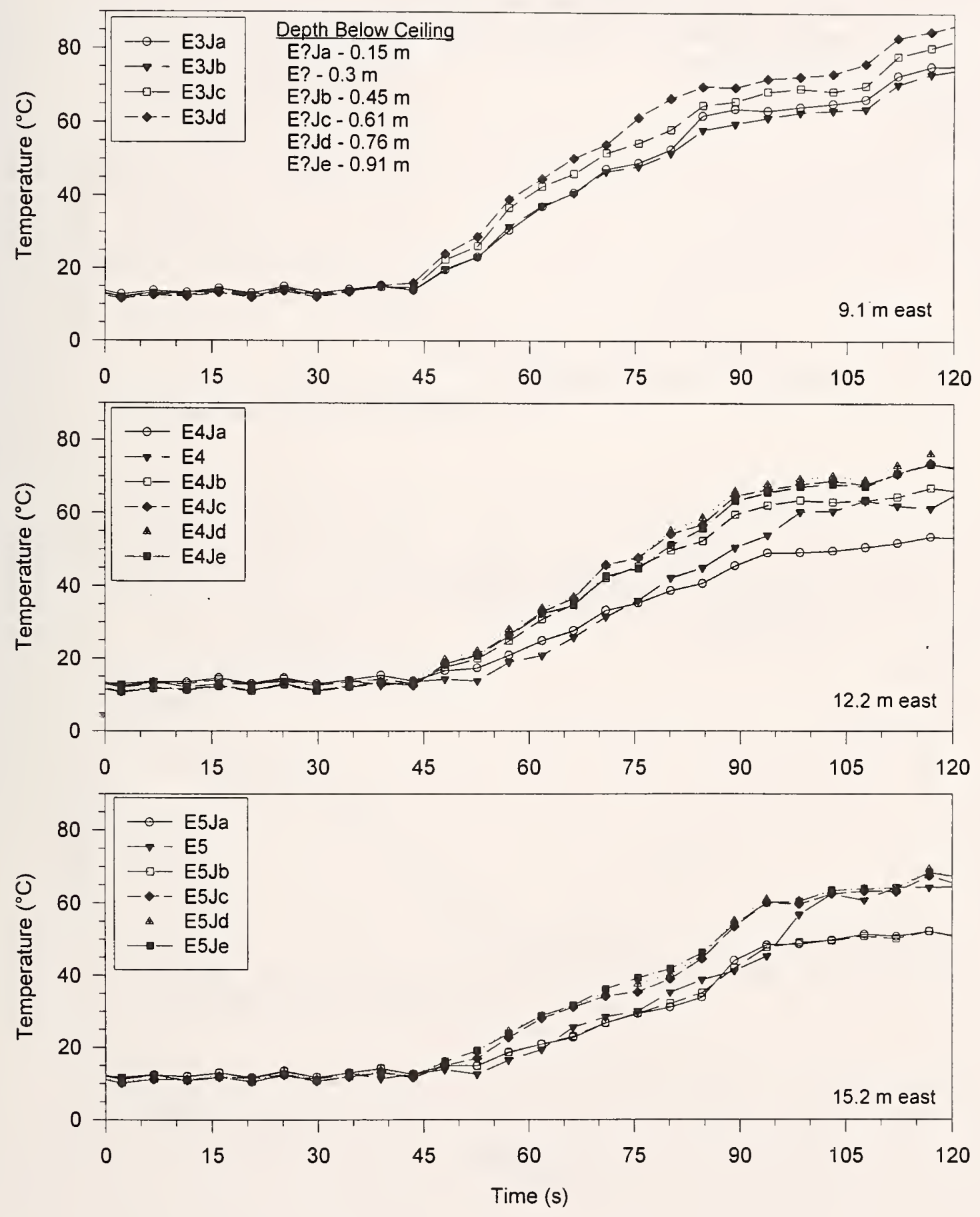

Figure 85. Temperature profiles of ceiling jet region for $3.0 \mathrm{~m} \times 3.0 \mathrm{~m}$ test fire (test 20). 

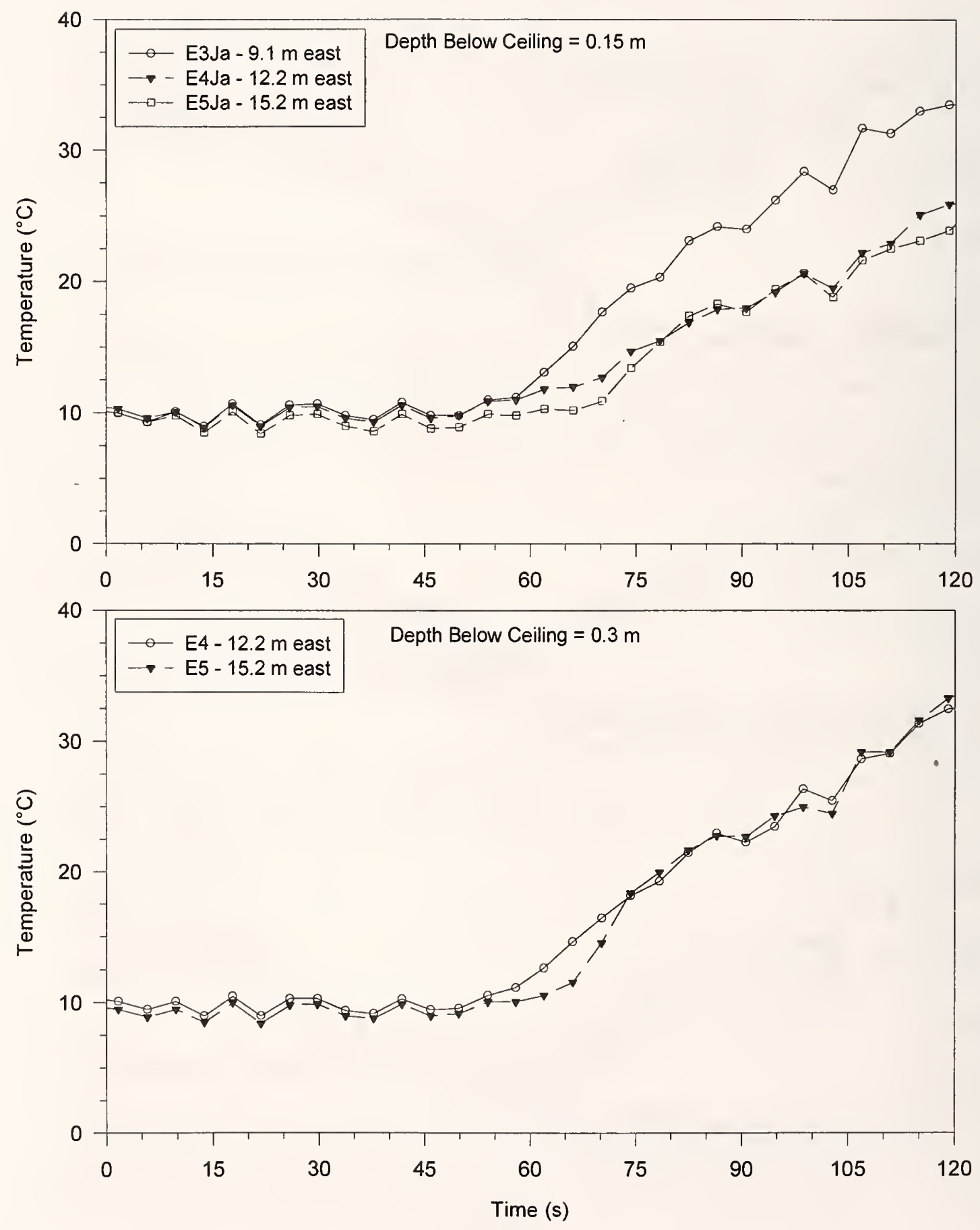

Figure 86. Ceiling jet temperature profiles at a depth of $0.15 \mathrm{~m}$ and $0.3 \mathrm{~m}$ below the ceiling for the $2.0 \mathrm{~m}$ diameter test fire. 


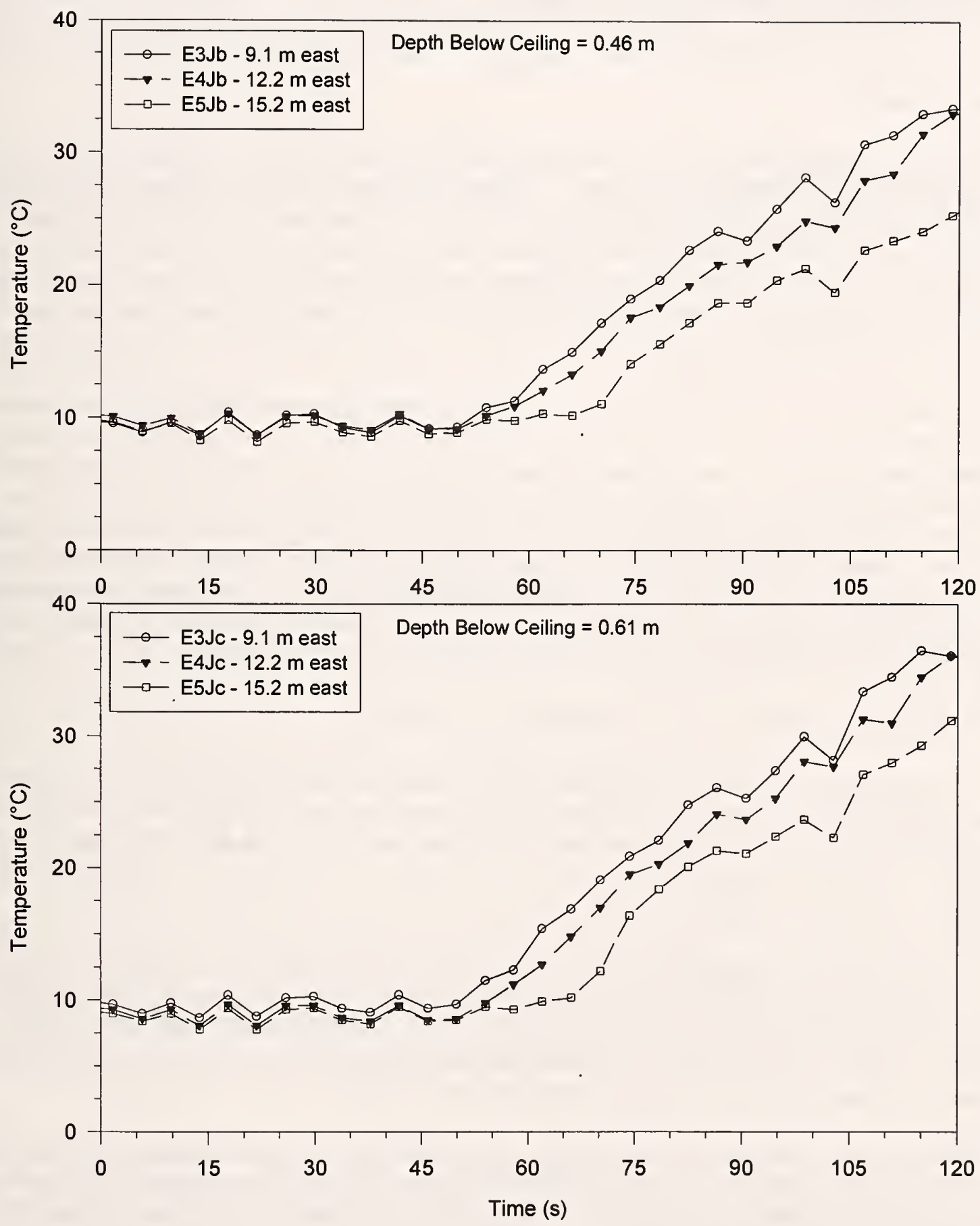

Figure 87. Ceiling jet temperature profiles at a depth of $0.46 \mathrm{~m}$ and $0.61 \mathrm{~m}$ below the ceiling for the $2.0 \mathrm{~m}$ diameter test fire. 
supported by the four point load cell and was therefore placed directly on the hangar floor. The sprinkler fires were ignited at one corner of the fire pan using an acetylene torch. The ambient fuel temperatures ranged from $9{ }^{\circ} \mathrm{C}$ to $17^{\circ} \mathrm{C}$. The time required for full pan involvement of each pan fire and observed flame heights are given in Table 48.

\section{Plume Symmetry}

The spatial location of the plume near the ceiling was determined using the regular array of thermocouples and the video images. Test 14 was a $2.5 \mathrm{~m}$ diameter JP-5 pan fire. The flame was upright for nearly the entire test showing only a $0.3 \mathrm{~m}$ lean to the west from $90 \mathrm{~s}$ to $360 \mathrm{~s}$ and a slight south lean after $520 \mathrm{~s}$. Thermocouple measurements at the ceiling indicated that the plume had a slight south lean between $70 \mathrm{~s}$ and $80 \mathrm{~s}, 150 \mathrm{~s}$ and $200 \mathrm{~s}$, and $300 \mathrm{~s}$ and $500 \mathrm{~s}$. In the east-west directions, the plume leaned slightly west between $300 \mathrm{~s}$ and $330 \mathrm{~s}$ and then leaned slightly east between $410 \mathrm{~s}$ and $440 \mathrm{~s}$.

Test 15 was a $3.0 \mathrm{~m} \times 3.0 \mathrm{~m} \mathrm{JP}-5$ pan fire. The fire was lit in the northwest corner of the pan and the smoke was observed to move straight upward during the entire test. The flames stayed upright during the entire test. At $350 \mathrm{~s}$, a small amount of fuel was observed to be burning off the south side of the pan. Temperature measurements at the ceiling indicated that between $30 \mathrm{~s}$ and $50 \mathrm{~s}$, the plume exhibited a slight west lean. Between $60 \mathrm{~s}$ and $260 \mathrm{~s}$, the plume began to lean to the south, reaching $1.5 \mathrm{~m}$ south between $150 \mathrm{~s}$ and $200 \mathrm{~s}$. The plume righted itself at $260 \mathrm{~s}$ and then only exhibited slight south leans between $310 \mathrm{~s}$ and $360 \mathrm{~s}$ and again between $470 \mathrm{~s}$ and $500 \mathrm{~s}$. In the east-west directions, the plume leaned slightly to the west until $80 \mathrm{~s}$ when it took on a slight east lean. At $140 \mathrm{~s}$, the plume righted itself but between $230 \mathrm{~s}$ and $500 \mathrm{~s}$, the plume leaned $1.5 \mathrm{~m}$ to the east.

Test 16 was an open door test and is described later in this section.

Test 17 was a $3.0 \mathrm{~m} \times 3.0 \mathrm{~m} \mathrm{JP}-8$ pan fire. The fire was lit in the northwest corner of the pan and the smoke was observed to move straight upward during the entire test. The flame was also upright during the entire test. Temperature measurements at the ceiling indicated that in the north - south direction, the plume exhibited a slight lean to the south at $60 \mathrm{~s}$ to $80 \mathrm{~s}, 1.10 \mathrm{~s}$ to $140 \mathrm{~s}, 270 \mathrm{~s}$ to $310 \mathrm{~s}$, and $360 \mathrm{~s}$ to $500 \mathrm{~s}$. In the east - west direction, the plume leaned $1.5 \mathrm{~m}$ to the east for the duration of the test.

Test 18 was a $2.0 \mathrm{~m}$ diameter JP-5 pan fire. The fire was lit on the north side of the pan and leaned $0.3 \mathrm{~m}$ to the north for the first $40 \mathrm{~s}$ of the test. At about $40 \mathrm{~s}$, there was substantial burning of JP-5 outside the pan to the north which was extinguished at $110 \mathrm{~s}$. Between $50 \mathrm{~s}$ and $100 \mathrm{~s}$, the flame was upright. At $100 \mathrm{~s}$, the flame began to lean to the northwest reaching $0.6 \mathrm{~m}$ at $200 \mathrm{~s}$. For the rest of the test, the flame exhibited a northwest lean of $0.3 \mathrm{~m}$ to $0.6 \mathrm{~m}$.

Temperature measurements for this test indicated that in the north - south direction, the plume leaned $1.5 \mathrm{~m}$ to the north at $40 \mathrm{~s}$ to $60 \mathrm{~s}, 120 \mathrm{~s}$ to $230 \mathrm{~s}, 260 \mathrm{~s}$ to $300 \mathrm{~s}$, and $380 \mathrm{~s}$ to $500 \mathrm{~s}$. The plume leaned $1.5 \mathrm{~m}$ to the south between $350 \mathrm{~s}$ and $370 \mathrm{~s}$. In the east - west direction, the plume leaned slightly to the west for the entire test duration.

Test 19 was another open door test and is described later in this section. 
Test 20 was a $3.0 \mathrm{~m} \times 3.0 \mathrm{~m} \mathrm{JP}-5$ pan fire. Only the video camera looking east was available for this fire. The fire was lit in the northwest corner with the smoke initially moving straight up. At $170 \mathrm{~s}$, the flame developed a $0.6 \mathrm{~m}$ north lean which became upright at $190 \mathrm{~s}$. Temperature measurements at the ceiling indicated that in the north - south direction, the plume was initially centered and only exhibited a slight south lean between $35 \mathrm{~s}$ and $160 \mathrm{~s}$ and again between $240 \mathrm{~s}$ and $400 \mathrm{~s}$. In the east-west directions, the plume leaned $1.5 \mathrm{~m}$ west between $20 \mathrm{~s}$ and $150 \mathrm{~s}$ and then gradually became upright at $230 \mathrm{~s}$.

Test 21 was a $4.6 \mathrm{~m} \mathrm{x} 4.6 \mathrm{~m} \mathrm{JP}-5$ pan fire. The fire was lit in the northwest corner of the pan and the smoke moved vertically upward. Thermocouples mounted at the ceiling indicated that in the north south direction, the plume leaned $3 \mathrm{~m}$ north at $30 \mathrm{~s}$ to $70 \mathrm{~s}$ and at $160 \mathrm{~s}$ to $250 \mathrm{~s}$. The plume leaned to the south at $70 \mathrm{~s}$ to $120 \mathrm{~s}$. In the east - west direction, the plume leaned slightly to the west at $30 \mathrm{~s}$ to $45 \mathrm{~s}$ and $65 \mathrm{~s}$ to $75 \mathrm{~s}$. The plume leaned $1.5 \mathrm{~m}$ to the east between $75 \mathrm{~s}$ and $140 \mathrm{~s}$ and $4.0 \mathrm{~m}$ to the east between $75 \mathrm{~s}$ and $140 \mathrm{~s}$. Between $210 \mathrm{~s}$ and $260 \mathrm{~s}$, temperature spikes were recorded on the W1 thermocouple but both the E1 and E2 thermocouples recorded higher temperatures than the W2 thermocouple indicating that the plume was leaning to the east. The temperature spikes recorded on W1 were due to intermittent flames impinging on the thermocouple.

\section{Temperature}

The ambient temperature for each of the eight sprinkler fires is listed in Table 49. Ambient temperatures for these tests ranged between $8{ }^{\circ} \mathrm{C}$ and $14^{\circ} \mathrm{C}$. Also listed in the table is the temperature rise above ambient recorded by thermocouples located $0.3 \mathrm{~m}$ beneath the ceiling (C, N1, $\mathrm{S} 1, \mathrm{E} 1$, and $\mathrm{W} 1$ ) radially at fire center and at $3.0 \mathrm{~m}$ to the north, south, east, and west of fire center. The temperature values reported are based on analyzing the temperature range over the time interval where the fire's mass loss rate appeared steady and choosing the value equal to $90 \%$ of the range. In general, the ceiling temperature increases with time, hence the temperature values reported in the table will typically be realized late in the test period. The temperatures reported in the table will not be useful in determining plume symmetry with respect to the fire center, since the ninety percent temperature values at each thermocouple could occur at different times as the plume center moves around the ceiling. Also listed in the table is the calculated heat release rate and pan size for each experimental fire size.

Test 21 was the $4.6 \mathrm{~m} \times 4.6 \mathrm{~m}$ (15 ft $\times 15 \mathrm{ft}$ ) JP-5 pan fire. The high temperature recorded in the table for the W1 thermocouple was probably due to intermittent flames striking that thermocouple. This assumption is based on the observed temperature spikes exhibited by the data rather than a more constant temperature profile that is exhibited by the other thermocouples. Thermocouples $\mathrm{C}$ and $\mathrm{N} 1$ should be used to determine the gas temperature near plume center.

\section{Heat Flow}

The impact of the draft curtain on hot gas flow can be studied by comparing the time required for the hot gas to produce a $3.0^{\circ} \mathrm{C}$ temperature rise at thermocouples E7 and S7. Thermocouple E7 was

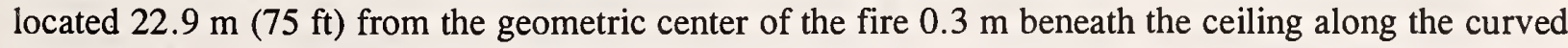
portion of the ceiling. Thermocouple S7 was located $21.6 \mathrm{~m}(71 \mathrm{ft}) \mathrm{from}$ the geometric center of the fire and $0.3 \mathrm{~m}$ beneath the ceiling in the adjacent draft curtain bay just before the second draft curtain. Since both thermocouples were located approximately the same radial distance from the fire, time 
differences in the arrival of the hot gas would give an indication of how effective the draft curtain was in containing heat and smoke. Figure 79 shows a comparison of the time required to produce a $3{ }^{\circ} \mathrm{C}$ temperature rise at thermocouples E7 and S7 as a function of heat release rate (HRR) for the JP-5 pan fires. The sprinkler fires, with heat release rates greater than $4 \mathrm{MW}$, produced hot gas arrival times of $32 \mathrm{~s}$ to $65 \mathrm{~s}$ earlier in the direction parallel to the draft curtain compared with the direction perpendicular to the draft curtain. Once the heat release rate exceed $7 \mathrm{MW}$, the arrival time difference became independent of heat release rate.

The single JP- 8 pan fire, test 17 , showed a $28 \mathrm{~s}$ difference in the two directions. The JP- 8 fire reached full pan involvement in $50 \mathrm{~s}$ which was $15 \mathrm{~s}$ faster than the comparable JP-5 fires. The more rapid flame spread across the pan may be responsible for the smaller time difference observed in the two directions based on a more rapidly growing fire in the test.

The flow of hot gas along the curved portion of the ceiling can be analyzed by comparing the $3{ }^{\circ} \mathrm{C}$ temperature rise times for thermocouples E1, E3, E5, and E7 at radial distances from fire center of 3.0 $\mathrm{m}, 9.1 \mathrm{~m}, 15.2 \mathrm{~m}$, and $22.9 \mathrm{~m}$ as shown in Table 50. The times shown in the table represent the actual elapsed time from ignition as recorded by the data collection system. Since the average time interval between channel scans was approximately $4 \mathrm{~s}$, the response times shown may differ by this amount. For the sprinkler fires, it took from $18 \mathrm{~s}$ to $24 \mathrm{~s}$ for the hot gas to move from thermocouple E1 to thermocouple E5. From thermocouple E5 to thermocouple E7 it took from $13 \mathrm{~s}$ to $24 \mathrm{~s}$ for the hot gas to cover this distance. The ceiling jet slows down substantially as it traverses the distance between E1 and E7.

The impact of the hot gas flow interacting with the ceiling beams produced an unexpected temperature distribution as a function of height. Using data from Test 21 which produced the highest ceiling temperatures, Figure 80 displays the temperature as a function of height measured by the thermocouple tree located at $12.2 \mathrm{~m}$ east from fire center. During the first $120 \mathrm{~s}$ of the fire the highest temperatures recorded were near the ceiling but after $120 \mathrm{~s}$, the hottest temperatures are found at thermocouple E4d which is located $3.5 \mathrm{~m}$ below the ceiling and the thermocouple $0.3 \mathrm{~m}$ below the ceiling recorded the coolest temperature. This thermocouple tree was located directly behind one of the ceiling beams which obstructed the flow along the ceiling.

Figure 81 displays the temperature as a function of height for the thermocouple tree located at $9.1 \mathrm{~m}$ east from fire center. This thermocouple tree was not located behind a beam. The temperature history provided by these thermocouples shows the highest temperatures are located near the ceiling with the temperatures recorded by each thermocouple approaching similar values as the smoke layer deepens. The unique temperature distribution recorded by the thermocouples located $12.2 \mathrm{~m}$ from fire center is assumed to be a result of the proximity of the beam altering the flow. There is also a possibility of the curved ceiling playing a role but without another thermocouple tree located further away from fire center, this speculation cannot be pursued.

\section{Ceiling Jet Velocities}

Ceiling jet velocities were measured using mass flow meters positioned at $6.1 \mathrm{~m}$ and $12.2 \mathrm{~m}$ from fire center along the curved roof in the east direction. The mass flow meters were located $0.3 \mathrm{~m}$ beneath the ceiling. Figures 82 and 83 present the time history of these measurements. The ceiling jet velocity for all the closed door tests usually reached its maximum value during the first $50 \mathrm{~s}$ of the test. The 
maximum measured ceiling jet velocity ranged from $1.0 \mathrm{~m} / \mathrm{s}$ to $1.7 \mathrm{~m} / \mathrm{s}$ for these sprinkler fires.

Ceiling jet velocities for the $3.0 \mathrm{~m} \times 3.0 \mathrm{~m}$ test (test 15 ) exhibit large drops in velocity roughly $100 \mathrm{~s}$ into the test as shown in Figure 82. The ceiling temperatures at the velocity measurement locations did not exceed $200{ }^{\circ} \mathrm{C}$ during these tests. Had the temperatures exceeded $200^{\circ} \mathrm{C}$, the temperature compensation range of the hot-wire anemometer would have also been exceeded. The low velocity measurements are probably the result of loss of buoyancy by the plume as it tries to penetrate the hot gas layer. The loss of buoyancy seems to have less effect on the flow patterns developed during the $2.0 \mathrm{~m}$ diameter test fire (test 18). Figure 83 indicates a higher measured velocity for this case.

The $4.6 \mathrm{~m} \times 4.6 \mathrm{~m}$ test fire produced the highest measured velocity. However, according to the velocity measurement as shown in Figure 82, the ceiling jet velocity for this large test dropped to zero $80 \mathrm{~s}$ into the test and remained at zero until the fire was extinguished. This test produced ceiling temperatures in excess of $200{ }^{\circ} \mathrm{C}$ which exceeded the temperature compensation range of the hot-wire anemometer. As soon as the center temperature dropped below $200{ }^{\circ} \mathrm{C}$, the mass flow meter began recording nonzero velocities. The zero velocity readings are therefore regarded as an instrumental effect based on high temperatures and should be discounted.

As in the case of the detector fires, the measured ceiling jet velocities are smaller than theory would predict using Alpert's correlations for a flat ceiling [31], because the hot gas flow at the ceiling is obstructed by beams and trusses.

The thermocouple configuration at the ceiling was changed for tests 18 through 20 such that the temperature profile of the ceiling jet could be measured. Thermocouples placed $0.15 \mathrm{~m}, 0.3 \mathrm{~m}$, $0.45 \mathrm{~m}, 0.61 \mathrm{~m}, 0.76 \mathrm{~m}$, and $0.9 \mathrm{~m}(0.5 \mathrm{ft}, 1.0 \mathrm{ft}, 1.5 \mathrm{ft}, 2.0 \mathrm{ft}, 2.5 \mathrm{ft}$, and $3.0 \mathrm{ft})$ below the ceiling

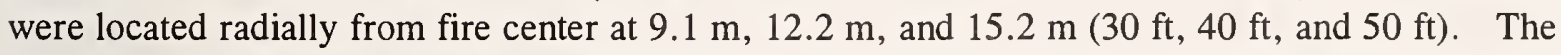
thermocouples (E3, E3Je) located $0.3 \mathrm{~m}$ and $0.9 \mathrm{~m}$ below the ceiling at a radial distance of $9.1 \mathrm{~m}$ east failed during these tests. Figures 84 and 85 provide temperature history of the ceiling jet during the first $120 \mathrm{~s}$ of test 18 and test 20 . The thermocouple tree located at $12.2 \mathrm{~m}$ was directly behind a ceiling beam whereas the other two thermocouple trees were located midway between the ceiling beams. Both test 18 and test 20 were JP-5 fires with test 18 reaching a steady state heat release rate of $4.9 \mathrm{MW}$ and test 20 reached a steady state heat release rate of $14.6 \mathrm{MW}$.

For test 18 , the highest temperatures during the first $120 \mathrm{~s}$ were consistently recorded by the thermocouples located at $0.76 \mathrm{~m}$ beneath the ceiling for all radial positions. Only at radial position $15.2 \mathrm{~m}$ did the thermocouple at $0.9 \mathrm{~m}$ reach similar temperatures. Lower temperatures were recorded by thermocouples located at $0.15 \mathrm{~m}$ below the ceiling for all radial positions. The impact on the temperature caused by the presence of the beam at $12.2 \mathrm{~m}$ is easily seen by comparing the temperatures recorded by the two thermocouples located $0.15 \mathrm{~m}$ and $0.45 \mathrm{~m}$ beneath the ceiling at all three radial positions. For the thermocouple positions located midway between the beans (i.e., $6.1 \mathrm{~m}$ and $15.2 \mathrm{~m}$ ), the temperatures measured by the two thermocouples agree to within $1{ }^{\circ} \mathrm{C}$. The thermocouple located behind the beam at $0.15 \mathrm{~m}(0.5 \mathrm{ft})$ beneath the ceiling consistently recorded substantially lower temperatures than the temperature at $0.45 \mathrm{~m}(1.5 \mathrm{ft})$ beneath the ceiling. Since the beam is approximately $0.3 \mathrm{~m}$ deep, the thermocouple closest to the ceiling is in the shadow of the beam resulting in temperatures at this position being substantially lower. The thermocouple at $0.45 \mathrm{~m}(1.5 \mathrm{ft})$ is slightly below the beam, therefore the shadow effect is lessened. 
Figures 86,87 , and 88 indicate the ceiling jet temperatures recorded at similar depths below the ceiling for the three radial positions from fire center. From these figures, a rough estimate of the initial velocity can be made. Figure 87 is perhaps the best representation of temperature profiles along the ceiling to determine the time-of-flight from the $9.1 \mathrm{~m}$ to the $15.2 \mathrm{~m}$ thermocouple positions. The change in temperatures at the depth of $0.46 \mathrm{~m}$ below the ceiling indicate an initial velocity of approximately $0.5 \mathrm{~m} / \mathrm{s}$. Similarly, the velocities at lower positions at $0.61 \mathrm{~m}, 0.76 \mathrm{~m}$, and $0.91 \mathrm{~m}$ below the ceiling are estimated to be nearly $0.5 \mathrm{~m} / \mathrm{s}$. These measurements show modest agreement with the measured ceiling jet velocity at $12.2 \mathrm{~m}$ using the hot wire anemometer. However, because the temperature data were recorded at a rate of $0.25 \mathrm{~Hz}$ to $0.2 \mathrm{~Hz}$, the time resolution for these data points is no worse than $4 \mathrm{~s}$.

Test 20 produced similar temperature results as shown in Figures 89, 90, and 91. The shadowing effect of the beam in front of the $12.2 \mathrm{~m}$ measurement location can also be seen in these figures. The initial velocities based on temperature measurements were approximately $0.5 \mathrm{~m} / \mathrm{s}, 0.7 \mathrm{~m} / \mathrm{s}$, and $0.8 \mathrm{~m} / \mathrm{s}$ for the depths of $0.46 \mathrm{~m}, 0.61 \mathrm{~m}$, and $0.76 \mathrm{~m}$ respectively.

\section{Heat Flux Measurements}

Heat flux was measured using three heat flux meters located as described earlier. Minimum detector sensitivity was $0.25 \mathrm{~kW} / \mathrm{m}^{2}$. Table 51 lists the average heat flux measured by R1 as a function of detector position from the center of the pan. Heat flux meter R1 was located near the floor and was not emersed in the hot gas layer during the fire tests. The heat flux measured by this meter was primarily radiative flux from the flame. Figure 92 presents the heat flux for $\mathrm{R} 1$ for tests $14,15,17,20$, and 21 where the position of R1 was kept approximately constant. The radiative flux at this position seems to scale linearly with the heat release rate. It should be pointed out that the heat release rate for test 21 was estimated based on fuel surface area.

The radiative flux produced by the JP- 8 fire of test 17 is equivalent to the radiative flux produced by the JP- 5 fire of test 20 . Both tests were $3.0 \mathrm{~m}$ by $3.0 \mathrm{~m}$ pan fires with nearly the same heat release rate. As with the detector tests, this result indicates that the radiative flux produced by these fuels is equivalent.

The heat flux measured by the radiometers located $0.3 \mathrm{~m}$ and $6.1 \mathrm{~m}$ below the ceiling at $12.2 \mathrm{~m}$ east from fire center are presented in Table 52. Since these meters were emersed in the hot gas layer for most of each test, the heat flux that is measured is a combination of radiation from the smoke layer and the flame and convective heat flux from the hot gas layer. An indication of what proportion each transfer mechanism contributes to the measurements can be obtained by calculating the radiation flux from the smoke layer. This calculation is based on the assumption that the smoke layer is a black body and the radiative flux from the flame is a point source with a radiative fraction of 0.35 . The radiation flux from the layer was calculated from

$$
R=\sigma\left(T_{l}^{4}-T_{a}^{4}\right)
$$

where $\mathrm{R}$ is the power per unit area received at the detector from the layer, $\mathrm{T}_{1}$ is the layer temperature at the heat flux meter and $T_{a}$ is the ambient temperature of the heat flux meter. The radiation from the flame was calculated assuming that the emitting region was a point source located at pan center and that 
the smoke layer covering the meter did not absorb any of the radiation. It was assumed that $35 \%$ of the heat release rate of the fire was converted into radiation.

Referring to Table 52, the expected contributions to the heat flux from the calculated flame and layer are generally about half the measured value. The heat flux measured by these ceiling mounted devices is probably due mostly to convective heating. This assumption is substantiated by analyzing the timing of the flux signals for test 21 as shown in Figure 93.

The heat flux gauge R1 provides a satisfactory time history of the radiation from the flame since it was located near the floor and out of the smoke layer. The timing for the initial reception of the heat flux is $25 \mathrm{~s}$ for R1, $80 \mathrm{~s}$ for R2 and $60 \mathrm{~s}$ for R3. If the majority of the radiation received by these heat flux meters came from the flame, the three detectors would be expected to respond simultaneously in time. If the layer radiation was the dominant source of heat flux for R2 and R3, these detectors would again be expected to respond nearly simultaneously. If the dominant contribution to the heat flux came from convective heating, R3 near the ceiling would be expected to respond first based on the ceiling jet convectively heating R3 before the layer drops to the position of R2. Since R3 responds before R2, the conclusion is that the heat flux is convective and that the contribution to the heat flux from radiation at these ceiling locations is at or below the minimum sensitivity of the heat flux gauges. Figure 94 presents the temperature profiles for thermocouples E4 located near R3, E4b located below R3 and E4d located near R2. The temperature response of thermocouple E4d lags the temperature response of E4 by about $10 \mathrm{~s}$ which nearly equals the $20 \mathrm{~s}$ delay observed when comparing R 2 to R3. These estimates include the data sampling uncertainty of approximately $4 \mathrm{~s}$. Since the thermocouple measurements will correlate with increased convective heat flux at these positions, this observation again suggests that the heat flux meters near the ceiling are measuring convective heat flux and not radiative heat flux.

\section{Heat Release Rate}

Heat release information for the eight sprinkler fires was calculated using time dependent mass loss data provided by the load platform. The four-point load platform used for the sprinkler fires could easily accommodate the $3.0 \mathrm{~m} \times 3.0 \mathrm{~m}$ pan. In addition, measurements of initial and final fuel volumes were made. This method of volume measurement has an estimated uncertainty of $\pm 3.8 \ell$ ( \pm 1 gallon), based on the error in reading the fuel volume from the containment barrels, and any spillage occurring during fuel transfer.

The amount of fuel consumed by the fire was determined using both the load platform (direct mass loss rate) method and volume consumed method. The heat release rate was then determined by multiplying the measured mass loss of fuel by the heat of combustion of the fuel. Using the volume of fuel consumed method, an estimate of heat release rate was made by calculating the average mass loss, using the density of the fuel multiplied by the measured volume, over the duration of the test. This method of determining heat release rate included the volume consumed over the entire test. Since the final volume was not measured until the residual fuel in the pan cooled to below its flash point, the total volume of fuel consumed would include any losses due to fuel vaporization and minimal losses during the extinguishment process. Table 53 shows the heat release rate using both methods of mass loss measurement, burning rates, and steady state time interval.

The mass loss rate using the load platform method is provided for all eight sprinkler fires with the exception of test 21 , which is not available because the $4.6 \mathrm{~m} \mathrm{x} 4.6 \mathrm{~m}$ fuel pan was not rigid enough to 
be safely placed on the load platform. For this case, the fuel pan was placed directly on the floor. For each test, a linear curve fit was used to determine burning rate after an approximate steady state condition was reached. The steady state condition was defined as the region on the mass loss curve where the slope was consistently decreasing without major fluctuations.

For each experiment a steady state region was determined and the linear fit extended to the limits of the steady state interval. It is important to realize that by changing the steady state interval, changes may occur in the resultant heat release value. The uncertainty of the calculated heat release rates was determined by evaluating upper and lower limits obtained by using curve fits during various portions of the mass loss curve. Figure 95 shows the measured mass loss for test 14 (2.5 m diameter pan) and test $17(3.0 \mathrm{~m} \mathrm{x} 3.0 \mathrm{~m} \mathrm{pan})$, the region where steady state was determined, and a linear curve fit of the steady state region.

The burning rate increased during the early part of the fire until a steady state condition was reached. The time required to reach this condition varied with pan size with the larger pans generally requiring more time to reach steady state. Figures 96 and 97 show the mass loss curves for the $2.0 \mathrm{~m}$ diameter, $2.5 \mathrm{~m}$ diameter and $3.0 \mathrm{~m} \times 3.0 \mathrm{~m}$ test fires using JP-5 and JP-8 fuels. Figure 98 shows a linear relationship between heat release rate and pan area. The extrapolated heat release value for a $4.6 \mathrm{~m} \mathrm{x}$ $4.6 \mathrm{~m}$ pan is approximately $33 \mathrm{MW}$.

As previously explained in the detector fire section, there were difficulties in determining the steady state heat release rate values for several of the sprinkler experiments. These problems were caused by fluctuations in the mass loss curves during the early stages of the experiment. Fluctuations occurred due to instrumental anomalies, non-uniform burning, and burning outside of the pan in some cases. Figure 97 shows the mass loss curve for test 15 (3.0 m x $3.0 \mathrm{~m}$ pan). This case represents some of the unusual behavior seen during the initial stages of the experiment. The portion of the mass loss curve from about $330 \mathrm{~s}$ to the end of the test appears to be the region with the most consistent slope, therefore, this region is considered steady state.

\subsubsection{Open Door Experiments}

Test 16 and 19 were both 2.5 m diameter JP-5 pan fires designed to test the impact of wind on detector activation. Both hangar doors on the north and south side of the hangar were fully opened for test 16 while only the north door was fully opened for test 19, as shown in Figure 99. Test 14, also a $2.5 \mathrm{~m}$ diameter JP-5 fire test, was conducted with both doors closed so that differences between open and closed door tests could be examined.

The steady state heat release rates for the three tests are found in Table 53. These values ranged from a high of $9 \mathrm{MW}$ for test 19 to a low of $7 \mathrm{MW}$ for test 16 . The mass loss curve for test 16 was sornewhat irregular compared with the mass loss data for tests 14 and 19 as shown in Figure 96. The 7 MW heat release rate for test 16 was based on a linear fit of the mass loss curve for the steady state region between $180 \mathrm{~s}$ and $280 \mathrm{~s}$. Looking at the total fuel burned during the first $300 \mathrm{~s}$ of the test 16 , the average heat release rate may have been as low as $5 \mathrm{MW}$. The irregular portions of the mass loss curve may have been the result of the wind blowing through the hangar and thus affecting the mass readings. 
Table 49. Temperature data for $22 \mathrm{~m}$ high facility sprinkler fire tests

\begin{tabular}{|c|c|c|c|c|c|c|c|c|c|c|}
\hline \multicolumn{4}{|c|}{ Test Information } & \multicolumn{6}{|c|}{ Temperature Data $\left.{ }^{\circ} \mathrm{C} \pm 2\right)$} \\
\hline $\begin{array}{c}\text { Test } \\
\#\end{array}$ & $\begin{array}{c}\text { Pan Size } \\
\mathrm{m}\end{array}$ & $\begin{array}{c}\mathrm{T}_{\text {amb }} \\
\text { Heat Release } \\
\text { Rate, MW }\end{array}$ & $\mathrm{C}$ & $\mathrm{N} 1$ & $\mathrm{~S} 1$ & $\mathrm{~W} 1$ & $\mathrm{E} 1$ & $\begin{array}{c}\text { Max. } \\
\text { Value }\end{array}$ & $\begin{array}{c}\text { Rise Above } \\
\mathrm{T}_{\text {amb }}\end{array}$ \\
\hline $14^{\text {a }}$ & 2.5 dia. & 12 & 7.9 & 91 & 90 & 93 & 90 & 87 & 93 & 81 \\
\hline 15 & $3.0 \times 3.0$ & 12 & 15.7 & 173 & 169 & 173 & 154 & 168 & 173 & 161 \\
\hline 16 & 2.5 dia. & 8 & 7 & 57 & 63 & 55 & 58 & 62 & 63 & 55 \\
\hline 17 & $3.0 \times 3.0$ & 11 & 14.3 & 174 & 175 & 178 & 154 & 169 & 178 & 167 \\
\hline 18 & 2.0 dia. & 10 & 4.9 & 66 & 66 & 63 & 63 & 62 & 66 & 56 \\
\hline $19^{\text {b }}$ & 2.5 dia. & 13 & 9.1 & 65 & 61 & 70 & 68 & 65 & 70 & 57 \\
\hline 20 & $3.0 \times 3.0$ & 14 & 14.6 & 165 & 165 & 166 & 163 & 164 & 166 & 152 \\
\hline 21 & $4.6 \times 4.6$ & 14 & $33^{\mathrm{c}}$ & 277 & 278 & 249 & 464 & 210 & 277 & 263 \\
\hline
\end{tabular}

a Both hangar doors fully open

b North hangar door fully open

c Heat release value extrapolated from previous test data

Table 50. Hot gas transport times along east direction of ceiling

\begin{tabular}{|c|c|c|c|c|c|c|}
\hline Test Num. & Pan Size & HRR & \multicolumn{4}{|c|}{ Transport Times $\left(\mathrm{s} \pm 4^{*}\right)$} \\
\cline { 4 - 7 } & $\mathrm{m}$ & MW & E1 & E3 & E5 & E7 \\
\hline Test $14^{\mathrm{b}}$ & 2.5 dia. & 7.9 & 30 & 44 & 49 & 77 \\
\hline Test 15 & $3.0 \times 3.0$ & 15.7 & 39 & 43 & 57 & 80 \\
\hline Test 16 & 2.5 dia. & 7 & 35 & 44 & 49 & 63 \\
\hline Test $17^{\mathrm{a}}$ & $3.0 \times 3.0$ & 14.3 & 22 & 42 & 38 & 62 \\
\hline Test 18 & 2.0 dia. & 4.9 & 46 & 66 & 66 & 91 \\
\hline Test $19^{\mathrm{c}}$ & 2.5 dia. & 9.1 & 46 & 58 & 54 & 78 \\
\hline Test 20 & $3.0 \times 3.0$ & 14.6 & 30 & 44 & 45 & 66 \\
\hline Test 21 & $4.6 \times 4.6$ & $33^{\mathrm{d}}$ & 31 & 39 & 48 & 62 \\
\hline
\end{tabular}

*indicates the average time interval between successive data scans

a JP-8 aviation fuel used

${ }^{\mathrm{b}}$ Both hangar doors fully open

${ }^{c}$ North hangar door fully open

${ }^{\mathrm{d}}$ Heat release rate estimated from previous data 
Table 51. Average heat flux measurements for detector fires

\begin{tabular}{|c|c|c|c|c|c|c|}
\hline $\begin{array}{c}\text { Test } \\
\text { Number }\end{array}$ & $\begin{array}{c}\text { Pan Size } \\
\mathrm{m}\end{array}$ & Fuel & $\begin{array}{c}\text { Heat Release } \\
\text { Rate } \\
\mathrm{MW}\end{array}$ & \multicolumn{2}{|c|}{$\begin{array}{c}\text { Location with Respect to Pan } \\
\text { Center, } \mathrm{m}( \pm 0.1) \\
\text { Distance }\end{array}$} & $\begin{array}{c}\text { Heat Flux, R1 } \\
\mathrm{kW} / \mathrm{m}^{2}( \pm 0.25)\end{array}$ \\
\hline 14 & 2.5 Dia. & JP-5 & 7.9 & 7.1 & 1.1 & 3.5 \\
\hline 15 & $3.0 \times 3.0$ & JP-5 & 15.7 & 7.6 & 1.1 & 5.0 \\
\hline 17 & $3.0 \times 3.0$ & JP-8 & 14.3 & 7.2 & 1.1 & 5.5 \\
\hline 18 & 2.0 Dia. & JP-5 & 4.9 & 4.2 & 1.1 & 7.0 \\
\hline 20 & $3.0 \times 3.0$ & JP-5 & 14.6 & 7.2 & 1.1 & 5.5 \\
\hline 21 & $4.6 \times 4.6$ & JP-5 & $33^{\mathrm{a}}$ & 7.2 & 1.1 & 9.0 \\
\hline
\end{tabular}

${ }^{a}$ Estimated heat release rate based on previous data

Table 52. Average measured heat flux at R3 \& R2 including calculated values.

\begin{tabular}{|c|c|c|c|c|c|c|c|}
\hline $\begin{array}{c}\text { Test } \\
\text { Number }\end{array}$ & $\begin{array}{c}\text { Heat } \\
\text { Release } \\
\mathrm{Rate} \\
\mathrm{MW}\end{array}$ & $\begin{array}{c}\mathrm{R} 3 \\
\text { Measured } \\
\mathrm{kW} / \mathrm{m}^{2} \\
\pm 0.25\end{array}$ & $\begin{array}{c}\mathrm{R} 2 \\
\text { Measured } \\
\mathrm{kW} / \mathrm{m}^{2} \\
\pm 0.25\end{array}$ & $\begin{array}{c}\mathrm{R} 3 \\
\text { Layer } \\
\text { Radiation } \\
\mathrm{kW} / \mathrm{m}^{2}\end{array}$ & $\begin{array}{c}\mathrm{R} 2 \\
\text { Layer } \\
\mathrm{Radiation} \\
\mathrm{kW} / \mathrm{m}^{2}\end{array}$ & $\begin{array}{c}\mathrm{R} 3 \\
\text { Flame } \\
\text { Radiation } \\
\mathrm{kW} / \mathrm{m}^{2}\end{array}$ & $\begin{array}{c}\mathrm{R} 2 \\
\text { Flame } \\
\text { Radiation } \\
\mathrm{kW} / \mathrm{m}^{2}\end{array}$ \\
\hline 14 & 7.9 & 1.5 & 1.0 & 0.40 & 0.39 & 0.27 & 0.35 \\
\hline 15 & 15.7 & 2.5 & 1.5 & 0.77 & 0.68 & 0.54 & 0.69 \\
\hline 17 & 14.3 & 2.5 & 1.2 & 0.73 & 0.64 & 0.50 & 0.63 \\
\hline 18 & 4.9 & 1.0 & 0.5 & 0.24 & 0.24 & 0.17 & 0.22 \\
\hline 20 & 14.6 & 3.0 & 2.0 & 0.76 & 0.69 & 0.51 & 0.64 \\
\hline 21 & 33 & 6.0 & 4.0 & 2.47 & 2.02 & 1.14 & 1.45 \\
\hline
\end{tabular}


Table 53. Heat release information for sprinkler fires

\begin{tabular}{|c|c|c|c|c|c|c|c|c|c|}
\hline $\begin{array}{l}\text { Test } \\
\text { Number }\end{array}$ & $\begin{array}{c}\text { Pan Size } \\
\mathrm{m}\end{array}$ & Fuel & $\begin{array}{c}\text { Eff. } \\
\text { Pan Dia. } \\
\text { m }\end{array}$ & $\begin{array}{c}\text { Res. } \\
\text { Volume } \\
\ell \\
\pm 3.8 \\
\end{array}$ & $\begin{array}{c}\text { Burn Rate } \\
\text { (vol.) } \\
\mathrm{kg} / \mathrm{m}^{2} \mathrm{~s} \\
\pm 0.001 \\
\end{array}$ & $\begin{array}{c}\text { Burn Rate } \\
\text { (load) } \\
\mathrm{kg} / \mathrm{m}^{2} \mathrm{~s} \\
\pm 0.001 \\
\end{array}$ & $\begin{array}{c}\text { HRR } \\
\text { (vol.) } \\
\text { MW } \\
\pm 1 \\
\end{array}$ & $\begin{array}{c}\text { HRR } \\
\text { (load) } \\
\text { MW } \\
\pm 1^{\text {a }} \\
\end{array}$ & $\begin{array}{c}\text { SS Range } \\
\text { s } \\
\pm 5 \\
\end{array}$ \\
\hline 14 & 2.5 dia. & JP-5 & 2.5 & 143.8 & 0.037 & 0.037 & 8 & 8 & $120-420$ \\
\hline 15 & $3.0 \times 3.0$ & JP-5 & 3.39 & 283.9 & 0.039 & 0.041 & 15 & 16 & $330-600$ \\
\hline $16^{\mathrm{b}}$ & 2.5 dia. & JP-5 & 2.5 & 109.8 & 0.047 & 0.033 & 10 & 7 & $180-270$ \\
\hline 17 & $3.0 \times 3.0$ & JP-8 & 3.39 & 325.5 & 0.044 & 0.037 & 17 & 14 & $270-540$ \\
\hline 18 & $2.0 \mathrm{dia}$. & JP-5 & 2 & 113.6 & 0.043 & 0.036 & 6 & 5 & $180-420$ \\
\hline $19^{b}$ & 2.5 dia. & JP-5 & 2.5 & 121.1 & 0.052 & 0.043 & 11 & 9 & $120-240$ \\
\hline 20 & $3.0 \times 3.0$ & JP-5 & 3.39 & 280.1 & 0.038 & 0.038 & 15 & 15 & $240-540$ \\
\hline 21 & $4.6 \times 4.6$ & JP-5 & 5.19 & $\mathrm{n} / \mathrm{a}$ & $\mathrm{n} / \mathrm{a}$ & $\mathrm{n} / \mathrm{a}$ & $\mathrm{n} / \mathrm{a}$ & $33^{b}$ & $\mathrm{n} / \mathrm{a}$ \\
\hline
\end{tabular}

a The uncertainty of this value is based on the quality of the measurement over the steady state time range reported.

${ }^{\mathrm{b}}$ Open door experiment.

${ }^{c}$ Heat release rate determined by extrapolation of pan area versus HRR for previous test data.

Table 54. Comparison of activation time ranges for $2.5 \mathrm{~m}$ diameter test fire with open and closed door configurations.

\begin{tabular}{|c|c|c|c|c|}
\hline \multicolumn{2}{|c|}{ Test Information } & \multicolumn{3}{c|}{ Detector Activation Time Range (s) } \\
\hline $\begin{array}{c}\text { Test } \\
\text { Number }\end{array}$ & $\begin{array}{c}\text { Hangar Door } \\
\text { Position }\end{array}$ & $79^{\circ} \mathrm{C}$ Sprinklers & $\begin{array}{c}57^{\circ} \mathrm{C} \text { Heat } \\
\text { Detectors }\end{array}$ & $\begin{array}{c}\text { Photoelectric } \\
\text { Smoke Detectors }\end{array}$ \\
\hline 14 & Closed & $262-560$ & $94-236$ & $59-105$ \\
\hline 16 & $\begin{array}{c}\text { North \& South } \\
\text { Fully Open }\end{array}$ & no activations & $130-174^{\mathrm{b}}$ & $50-83$ \\
\hline 19 & $\begin{array}{c}\text { North Only } \\
\text { Fully Open }\end{array}$ & no activations & $151-330$ & $45-115$ \\
\hline
\end{tabular}

${ }^{a}$ Includes all detector locations.

b No activations outside of $3.1 \mathrm{~m}$ from fire center. 


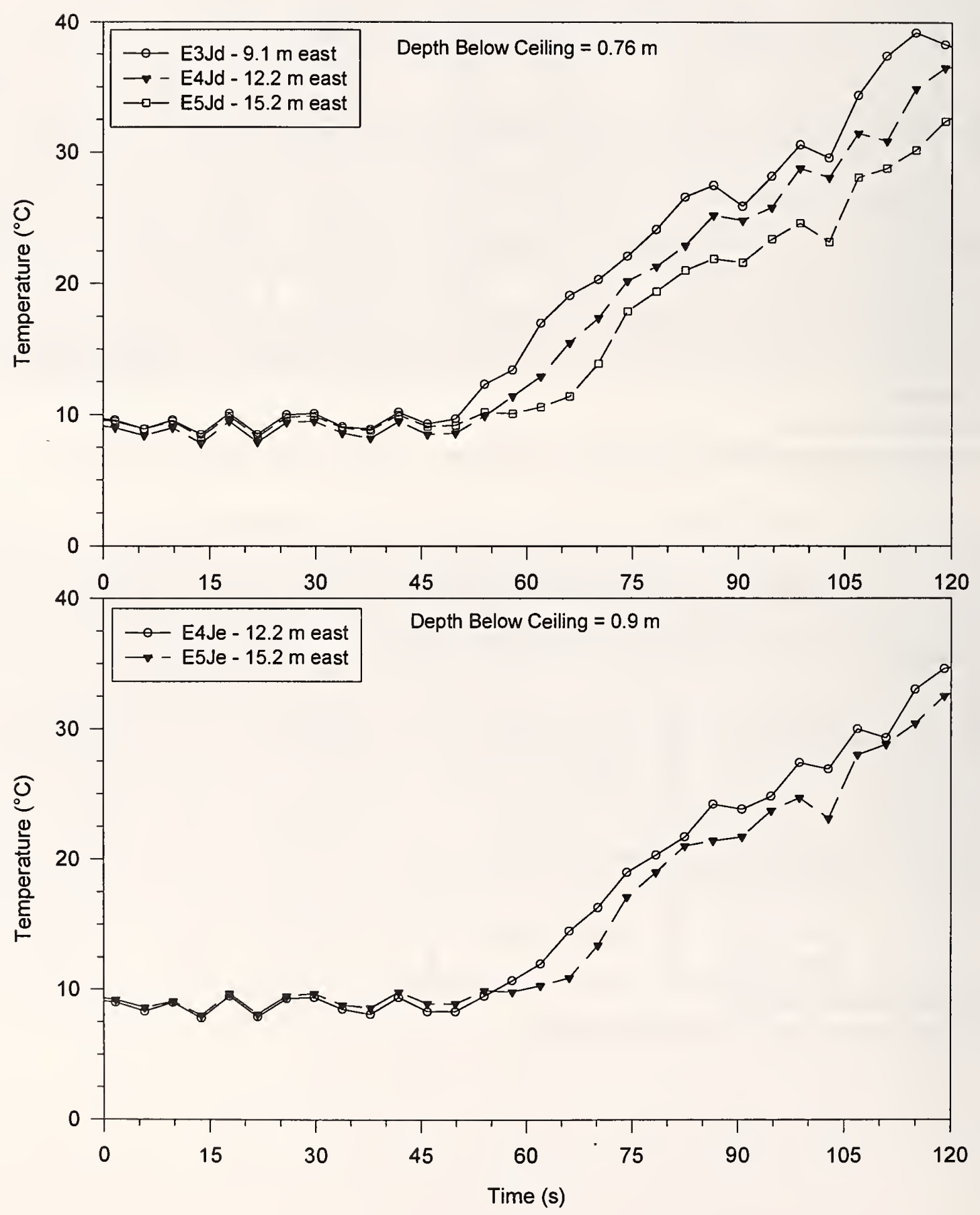

Figure 88. Ceiling jet temperature profiles at a depth of $0.76 \mathrm{~m}$ and $0.9 \mathrm{~m}$ below the ceiling for the $2.0 \mathrm{~m}$ diameter test fire. 

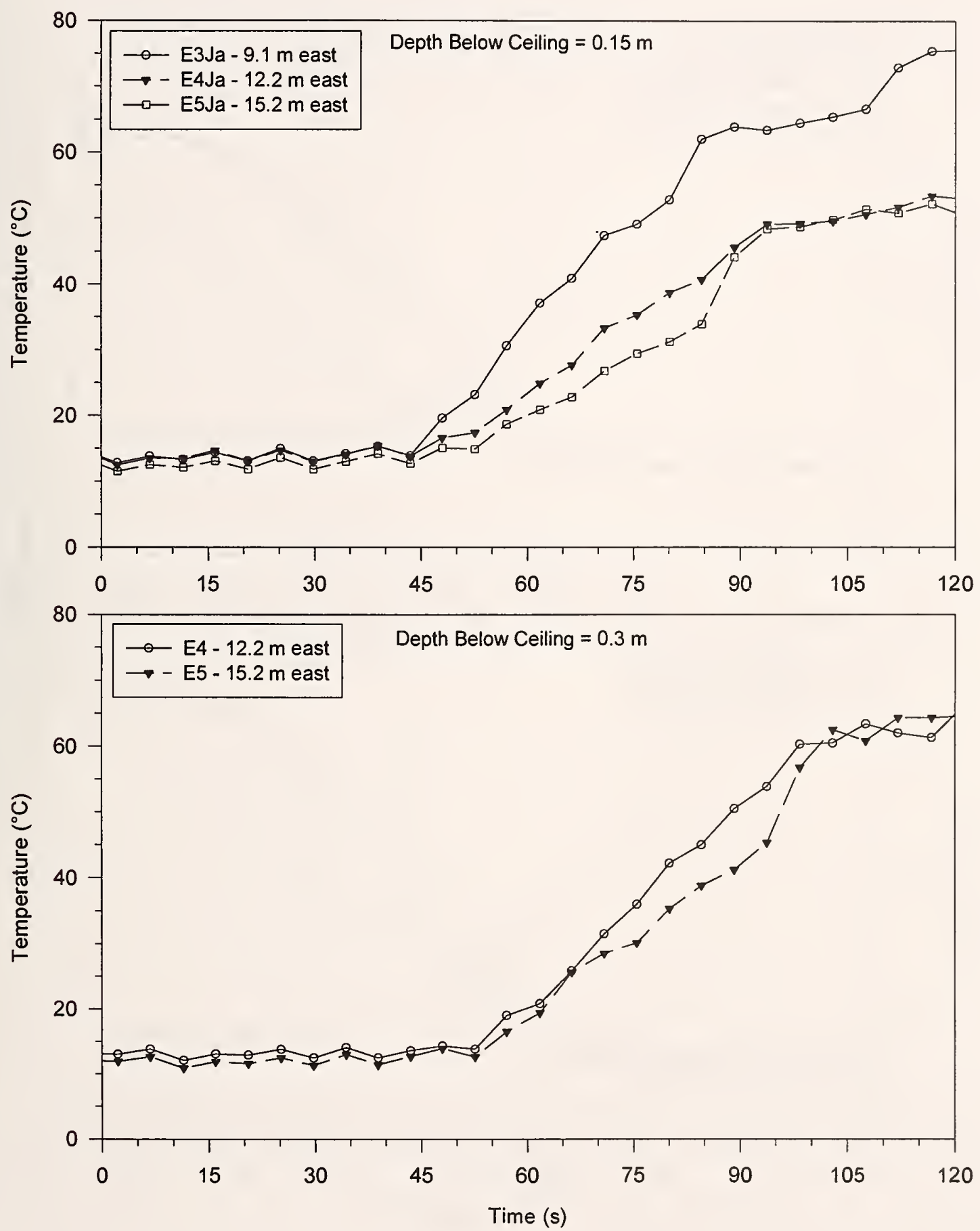

Figure 89. Ceiling jet temperature profiles at a depth of $0.15 \mathrm{~m}$ and $0.3 \mathrm{~m}$ below the ceiling for the $3.0 \mathrm{~m} \times 3.0 \mathrm{~m}$ test fire (test 20 ). 

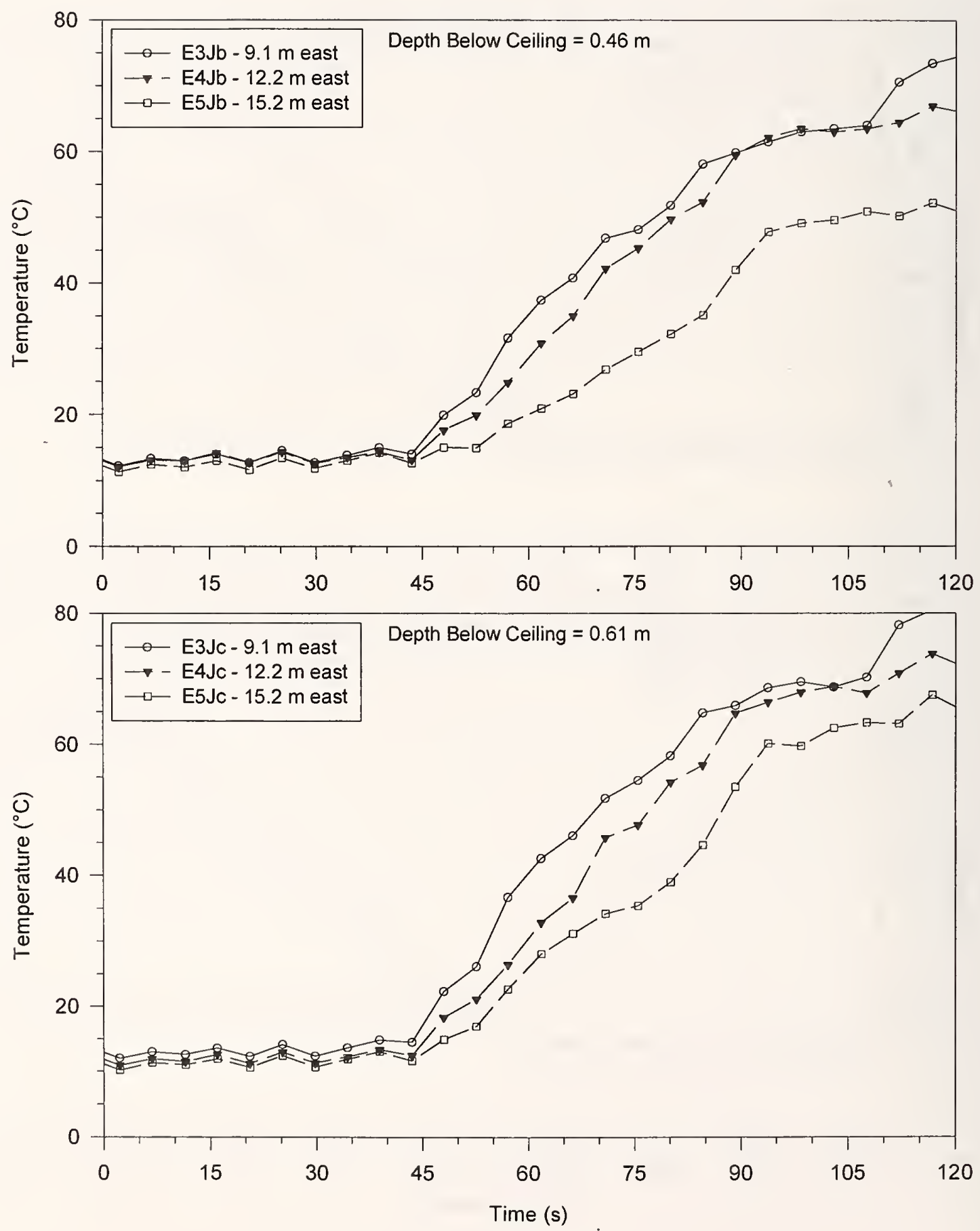

Figure 90. Ceiling jet temperature profiles at a depth of $0.46 \mathrm{~m}$ and $0.61 \mathrm{~m}$ below the ceiling for the $3.0 \mathrm{~m} \mathrm{x} 3.0 \mathrm{~m}$ test fire. 

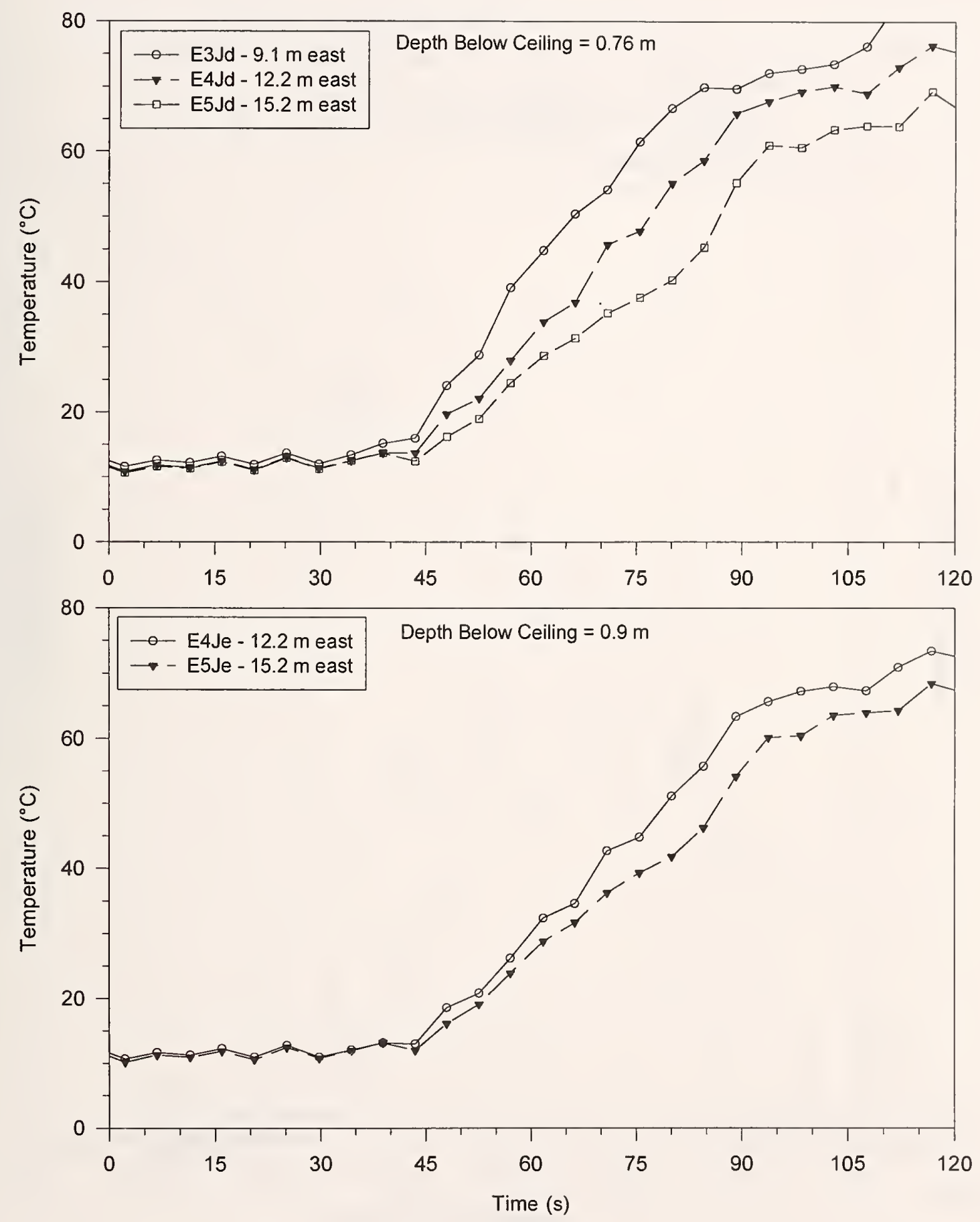

Figure 91. Ceiling jet temperature profiles at a depth of $0.76 \mathrm{~m}$ and $0.9 \mathrm{~m}$ below the ceiling for the $3.0 \mathrm{~m} \times 3.0 \mathrm{~m}$ test fire. 


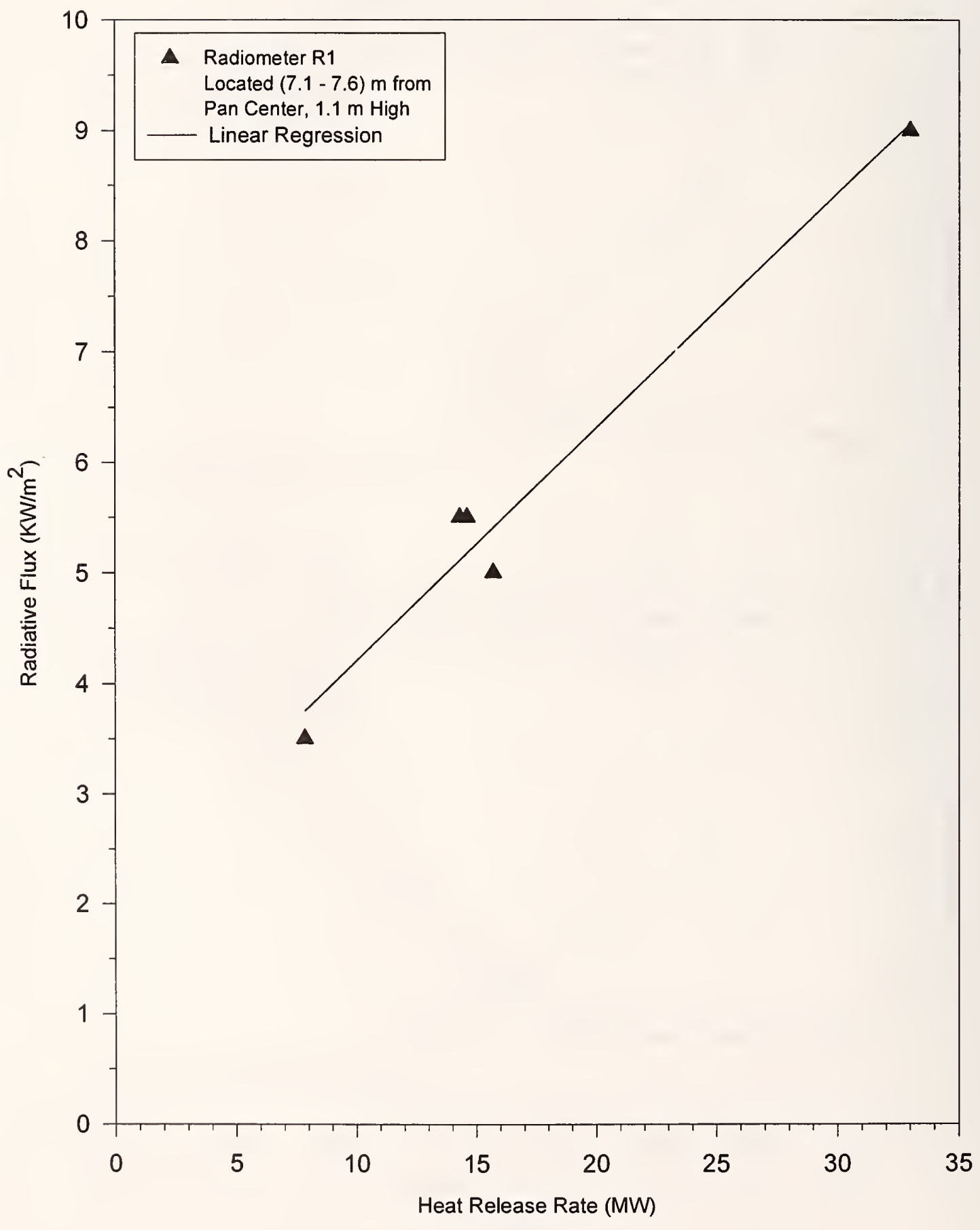

Figure 92. Average measured heat flux for sprinkler fires from radiometer (R1) position. 


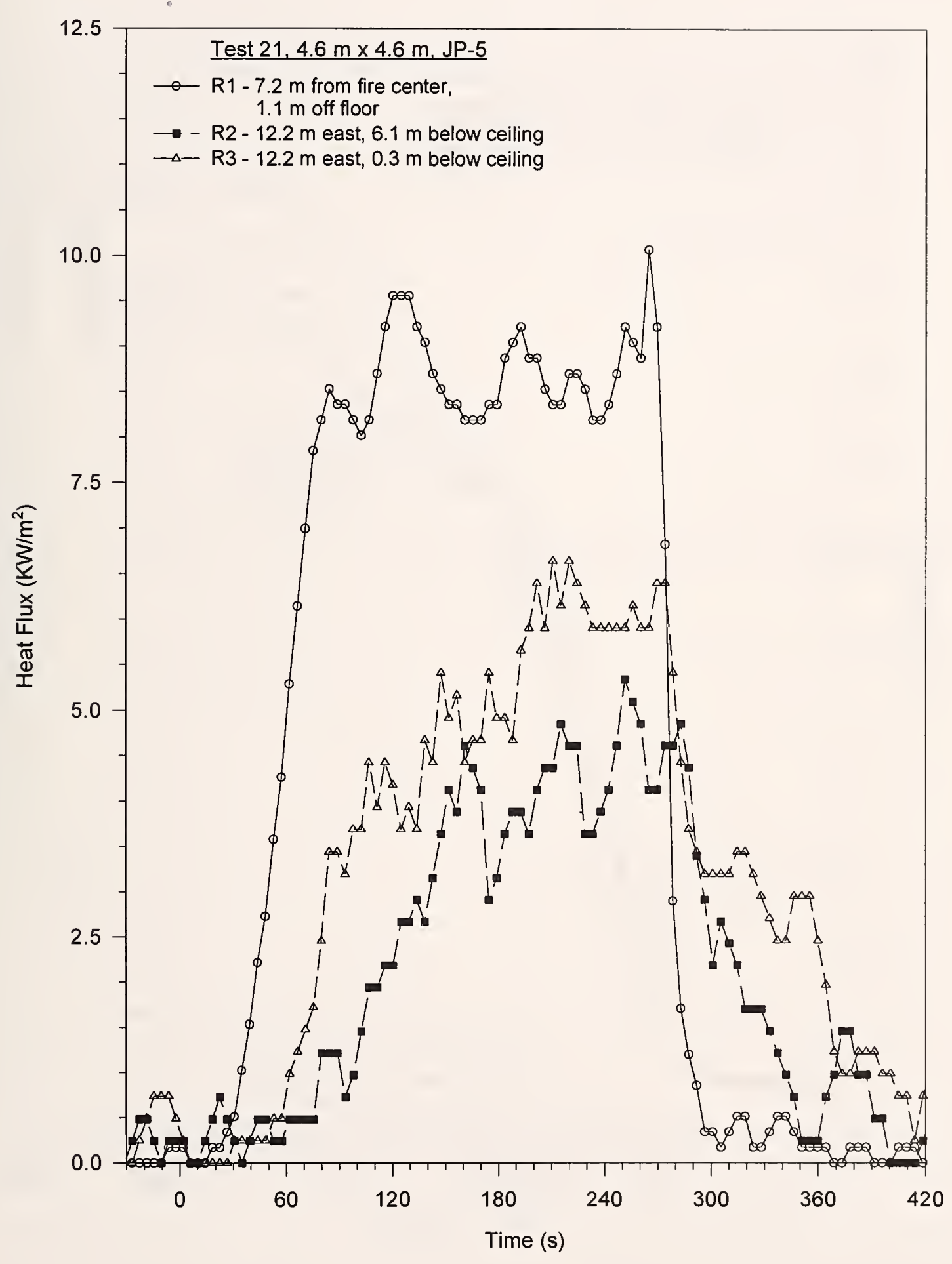

Figure 93. Heat flux profiles for $4.6 \mathrm{~m} \mathrm{x} 4.6 \mathrm{~m}$ test fire. 


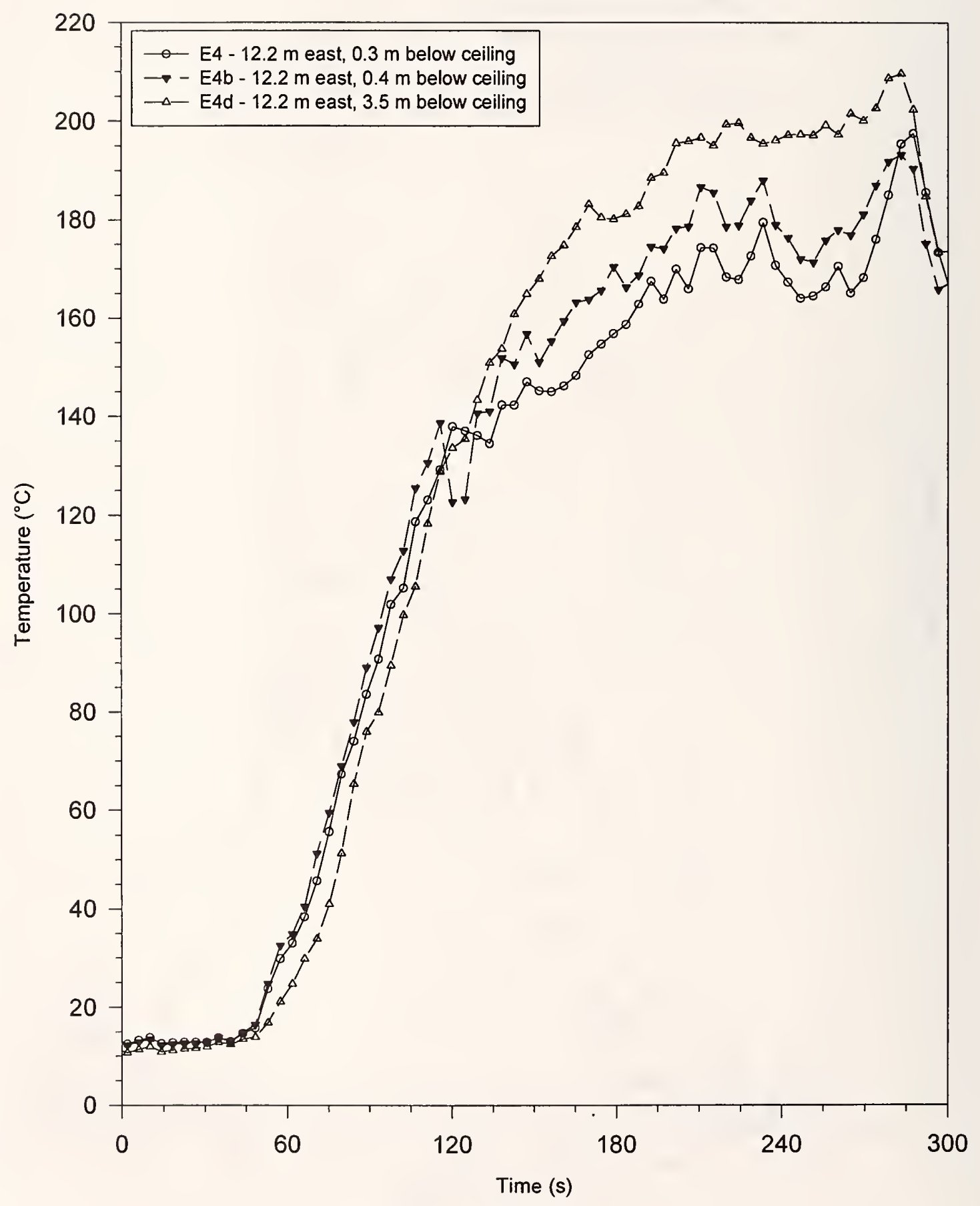

Figure 94. Temperature profiles in the vicinity of heat flux gauges for $4.6 \mathrm{~m} \times 4.6 \mathrm{~m}$ test fire. 


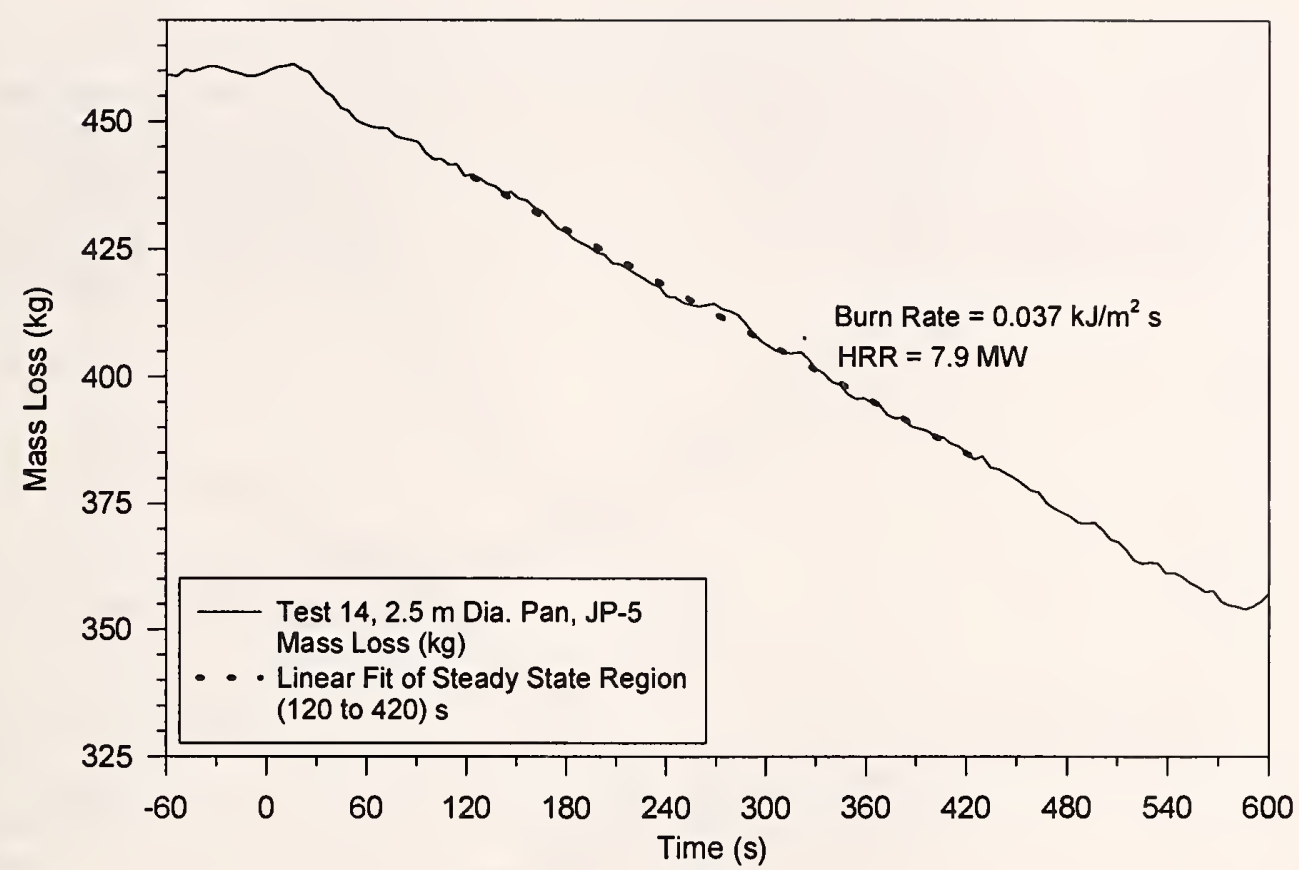

(A)

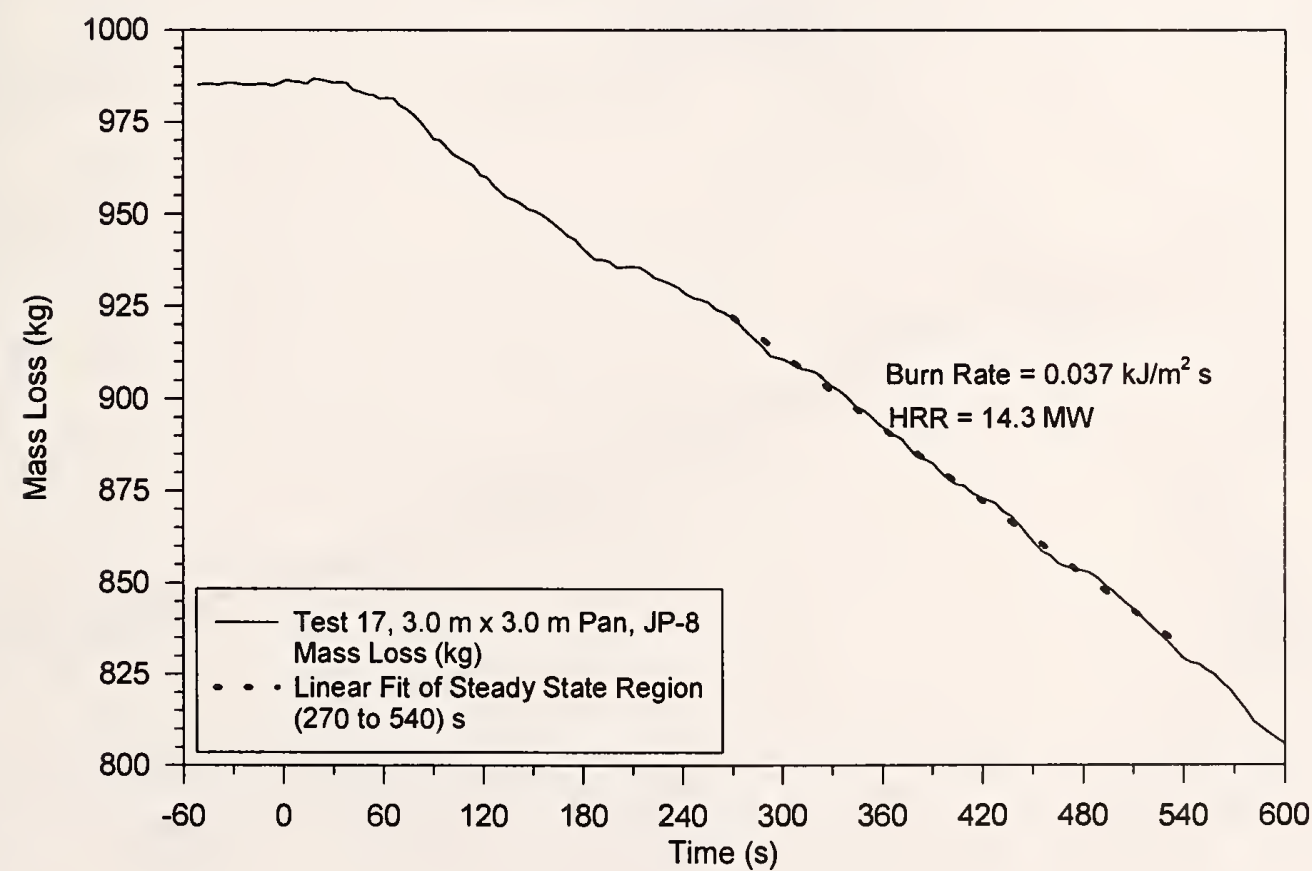

(B)

Figure 95. Test 14 mass loss curve with linear fit of steady state region (A). Test 17 mass loss curve with linear fit of steady state region (B). 


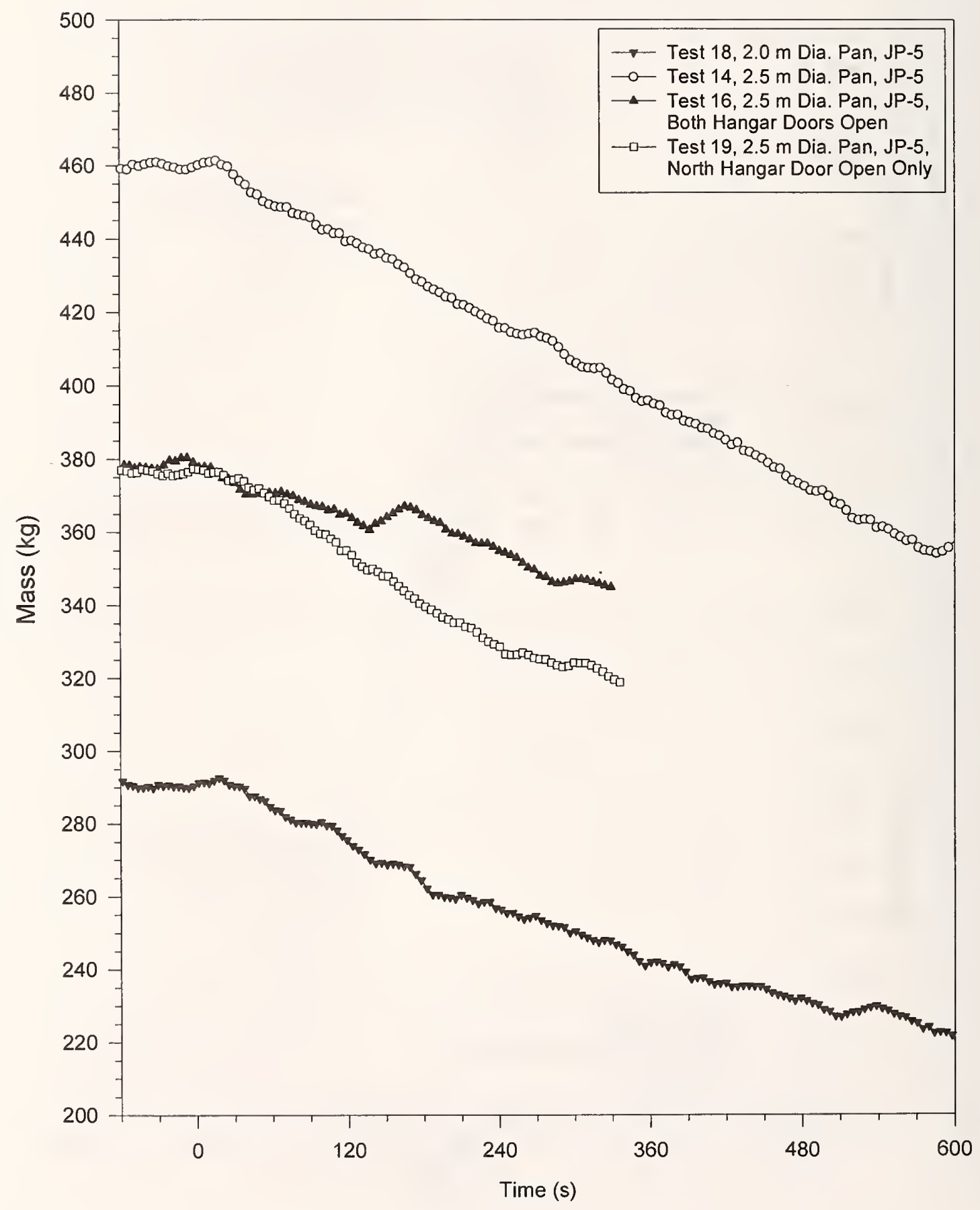

Figure 96. Mass loss curves for $2.0 \mathrm{~m}$ diameter and $2.5 \mathrm{~m}$ diameter test fires including open door experiments (tests 16 and 19). 


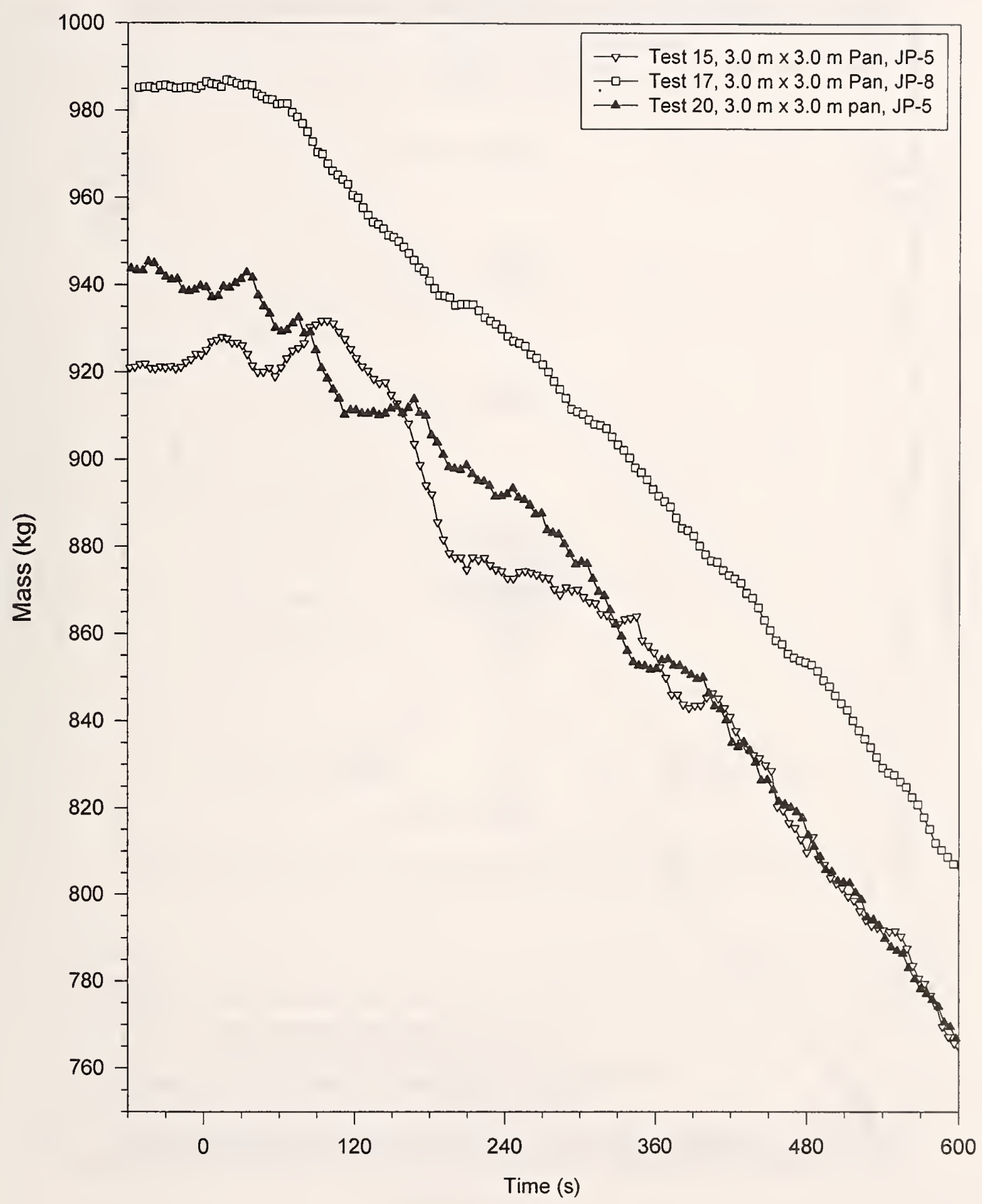

Figure 97. Mass loss curves for $3.0 \mathrm{~m} \times 3.0 \mathrm{~m}$ test fires using JP-5 and JP-8 fuels. 


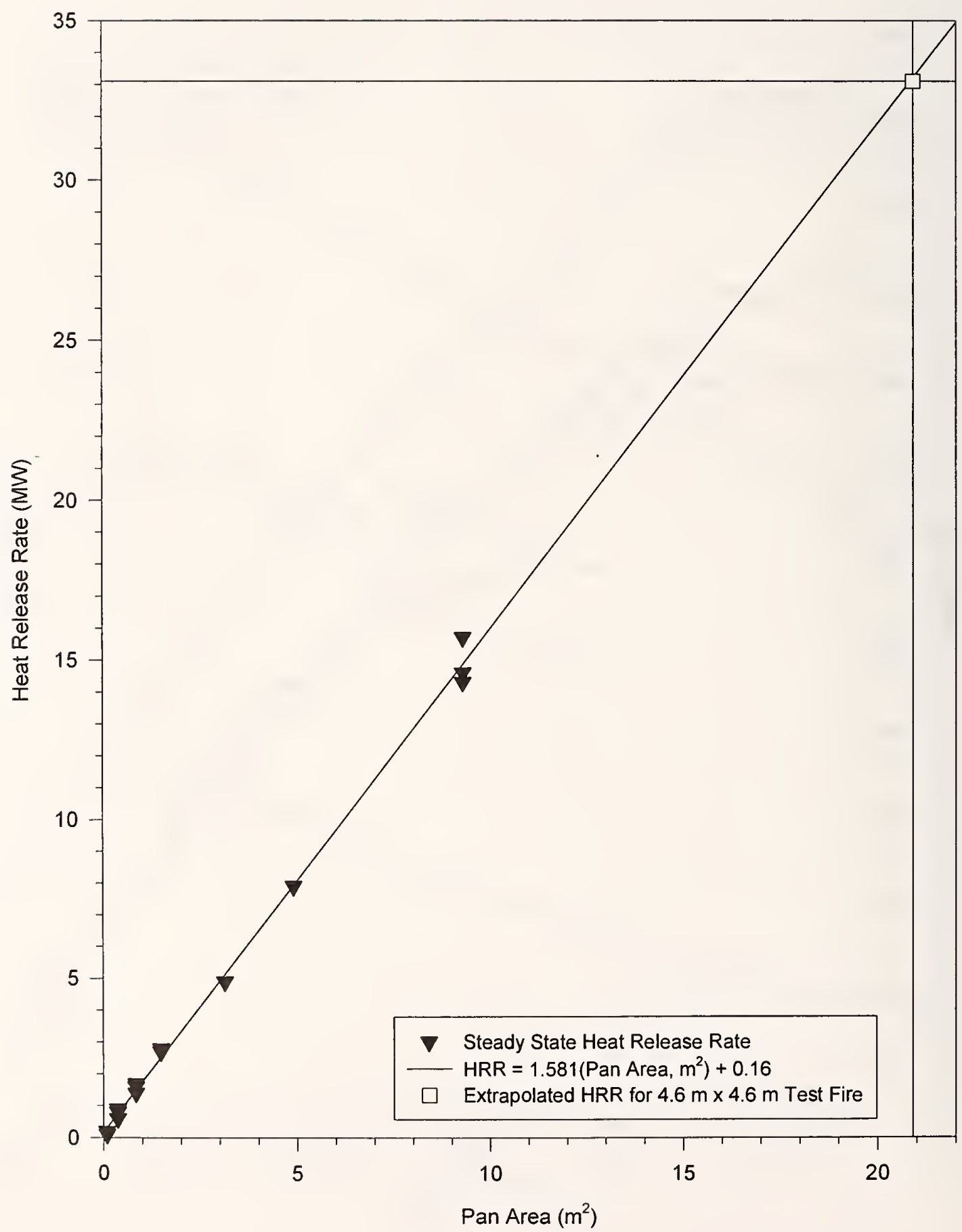

Figure 98. Pan area versus heat release rates for sprinkler fires. 


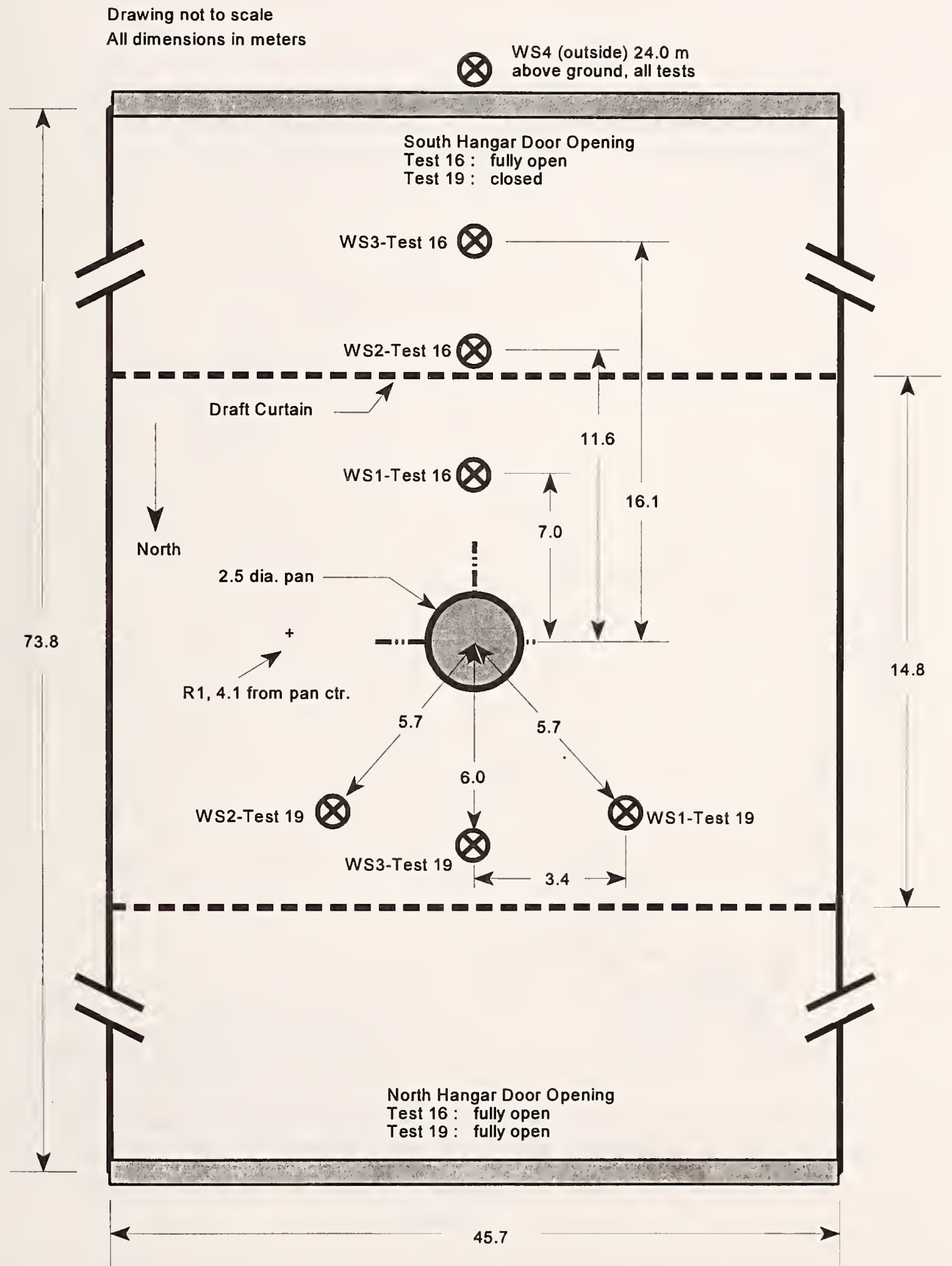

Figure 99. Instrumentation configuration for open door experiments in $22 \mathrm{~m}$ high facility. 


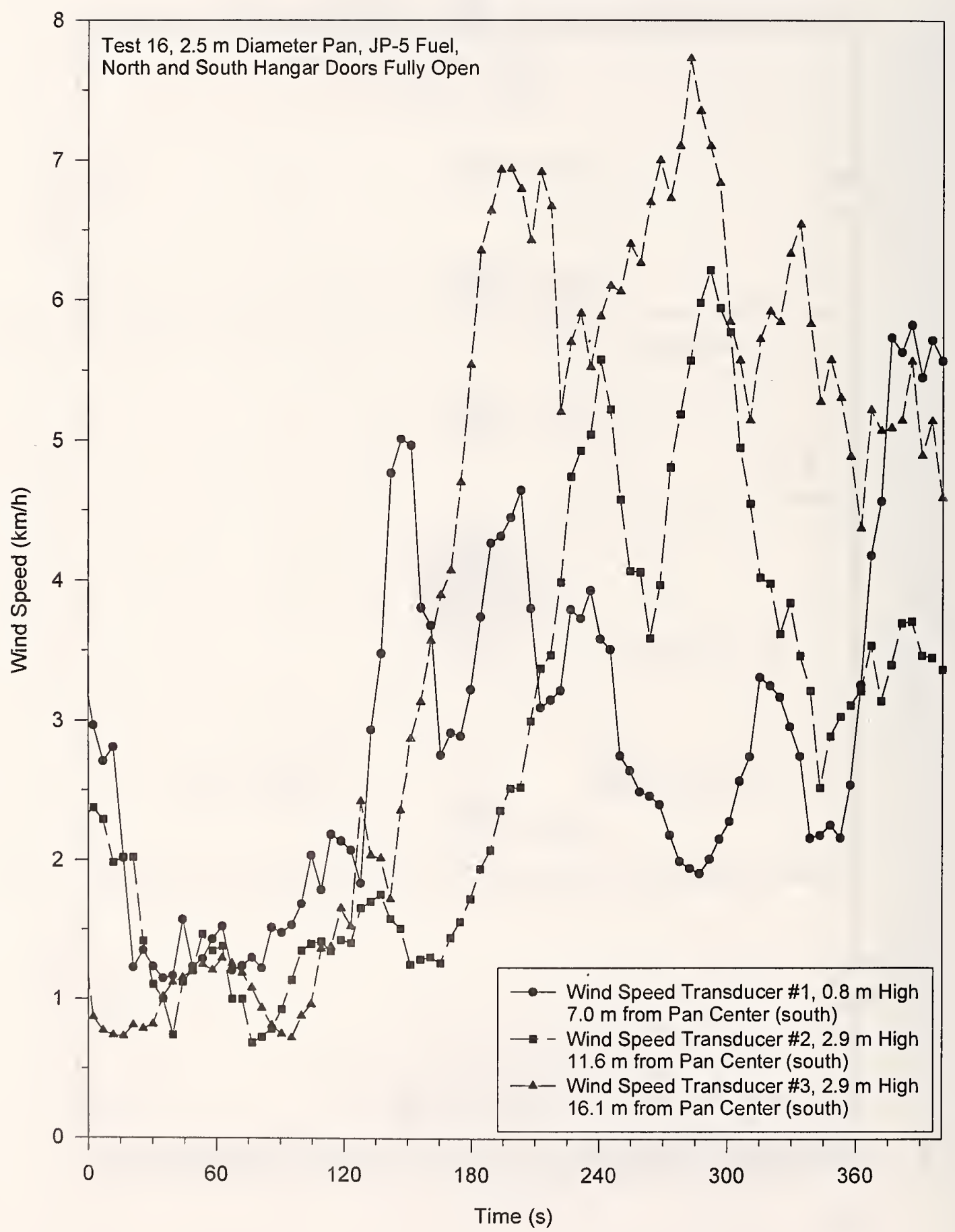

Figure 100. Wind speed measurements for test 16 . North and south hangar doors open fully. 


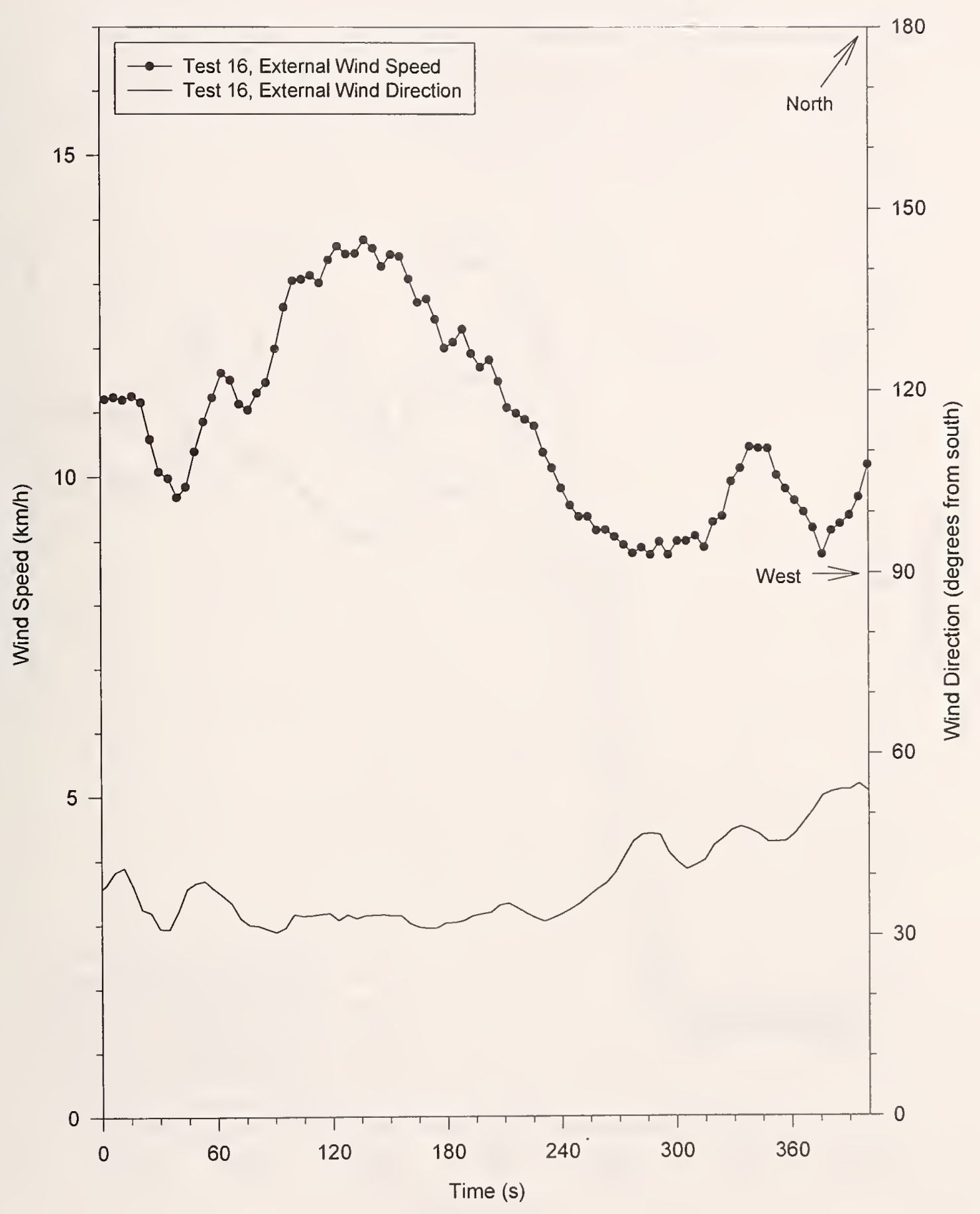

Figure 101. External wind speed and direction measurement for test 16. Sensor was located on the roof at the south end of the hangar $24 \mathrm{~m}$ above floor level. 


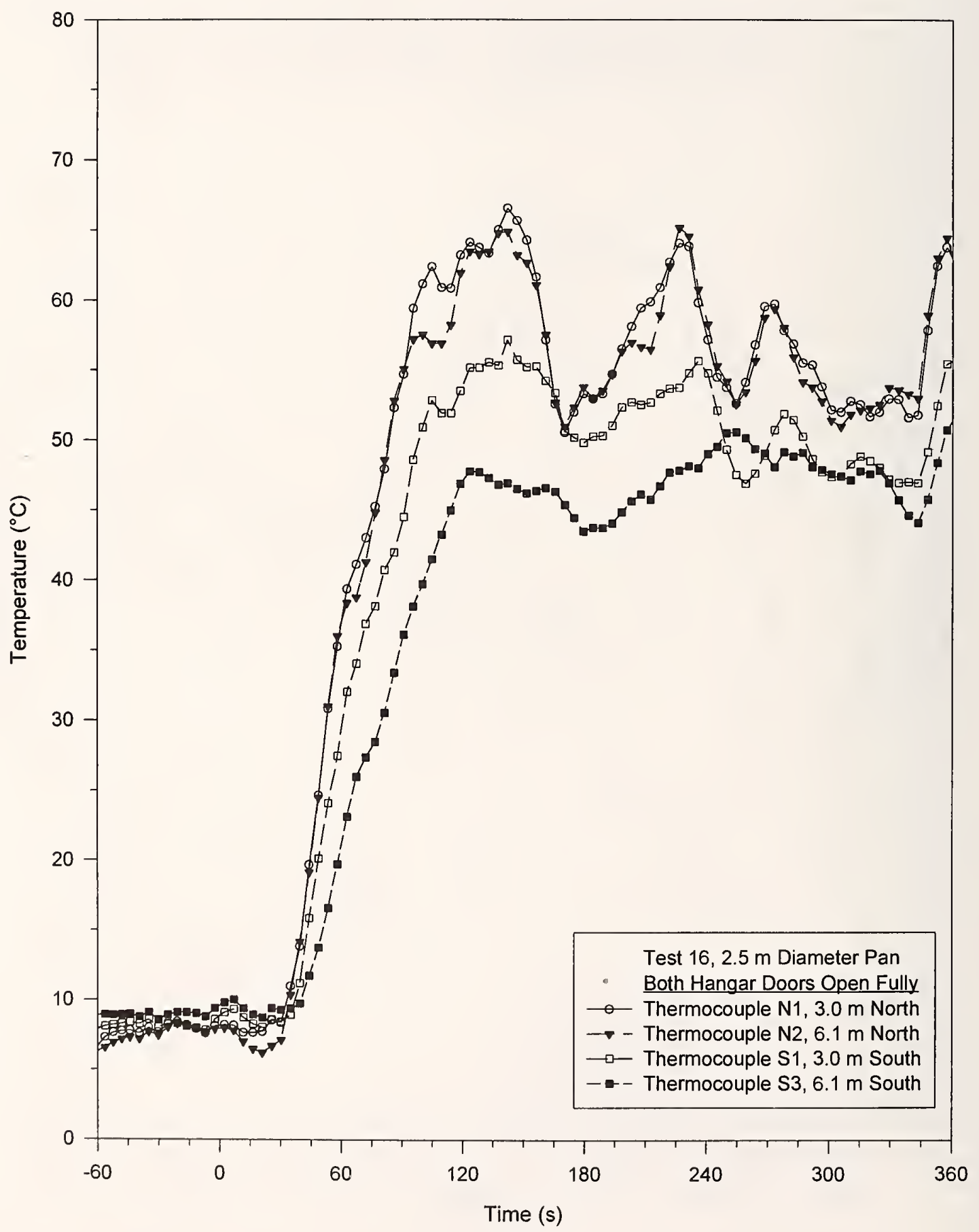

Figure 102. Temperature profiles at $0.3 \mathrm{~m}$ below ceiling for test 16 . 


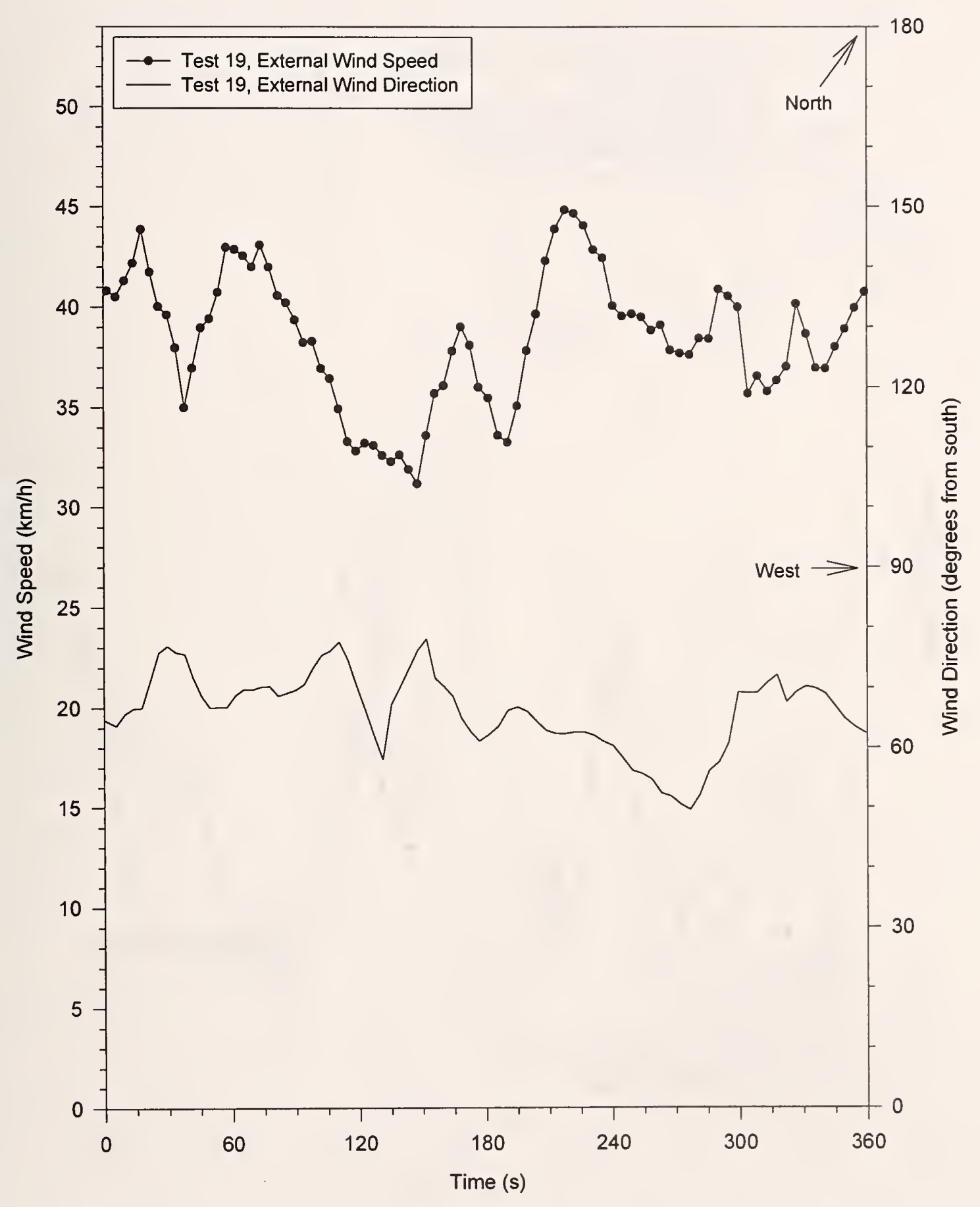

Figure 103. External wind speed and direction measurement for test 19. 


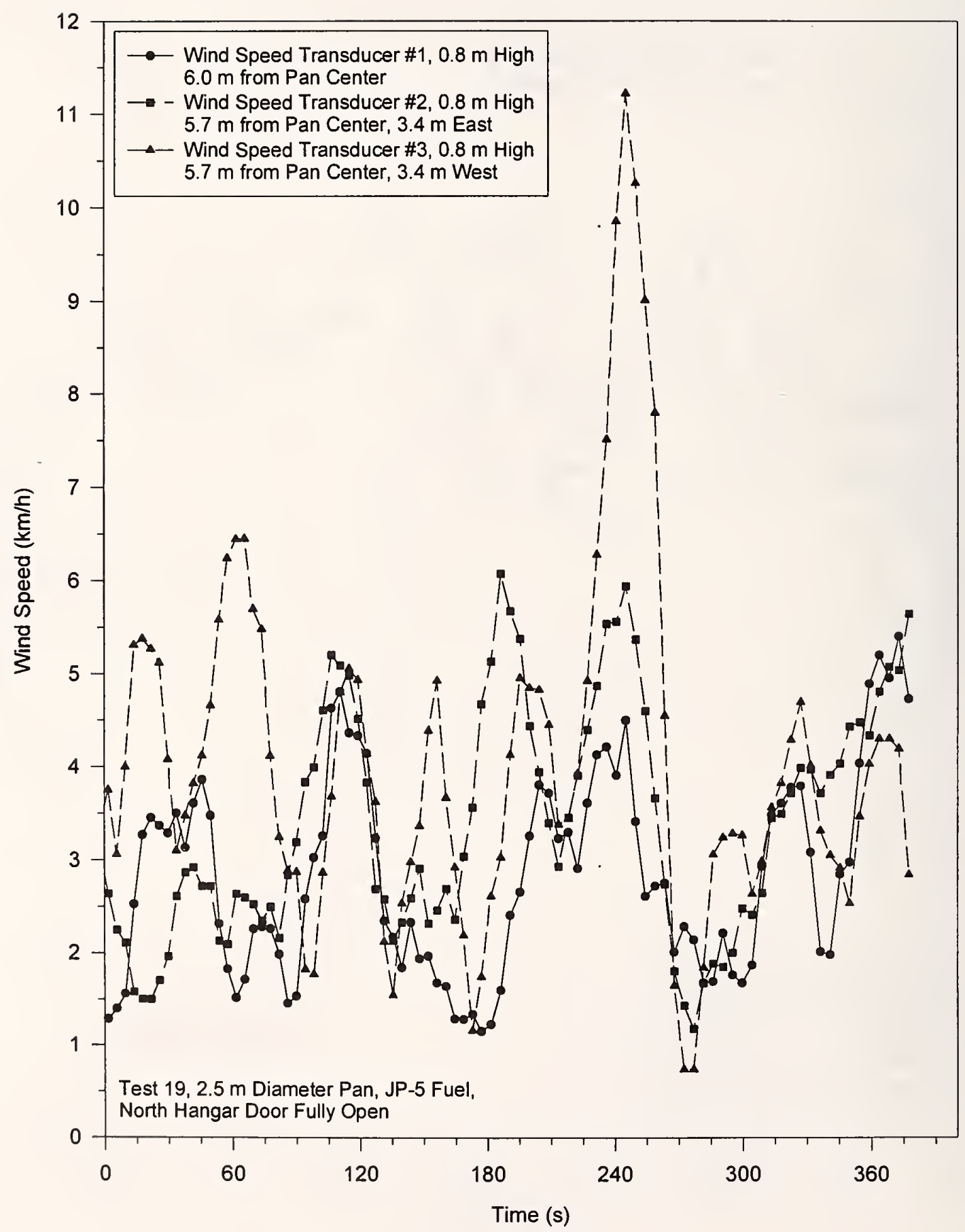

Figure 104. Wind speed measurements for test 19. North hangar door fully open. 


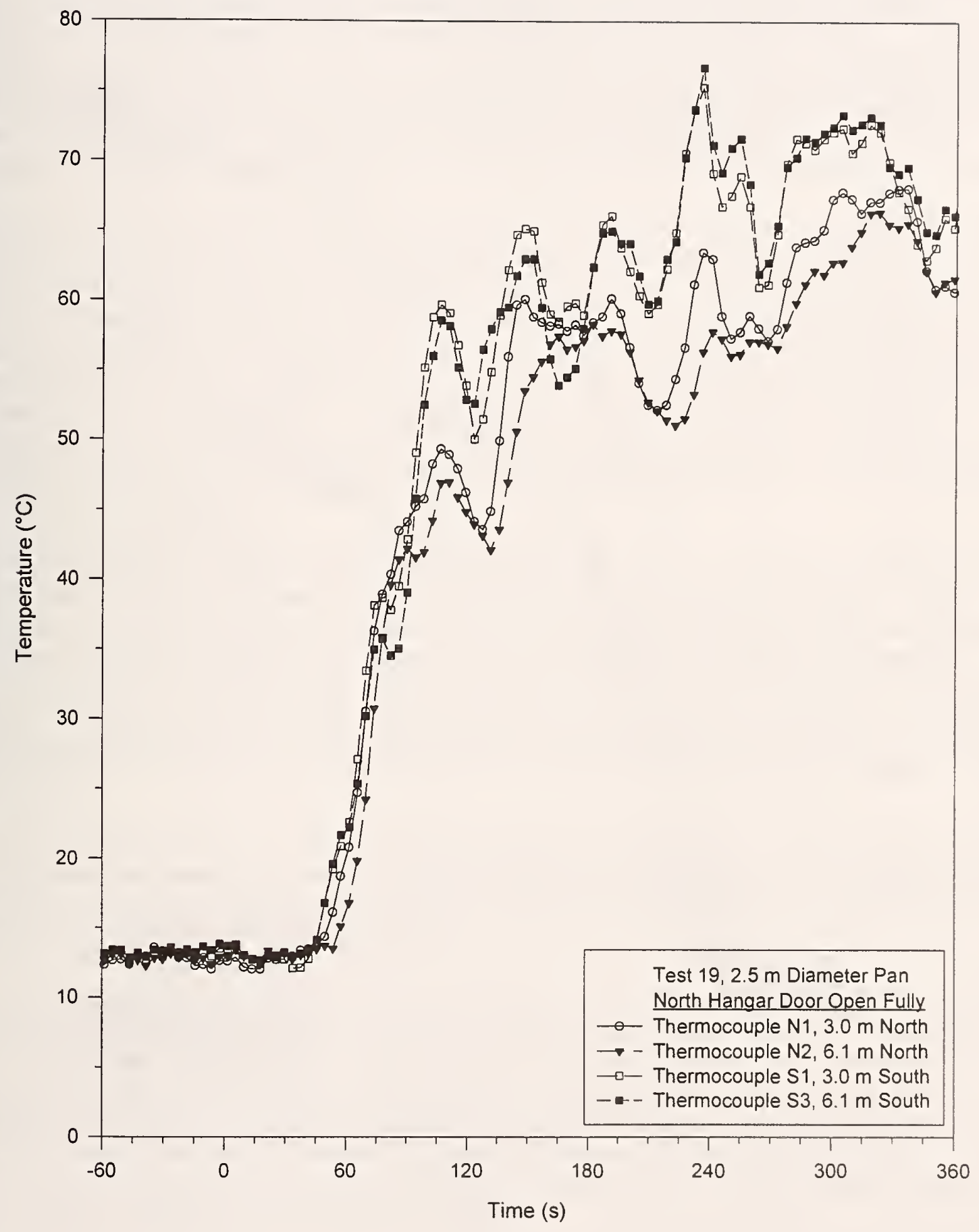

Figure 105. Temperature profiles at $0.3 \mathrm{~m}$ below ceiling for test 19 . 


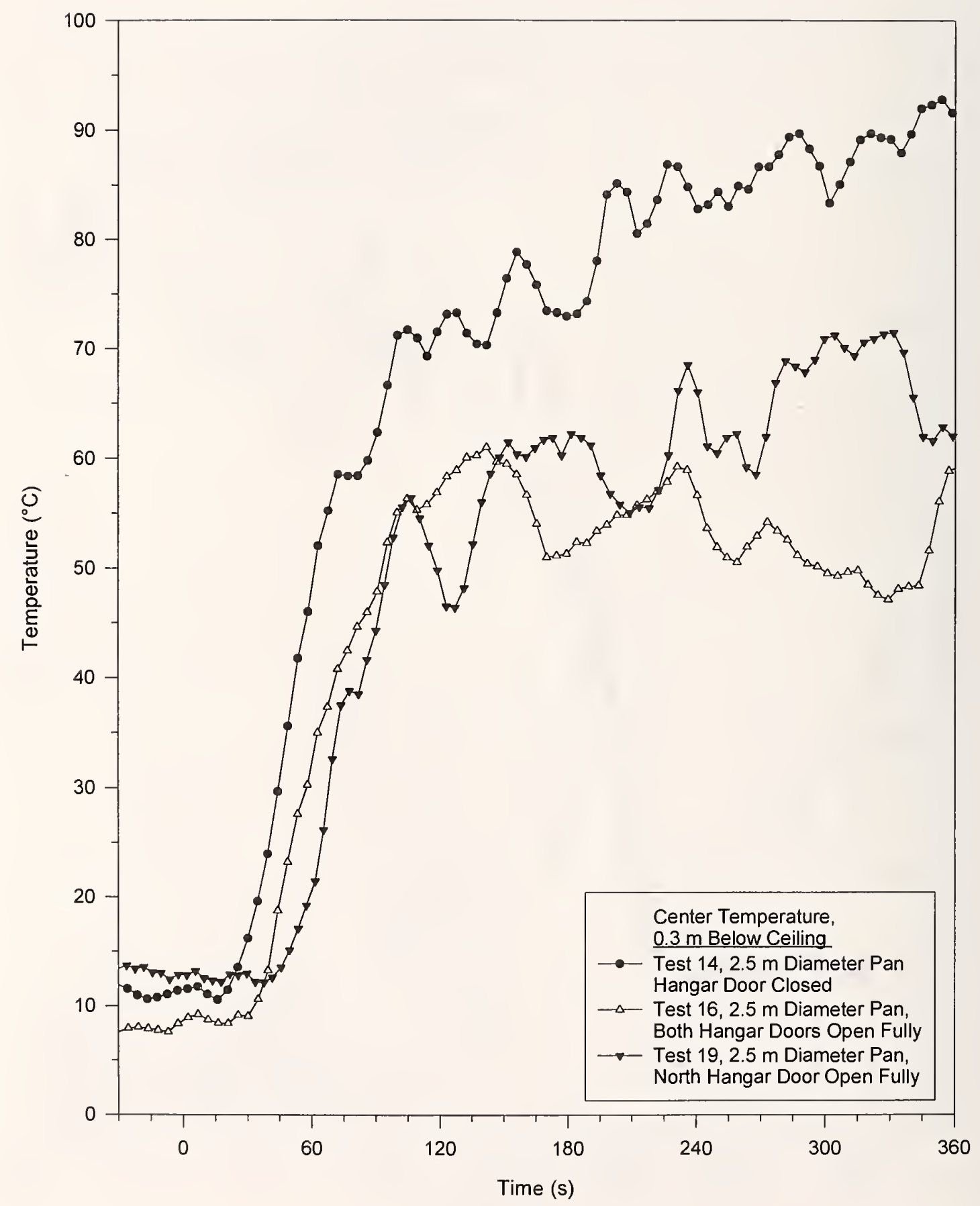

Figure 106. Comparison of open door and closed door experiments and the effect on center temperatures measured at $0.3 \mathrm{~m}$ below ceiling. 
Wind speed profiles are shown in Figure 100 for test 16. The location of the wind speed sensors are given in Figure 99. For test 16, wind sensors 2 and 3 were located at a height of $2.9 \mathrm{~m}$ above the floor while the wind sensor 1 was located $0.8 \mathrm{~m}$ above the floor. The different heights were chosen based on CFD modeling which suggested that for wind blowing perpendicular to the open hangar doors, the wind speed would be higher near the floor. This was realized for test 16 and as a result, wind sensor 2 was reduced in height to $0.8 \mathrm{~m}$ above the floor for test 19 . At about $130 \mathrm{~s}$, the load cell data for test 16 shows an increase of mass, but this measurement may be affected by the wind blowing through the hangar which increases from about $1 \mathrm{~km} / \mathrm{hr}$ to $3 \mathrm{~km} / \mathrm{hr}$ to $6 \mathrm{~km} / \mathrm{hr}$ at about the same time. If the increasing wind caused an upward lift on the load cell, a fictitious increase in mass could be measur ed.

Analyzing test 16 first, at the start of the fire the flame was initially upright and then leaned to the north from $15^{\circ}$ to $30^{\circ}$ between $30 \mathrm{~s}$ and $120 \mathrm{~s}$ into the test. Wind speeds measured $5.7 \mathrm{~m}$ from the edge of the pan and $0.8 \mathrm{~m}$ above the floor were less than $2 \mathrm{~km} / \mathrm{hr}$ for the first $120 \mathrm{~s}$ of the test. At $60 \mathrm{~s}$ into the test, there was some fuel burning off the north side of the pan. A rotation in the north side of the flame developed at about $100 \mathrm{~s}$ which persisted for about $40 \mathrm{~s}$. At $120 \mathrm{~s}$, the flame began leaning further to the north reaching a lean of $60^{\circ}$ north by $160 \mathrm{~s}$. The wind speed during this time had increased at all three monitoring locations with the $5.7 \mathrm{~m}$ location reaching $6 \mathrm{~km} / \mathrm{hr}$. The flame lean continued to maintain a $45^{\circ}$ to $60^{\circ}$ lean for the next $100 \mathrm{~s}$. By $260 \mathrm{~s}$, the flame was leaning $75^{\circ}$ to the north and the wind speed at the $5.7 \mathrm{~m}$ location had increased $7 \mathrm{~km} / \mathrm{hr}$. The $75^{\circ}$ lean to the north persisted until the end of the experiment.

One notable difference between this experiment and the closed door test 14 was the amount of smoke introduced into the ambient air near the floor. By $240 \mathrm{~s}$ into the test, the air was becoming very smokey close to the floor for this test whereas the same area for test 14 remained almost free of smoke. The difference in smoke density at this height may be verified qualitatively using the flame height camera video and observing the clarity of the image of the east wall. For test 14 , the east wall remains clear for the entire test with the leading edge of the smoke layer apparent on the wall. For test 16, the leading edge of the smoke layer is still apparent but the clarity of the wall image below the smoke layer is not as good.

Outside wind speed and wind direction for this test are shown in Figure 101. The measurement was made above the roof at the south end of the hangar. Since the hangar doors were oriented in the north - south direction, the wind was blowing at an angle to the doors which increased from $30^{\circ}$ west of south to $50^{\circ}$ west of south by the end of the test.

Ceiling temperatures for this test followed the flame lean analysis fairly closely. Early in the test when the flame lean was 45 degrees or less, temperatures at thermocouple positions $\mathrm{N} 1$ and $\mathrm{N} 2$ reached about $65^{\circ} \mathrm{C}$ as shown in Figure 102. At $160 \mathrm{~s}$ when the flame lean increased to $60^{\circ}$ north, the maximum ceiling temperature decreased to about $53{ }^{\circ} \mathrm{C}$. The temperature then began to increase reaching $65{ }^{\circ} \mathrm{C}$ at about $230 \mathrm{~s}$ into the test but as the flame leaned over to about $75^{\circ}$ north, the temperature near the ceiling fell to below $55^{\circ} \mathrm{C}$ for the duration of the test. The $\mathrm{N} 1$ and $\mathrm{N} 2$ thermocouples consistently read between $5{ }^{\circ} \mathrm{C}$ and $10^{\circ} \mathrm{C}$ higher than the $\mathrm{S} 1$ and $\mathrm{S} 3$ thermocouples which is consistent with the northward lean of the flame.

Heat detectors with activation temperatures of $57^{\circ} \mathrm{C}\left(135^{\circ} \mathrm{F}\right)$ activated in the north, east and west directions $3.0 \mathrm{~m}$ from the fire center and also in the north direction $6.1 \mathrm{~m}$ from the fire center as shown in Table 52. No heat detectors activated in the south direction which is consistent with the observed 
flame lean to the north and the lower temperatures measured by the south thermocouples. The heat detector located $3.0 \mathrm{~m}$ to the east of fire center activated $34 \mathrm{~s}$ earlier than the heat detector located 3.0 $\mathrm{m}$ to the west of fire center which is consistent with the higher temperature readings by thermocouple E1 compared with $\mathrm{W} 1$ and is also consistent with the wind blowing $30^{\circ}$ west of south.

No sprinklers were activated during the test since the minimum activation temperature of $79^{\circ} \mathrm{C}$ was not reached. This is in contrast to test 14 , a closed door test, where all but two of the $79^{\circ} \mathrm{C}$ sprinklers were activated within $3.1 \mathrm{~m}$ of fire center. Table 54 shows the activation time ranges for $79^{\circ} \mathrm{C}$ sprinklers in both open and closed door $2.5 \mathrm{~m}$ diameter test fires.

Smoke detector activation occurred between $46 \mathrm{~s}$ and $58 \mathrm{~s}$ for all smoke detectors located within $9.1 \mathrm{~m}$ of fire center. Outside the draft curtain, the smoke detector to the north at $9.1 \mathrm{~m}$ from fire center activated $8 \mathrm{~s}$ before the smoke detector located to the south at $9.1 \mathrm{~m}$. These activation times were substantially longer than the activation times in the east - west direction where smoke detectors $12.2 \mathrm{~m}$ from fire center were activating $16 \mathrm{~s}$ and $21 \mathrm{~s}$ earlier than the north - south detector at $9.1 \mathrm{~m}$. The later activation times in the north - south directions indicate that the draft curtain was able to contain the smoke even with the wind blowing through the hangar.

Test 19 was conducted with only the north door fully open. While the south door was closed, there was substantial leakage of air around the east and west corners of the door which would provide some potential for the movement of air out of the south side of the building. Outside wind velocities for this test averaged $39 \mathrm{~km} / \mathrm{hr}$ with the wind direction varying from $50^{\circ}$ west of south to $80^{\circ}$ west of south as shown in Figure 103.

The flame exhibited a $15^{\circ}$ lean to the south at the start of the test which increased to $45^{\circ}$ to the south by $50 \mathrm{~s}$. At $70 \mathrm{~s}$, the flame lean had returned to $15^{\circ}$ to the south and completely disappeared by $80 \mathrm{~s}$. At this time some fuel was observed to be burning off the side of the pan. By $110 \mathrm{~s}$, the flame again leaned $15^{\circ}$ to $30^{\circ}$ to the south, became more upright with about a $15^{\circ}$ lean at $170 \mathrm{~s}$, and then returned to the $15^{\circ}$ to $30^{\circ}$ south lean at $180 \mathrm{~s}$. At $230 \mathrm{~s}$, the flame lean increased to $45^{\circ}$ and persisted throughout the rest of the test.

At $240 \mathrm{~s}$ the area near the floor began to become extremely smokey. The smoke near the ceiling was observed to be flowing toward the south part of the building. The smoke would then deflect down and flow north back toward the fire near the floor. This mixing of smoke into the lower layer near the floor caused an evacuation of the hangar by people not having breathing apparatus at $330 \mathrm{~s}$ into the test. Neither test 14 where the air stayed relatively clear near the floor for the entire test nor test 16 where smoke did mix into the air near the floor generated the smokey condition near the floor that was realized for test 19 .

The location of the wind speed direction sensors for test 19 are presented in Figure 99 . Since only one hangar door was open and since the wind direction was at an angle to the door opening, the wind sensors orientation was changed from the one used for test 16 in an effort to pick up any east - west asymmetry in the wind speed near the fire. Even though the outside wind speed for test 19 was 3.5 times that measured in test 16 , the wind speed within the hangar was equal to or less than the wind speeds measured in test 16 with the exception of a single gust at $250 \mathrm{~s}$ which reached a peak speed of $18 \mathrm{~km} / \mathrm{hr}$ at wind sensor 3. The wind speeds measured by all three sensors is shown in Figure 104. This gust coincided with the flame lean increasing to $45^{\circ}$ to the south. Wind sensor 3 , which was 
located on the east side of the fire consistently gave higher wind speeds which would be expected with a wind blowing from the southwest since this sensor would be least shielded by the west building wall.

Temperature profiles for this test are given in Figure 105. Maximum temperatures at the ceiling reached as high as $80^{\circ} \mathrm{C}$ for the thermocouples located at $\mathrm{S} 1$ and $\mathrm{S} 3$ which is consistent with the south lean observed by the flame. The ceiling temperatures are higher than the temperatures measured in test 16 but lower than those of test 14 . Ceiling temperatures for test 14 , where the doors were closed, reached as high as $95^{\circ} \mathrm{C}$ as shown in Figure 106. Temperatures were higher in the south and west directions for test 19. The west direction is curious since the wind was blowing from the west, the shadowing of the west wall would be expected to produce higher temperatures to the east as seen in test 16. It is possible that the closed door at the south end of the hangar generated a swirling wind pattern near the ceiling which caused the air flow to be toward the west at these elevations.

All the heat detectors activated out to $6.1 \mathrm{~m}$ from fire center with the heat detectors toward the south and west activating first, consistent with the thermocouple temperatures. Additional heat detectors activated $9.1 \mathrm{~m}$ and $12.2 \mathrm{~m}$ to the west of fire center. There were no heat detector activations to the north beyond the draft curtain. Table 54 shows the activation time ranges for heat detectors within 6.1 $\mathrm{m}$ of fire center for closed and open door test fires.

No sprinklers were activated for this test as ceiling temperatures did not reach the necessary threshold of $79^{\circ} \mathrm{C}$.

All smoke detectors activated within $18.3 \mathrm{~m}$ of fire center as seen in Table 54. The earliest activation times occurred to the south which is consistent with the early rise of the thermocouples located at S1 and S3. The early activation of smoke detectors to the west at $12.2 \mathrm{~m}, 15.2 \mathrm{~m}$ and $18.3 \mathrm{~m}$ from fire center compared with smoke detectors located to the east at the same distances is consistent with the higher thermocouple readings to the west. The two smoke detectors in the north - south direction located $9.1 \mathrm{~m}$ from fire center outside the draft curtain activated within $13 \mathrm{~s}$ of each other. The north smoke detector activated first which suggests that the general flow pattern is out of the hangar near the ceiling and into the hangar near the floor. 


\subsection{Response of Detection and Sprinkler Activation Systems to Fires}

\subsubsection{Sprinkler Activation Times}

The spacing and installation of the automatic sprinklers are described earlier in section 4 . Figure 56 shows the location of the automatic sprinklers installed for these experiments. In the $22 \mathrm{~m}$ high facility, the sprinkler response analysis included number and type of sprinklers activated, response times, effect of draft curtains, threshold fire sizes for detector and sprinkler response, effects of ceiling configuration, effects of thermal element, the conductive heat transfer effects of wet-pipe versus drypipe sprinkler configurations, and the effects of ceiling height.

None of the sprinklers responded in any of the experiments where the fire size was less than 3 MW. For fire sizes greater than $3 \mathrm{MW}$, tests 16,18 , and 19 did not activate any automatic sprinklers. Tests 16 and 19 were $2.5 \mathrm{~m}$ diameter pan fires with heat release rates of $7.0 \mathrm{MW}$ and $9.1 \mathrm{MW}$ respectively. Both of these experiments were conducted with the hangar doors open. Tests 18 was a $2.0 \mathrm{~m}$ diameter pan fire conducted with the doors closed which produced a heat release rate of $4.9 \mathrm{MW}$.

In the remaining closed-door experiments, five fires with heat release rates of $7.9 \mathrm{MW}$ and greater activated sprinklers in the $22 \mathrm{~m}$ hangar. Table 55 shows the response times of all the sprinklers which activated in those five experiments as well as indicating which tests were performed using JP-5 or JP-8 fuels. Also, all five tests were performed with the hangar doors closed and with draft curtains in place. The smallest size fire to activate any automatic sprinklers was test 14 which used the $2.5 \mathrm{~m}$ diameter pan fire with a heat release rate of approximately $7.9 \mathrm{MW}$. Tests 15,17 and 20 , which were the $3.0 \mathrm{~m}$ $\mathrm{x} 3.0 \mathrm{~m}$ pan fires, had heat release rates ranging from approximately $14.3 \mathrm{MW}$ to $15.7 \mathrm{MW}$. Test 21 used the $4.6 \mathrm{~m} \mathrm{x} 4.6 \mathrm{~m}$ pan fire with a heat release rate of approximately $33 \mathrm{MW}$.

\section{Effects of Fire Size}

The experimental fires were designed to determine the threshold fire sizes needed to activate a variety of sprinklers, with the primary focus on the $79^{\circ} \mathrm{C}$ and $141{ }^{\circ} \mathrm{C}$ sprinklers. The threshold fire size needed to activate the $79{ }^{\circ} \mathrm{C}$ sprinklers in the $22 \mathrm{~m}$ hangar was the $2.5 \mathrm{~m}$ diameter pan fire which produced a heat release rate of approximately 7.9 MW. The threshold fire size needed to activate the $93{ }^{\circ} \mathrm{C}$ and $141{ }^{\circ} \mathrm{C}$ sprinklers in the $22 \mathrm{~m}$ hangar was the $3.0 \mathrm{~m} \mathrm{x} 3.0 \mathrm{~m}$ pan fire which produced heat release rates ranging from approximately $14.3 \mathrm{MW}$ to $15.7 \mathrm{MW}$. The $4.6 \mathrm{~m} \mathrm{x} 4.6 \mathrm{~m}$ pan fire (test 21) which produced a heat release rate of approximately $33 \mathrm{MW}$ was the largest fire conducted in the $22 \mathrm{~m}$ hangar. Although Table 55 indicates that not all of the sprinklers activated in test 21 , it is important to note that the test was terminated at $294 \mathrm{~s}$ because ceiling temperatures exceeded the predetermined safety level.

Fire size affected both the number of sprinklers activated and the response times. Table 56 shows the number of sprinklers activated for each of the experiments. The effect of fire size on sprinkler response time can be examined by comparing the response times of the same sprinkler heads to various fire sizes. Figure 108 graphically shows the effect of fire size on sprinkler response times for a variety of sprinkler heads. Fire size also affected sprinkler activation distance from the plume center. For example, in test 14 , no sprinklers activated beyond $3.1 \mathrm{~m}$ from plume centerline. Whereas in test 21 , sprinkler activation occurred as far away as $15.2 \mathrm{~m}$ from plume centerline. 
Table 55. Sprinkler activation times, seconds; $n=$ no activation; $a=$ activation, time unknown; $*=$ no sprinklers installed

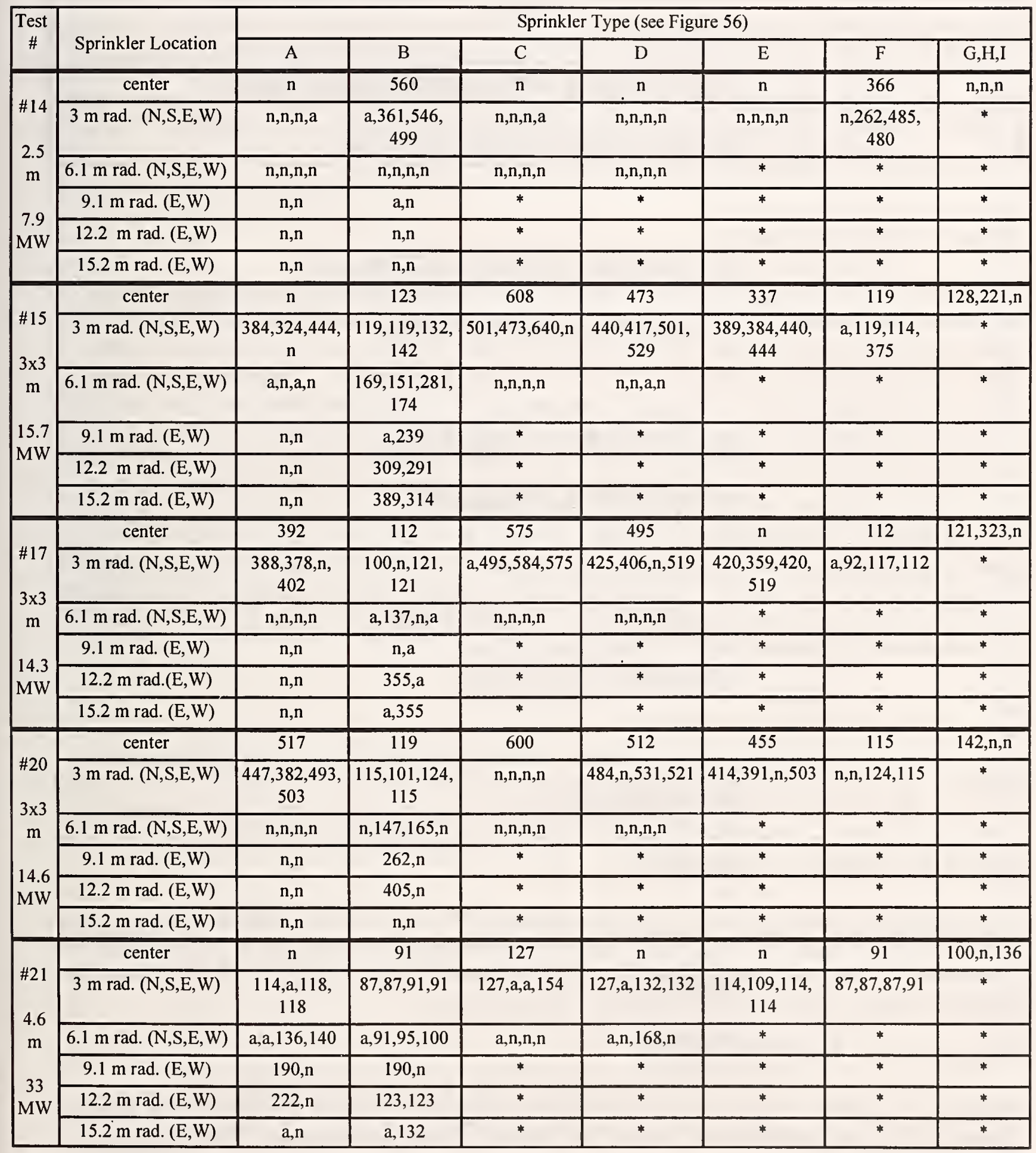


Table 56. Comparison of fire size to number of sprinklers activated

\begin{tabular}{|c|c|c|}
\hline Test Number & HRR (MW) & No. of Sprinklers Activated \\
\hline 14 & 7.9 & 8 \\
\hline 17 & 14.3 & 29 \\
\hline 20 & 14.6 & 27 \\
\hline 15 & 15.7 & 37 \\
\hline 21 & 33 & 37 \\
\hline
\end{tabular}

\section{Effects of Ceiling Configuration}

The roof of the $22 \mathrm{~m}$ hangar consisted of a series of open steel trusses which formed arches spanning the width of the hangar bay. Although the trusses would not be expected to have an effect on the response times, since they would not obstruct the movement of heated gases from a fire, the overall shape of the curved roof was evaluated for its effect on sprinkler response. The effects of ceiling curvature were analyzed by comparing the response times of the sprinklers along the north/ south axis to those along the east/west axis. This comparison was limited to the sprinklers at $3.1 \mathrm{~m}$ and $6.1 \mathrm{~m}$ from plume centerline. The sprinklers mounted along the north/south axis were located along the peak of the curved ceiling, while the sprinklers located along the east/west axis were at slightly lower elevations due to the curvature of the ceiling. Figure 107 compares the average response times of six different sprinkler types along the north/south axis versus the east/west axis, at a distance of $3.1 \mathrm{~m}$ from plume centerline. As one might expect, the sprinklers at the highest elevation of the curved roof activated faster than the same heads at a slightly lower elevation. Over 27 comparisons throughout the five fire tests which activated sprinklers showed the sprinklers in the north/south direction had faster response times than the sprinklers in the east/west direction.

\section{Effects of Thermal Element}

Two factors were analyzed regarding the effects of the thermal element used in the sprinkler head assembly. The first was the temperature rating of the sprinklers used (i.e., $79^{\circ} \mathrm{C}, 93^{\circ} \mathrm{C}, 141{ }^{\circ} \mathrm{C}$, and $182^{\circ} \mathrm{C}$ ). The primary concern with respect to temperature rating deals with the fire size needed to activate various temperature heads as discussed above. As expected, the $79{ }^{\circ} \mathrm{C}$ heads responded faster than the $93{ }^{\circ} \mathrm{C}$ heads.

The second factor analyzed was the response time index (RTI), which for this analysis focused on quick response versus standard response heads. Figure 109 shows a comparison of the $79{ }^{\circ} \mathrm{C}$ quick response versus standard response sprinklers located at plume centerline in tests 15 and 17 . This illustrates the significantly faster response times of the quick response heads.

\section{Effects of Wet- vs. Dry-Pipe Sprinklers}

Several $79{ }^{\circ} \mathrm{C}$ sprinkler heads were piped in both the wet-pipe and dry-pipe configurations in order to determine if the type of system (i.e., wet or dry) affected sprinkler response time. Table 57 shows the 


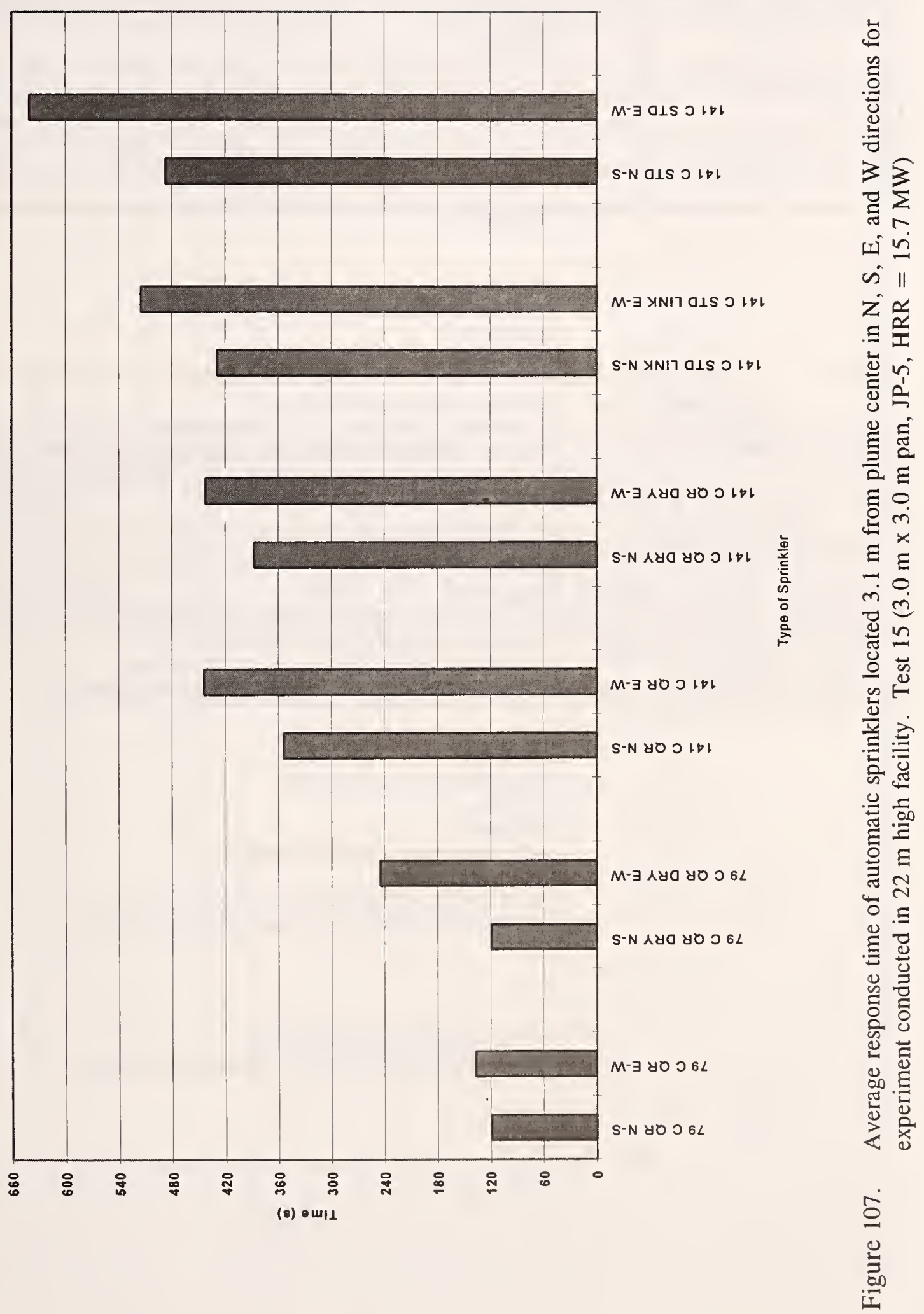


Table 57. Comparison of average response times of wet-pipe and dry-pipe sprinklers

\begin{tabular}{|c|c|c|c|}
\hline Test Number & $\mathbf{7 9}^{\circ} \mathbf{C}$ QR-Wet (s) & ${79^{\circ} \mathbf{C} \text { QR-Dry (s) }}^{\text {Q }}$ & \% Difference \\
\hline 14 & 469 & N/A & N/A \\
\hline 15 & 128 & 203 & -58.6 \\
\hline 17 & 114 & 107 & 6.1 \\
\hline 20 & 114 & 120 & -5.3 \\
\hline 21 & 89 & 88 & 1.1 \\
\hline
\end{tabular}

Table 58. Comparison of sprinkler response times for tests conducted in $15 \mathrm{~m}$ and $22 \mathrm{~m}$ high facilities

\begin{tabular}{|c|c|c|}
\hline Parameters & $\begin{array}{c}\mathbf{1 5} \mathbf{~ m} \text { hangar } \\
\text { Test } \mathbf{6 b}-\mathbf{2 . 5} \mathbf{~ m} \text { pan, JP-5 }\end{array}$ & $\begin{array}{c}\text { 22 } \mathbf{~ m} \text { hangar } \\
\text { Test 14-2.5 m pan, JP-5 }\end{array}$ \\
\hline Heat Release Rate & $7.7 \mathrm{MW}$ & $7.9 \mathrm{MW}$ \\
\hline No of sprinklers activated & 18 & 8 \\
\hline Time of 1st sprinkler response & $78 \mathrm{~s}\left(79^{\circ} \mathrm{C} \mathrm{QR}\right)$ & $262 \mathrm{~s}\left(79^{\circ} \mathrm{C} \mathrm{QR}\right)$ \\
\hline Time range; sprinkler response & $78-439 \mathrm{~s}$ & $262-560 \mathrm{~s}$ \\
\hline $\begin{array}{c}\text { Furthest distance of sprinkler } \\
\text { response from plume center }\end{array}$ & $9.1 \mathrm{~m}$ & $3.1 \mathrm{~m}$ \\
\hline
\end{tabular}




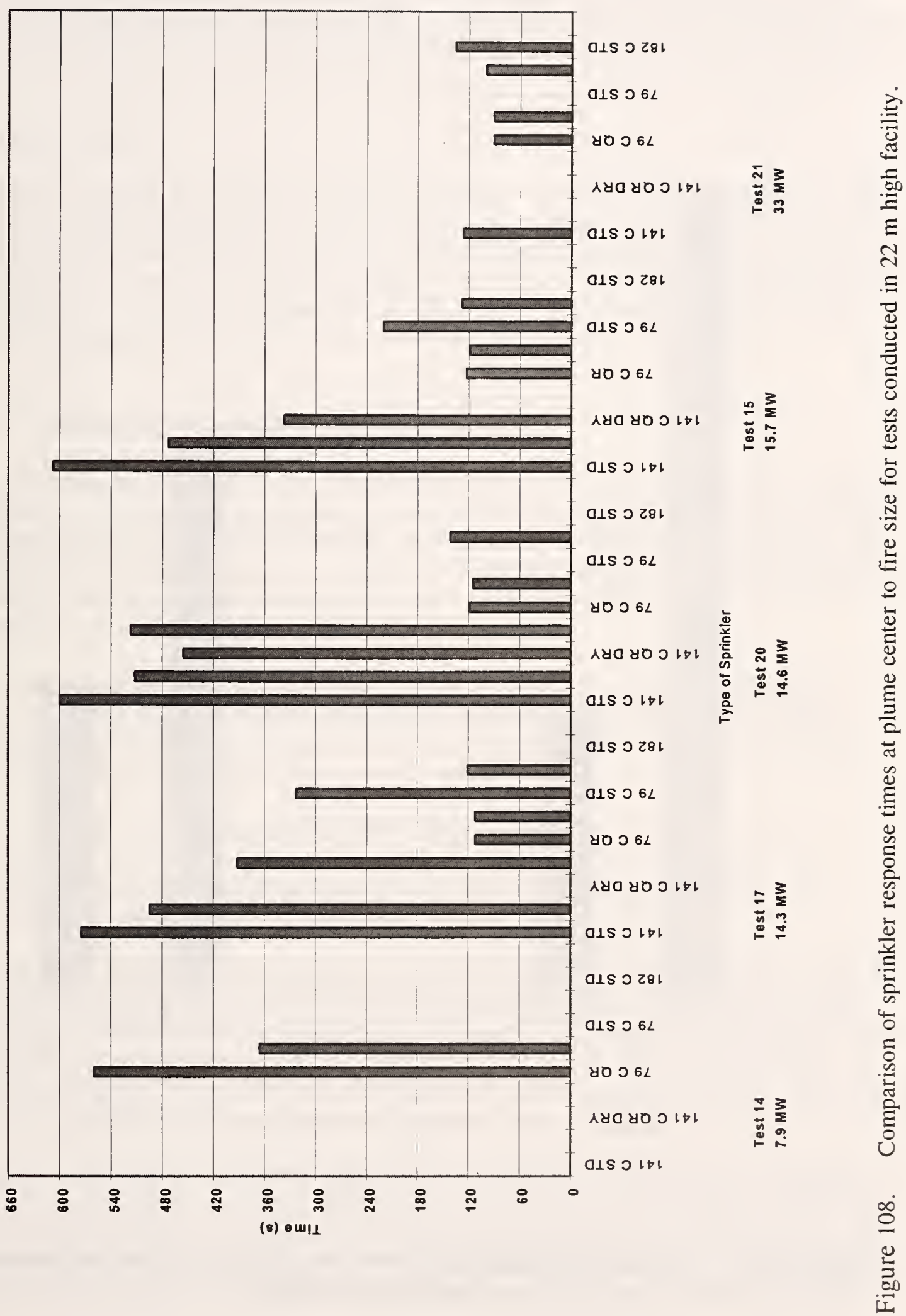




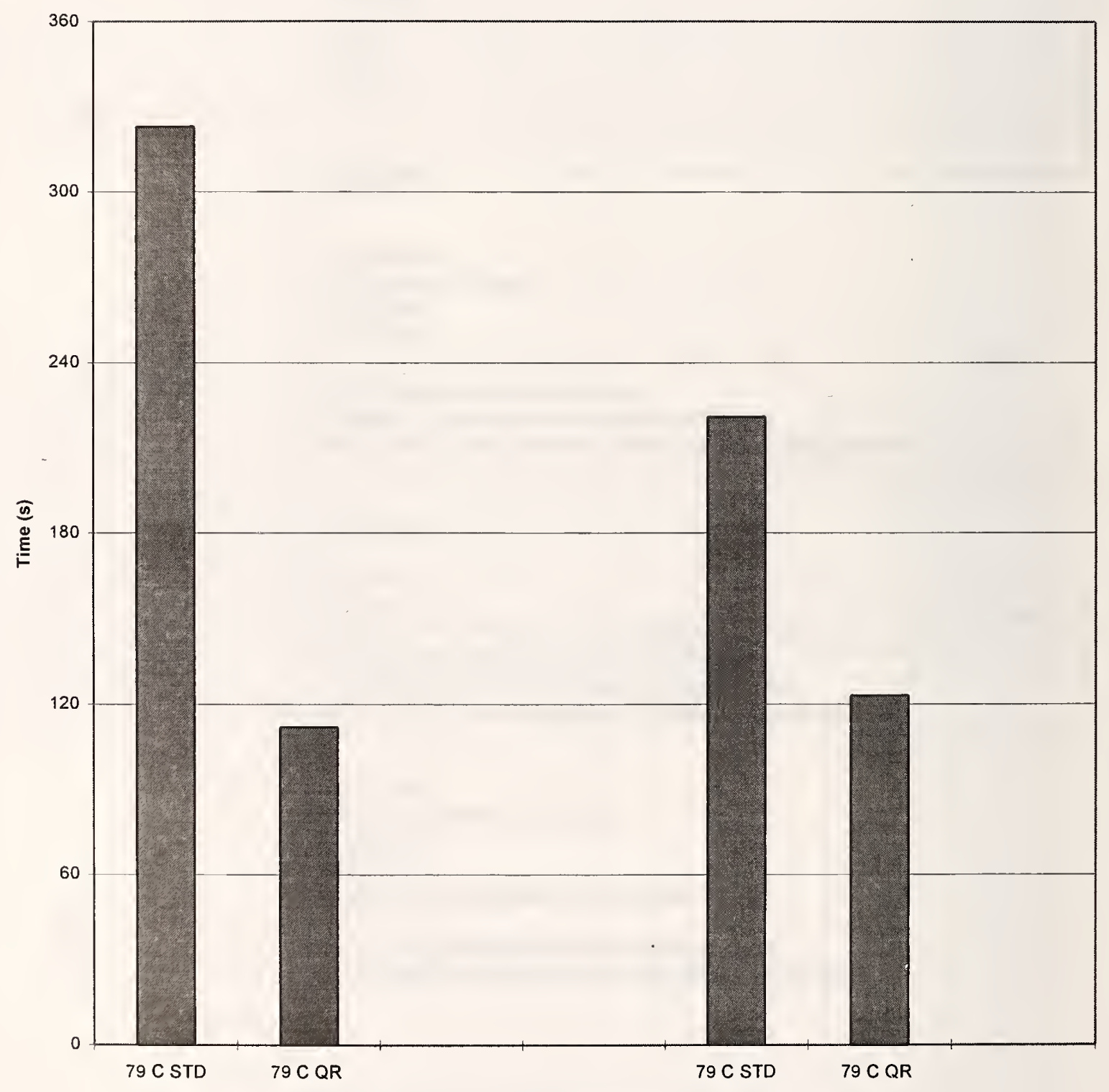

Test 17

13.3 MW
Test 15

15.1 MW

Type of Sprinkler

Figure 109. Response time comparison of $79^{\circ} \mathrm{C}$ STD sprinkler to $79^{\circ} \mathrm{C} \mathrm{QR}$ sprinkler for two 3.0 $\mathrm{m} \times 3.0 \mathrm{~m}$ test fires conducted in $22 \mathrm{~m}$ hangar. 
average response times for the $79^{\circ} \mathrm{C}$ quick response (wet) vs the $79^{\circ} \mathrm{C}$ quick response (dry) sprinklers located $3.1 \mathrm{~m}$ from plume centerline. This illustrates no significant difference in sprinkler response times with respect to wet-pipe versus dry-pipe sprinklers. Obviously, there is still a time delay on drypipe or pre-action systems associated with opening the alarm valve and filling the distribution piping with water.

\section{Effects of Ceiling Height}

Given the differences in size, construction and climatic conditions between the $15 \mathrm{~m}$ and $22 \mathrm{~m}$ hangars, the effects of ceiling height on sprinkler response cannot be fully analyzed from this data set. Attempts to compare sprinkler response times between the two sets of experiments must also consider ambient air and fuel temperatures, as well as the volume of the draft curtain spaces. In addition, only similar sized fires can be compared. Given those limitations, Table 58 shows a comparison of sprinkler response times for the $2.5 \mathrm{~m}$ diameter pan fires in both the $15 \mathrm{~m}$ and $22 \mathrm{~m}$ hangars.

\subsubsection{Response of Projected Beam Smoke Detectors}

Fire tests conducted in the $22 \mathrm{~m}$ high facility provided information relative to the response of projected beam smoke detectors as a function of location (i.e., depth below ceiling), sensitivity settings, window settings, and spacing. The projected beam detectors were installed parallel with the curved portion of the ceiling at three elevations, $1.9 \mathrm{~m}(6.2 \mathrm{ft}), 4.2 \mathrm{~m}(13.8 \mathrm{ft})$, and $10.9 \mathrm{~m}(35.8 \mathrm{ft})$ below the peak of

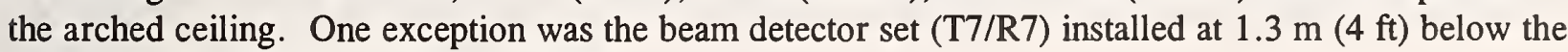
ceiling perpendicular to the draft curtain.

In all the fire tests performed in the $22 \mathrm{~m}$ high facility, detectors located $1.3 \mathrm{~m}$ and $1.9 \mathrm{~m}$ below the ceiling peak (i.e., B7, B1, B2) used an alarm sensitivity of $20 \%$ signal loss with an alarm window setting of $5 \mathrm{~s}$. Detectors located at $4.2 \mathrm{~m}$ and $10.9 \mathrm{~m}$ below the ceiling peak (i.e., B3, B4, B5, B6) used an alarm sensitivity of $30 \%$ with an alarm window setting of $5 \mathrm{~s}$.

\subsubsection{Fires less than 3 MW (tests 1-13)}

Detector fires were used to determine the response characteristics of the projected beam smoke detectors. The detector response times for these smaller fires are listed in Table 59.

The alarm times given indicate the length of time needed for the smoke to fill the test bay and reach the depth of the detector. Figures are included which show each pan size tested and the resulting alarm time for detectors at various detector depths below the ceiling peak. It is important to note that figures which include detectors at $1.3 \mathrm{~m}$ and $1.9 \mathrm{~m}$ below the ceiling (i.e., B7, B1, B2), have sensitivity settings of $20 \%$ signal loss. Whereas the pairs of detectors at $4.2 \mathrm{~m}$ and $10.9 \mathrm{~m}$ depth have sensitivity settings of $30 \%$ signal loss. In both configurations, the alarm window setting was $5 \mathrm{~s}$.

For the $0.3 \mathrm{~m} \times 0.3 \mathrm{~m}$ test fires alarm times range from an average of $57 \mathrm{~s}$ for detector B7, located $1.3 \mathrm{~m}$ below the ceiling peak, to an average of $351 \mathrm{~s}$ for detector B6, located $10.9 \mathrm{~m}$ below the ceiling peak. Averages for these tests do not include test 9. In test 9, JP-8 fuel was used in the $0.3 \mathrm{~m} \times 0.3 \mathrm{~m}$ pan. The alarm values, in this case, for the lower two detectors located $5.5 \mathrm{~m}$ south of center (i.e., B4, B6) are significantly higher than the corresponding detector located $5.5 \mathrm{~m}$ north. This irregularity is 
Table 59. Results of projected beam smoke detector activation to detector fires conducted in $22 \mathrm{~m}$ high facility

\begin{tabular}{|c|c|c|c|c|c|c|c|c|c|}
\hline \multicolumn{3}{|c|}{ Test Information } & \multicolumn{6}{|c|}{ Projected Beam Detector Response Times $(\mathrm{s}, \pm 5)$} \\
\hline Test \# & $\begin{array}{c}\text { Pan Size } \\
\mathrm{m}\end{array}$ & Fuel & B1 $^{\mathrm{a}}$ & B2 $^{\mathrm{a}}$ & B $^{\mathrm{b}}$ & B4 $^{\mathrm{b}}$ & B5 $^{\mathrm{b}}$ & B6 $^{\mathrm{b}}$ & B7 $^{\mathrm{a}}$ \\
\hline 1 & $0.3 \times 0.3$ & JP-5 & 93 & 88 & 111 & 118 & 392 & 377 & 53 \\
\hline 2 & $0.3 \times 0.3$ & JP-5 & 78 & 78 & 99 & 97 & 362 & 325 & 60 \\
\hline 3 & $0.6 \times 0.6$ & JP-5 & 38 & 47 & 49 & 57 & 205 & 211 & 36 \\
\hline 4 & $0.6 \times 0.6$ & JP-5 & 24 & 29 & 36 & 45 & 214 & 244 & 19 \\
\hline 5 & $0.9 \times 0.9$ & JP-5 & 28 & 31 & 33 & 42 & 154 & 149 & 25 \\
\hline 6 & $0.9 \times 0.9$ & JP-5 & 34 & 39 & 39 & 44 & 161 & 171 & 31 \\
\hline 7 & $1.2 \times 1.2$ & JP-5 & 39 & 39 & 38 & 42 & 106 & 125 & 31 \\
\hline 8 & $1.2 \times 1.2$ & JP-5 & 34 & 38 & 35 & 42 & 118 & 122 & 27 \\
\hline 9 & $0.3 \times 0.3$ & JP-8 & 94 & 149 & 85 & 165 & 126 & 205 & 108 \\
\hline 10 & $0.6 \times 0.6$ & JP-8 & 47 & 58 & 60 & 60 & 161 & 142 & 47 \\
\hline 11 & $0.6 \times 0.6$ & JP-8 & 35 & 49 & 45 & 58 & 125 & 153 & 35 \\
\hline 12 & $0.9 \times 0.9$ & JP-8 & 33 & 43 & 39 & 49 & 103 & 96 & 34 \\
\hline 13 & $1.2 \times 1.2$ & JP-8 & 31 & 41 & 42 & 49 & 85 & 83 & 37 \\
\hline
\end{tabular}

${ }^{a}$ alarm sensitivity setting, $20 \%$, alarm window, 5 ; $^{\mathrm{b}}$ alarm sensitivity setting, $30 \%$, alarm window, $5 \mathrm{~s}$

due to excessive plume lean during the early stages of test 9. During this test, external wind speeds were measured at $35 \mathrm{~km} / \mathrm{hr}$ to $50 \mathrm{~km} / \mathrm{hr}$ (21 mph to $31 \mathrm{mph}$ ) from the south direction. The upper graph in Figure 110 shows the alarm times for all $0.3 \mathrm{~m} \mathrm{x} 0.3 \mathrm{~m}$ test fires.

For the $0.6 \mathrm{~m} \times 0.6 \mathrm{~m}$ test fires, alarm times were reported between $19 \mathrm{~s}$ to $47 \mathrm{~s}$ at the highest location and $125 \mathrm{~s}$ to $244 \mathrm{~s}$ at the lowest detector depth. In comparison to the $0.3 \mathrm{~m} \mathrm{x} 0.3 \mathrm{~m}$ test fires, the detector located $1.3 \mathrm{~m}$ below the ceiling peak responded nearly $25 \mathrm{~s}$ faster. Detectors located $1.9 \mathrm{~m}$ below the ceiling peak responded nearly $50 \mathrm{~s}$ faster. The lower two detector sets alarmed at an average value of $52 \mathrm{~s}$ for the $4.2 \mathrm{~m}$ depth and $182 \mathrm{~s}$ for the $10.9 \mathrm{~m}$ depth. The alarm values at these two depths are about one-half compared to the $0.3 \mathrm{~m} \mathrm{x} 0.3 \mathrm{~m}$ tests. The lower graph in Figure 113 shows the alarm times for all $0.6 \mathrm{~m} \times 0.6 \mathrm{~m}$ fires.

The detector response times for the $0.9 \mathrm{~m} \times 0.9 \mathrm{~m}$ and $1.2 \mathrm{mx} 1.2 \mathrm{~m}$ pans ranged from $30 \mathrm{~s}$ to $45 \mathrm{~s}$ for the detectors at $1.3 \mathrm{~m}, 1.9 \mathrm{~m}$, and $4.2 \mathrm{~m}$ below the ceiling peak. Detectors B5 and B6, at the lowest elevation, responded within an average of $139 \mathrm{~s}$ for the $0.9 \mathrm{~m} \mathrm{x} 0.9 \mathrm{~m}$ pan and $106 \mathrm{~s}$ for the $1.2 \mathrm{~m} \mathrm{x}$ $1.2 \mathrm{~m}$ pan. Figure 111 shows the alarm times for all test fires using the $0.9 \mathrm{~m} \times 0.9 \mathrm{~m}$ and $1.2 \mathrm{~m} \mathrm{x}$ $1.2 \mathrm{~m}$ pans.

The test fires using JP-8 indicate slightly faster response times at the lowest elevation compared to test fires using JP-5. The upper elevations (i.e., $1.3 \mathrm{~m}, 1.9 \mathrm{~m}$, and $4.2 \mathrm{~m}$ ) do not show this increase in response time. One factor that may explain this is that the external wind speed during tests 9 through 13 was nearly 2.5 times higher than previous tests. The draft curtains may have provided some protection from air currents affecting the upper areas of the test bay. However, the lower set of detectors at $10.9 \mathrm{~m}$ below the ceiling peak could have been in an area where air currents caused 
increased smoke mixing, therefore, producing alarm times faster than in previous "calm" tests. In addition, video footage taken during these tests indicate significant plume lean and changes in smoke movement patterns.

Additional figures are shown that provide information on the relationship between fire size and detector response times at various elevations in the test bay. Figure 112 shows the response of detectors at 1.3 $\mathrm{m}$ and $1.9 \mathrm{~m}$ below the ceiling peak. The detectors at these locations had sensitivity settings of $20 \%$ signal loss and a $5 \mathrm{~s}$ alarm window. Figure 113 shows the response of detectors at the $4.2 \mathrm{~m}$ and 10.9 $\mathrm{m}$ elevations. These detectors used a sensitivity setting of $30 \%$ signal loss and a $5 \mathrm{~s}$ alarm window. These figures include the results from tests run with both JP-5 and JP-8 fuels.

The differences in response time values reported for the detectors at $1.3 \mathrm{~m}$ and $1.9 \mathrm{~m}$ versus the detectors at $4.2 \mathrm{~m}$ and $10.9 \mathrm{~m}$ may also be attributed to the difference in sensitivity settings. The detectors using the $20 \%$ sensitivity setting are more sensitive to the developing smoke layer. An analysis of the detector's output signal shows a rapid decrease in strength when sensing the developing smoke layer, meaning that any change in response time would be negligible if a lower sensitivity setting was chosen (i.e., 30\% signal loss). However, those experiments where the smoke layer developed gradually (i.e., $0.3 \mathrm{~m} \mathrm{x} 0.3 \mathrm{~m}$ and $0.6 \mathrm{~m} \mathrm{x} 0.6 \mathrm{~m}$ test fires) show a slower decrease in detector signal. For example, during test $4(0.6 \mathrm{~m} \mathrm{x} 0.6 \mathrm{~m}$ test fire) the detectors at $10.9 \mathrm{~m}$ depth below the ceiling alarmed at $214 \mathrm{~s}$ and $244 \mathrm{~s}$. If their sensitivity settings were increased (i.e., $20 \%$ signal loss) the detectors would have responded $20 \mathrm{~s}$ to $30 \mathrm{~s}$ faster. The detectors at the next higher elevation would have responded only $5 \mathrm{~s}$ to $10 \mathrm{~s}$ faster. For the detectors at the highest elevation the difference is less than $3 \mathrm{~s}$.

\subsubsection{Fires greater than $3 \mathrm{MW}$ (tests 14-21)}

For the test fires with heat outputs greater than $3 \mathrm{MW}$, the response times of the projected beam smoke detectors are presented in Table 60.

For the $2.0 \mathrm{~m}$ diameter test fire the detectors all responded within $97 \mathrm{~s}$. The detector at the highest elevation responded at $42 \mathrm{~s}$ and the detectors at $1.9 \mathrm{~m}$ an $4.2 \mathrm{~m}$ responded within $16 \mathrm{~s}$ later. The detectors at the $10.9 \mathrm{~m}$ elevation responded at $90 \mathrm{~s}$ and $97 \mathrm{~s}$. The upper graph in Figure 114 shows the response times for this test.

Of the three tests conducted using the $2.5 \mathrm{~m}$ pan, only test 14 was conducted with the hangar doors in the closed position. The first open door test (16) was conducted with both north and south hangar doors partially open and for the second open door test (19) only the south hangar door was open. The first experiment using the $2.5 \mathrm{~m}$ diameter pan produced projected beam response times from $38 \mathrm{~s}$ at the highest elevation to $87 \mathrm{~s}$ at the lowest elevation. The first open door test produced trouble conditions on all but the two detectors located $10.9 \mathrm{~m}$ below the ceiling. The trouble condition arises when the detector experiences a $90 \%$ signal loss for a pre-set length of time (i.e., 2 s). Once the trouble condition occurs the detector may be able to reenter alarm status if the smoke thins or the object blocking the beam is removed.

According to video footage and visual accounts, during test 16 the severity of the plume lean caused the majority of the smoke to collect in the adjacent bay. When the cross-wind decreased, the plume 

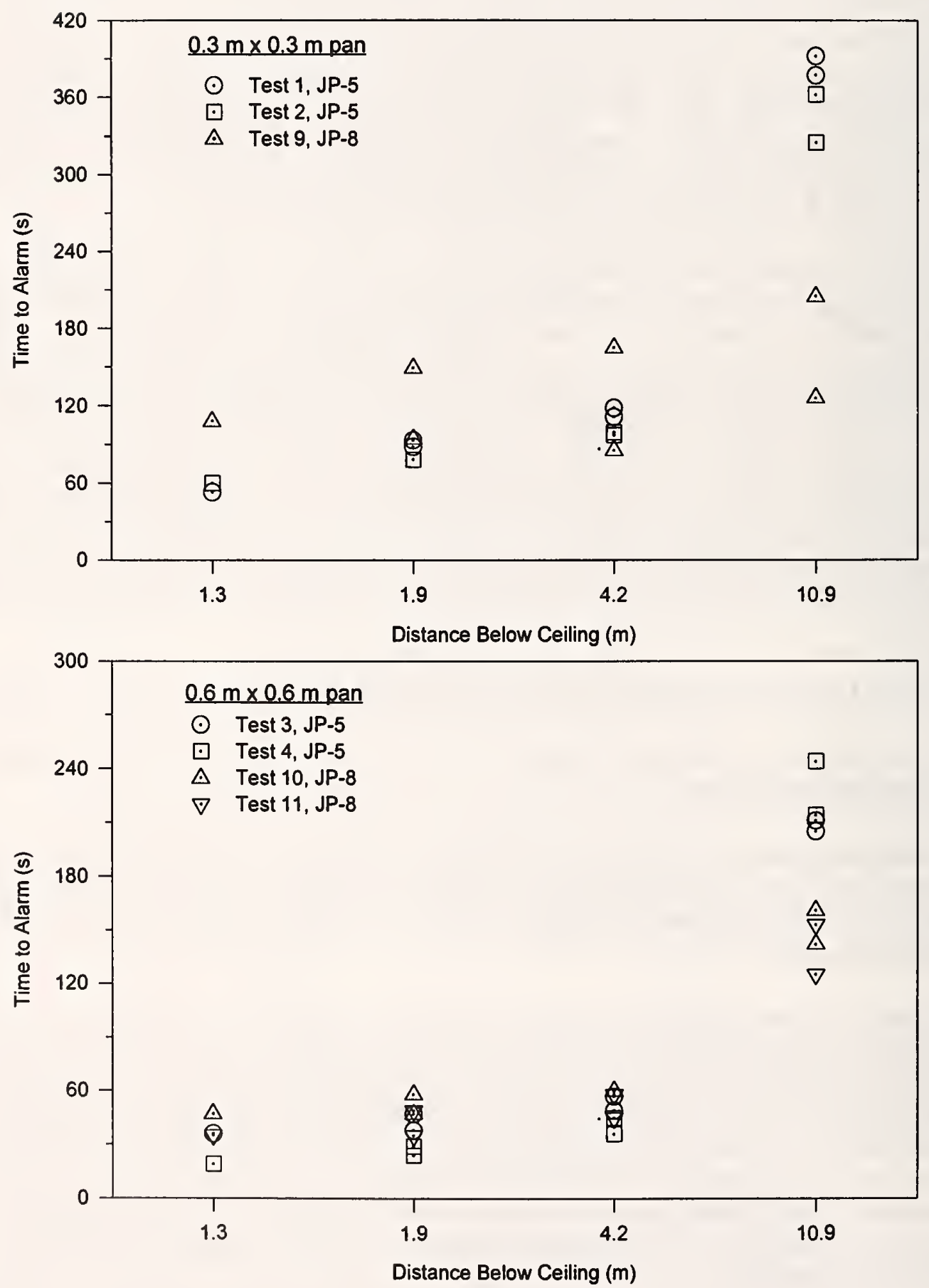

Figure 110. Projected beam detector response times for $0.3 \mathrm{~m} \mathrm{x} 0.3 \mathrm{~m}$ and $0.6 \mathrm{~m} \mathrm{x} 0.6 \mathrm{~m}$ test fires in $22 \mathrm{~m}$ high facility. 

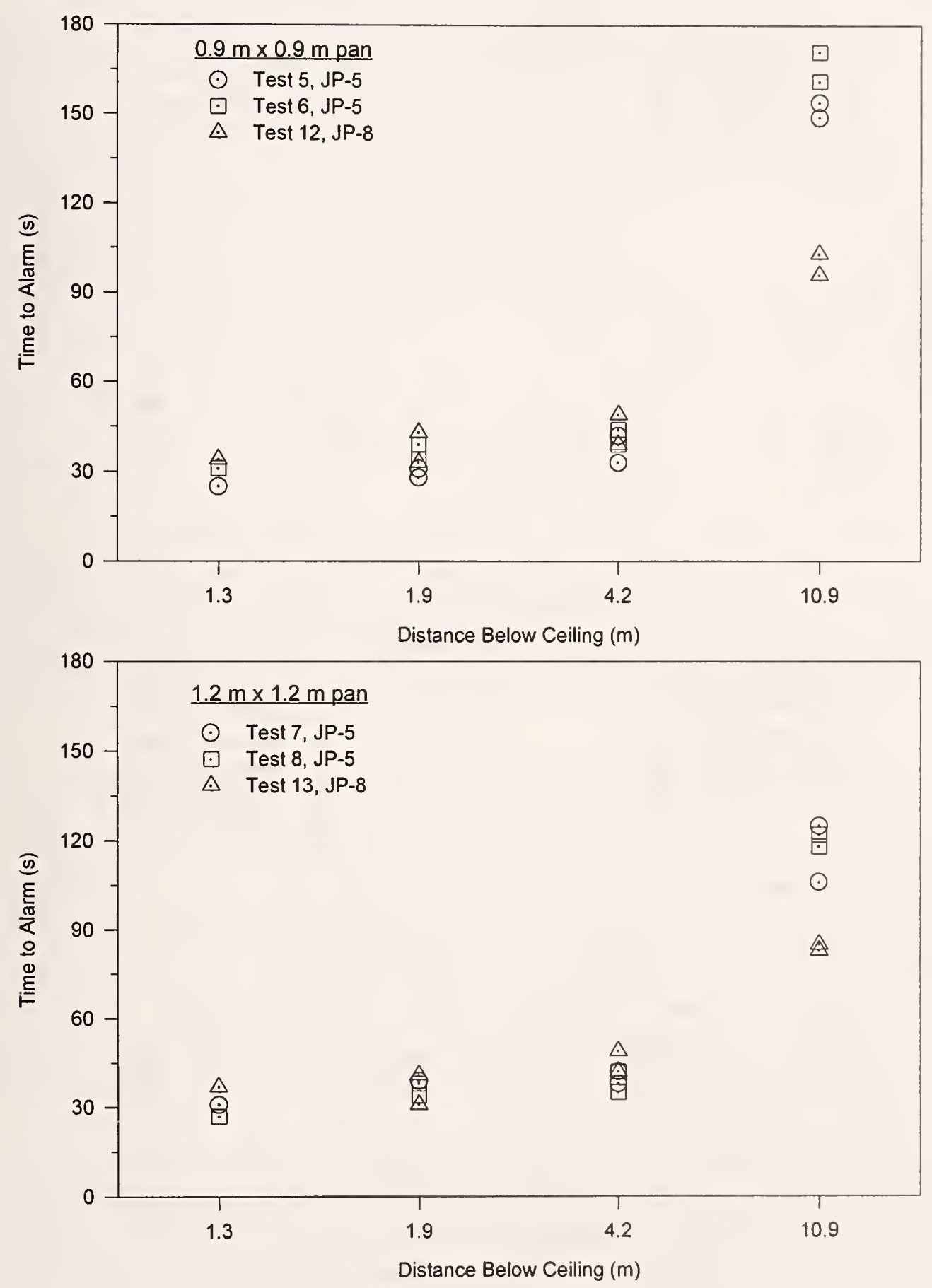

Figure 111. Projected beam detector response times for $0.9 \mathrm{~m} \mathrm{x} 0.9 \mathrm{~m}$ and $1.2 \mathrm{~m} \times 1.2 \mathrm{~m}$ test fires in $22 \mathrm{~m}$ high facility. 

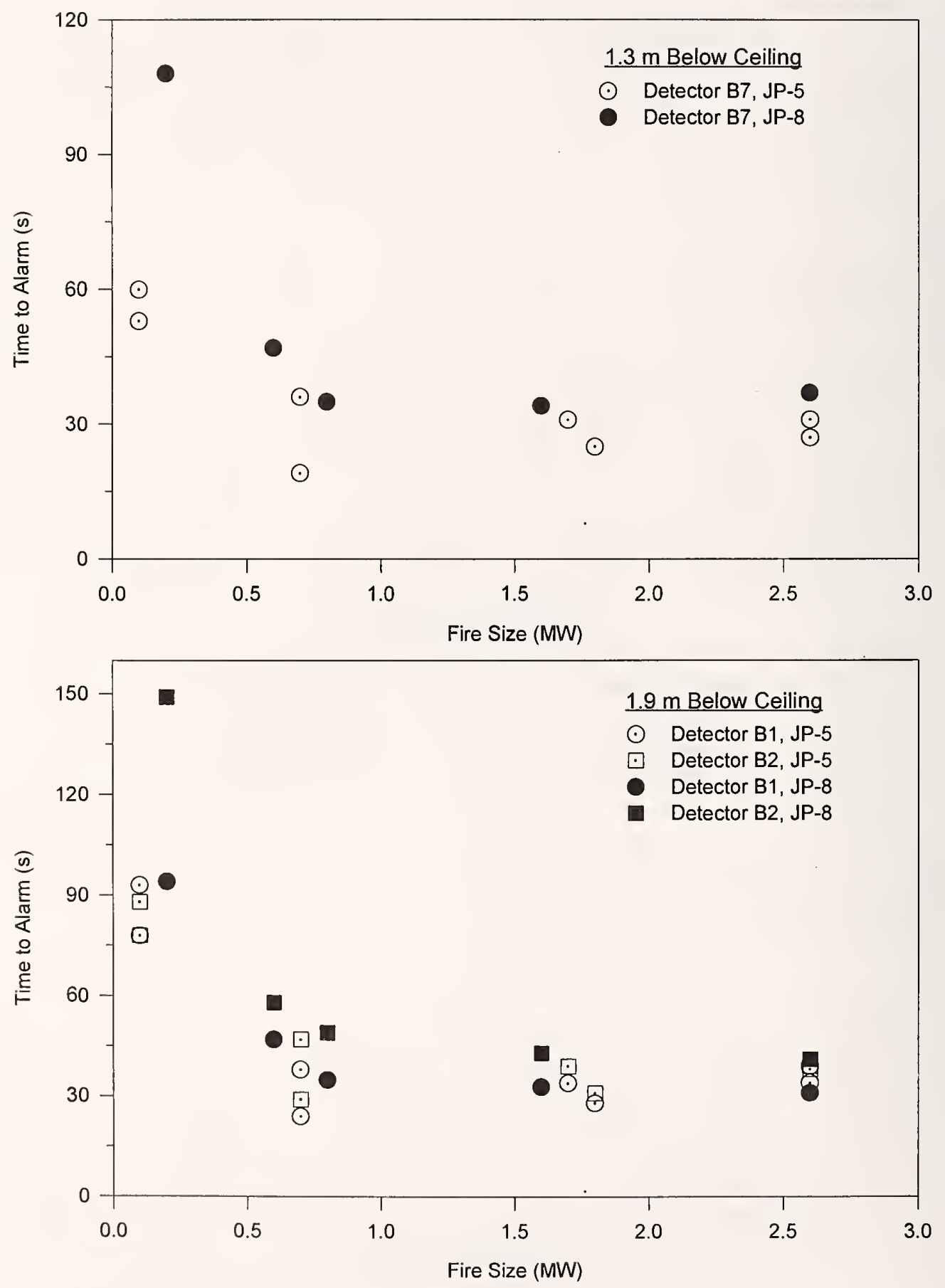

Figure 112. Projected beam response times for detectors at $1.3 \mathrm{~m}$ and $1.9 \mathrm{~m}$ elevations with respect to fire size. 

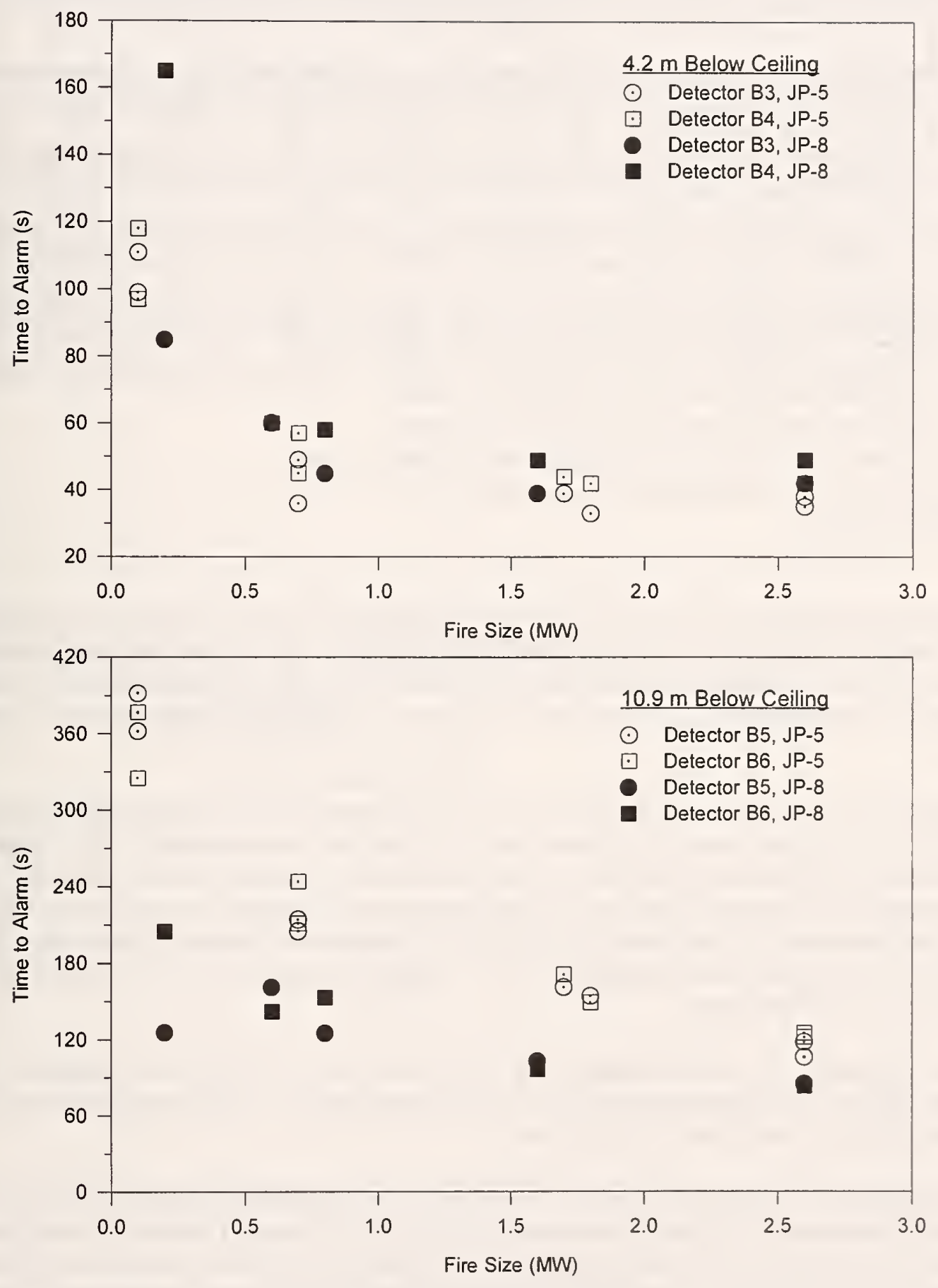

Figure 113. Projected beam smoke detector response times for detectors at $4.2 \mathrm{~m}$ and $10.9 \mathrm{~m}$ elevations with respect to fire size. 
Table 60. Results of projected beam smoke detector activation to sprinkler fires conducted in 22 $\mathrm{m}$ high facility

\begin{tabular}{|c|c|c|c|c|c|c|c|c|c|}
\hline \multicolumn{4}{|c|}{ Test Information } & \multicolumn{6}{c|}{ Projected Beam Detector Response Times $(\mathrm{s}, \pm 5)$} \\
\hline Test \# & $\begin{array}{c}\text { Pan Size } \\
m\end{array}$ & Fuel & B1 $^{\mathrm{a}}$ & B2 $^{\mathrm{a}}$ & B3 $^{\mathrm{b}}$ & B4 $^{\mathrm{b}}$ & B5 $^{\mathrm{b}}$ & B6 $^{\mathrm{b}}$ & B $^{\mathrm{a}}$ \\
\hline 14 & 2.5 dia. & JP-5 & 46 & 46 & 50 & 53 & 87 & 87 & 38 \\
\hline 15 & $3.0 \times 3.0$ & JP-5 & 43 & 43 & 49 & 49 & 84 & 85 & 33 \\
\hline $16^{\mathrm{c}}$ & 2.5 dia. & JP-5 & $\mathrm{T}$ & $\mathrm{T}$ & $\mathrm{T}$ & 52 & 37 & $\mathrm{~T}$ & $\mathrm{~T}$ \\
\hline 17 & $3.0 \times 3.0$ & $\mathrm{JP}-8$ & 32 & 34 & 35 & 35 & 67 & 107 & 27 \\
\hline 18 & 2.0 dia. & JP-5 & 48 & 55 & 50 & 58 & 97 & 90 & 42 \\
\hline $19^{\mathrm{d}}$ & 2.5 dia. & JP-5 & 47 & 40 & 44 & 42 & 47 & T & 39 \\
\hline 20 & $3.0 \times 3.0$ & JP-5 & 37 & 37 & 40 & 40 & 75 & 74 & 31 \\
\hline 21 & $4.6 \times 4.6$ & JP-5 & 33 & 45 & 39 & 48 & 75 & 72 & 30 \\
\hline
\end{tabular}

a Alarm sensitivity setting, 20\%, alarm window, 5 seconds

b Alarm sensitivity setting, $30 \%$, alarm window, 5 seconds

c Open door test (both north and south hangar doors partially open)

d Open door test (only south hangar door partially open)

$\mathrm{T}$ - Trouble condition

straightened and immediately filled the test bay, thus inundating the upper detectors and causing a trouble condition. The second open door experiment using the $2.5 \mathrm{~m}$ diameter pan produced alarm times from $39 \mathrm{~s}$ at the highest elevation to $47 \mathrm{~s}$ at the lowest elevation. In this experiment only detector B6 sensed a trouble condition. The lower graph in Figure 114 shows the results for the $2.5 \mathrm{~m}$ diameter fire tests.

The larger test fires conducted using the $3.0 \mathrm{~m} \times 3.0 \mathrm{~m}$ pan produced alarm times that ranged from $27 \mathrm{~s}$ to $33 \mathrm{~s}$ at the highest elevation and from $74 \mathrm{~s}$ to $107 \mathrm{~s}$ at the lowest elevation. The alarm time value for detector B6 seems to be the only anomaly in these data. For this particular test, the analog signal produced by the detector indicates that the detector was completely obscured by the smoke at 65 $\mathrm{s}$. This condition remained until about $100 \mathrm{~s}$. When the smoke abated enough, the detector reentered alarm stage, thus producing an alarm time of $107 \mathrm{~s}$. The upper graph in Figure 115 shows the results for the $3.0 \mathrm{~m} \times 3.0 \mathrm{~m}$ fire tests.

A single experiment was performed using the $4.6 \mathrm{~m} \times 4.6 \mathrm{~m}$ pan. This experiment produced alarm times from $30 \mathrm{~s}$ at the highest elevation to $75 \mathrm{~s}$ at the lowest elevation. The lower graph in Figure 115 shows the results for the $4.6 \mathrm{~m} \times 4.6 \mathrm{~m}$ fire test.

Additional figures are shown that provide information on the relationship between the larger fire sizes and detector response times at various elevations in the test bay. Figure 116 shows the response of detectors at $1.3 \mathrm{~m}$ and $1.9 \mathrm{~m}$ below the ceiling peak. Figure 117 shows the response of detectors at the $4.2 \mathrm{~m}$ and $10.9 \mathrm{~m}$ elevations. These figures include the results from tests run with both JP-5 and JP-8 

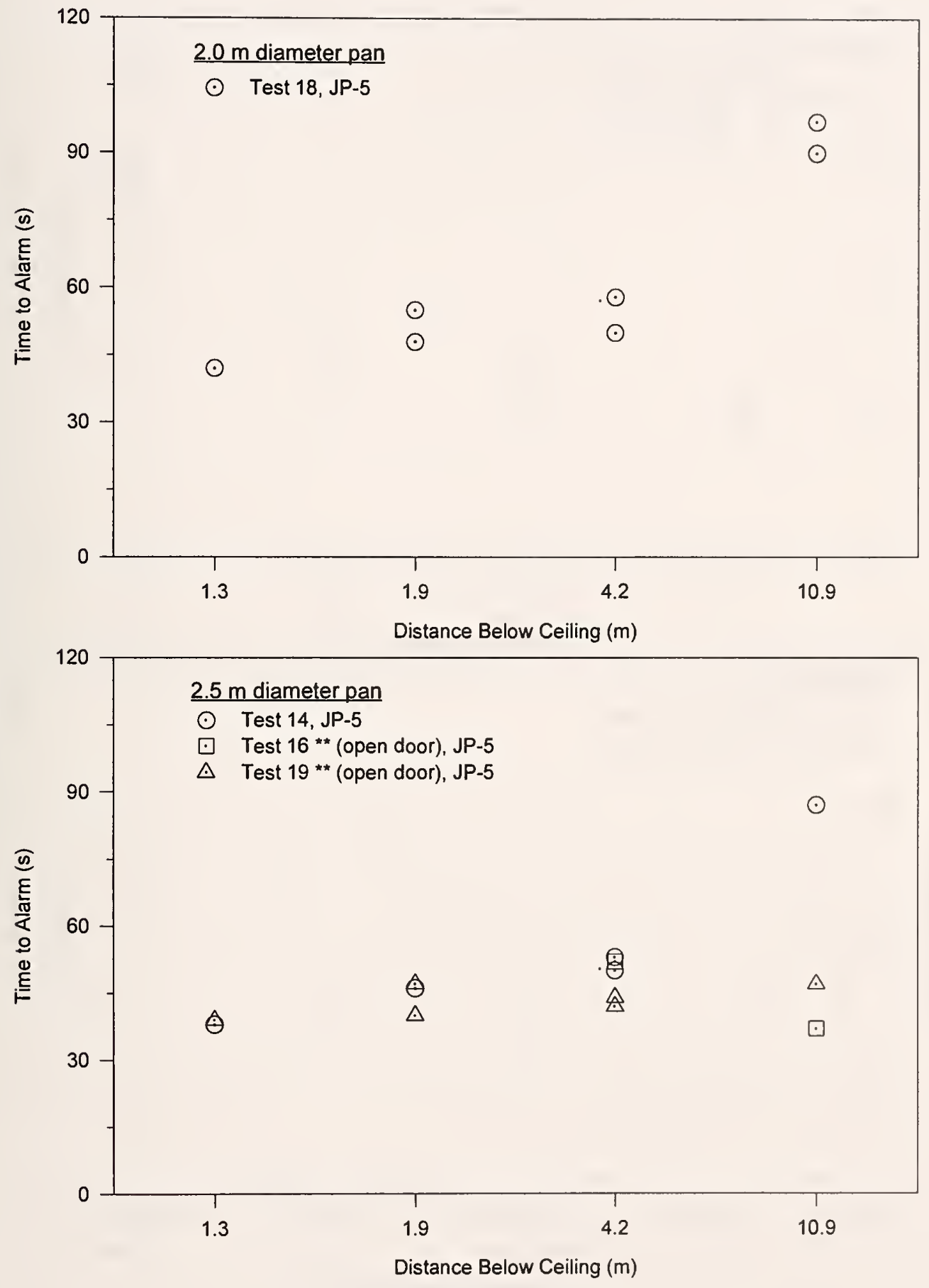

Figure 114. Projected beam activation times for $2.0 \mathrm{~m}$ and $2.5 \mathrm{~m}$ diameter test fires, including open door experiments. 

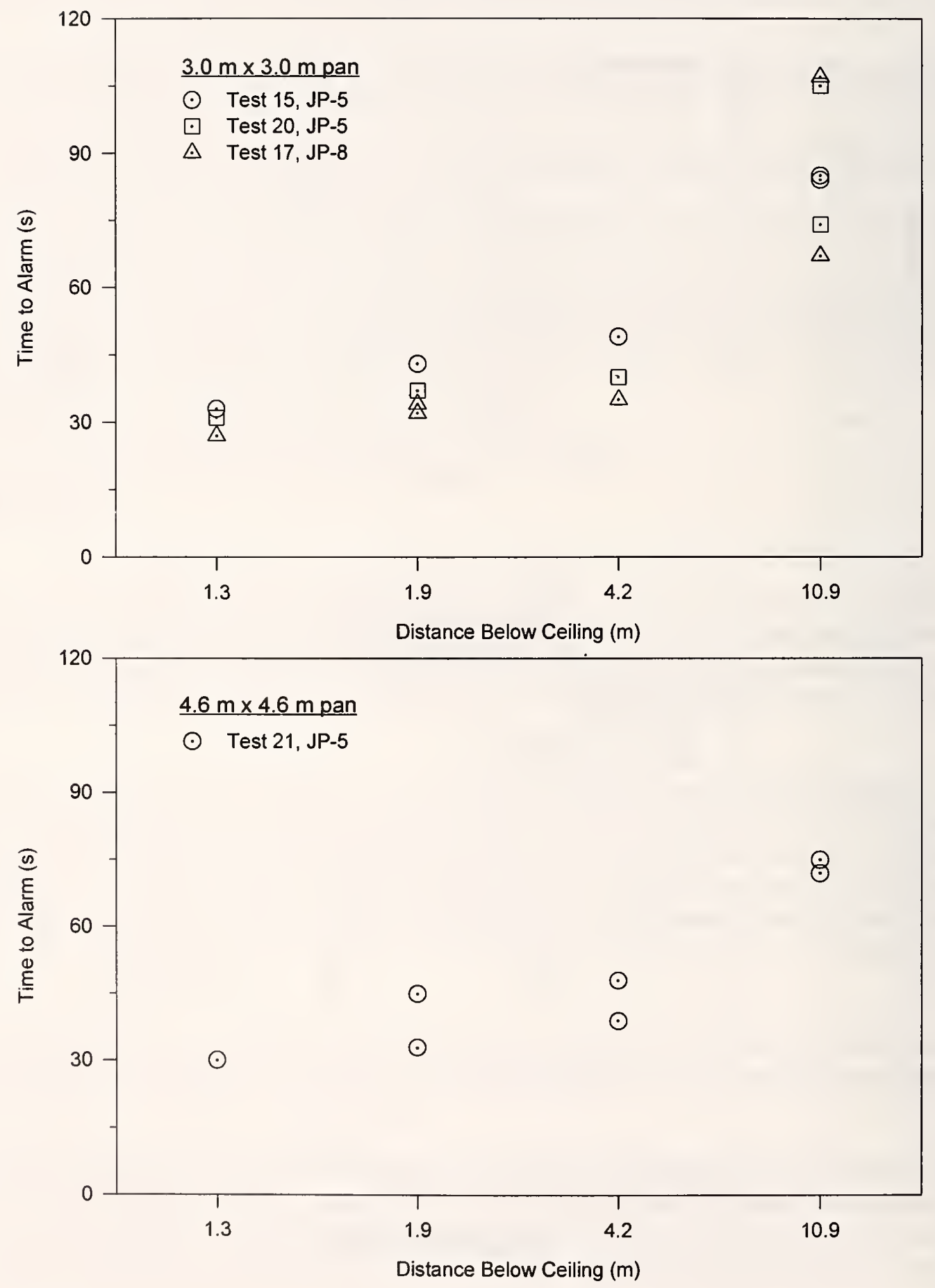

Figure 115. Projected beam activation results for $3.0 \times 3.0 \mathrm{~m}$ and $4.6 \mathrm{~m} \times 4.6 \mathrm{~m}$ test fires. 

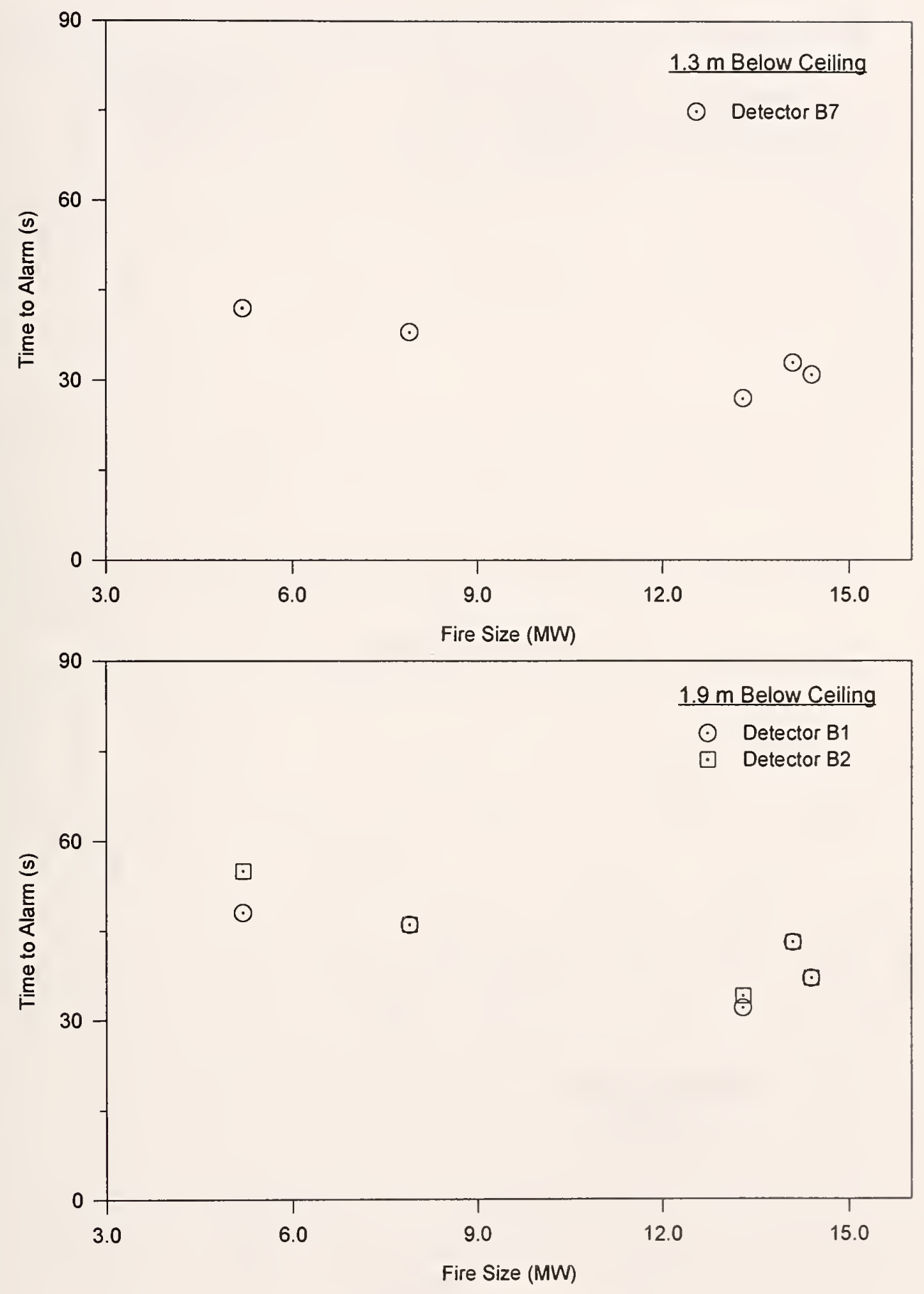

Figure 116. Projected beam activation results at $1.3 \mathrm{~m}$ and $1.9 \mathrm{~m}$ elevations, with respect to fire size. 

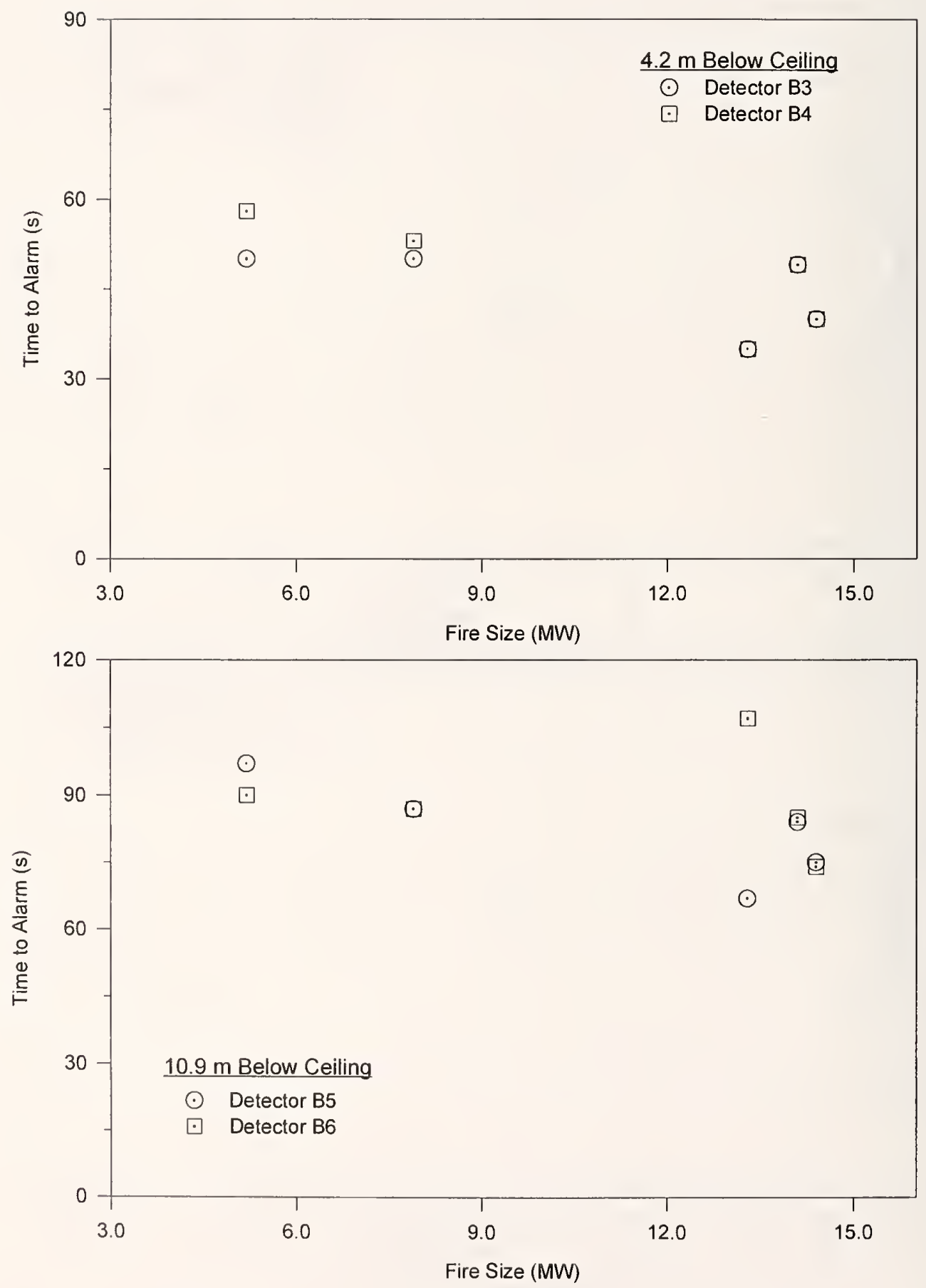

Figure 117. Projected beam activation results at $4.2 \mathrm{~m}$ and $10.9 \mathrm{~m}$ elevations, with respect to fire size. 


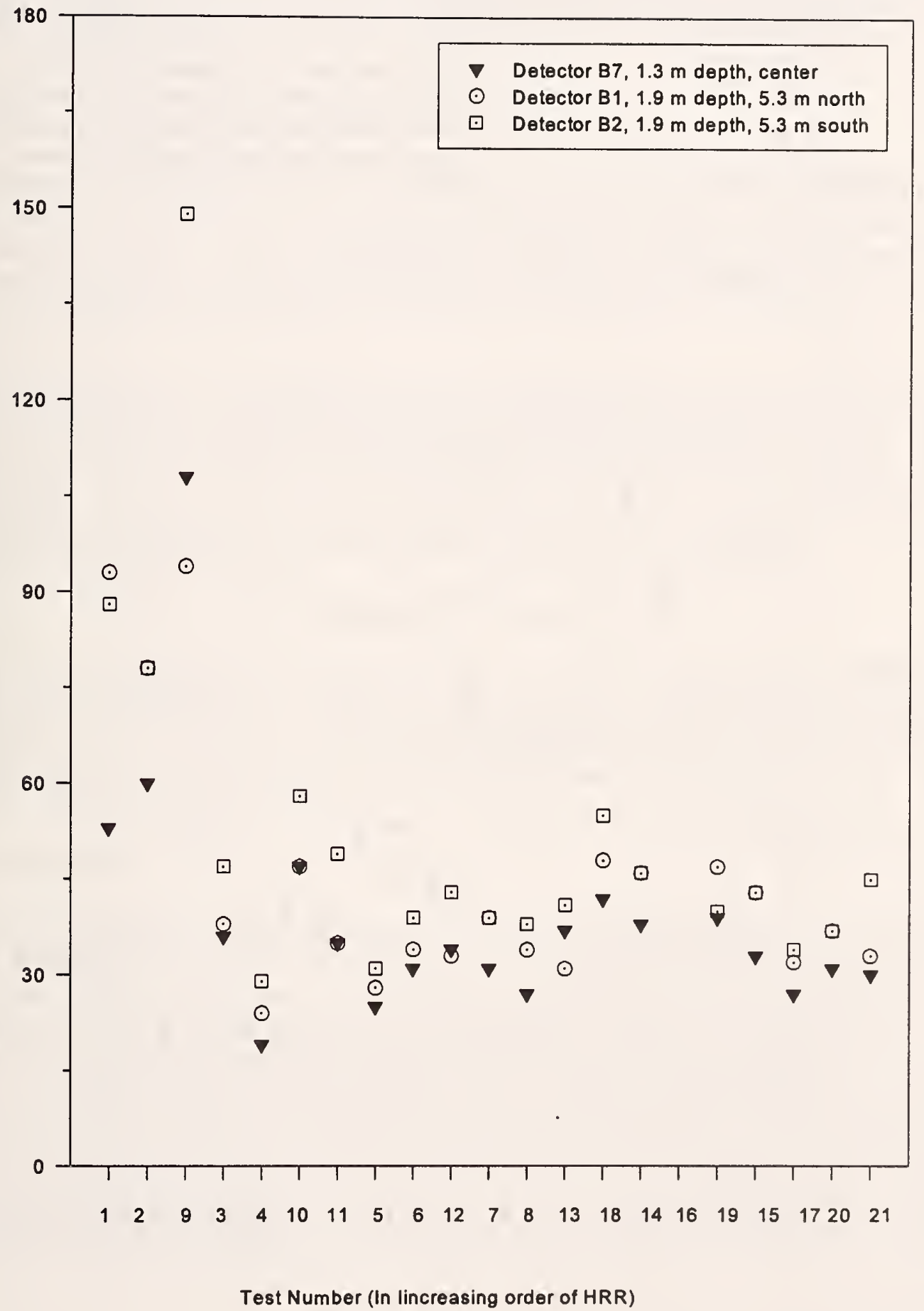

Figure 118. Projected beam smoke detector results, $20 \%$ sensitivity setting. 


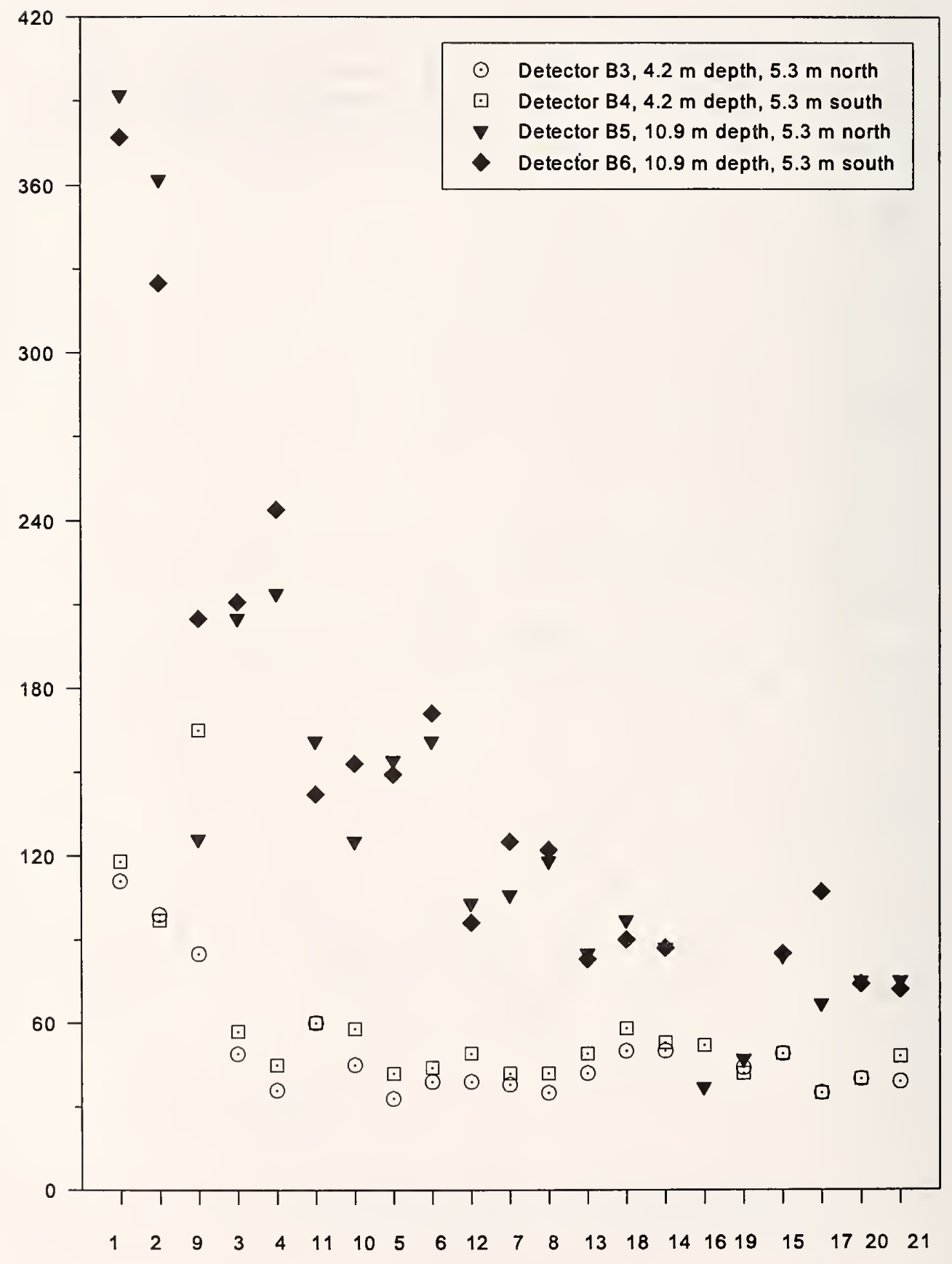

Test Number (In increasing order of HRR)

Figure 119 . Projected beam smoke detector results, $30 \%$ sensitivity setting. 
fuels.

Figures 118 and 119 include all detectors with respect to HRR. All tests are shown, including test fires with open door configurations and test fires using JP-8 fuel. Figure 118 shows those detectors with a $20 \%$ sensitivity setting. Figure 119 shows those detectors with a $30 \%$ sensitivity setting.

\subsubsection{Response of Photoelectric Smoke Detectors}

It is important to note that photoelectric smoke detectors would not normally be installed in an aircraft hangar for a variety of reasons. However, these experiments included photoelectric smoke detectors to help analyze their response in high bay applications. This may be useful in evaluating detector response and spacing in other high bay occupancies. The locations of the smoke detectors in the $22 \mathrm{~m}$ high facility are shown in Figure 57.

The spacing of detectors from the source of the fire was slightly different along the north/south axis than the east/west axis due to the location of the permanent draft curtains. Both axes had detectors located at $3.1 \mathrm{~m}$ and $6.1 \mathrm{~m}$ within the draft curtain. The detectors located at $9.1 \mathrm{~m}$ along north/south axis were located outside the draft curtain. The detectors located at $9.1 \mathrm{~m}, 12.2 \mathrm{~m}, 15.2 \mathrm{~m}$, and $18.3 \mathrm{~m}$ along the east/west axis were all located within the draft curtain. These distances were selected in order to achieve the most uniform spacing from the edges of the draft curtains.

\subsubsection{Fires less than 3 MW (tests 1-13)}

Tests 1 through 13 all produced heat release rates less than $3 \mathrm{MW}$. Tests 1,2 and 9, which were $0.3 \mathrm{~m}$ x $0.3 \mathrm{~m}$ pans with heat release rates of approximately $100 \mathrm{~kW}$, did not activate any of the photoelectric smoke detectors. Tests 3 through 8 , and 10 through 13 all produced sufficient smoke to activate the photoelectric smoke detectors. The response times of the photoelectric smoke detectors for fire sizes less than $3 \mathrm{MW}$ are shown in Table 61.

\section{Effects of Ceiling Curvature}

Because the $22 \mathrm{~m}$ hangar has a barrel-shaped roof, not all of the smoke detectors were at the same elevation with respect to the floor. All detectors were mounted approximately $0.3 \mathrm{~m}$ below the ceiling. The effects of ceiling curvature can only be analyzed for the detectors at $3.1 \mathrm{~m}$ and $6.1 \mathrm{~m}$ from fire center due to the presence of the draft curtains. The detectors along the east/west axis at $3.1 \mathrm{~m}$ and 6.1 $\mathrm{m}$ from the fire center were installed at a height of $21.9 \mathrm{~m}$ and $21.7 \mathrm{~m}$ respectively above the floor. A comparison of the average response times for the detectors along the north/south axis versus those along the east/west axis shows that the ceiling curvature had no significant effect on the response times of the photoelectric smoke detectors located $3.1 \mathrm{~m}$ and $6.1 \mathrm{~m}$ from fire center. This is illustrated graphically in Figures 120 and 121. A comparison of detector response times beyond $6.1 \mathrm{~m}$ from plume center could not be evaluated with respect to the effect of ceiling curvature because of the configuration of the draft curtains. 


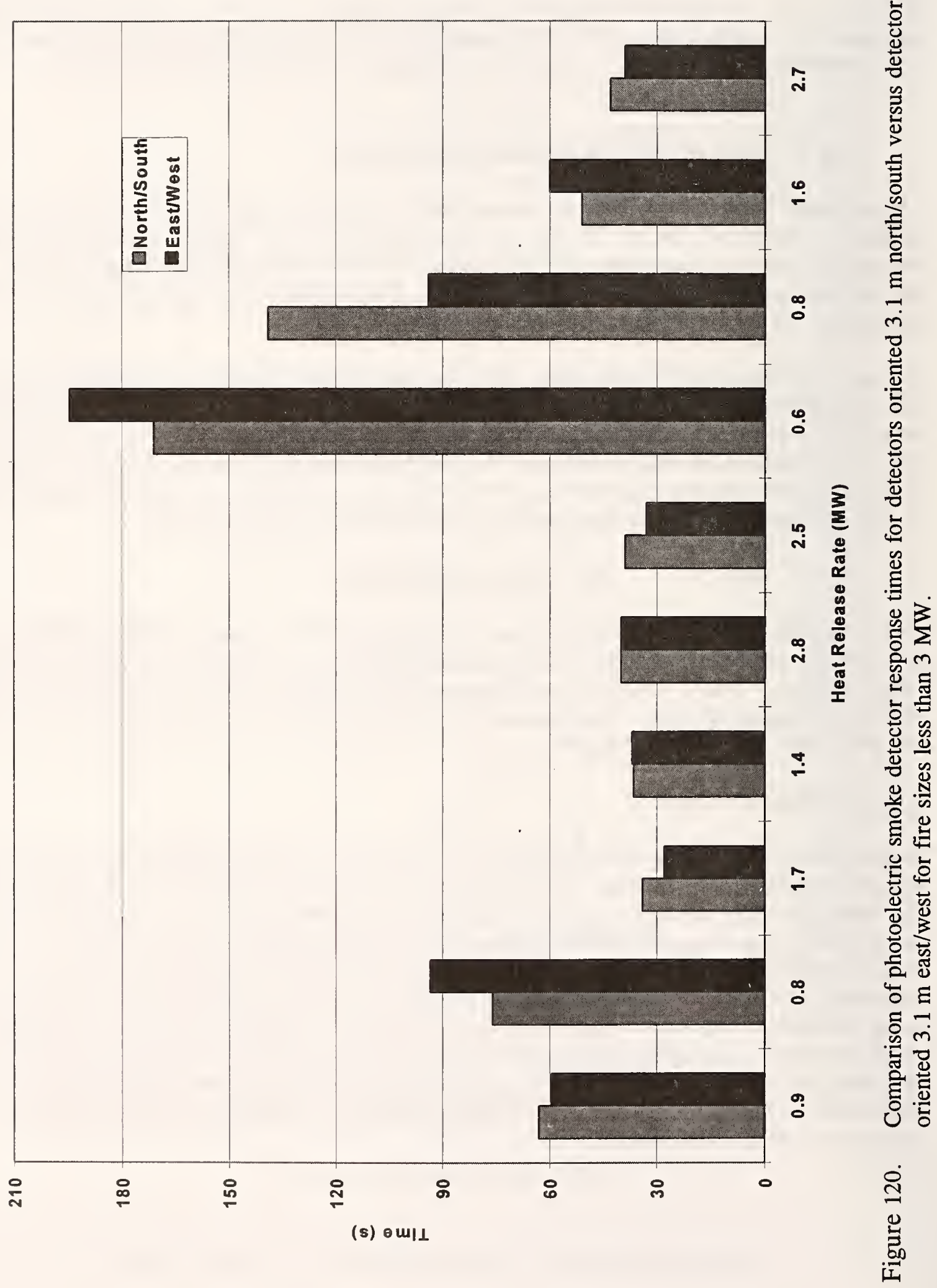




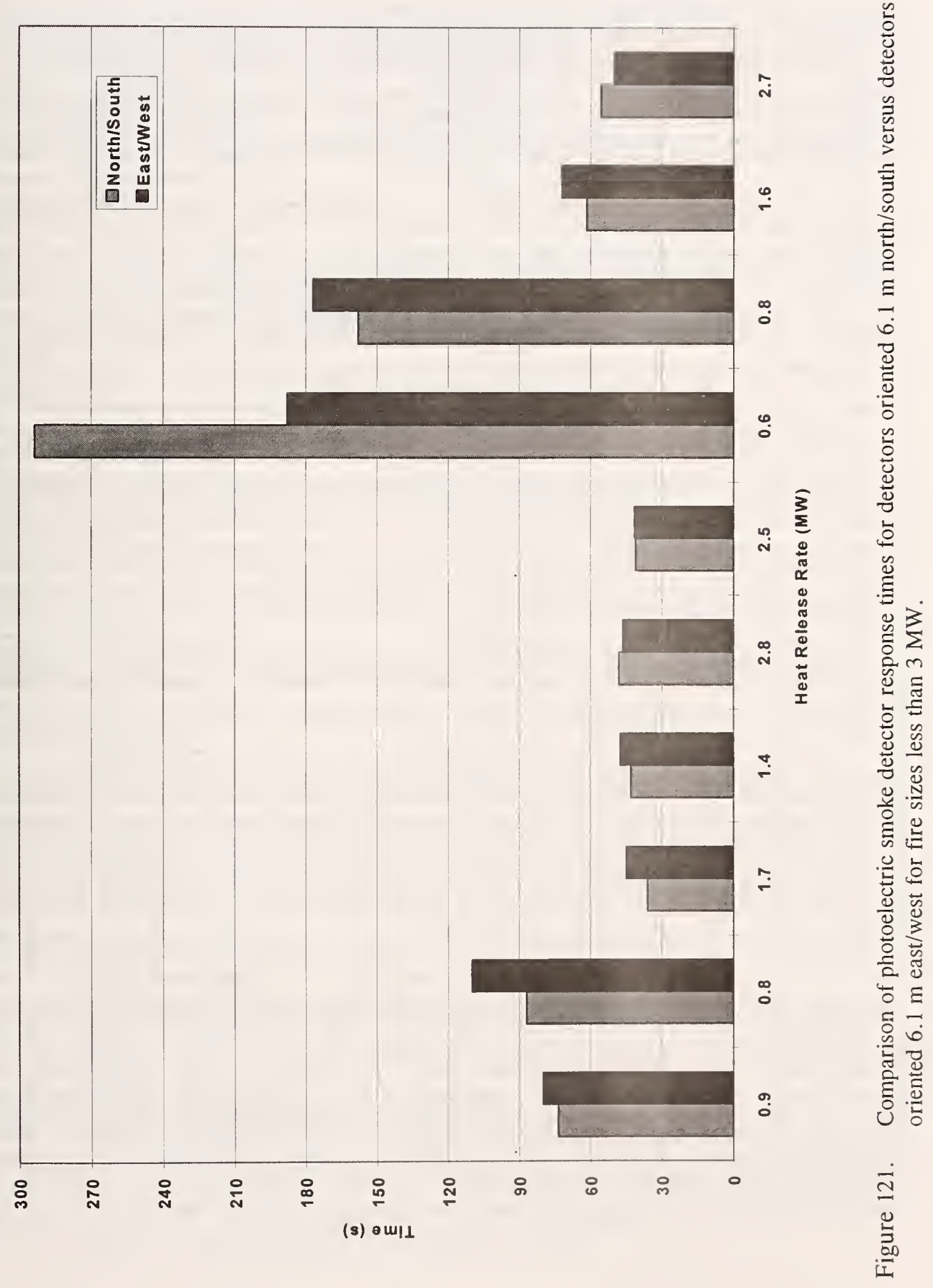


Table 61. Response times (s) of photoelectric smoke detectors installed in $22 \mathrm{~m}$ high facility for fires less than $3 \mathrm{MW}$

\begin{tabular}{|c|c|c|c|c|c|c|c|}
\hline $10 \mathrm{cat} 10 \mathrm{n}$ & $(10 \mathrm{ft})$ & $\begin{array}{l}6.1 \% \\
(20 \mathrm{ft})\end{array}$ & $(30 \mathrm{ft})$ & (outside DC) & $(40 \mathrm{ft})$ & $(402 \mathrm{n})$ & $16 \%$ m \\
\hline \multicolumn{8}{|c|}{ Test \# $3-0.6 \mathrm{~m} \mathrm{x} 0.6 \mathrm{~m} \mathrm{JP}-5(0.9 \mathrm{MW})$} \\
\hline Nonth & 578 & 65 & $1 \%$ & 382 & 18 & $8 \%$ & 1 \\
\hline East & 53 & 78 & 123 & - & 132 & 144 & 178 \\
\hline Soutb & 69 & 82 & 18 & 386 & 18 & 8 & $\%$ \\
\hline West & 66 & 82 & 119 & - & 145 & 140 & 190 \\
\hline \multicolumn{8}{|c|}{ Test \# $4-0.6 \mathrm{~m} \times 0.6 \mathrm{~m} \mathrm{JP}-5(0.8 \mathrm{MW})$} \\
\hline North & $51 \%$ & 85 & 10 & 333 & 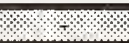 & 1 & \% \\
\hline East & 77 & 106 & 114 & - & 139 & 160 & 201 \\
\hline South & 101 & 89 & 8 & 271 & 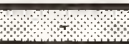 & 18 & 18 \\
\hline West & 110 & 114 & 127 & - & 172 & 127 & 210 \\
\hline \multicolumn{8}{|c|}{ Test \# $5-0.9 \mathrm{~m} \mathrm{x} \mathrm{0.9 \textrm {m } \mathrm { JP } - 5 ( 1 . 7 \mathrm { MW } )}$} \\
\hline Noriti & 36 & 36 & +8 & 203 & +3 & 3 & +6 \\
\hline East & 28 & 41 & 57 & - & 66 & 82 & 95 \\
\hline Solith & 32 & 36 & $\%$ & 224 & 8 & \% & \% \\
\hline West & 28 & 49 & 70 & - & 79 & 87 & 108 \\
\hline \multicolumn{8}{|c|}{ Test \# $6-0.9 \mathrm{~m} \times 0.9 \mathrm{~m} \mathrm{JP}-5(1.4 \mathrm{MW})$} \\
\hline North & 418 & 418 & $1 \%$ & (103. & 18 & 1 & \% \\
\hline East - & 41 & 46 & 66 & - & 70 & 87 & 104 \\
\hline Soutb & 32 & 45 & 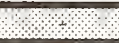 & 170 & 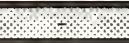 & 18 & 18 \\
\hline West & 33 & 49 & 49 & - & 74 & 79 & 108 \\
\hline \multicolumn{8}{|c|}{ Test \# $7-1.2 \mathrm{~m} \mathrm{x} 1.2 \mathrm{~m} \mathrm{JP}-5(2.8 \mathrm{MW})$} \\
\hline North & 40 & 48 & $1 \times$ & 94 & (1) & 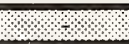 & $1 \%$ \\
\hline East & 36 & 44 & 57 & - & 57 & 69 & 73 \\
\hline Soutri & 40 & 48 & 1 & 440 & 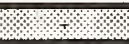 & $\overline{10}$ & 18 \\
\hline West & 44 & 49 & 53 & - & 78 & 65 & 91 \\
\hline \multicolumn{8}{|c|}{ Test \# $8-1.2 \mathrm{~m} \times 1.2 \mathrm{~m} \mathrm{JP}-5(2.5 \mathrm{MW})$} \\
\hline Nottl & 41 & $37 \%$ & + & 78 & 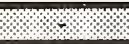 & 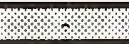 & 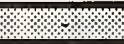 \\
\hline East & 33 & 46 & 46 & - & 62 & 62 & 70 \\
\hline South & 37 & 45 & \% & 145 & (2) & $+\%$ & 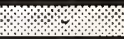 \\
\hline West & 33 & 37 & 54 & - & 63 & 66 & 94 \\
\hline \multicolumn{8}{|c|}{ Test \# $10-0.6 \mathrm{~m} \times 0.6 \mathrm{~m} \mathrm{JP}-8(0.6 \mathrm{MW})$} \\
\hline Nonth & 192 & 143 & \% & 1 & 3 & 8 & $\%$ \\
\hline East & 196 & 183 & 183 & - & 158 & 192 & 217 \\
\hline South & 150 & 444 & 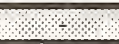 & 404 & $\longdiv { 8 }$ & 10 & 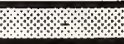 \\
\hline West & 193 & 193 & 229 & - & 292 & 217 & 230 \\
\hline \multicolumn{8}{|c|}{ Test \# $11-0.6 \mathrm{~m} \times 0.6 \mathrm{~m} \mathrm{JP}-8(0.8 \mathrm{MW})$} \\
\hline North & 185 & 93 & मे & 556 & 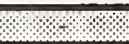 & 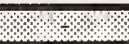 & \% \\
\hline East & 90 & 148 & 136 & - & 136 & 181 & 164 \\
\hline South & 93 & 223 & 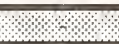 & 331 & 18 & $\bar{l}$ & 1 \\
\hline West & 98 & 206 & 198 & - & 215 & 190 & 198 \\
\hline \multicolumn{8}{|c|}{ Test \# $12-0.9 \mathrm{~m} \times 0.9 \mathrm{~m} \mathrm{JP}-8(1.6 \mathrm{MW})$} \\
\hline North & 45 & 49 & 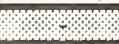 & 16 & 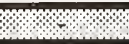 & 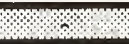 & +3 \\
\hline East & 58 & 78 & 66 & - & 66 & 99 & 95 \\
\hline South: & 57 & 74 & + & 166 & 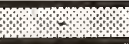 & 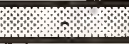 & 1 \\
\hline West & 62 & 66 & 70 & - & 87 & 75 & 100 \\
\hline \multicolumn{8}{|c|}{ Test \# $13-1.2 \mathrm{~m} \times 1.2 \mathrm{~m} \mathrm{JP}-8(2.7 \mathrm{MW})$} \\
\hline North & 49 & $45 \%$ & \%" & 90 & 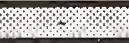 & 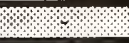 & 8 \\
\hline East & 41 & 50 & 50 & - & $\overline{62}$ & 66 & 78 \\
\hline South: & 37 & 66 & 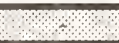 & 128 & 8 & 3 & \% \\
\hline West & 37 & 50 & 55 & - & 62 & 58 & 79 \\
\hline
\end{tabular}

- detector did not activate

no detector installed 


\section{Effect of Draft Curtains}

To analyze the effects of the draft curtains, the detectors located along the east/west axis were compared to those along the north/south axis at a distance of $9.1 \mathrm{~m}$ from fire center. The north/south detectors were located outside the draft curtain. The draft curtain had a measurable effect on the response time of the photoelectric smoke detectors for fire sizes less than $3 \mathrm{MW}$. This can be seen graphically by comparing Figure 122 with Figure 123 . The detectors located inside the draft curtain responded an average of 2.3 times faster than those detectors located outside the draft curtain.

\section{Effect of Fuel Type}

To study the effects of fuel type on photoelectric detector response, the response times of tests 3 and 4 ( $0.6 \mathrm{~m} \times 0.6 \mathrm{~m}, \mathrm{JP}-5)$ were compared to those of tests 10 and $11(0.6 \mathrm{~m} \mathrm{x} 0.6 \mathrm{~m}, \mathrm{JP}-8)$. Figure 124 shows that the JP-5 fires were consistently detected earlier than the JP- 8 fires, although the wind conditions may have affected the results as much as the fuel type.

\section{Effect of Spacing}

Analysis of Table 61 indicates that fire sizes less than $1 \mathrm{MW}$ were difficult to detect via the photoelectric detectors in the $22 \mathrm{~m}$ hangar. However, for all fire sizes greater than $1 \mathrm{MW}$, detector

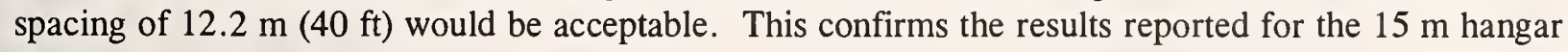
as stated in section 3 .

\subsubsection{Fires greater than $3 \mathrm{MW}$ (tests 14-21)}

Tests 14 through 21 generated heat release rates greater than $3 \mathrm{MW}$. The response times of the photoelectric smoke detectors for fire sizes greater than $3 \mathrm{MW}$ are shown in Table 62.

\section{Open Door Vs. Closed Door}

A comparison of test 14 with test 16 (both $2.5 \mathrm{~m}$ diameter pan fires) can be used to investigate the effects that open hangar doors have on photoelectric detector response. The smoke detector response with the hangar doors open was actually faster than with the doors closed. For example, in test 16 the average response time of the detectors located $3.1 \mathrm{~m}$ from fire center was $51 \mathrm{~s}$ compared to an average response time of $65 \mathrm{~s}$ in test 14 .

\section{Effect of Ceiling Height}

To analyze the effects of ceiling height, one can compare the average smoke detector response times for the $2.0 \mathrm{~m}$ and $2.5 \mathrm{~m}$ diameter pan fires in both the $15 \mathrm{~m}$ and $22 \mathrm{~m}$ hangars. For the $2.0 \mathrm{~m}$ diameter pan fire, the average response time of the smoke detectors located $6.1 \mathrm{~m}$ from the fire center in the $15 \mathrm{~m}$ hangar was $35 \mathrm{~s}$ compared to $50 \mathrm{~s}$ in the $22 \mathrm{~m}$ hangar. Similarly for the $2.5 \mathrm{~m}$ diameter pan fire, the average response time of the smoke detectors located $6.1 \mathrm{~m}$ from the fire center in the $15 \mathrm{~m}$ hangar was $31 \mathrm{~s}$ compared to $69 \mathrm{~s}$ in the $22 \mathrm{~m}$ hangar. While this comparison shows a significant difference in average response times, the difference is not solely attributable to ceiling height. It does not account for the differences in ambient air and fuel temperatures, ignition sequence, nor the difference in the volume of the draft curtain areas between the two experimental sites. 


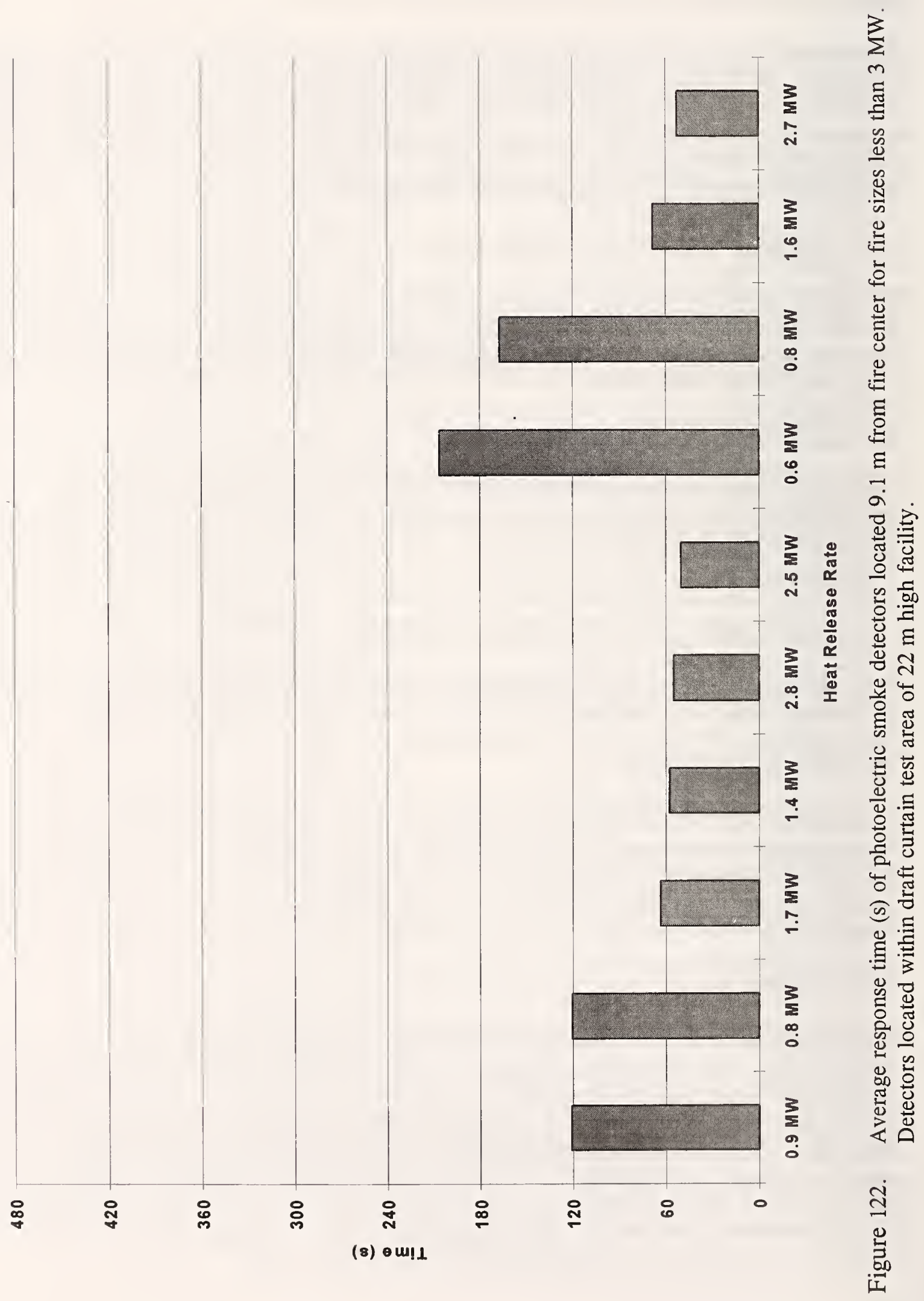




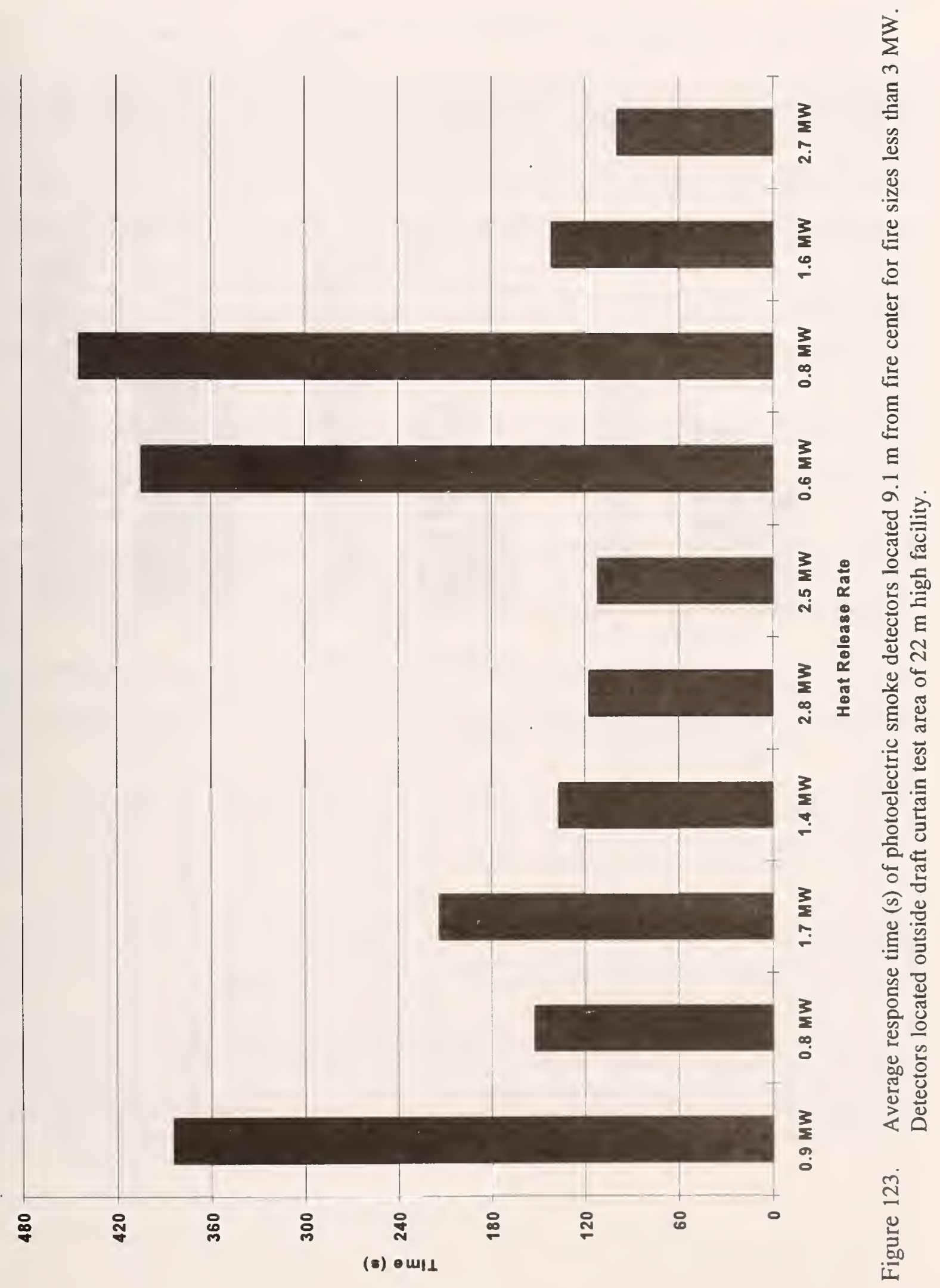




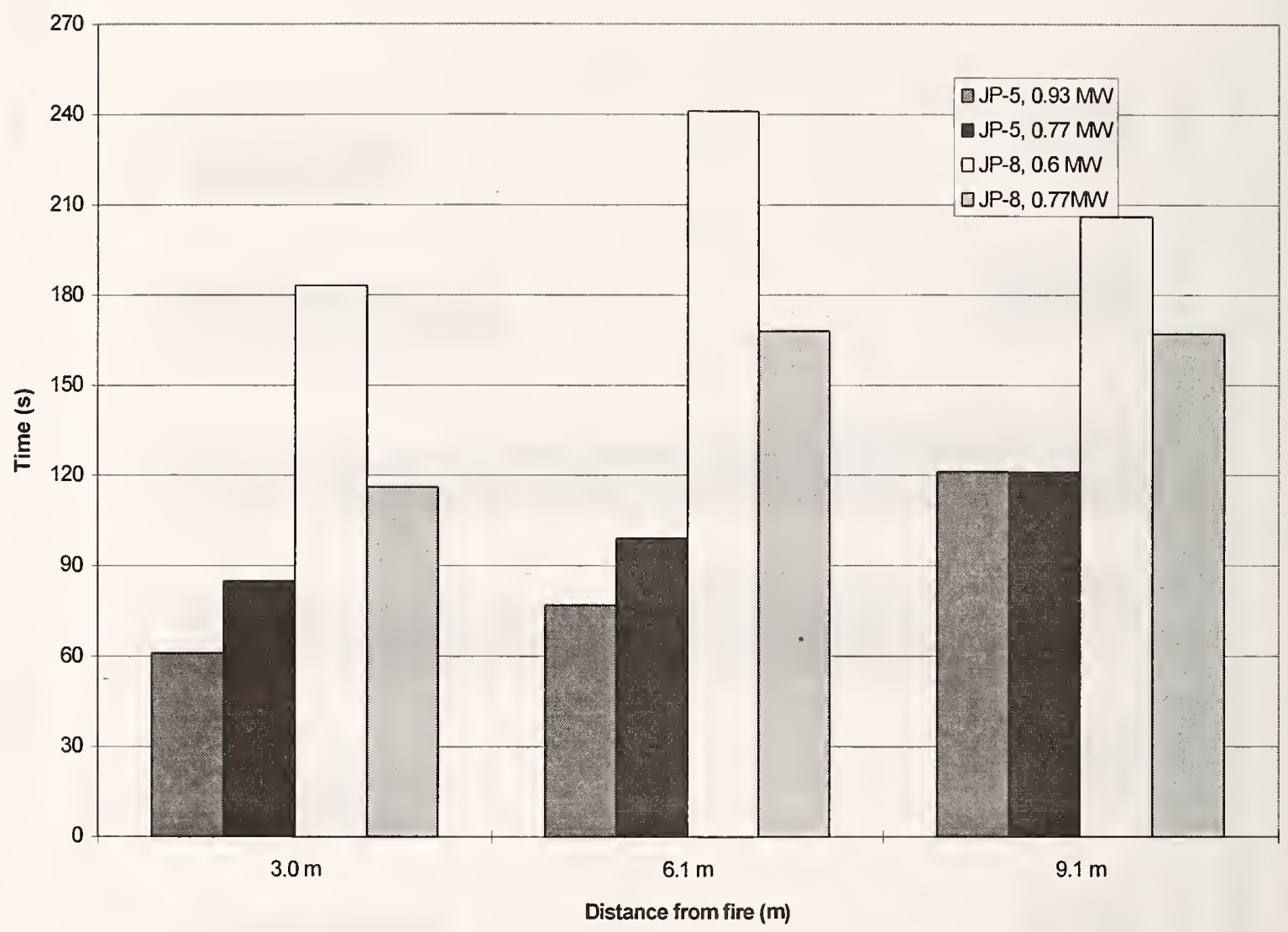

Figure 124. Comparison of JP-5 to JP-8 fuels on photoelectric detector response time for fire sizes less than $3 \mathrm{MW}$. 
Table 62. Response times (s) for photoelectric smoke detectors installed in $22 \mathrm{~m}$ high facility to fire size greater than $3 \mathrm{MW}$

\begin{tabular}{|c|c|c|c|c|c|c|c|}
\hline Location & $(10 \mathrm{n})$ & $\begin{array}{l}6.1 \mathrm{~m} \\
(20 \mathrm{ft}) \\
\end{array}$ & $9.9 \mathrm{~m}$ & (outside DC) & $(40.2 \mathrm{~m}$ & $\begin{array}{l}15.2 \mathrm{~m} \\
(40 \mathrm{ft})\end{array}$ & $\begin{array}{l}18.3 \mathrm{~m} \\
(60 \mathrm{ft})\end{array}$ \\
\hline \multicolumn{8}{|c|}{ Test \# $14-2.5 \mathrm{~m}$ diameter JP-5 (7.9 MW) } \\
\hline North & 59 & 68 & 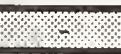 & 101 & ?as & 2 & - \\
\hline East & 64 & 72 & 77 & - & 80 & 89 & 93 \\
\hline South & 76 & 68 & 2 & 105 & 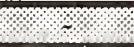 & 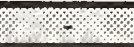 & 1. \\
\hline West & 60 & 69 & 73 & - & 89 & 89 & 97 \\
\hline \multicolumn{8}{|c|}{ Test \# 15-3.0 m x 3.0 m JP-8 (15.7 MW) } \\
\hline North & $47 \%$ & 81 : & 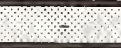 & 64 & . & $=0$ & ( \\
\hline East & 49 & 49 & 56 & - & 68 & 72 & 85 \\
\hline Souli & 43 & 56 & 1, & 97. & (1) & 8 & 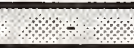 \\
\hline West & 44 & 49 & 53 & - & 65 & 65 & 77 \\
\hline \multicolumn{8}{|c|}{ Test \# $16-2.5 \mathrm{~m}$ diameter JP-5 (7.0 MW) } \\
\hline North & 50 & 46. & 18 & 65 & 2 & \%. & -0 \\
\hline East & 50 & 54 & 54 & - & 59 & 67 & 71 \\
\hline South & 54 & 58 & $y-$ & 83 & -2 & -2 & - \\
\hline West & 51 & 51 & 54 & - & 54 & 59 & 63 \\
\hline \multicolumn{8}{|c|}{ Test \# $17-3.0 \mathrm{~m} \mathrm{x} 3.0 \mathrm{~m} \mathrm{JP}-8(14.3 \mathrm{MW})$} \\
\hline North & 29.2 & 833. & (1.:- & 71 & 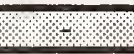 & 举 & -5 \\
\hline East & 38 & 42 & 54 & - & 54 & 67 & 71 \\
\hline Soitit & 29 & 88 & 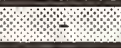 & प1: & $1 \%$ & (1) & + \\
\hline West & 25 & 30 & 42 & - & 50 & 55 & 59 \\
\hline \multicolumn{8}{|c|}{ Test \# 18 - 2.0 m diameter JP-5 (4.9 MW) } \\
\hline North & $544 \times 1 \times$ & 50 & 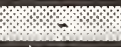 & 84 & 10 & -5 & -7 \\
\hline East & 46 & $\diamond$ & 75 & - & $\diamond$ & 135 & 102 \\
\hline Soluth & 46 & 54 & (a) & 231 & 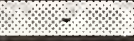 & $\sqrt{2}-1$ & 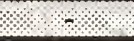 \\
\hline West & 51 & 46 & 59 & - & 63 & 71 & 80 \\
\hline \multicolumn{8}{|c|}{ Test \# $19-2.5$ m diameter JP-5 (9.1 MW) } \\
\hline North & 56.2 & 65 & 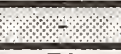 & $\sqrt{102}$ & 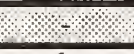 & V. & $\because$ \\
\hline East & 54 & 82 & 73 & - & 61 & 98 & 103 \\
\hline South & 52 & 52 & 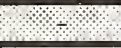 & 115 & + & (3) & 8 \\
\hline West & 61 & 45 & 45 & - & 65 & 61 & 69 \\
\hline \multicolumn{8}{|c|}{ Test \# $20-3.0 \mathrm{~m} \times 3.0 \mathrm{~m} \mathrm{JP}-5(14.6 \mathrm{MW})$} \\
\hline North & 36 & 40 & -2 & 1.77? & $-{ }^{2}$ & -3 & - \\
\hline East & 41 & 45 & 52 & - & 61 & 69 & 81 \\
\hline Soluth & 36 & 48 & -8 & 81 & + & -2 & 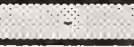 \\
\hline West & 41 & 41 & 49 & - & 57 & 65 & 70 \\
\hline \multicolumn{8}{|c|}{ Test \# $21-4.6 \mathrm{~m} \times 4.6 \mathrm{~m} \mathrm{JP}-5$ (33 MW) } \\
\hline North & 34 & 34 & 1.8. & 16 & +4 & $\sqrt{-3}$ & - \\
\hline East & 40 & 51 & 51 & - & 59 & 67 & 63 \\
\hline Sowith & 38 & 55 & (x) & 109 & 1. & 3 & (3) \\
\hline West & 35 & 35 & 40 & - & 51 & 56 & 68 \\
\hline
\end{tabular}




\subsubsection{Response of Heat Detectors}

The heat detectors utilized in the $22 \mathrm{~m}$ facility included the same type of addressable $57^{\circ} \mathrm{C}\left(135^{\circ} \mathrm{F}\right)$ rate-compensated, fixed-temperature heat detectors used in the $15 \mathrm{~m}$ hangar experiments, as well as $93{ }^{\circ} \mathrm{C}\left(200{ }^{\circ} \mathrm{F}\right)$ hard wired, thermistor-type heat detectors. The $57^{\circ} \mathrm{C}$ heat detectors would not normally be suitable for a high bay hangar application, but were chosen to represent the lowest possible temperature rating which may be used in an aircraft hangar. The $93{ }^{\circ} \mathrm{C}$ detectors were selected to represent the highest temperature heat detectors typically installed in a high bay hangar.

The spacing of the detectors beyond $6.1 \mathrm{~m}$ from the source of the fire was slightly different along the north/south axis than the east/west axis because of the presence of the draft curtain.

None of the $57{ }^{\circ} \mathrm{C}$ or $93{ }^{\circ} \mathrm{C}$ heat detectors responded in any of the experiments where the fire size was less than $3 \mathrm{MW}$. Fire sizes with heat release rates greater than $3 \mathrm{MW}$ activated both the $57^{\circ} \mathrm{C}$ and $93{ }^{\circ} \mathrm{C}$ heat detectors. Table 63 shows the response times of the $57^{\circ} \mathrm{C}$ and $93{ }^{\circ} \mathrm{C}$ heat detectors for all experiments conducted in the $22 \mathrm{~m}$ hangar.

\section{Effect of Ceiling Curvature}

The heat detectors were installed adjacent to the photoelectric smoke detectors whose mounting details with respect to the ceiling curvature were described earlier in section 4 . Since the detectors within the draft curtain along the north/south axis could only be installed a maximum distance of $6.1 \mathrm{~m}$ from the plume, the analysis of the curved ceiling effect on heat detector response must practically be limited to those detectors located within $6.1 \mathrm{~m}$ of the plume centerline. Figure 125 graphically depicts the effects of the curved ceiling on the response time of the $57^{\circ} \mathrm{C}$ heat detectors for five of the larger experiments conducted in the $22 \mathrm{~m}$ hangar. This shows that the ceiling curvature had no significant impact on the response times of heat detectors located $6.1 \mathrm{~m}$ from plume centerline. The shorter response time in the $\mathrm{N}-\mathrm{S}$ direction is probably due to the presence of the draft curtains and not the absence of ceiling curvature.

While additional heat detectors installed along the east/west axis at distances of $12.2 \mathrm{~m}, 15.2 \mathrm{~m}$, and $18.3 \mathrm{~m}$ were mounted at lower elevations than those at $6.1 \mathrm{~m}$, there are no comparative heat detectors along the north/south axis because of the draft curtains. One can certainly look at the response times of the detectors beyond $6.1 \mathrm{~m}$ as shown in Table 63, but the reader is cautioned to avoid a direct comparison unless it also considers the greater distance of these detectors from plume centerline.

\section{Effect of Draft Curtains}

Table 63 shows the response times of the $57^{\circ} \mathrm{C}$ and $93{ }^{\circ} \mathrm{C}$ heat detectors outside the draft curtain. These were installed along the north/south axis at a distance of $9.1 \mathrm{~m}$ from the plume centerline. The table shows that not a single $93{ }^{\circ} \mathrm{C}$ heat detector responded outside the draft curtain for any of the experimental fires. The table also shows that several of the $57{ }^{\circ} \mathrm{C}$ detectors activated outside the draft curtains. However, the response times of those detectors outside the draft curtain are twice as long as the $57^{\circ} \mathrm{C}$ detectors located inside the draft curtain as shown in Figure 126. This clearly demonstrates the ability of the draft curtain to confine the heat within the boundaries of the draft curtain. This also shows the ability of the draft curtains to limit the number of sprinkler heads activated in adjacent draft curtain areas. 
Table 63. Response times (s) of heat detectors installed in $22 \mathrm{~m}$ high facility test area for fire sizes greater than $3 \mathrm{MW}$

\begin{tabular}{|c|c|c|c|c|c|c|c|c|c|c|c|c|c|c|}
\hline $10 \mathrm{cation}$ & \multicolumn{2}{|c|}{3.10} & \multicolumn{2}{|c|}{611} & \multicolumn{2}{|c|}{$91 \%$ } & \multicolumn{2}{|c|}{ 9. in routside bor } & \multicolumn{2}{|c|}{$12,2,10$} & \multicolumn{2}{|c|}{$15,2,1$} & \multicolumn{2}{|c|}{$18.3 \mathrm{~m}$} \\
\hline betretor: & $5 \%$ & $93^{\circ} \mathrm{C}$ & $57 \%$ & $93^{\circ} \mathrm{C}$ & $57 \%$ & $93^{\circ} \mathbf{F}$ & $57 \%$ & $93^{\circ} \mathrm{C}$ & 37: \% & $93^{\circ} \mathrm{C}$ & 57.8 & $93^{\circ} \mathrm{C}$ & S? & $93^{\circ} \mathrm{C}$ \\
\hline \multicolumn{15}{|c|}{ 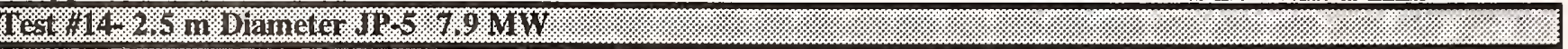 } \\
\hline North & $10 \times$ & & 140 & $>$ & $1 \%$ & $\sim$ & 645 & 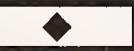 & 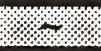 & $\sim$ & 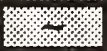 & $\sim$ & \% & $\sim$ \\
\hline So110 & 94. & 629 & $18 \%$ & $\Delta$ & \% & $\sim$ & 653 & $\Delta$ & (4. & $\sim$ & \% & $\sim$ & : & $\sim$ \\
\hline East & $28 \%$ & $\diamond$ & 26 & 198 & $28 \%$ & 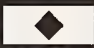 & ma & $\sim$ & 336 & 331 & 54 & 468 & 361 & 565 \\
\hline 1086 & XIX & 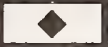 & $141 \%$ & $\Delta$ & 286 & $\Delta$ & \% & $\sim$ & 832 & 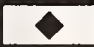 & 349 & $\bullet$ & 631 & 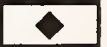 \\
\hline \multicolumn{15}{|c|}{ Test \#15-3.0 m x 3.0 m JP-5 $15.7 \mathrm{MW}$} \\
\hline North & 189 & 155 & 68 & 227 & (2) & $\sim$ & 256 & 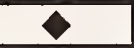 & - =. & $\sim$ & s. & $\sim$ & s. & $\sim$ \\
\hline S103in & 82 & 127 & 88 & 222 & 1 & $\sim$ & 26. & $>$ & (2) & $\sim$ & 2 & $\sim$ & (x) & $\sim$ \\
\hline East & 10 & 344 & 106 & 103 & 119 & 150 & - & $\sim$ & 166 & 142 & $185 \div$ & 161 & 869 & 199 \\
\hline Wesl & 60 & 149 & WO & 216 & $1 \%$ & 309 & 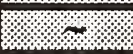 & $\sim$ & 128 & 344 & 157. & 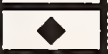 & 215 & 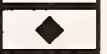 \\
\hline \multicolumn{15}{|c|}{ 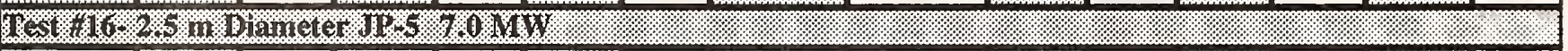 } \\
\hline North & 134 & $\diamond$ & $164:$ & 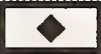 & V. & $\sim$ & 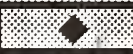 & $>$ & t. & $\sim$ & 4 & $\sim$ & $1+$ & $\sim$ \\
\hline South & 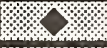 & 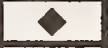 & 10 & $\diamond$ & - & $\sim$ & 8 & 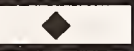 & 3. & $\sim$ & 8 & $\sim$ & (1) & $\sim$ \\
\hline East & 100 & 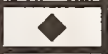 & 10 & $\Delta$ & (2) & $\Delta$ & 2. & $\sim$ & 2. & $\Delta$ & 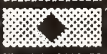 & 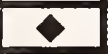 & 2 & 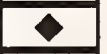 \\
\hline 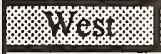 & 174. & $\bullet$ & 16 & 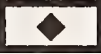 & 8 & $\Delta$ & ?. & $\sim$ & 2. & 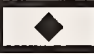 & (2) & 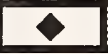 & 20 & $\Delta$ \\
\hline \multicolumn{15}{|c|}{ Test \#17-3.0 m x 3.0 m JP-8 $14.3 \mathrm{MW}$} \\
\hline North & 16 . & 158 & $1 / 6$ & 258 & 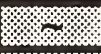 & $\sim$ & 14 & 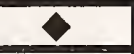 & ?. & $\sim$ & צ. & $\sim$ & 1 & $\sim$ \\
\hline Sourati & 863 & 124 & 80 & 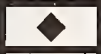 & \%. & $\sim$ & 250 & $>$ & 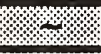 & $\sim$ & \%. & $\sim$ & . & $\sim$ \\
\hline East & 63 & 350 & 80 & 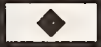 & 126 & 156 & 1. & $\sim$ & 138 & 143 & 176 & 173 & 189 & 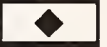 \\
\hline 168 & 112 & 160 & 18 & 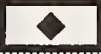 & $1 / 18$ & 293 & 2 & $\sim$ & 166 & 316 & 116\% & 456 & 8 & 196 \\
\hline \multicolumn{15}{|c|}{ 1 } \\
\hline North & 292 & 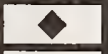 & 136 & 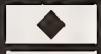 & 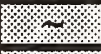 & $\sim$ & 1 & $\diamond$ & $+\%$ & $\sim$ & ?.: & $\sim$ & (2) & $\sim$ \\
\hline 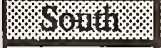 & 310 & 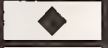 & 18 & 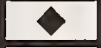 & - & $\sim$ & s & 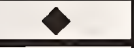 & \% & $\sim$ & - & $\sim$ & 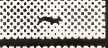 & $\sim$ \\
\hline East & 30 & 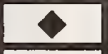 & 48 & 482 & se. & 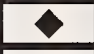 & 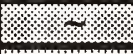 & $\sim$ & (2) & 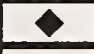 & 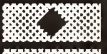 & $>$ & 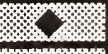 & 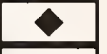 \\
\hline WISt: & $602 \%$ & 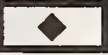 & 168. & 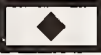 & 18 & $\Delta$ & ? & $\sim$ & 18 & 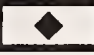 & 4 & $>$ & 2 & 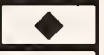 \\
\hline \multicolumn{15}{|c|}{ Test \#19- 2.5 m Diameter JP-5 9.1 MW } \\
\hline North & 1286 & $\diamond$ & (3. & 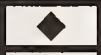 & \%. & $\sim$ & 21 & $\Delta$ & 2 & $\sim$ & 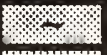 & $\sim$ & - & $\sim$ \\
\hline Sowitio & 101 & 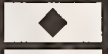 & 196 & 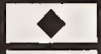 & r. & $\sim$ & 2 & $>$ & \% & $\sim$ & \% & $\sim$ & - & $\sim$ \\
\hline East & 243 & 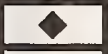 & 330 & 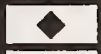 & 1 & $\Delta$ & 1. & $\sim$ & (1) & 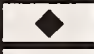 & 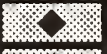 & $>$ & 8 & 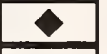 \\
\hline 1) & 188 & $>$ & 168 & 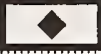 & 105 & 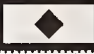 & \%. & $\sim$ & 310 & 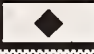 & 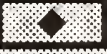 & $>$ & 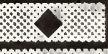 & 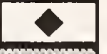 \\
\hline \multicolumn{15}{|c|}{ 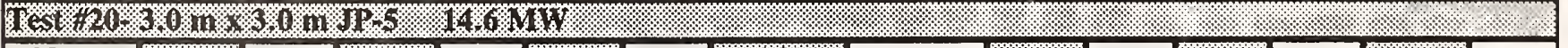 } \\
\hline North & 183 & 186 & 90 & 286 & $\sqrt[6]{6}$ & $\sim$ & 261 & $>$ & 2. & $\sim$ & 1. & $\sim$ & -1 & $\sim$ \\
\hline Som & 勧的 & 109 & 83 & 237 & \% & $\sim$ & $2 \%$ & $\gamma$ & צ- & $\sim$ & ( & $\sim$ & s. & $\sim$ \\
\hline East & 18 & 472 & $91 \%$ & 108 & 65 & 150 & \% & $\sim$ & 136 & 137 & 170 & 174 & 161 & 184 \\
\hline West & 10 & 137 & 91 . & 245 & 124 & 441 & . & $\sim$ & 137 & 546 & 149 & 558 & 195 & $\bullet$ \\
\hline
\end{tabular}

No heat detector at that location.

- Heat detector at that location did not activate. 


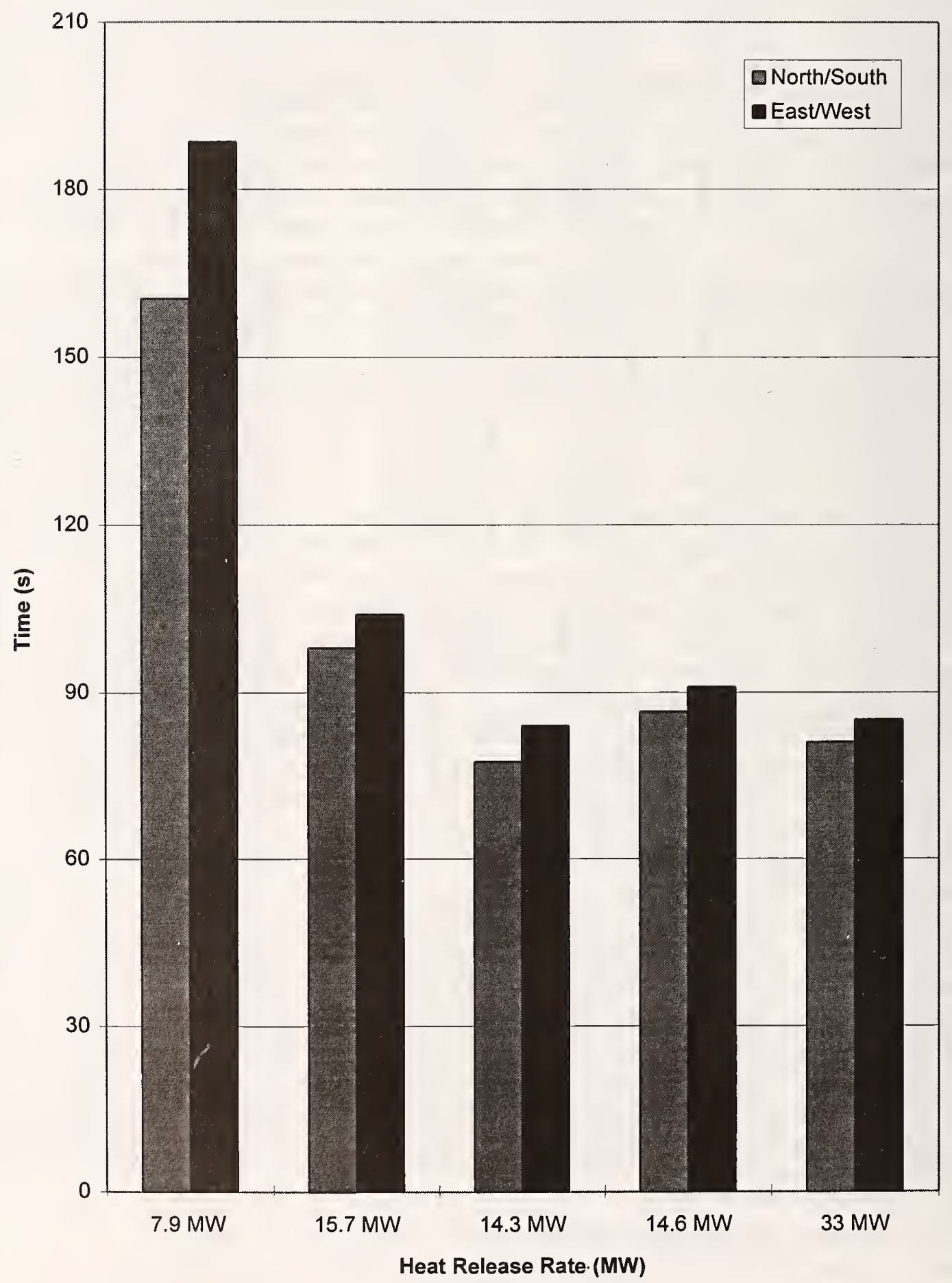

Figure 125. Comparison of $57{ }^{\circ} \mathrm{C}$ heat detectors located $6.1 \mathrm{~m}$ from the plume centerline to determine effect of curved ceiling in $22 \mathrm{~m}$ high facility. 


\section{Effect of Fuel Type}

A comparison of the heat detector response times for similar sized using JP-5 and JP-8 fuels, showed no significant difference in the response times of either the $57^{\circ} \mathrm{C}$ or $93{ }^{\circ} \mathrm{C}$ heat detectors.

\section{Effect of Spacing}

Figure 127 shows a comparison of both the $57{ }^{\circ} \mathrm{C}$ and $93{ }^{\circ} \mathrm{C}$ average heat detector response times at $3.1 \mathrm{~m}$ and $6.1 \mathrm{~m}$ from plume centerline. With the exception of the $7.9 \mathrm{MW}$ fire, the figure shows little or no difference between the response times of the detectors at $3.1 \mathrm{~m}$ or $6.1 \mathrm{~m}$ from the fire. (Note: the bar on Figure 127 which depicts the response time of the $93{ }^{\circ} \mathrm{C}$ detector at $6.1 \mathrm{~m}$ from the $7.9 \mathrm{MW}$ fire represents the response time of only one detector. Further analysis of Table 63 indicates that the detector was faulty. Consequently, the data should show no response of the $93{ }^{\circ} \mathrm{C}$ heat detector located $6.1 \mathrm{~m}$ from plume centerline in the $7.9 \mathrm{MW}$ fire.) This again indicates that a detector spacing of $12.2 \mathrm{~m}$ between detectors would be a suitable spacing for a $22 \mathrm{~m}$ hangar. Further analysis of Figure 127 also shows the difference in average response times between the $57^{\circ} \mathrm{C}$ and $93{ }^{\circ} \mathrm{C}$ heat detectors. For all the test fires under $33 \mathrm{MW}$, the average response time of the $93^{\circ} \mathrm{C}$ detectors was over twice as long as the response time of the $57^{\circ} \mathrm{C}$ detectors.

\section{Comparison of Heat Detector Response to Quick Response Sprinkler Heads}

To date, existing pre-action sprinklers in military aircraft hangars have been activated primarily by the use of rate-compensated heat detectors with a listed temperature rating of approximately $93{ }^{\circ} \mathrm{C}$. The existing closed head sprinklers have a temperature rating of $141{ }^{\circ} \mathrm{C}$. These tests indicate that $79{ }^{\circ} \mathrm{C}$ quick response automatic sprinklers should be used if the overhead sprinklers are to provide any cooling effects for aircraft adjacent to the fuel spill area. Hangars located in cold climates require the use of pre-action type sprinkler systems whose alarm valves (i.e., deluge valves) must be activated by a detection system. Consequently, if $79^{\circ} \mathrm{C}$ quick response sprinklers are to be used, it is important to select the appropriate temperature heat detectors in order to ensure activation of the deluge valves prior to the response of a large number of sprinkler heads. In most hangar fire protection designs, the optical flame detectors will also activate the deluge valves on the pre-action sprinkler risers. Nevertheless, it is still essential that the temperature rating of ceiling mounted spot-type heat detectors be closely matched to that of the closed-head sprinklers.

Figures 128 and 129 show the average response time comparison of the $57{ }^{\circ} \mathrm{C}$ and $93{ }^{\circ} \mathrm{C}$ heat detectors with the $79^{\circ} \mathrm{C}$ quick response sprinklers at $3.1 \mathrm{~m}$ and $6.1 \mathrm{~m}$ from plume centerline. Although the $57{ }^{\circ} \mathrm{C}$ heat detectors always activated prior to the $79{ }^{\circ} \mathrm{C}$ sprinklers, they are typically a poor choice for aircraft hangars because they will often activate during hot summer months. As shown in the figures, the $93{ }^{\circ} \mathrm{C}$ sprinklers responded after the sprinklers which is unacceptable. These figures suggest that the appropriate temperature rating for the heat detectors would be approximately in the $71{ }^{\circ} \mathrm{C}$ range.

\section{Open Door vs Closed Door}

A comparison of test 14 with tests 16 and 19 (all using $2.5 \mathrm{~m}$ diameter pan fires) can be used to investigate the effects that open hangar doors have on heat detector response. Both hangar doors were open in test 16 while only one hangar door was open in test 19 . Contrary to the response of the photoelectric smoke detectors, the open door experiments had longer heat detector response times than 


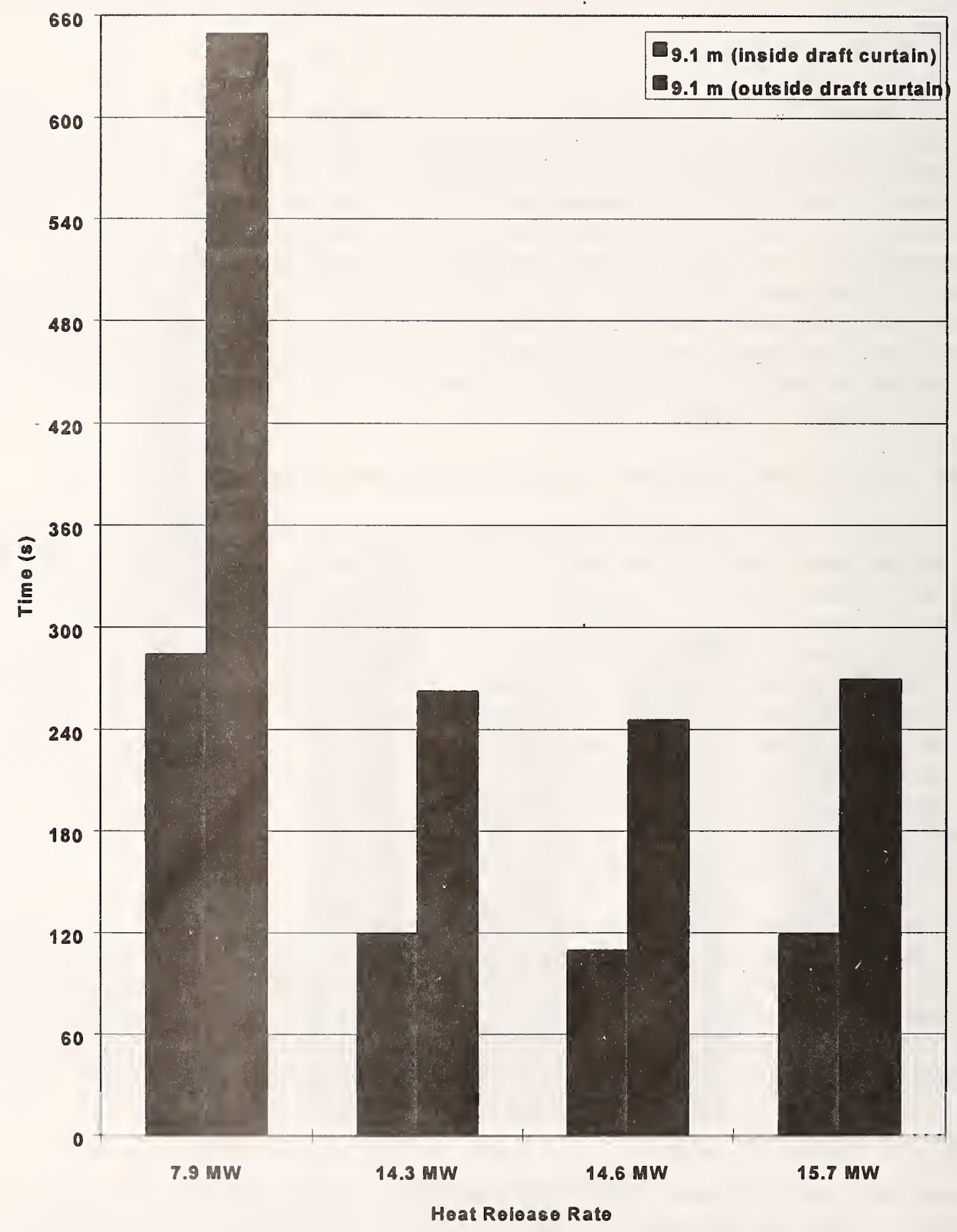

Figure 126. Effect of draft curtain on $57^{\circ} \mathrm{C}$ heat detector response time. 


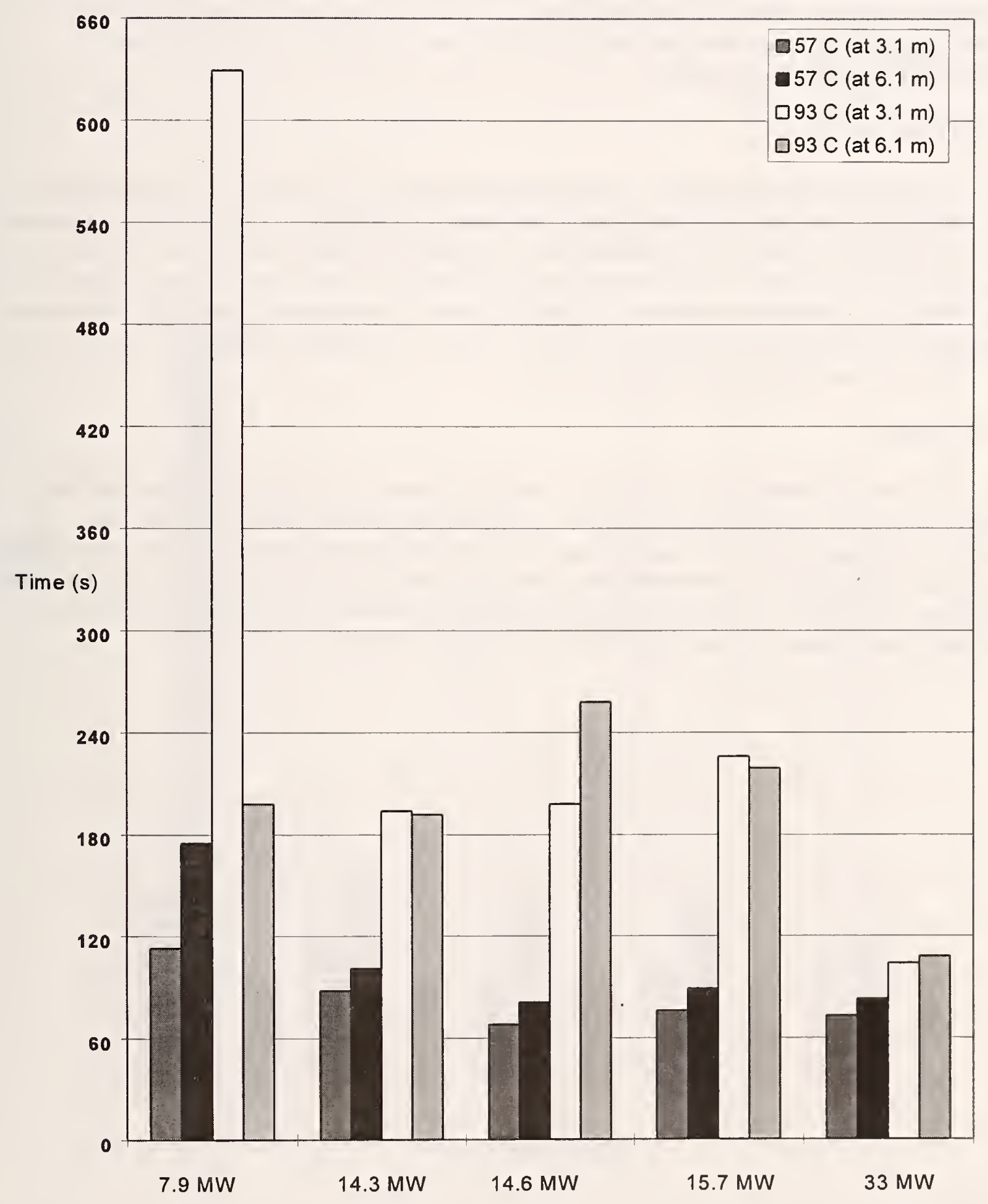

Figure 127. Comparison of response times of $57{ }^{\circ} \mathrm{C}$ and $93{ }^{\circ} \mathrm{C}$ heat detectors located at $3.1 \mathrm{~m}$ and $6.1 \mathrm{~m}$ from plume center. 
a similarly sized closed door experiment. For example, in test 14 , the average response time of the $57^{\circ} \mathrm{C}$ detectors located $3.1 \mathrm{~m}$ from the fire was $113 \mathrm{~s}$ compared to $146 \mathrm{~s}$ in test 16 and $207 \mathrm{~s}$ in test 19. In addition, none of the $93{ }^{\circ} \mathrm{C}$ detectors activated in either of the open door experiments, yet five of the higher temperature detectors activated in test 14 . A similar comparison using the $57^{\circ} \mathrm{C}$ detectors shows that all 18 detectors activated in test 14 , while tests 16 and 19 only activated 4 detectors and 10 detectors respectively.

\section{Effect of Ceiling Height}

Attempts to compare the heat detector response times between the $15 \mathrm{~m}$ and $22 \mathrm{~m}$ hangars for the purpose of analyzing the effects of ceiling height must also acknowledge the differences in ambient air and fuel temperatures, as well as the difference in the volume of the draft curtain areas. The typical ambient temperature for the $15 \mathrm{~m}$ hangar was about $29^{\circ} \mathrm{C}$ while it was about $11^{\circ} \mathrm{C}$ for the $22 \mathrm{~m}$ hangar. With those limitations understood, Figure 130 shows a comparison of the $57^{\circ} \mathrm{C}$ heat detector average response times for the experiments in the $15 \mathrm{~m}$ and $22 \mathrm{~m}$ hangars at distances of $3.1 \mathrm{~m}, 6.1 \mathrm{~m}$, and $9.1 \mathrm{~m}$ from plume center for comparable fire size.

\section{Effect of Fire Size}

Figure 131 shows the effects of fire size on the average response times of the $57^{\circ} \mathrm{C}$ heat detectors located $3.1 \mathrm{~m}$ and $6.1 \mathrm{~m}$ from plume centerline. As fire sizes increased above $14.3 \mathrm{MW}$, the difference in average heat detector response time at the two distances decreased. For example, Figure 131 shows the average detector response time to be approximately $68 \mathrm{~s}$ in the $14.3 \mathrm{MW}$ fire compared to $73 \mathrm{~s}$ in the $33 \mathrm{MW}$ fire. For these large fires the detection system is responding during the fire growth stage since it took between $50 \mathrm{~s}$ and $80 \mathrm{~s}$ for full-pan involvement to occur. 


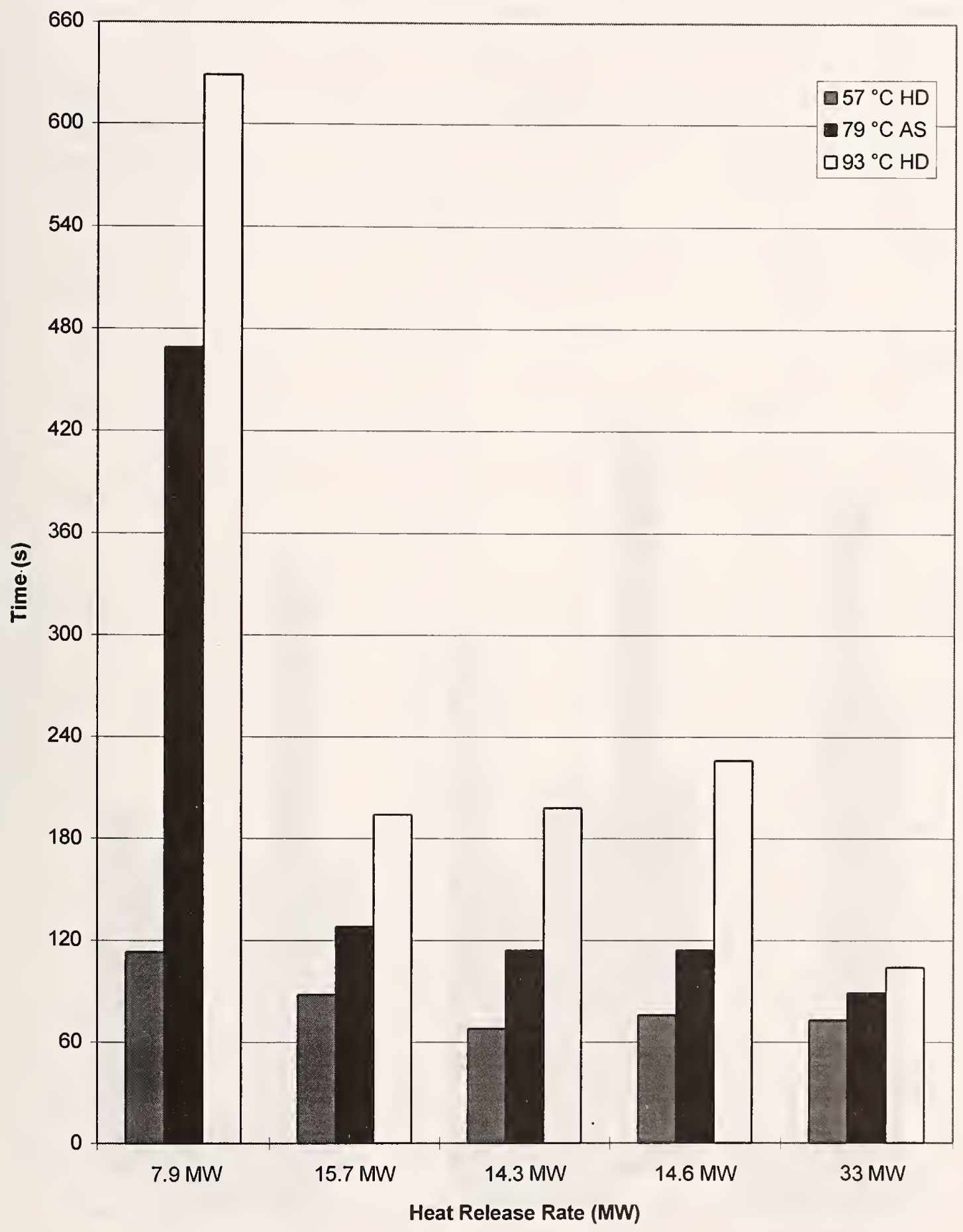

Figure 128. Activation time comparison of heat detectors to $79^{\circ} \mathrm{C}$ quick response sprinklers located $3.1 \mathrm{~m}$ from plume center for tests conducted in $22 \mathrm{~m}$ high facility. 


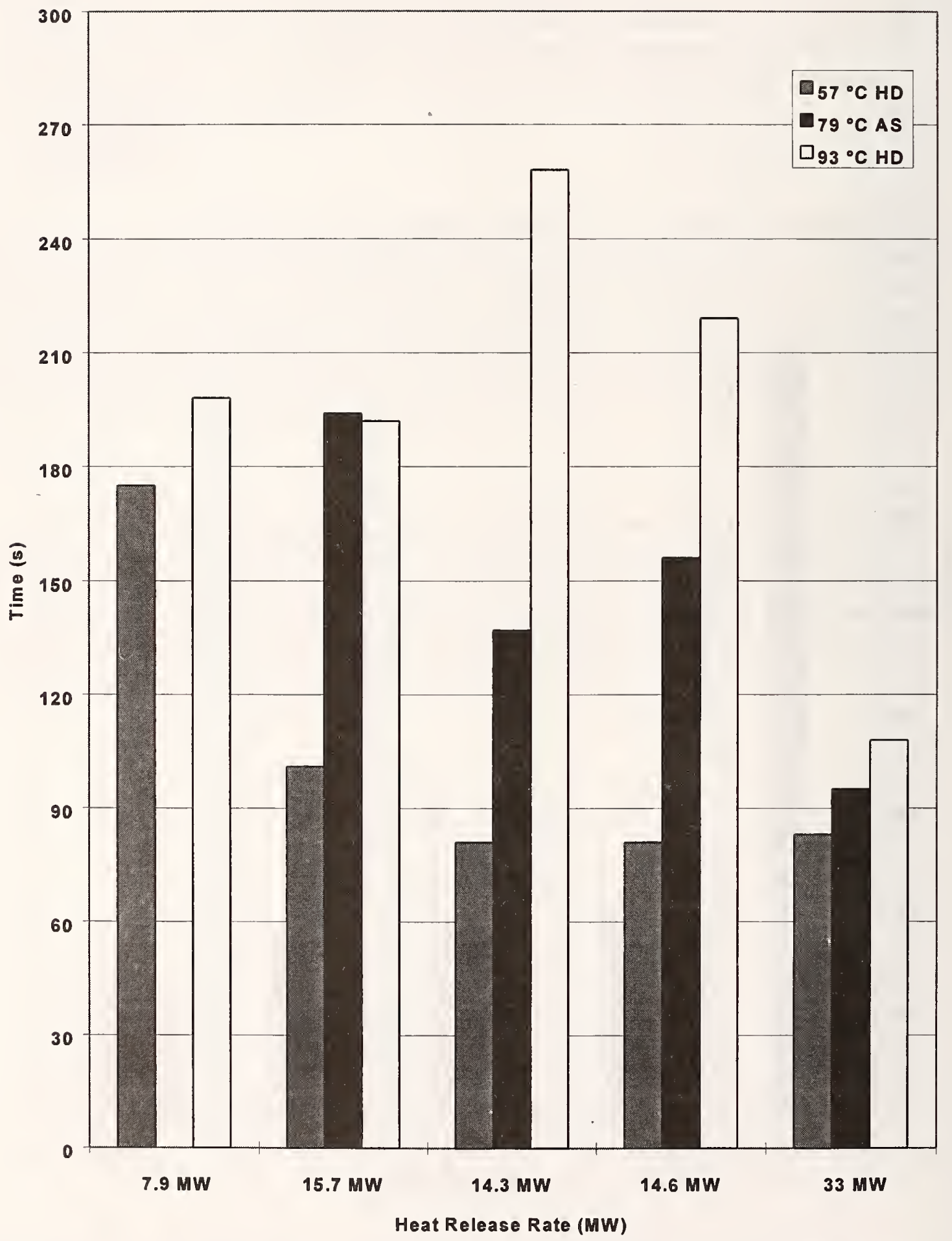

Figure 129. Activation time comparison of heat detectors to $79^{\circ} \mathrm{C}$ quick response sprinklers located $6.1 \mathrm{~m}$ from plume center. 


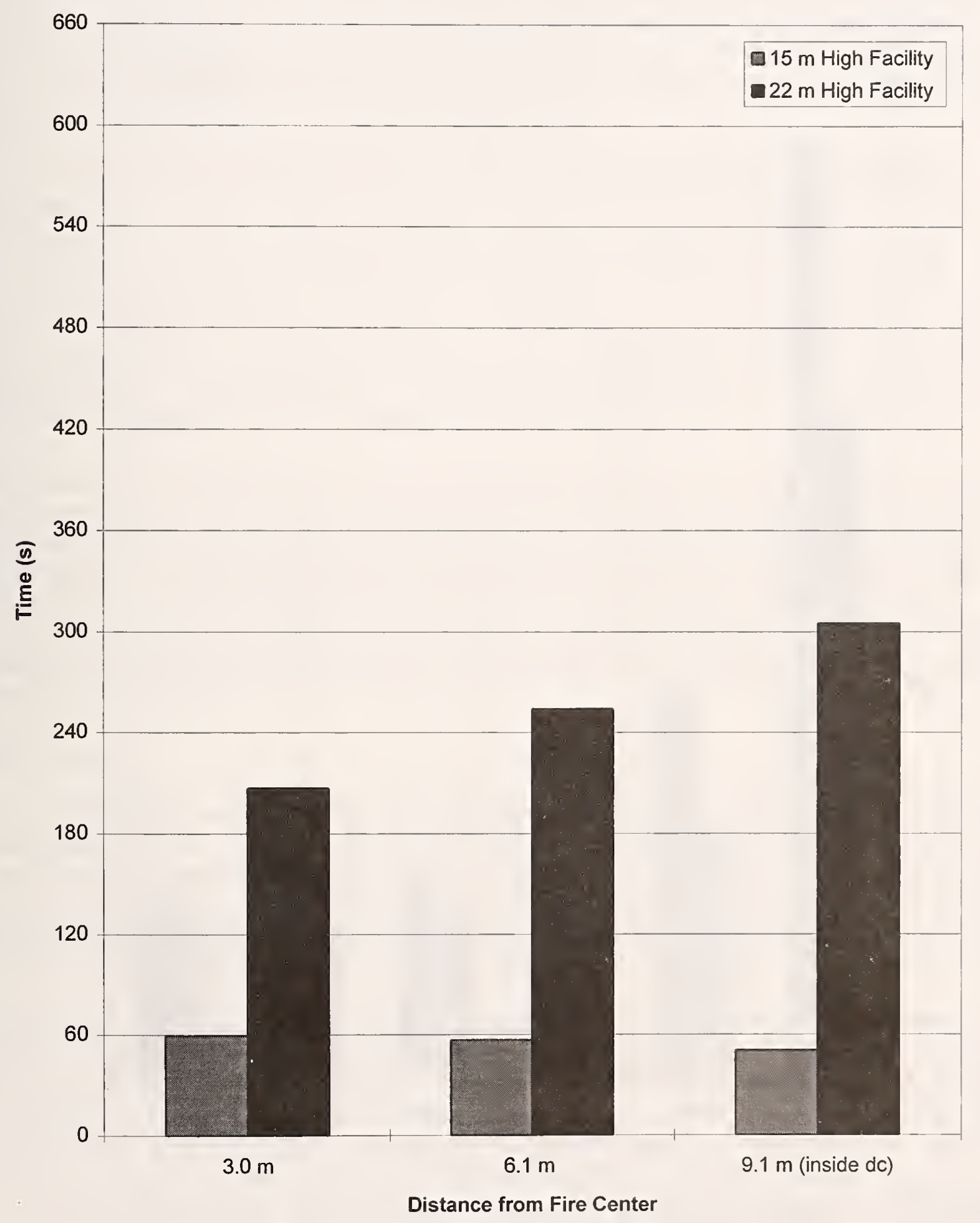

Figure 130. Average response times of $57^{\circ} \mathrm{C}$ heat detectors to $2.5 \mathrm{~m}$ diameter pan fires conducted in $15 \mathrm{~m}$ and $22 \mathrm{~m}$ high facilities. 


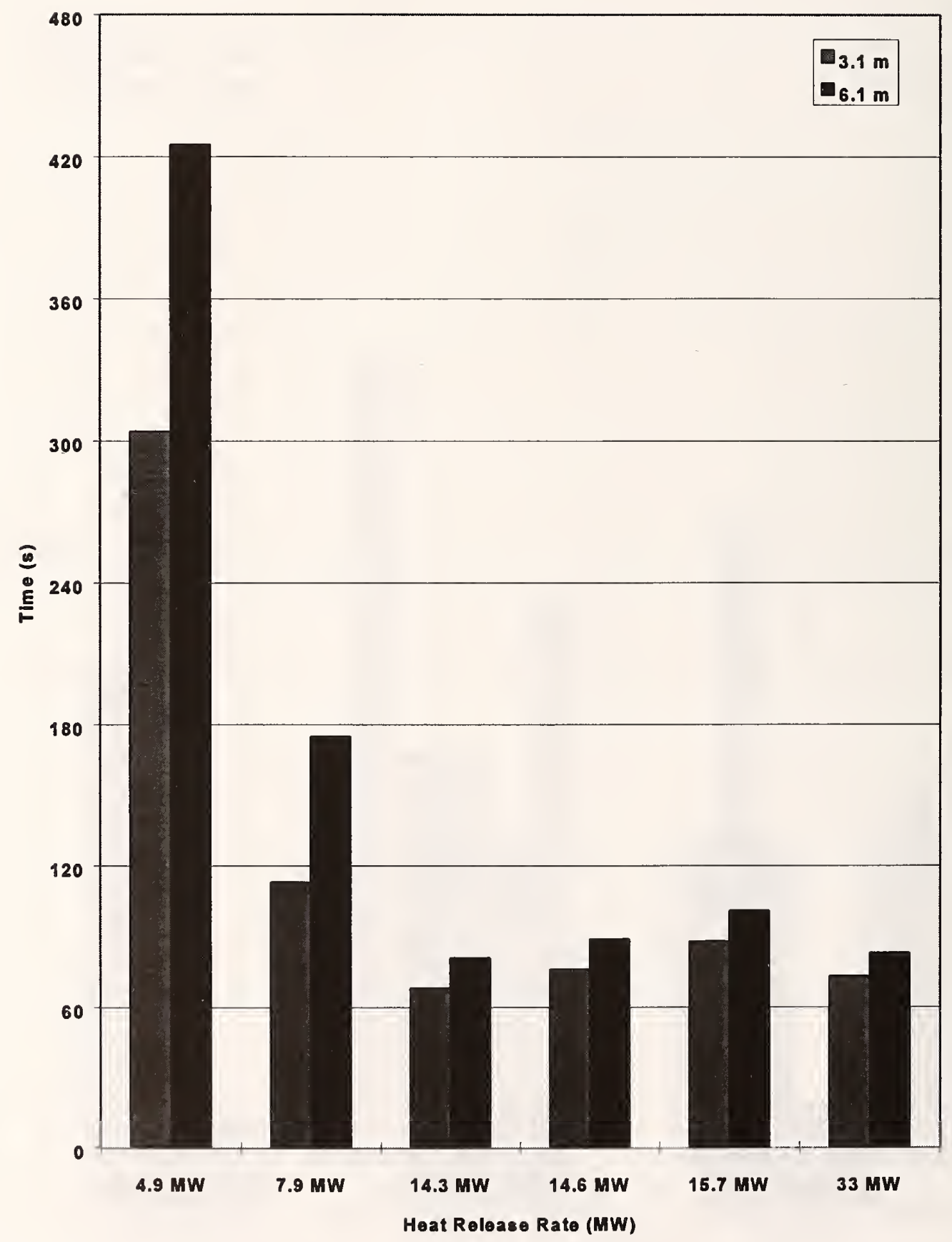

Figure 131. Effects of fire size on $57^{\circ} \mathrm{C}$ heat detector response for detectors located $3.1 \mathrm{~m}$ and $6.1 \mathrm{~m}$ from plume center in $22 \mathrm{~m}$ high facility. 


\subsubsection{Response of Optical Flame Detectors}

The settings, configuration and mounting height of the combination UV/IR optical detectors were discussed earlier in section 4 and the locations were shown schematically in Figure 59. The effects of ceiling height and draft curtains were not evaluated for these detectors because each detector was mounted approximately $2.44 \mathrm{~m}$ above the floor. The physical dimensions of the $22 \mathrm{~m}$ hangar permitted detectors to be located a maximum distance of $45.7 \mathrm{~m}$ from the fire center. The response thresholds of the optical flame detectors were determined for each test fire.

There are three significant facts regarding the controller settings and the physical location of the detectors that warrant further discussion. First, because the experiments included a variety of fire sizes, detectors were located in three different configurations. Second, the UV/IR controller settings were varied for the $0.3 \mathrm{~m} \mathrm{x} 0.3 \mathrm{~m}$ and $0.9 \mathrm{~m} \mathrm{x} 0.9 \mathrm{~m}$ pan fires. The main effect of changing the controller settings is to increase or decrease the detector's range. The controller setting of $0.25 \mathrm{~s}$ gate length, 2 counts per gate, and 3 consecutive gates $(0.25 / 2 / 3)$ requires a minimal signal strength of 6 counts occurring in $0.75 \mathrm{~s}$ to reach alarm state $(8 \mathrm{CPS})$. The controller setting of $0.25 \mathrm{~s}$ gate length, 4 counts per gate, and 4 consecutive gates $(0.25 / 4 / 4)$ requires a signal strength of $16 \mathrm{CPS}$ for one second to reach alarm state from both the UV and IR portions of the detector.

The third factor involves the manner in which the optical flame detectors were aimed during these tests. All experiments were conducted with the optical flame detectors positioned such that each detector had a direct line of sight to the fire source, with the fuel pan centered in each detector's cone of vision for optimum response. Consequently, these test results represent the best case response scenario for the optical detectors. Fires that occur within the detector's cone of vision, but not directly along the centerline axis will have slower response times and shorter threshold response distances. The response characteristics will decrease proportionally as the viewing angle increases towards the maximum listed viewing angle of the detector.

\section{General Analysis}

The raw CPS data files compiled by Detector Electronics Corporation were examined for response time from three distinct events. These events are ignition, full pan involvement, and steady state burning. The determination of response time to these three events yields a representation of threshold response distances to a variety of fire sizes, at various stages of fire growth. The data is presented in this format to aid design engineers in determining when and at what distance these optical detectors will respond to a growing fire in an aircraft hangar.

For the purpose of analyzing this data, ignition is defined as that time that self-sustained combustion was achieved. Full pan involvement was determined by visual observation, and was considered to be the time at which the flame front completely covered the fuel surface. The time to steady state burning was calculated using the mass loss measurements recorded by the load cell. Where load cell data was not available, a conservative estimate of the time to steady state burning was made based on similar size fires and by analyzing the steady state infrared signature recorded by the optical detectors.

The response times from ignition are listed in Table 64 for JP- 5 fueled fires and Table 65 for JP- 8 fueled fires. Tables 64 and 65 show pan size, heat release rate (HRR), controller settings, time to full pan involvement from ignition, time to steady state burning from ignition. 
During each experiment all of the UV/IR detectors were repeatedly reset at various times during the test. The purpose of these resets was to obtain response time data at various stages of the fire (i.e., from ignition, full pan involvement from ignition, and steady state burning from ignition). Tables 66 and 67 show the response times corresponding to the first two manual resets after full pan involvement. Times associated with each reset represents elapsed time from ignition. Tables 66 and 67 also show pan size, HRR, controller settings, time to full pan involvement from ignition, and time to steady state burning from ignition. In most cases the manual resets occurred after most or all detectors had responded, or changes had stopped occurring. The average time between resets ranged from $10 \mathrm{~s}$ to $30 \mathrm{~s}$. The minimum response time from reset for any detector was $0.3 \mathrm{~s}$, corresponding to the time it takes to actually reset the controller. The number of resets analyzed after achieving full pan involvement and steady state burning reflects the lowest common denominator (i.e., number of resets) for the vast majority of experiments. In most cases, response time results for full pan and steady state conditions were taken from the first two manual resets that occurred after these conditions were reached.

The response times from manual reset after steady state burning are listed in Tables 68 and 69 for JP-5 and JP-8 fueled fires respectively. Tables 68 and 69 also show pan size, HRR, controller settings, time to full pan involvement from ignition, time to steady state burning from ignition. As with the response times from full pan involvement, the response time of each detector was determined from a manual reset during the period of steady state burning.

\section{Threshold Response Distances at Selected Response Times}

Threshold response distances from ignition, full pan involvement and steady state burning were examined at response times of $5,10,20,30$, and $45 \mathrm{~s}$. Table 70 shows the threshold response distances of the optical detectors for each fire size as a function of these selected response times. For example, if the threshold response distance from ignition for the $0.8 \mathrm{MW}$ fire in test 4 is shown as 45.7 $\mathrm{m}$ at $30 \mathrm{~s}$, that means that $45.7 \mathrm{~m}$ was the maximum distance at which an optical detector responded within $30 \mathrm{~s}$ for that fire test. (Note that $45.7 \mathrm{~m}$ was the maximum distance that the detector could be located from the fire center within the hangar. The actual usable distance for this type of detector may exceed this value.) These times were selected to indicate the maximum affective response "distance" at which the detectors responded within a number of response time intervals.

It is believed that the existing testing and approval criteria for optical flame detectors should be reevaluated. It has been primarily based on two sets of acceptance criteria. First, the Navy and Air

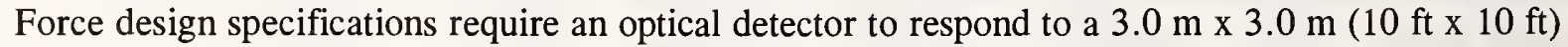
steady state JP-4 fire within $5 \mathrm{~s}$. Factory Mutual requires an optical detector to respond to a $1.5 \mathrm{~m} \mathrm{x}$ $1.5 \mathrm{~m}$ steady state JP-4 fire within $10 \mathrm{~s}$. Based on those requirements, the actual voluntary tests standards which the industry has developed over the years identify the following response distance thresholds:

\section{Fire Size}

$0.3 \mathrm{~m} \times 0.3 \mathrm{~m}(1 \mathrm{ft} \times 1 \mathrm{ft})$

$0.6 \mathrm{~m} \times 0.6 \mathrm{~m}(2 \mathrm{ft} \times 2 \mathrm{ft})$

$3.0 \mathrm{~m} \times 3.0 \mathrm{~m}(10 \mathrm{ft} \times 10 \mathrm{ft})$
Response Distance Threshold

$16.4 \mathrm{~m}(50 \mathrm{ft})$

$32.8 \mathrm{mi}(100 \mathrm{ft})$

$49.2 \mathrm{~m}(150 \mathrm{ft})$ 
Table 64. UV/IR response times for JP-5 test fires conducted in $22 \mathrm{~m}$ high facility

\begin{tabular}{|c|c|c|c|c|c|c|c|c|c|c|c|c|c|}
\hline PAN SIZE (m) & FACILITY & HRR (MW) & TEST No. & & DET & ETOR & DISTA & CEE FI & OM SC & JRCE & ENTE & (m) & \\
\hline $0.3 \times 0.3$ & $22 \mathrm{~m}$ & 0.09 & 1. & 9.1 & 107 & 12.2 & 13.7 & 15.2 & 16.8 & 18.3 & 21.3 & 30.5 & 45.7 \\
\hline Controller: & $.25 / 2 / 3$ & Respor & nse Time (s) & 4.9 & 15 & 17 & 16 & 28 & 29 & NR & NR & NR & NR \\
\hline Full Pan: & $2 \mathrm{~s}$ & St. State: & $110 \mathrm{~s}$ & & & & & & & & & & \\
\hline $0.3 \times 0.3$ & $22 \mathrm{~m}$ & 0.08 & 2 & 9.1 & 10.7 & 12,2 & 137 & 15.2 & 16.8 & 18.3 & 21.3 & 30.5 & 45.7 \\
\hline Controller: & $.25 / 2 / 3$ & Respor & nse Time (s) & 2.6 & 6.9 & 10 & 10 & 19 & 25 & 40 & NR & NR & NR \\
\hline Full Pan: & $2 \mathrm{~s}$ & St. State: & $150 \mathrm{~s}$ & & & & & & & & & & \\
\hline $0.6 \times 0.6$ & $22 \mathrm{~m}$ & 0.93 & 3 & $21: 3$ & 22.9 & 24.4 & 25.9 & 27.4 & 30.5 & 33.5 & 36.6 & 39.6 & 45.7 \\
\hline Controller: & $.25 / 2 / 3$ & Respor & nse Time (s) & 22 & 23 & 23 & 26 & 25 & 28 & 29 & 50 & NR & NR \\
\hline Full Pan: & $15 \mathrm{~s}$ & St. State: & $120 \mathrm{~s}$ & & & & & & & & & & \\
\hline $0.6 \times 0.6$ & $22 \mathrm{~m}$ & 0.77 & 4 & $21: 3$ & 22.9 & 24.4 & 25.9 & 27.4 & 30.5 & 33.5 & 36.6 & 39.6 & 45.7 \\
\hline Controller: & $.25 / 2 / 3$ & Respor & nse Time (s) & 16 & 16 & 25 & 35 & 26 & 37 & 38 & 44 & 59 & 62 \\
\hline Full Pan: & $15 \mathrm{~s}$ & St. State: & $125 \mathrm{~s}$ & & & & & & & & & & \\
\hline $0.9 \times 0.9$ & $22 \mathrm{~m}$ & 1.69 & 5 & 21.3 & 24,4 & 25.9 & 27.4 & 30.5 & 33.5 & 36.6 & 39.6 & 42.7 & 45.7 \\
\hline Controller: & $.25 / 2 / 3$ & Respor & nse Time (s) & 15 & 18 & 20 & 16 & 21 & 24 & 28 & 28 & 31 & 28 \\
\hline Full Pan: & $20 \mathrm{~s}$ & St. State: & $90 \mathrm{~s}$ & & & & & & & & & & \\
\hline $0.9 \times 0.9$ & $22 \mathrm{~m}$ & 1.39 & 6 & 21.3 & 24.4 & 25.9 & 27.4 & 30.5 & 33.5 & 36.6 & 39.6 & 42.7 & 45.7 \\
\hline Controller: & $.25 / 4 / 4$ & Respor & nse Time (s) & 23 & 34 & 35 & 34 & 37 & 39 & 43 & 56 & 56 & 56 \\
\hline Full Pan: & $20 s$ & St. State: & $120 \mathrm{~s}$ & & & & & & & & & & \\
\hline $1.2 \times 1.2$ & $22 \mathrm{~m}$ & 2.81 & 7 & 21.3 & 24.4 & 25.9 & 27.4 & 30.5 & 33.5 & 36.6 & 39.6 & 42.7 & 45,7 \\
\hline Controller: & $.25 / 4 / 4$ & Respor & nse Time (s) & 25 & 29 & 27 & 27 & 34 & 36 & 39 & 47 & 48 & 54 \\
\hline Full Pan: & $30 \mathrm{~s}$ & St. State: & $150 \mathrm{~s}$ & & & & & & & & & & \\
\hline 2.0 Dia & $22 \mathrm{~m}$ & 4.92 & 18 & 21.3 & 24.4 & 25.9 & 27.4 & 30.5 & 33.5 & 36.6 & 39.6 & 42.7 & 45.7 \\
\hline Controller: & $.25 / 4 / 4$ & Respor & nse Time (s) & 40 & 41 & 41 & 41 & 41 & 41 & 49 & 55 & 55 & 55 \\
\hline Full Pan: & $40 \mathrm{~s}$ & St. State: & $180 \mathrm{~s}$ & & & & & & & & & & \\
\hline $2.5 \mathrm{Dia}$ & $22 \mathrm{~m}$ & 7.86 & 14 & $21: 3$ & 24.4 & 25.9 & 27.4 & 30.5 & 33.5 & 36.6 & 39.6 & 42.7 & 45.7 \\
\hline Controller: & $.25 / 4 / 4$ & Respor & nse Time (s) & 26 & 33 & 33 & 33 & 38 & 37 & 39 & 48 & 46 & 46 \\
\hline Full Pan: & $50 \mathrm{~s}$ & St. State: & $120 \mathrm{~s}$ & & & & & & & & & & \\
\hline 2.5 Dia & $22 \mathrm{~m}$ & 7. & 16 & 21.3 & 24.4 & 25.9 & 27.4 & 30.5 & 33.5 & 36.6 & 39.6 & 42.7 & 45.7 \\
\hline Controller: & $.25 / 4 / 4$ & Respor & nse Time (s) & 31 & 31 & 32 & 31 & 35 & 35 & 35 & 45 & 47 & 45 \\
\hline Full Pan: & $50 \mathrm{~s}$ & St. State: & $180 \mathrm{~s}$ & & & & & & & & & & \\
\hline $2.5 \mathrm{Dia}$ & $22 \mathrm{~m}$ & 9.13 & 19 & 21.3 & 24.4 & 25.9 & 27.4 & 30.5 & 33.5 & 36.6 & 39.6 & 42.7 & 45.7 \\
\hline Controller: & $.25 / 4 / 4$ & Respor & nse Time (s) & 30 & 33 & 33 & 33 & 44 & 43 & 44 & 50 & 50 & 50 \\
\hline Full Pan: & $50 \mathrm{~s}$ & St. State: & $120 \mathrm{~s}$ & & & & & & & & & & \\
\hline $3.0 \times 3.0$ & $22 \mathrm{~m}$ & 15.73 & 15 & 21,3 & 24.4 & 25.9 & 27.4 & 30.5 & 33.5 & 36.6 & 39.6 & 42.7 & 45.7 \\
\hline Controller: & $.25 / 4 / 4$ & Respor & nse Time (s) & 15 & 18 & 20 & 20 & 26 & 29 & 30 & 37 & 36 & 41 \\
\hline Full Pan: & $65 \mathrm{~s}$ & St. State: & $330 \mathrm{~s}$ & & & & & & & & & & \\
\hline $3.0 \times 3.0$ & $22 \mathrm{~m}$ & 14.6 & 20 & 21,3 & 24.4 & 25.9 & 27.4 & 30.5 & 33.5 & 36.6 & 39.6 & 42.7 & 45.7 \\
\hline Controller: & $.25 / 4 / 4$ & Respor & nse Time (s) & 23 & 29 & 29 & 29 & 32 & 34 & 37 & 37 & 41 & 44 \\
\hline Full Pan: & $65 \mathrm{~s}$ & St. State: & $240 \mathrm{~s}$ & & & & & & & & & & \\
\hline $4.6 \times 4.6$ & $22 \mathrm{~m}$ & $\Omega / a$ & 21 & 21,3 & 24.4 & 25.9 & 27.4 & 30.5 & 33.5 & 36.6 & 39.6 & 42.7 & 45.7 \\
\hline Controller: & $.25 / 4 / 4$ & Respo & nse Time (s) & 23 & 28 & 27 & 27 & 37 & 38 & 41 & 46 & 45 & 45 \\
\hline Full Pan: & $80 \mathrm{~s}$ & St. State: & $\mathrm{n} / \mathrm{a}$ & & & & & & & & & & \\
\hline $\begin{aligned} \text { NOTE: Respons } \\
\\
\text { or from } \\
\text { Full Pan } \\
\end{aligned}$ & $\begin{array}{l}\text { times are me } \\
\text { a controller re } \\
\text { and Steady St }\end{array}$ & easured in refe & $\begin{array}{l}\text { rence to elaps } \\
\text { and steady s } \\
\text { he time to re: }\end{array}$ & $\begin{array}{l}\text { sed tim } \\
\text { state res } \\
\text { ach that }\end{array}$ & $\begin{array}{l}\text { from " } \\
\text { ponses. } \\
\text { respect }\end{array}$ & ne ze & (mark & ne) fo & gnitio & espor & & & \\
\hline
\end{tabular}


Table 65. UV/IR response times for JP-8 test fires conducted in $22 \mathrm{~m}$ high facility

\begin{tabular}{|c|c|c|c|c|c|c|c|c|c|c|c|c|c|}
\hline \multirow{2}{*}{$\begin{array}{c}\begin{array}{c}\text { PAN SIZE } \\
(\mathbf{m})\end{array} \\
0.3 \times 0.3 \\
\end{array}$} & \multirow{2}{*}{$\begin{array}{c}\text { FACILITY } \\
22 \mathrm{~m} \\
\end{array}$} & \multirow{2}{*}{ HRR (MW) } & \multirow{2}{*}{ TEST No. } & \multicolumn{10}{|c|}{ DETECTOR DISTANCE FROM SOURCE CENTER (m) } \\
\hline & & & & 9.14 & 10.67 & 12.2 & 13.7 & 15.2 & 16.8 & 18.3 & 21.3 & 30.5 & 45.7 \\
\hline Controller: & $.25 / 4 / 4$ & \multicolumn{2}{|c|}{ Response Time (s) } & 25.6 & 43.6 & 44.1 & 59.8 & 74.6 & NR & NR & NR & NR & NR \\
\hline Full Pan: & $2 \mathrm{~s}$ & St. State: & \multicolumn{2}{|c|}{$120 \mathrm{~s}$} & & & & & & & & & \\
\hline $0.6 \times 0.6$ & $22 \mathrm{~m}$ & 0.6 & 10 & 21.3 & 24.38 & 25.9 & 27.4 & 30.5 & 33.5 & 36.6 & 39.6 & 42.7 & 45.7 \\
\hline Controller: & $.25 / 2 / 3$ & \multicolumn{2}{|c|}{ Response Time (s) } & 11.5 & 17 & 18.5 & 21.8 & 18.5 & 34.7 & 36.2 & 36.4 & NR & NR \\
\hline Full Pan: & $15 \mathrm{~s}$ & St. State: & \multicolumn{2}{|c|}{$120 \mathrm{~s}$} & & & & & & & & & \\
\hline $0.6 \times 0.6$ & $22 \mathrm{~m}$ & 0.77 & 11 & 21.3 & 24.38 & 25.9 & 27.4 & 30.5 & 33.5 & 36.6 & 39.6 & 42.7 & 45.7 \\
\hline Controller: & $.25 / 2 / 3$ & \multicolumn{2}{|c|}{ Response Time (s) } & 20.8 & 22.8 & 27.1 & 32.4 & 23.3 & 38.8 & 39.2 & 48.3 & 54 & NR \\
\hline Full Pan: & $15 \mathrm{~s}$ & St. State: & \multicolumn{2}{|c|}{$120 \mathrm{~s}$} & & & & & & & & & \\
\hline $0.9 \times 0.9$ & $22 \mathrm{~m}$ & 1.62 & 12 & 21.3 & 24.38 & 25.9 & 27.4 & 30.5 & 33.5 & 36.6 & 39.6 & 42.7 & 45.7 \\
\hline Controller: & $.25 / 2 / 3$ & \multicolumn{2}{|c|}{ Response Time (s) } & 18.2 & 21.1 & 25.4 & 20.9 & 29.8 & 32 & 34.8 & 35.3 & 35.2 & 35.1 \\
\hline Full Pan: & $20 \mathrm{~s}$ & St. State: & \multicolumn{2}{|l|}{$180 \mathrm{~s}$} & & & & & & & & & \\
\hline $1.2 \times 1.2$ & $22 \mathrm{~m}$ & 2.65 & 13 & 21.3 & 24.38 & 25.9 & 27.4 & 30.5 & 33.5 & 36.6 & 39.6 & 42.7 & 45.7 \\
\hline Controller: & $.25 / 4 / 4$ & \multicolumn{2}{|c|}{ Response Time (s) } & 24.1 & 25.1 & 32.1 & 24.6 & 32.6 & 32.9 & 39.2 & 49.4 & 50.1 & 49.5 \\
\hline Full Pan: & $30 \mathrm{~s}$ & St. State: & \multicolumn{2}{|c|}{$120 \mathrm{~s}$} & & & & & & & & & \\
\hline $3.0 \times 3.0$ & $22 \mathrm{~m}$ & 14.3 & 17 & 21.3 & 24.38 & 25.9 & 27.4 & 30.5 & 33.5 & 36.6 & 39.6 & 42.7 & 45.7 \\
\hline Controller: & $.25 / 4 / 4$ & \multicolumn{2}{|c|}{ Response Time (s) } & 16.4 & 22.7 & 23.2 & 22.9 & 27.3 & 26 & 28.2 & 33.5 & 30.6 & 40.4 \\
\hline Full Pan: & $50 \mathrm{~s}$ & St. State: & $270 \mathrm{~s}$ & & & & & & & & & & \\
\hline
\end{tabular}


Table 66. UV/IR response times corresponding to first two manual resets after full pan involvement for JP-5 test fires conducted in $22 \mathrm{~m}$ high facility

\begin{tabular}{|c|c|c|c|c|c|c|c|c|c|c|c|c|c|}
\hline \multirow{2}{*}{$\begin{array}{c}\begin{array}{c}\text { PAN SIZE } \\
(\mathrm{m})\end{array} \\
0.3 \times 0.3 \\
\end{array}$} & \multirow{2}{*}{$\begin{array}{c}\text { FACILITY } \\
22 \mathrm{~m} \\
\end{array}$} & \multirow{2}{*}{$\frac{\text { HRR (MW) }}{0.09}$} & \multirow{2}{*}{$\frac{\text { TEST No. }}{1}$} & \multicolumn{10}{|c|}{ DETECTOR DISTANCE FROM SOURCE CENTER (m) } \\
\hline & & & & 9.14 & 10.67 & 12.2 & 13.7 & 15.2 & 16.8 & 18.3 & 21.3 & 30.5 & 45.7 \\
\hline 1 st Reset & $56.5 \mathrm{~s}$ & Response & Time (s) & 0.3 & 0.3 & 0.3 & 0.3 & 0.3 & 0.8 & 1 & NR & NR & NR \\
\hline 2nd Reset & $72.1 \mathrm{~s}$ & & & 0.3 & 0.3 & 0.3 & 0.3 & 0.3 & 0.3 & 9.1 & NR & NR & NR \\
\hline Controller: & $.25 / 2 / 3$ & & & & & & & & & & & & \\
\hline Full Pan: & $2 \mathrm{~s}$ & St. State: & $110 \mathrm{~s}$ & & & & & & & & & & \\
\hline $0.3 \times 0.3$ & $22 \mathrm{~m}$ & 0.08 & 2 & 9.14 & 10.67 & 12.2 & 13.7 & 15.2 & 16.8 & 18.3 & 21.3 & 30.5 & $\overline{45.7}$ \\
\hline 1 st Reset & $70.6 \mathrm{~s}$ & Response & Time (s) & 0.3 & 0.3 & 0.3 & 0.3 & 0.3 & 0.8 & 2.3 & 2.5 & NR & $\overline{N R}$ \\
\hline 2nd Reset & $93.1 \mathrm{~s}$ & & & 0.3 & 0.3 & 0.3 & 0.3 & 0.6 & 0.8 & 0.8 & 4.1 & NR & NR \\
\hline Controller: & $.25 / 2 / 3$ & & & & & & & & & & & & \\
\hline Full Pan: & $2 \mathrm{~s}$ & St. State: & $150 \mathrm{~s}$ & & & & & & & & & & \\
\hline $0.6 \times 0.6$ & $22 \mathrm{~m}$ & 0.93 & \begin{tabular}{l|l}
3 \\
\end{tabular} & 21.3 & 22.86 & 24.4 & 25.9 & 27.4 & 30.5 & 33.5 & 36.6 & 39.6 & $\overline{45.7}$ \\
\hline 1st Reset & $67.7 \mathrm{~s}$ & Response & ime (s) & 0.3 & 0.3 & 0.3 & 0.3 & 0.3 & 1.9 & 1.1 & 4.1 & NR & NR \\
\hline 2nd Reset & $81.3 \mathrm{~s}$ & & & 0.3 & 0.3 & 0.3 & 0.3 & 0.3 & 1.8 & 0.3 & 0.8 & NR & NR \\
\hline Controller: & $.25 / 2 / 3$ & & & & & & & & & & & & \\
\hline Full Pan: & $15 \mathrm{~s}$ & St. State: & $120 \mathrm{~s}$ & & & & & & & & & & \\
\hline $0.6 \times 0.6$ & $22 \mathrm{~m}$ & 0.77 & \begin{tabular}{l|l|}
4 \\
\end{tabular} & $21: 3$ & 22.86 & 24.4 & 25.9 & 27.4 & 30.5 & 33.5 & 36.6 & $\overline{39.6}$ & 45.7 \\
\hline 1st Reset & $76.4 \mathrm{~s}$ & Response & Time (s) & 0.3 & 0.3 & 0.3 & 0.3 & 0.3 & 0.3 & 0.3 & 0.3 & 1.1 & 1.1 \\
\hline 2nd Reset & $95.3 \mathrm{~s}$ & & & 0.3 & 0.3 & 0.3 & 0.3 & 0.3 & 0.3 & 0.3 & 0.3 & 6.8 & NR \\
\hline Controller: & $.25 / 2 / 3$ & & & & & & & & & & & & \\
\hline Full Pan: & $15 \mathrm{~s}$ & St. State: & $125 \mathrm{~s}$ & & & & & & & & & & \\
\hline $0.9 \times 0.9$ & $22 \mathrm{~m}$ & 1.69 & \begin{tabular}{l|l|}
5 &
\end{tabular} & 21.3 & 24.38 & 25.9 & 27.4 & 30.5 & 33.5 & 36.6 & 39.6 & 42.7 & $\overline{45.7}$ \\
\hline 1st Reset & $60.2 \mathrm{~s}$ & Response & ime (s) & 0.3 & 0.3 & 0.3 & 0.3 & 0.3 & 0.3 & 0.3 & 0.3 & 0.3 & 0.3 \\
\hline 2nd Reset & $74.8 \mathrm{~s}$ & & & 0.3 & 0.3 & 0.3 & 0.3 & 0.3 & 0.3 & 0.3 & 0.3 & 0.3 & 0.3 \\
\hline Controller: & $.25 / 2 / 3$ & & & & & & & & & & & & \\
\hline Full Pan: & $20 \mathrm{~s}$ & St. State: & $90 \mathrm{~s}$ & & & & & & & & & & \\
\hline $0.9 \times 0.9$ & $22 \mathrm{~m}$ & 1.39 & 6 & 21.3 & 24.38 & 25.9 & 27.4 & 30.5 & 33.5 & 36.6 & 39.6 & 42.7 & 45.7 \\
\hline 1st Reset & $96 \mathrm{~s}$ & Response & ime $(s)$ & 0.3 & 0.3 & 0.3 & 0.3 & 0.3 & 0.3 & 0.3 & 0.3 & 0.3 & 1.9 \\
\hline 2nd Reset & $117.2 \mathrm{~s}$ & & & 0.3 & 0.3 & 0.3 & 0.3 & 0.3 & 0.3 & 0.3 & 1.1 & 4.6 & 4.6 \\
\hline Controller: & $.25 / 4 / 4$ & & & & & & & & & & & & \\
\hline Full Pan: & $20 \mathrm{~s}$ & St. State: & $120 \mathrm{~s}$ & & & & & & & & & & \\
\hline $1.2 \times 1.2$ & $22 \mathrm{~m}$ & 2.81 & \begin{tabular}{l|l}
7 \\
\end{tabular} & 21.3 & 24.38 & 25.9 & 27.4 & 30.5 & 33.5 & 36.6 & 39.6 & 42.7 & $\overline{45.7}$ \\
\hline 1st Reset & $62.7 \mathrm{~s}$ & Response & Time (s) & 0.3 & 0.3 & 0.3 & 0.3 & 0.3 & 0.3 & 0.3 & 0.3 & 0.3 & 0.3 \\
\hline 2nd Reset & $79.5 \mathrm{~s}$ & & & 0.3 & 0.3 & 0.3 & 0.3 & 0.3 & 0.3 & 0.3 & 0.5 & 0.5 & 0.5 \\
\hline Controller: & $.25 / 4 / 4$ & & & & & & & & & & & & \\
\hline Full Pan: & $30 \mathrm{~s}$ & St. State: & $150 \mathrm{~s}$ & & & & & & & & & & \\
\hline 2.0. Dia & $22 \mathrm{~m}$ & 4.92 & 18 & 21.3 & 24.38 & 25.9 & 27.4 & 30.5 & 33.5 & 36.6 & 39.6 & 42.7 & $\overline{45.7}$ \\
\hline 1 st Reset & $79.5 \mathrm{~s}$ & Response & Time (s) & 0.3 & 0.3 & 0.3 & 0.3 & 0.3 & 0.3 & 0.3 & 1.8 & 0.3 & 3.1 \\
\hline 2nd Reset & $95.4 \mathrm{~s}$ & & & 0.3 & 0.3 & 0.3 & 0.3 & 0.3 & 0.3 & 0.3 & 0.3 & 0.3 & 0.3 \\
\hline Controller: & $.25 / 4 / 4$ & & & & & & & & & & & & \\
\hline Full Pan: & $40 s$ & St. State: & $180 \mathrm{~s}$ & & & & & & & & & & \\
\hline $2.5 \mathrm{Dia}$ & $22 \mathrm{~m}$ & 7.86 & 14 & 21.3 & 24.38 & 25.9 & 27.4 & 30.5 & 33.5 & 36.6 & 39.6 & 42.7 & 45.7 \\
\hline 1st Reset & $58.4 \mathrm{~s}$ & Response & Time (s) & 0.3 & 0.3 & 0.3 & 0.3 & 0.3 & 0.3 & 0.3 & 0.3 & 0.3 & 0.3 \\
\hline 2nd Reset & $70.6 \mathrm{~s}$ & & & 0.3 & 0.3 & 0.3 & 0.3 & 0.3 & 0.3 & 0.3 & 0.3 & 0.3 & 0.3 \\
\hline Controller: & $.25 / 4 / 4$ & & & & & & & & & & & & \\
\hline Full Pan: & $50 \mathrm{~s}$ & St. State: & $120 \mathrm{~s}$ & & & & & & & & & & \\
\hline
\end{tabular}




\begin{tabular}{|c|c|c|c|c|c|c|c|c|c|c|c|c|c|}
\hline PAN SIZE & FACILITY & HRR (MW) & TEST No. & \multicolumn{10}{|c|}{ DETECTOR DISTANCE FROM SOURCE CENTER (m) } \\
\hline $2.5 \mathrm{Dia}$ & $22 \mathrm{~m}$ & 7 & 16 & 21.3 & 24.38 & 25.9 & 27.4 & 30.5 & $3 \overline{3.5}$ & 36.6 & 39.6 & 42.7 & 45.7 \\
\hline 1st Reset & $60.8 \mathrm{~s}$ & Response & rime (s) & 0.3 & 0.3 & 0.3 & 0.3 & 0.3 & 0.3 & 0.3 & 1 & 1 & 1 \\
\hline 2nd Reset & $82.0 \mathrm{~s}$ & & & 0.3 & 0.3 & 0.3 & 0.3 & 0.3 & 0.3 & 0.3 & 0.3 & 0.8 & 1.3 \\
\hline Controller: & $.25 / 4 / 4$ & & & & & & & & & & & & \\
\hline Full Pan: & $50 \mathrm{~s}$ & St. State: & $180 \mathrm{~s}$ & & & & & & & & & & \\
\hline $2.5 \mathrm{Dia}$ & $22 \mathrm{~m}$ & 9.13 & 19 & $21: 3$ & 24.38 & 25.9 & 27.4 & 30.5 & 33.5 & 36.6 & 39.6 & 427 & 45.7 \\
\hline 1st Reset & $77 \mathrm{~s}$ & Response & Time (s) & 0.3 & 0.3 & 0.3 & 0.3 & 0.3 & 0.3 & 0.3 & 0.3 & 0.3 & 1.1 \\
\hline 2nd Reset & $93.2 \mathrm{~s}$ & & & 0.3 & 0.4 & 0.3 & 0.3 & 0.4 & 0.3 & 0.3 & 0.3 & 0.4 & 0.4 \\
\hline Controller: & $.25 / 4 / 4$ & & & & & & & & & & & & \\
\hline Full Pan: & $50 \mathrm{~s}$ & St. State: & $120 \mathrm{~s}$ & & & & & & & & & & \\
\hline $3.0 \times 3.0$ & $22 \mathrm{~m}$ & 15.73 & 15 & 21.3 & 24.38 & 25.9 & 27.4 & $\overline{30.5}$ & 33.5 & 36.6 & 39.6 & 42.7 & 45.7 \\
\hline 1st Reset & $84.4 \mathrm{~s}$ & Response & Time (s) & 0.3 & 0.3 & 0.3 & 0.3 & 0.3 & 0.3 & 0.3 & 0.3 & 0.3 & 0.3 \\
\hline 2nd Reset & $96.0 \mathrm{~s}$ & & & 0.3 & 0.3 & 0.3 & 0.3 & 0.3 & 0.3 & 0.3 & 0.3 & 0.3 & 0.3 \\
\hline Controller: & $.25 / 4 / 4$ & & & & & & & & & & & & \\
\hline Full Pan: & $65 \mathrm{~s}$ & St. State: & $330 \mathrm{~s}$ & & & & . & & & & & & \\
\hline $3.0 \times 3.0$ & $22 \mathrm{~m}$ & 14.6 & 20 & 21.3 & 24.38 & 25.9 & 27.4 & 30.5 & 33.5 & 36.6 & 39.6 & 42.7 & 45.7 \\
\hline 1st Reset & $66.7 \mathrm{~s}$ & Response & Time (s) & 0.3 & 0.3 & 0.3 & 0.3 & 0.3 & 0.3 & 0.3 & 0.3 & 0.3 & 0.3 \\
\hline 2nd Reset & $79.3 \mathrm{~s}$ & & & 0.3 & 0.4 & 0.4 & 0.3 & 0.3 & 0.3 & 0.3 & 0.3 & 0.4 & 0.3 \\
\hline Controller: & $.25 / 4 / 4$ & & & & & & & & & & & & \\
\hline Full Pan: & $65 s$ & St. State: & $240 \mathrm{~s}$ & & & & & & & & & & \\
\hline $4.6 \times 4.6$ & $22 \mathrm{~m}$ & $\mathrm{n} / \mathrm{a}$ & 21 & 21.3 & 24.38 & 25.9 & 27.4 & 30,5 & 33.5 & 36.6 & 39.6 & 42.7 & 45.7 \\
\hline 1st Reset & $83.1 \mathrm{~s}$ & Response & Time (s) & 0.3 & 0.3 & 0.3 & 0.3 & 0.3 & 0.3 & 0.3 & 0.3 & 0.3 & 0.8 \\
\hline 2nd Reset & $100.5 \mathrm{~s}$ & & & 0.3 & 0.3 & 0.3 & 0.3 & 0.3 & 0.3 & 0.3 & 0.3 & 0.3 & 0.3 \\
\hline Controller: & $.25 / 4 / 4$ & & & & & & & & & & & & \\
\hline Full Pan: & $80 \mathrm{~s}$ & St. State: & & & & & & & & & & & \\
\hline
\end{tabular}


Table 67. UV/IR response times corresponding to first two manual resets after full pan involvement for JP-8 test fires conducted in $22 \mathrm{~m}$ high facility

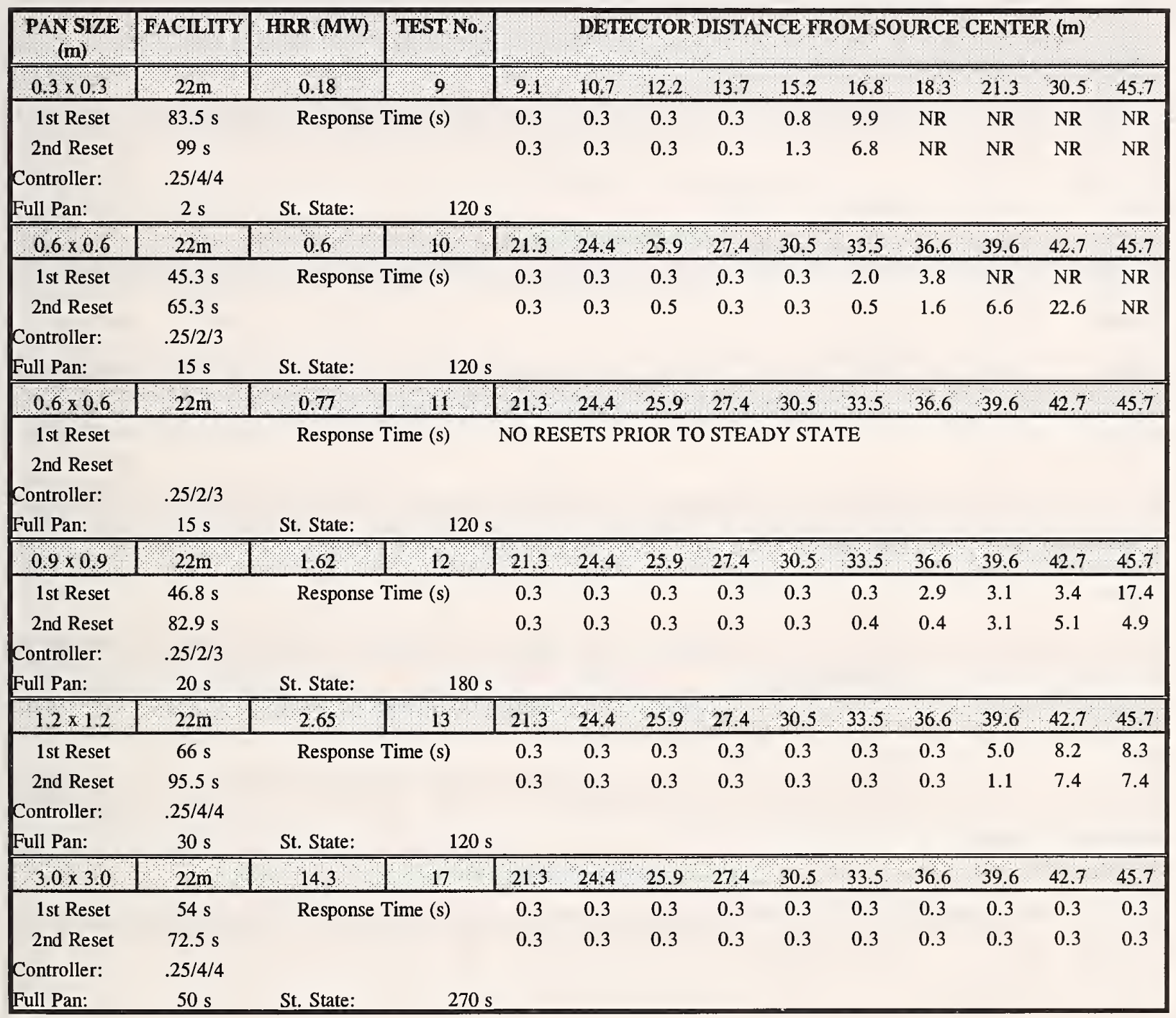


Table 68. UV/IR response times from manual reset after steady state burning for JP-5 test fires conducted in $22 \mathrm{~m}$ high facility

\begin{tabular}{|c|c|c|c|c|c|c|c|c|c|c|c|c|c|}
\hline PAN SIZE & FACILITY & HRR (MW) & TEST No. & \multicolumn{10}{|c|}{ DETECTOR DISTANCE FROM SOURCE CENTER (m) } \\
\hline $0.3 \times 0.3$ & $22 \mathrm{~m}$ & 0.09 & 1 & 9.14 & 10.7 & 12.2 & 13.7 & 15.2 & 16.8 & 18.3 & 21.3 & 30.5 & 4572 \\
\hline 1st Reset & $116.1 \mathrm{~s}$ & Response & Time (s) & 0.3 & 0.3 & 0.3 & 0.3 & 0.6 & 0.3 & 2.8 & NR & NR & NR \\
\hline 2nd Reset & $145.5 \mathrm{~s}$ & & & 0.3 & 0.3 & 0.3 & 0.3 & 0.3 & 0.3 & 0.3 & 5.3 & NR & NR \\
\hline Controller: & $.25 / 2 / 3$ & & & & & & & & & & & & \\
\hline Full Pan: & $2 \mathrm{~s}$ & St. State: & $110 \mathrm{~s}$ & & & & & & & & & & \\
\hline $0.3 \times 0.3$ & $22 \mathrm{~m}$ & 0.08 & 2 & 9.14 & 10.7 & 12.2 & 13.7 & 15.2 & 16.8 & 183 & 213 & 30.5 & 45.72 \\
\hline 1st Reset & $172.8 \mathrm{~s}$ & Response & Time (s) & 0.3 & 0.3 & 0.3 & 0.3 & 0.3 & 0.3 & 2.1 & 6.1 & NR & NR \\
\hline 2nd Reset & $502.1 \mathrm{~s}$ & & & 0.3 & 0.3 & 0.3 & 0.3 & 0.3 & 0.3 & 0.3 & 1.3 & NR & NR \\
\hline Controller: & $.25 / 2 / 3$ & & & & & & & & & & & & \\
\hline Full Pan: & $2 \mathrm{~s}$ & St. State: & $150 \mathrm{~s}$ & & & & & & & & & & \\
\hline $0.6 \times 0.6$ & $22 \mathrm{~m}$ & 0.93 & 3 & 21.3 & 22.9 & 24.4 & 25.9 & 27.4 & 30.5 & 33.5 & 36.6 & 39.6 & 45.72 \\
\hline 1st Reset & $128.7 \mathrm{~s}$ & Response & Time (s) & 0.3 & 0.3 & 0.3 & 0.3 & 0.3 & 0.3 & 0.3 & 4.6 & 8.6 & 8.8 \\
\hline 2nd Reset & $146 \mathrm{~s}$ & & & 0.3 & 0.3 & 0.3 & 0.3 & 0.3 & 1.8 & 3.6 & 3.3 & 3.8 & 4.3 \\
\hline Controller: & $.25 / 2 / 3$ & & & & & & & & & & & & \\
\hline Full Pan: & $15 \mathrm{~s}$ & St. State: & $120 \mathrm{~s}$ & & & & & & & & & & \\
\hline $0.6 \times 0.6$ & $22 \mathrm{~m}$ & 0.77 & 4 & 213 & 22.9 & 24.4 & 25.9 & 27.4 & 305 & 335 & 36.6 & 39.6 & 4572 \\
\hline 1st Reset & $158.6 \mathrm{~s}$ & Response & Time (s) & 0.3 & 0.3 & 0.3 & 0.3 & 0.3 & 0.3 & 0.3 & 0.3 & 0.3 & 0.3 \\
\hline 2nd Reset & $182.1 \mathrm{~s}$ & & & 0.3 & 0.3 & 0.3 & 0.3 & 0.3 & 0.3 & 0.3 & 0.3 & 1.5 & 1.8 \\
\hline Controller: & $.25 / 2 / 3$ & & & & & & & & & & & & \\
\hline Full Pan: & $15 \mathrm{~s}$ & St. State: & $125 \mathrm{~s}$ & & & & & & & & & & \\
\hline $0.9 \times 0.9$ & $22 \mathrm{~m}$ & 1.69 & 5 & 21.3 & 24.4 & $25: 9$ & 27.4 & 30.5 & 33.5 & 36.6 & 39.6 & 427 & 45,72 \\
\hline 1st Reset & $104.4 \mathrm{~s}$ & Response & Time (s) & 0.3 & 0.3 & 0.3 & 0.3 & 0.8 & 0.5 & 0.5 & 1.8 & 1.8 & 1.8 \\
\hline 2nd Reset & $114.1 \mathrm{~s}$ & & & 0.3 & 0.3 & 0.3 & 0.3 & 0.3 & 0.3 & 0.3 & 1.5 & 1.3 & 1.5 \\
\hline Controller: & $.25 / 2 / 3$ & & & & & & & & & & & & \\
\hline Full Pan: & $20 \mathrm{~s}$ & St. State: & $90 \mathrm{~s}$ & & & & & & & & & & \\
\hline $0.9 \times 0.9$ & $22 m$ & 1.39 & 6 & 21.3 & 24.4 & 259 & 27.4 & 30.5 & 33.5 & 36.6 & 39.6 & 42,7 & 4572 \\
\hline 1st Reset & $144 \mathrm{~s}$ & Response & Time (s) & 0.3 & 0.3 & 0.3 & 0.3 & 0.3 & 0.3 & 0.3 & 1 & 0.8 & 1 \\
\hline 2nd Reset & $158.6 \mathrm{~s}$ & & & 0.3 & 0.3 & 0.3 & 0.3 & 0.3 & 0.3 & 0.3 & 17.1 & 17.1 & 17.1 \\
\hline Controller: & $.25 / 4 / 4$ & & & & & & & & & & & & \\
\hline Full Pan: & $20 \mathrm{~s}$ & St. State: & $120 \mathrm{~s}$ & & & & & & & & & & \\
\hline $1.2 \times 1.2$ & $22 \mathrm{~m}$ & 2.81 & 7 & 213 & 24.4 & 25.9 & 27.4 & 30.5 & 33.5 & 36.6 & 39.6 & 427 & 4572 \\
\hline 1st Reset & $153.1 \mathrm{~s}$ & Response & Time (s) & 0.3 & 0.3 & 0.3 & 0.3 & 0.3 & 0.3 & 0.3 & 0.3 & 0.3 & 1.6 \\
\hline 2nd Reset & $168.6 \mathrm{~s}$ & & & 0.3 & 0.3 & 0.3 & 0.3 & 0.3 & 0.3 & 0.3 & 4.6 & 4.6 & 4.6 \\
\hline Controller: & $.25 / 4 / 4$ & & & & & & & & & & & & \\
\hline Full Pan: & $30 \mathrm{~s}$ & St. State: & $150 \mathrm{~s}$ & & & & & & & & & & \\
\hline $2.0 \mathrm{Dia}$ & $22 \mathrm{~m}$ & 4.92 & 18 & 21.3 & 24.4 & 25.9 & 27.4 & 30.5 & 33.5 & 36.6 & 39.6 & 42.7 & 45.72 \\
\hline 1st Reset & $182.1 \mathrm{~s}$ & Response & Time (s) & 0.3 & 0.3 & 0.3 & 0.3 & 0.3 & 0.3 & 0.3 & 0.5 & 0.5 & 0.5 \\
\hline 2nd Reset & $195.1 \mathrm{~s}$ & & & 0.3 & 0.3 & 0.3 & 0.3 & 0.3 & 0.3 & 0.3 & 0.3 & 0.3 & 0.3 \\
\hline Controller: & $.25 / 4 / 4$ & & & & & & & & & & & & \\
\hline Full Pan: & $40 \mathrm{~s}$ & St. State: & $180 \mathrm{~s}$ & & & & & & & & & & \\
\hline $2.5 \mathrm{Dia}$ & $22 \mathrm{~m}$ & 7.86 & 14 & 21.3 & 24.4 & 25.9 & 27.4 & 30.5 & 33.5 & 36.6 & 39.6 & 427 & 45.72 \\
\hline 1st Reset & $137.9 \mathrm{~s}$ & Response & Time (s) & 0.3 & 0.3 & 0.3 & 0.3 & 0.3 & 0.3 & 0.3 & 0.3 & 0.3 & 0.3 \\
\hline 2nd Reset & $150.6 \mathrm{~s}$ & & & 0.3 & 0.3 & 0.3 & 0.3 & 0.3 & 0.3 & 0.3 & 0.3 & 0.3 & 0.3 \\
\hline Controller: & $.25 / 4 / 4$ & & & & & & & & & & & & \\
\hline Full Pan: & $50 \mathrm{~s}$ & St. State: & $120 \mathrm{~s}$ & & & & & & & & & & \\
\hline $2.5 \mathrm{Dia}$ & $22 \mathrm{~m}$ & 7 & 16 & 21.3 & 24.4 & 25.9 & 27.4 & 30.5 & 33.5 & 36.6 & 39.6 & 42.7 & 45.72 \\
\hline 1st Reset & $236.2 \mathrm{~s}$ & Response & Time (s) & 0.3 & 0.3 & 0.3 & 0.3 & 0.3 & 1.1 & 3.1 & NR & NR & NR \\
\hline 2nd Reset & NO 2 ND RE & ET & & & & & & & & & & & \\
\hline Controller: & $.25 / 4 / 4$ & & & & & & & & & & & & \\
\hline Full Pan: & $50 \mathrm{~s}$ & St. State: & $180 \mathrm{~s}$ & & & & & & & & & & \\
\hline
\end{tabular}




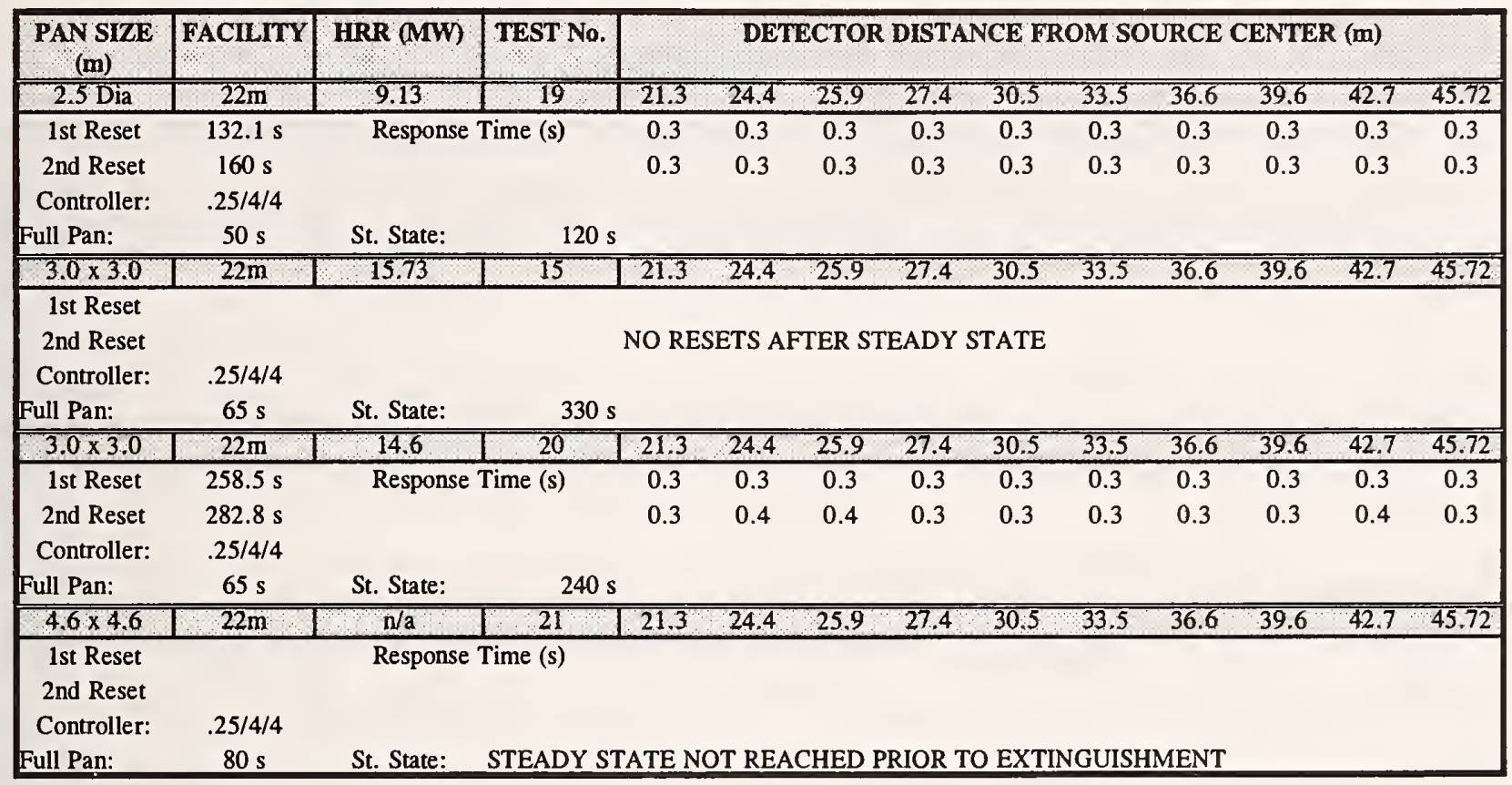


Table 69. UV/IR response times corresponding to manual reset after steady state burning for JP-8 test fires conducted in $22 \mathrm{~m}$ high facility

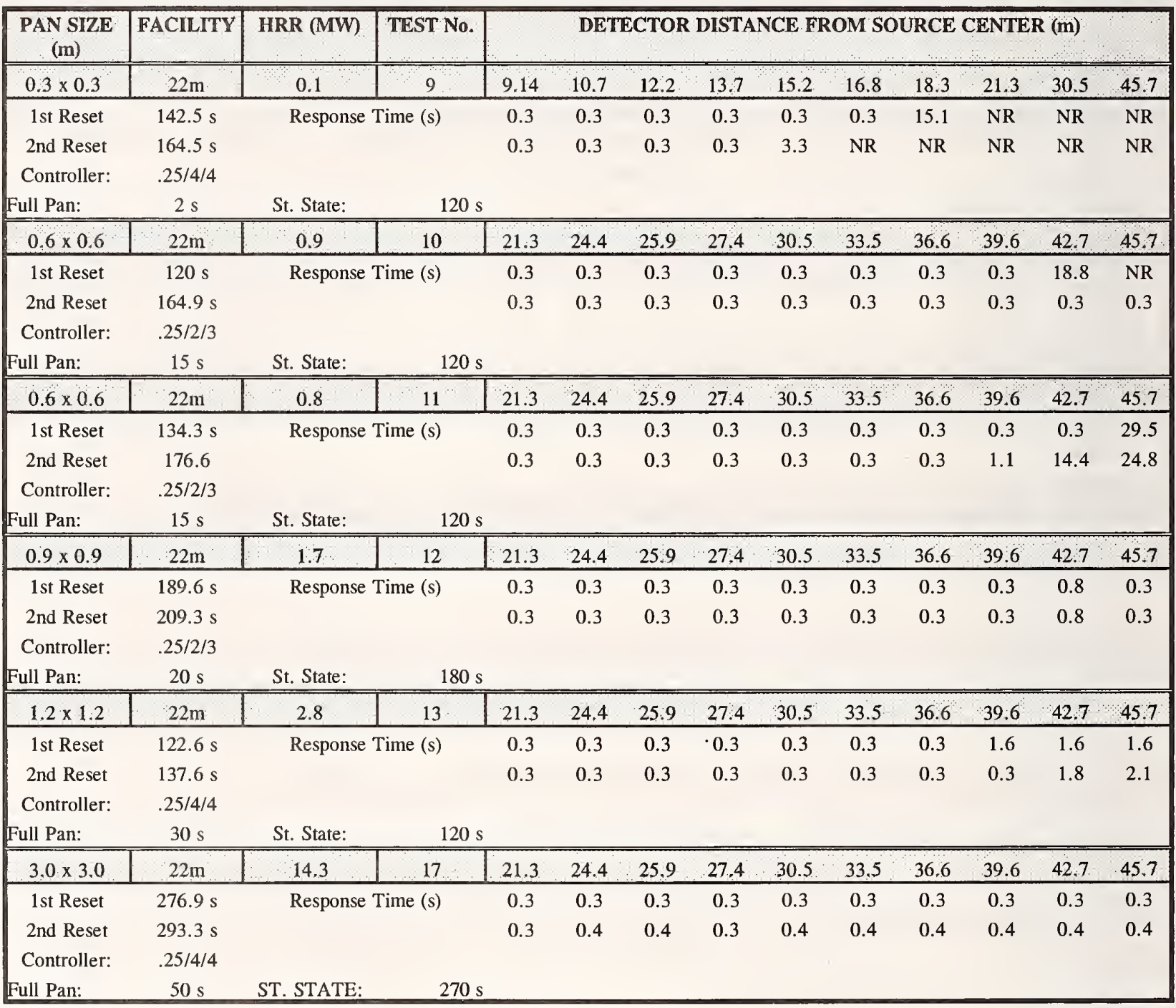

Previous studies by the Factory Mutual Engineering Corporation indicate that the skin of aircraft fuselages will fail after $45 \mathrm{~s}$ of spill fire exposure [30]. Unfortunately, those data do not represent the decreased resistance to fire of today's typical composite material (i.e., stealth aircraft). Nevertheless, $45 \mathrm{~s}$ was the maximum response time used in determining threshold response distances. Further studies on the effect of fire exposure on aircraft skin will help determine acceptable response times of optical detectors. An additional element which must be considered in determining the acceptable response time is the time required to achieve foam coverage of the designated floor areas after the fire has been detected.

The controller settings of combination UV/IR detector varies with respect to test number. The controller setting variations for similar sized fires was done on a very limited basis in the $22 \mathrm{~m}$ high 
facility. However, Figures 132 and 133 graphically illustrate the effects on the $0.3 \mathrm{~m} \mathrm{x} 0.3 \mathrm{~m}$ and $0.9 \mathrm{~m} \mathrm{x} 0.9 \mathrm{~m}$ pan fires respectively. Figure 132 clearly shows the detectors in test 9 with a setting of $0.25 / 4 / 4$, failed to respond in the $5 \mathrm{~s}, 10 \mathrm{~s}$, and $20 \mathrm{~s}$ time intervals. The detectors in tests 1 and 2 , with a setting of $0.25 / 2 / 3$ responded in all selected times. Where the detectors in test 9 (i.e., $0.25 / 4 / 4$ ) do respond at $30 \mathrm{~s}$ and $45 \mathrm{~s}$, the threshold response distances are $27 \%$ to $46 \%$ shorter than they are in tests 1 and 2 (i.e., $0.25 / 2 / 3$ ).

\section{Maximum Response Distances}

The maximum response distances for optical flame detectors for the tests conducted in the $22 \mathrm{~m}$ facility were determined to be the maximum distance at which a detector responded without respect to the selected response times. Since detector response was measured at three fire events, the time at which the maximum response distance was reached is represented for each stage of fire growth. The maximum response distances are presented in Table 71. The effect of different controller sensitivity settings on the maximum response distance was studied for the $0.3 \mathrm{~m} \mathrm{x} 0.3 \mathrm{~m}$ and $0.9 \mathrm{~m} \mathrm{x} 0.9 \mathrm{~m}$ pan fires. Figures 132 and 133 illustrate that the detectors having a controller setting of $0.25 / 4 / 4$ cannot be expected to respond within $45 \mathrm{~s}$ when placed beyond $12.2 \mathrm{~m}$ for the $0.3 \mathrm{~m} \mathrm{x} 0.3 \mathrm{~m}$ pan fire and $36.6 \mathrm{~m}$ for the $0.9 \mathrm{~m} \mathrm{x} 0.9 \mathrm{~m}$ pan fire respectively.

\section{Predicted Response of Unitized UV/IR Optical Flame Detectors.}

The researchers from Detector Electronics Corporation were asked to take the actual raw counts per second data acquired from the fire tests and mathematically predict the response of unitized optical flame detectors and compare them to the responses of the controller based detectors. This analysis was performed for responses from ignition during a select time interval. 
Table 70. UV/IR detector response threshold distances $(\mathrm{m})$ at selected times after steady state for all test fires conducted in $22 \mathrm{~m}$ high facility. Note: maximum distance $(45.7 \mathrm{~m})$ limited by hangar arrangement.

\begin{tabular}{|c|c|c|c|c|c|c|c|c|}
\hline \multirow[b]{2}{*}{ TEST } & \multirow[b]{2}{*}{ HRR (PAN SIZE) } & \multirow[b]{2}{*}{ CONTROLLER } & \multirow[b]{2}{*}{ FUEL } & \multicolumn{5}{|c|}{ SELECTED TIMES } \\
\hline & & & & $5 \mathrm{~s}$ & $10 \mathrm{~s}$ & $20 \mathrm{~s}$ & $30 \mathrm{~s}$ & $45 \mathrm{~s}$ \\
\hline 1 & $0.1 \mathrm{MW}(0.3 \mathrm{~m} \times 0.3 \mathrm{~m})$ & $0.25 / 2 / 3$ & -JP-5 & 18.3 & 18.3 & 18.3 & 18.3 & 18.3 \\
\hline 2. & $0.1 \mathrm{MW}(0.3 \mathrm{~m} \times 0.3 \mathrm{~m})$ & $0.25 / 2 / 3$ & $\mathrm{JP}-5$ & 18.3 & 21.3 & 21.3 & 21.3 & 21.3 \\
\hline 9 & $0.2 \mathrm{MW}(0.3 \mathrm{~m} \times 0.3 \mathrm{~m})$ & $0.25 / 4 / 4$ & $\mathrm{JP}-8$ & 15.2 & 15.2 & 15.2 & 15.2 & 15.2 \\
\hline 3 & $0.9 \mathrm{MW}(0.6 \mathrm{~m} \times 0.6 \mathrm{~m})$ & $0.25 / 2 / 3$ & JP-5 & 36.6 & 45.7 & 45.7 & 45.7 & 45.7 \\
\hline 4 & $0.8 \mathrm{MW}(0.6 \mathrm{~m} \times 0.6 \mathrm{~m})$ & $0.25 / 2 / 3$ & JP-5 & 45.7 & 45.7 & 45.7 & 45.7 & 45.7 \\
\hline 10 & $0.6 \mathrm{MW}(0.6 \mathrm{~m} \times 0.6 \mathrm{~m})$ & $0.25 / 2 / 3$ & JP-8 & 39.6 & 39.6 & 39.6 & 42.7 & 42.7 \\
\hline 11 & $0.8 \mathrm{MW}(0.6 \mathrm{~m} \times 0.6 \mathrm{~m})$ & $0.25 / 2 / 3$ & JP-8 & 39.6 & 39.6 & 42.7 & 45.7 & 45.7 \\
\hline 5 & $1.7 \mathrm{MW}(0.9 \mathrm{~m} \times 0.9 \mathrm{~m})$ & $0.25 / 2 / 3$ & JP-5 & 45.7 & 45.7 & 45.7 & 45.7 & 45.7 \\
\hline 6 & $1.4 \mathrm{MW}(0.9 \mathrm{~m} \times 0.9 \mathrm{~m})$ & $0.25 / 4 / 4$ & JP-5 & 36.6 & 36.6 & 45.7 & 45.7 & 45.7 \\
\hline 12 & $1.6 \mathrm{MW}(0.9 \mathrm{~m} \times 0.9 \mathrm{~m})$ & $0.25 / 2 / 3$ & JP-8 & 45.7 & 45.7 & 45.7 & 45.7 & 45.7 \\
\hline 7 & $2.8 \mathrm{MW}(1.2 \mathrm{~m} \mathrm{x} 1.2 \mathrm{~m})$ & $0.25 / 4 / 4$ & JP-5 & 45.7 & 45.7 & 45.7 & 45.7 & 45.7 \\
\hline 13 & $2.7 \mathrm{MW}(1.2 \mathrm{~m} \mathrm{x} 1.2 \mathrm{~m})$ & $0.25 / 4 / 4$ & JP-8 & 45.7 & 45.7 & 45.7 & 45.7 & 45.7 \\
\hline 18 & 4.9 MW (2.0 m Dia.) & $0.25 / 4 / 4$ & JP-5 & 45.7 & 45.7 & 45.7 & 45.7 & 45.7 \\
\hline 14 & 7.9 MW (2.5 m Dia.) & $0.25 / 4 / 4$ & JP-5 & 45.7 & 45.7 & 45.7 & 45.7 & 45.7 \\
\hline 16 & 7.0 MW (2.5 m Dia.) & $0.25 / 4 / 4$ & JP-5 & 36.6 & 36.6 & 36.6 & 36.6 & 36.6 \\
\hline 19 & $9.1 \mathrm{MW}(2.5 \mathrm{~m} \mathrm{Dia})$. & $0.25 / 4 / 4$ & JP-5 & 45.7 & 45.7 & 45.7 & 45.7 & 45.7 \\
\hline 15 & $15.7 \mathrm{MW}(3.0 \mathrm{~m} \times 3.0 \mathrm{~m})$ & $0.25 / 4 / 4$ & JP-5 & $\mathrm{N} / \mathrm{A}^{\mathrm{b}}$ & $\mathrm{N} / \mathrm{A}^{\mathrm{h}}$ & $\mathrm{N} / \mathrm{A}^{\mathrm{b}}$ & $\mathrm{N} / \mathrm{A}^{\mathrm{b}}$ & $\mathrm{N} / \mathrm{A}^{\mathrm{b}}$ \\
\hline 20 & $14.6 \mathrm{MW}(3.0 \mathrm{~m} \times 3.0 \mathrm{~m})$ & $0.25 / 4 / 4$ & $\mathrm{JP}-5$ & 45.7 & 45.7 & 45.7 & 45.7 & 45.7 \\
\hline 17 & $14.3 \mathrm{MW}(3.0 \mathrm{~m} \times 3.0 \mathrm{~m})$ & $0.25 / 4 / 4$ & JP-8 & 45.7 & 45.7 & 45.7 & 45.7 & 45.7 \\
\hline 21 & $33 \mathrm{MW}(4.6 \mathrm{~m} \mathrm{x} 4.6 \mathrm{~m})$ & $0.25 / 4 / 4$ & $\cdot J P-5$ & $\mathrm{~N} / \mathrm{A}^{\mathrm{c}}$ & N/A & $N / A^{c}$ & $N / A^{c}$ & $\mathrm{~N} / \mathrm{A}^{\mathrm{c}}$ \\
\hline
\end{tabular}


Table 71. UV/IR maximum response distances and response times from selected events for all test fires conducted in $22 \mathrm{~m}$ high facility

\begin{tabular}{|c|c|c|c|c|c|c|c|c|}
\hline \multirow{2}{*}{ TEST } & \multirow{2}{*}{ HRR (PAN SIZE, m) } & \multirow{2}{*}{ FUEL } & \multirow{2}{*}{$\begin{array}{l}\text { CONTROLLER } \\
\text { SETTING }\end{array}$} & \multirow{2}{*}{$\begin{array}{c}\text { THRESHOLD } \\
\text { DETECTOR } \\
\text { DISTANCE } \\
(\mathrm{m})\end{array}$} & \multirow{2}{*}{$\begin{array}{c}\text { MAXIMUM } \\
\text { DETECTOR } \\
\text { PLACEMENT } \\
(\mathrm{m})\end{array}$} & \multicolumn{3}{|c|}{ RESPONSE TIMES (s) } \\
\hline & & & & & & IGNITION & $\begin{array}{l}\text { FULL } \\
\text { PAN }\end{array}$ & $\begin{array}{c}\text { ST. } \\
\text { STATE }\end{array}$ \\
\hline 1 & $0.09 \mathrm{MW}(0.3 \times 0.3)$ & JP-5 & $.25 / 2 / 3$ & 16.8 & 45.7 & 28.8 & 0.8 & 0.3 \\
\hline 2 & $0.08 \mathrm{MW}(0.3 \times 0.3)$ & JP-5 & $.25 / 2 / 3$ & 18.3 & 45.7 & 39.8 & 2.3 & 2.1 \\
\hline 9 & $0.18 \mathrm{MW}(0.3 \times 0.3)$ & JP-8 & $.25 / 4 / 4$ & 15.2 & 45.7 & 74.6 & 1.3 & 3.3 \\
\hline 3 & $0.93 \mathrm{MW}(0.6 \times 0.6)$ & $\mathrm{JP}-5$ & $25 / 2 / 3$ & 36.6 & 45.7 & 49.5 & 4.1 & 4.6 \\
\hline 4 & $0.77 \mathrm{MW}(0.6 \times 0.6)$ & JP-5 & $.25 / 2 / 3$ & 39.6 & 45.7 & 59.1 & 6.8 & 1.5 \\
\hline 10 & $0.6 \mathrm{MW}(0.6 \times 0.6)$ & $\mathrm{JP}-8$ & $.25 / 2 / 3$ & 36.6 & 45.7 & 36.2 & 3.8 & 0.3 \\
\hline 11 & $0.77 \mathrm{MW}(0.6 \times 0.6)$ & JP-8 & $.25 / 2 / 3$ & 42.7 & 45.7 & 54 & $\mathrm{~N} / \mathrm{A}^{\mathrm{a}}$ & 14.4 \\
\hline 5 & $1.69 \mathrm{MW}(0.9 \times 0.9)$ & $\mathrm{JP}-5$ & $.25 / 2 / 3$ & 45.7 & 45.7 & 28.1 & 0.3 & 1.8 \\
\hline 6 & $1.39 \mathrm{MW}(0.9 \times 0.9)$ & JP-5 & $.25 / 4 / 4$ & 45.7 & 45.7 & 56.3 & 4.6 & 17.1 \\
\hline 12 & $1.62 \mathrm{MW}(0.9 \times 0.9)$ & JP-8 & $.25 / 2 / 3$ & 45.7 & 45.7 & 35.1 & 17.4 & 0.3 \\
\hline 7 & $2.81 \mathrm{MW}(1.2 \times 1.2)$ & JP-5 & $.25 / 4 / 4$ & 45.7 & 45.7 & 53.7 & 0.5 & 4.6 \\
\hline 13 & $2.65 \mathrm{MW}(1.2 \times 1.2)$ & JP-8 & $.25 / 4 / 4$ & 45.7 & 45.7 & 49.5 & 8.3 & 2.1 \\
\hline 18 & 4.92 MW (2.0 Dia.) & $\mathrm{JP}-5$ & $.25 / 4 / 4$ & 45.7 & 45.7 & 54.9 & 3.1 & 0.5 \\
\hline 14 & $7.86 \mathrm{MW}(2.5 \mathrm{Dia})$ & JP-5 & $.25 / 4 / 4$ & 45.7 & 45.7 & 46.3 & 0.3 & 0.3 \\
\hline 16 & 7.0 MW (2.5 Dia.) & JP-5 & $.25 / 4 / 4$ & 36.6 & 45.7 & 35.4 & 0.3 & 3.1 \\
\hline 19 & $9.13 \mathrm{MW}(2,5$ Dia $)$ & $\mathrm{JP}-5$ & $.25 / 4 / 4$ & 45.7 & 45.7 & 49.8 & 1.1 & 0.3 \\
\hline 15 & $15.73 \mathrm{MW}(3.0 \times 3.0)$ & $\mathrm{JP}-5$ & $.25 / 4 / 4$ & 45.7 & 45.7 & 40.7 & 0.3 & $\mathrm{~N} / \mathrm{A}^{\mathrm{b}}$ \\
\hline 20 & $14.6 \mathrm{MW}(3.0 \times 3.0)$ & JP-5 & $.25 / 4 / 4$ & 45.7 & 45.7 & 44.1 & 0.3 & 0.3 \\
\hline 17 & $14.3 \mathrm{MW}(3.0 \times 3.0)$ & JP-8 & $.25 / 4 / 4$ & 45.7 & 45.7 & 40.4 & 0.3 & 0.04 \\
\hline 21 & $33 \mathrm{MW}(4.6 \times 4.6)$ & $\mathrm{JP}-5$ & $.25 / 4 / 4$ & 45.7 & 45.7 & 44.5 & 0.8 & $N / A^{c}$ \\
\hline $\mathrm{NR}-\mathrm{N}$ & To detector response & te. & & & & & & \\
\hline
\end{tabular}




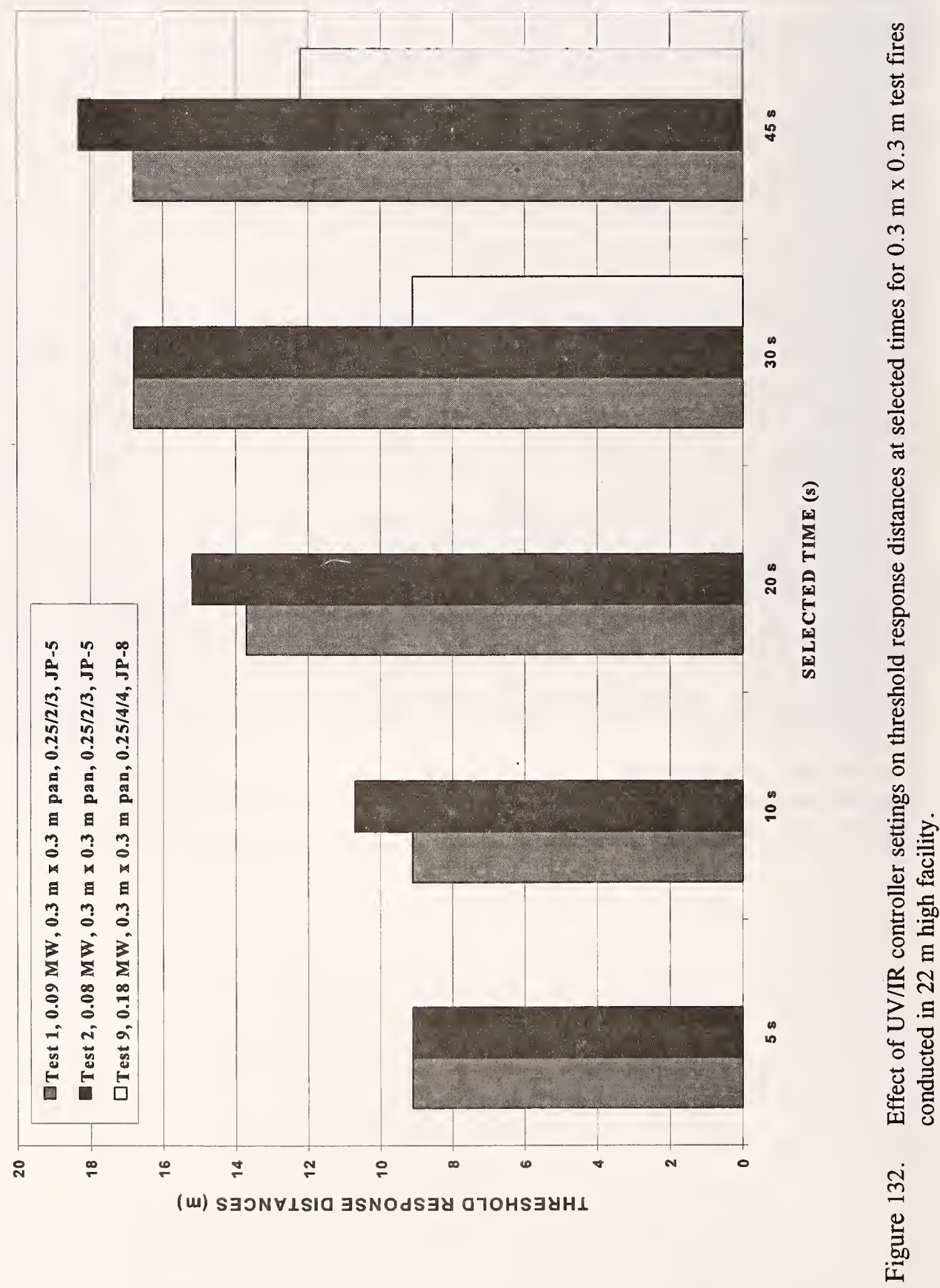




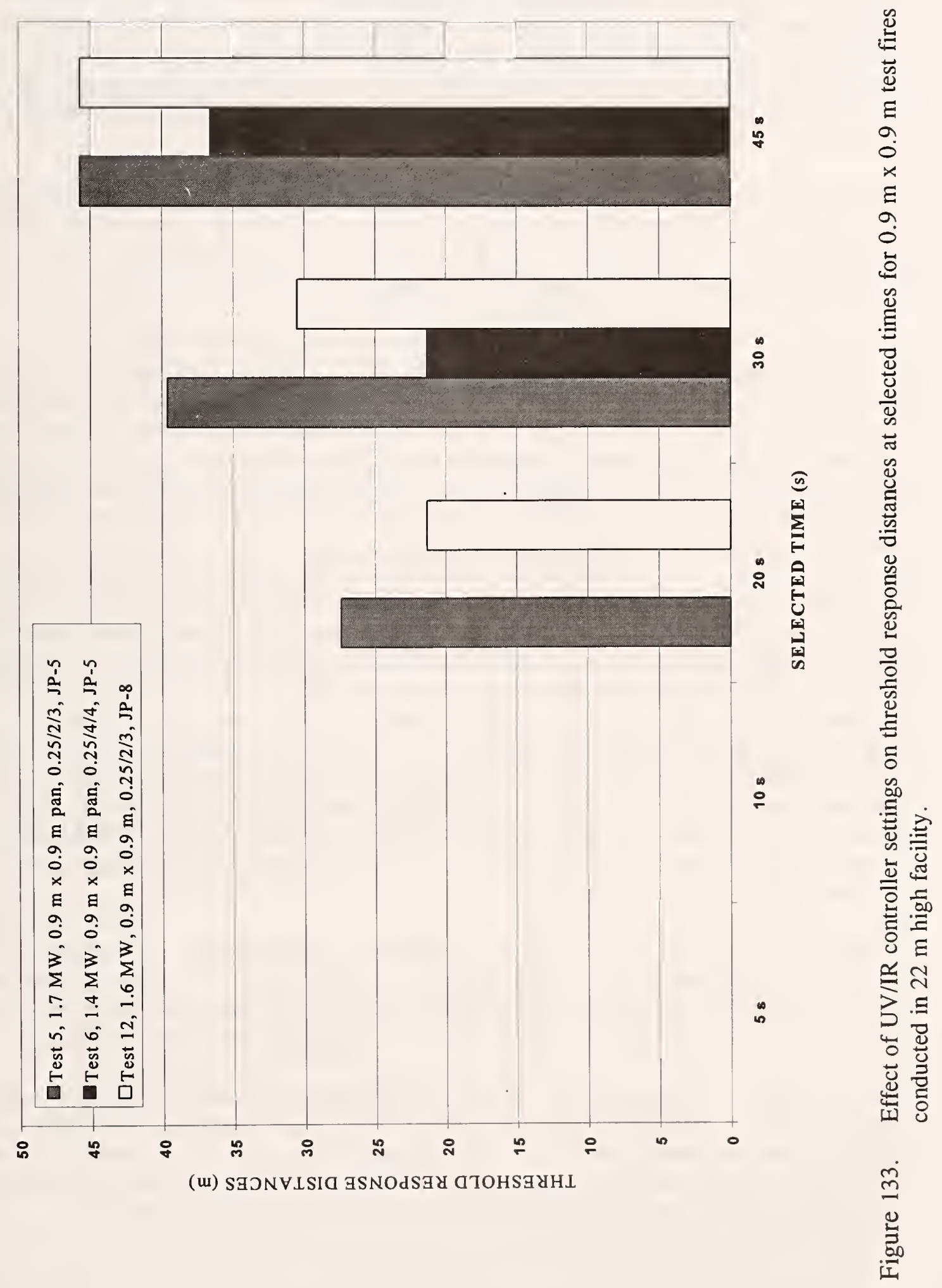




\subsubsection{Response of Line-Type Heat Detector}

The line-type heat detector installed in the $22 \mathrm{~m}$ high facility provided continuous measurement of ceiling temperature as a function of fire size. A description of the way the sensor was installed was provided earlier in section 4, and the theory of its operation and characteristics was given in section 3 . The following table and graphs describe how the linear sensor responded to various fire sizes. A comparison to automatic sprinkler response and spot-type heat detector response is made. Also, a linear heat detector is characterizing (for a high bay) space where there may be temperature stratification in the upper layer.

Table 72 describes how the linear heat sensor responded to various fire sizes. The table shows fire parameters, the maximum ceiling temperature, maximum sensor temperature, and the time the sensor reached $57^{\circ} \mathrm{C}\left(135^{\circ} \mathrm{F}\right)$ and $79^{\circ} \mathrm{C}\left(175^{\circ} \mathrm{F}\right)$. These temperatures correspond to the activation thresholds for spot-type heat detectors and intermediate range automatic sprinklers.

From Table 72 it is shown that for smaller test fires, $0.3 \mathrm{~m} \mathrm{x} 0.3 \mathrm{~m}$ pan to $1.2 \mathrm{~m} \mathrm{x} 1.2 \mathrm{~m}$ pan, the maximum temperature at the center never exceeds $50^{\circ} \mathrm{C}\left(122^{\circ} \mathrm{F}\right)$. Likewise, the maximum sensor temperature does not exceed $37^{\circ} \mathrm{C}\left(99^{\circ} \mathrm{F}\right)$. Therefore, using criteria designed for spot-type heat detector or automatic sprinkler response may not be appropriate for this sensor. Figure 134 shows the response of the linear heat sensor along with the center thermocouple measurement for each of these smaller test fires. Additional experiments were conducted using JP-8 aviation fuel in the smaller pan sizes (tests 9-13). These tests were omitted from the table since the burning characteristics and heat output were similar to the JP-5 fueled experiments.

For the larger JP-5 fires the maximum temperature at the ceiling ranged from $59{ }^{\circ} \mathrm{C}$ to $272{ }^{\circ} \mathrm{C}$. However, the maximum temperature recorded with the linear heat sensor ranged from $49^{\circ} \mathrm{C}$ to $205^{\circ} \mathrm{C}$. Figures 135 and 136 show the comparison of ceiling temperature to linear heat sensor response for many of the larger fires. For example, test 14 used a $2.5 \mathrm{~m}$ diameter pan fueled with JP5. The maximum center temperature at $0.3 \mathrm{~m}$ below the ceiling reached $93{ }^{\circ} \mathrm{C}\left(199^{\circ} \mathrm{F}\right)$. The linear heat sensor reached a maximum temperature of $75^{\circ} \mathrm{C}\left(167^{\circ} \mathrm{F}\right)$ and surpassed the $57^{\circ} \mathrm{C}$ threshold in $222 \mathrm{~s}$. The time to reach this threshold is nearly $120 \mathrm{~s}$ slower than the time it took the first $57^{\circ} \mathrm{C}$ spottype heat detector to alarm. In addition, intermediate range sprinklers (i.e., $79^{\circ} \mathrm{C}$, quick response) activated at $262 \mathrm{~s}$. The linear heat sensor in this case never reached the $79^{\circ} \mathrm{C}$ threshold. Figure 137 shows the response times of spot-type heat detectors and automatic sprinklers with respect to the linetype heat detector response for this case.

In test 15 , a $3.0 \mathrm{~m} \times 3.0 \mathrm{~m}$ pan produced a maximum ceiling temperature of $170^{\circ} \mathrm{C}\left(338^{\circ} \mathrm{F}\right)$. Whereas the linear heat sensor reached a maximum of $139^{\circ} \mathrm{C}\left(282^{\circ} \mathrm{F}\right)$. Spot-type heat detectors began activating at $82 \mathrm{~s}$ and $79^{\circ} \mathrm{C}$ QR sprinklers at $119 \mathrm{~s}$. The linear heat sensor reached the $57^{\circ} \mathrm{C}$ threshold at $116 \mathrm{~s}$ and the $79^{\circ} \mathrm{C}$ threshold at $171 \mathrm{~s}$. This comparison is shown in Figure 138.

A comparison can be made between the center temperature profiles and line-type heat detector response. The preceding figures show a marked difference in temperature between the center thermocouple and line-type heat detector. It is understood that the center thermocouple, within the plume region, would indicate a higher temperature than thermocouples outside the plume region. The linear heat sensor is within the plume region for only a small portion of its length. 
Table 72. Results of line-type heat detector response to test fires in $22 \mathrm{~m}$ high facility.

\begin{tabular}{|c|c|c|c|c|c|c|}
\hline \multicolumn{3}{|c|}{ Test Information } & \multicolumn{4}{|c|}{ Measured Temperatures and Response Times } \\
\hline $\begin{array}{c}\text { Test } \\
\text { Number }\end{array}$ & $\begin{array}{c}\text { Pan Size } \\
\mathrm{m}\end{array}$ & $\begin{array}{c}\text { Fire Size } \\
\text { MW }\end{array}$ & $\begin{array}{l}\text { Max. Ceiling } \\
\text { Temperature }{ }^{\mathrm{a}} \\
{ }^{\circ} \mathrm{C}, \pm 2\end{array}$ & $\begin{array}{c}\text { Max. Sensor } \\
\text { Temperature } \\
{ }^{\circ} \mathrm{C}, \pm 2\end{array}$ & $\begin{array}{l}\text { Time to } \\
57^{\circ} \mathrm{C} \\
\mathrm{s}, \pm 4\end{array}$ & $\begin{array}{l}\text { Time to } \\
79{ }^{\circ} \mathrm{C} \\
\mathrm{s}, \pm 4\end{array}$ \\
\hline 1 & $0.3 \times 0.3$ & 0.1 & 12 & 14 & - & - \\
\hline 2 & $0.3 \times 0.3$ & 0.1 & 14 & 15 & -- & -- \\
\hline 3 & $0.6 \times 0.6$ & 0.9 & 21 & 18 & - & -- \\
\hline 4 & $0.6 \times 0.6$ & 0.8 & 23 & 20 & -- & -- \\
\hline 5 & $0.9 \times 0.9$ & 1.7 & 34 & 27 & - & - \\
\hline 6 & $0.9 \times 0.9$ & 1.4 & 33 & 28 & -- & -- \\
\hline 7 & $1.2 \times 1.2$ & 2.8 & 49 & 36 & - & \\
\hline 8 & $1.2 \times 1.2$ & $\mathrm{n} / \mathrm{a}$ & $\mathrm{n} / \mathrm{a}$ & $\mathrm{n} / \mathrm{a}$ & $\mathrm{n} / \mathrm{a}$ & $\mathrm{n} / \mathrm{a}$ \\
\hline 14 & $2.5 \mathrm{dia}$. & 7.9 & 93 & 75 & 222 & - \\
\hline 15 & $3.0 \times 3.0$ & 15.7 & 170 & 139 & 116 & 171 \\
\hline $16^{*}$ & 2.5 dia. & 7.0 & 59 & 49 & - & - \\
\hline $17(\mathrm{JP}-8)$ & $3.0 \times 3.0$ & 14.3 & 175 & 137 & 106 & 184 \\
\hline 18 & $2.0 \mathrm{dia}$ & 4.9 & 71 & 53 & - & - \\
\hline $19^{*}$ & $2.5 \mathrm{dia}$ & 9.1 & 72 & 56 & -- & -- \\
\hline 20 & $3.0 \times 3.0$ & 14.6 & 176 & 136 & 103 & 190 \\
\hline 21 & $4.6 \times 4.6$ & 33 & 272 & 205 & 90 & 100 \\
\hline
\end{tabular}

* Open door test.

-- Did not reach temperature threshold.

n/a No data available.

a Center thermocouple at $0.3 \mathrm{~m}$ below the ceiling. 


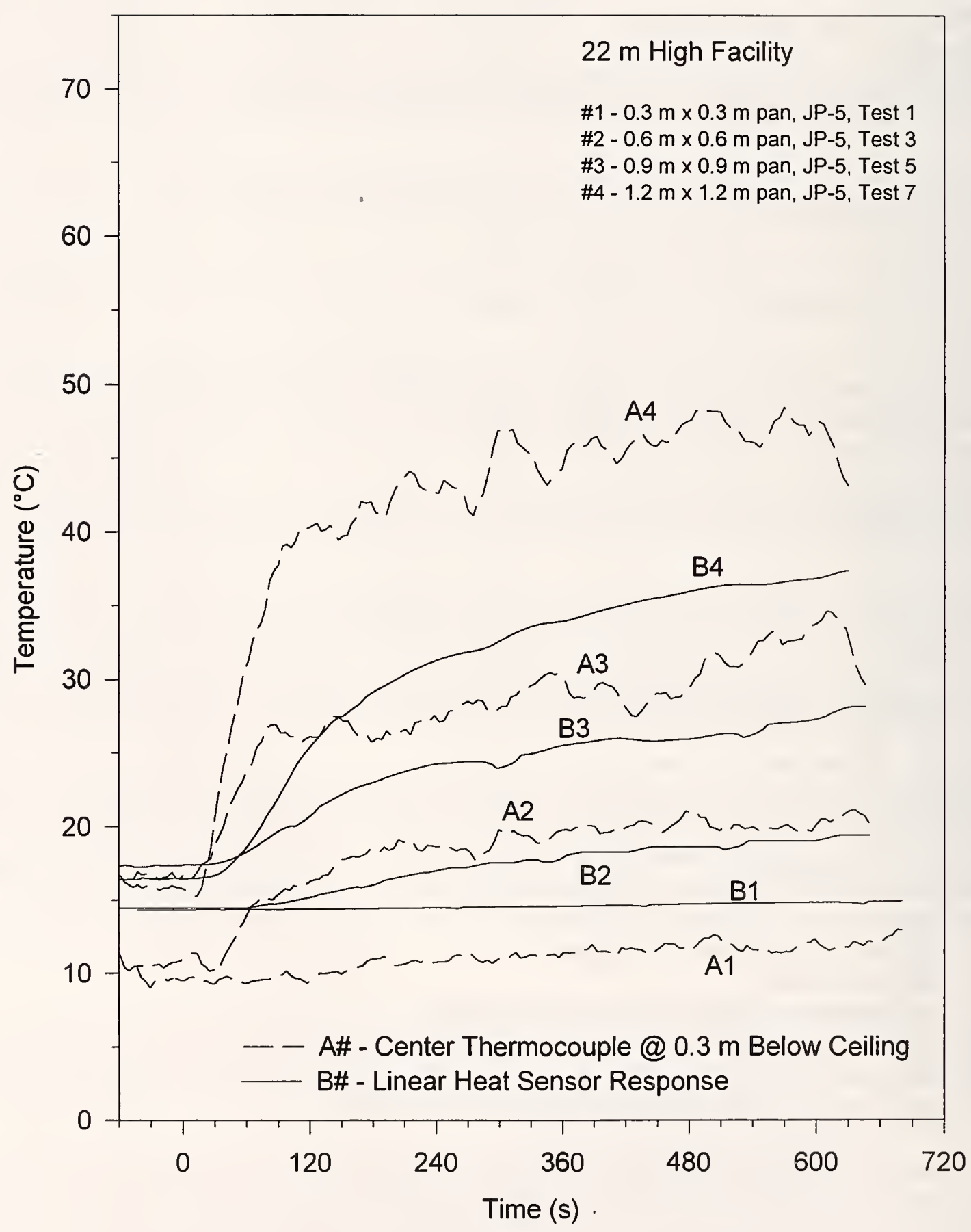

Figure 134. Comparison of line-type heat detector to center temperature for smaller fires conducted in $22 \mathrm{~m}$ high facility. 


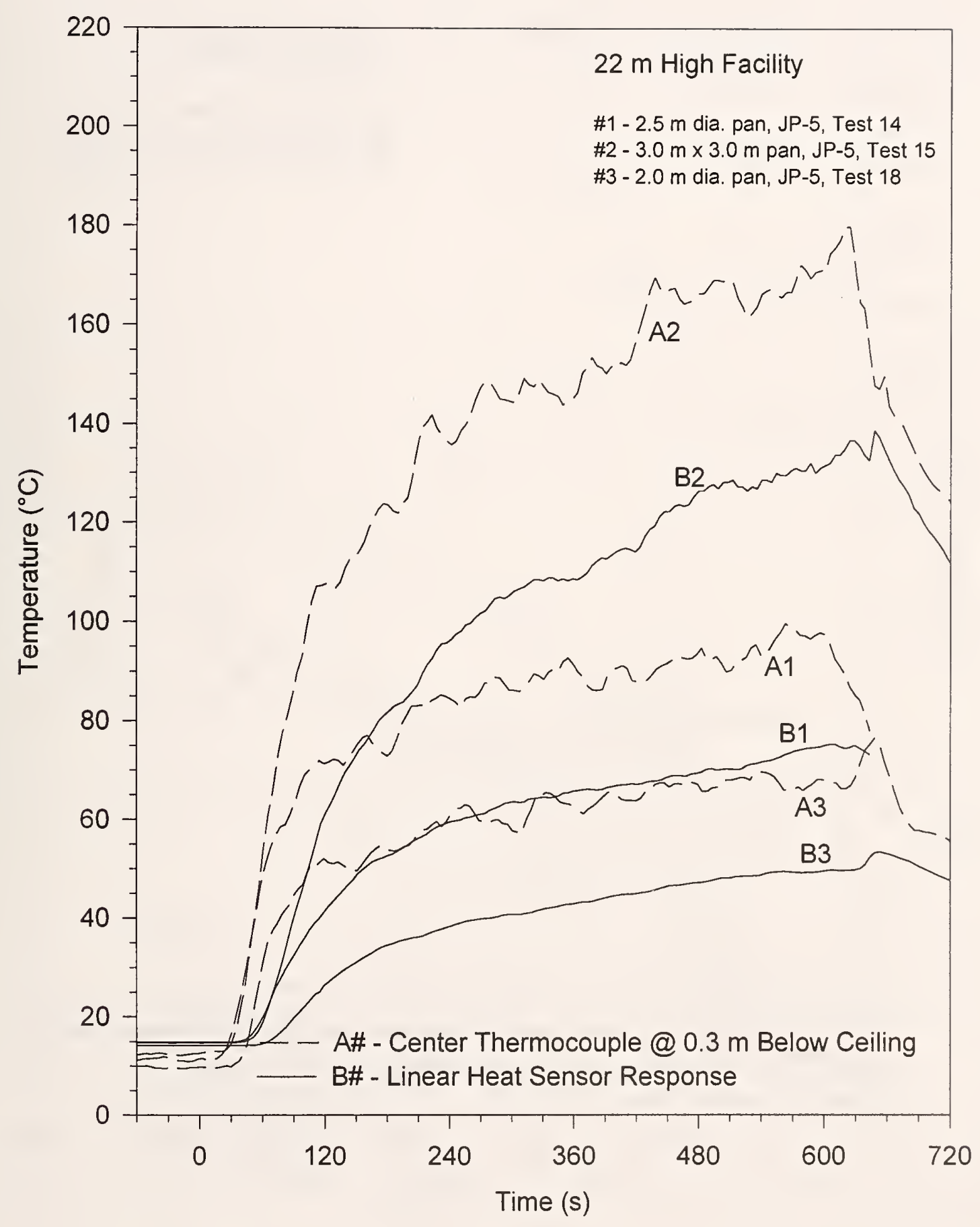

Figure 135. Line-type heat detector response and center temperature profiles for test fires using 2.0 $\mathrm{m}$ dia., $2.5 \mathrm{~m}$ dia., and $3.0 \mathrm{~m} \mathrm{x} 3.0 \mathrm{~m}$ pans (tests $14,15,18$ ). 


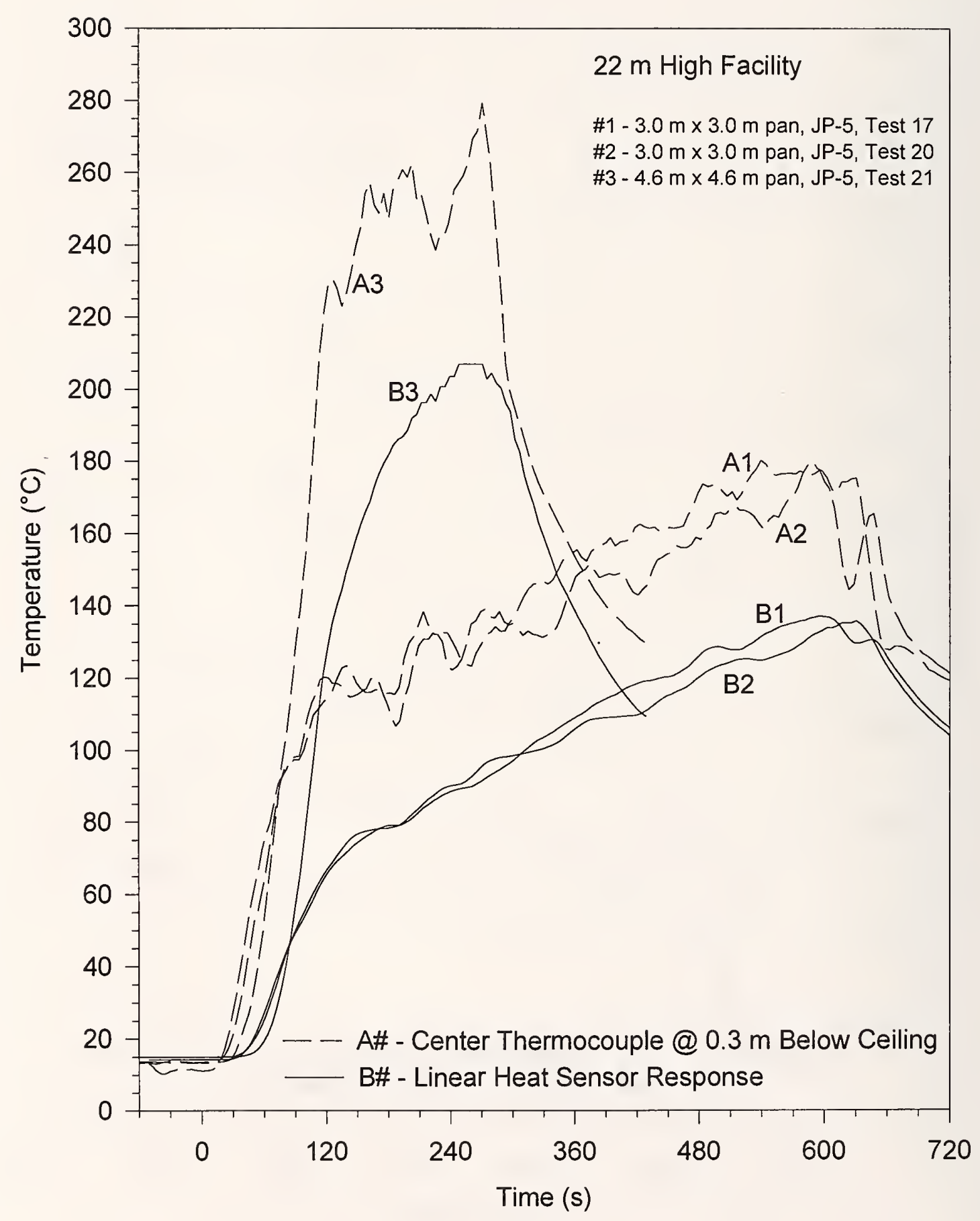

Figure 136. Line-type heat detector response and center temperature profiles for tests using $3.0 \mathrm{~m} \mathrm{x}$ $3.0 \mathrm{~m}$ and $4.6 \mathrm{~m} \times 4.6 \mathrm{~m}$ pans (tests 17, 20,21). 


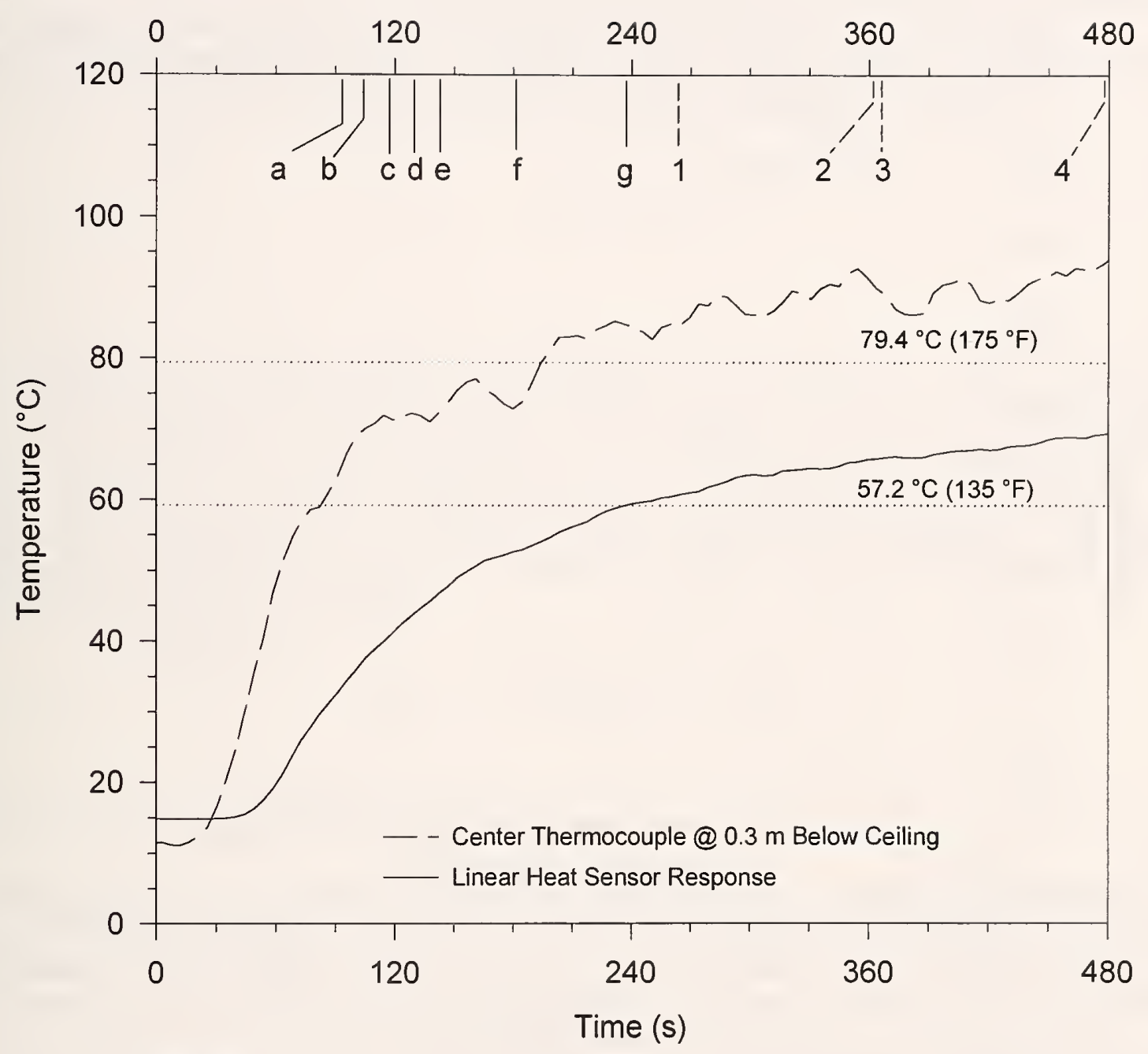

Events

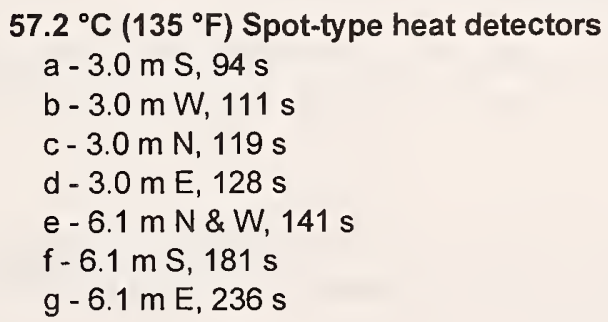

Automatic Sprinklers

1 - S1F, $79^{\circ} \mathrm{C}$ QR dry, $262 \mathrm{~s}$

2 - S1B, $79^{\circ} \mathrm{C}$ QR, $361 \mathrm{~s}$

3 - CF, $79^{\circ} \mathrm{C}$ QR dry, $366 \mathrm{~s}$

4 - W1F, $79{ }^{\circ} \mathrm{C}$ QR dry, $480 \mathrm{~s}$

Figure 137. Comparison of spot-type heat detectors and automatic sprinkler activation to line-type heat detector for $2.5 \mathrm{~m}$ dia. test fire (test 14 ). 


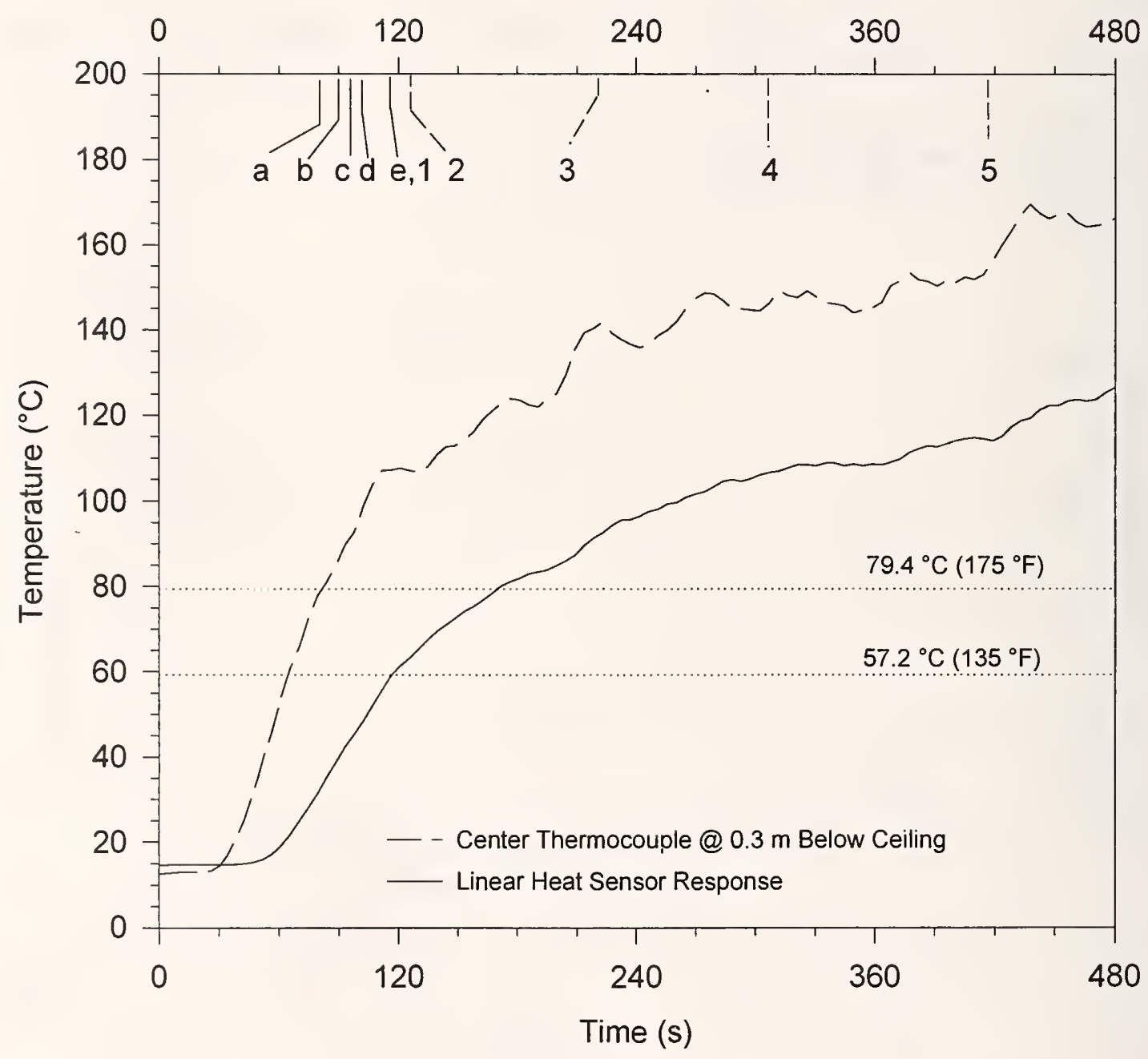

Events

$57.2^{\circ} \mathrm{C}\left(135^{\circ} \mathrm{F}\right)$ Spot-type heat detectors

a $-3.0 \mathrm{~m} \mathrm{~S}, 82 \mathrm{~s}$

b- $3.0 \mathrm{~m} \mathrm{~N}$ N/E, $90 \mathrm{~s}$

c $-6.1 \mathrm{~m} \mathrm{~N} / \mathrm{S}, 98 \mathrm{~s}$

$\mathrm{d}-6.1 \mathrm{~m} \mathrm{EN}, 102 \mathrm{~s}$

e $-9.1 \mathrm{~m}$ EN, $119 \mathrm{~s}$

\section{Automatic Sprinklers}

1 - S1, S1F, N1B, E1F, $79^{\circ} \mathrm{C}$ QR dry, $119 \mathrm{~s}$

2 - CB, CG, $79^{\circ} \mathrm{C} Q R,(123$ to 127$) \mathrm{s}$

$\mathrm{CG}, 93^{\circ} \mathrm{C} \mathrm{QR}, 127 \mathrm{~s}$

$3-\mathrm{CH}, 79^{\circ} \mathrm{C}$ SR, $220 \mathrm{~s}$

4 - W5B, S1E, S1A, CE

$141^{\circ} \mathrm{C}$ QR , (314 to 338)s

5 - S1D, $141^{\circ} \mathrm{C}$ SR LINK

Figure 138. Comparison of spot-type heat detectors and automatic sprinkler activation to line-type detector for $3.0 \mathrm{~m} \times 3.0 \mathrm{~m}$ pan fire (test 15 ). 
Since this sensor was installed along the curvature of the hangar ceiling, if temperature stratification occurred during an experiment, portions of the sensor would be at different temperatures. The sensor measures a weighted average over its entire length. Therefore, a temperature gradient will have a dramatic effect on the overall output. A simple example is shown of how temperature gradients can effect the output of this type of sensor when installed along the curved portion of a ceiling.

Temperature measurements are made at various points along the ceiling. Figure 139 shows an example configuration. The relationship between temperature and sensor resistance is defined by;

$$
R=C_{1} \cdot e^{C_{2}\left[\frac{1}{(T+459.7)}-\frac{1}{C_{3}}\right]}
$$

where $\mathrm{R}$ is the sensor resistance, $\mathrm{T}$ is the temperature $\left({ }^{\circ} \mathrm{F}\right)$, and $\mathrm{C}_{1}, \mathrm{C}_{2}$, and $\mathrm{C}_{3}$ are constants. From the figure, each $3 \mathrm{~m}$ section is defined by an average temperature along that portion. This is similar to the actual layout of temperature measurement points in the $22 \mathrm{~m}$ high facility. Each $3 \mathrm{~m}$ section of sensor has a corresponding resistance, $R_{n}$, based on the temperature of that zone. The resistance is calculated for each $3 \mathrm{~m}$ section and then summed using the relationship of parallel resistors. Once the total resistance has been calculated, the resistance for the entire length of sensor is found to be $2.52 \mathrm{M} \Omega$ by multiplying by the total length, $21 \mathrm{~m}$. By solving the above equation for $\mathrm{T}$, the resulting temperature output of the sensor can be computed.

$$
T_{\text {sensor }}=\left[\frac{\ln \left(R_{\text {sensor }} / C_{1}\right)}{C_{2}}+\frac{1}{C_{3}}\right]^{-1}
$$

For the above example, the calculations indicate that $\mathrm{T}_{\text {sensor }}$ is equal to $27.3^{\circ} \mathrm{C}$.

A similar method was used to analyze the data from the actual fire tests. Thermocouple measurements were used to determine the average temperature over the center portion of the linear heat sensor. By assuming that the temperature "zones" were approximately uniform across the ceiling, perpendicular to the curvature, an estimate of the overall sensor temperature was found. The calculations were carried out for test 14 and 15. Figure 140 describes the comparison between actual sensor response and computed sensor response. The computed temperature response of the linear heat sensor is similar to but higher than the measured response. This information may provide guidance on how the sensor should be installed in a space with a similar curved roof structure. Recalling that the roof structure of the $15 \mathrm{~m}$ high facility was relatively flat, the response of the linear heat detector closely resembled actual temperature measurements, which were closer to uniform in the layer where the linear detector was installed.

The ability to predict the response of this type of sensor allows one to anticipate how various ceiling configurations will affect the detector's performance. Based on calculated temperature profiles from a fire model, an alarm point value and temperature response characteristics for this type of sensor can be evaluated. 


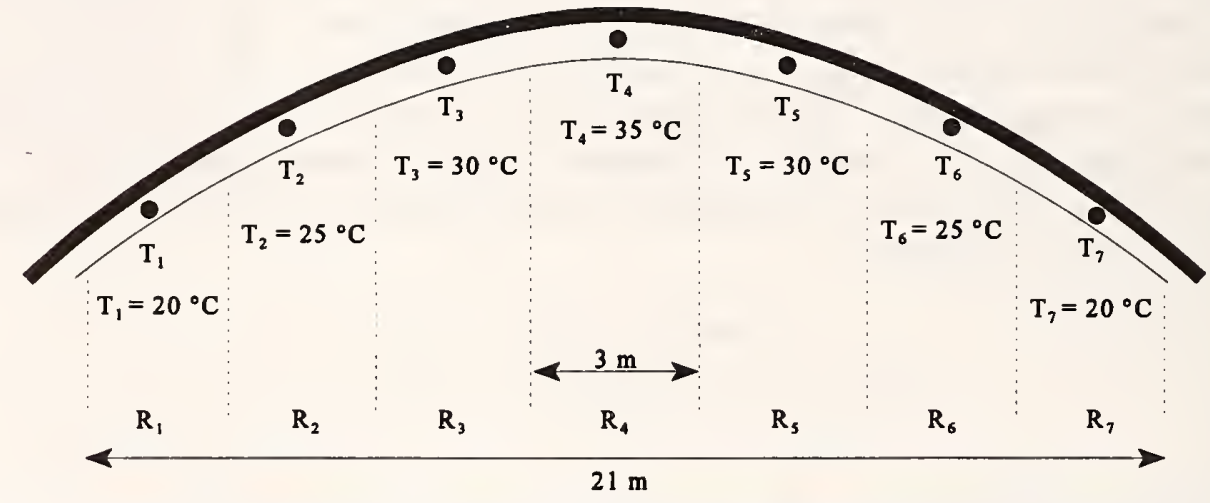

Figure 139. Example configuration of linear heat detector installation in a facility with a curved roof . 

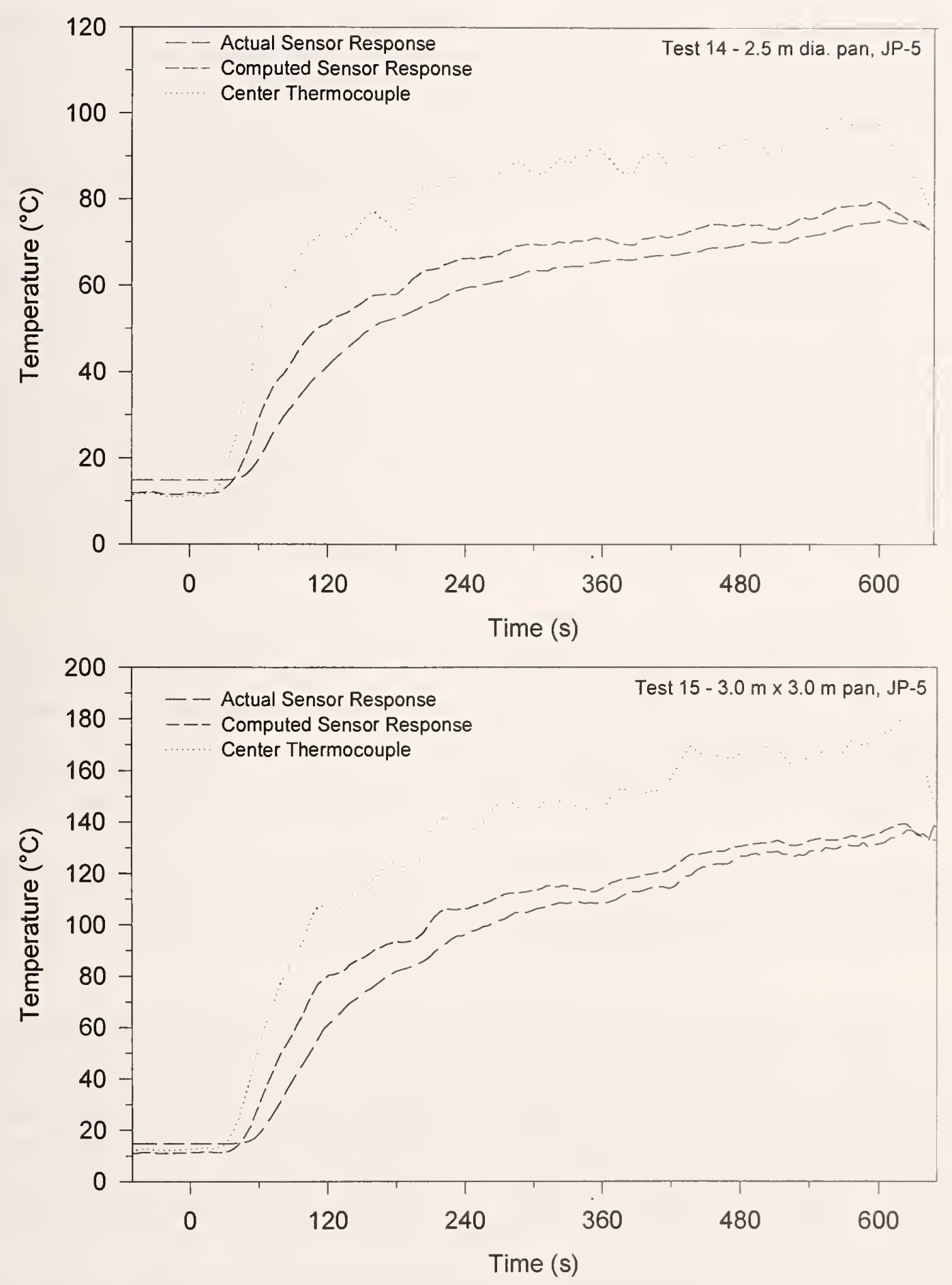

Figure 140. Comparison of measured line-type heat detector temperature to computed values for $2.5 \mathrm{~m}$ dia. and $3.0 \mathrm{~m} \times 3.0 \mathrm{~m}$ test fires in $22 \mathrm{~m}$ high facility. 



\section{$5 \quad$ APPLICATIONS OF FIRE MODELS}

The computational fluid dynamics model FLOW3D [29] was used prior to conducting the full-scale fire tests to predict the size fires necessary to activate the sprinklers. These calculations (discussed in sections 3 and 4) were also useful for estimating the range of conditions that would exist in the vicinity of the fire. Rather than a detailed field model such as FLOW3D, fire protection engineers more typically use simple correlations or zone models for guidance in the analysis of fire protection strategies for structures. However, the performance of fire correlations and zone fire models have not been extensively tested at the heights studied in these experiments.

The purpose of this section is to look at the capabilities of some of these models and assess their ability to predict maximum ceiling temperature and sprinkler activation. The models considered include the plume correlation of Heskestad [11], DETACT [12], and FPEtool [13]. All three models allow for the calculation of peak ceiling temperature over plume center and both DETACT and FPEtool provide ceiling jet models for sprinkler activation predictions. The sprinkler activation model in DETACT is based on the ceiling jet correlation of Alpert [14]. This correlation is also included in FPEtool. A second sprinkler detection algorithm is included in the Fire Simulator part of FPEtool and simulates the impact of the presence of an upper layer on the plume entrainment. Details of each of these models may be found in the cited references. The ceiling plume temperature model in FPEtool is based on the correlation developed by Alpert and Ward [15].

In order to simulate plume centerline temperatures, the estimated steady state heat release rate for each test was used to represent the fire. These heat release rates were determined using load cell measurements as discussed in section 3.3 with the exception of tests $6 \mathrm{~b}$ and 7 in Hawaii where a measurement of fuel consumption during the fire yielded an estimated average heat release rate for the fire. The fire was assumed to grow linearly from zero at the start of each test and reach its steady-state value $60 \mathrm{~s}$ after full pan involvement of the fire which was determined using visual observation. A 30 $\%$ radiative fraction was used to account for heat lost by radiation from the fire to the walls.

The ceiling heights used for the calculations were $14.9 \mathrm{~m}$ and $22 \mathrm{~m}$. All the fire models simulate smooth, flat ceiling geometry, hence the impact of large structural members found at the ceiling in both hangars and the effect of the curved ceiling in the $22 \mathrm{~m}$ hangar could not be included in the calculations.

A comparison of the measured plume centerline temperature and the predictions of the correlation and models are presented in Figures 141 and 142. The uncertainty in the thermocouple measurements are represented by the brackets on the experimental Tmax bars. For the Hawaii tests, both the ceiling plume temperature model in FPEtool and Heskestad's plume theory provided good predictive results when compared with the measurements. Only for test $6 \mathrm{~b}$, with a heat release rate of $7.7 \mathrm{MW}$, did the predictions significantly disagree with measurements. For this test, the heat release rate was based on the volume of fuel burned and hence the discrepancy with predictions may be a result of an incorrect heat release rate rather than a problem with the models.

The İceland fire tests provided a larger data base to do model comparisons. Tests $1-7$ and $14,15,18$, and 20 were closed door JP-5 tests. Tests 16 and 19 were open door JP-5 tests and tests $9-13$ and 18 were closed door JP-8 tests. For the closed door JP-5 tests, the models tended to over predict the 


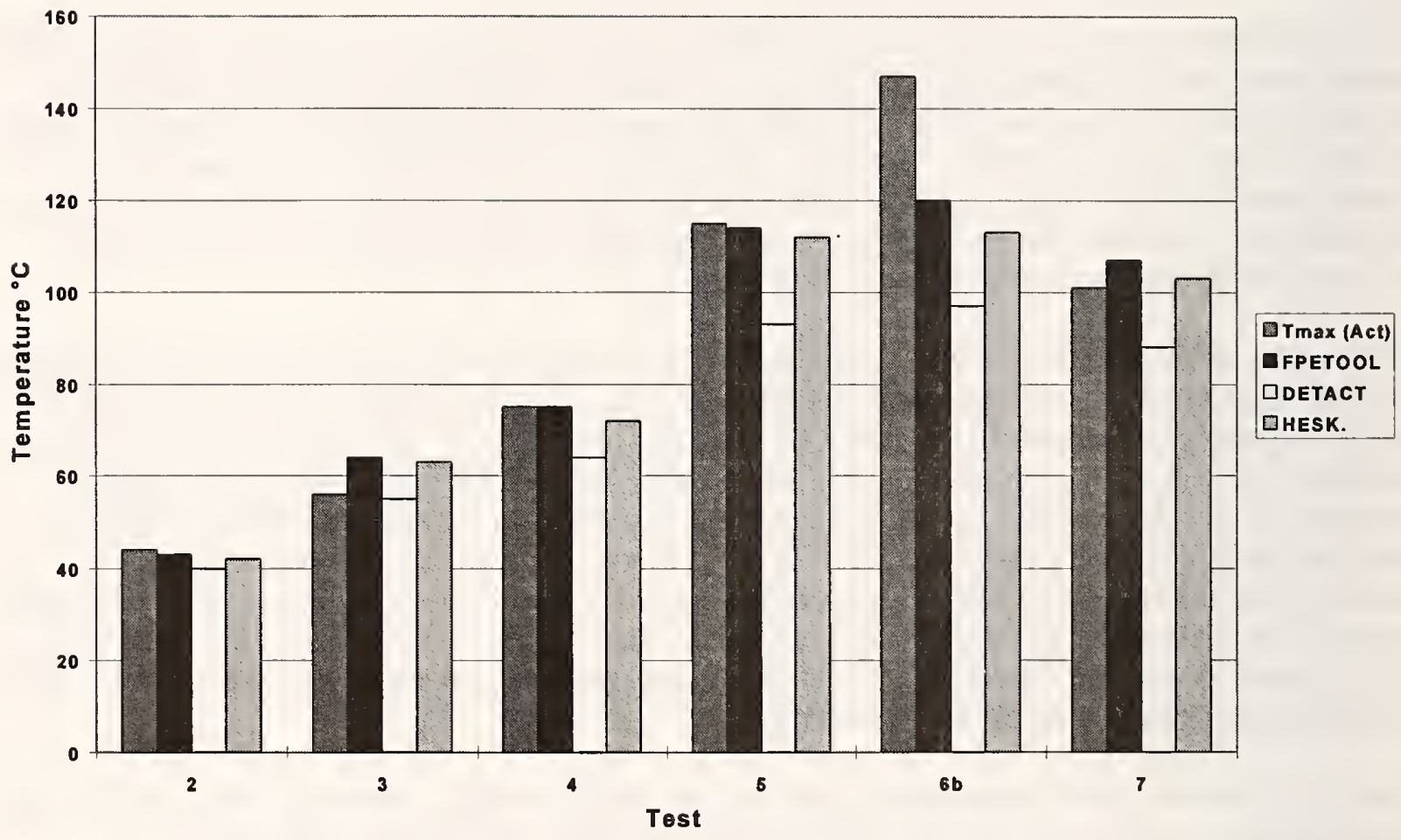

Figure 141. Hawaii Plume Centerline Temperatures. 


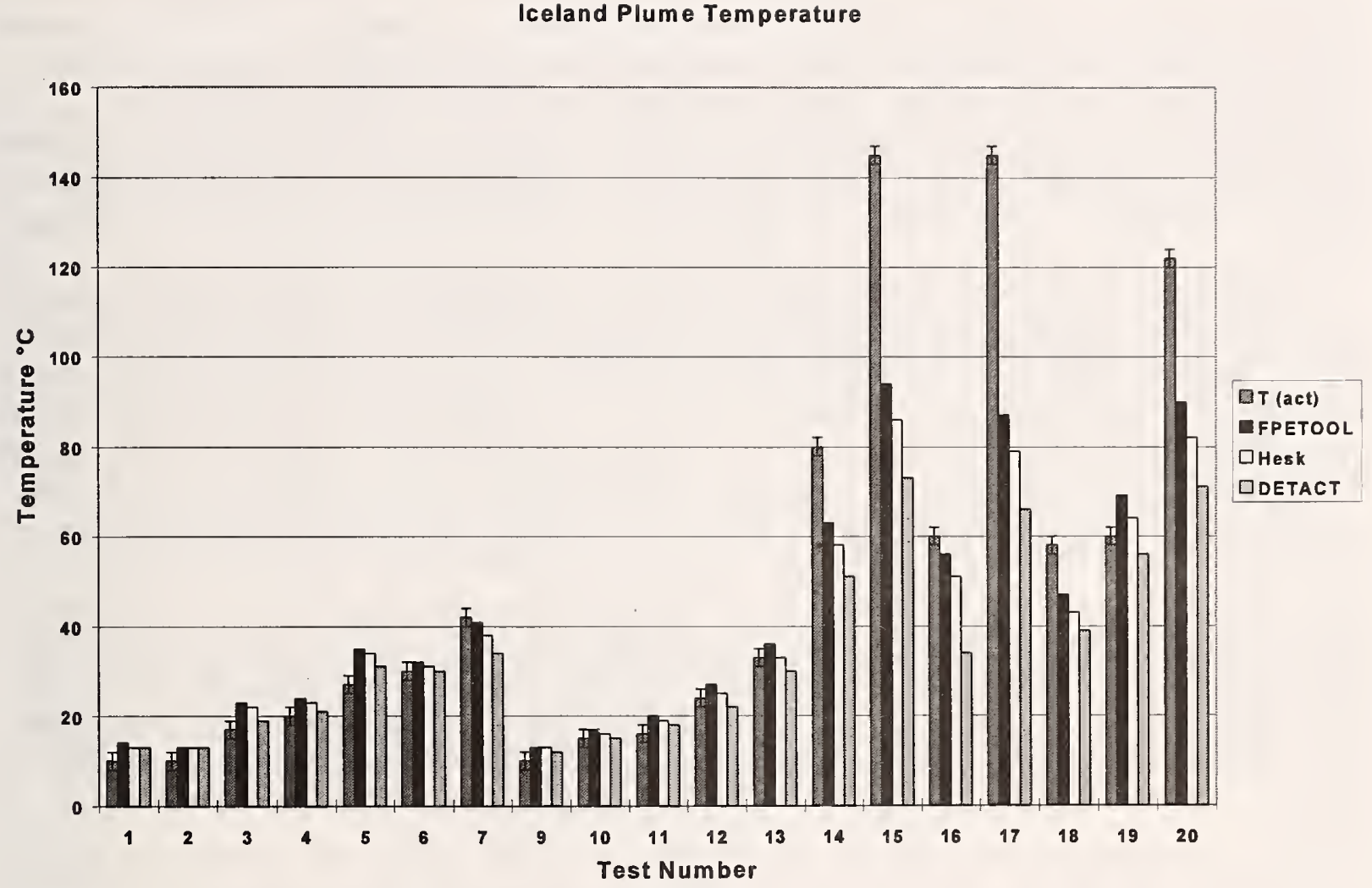

Figure 142. Iceland Plume Centerline Temperatures. 
ceiling temperature for the smaller fires but as the fire size increased, the models substantially under predicted the observed ceiling temperature. Model predictions for the open door JP-5 fire were closer to the measured values but the lower ceiling temperatures produced by the fires were due to wind effects and since none of the models include wind interactions, any agreement between model predictions and experimental results should be regarded as fortunate. The JP-8 closed door fire tests followed the same trend as the JP- 5 closed door fire tests in that the models provided good predictive results for the small fires but substantially under predicted the ceiling temperature for the large fires.

There are several possible reasons for the model failure in the large fires. The first reason is that the radiative fraction drops significantly for large pan fires [16] due to the fire volume becoming optically thick. The drop in radiative loss increases the convective heat release rate and would boost the model predictions above the temperatures predicted using the $30 \%$ radiative fraction. Inclusion of this effect would change model predictions of ceiling temperature for the largest fires by about $12{ }^{\circ} \mathrm{C}$ which is not sufficient to explain the temperature gap between model predictions and experimental results for the large fires. A second explanation would be that due to the extremely high flame heights produced by the large fires, the measurements done at the ceiling were not sufficiently far out of the combustion region for the plume theories to be valid. Flame heights for these experiments are given in table 48 and with the possible exception of test 21 where temperature spikes were observed at the ceiling, the observed flame height was substantially less than the ceiling height. A final reason may lie with the plume correlations. The data sets used to derive the correlations typically favor smaller fires and are based on data from unconfined ceiling experiments. These correlations, which do not include the impact of a smoke layer, are not adequate for large fires where a hot, deep, smoke layer develops quickly.

Of the three models used to predict ceiling temperature, the ceiling plume temperature model in FPEtool predicted the highest ceiling temperatures and DETACT predicted the lowest ceiling temperatures. This difference is due to the conservative design of both models. The correlation used in FPEtool is designed to be high to provide structural damage estimates while the DETACT correlation is designed to give lower temperatures for sprinkler activation. None of the models gave accurate temperature predictions for experiments with ceiling temperatures in excess of $79^{\circ} \mathrm{C}$.

To investigate model predictions of sprinkler activation, FPEtool was used to calculate sprinkler activation for the test fires in Hawaii and Iceland where sprinkler activation was observed. Both the ceiling jet correlation of Alpert and the ceiling jet correlation in Fire Simulator were included in the comparison. Alpert's correlation is designed for smooth, unconfined ceilings while the correlation in Fire Simulator uses a smooth ceiling correlation but includes the impact of a growing layer on the ceiling jet temperature.

Tables 73 and 74 present the results of this analysis for the $15 \mathrm{~m}$ and $22 \mathrm{~m}$ facilities. In the tables, "Alpert" refers to Albert's ceiling jet model which is available in both DETACT and FPEtool.

"FPEtool F.S." refers to Fire Simulator which accounts for entrainment changes in the plume due to layer formation. The average activation time for the quick response sprinklers are tabulated in the row labeled "Actual." Entries containing asterisks indicate that one or more sprinklers did not activate during the experiment. Albert's correlation was computed using FPEtool but similar results would be obtained using DETACT. The fire was modeled using a heat release rate that started at zero and linearly grew to its steady state value by $60 \mathrm{~s}$ after full pan involvement. The radiative fraction used for the computation was 0.3 . The sprinklers simulated had an activation temperature of $79{ }^{\circ} \mathrm{C}$ and a 
RTI of $35(\mathrm{~m} \mathrm{~s})^{1 / 2}$.

The activation times predicted by both ceiling jet models for tests 5 and 7 are much too short compared to the measured response times. A major reason for this discrepancy is probably due to the changing location of the plume center. Typically, the plume center, which is the hottest part of the plume moves around the center of the ceiling as discussed in section 3.3.2. As the plume moves or the fire pulsates, the local temperature at the thermocouple will vary. These experiments were designed to be threshold experiments for sprinkler activation. When the temperature at the sprinkler head is marginally above the activation temperature, the heating rate, which is proportional to the temperature difference between the gas and the thermal element, is not as fast as would be calculated using computer analysis which does not include plume movement and intermittent temperatures. These models assume a steady temperature above the activation temperature. An example of this effect can be found in Figure 41 where the local gas temperature fluctuates substantially prior to the activation of the sprinkler. Other effects which impact the accuracy of the model predictions include the uncertainty in the RTI and activation temperature of the sprinkler head and the effect of the ceiling structures on the hot gas flow.

For the larger fire, test $6 \mathrm{~b}$, the model provided good predictions for the sprinkler located on the center line and for the one at $3.0 \mathrm{~m}$. Alpert's model failed to predict sprinkler activations further from the plume centerline which may be a failing of the ceiling jet algorithm or the result of plume movement. FPEtool F.S. predicted much quicker activation times for the sprinklers at $6.1 \mathrm{~m}$ and $8.5 \mathrm{~m}$ and also predicted activation at $11.6 \mathrm{~m}$ even though no sprinkler activated at this distance.

For the $22 \mathrm{~m}$ hangar tests, Alpert's ceiling jet model predicted sprinkler activation only for the $33 \mathrm{MW}$ fire while quick response sprinklers were activated for a fire size as small as 7.9 MW. The failure of this model is understandable as the smoke layer develops rapidly in these experiments. The presence of the smoke layer will produce ceiling jet temperatures in excess of those predicted using an algorithm which does not include layer formation.

FPEtool F.S. results were obtained using fire simulator in FPEtool. Modeling of the $22 \mathrm{~m}$ hangar was done by assuming that the ceiling was flat and located $22.3 \mathrm{~m}$ above the floor. The draft curtained space had a ceiling area of $676 \mathrm{~m}^{2}$. A leak of length $45.7 \mathrm{~m}$ with a height of $0.1 \mathrm{~m}$ above the floor was used to simulate door leakage. Since fire simulator includes the effects of the layer on the plume and ceiling jet, a second modeling calculation, designated (2) in the table, was done using test 15 to investigate the sensitivity of layer depth on the calculation. In this second calculation, the draft curtain was simulated as two doors, each of height $13.4 \mathrm{~m}$ and length $45.7 \mathrm{~m}$. This calculation should keep the layer depth to just below the draft curtain which will be a smaller depth than observed experimentally.

The predictions for the 14 to $33 \mathrm{MW}$ fires using fire simulator were very close to the measured values for distances of $6.1 \mathrm{~m}$ or less. Fire simulator consistently predicted values that were less than measured, but this is understandable based on the fact that travel time of the smoke from the fire to the detectors is ignored in the calculations. The travel times would add anywhere from $5 \mathrm{~s}$ to $30 \mathrm{~s}$ to the calculated results depending on radial position. For distances beyond $6.1 \mathrm{~m}$, the agreement is not good but at these radial distances, the curved roof begins to be important which violates the physics of the model. FPEtool did not predict the sprinkler activations correctly in test 14 . This test is a threshold test which means that the sprinklers are barely able to activate during the test. To predict threshold activation correctly is beyond the current accuracy of the correlations in these models and requires knowing the RTI and activation temperature of the sprinkler head accurately. 
FPEtool contains an atrium model which provides the smoke temperature for a high space which is ventilated at a rate equal to the plume flow to the ceiling. These experiments did not provide ceiling ventilation and so the application of this model is not valid for these experiments but since fire protection engineers may be tempted to use the model, two modeling calculations were made to indicate how badly the model fails when used improperly. The model predicted a $11{ }^{\circ} \mathrm{C}$ temperature rise in the smoke layer for the $33 \mathrm{MW}$ fire in Iceland and a $4{ }^{\circ} \mathrm{C}$ temperature rise for the $7.8 \mathrm{MW}$ fire in Hawaii. The observed temperature rise near the ceiling for both these experiments far exceeded the predicted values which is expected since the measurements near the ceiling are in the ceiling jet and the model is predicting smoke temperatures in a well ventilated space and not ceiling jet temperatures.

Table 73. Sprinkler Analysis in $15 \mathrm{~m}$ Facility

\begin{tabular}{|c|c|c|c|c|c|}
\hline \multicolumn{6}{|c|}{ Test \#5 - $2.0 \mathrm{~m}$ diameter JP-5, 6.8 MW } \\
\hline Radius & $0 \mathrm{~m}$ & $3 \mathrm{~m}$ & $6.1 \mathrm{~m}$ & $8.5 \mathrm{~m} / 9.1 \mathrm{~m}$ & $11.6 \mathrm{~m}$ \\
\hline Alpert & $79 \mathrm{~s}$ & $88 \mathrm{~s}$ & NR & NR & NR \\
\hline FPEtool F.S. & $80 \mathrm{~s}$ & $85 \mathrm{~s}$ & $120 \mathrm{~s}$ & $153 / 165 s$ & NR \\
\hline Actual & $182 \mathrm{~s}$ & $186 \mathrm{~s}$ & $297 \mathrm{~s}$ & NR & NR \\
\hline \multicolumn{6}{|c|}{ Test \#6b - $2.5 \mathrm{~m}$ diameter JP-5, $7.7 \mathrm{MW}$} \\
\hline Alpert & $76 \mathrm{~s}$ & $84 \mathrm{~s}$ & NR & NR & NR \\
\hline FPEtool F.S. & $76 \mathrm{~s}$ & $81 \mathrm{~s}$ & $109 \mathrm{~s}$ & $122 \mathrm{~s} / 132 \mathrm{~s}$ & $152 \mathrm{~s}$ \\
\hline Actual & $85 \mathrm{~s}$ & $112 \mathrm{~s}$ & $186 \mathrm{~s}$ & $327 \mathrm{~s}$ & NR \\
\hline \multicolumn{6}{|c|}{ Test \#7 - $2.0 \mathrm{~m}$ diameter JP-5, 5.6 MW } \\
\hline Alpert & $87 \mathrm{~s}$ & $98 \mathrm{~s}$ & NR & NR & NR \\
\hline FPEtool F.S. & $89 \mathrm{~s}$ & $95 \mathrm{~s}$ & NR & NR & NR \\
\hline Actual & $397 \mathrm{~s}$ & $479 \mathrm{~s}$ & NR & NR & NR \\
\hline
\end{tabular}


Table 74. Sprinkler Analysis in $22 \mathrm{~m}$ Facility

\begin{tabular}{|c|c|c|c|c|c|c|}
\hline \multicolumn{7}{|c|}{ Test \# $142.5 \mathrm{~m}$ diameter JP-5 7.9 MW } \\
\hline Radius & $0.0 \mathrm{~m}$ & $3.0 \mathrm{~m}$ & $6.1 \mathrm{~m}$ & $9.1 \mathrm{~m}$ & $12.2 \mathrm{~m}$ & $15.2 \mathrm{~m}$ \\
\hline Alpert & NR & NR & NR & NR & NR & NR \\
\hline $\begin{array}{l}\text { FPEtool } \\
\text { F.S. }\end{array}$ & $139 \mathrm{~s}$ & $139 \mathrm{~s}$ & $162 \mathrm{~s}$ & $186 \mathrm{~s}$ & $203 \mathrm{~s}$ & $215 \mathrm{~s}$ \\
\hline Actual & $463 \mathrm{~s}$ & $438 \mathrm{~s}^{*}$ & NR & NR & NR & NR \\
\hline \multicolumn{7}{|c|}{ Test \#15 $3.0 \mathrm{~m} \mathrm{x} 3.0 \mathrm{~m} \mathrm{JP}-515.7 \mathrm{MW}$} \\
\hline Alpert & NR & NR & NR & NR & NR & NR \\
\hline $\begin{array}{l}\text { FPEtool } \\
\text { F.S. (1) }\end{array}$ & $92 \mathrm{~s}$ & $92 \mathrm{~s}$ & $105 \mathrm{~s}$ & $116 \mathrm{~s}$ & $124 \mathrm{~s}$ & $129 \mathrm{~s}$ \\
\hline $\begin{array}{l}\text { FPEtool } \\
\text { F.S. (2) }\end{array}$ & $98 \mathrm{~s}$ & $98 \mathrm{~s}$ & $116 \mathrm{~s}$ & $132 \mathrm{~s}$ & $147 \mathrm{~s}$ & $159 \mathrm{~s}$ \\
\hline Actual & $121 \mathrm{~s}$ & $160 s^{*}$ & $194 \mathrm{~s}$ & $239 \mathrm{~s}$ & $300 \mathrm{~s}$ & $352 \mathrm{~s}$ \\
\hline \multicolumn{7}{|c|}{ Test \#17 $3.0 \mathrm{~m}$ x $3.0 \mathrm{~m} \mathrm{JP}-814.3 \mathrm{MW}$} \\
\hline Alpert & NR & NR & NR & NR & NR & NR \\
\hline $\begin{array}{l}\text { FPEtool } \\
\text { F.S. }\end{array}$ & $90 \mathrm{~s}$ & $90 \mathrm{~s}$ & $103 \mathrm{~s}$ & $114 \mathrm{~s}$ & $122 \mathrm{~s}$ & $128 \mathrm{~s}$ \\
\hline Actual & $112 \mathrm{~s}$ & $112 \mathrm{~s}^{*}$ & $137 \mathrm{~s}^{*}$ & NR & $355 \mathrm{~s}^{*}$ & $355 \mathrm{~s} *$ \\
\hline \multicolumn{7}{|c|}{ Test \#20 3.0 x $3.0 \mathrm{~m}$ JP-5 $14.6 \mathrm{MW}$} \\
\hline Alpert & NR & NR & NR & NR & NR & NR \\
\hline $\begin{array}{l}\text { FPEtool } \\
\text { F.S. }\end{array}$ & $98 \mathrm{~s}$ & $98 \mathrm{~s}$ & $111 \mathrm{~s}$ & $123 \mathrm{~s}$ & $131 \mathrm{~s}$ & $137 \mathrm{~s}$ \\
\hline Actual & $117 \mathrm{~s}$ & $116 \mathrm{~s}^{*}$ & $156 \mathrm{~s}^{*}$ & $262 s^{*}$ & $405 \mathrm{~s}^{*}$ & NR \\
\hline \multicolumn{7}{|c|}{ Test \#21 $4.6 \mathrm{~m} \mathrm{x} 4.6 \mathrm{~m} \mathrm{JP}-533 \mathrm{MW}$} \\
\hline Alpert & $92 \mathrm{~s}$ & $92 \mathrm{~s}$ & $135 \mathrm{~s}$ & NR & NR & NR \\
\hline FPEtool & $62 \mathrm{~s}$ & $62 \mathrm{~s}$ & $72 \mathrm{~s}$ & $80 \mathrm{~s}$ & $86 \mathrm{~s}$ & $90 \mathrm{~s}$ \\
\hline Actual & $91 \mathrm{~s}$ & $88 \mathrm{~s} *$ & $95 \mathrm{~s}^{*}$ & $190 \mathrm{~s}^{*}$ & $123 \mathrm{~s}$ & $132 \mathrm{~s}^{*}$ \\
\hline
\end{tabular}





\section{CONCLUSIONS AND RECOMMENDATIONS}

\subsection{Observations on Behavior of Fires}

\subsubsection{Experimental}

Because a growing fire may damage aircraft adjacent to the site of ignition, it is important to evaluate how the heat is released from realistic size fires. This test program provided a unique opportunity to study the behavior of jet fuel pool fires in large confined spaces under environmentally controlled conditions. Fire sizes ranged from $0.3 \mathrm{~m} \times 0.3 \mathrm{~m}$ to $4.6 \mathrm{~m} \mathrm{x} 4.6 \mathrm{~m}$, releasing heat at rates between $100 \mathrm{~kW}$ and $33 \mathrm{MW}$. Two different jet fuels (JP-5 and JP-8) were used, and the hangar geometry was varied in a systematic way to study the impact of ceiling height $(15 \mathrm{~m}$ and $22 \mathrm{~m}$ ), ceiling shape (flat and barrel vaulted), draft curtains (with and without) and cross flow created by large open doors.

Reduced scale experiments conducted at NIST examined the heat release rates of JP-4, JP-5, and JP-8. While JP-5 and JP-8 are the primary fuels now used for military aircraft, existing fire protection guidelines are based upon the threat posed by the fuel they have superseded, JP-4. The results from the cone calorimeter show that JP-4 burns at a rate nearly $25 \%$ faster than both the JP- 5 and JP- 8 fuels. This difference in burning rate is also seen in the large calorimeter experiments where a $1.0 \mathrm{~m}$ diameter pan of JP-4 produced heat release rates of $1.9 \mathrm{MW}$, compared to $1.35 \mathrm{MW}$ and $1.5 \mathrm{MW}$ release rates for JP-5 and JP-8, respectively. The cone calorimeter, using $75 \mathrm{~mm}$ pans, produced enthalpy fluxes about five times smaller, which is a result consistent with the literature [35].

The heat release rate from all full-scale test fires can be correlated with a single straight line with a slope of about $1.6 \mathrm{MW} / \mathrm{m}^{2}$ (see, for example, Figure 98 ), and can be compared to enthalpy fluxes of $1.74 \mathrm{MW} / \mathrm{m}^{2}$ and $1.90 \mathrm{MW} / \mathrm{m}^{2}$ measured in 1.0 and $1.2 \mathrm{~m}$ diameter pans for JP-5 and JP-8, respectively, at NIST. These results indicate that a common energy flux around $1.7 \mathrm{MW} / \mathrm{m}^{2}$ can be assumed for JP-5 and JP-8 fires as long as the pan is greater than $0.9 \mathrm{~m}^{2}$, independent of the ambient fuel temperature, precise geometry of the room or fuel pan.

In the larger test fires, a significant amount of time was required to achieve full pan involvement. Excluding the smallest pans, for which fire spread was faster, the average flame propagation rate (starting from ignition at a corner) is estimated to be $0.055 \mathrm{~m} / \mathrm{s} \pm 0.010 \mathrm{~m} / \mathrm{s}$ for both JP-5 and JP-8. The time to full pan involvement can then be found from $t=(4 \mathrm{~A} / \pi)^{1 / 2} / \mathrm{v}$, with $v$ chosen as $0.055 \mathrm{~m} / \mathrm{s}$.

From the temperature data collected and visual observations made during this test series, it is clear that no significant heat or smoke stratification occurred. The maximum temperature rise above ambient for the JP-5 experiments ranged from $3{ }^{\circ} \mathrm{C}$ for the $0.3 \mathrm{~m} \mathrm{x} 0.3 \mathrm{~m}$ pan to nearly $123{ }^{\circ} \mathrm{C}$ for the $2.5 \mathrm{~m}$ diameter pan in the $15 \mathrm{~m}$ high Hawaiian hangar. For the 2.5 meter fire in Iceland, temperature rise was $81^{\circ} \mathrm{C}$ above ambient. The ambient temperature itself $\left(28^{\circ} \mathrm{C}\right.$ in Hawaii compared to $12^{\circ} \mathrm{C}$ in Iceland $)$ did not appear to be a significant factor in the behavior of the fires.

The data show that the use of draft curtains can improve the response time of sprinklers and heat detectors significantly in these hangars. Draft curtains contained the heat which lessened the time for the sprinklers to respond and increased the number of sprinkler heads activated within the fire area. Another question answered by these experiments was whether the draft curtain completely filled before spilling 
over into the adjacent curtained areas. Temperatures were measured at intervals spanning the full depth of the draft curtain including positions outside the draft curtain space. Based on these measurements and visual observations of the larger fires, it is concluded that hot gases and smoke can flow under draft curtains and spill into adjacent spaces prior to filling the first draft curtain area. However, for the depths of curtains used in these tests, this spillage does not detract significantly from the performance enhancement provided by the curtains.

As expected, having the hangar doors open significantly affects the behavior of the fires. The $2.0 \mathrm{~m}$ diameter pan fires conducted with hangar doors open resulted in severe plume lean and reduced visibility. In some cases, the plume lean approached $80^{\circ}$ from vertical, and those experiments had to be terminated approximately two minutes into the test. A fire with the hangar doors open can seriously increase the response time of detectors and sprinklers, threaten adjacent aircraft, reduce visibility, and hamper firefighting operations.

The experimental data indicate the following parameters have the most impact on the behavior of the fire (in decreasing order of importance), and are most likely to affect detection strategies:

- fire size

- cross winds (such as through large door openings)

- $\quad$ ceiling height

The presence of draft curtains has a significant effect on the movement of the ceiling jet, but not on the fire itself nor on the properties at the plume centerline.

Parameters of lesser importance in determining the structure of the pool fire are the following:

- $\quad$ fuel type (JP-5 vs. JP-8)

- $\quad$ pool shape (square vs. round)

- $\quad$ ambient temperature $\left(12^{\circ} \mathrm{C}\right.$ vs. $\left.28^{\circ} \mathrm{C}\right)$

\subsubsection{Numerical Models}

A limited number of field model calculations proved their worth for designing the proper fire size and determining appropriate locations for some of the experimental measurements. No attempt was made to assess their ability to duplicate the experimental results.

Zone models and simple correlations were used to estimate plume and ceiling velocities and temperatures, and to approximate sprinkler and detection response times in these experiments. These models were not originally developed for high bay applications, nor are they currently used for designing fire protection devices for hangars. Generally speaking, the predictions of the models did not correlate well with the large jet fuel fires. Measured ceiling jet velocities were significantly different from the estimated values. A comparison between the actual data and the output of these models shows that in their current form they should not be used to predict ceiling temperatures, detector response times, sprinkler response times, nor structural damage from large fires. in aircraft hangars. This is due in part to the fact that most of these models are based on experiments conducted with smaller fires and/or lower ceiling heights, where buoyancy-induced plume entrainment is considerably different from that encountered in the aircraft hangar test program. 


\subsection{Summary of Detection System Performance}

\subsubsection{Detection of Smoke}

\section{Projected Beam Smoke Detectors}

The present UL listings for projected beam smoke detectors are not suitable for detecting jet fuel fires in aircraft hangars. When tested using their listed settings, the dense smoke produced by jet fuel fires caused the projected beam detectors to activate a trouble alarm rather than a fire alarm. This is because the light beam was quickly obscured by dense black smoke well before the detector could produce a fire alarm condition. These detectors use the trouble alarm state to indicate beam blockage (e.g., caused by overhead cranes passing through the beam), a malfunction, or accumulation of dust or dirt on the detector's optics. When initially set to a sensitivity less than that established under current UL listing requirements, the projected beam detectors did activate fire alarm signals. However, the question remains whether or not the revised settings will affect the trouble alarm functions of these detectors.

The response of the projected beam smoke detectors with and without draft curtains was also investigated during these experiments. These detectors, when located to monitor the smoke within the draft curtain volume, respond faster to fires than when draft curtains are not used. Projected beam detectors mounted below the lower edge of draft curtains, however, require an unacceptable amount of time to respond.

\section{Photoelectric Smoke Detectors}

Although spot-type photoelectric smoke detectors would not typically be used in hangar applications, the data collected can be helpful in determining proper spacing for this type of detector in similar high bay spaces in which liquid fuels are present. The $0.3 \mathrm{~m} \times 0.3 \mathrm{~m}$ fires did not produce enough smoke to activate any photoelectric smoke detectors. For the larger fires, ceiling curvature had no significant effect on photoelectric detector response at $3.1 \mathrm{~m}$ and $6.1 \mathrm{~m}$ from the plume centerline. It was found that the detectors located $9.1 \mathrm{~m}$ from plume centerline compared to those spaced $3.0 \mathrm{~m}$ and $6.1 \mathrm{~m}$ from the plume showed no significant difference in response times. Tests support that the spacing of photoelectric smoke detectors of up to $12.2 \mathrm{~m}$ is acceptable (for these fast growing fires). This is contrary to the present practice prescribed in NFPA 72 of reducing detector spacing with increased ceiling heights.

The presence of the draft curtains did not significantly affect the response time of these detectors, in contrast with the other detection devices, most likely because these detectors were installed within $0.3 \mathrm{~m}$ of the ceiling (and thus in the ceiling jet).

The photoelectric smoke detectors sensed both JP-5 and JP-8 fires, and may be applied to other combustible liquid fires that produce similar dense smoke. The measured response times for JP- 5 fires were generally faster than for JP-8 fires, but this may be affected as much by the variations among the tests as to the different fuel compositions.

\subsubsection{Detection of Heat}

\section{Spot-Type Heat Detectors}


Temperature settings and detector spacings are the primary issues of concern when selecting heat detectors. Two temperature responses were investigated in these tests: $57{ }^{\circ} \mathrm{C}$ and $93^{\circ} \mathrm{C}$. As expected, $57^{\circ} \mathrm{C}$ heat detectors performed significantly faster than the $93^{\circ} \mathrm{C}$ detectors. None of the heat detectors responded to any fires less than $3 \mathrm{MW}$. When placed outside the draft curtain in the $22 \mathrm{~m}$ high hangar, no $93{ }^{\circ} \mathrm{C}$ heat detectors responded in any of the tests including the $33 \mathrm{MW}$ fire. In the open door tests, none of the $93{ }^{\circ} \mathrm{C}$ detectors responded even when placed within the draft curtain area. The data obtained for the $2.0 \mathrm{~m}$ diameter pan fires in the $15 \mathrm{~m}$ hangar indicate that the $57^{\circ} \mathrm{C}$ spot-type heat detectors activated nearly twice as fast with draft curtains in place as without draft curtains. The response times of $57^{\circ} \mathrm{C}$ heat detectors in the $22 \mathrm{~m}$ facility took 3 times as long as those in the $15 \mathrm{~m}$ hangar.

Since these detectors were installed at approximately $3 \mathrm{~m}$ intervals, the question of how far to space these detectors for reliable activation in a high bay space was answered. The response of the $57^{\circ} \mathrm{C}$ heat detectors in the $15 \mathrm{~m}$ high facility showed that detectors could be installed at a spacing of $12.2 \mathrm{~m}(40 \mathrm{ft})$ without adversely affecting response times. This finding is contrary to the current practice of reducing detector spacing with increased ceiling heights.

A secondary issue related to the performance of this type of detector is the complexity of the ceiling configuration (i.e., structural beams). For the tests conducted in the $15 \mathrm{~m}$ high facility, the configuration of ceiling level structural beams had no significant effect on heat detector response times.

Rate-compensated heat detectors are the preferred spot-type heat detector, but temperature selection is still critical. The $57^{\circ} \mathrm{C}$ heat detectors may be appropriate in a cold climate such as Iceland or Alaska, but generally will not be appropriate in most other climates due to the possibility of false alarms during warmer weather. The $93^{\circ} \mathrm{C}$ heat detectors proved unsuitable because they took longer to respond than the $79^{\circ} \mathrm{C}$ quick response sprinklers. On a pre-action type system, it is important to open the sprinkler alarm valve before a number of sprinklers have activated. With closed-head sprinkler systems, it is important to match the temperature rating of the heat detector as closely as possible to that of the automatic sprinklers.

\section{Linear Heat Detectors}

A linear heat detector was installed with a spacing based on the manufacturer's recommendation. In a nominally flat ceiling, using the NFPA 72 spacing for the detectors at a maximum ceiling height of $9.1 \mathrm{~m}$ $(30 \mathrm{ft})$, the line type detector cable reached the listed temperature of the spot type heat detectors at roughly the same time the heat detector responded. The linear heat detector closely resembled the temperature readings measured by the thermocouples, agreeing to within $\pm 7^{\circ} \mathrm{C}$ for all experiments in the flat $15 \mathrm{~m}$ high facility. In nearly all cases the linear heat detector reached the $79^{\circ} \mathrm{C}$ threshold before any sprinkler activated and reached the $57^{\circ} \mathrm{C}$ threshold within $\pm 15 \mathrm{~s}$ of spot-type heat detector activation.

Because this detector was tested in a temperature measurement mode only, no alarms were initiated. One would normally select an alarm setting from the calibration curve given for each sensor and perform several large fire tests to see when the detector reaches a certain temperature. In many cases, such as new facilities and/or "clean" facilities, this practice is not feasible. However, based on the data collected during these test fires, alarm settings could be determined by evaluating predicted ceiling temperatures and choosing a temperature threshold. It is important to note that the existing fire models would first have to be validated using the data collected during these experiments. This temperature threshold 
would be well above ambient temperature fluctuations but yet below the temperature ratings for the sprinkler system.

The use of line type heat detector cable in a curved roof application is not recommended. There is not yet enough experience installing the detectors in these applications. The line-type heat detector cable under the curved roof had a much longer response time than any of the spot type heat detectors, yielding average upper layer temperatures that were far lower than the peak local temperatures.

\subsubsection{Detection of Flame Radiation}

The UV/IR optical flame detectors respond much faster to a growing spill fire than any other detection method examined, and long before overhead sprinklers or heat detection systems. This indicates that UV/IR-activated foam monitors (or a similar system) might extinguish a spill fire before the overhead systems are even activated. However, appropriate performance criteria need to be established, and problems associated with existing foam monitor designs need to be eliminated. Until now, optical flame detectors have only been tested and listed for their response to steady state fire conditions. From a fire protection standpoint, it is more important to evaluate their response times from the point of ignition and during fire growth.

Controller-based optical flame detectors offer a much greater flexibility in detector setting and responded faster than the predicted responses of the unitized optical detectors. Optical flame detectors designed for JP-4 fires are suited for JP-5 and JP-8 fires as well.

\subsection{Summary of Sprinkler Activation Performance}

The data collected in the fire experiments support the use of closed head sprinkler systems in aircraft hangars. In arriving at this conclusion, four different closed head sprinkler design parameters were investigated to determine their impact on the activation time in the $15 \mathrm{~m}$ and $22 \mathrm{~m}$ hangars: temperature setting, response time, link design, and dry vs. wet installations. The temperature set point is, by far, the most important characteristic of the sprinkler, followed by the RTI. The wet-pipe versus dry-pipe sprinkler configurations had no significant effect on the sprinkler response time to a variety of fire sizes. However, any dry-pipe or pre-action sprinkler system will incur an additional time delay delivering water from an alarm check valve.

The $79^{\circ} \mathrm{C}$ quick response sprinkler heads proved to activate most effectively of all the sprinkler heads tested in these large fire, high bay hangar tests. Closed head sprinklers using $79^{\circ} \mathrm{C}$ quick response heads could circumvent the problems associated with false activation of deluge systems, and may provide a similar degree of protection. The primary reason is that by the time the fire is large enough to activate closed head sprinklers (or spot-type detectors) at the ceiling, the plume is large enough to activate a number of sprinklers, provided draft curtains are in place. A comparison of quick response vs. standard response sprinklers shows the quick response heads activated 1.5 to 2.5 times faster than the standard response heads.

Test fires conducted in the $15 \mathrm{~m}$ high facility revealed that none of the automatic sprinklers installed activated for the fire sizes less than $2.8 \mathrm{MW}$. The smallest test fire to activate any installed automatic sprinklers was the $2.0 \mathrm{~m}$ diameter pan with a heat release rate of approximately $6 \mathrm{MW}$. In addition, 
none of the $141{ }^{\circ} \mathrm{C}$ sprinklers installed activated during any of the experiments conducted in the $15 \mathrm{~m}$ high facility. The smallest fire to activate sprinklers in the $22 \mathrm{~m}$ hangar was $7.9 \mathrm{MW}$. The sprinklers at the peak of the $22 \mathrm{~m}$ roof activated approximately $20 \%$ faster than those at the same radial distance but lower than the peak. The smallest fires to activate the $93{ }^{\circ} \mathrm{C}$ and $141{ }^{\circ} \mathrm{C}$ sprinklers were, respectively, 13.3 MW and 15.1 MW in size. In the $2.5 \mathrm{~m}$ open door test, no sprinklers activated; however, the duration of this test was considerably shorter.

Fire size affects both the number of sprinklers activated and their response times. The tests performed in the $15 \mathrm{~m}$ hangar also evaluated sprinkler response with and without draft curtains. The same fire size tests were conducted in both situations. With the draft curtains in place, more sprinklers operated with faster response times. The draft curtains also improved sprinkler response farther from the centerline of the plume. Without the draft curtains in place, the hot gas layer was unable to accumulate sufficiently to activate the sprinklers in a reasonable time.

The use of $141^{\circ} \mathrm{C}$ closed head sprinklers in hangars is not acceptable because of the large fire size required to actuate these sprinklers in a short enough period of time. In the $22 \mathrm{~m}$ hangar, a $2.5 \mathrm{~m}$ diameter pan fire with a heat release rate of approximately $7.9 \mathrm{MW}$ did not activate any of the $141{ }^{\circ} \mathrm{C}$ sprinklers for the duration of the test. A fire of this magnitude could easily damage adjacent aircraft.

\subsection{Overall Conclusions and Specific Recommendations}

It can be concluded that current fire detection and sprinkler activation design criteria for high bay aircraft hangars are insufficient to assure the protection of aircraft adjacent to the point of ignition. However, there exist alternative designs and detection technologies that could be adopted to provide a much earlier indication that a hazardous fire is present, permitting suppression strategies to be applied more effectively.

The results of the experiments conducted in this program and the conclusions drawn from the subsequent analysis and modeling are supportive of the following specific recommendations:

- A systematic review of the fire codes for large and high bay spaces should be initiated. The review should include methods for large scale testing of fire detection devices and means for appropriate model validation.

- When the protection of adjacent aircraft is a design goal for hangar fire protection systems, NFPA 409 will need to be revised.

- Sprinkler heads with $79^{\circ} \mathrm{C}$ quick response elements should be used in all closed head sprinkler systems protecting aircraft hangars.

- Where spot-type heat detectors are used in conjunction with pre-action type sprinkler systems, rate-compensated heat detectors should be selected with activation temperatures closely matched to automatic sprinkler heads.

- Spot-type detector spacing for jet fuel fires in high bay hangars can be increased beyond the limitations presently suggested in NFPA 72 for hangars up to $22 \mathrm{~m}$ in height. 
- Optical flame detectors should be used if one wants to detect a growing spill fire quickly. However, additional research is needed to determine response time and placement criteria based upon hangar geometry, type and composition of aircraft.

- More research is needed to determine alarm set points for line-type heat detectors in hangars in nominally flat ceilings if test fires during installation are to be eliminated. Additional research is also needed for installation and spacing of line-type heat detectors in hangars whose ceilings are curved or with significant height variations.

- If accurate sprinkler or detector response, ceiling temperatures, or structural damage predictions are sought, current fire zone models should not be applied to high bay hangars without first accounting for the growing hot ceiling layer. The data generated in this study can be used as the basis for validation prior to the use of improved fire zone models in assessing fire protection strategies.

- The data collected in these experiments should be compared against predictions from computational fluid dynamic models as a way to build confidence in and extend the range of applicability of the models. With further validation, these numerical models can be used to complement experience and testing when selecting fire detection options for aircraft hangars and other high bay spaćes, but no single model prediction should be the basis of design change. 



\section{REFERENCES}

[1] Krasner, L., Chicarello, P., and Fitzgerald, P., "Fire Protection of Large Air Force Hangars," Air Force Weapons Laboratory, Kirtland AFB, Report AFWL-TR-74-23, July 1974.

[2] NFPA 16A, Standard for the Installation of Closed-Head Foam-Water Sprinkler Systems, National Fire Codes, National Fire Protection Association, Quincy, MA, 1994.

[3] Notarianni, K. and Davis, W., The Use of Computer Models to Predict Temperature and Smoke Movement in High Bay Spaces. NISTIR 5304, National Institute of Standards and Technology, Gaithersburg, MD, 1993.

[4] Alpert, R.L., Calculation of Response Time of Ceiling Mounted Fire Detectors, Fire Technology, Volume 8 Number 3, August 1972.

[5] Military Specification: Turbine Fuel, Aviation, Grades JP-4, JP-5, and JP-5/JP-8 ST, MILT5624P, September, 1992.

[6] Military Specification: Turbine Fuel, Aviation, Kerosene Types, NATO F-34 (JP-8) and NATO F-35, MIL-T-83133D, January, 1992.

[7] Babrauskas, V., Development of the Cone Calorimeter -- A Bench-Scale Heat Release Rate Apparatus Based on Oxygen Consumption, NBSIR 82-2611, November 1982.

[8] Standard Test Method for Heat and Visible Smoke Release Rates for Materials and Products Using an Oxygen Consumption Calorimeter, ASTM E-1354, Annual Book of ASTM Standard, Volume 4.07, American Society for Testing and Materials (1990).

[9] Babrauskas, V., Lawson, J.R., Walton, W.D., and Twilley, W.H., Upholstered Furniture Heat Release Rates Measured with a Furniture Calorimeter, NBSIR 82-2604, Natl. Bur. Stand. (U.S.), 1982.

[10] Affens, W. A., McLaren G. W., and Carhart, H. W., .Flammability Properties of Hydrocarbon Fuels, Part 4 - The Significance of Flash Point as an Indicator of the Flammability Hazard of Hydrocarbon Fuels, NRL Report 7549, March, 1973.

[11] Heskestad, G., "Fire Plumes," in SFPE Handbook of Fire Protection Engineering, second edition, P. J. Dinenno, editor, NFPA, Quincy, Mass., 1995.

[12] Evans, D. D., and Stroup, D. W., "Methods to Calculate the Response Time of Heat and Smoke Detectors Installed Below Large Unobstructed Ceilings," Fire Tech. 22, 54 (1986).

[13] Deal, S., Technical Reference Guide for FPEtool, Version 3.2, NISTIR 5486-1, National Institute of Standards and Technology, 1995.

[14] Alpert, R., L., "Calculation of Response Time of Ceiling-Mounted Fire Detectors," Fire, Tech. 
8, 181 (1972).

[15] Alpert, R.L., and Ward, E. J.,"Evaluating Unsprinklered Fire Hazards," SFPE Technology Report 83-2, Society of Fire Protection Engineers, Boston, MA, 1983.

[16] Yang, J. C., Hamins, A., and Kashiwagi, T, Combust. Sci. and Tech. 96, 183 (1994).

[17] NFPA 409, "Standard on Aircraft Hangars," National Fire Codes, National Fire Protections Association, Quincy, MA, 1995.

[18] NFPA 13, "Standard for the Installation of Sprinkler Systems," National Fire Codes, National Fire Protections Association, Quincy, MA, 1994.

[19] Military Handbook 1008B, Fire Protection for Facilities Engineering, Design, and Construction, Headquarters, Naval Facilities Engineering Command, Alexandria, VA 1994.

[20] NFPA 72, National Fire Alarm Code, National Fire Protections Association, Quincy, MA, 1993.

[21] UL 268, "Smoke Detectors for Fire Signaling Systems, " Underwriters Laboratories Inc., Northbrook, IL, 1994.

[22] "Beam Smoke Detection Systems Installation Instructions," Detection Systems Inc., Fairport, NY, 1993.

[23] "Principles of Long-range Beam Smoke Detection," Detection Systems Inc., Fairport, NY, 1994.

[24] Mechler, T., (personal correspondence with K. Notarianni), Detection Systems Inc., Fairport, NY, March 29,1995.

[25] Alt, J., (personal correspondence with J. Gott), Detector Electronics, Bloomington, MN, June $27,1995$.

[26] Instruction Manual for 9090 Sensor (PN A8MSN2), Alison Control, Inc., Fairfield, NJ, February 1995.

[27] Davis, W., and Cooper, L., "Estimating the Environment and the Response of Sprinkler Links in Compartment Fires with Draft Curtains and Fusible Line-actuated Ceiling Vents - Part II: User Guide for the Computer Code LAVENT," NISTIR 89-4122, National Institute of Standards and Technology, Gaithersburg, MD, August 1989.

[28] Evans, D. D., and Stroup, D. W., "Methods to Calculate the Response Time of Heat and Smoke Detectors Installed Below Large Unobstructed Ceilings," Fire Tech. 22, 54 (1986).

[29] FLOW3D Release 3.2 : USER MANUAL, CFD Department, AEA Industrial Technology, Harwell Laboratory, United Kingdom, October, 1992. 
[30] Loss Prevention Data Sheet 7-93N, Loss Prevention Data, Factory Mutual Engineering Corporation, Inc., Norwood, MA, March 1991.

[31] Alpert, R., Comb. Sci. and Tech. 11, 197 (1975).

[32] Moore, W.D., editor, National Fire Alarm Code Handbook, First Edition, National Fire Protection Association, Quincy, MA, 1994.

[33] Zimmerman, C.E., Bukowski, R.W., O'Laughlin, R.J., Editors, Fire Alarm Signaling Systems Handbook, First Edition, National Fire Protection Association, Quincy, MA, 1987.

[34] Fraser, B., (personal correspondence with J. Gott), Simplex Time Recorder Co., Gardner, MA, June 14, 1995.

[35] Hottel, H.C., "Certain Laws Governing Diffusive Burning of Liquids," Fire Research Abstracts and Reviews 1, p. 41 (1959). 



\section{APPENDIX \\ Wood Crib Fire Tests, 15 m High Facility}

Two wood crib fire tests were conducted in the $15 \mathrm{~m}$ high facility (test numbers 9 and 10 ). The purpose of the wood crib tests was to evaluate the response of a variety of fire detection devices and sprinklers to fires involving ordinary combustibles in high spaces. The devices evaluated included photoelectric smoke detectors, heat detectors, projected beam smoke detectors, ultraviolet/infrared optical flame detectors, and quick and standard response sprinkler heads with various activation temperatures. In addition, the maximum ceiling temperature and temperature rise above ambient were obtained from thermocouples installed throughout the test area. General information regarding these tests is shown in Table 75. It is important to note that test 10 consisted of two separate wood cribs (i.e., crib numbers 2 and 3) stacked on top of each other with each crib having dimensions of $0.6 \mathrm{~m} \times 0.6 \mathrm{~m} \times 0.6 \mathrm{~m}$. Both tests were conducted without draft curtains in place. Furthermore, there was no load cell present during these tests; therefore, the heat release rate was calculated by the following equation:

$$
\mathrm{Q}=\Delta \mathrm{h}_{\mathrm{c}} \times \mathrm{m}_{\mathrm{f}}
$$

where

$\mathrm{Q}$ is the heat release rate $(\mathrm{kW})$

$\Delta h_{c}$ is the convective heat of combustion of the crib material $(\mathrm{kJ} / \mathrm{kg})$

$\mathrm{m}_{\mathrm{f}}$ is the fuel mass burning rate $(\mathrm{kg} / \mathrm{s})$.

The convective heat of combustion is a percentage of the total heat of combustion. The remaining percentage is loss to the environment by radiation. The fuel mass burning rate was determined by:

$$
m_{f}=(4 / D) m_{o} v_{p}\left[1-\left(2 v_{p} t / D\right)\right]
$$

where

$D$ is the stick thickness $(\mathrm{m})$

$\mathrm{m}_{\mathrm{o}}$ is the initial crib mass $(\mathrm{kg})$

$t$ is the time since ignition (s)

$v_{\mathrm{p}}$ is the fuel surface regression velocity $(\mathrm{m} / \mathrm{s})$.

The fuel surface regression velocity is given by:

$$
v_{p}=2.2 \times 10^{-6} \mathrm{D}^{-0.6}
$$

\section{Response of Photoelectric Smoke Detectors}

The response times of the photoelectric smoke detectors for tests 9 and 10 are shown in Table 76 . The photoelectric detector installation parameters are discussed in section 3, along with locations of the

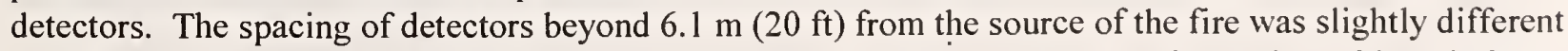
along the north/south axis than the east/west axis due to the location of the draft curtain. Although the draft curtain was removed for test 7-13 the detector locations were not changed. 
In test 9 , only 5 of 17 detectors installed responded to the $0.6 \mathrm{~m} \times 0.6 \mathrm{~m} \mathrm{x} 0.6 \mathrm{~m}$ wood crib fire. The average response times at $3.0 \mathrm{~m}(10 \mathrm{ft})$ and $6.1 \mathrm{~m}(20 \mathrm{ft})$ from the source were $52 \mathrm{~s}$ and $58 \mathrm{~s}$ respectively. Figure 143 shows the comparison of response times versus detector location. The spacing of detectors showed no significant difference in the response times of detectors located $6.1 \mathrm{~m}(20 \mathrm{ft})$ away compared to those spaced $3.0 \mathrm{~m}(10 \mathrm{ft}$ ) away. This indicates that a detector spacing of $12.2 \mathrm{~m} \mathrm{(40} \mathrm{ft)} \mathrm{would} \mathrm{be}$ acceptable for detecting a $0.6 \mathrm{~m} \times 0.6 \mathrm{~m} \times 0.6 \mathrm{~m}$ wood crib fire in a $15 \mathrm{~m}$ high facility. This is contrary to the present practice of reducing detector spacing in high bay areas. No detectors beyond $6.1 \mathrm{~m} \mathrm{(20 \textrm {ft } )}$ from the source responded during this test.

In test 10 , all 17 detectors installed responded within $159 \mathrm{~s}$. The average response time of the detectors located $3.0 \mathrm{~m}(10 \mathrm{ft})$ from the source was $58 \mathrm{~s}$, compared to $78 \mathrm{~s}$ for the detectors located $6.1 \mathrm{~m}(20 \mathrm{ft})$ from the source. These two detector locations showed no significant difference in response times. Again, this is contrary to the present practice of reducing detector spacing in high bay areas. Figure 144 shows the comparison of response times versus detector spacing.

\section{Response of Heat Detectors}

The heat detector installation parameters and mounting locations are discussed in section 3 . No heat detectors in either test 9 or 10 responded to the wood crib fires. The detectors were fixed temperature, rate-compensated heat detectors with a listed temperature of $57^{\circ} \mathrm{C}\left(135^{\circ} \mathrm{F}\right)$. The maximum ceiling temperatures directly above the plume centerline were $52^{\circ} \mathrm{C}\left(125.6^{\circ} \mathrm{F}\right)$ for test 9 and $53^{\circ} \mathrm{C}\left(127.4^{\circ} \mathrm{F}\right)$ for test 10 .

\section{Response of Projected Beam Smoke Detectors}

The projected beam smoke detector installation parameters and mounting locations are described in section 3. The detectors were programmed with different settings (i.e., alarm sensitivity and alarm window), some of which were outside their UL listing. The alarm sensitivity setting, which ranges from $20 \%$ to $70 \%$, represents a decrease in signal strength. The alarm window setting is the time the signal must remain below the preset sensitivity level before an alarm is generated. The UL approved alarm window setting is $30 \mathrm{~s}$ which is based on ordinary combustible fire loads. In the two wood crib tests, there were three different alarm window settings used $(5 \mathrm{~s}, 10 \mathrm{~s}$, and $30 \mathrm{~s})$ to determine the difference in response of the projected beam detectors with shorter alarm windows. The projected beam detector response times for tests 9 and 10 are shown in Table 77.

In test 9 , all three detectors at the highest elevation (i.e., $0.3 \mathrm{~m}$ below the ceiling) responded with an average response time of $80 \mathrm{~s}$. The three detectors at the middle elevation (i.e., $1.8 \mathrm{~m}$ below the ceiling) did not respond. Of the three detectors at the lowest elevation (i.e., $2.7 \mathrm{~m}$ below the ceiling) only the center detector activated, with a response time of $46 \mathrm{~s}$. It is important to note that this detector was positioned directly in the fire plume.

In test 10 , the average response time for the three detectors at the highest elevation was $124 \mathrm{~s}$. Only 2 of 3 detectors located at the middle elevation activated, with a response time exceeding $560 \mathrm{~s}$. Of the three detectors located at the lowest elevation, only the center detector activated, with a response time of $41 \mathrm{~s}$. Again, it is important to note that this detector was positioned directly in the fire plume. 
Table 75. General test information, wood crib experiments in $15 \mathrm{~m}$ high facility

\begin{tabular}{|c|c|c|c|c|c|c|c|c|}
\hline $\begin{array}{c}\text { Test } \\
\text { Number }\end{array}$ & $\begin{array}{c}\text { Crib } \\
\text { Number }\end{array}$ & Material & Dimensions & Weight & $\begin{array}{c}\text { Estimated } \\
\text { Moisture } \\
\text { Content }\end{array}$ & $\begin{array}{l}\text { Relative } \\
\text { Humidity }\end{array}$ & $\begin{array}{c}\text { Heat } \\
\text { Release } \\
\text { Rate }\end{array}$ & $\begin{array}{c}\text { Test } \\
\text { Duration }\end{array}$ \\
\hline Test 9 & Crib 1 & Fir & $\begin{array}{l}.6 \times .6 \times .6 \mathrm{~m} \\
(2 \times 2 \times 2 \mathrm{ft})\end{array}$ & $\begin{array}{l}48.1 \mathrm{~kg} \\
(106 \mathrm{lb})\end{array}$ & $13 \%$ & $63 \%$ & $\begin{array}{l}0.41 \\
M W\end{array}$ & $275 \mathrm{~s}$ \\
\hline \multirow{2}{*}{ Test 10} & Crib 2 & \multirow{2}{*}{ Fir } & $\begin{array}{l}.6 \times .6 \times .6 \mathrm{~m} \\
(2 \times 2 \times 2 \mathrm{ft})\end{array}$ & $\begin{array}{l}50.8 \mathrm{~kg} \\
(112 \mathrm{lb})\end{array}$ & \multirow{2}{*}{$13 \%$} & \multirow{2}{*}{$63 \%$} & \multirow{2}{*}{$\begin{array}{l}0.64 \\
\mathrm{MW}\end{array}$} & \multirow{2}{*}{$615 \mathrm{~s}$} \\
\hline & Crib 3 & & $\begin{array}{l}.6 \times .6 \times .6 \mathrm{~m} \\
(2 \times 2 \times 2 \mathrm{ft})\end{array}$ & $\begin{array}{l}51.2 \mathrm{~kg} \\
(113 \mathrm{lb})\end{array}$ & & & & \\
\hline
\end{tabular}

Table 76. Response times of photoelectric smoke detectors during wood crib fires conducted in 15 m high facility.

\begin{tabular}{|c|c|c|c|c|c|c|c|}
\hline Location & $\begin{array}{l}3.0 \mathrm{~m} \\
(10 \mathrm{ft})\end{array}$ & $\begin{array}{l}6.1 \mathrm{~m} \\
(20 \mathrm{ft})\end{array}$ & $\begin{array}{l}8.5 \mathrm{~m} \\
(28 \mathrm{ft})\end{array}$ & $\begin{array}{l}9.1 \mathrm{~m} \\
(30 \mathrm{ft})\end{array}$ & $\begin{array}{l}10.7 \mathrm{~m} \\
(35 \mathrm{ft})\end{array}$ & $\begin{array}{l}11.6 \mathrm{~m} \\
(38 \mathrm{ft})\end{array}$ & $\begin{array}{l}13.7 \mathrm{~m} \\
(45 \mathrm{ft})\end{array}$ \\
\hline \multicolumn{8}{|c|}{ Test $9-0.6 \mathrm{~m} \times 0.6 \mathrm{~m} \times 0.6 \mathrm{~m}$ wood crib } \\
\hline North & $67 \mathrm{~s}$ & $58 \mathrm{~s}$ & $\diamond$ & - & - & - & - \\
\hline East & $42 \mathrm{~s}$ & $\diamond$ & - & $\diamond$ & - & $\diamond$ & $\diamond$ \\
\hline South & $\diamond$ & $59 \mathrm{~s}$ & $\diamond$ & - & $\diamond$ & - & - \\
\hline West & $46 \mathrm{~s}$ & $\diamond$ & - & $\diamond$ & - & $\diamond$ & $\diamond$ \\
\hline Average & $52 \mathrm{~s}$ & 58 & $\mathrm{n} / \mathrm{a}$ & $\mathrm{n} / \mathrm{a}$ & $\mathrm{n} / \mathrm{a}$ & $\mathrm{n} / \mathrm{a}$ & $\mathrm{n} / \mathrm{a}$ \\
\hline \multicolumn{8}{|c|}{ Test $10-0.6 \times 0.6 \mathrm{~m} \times 1.2 \mathrm{~m}$ wood crib } \\
\hline North & $76 \mathrm{~s}$ & $80 \mathrm{~s}$ & $89 \mathrm{~s}$ & - & - & - & - \\
\hline East & $59 \mathrm{~s}$ & $88 \mathrm{~s}$ & - & $121 \mathrm{~s}$ & - & $138 \mathrm{~s}$ & $126 \mathrm{~s}$ \\
\hline South & $60 \mathrm{~s}$ & $72 \mathrm{~s}$ & $113 \mathrm{~s}$ & - & $118 \mathrm{~s}$ & - & - \\
\hline West & $38 \mathrm{~s}$ & $72 \mathrm{~s}$ & - & $100 \mathrm{~s}$ & - & $134 \mathrm{~s}$ & $159 \mathrm{~s}$ \\
\hline Average & $58 \mathrm{~s}$ & $78 \mathrm{~s}$ & $101 \mathrm{~s}$ & $111 \mathrm{~s}$ & $118 \mathrm{~s}$ & $136 \mathrm{~s}$ & $143 \mathrm{~s}$ \\
\hline
\end{tabular}

detector did not activate

- no detector installed

$\mathrm{n} / \mathrm{a}$ no average 
Table 77. Projected beam detector response times for wood crib fires (tests 9 and 10) conducted in $15 \mathrm{~m}$ high facility

\begin{tabular}{|c|c|c|c|c|c|c|c|c|c|}
\hline \multirow{2}{*}{$\begin{array}{c}\text { Location } \\
\text { Below } \\
\text { Ceiling }\end{array}$} & \multicolumn{9}{|c|}{ Sensor Number } \\
\hline & BII) & $12^{2}$ & $\mathrm{B3}$ (9) & $18^{6 / 9}$ & 856 & $\mathrm{~B} 66^{\circ} \times$ & (B7\% & B8ro: & 1896 \\
\hline \multicolumn{10}{|c|}{ Test $9-0.6 \mathrm{~m} \times 0.6 \mathrm{~m} \times 06 . \mathrm{m}$ wood crib } \\
\hline $0.31 \%$ & 88 . & $66 \%$ & 858 & 1. & 3. & . & \% & 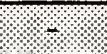 & 策 \\
\hline $1.8 \mathrm{~m}$ & - & - & - & - & - & - & $330 \mathrm{~s}$ & $313 \mathrm{~s}$ & $305 \mathrm{~s}$ \\
\hline 2711 & ta & 兹 & 原 & $31 \%=$ & $46 \%$ & $605 \%$ & $\sqrt{3}$ & 厓 & ? \\
\hline \multicolumn{10}{|c|}{ Test $10-0.6 \mathrm{~m} \mathrm{x} 0.6 \mathrm{~m} \times 1.2 \mathrm{~m}$ wood crib } \\
\hline 0.310 & $205 \%$ & 675 & 100 & \% & - & , & $\%$ & \% & . \\
\hline $1.8 \mathrm{~m}$ & - & - & - & - & - & - & 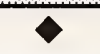 & $568 \mathrm{~s}$ & $563 \mathrm{~s}$ \\
\hline $2 / \mathrm{m}$ & \% & \% & \% & 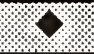 & $4 \%$ & 4 & ? & \% & ? \\
\hline
\end{tabular}

detector did not activate

- no detector installed

(a) alarm sensitivity setting, $30 \%$; alarm window, $30 \mathrm{~s}$

(b) alarm sensitivity setting, 20\%; alarm window, $5 \mathrm{~s}$

(c) alarm sensitivity setting, $50 \%$; alarm window, $30 \mathrm{~s}$

(d) alarm sensitivity setting, 50\%; alarm window, $10 \mathrm{~s}$

(e) alarm sensitivity setting, 50\%; alarm window, $5 \mathrm{~s}$

Table 78. UV/IR optical flame detector response times for wood crib test fires conducted in $15 \mathrm{~m}$ high facility

\begin{tabular}{|c|c|c|c|c|c|c|c|c|c|c|}
\hline \multicolumn{10}{|c|}{ Test 9: 0.6 m x 0.6 m x 0.6 m wood crib } \\
\hline Location (m) & $\begin{array}{c}9.7 \\
\text { OVHD }\end{array}$ & 12.2 & 15.2 & $\begin{array}{c}15.2 \\
\text { Off Axis }\end{array}$ & 18.3 & 21.3 & 24.4 & 27.4 & 30.5 & 48.8 \\
\hline $\begin{array}{c}\text { Response } \\
\text { Time (s) }\end{array}$ & 0.3 & 35.9 & 71.7 & 36.0 & 81.3 & 93.2 & 113.9 & 121.7 & 180.3 & \\
\hline \multicolumn{7}{|c|}{ Test 10: 0.6 m x 0.6 m x 1.2 m wood crib } & \\
\hline $\begin{array}{c}\text { Location (m) } \\
\text { OVHD }\end{array}$ & $\begin{array}{c}15.2 \\
\text { Off Axis }\end{array}$ & 18.3 & 21.3 & 24.4 & 27.4 & 30.5 & 36.6 & 42.7 & 48.8 \\
\hline $\begin{array}{c}\text { Response } \\
\text { Time (s) }\end{array}$ & 528.1 & 102.7 & 387.5 & 392.6 & 441.3 & 445.7 & 552.0 & 584.8 & & \\
\hline
\end{tabular}

detector did not activate 


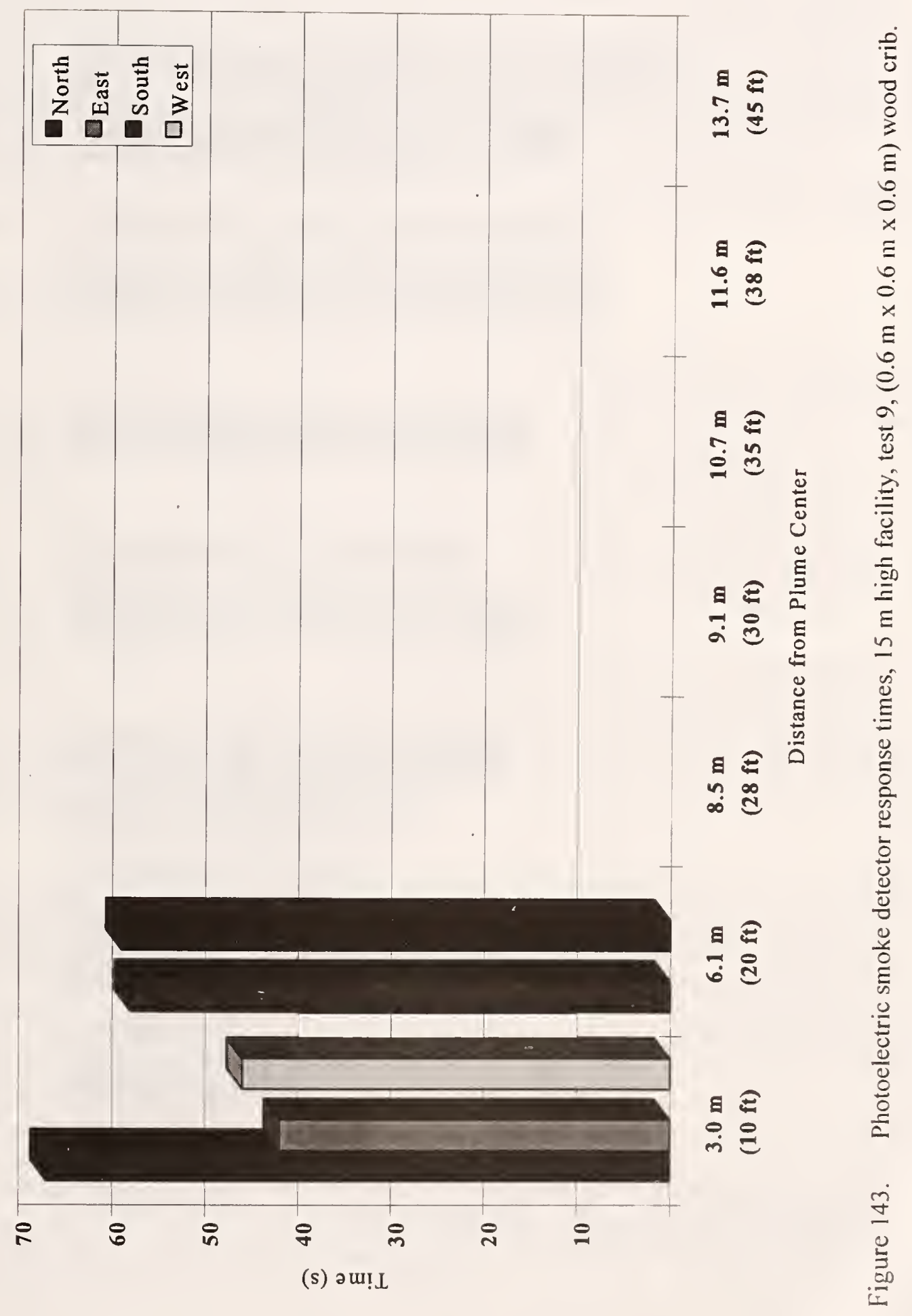




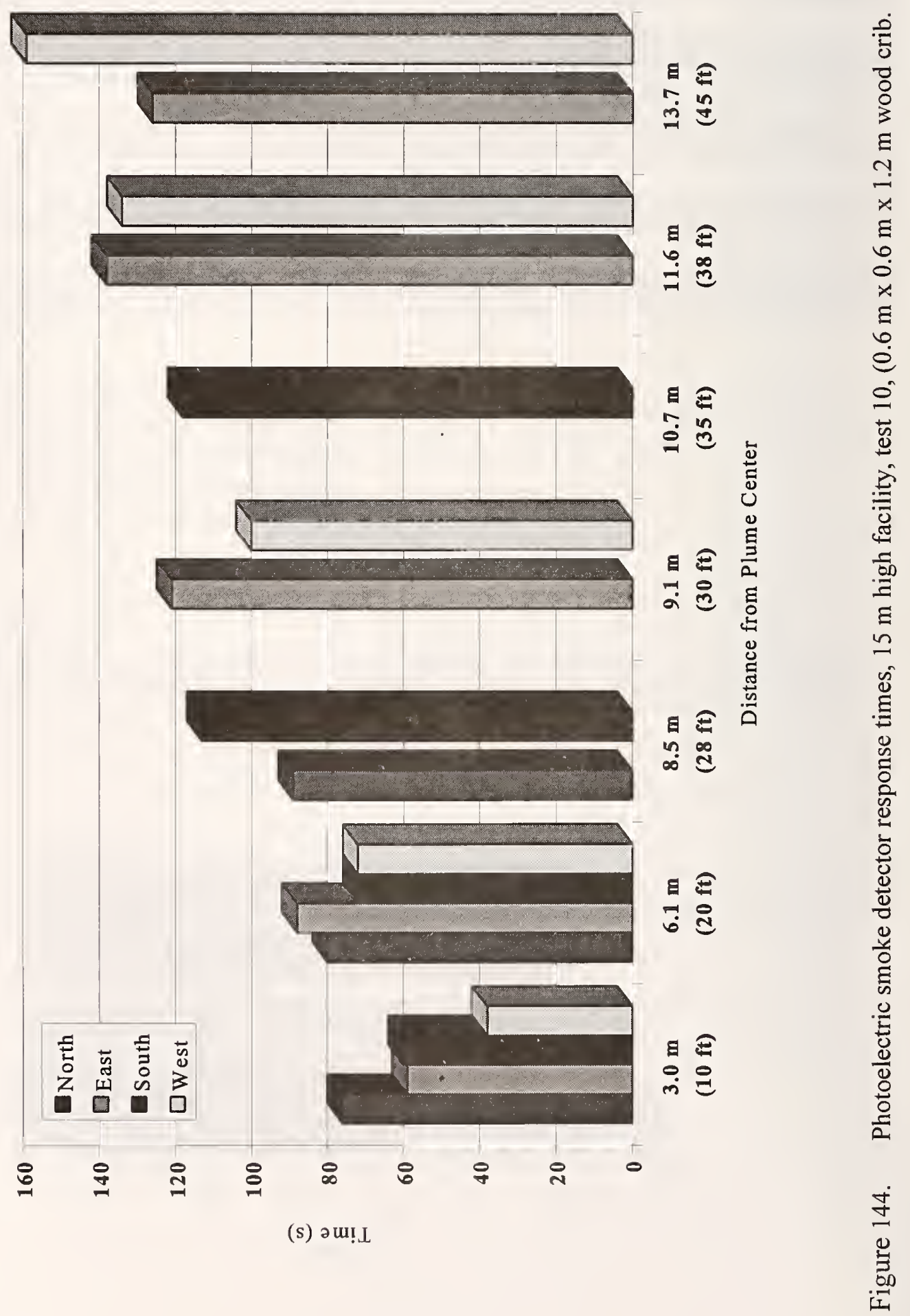


Analysis of tests 9 and 10 show a distinct pattern. Two of the three detectors at the lowest elevation (i.e., $2.7 \mathrm{~m}$ below the ceiling) did not activate because the smoke layer did not descend to that level. The center detector responded quickly because its beam was aimed directly through the plume. Had this detector been located elsewhere it probably would not have responded. The detectors at the middle elevation (i.e., $1.8 \mathrm{~m}$ below the ceiling) either did not respond or took longer than $560 \mathrm{~s}$ to respond. The sensitivity setting of the detectors at this level was set at $50 \%$. A $50 \%$ decrease in signal strength was too high for the beam detectors to generate an alarm. The response times for the detectors located at the highest elevation (i.e., $0.3 \mathrm{~m}$ below the ceiling) were consistent between test 9 and test 10 . It is important to note that the draft curtains were removed prior to conducting the wood crib tests. Had the draft curtains been in place, there is a high probability that the projected beam detector response would have been significantly different.

\section{Response of Combination UVIIR Optical Flame Detectors}

The installation parameters for the UV/IR detectors are described in section 3. The location of the UV/IR detectors is shown in Figure 145. For both wood crib tests the controllers for the UV/IR detectors had the following settings: $0.25 \mathrm{~s}$ gate length, 4 counts per gate and 4 consecutive gates. There were nine UV/IR detectors mounted on the floor, approximately $2.0 \mathrm{~m}$ high. Eight of these detectors were positioned to provide a direct line of sight to the fire and one detector was positioned off axis at a $45^{\circ}$ angle to the fire. In addition there was one detector installed directly over the crib, attached to the bottom of the truss, $9.7 \mathrm{~m}$ above the floor. The UV/IR detector response times for tests 9 and 10 are shown in Table 78. In all of the jet fuel experiments, the manufacturer also furnished the predicted response on unitized UV/IR detectors; however, this was not done for the wood crib experiments.

Figure 146 shows the comparison of response times versus detector locations in test 9 . The response times ranged from 0.3 seconds at the overhead detector to 180 seconds at the detector located $30.5 \mathrm{~m}$ from the fire. The detector $48.8 \mathrm{~m}$ from the fire did not activate. There was a noticeable difference between the two detectors $15.2 \mathrm{~m}$ from the fire (i.e., the off axis detector and a detector looking directly at the source). The detector that was positioned off axis from the source responded in half the time as the detector that was looking directly at the source.

In test 10 , the response times were very different from test 9 . The off axis detector (i.e., $15.2 \mathrm{~m}$ from the source) responded in $103 \mathrm{~s}$, while the other detectors responded between $387 \mathrm{~s}$ and $585 \mathrm{~s}$. Visual observations showed (Figure 147) that in test 10 , the flames were primarily confined to the interior of the crib for the first $6 \mathrm{~min}$ of the test. During this time the flame detectors were being blocked by the smoke and could not pick up the deep seated fire within the crib, even though there was significant flaming combustion. These detectors did not respond until the flames grew to a height above the wood crib which than became visible to the detectors.

\section{Response of Automatic Sprinklers}

The automatic sprinkler installation parameters and mounting locations are discussed in section 3. No sprinklers activated in either test 9 or 10 . The maximum temperature recorded at the ceiling directly above the plume centerline were $53{ }^{\circ} \mathrm{C}\left(127.4^{\circ} \mathrm{F}\right)$ in test 9 and $52{ }^{\circ} \mathrm{C}\left(125.6{ }^{\circ} \mathrm{F}\right)$ in test 10 . The lowest temperature sprinklers installed were rated at $79^{\circ} \mathrm{C}\left(175^{\circ} \mathrm{F}\right)$. 
Maximum Ceiling Temperature and Temperature Rise Above Ambient

There were 64 thermocouples installed in the test area as described in section 3 . For tests 9 and 10 , the maximum ceiling temperatures were $53^{\circ} \mathrm{C}\left(127.4^{\circ} \mathrm{F}\right)$ and $52^{\circ} \mathrm{C}\left(125.6^{\circ} \mathrm{F}\right)$ respectively. In addition the temperature rise above ambient was $24^{\circ} \mathrm{C}\left(43.2^{\circ} \mathrm{F}\right)$ for test 9 and $23^{\circ} \mathrm{C}\left(41.4^{\circ} \mathrm{F}\right)$ for test 10 . It is important to note that the maximum ceiling temperature and temperature rise above ambient were obtained from the thermocouples mounted at the ceiling, directly over the fire plume. 


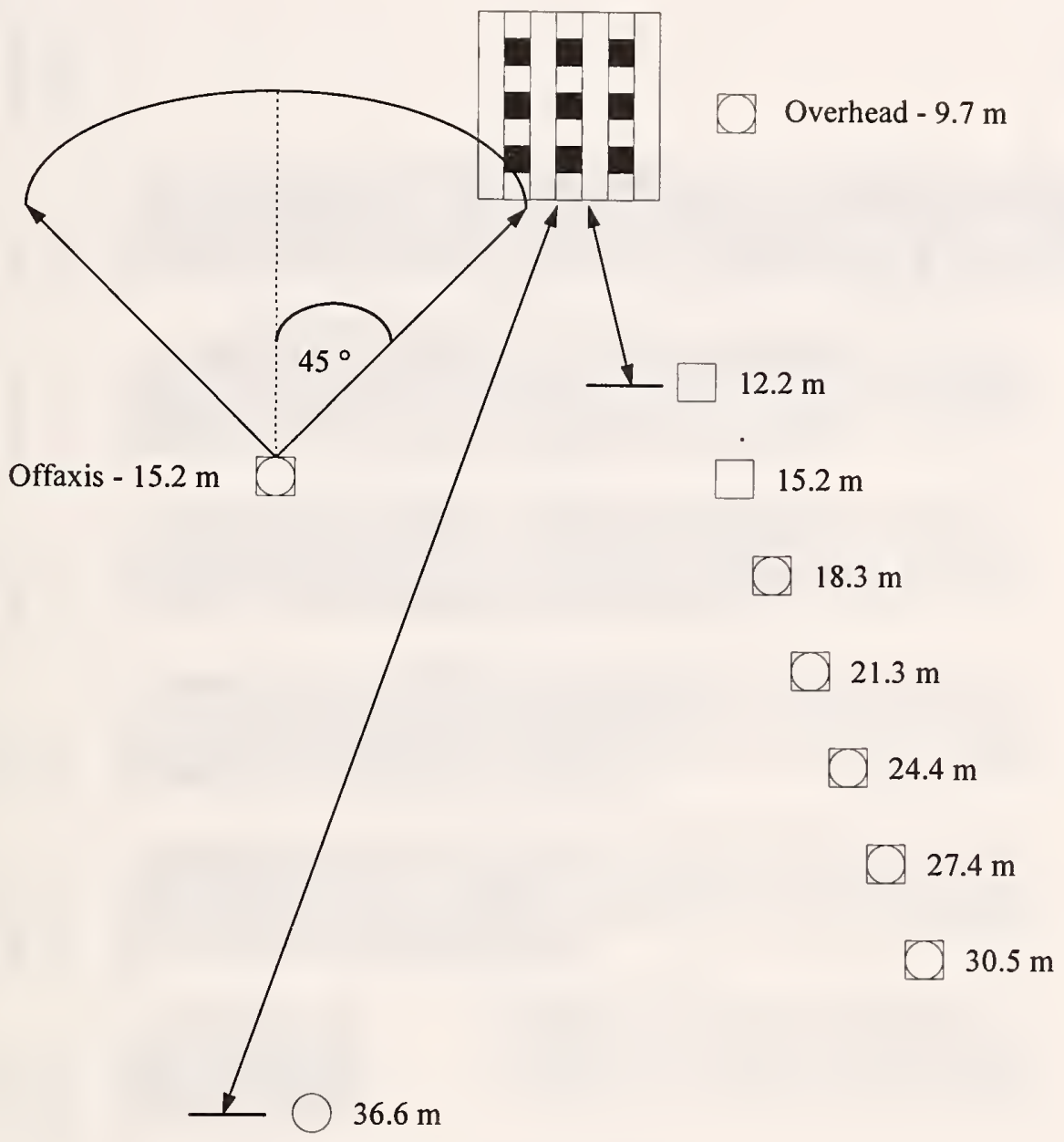

$42.7 \mathrm{~m}$

D $48.8 \mathrm{~m}$

$\square$ Test \#9 Only

Test \#10 Only

Both Test $\# 9$ and $\# 10$

Figure 145. UV/IR optical flame detector layout for wood crib fire tests (tests 9 and 10) conducted in $15 \mathrm{~m}$ high facility. 


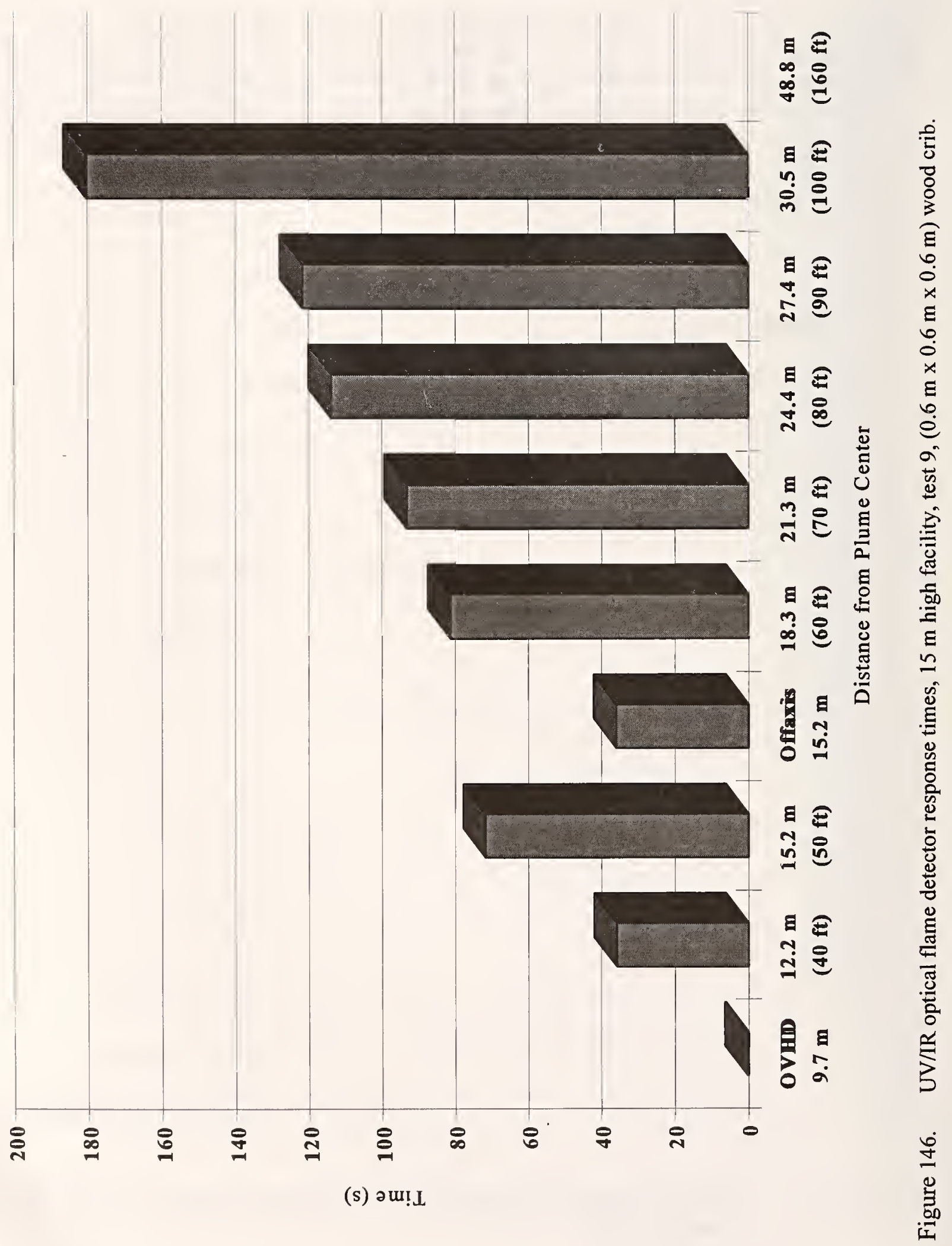




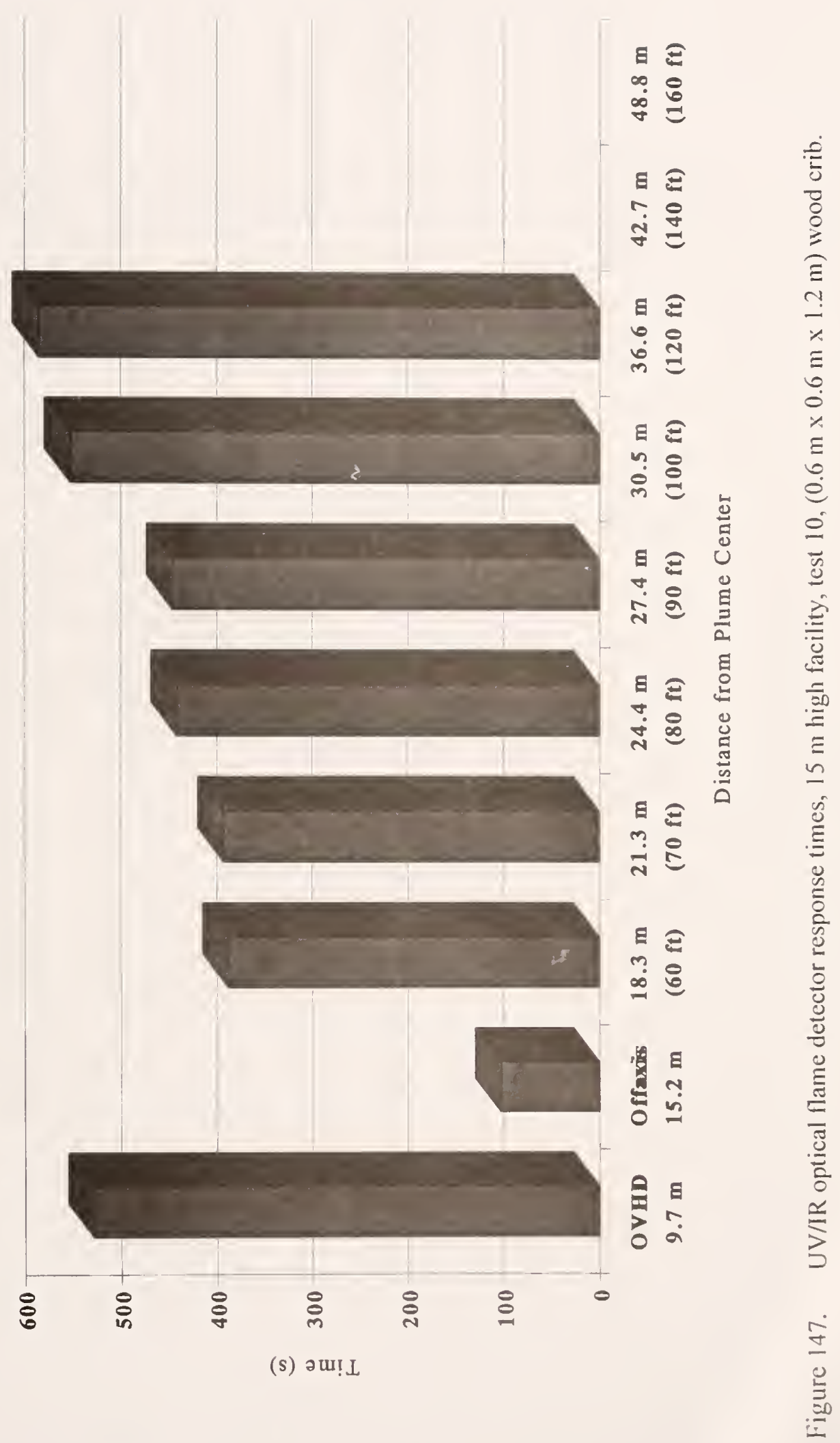

\& U.S. GOVERNMENT PRINTING OPPICP: 1997-117-392/72652 





\section{NTST Technical Publications}

\section{Periodical}

Journal of Research of the National Institute of Standards and Technology-Reports NIST research and development in those disciplines of the physical and engineering sciences in which the Institute is active. These include physics, chemistry, engineering, mathematics, and computer sciences. Papers cover a broad range of subjects, with major emphasis on measurement methodology and the basic technology underlying standardization. Also included from time to time are survey articles on topics closely related to the Institute's technical and scientific programs. Issued six times a year.

\section{Nonperiodicals}

Monographs-Major contributions to the technical literature on various subjects related to the Institute's scientific and technical activities.

Handbooks-Recommended codes of engineering and industrial practice (including safety codes) developed in cooperation with interested industries, professional organizations, and regulatory bodies.

Special Publications-Include proceedings of conferences sponsored by NIST, NIST annual reports, and other special publications appropriate to this grouping such as wall charts, pocket cards, and bibliographies.

National Standard Reference Data Series-Provides quantitative data on the physical and chemical properties of materials, compiled from the world's literature and critically evaluated. Developed under a worldwide program coordinated by NIST under the authority of the National Standard Data Act (Public Law 90-396). NOTE: The Journal of Physical and Chemical Reference Data (JPCRD) is published bimonthly for NIST by the American Chemical Society (ACS) and the American Institute of Physics (AIP). Subscriptions, reprints, and supplements are available from ACS, 1155 Sixteenth St., NW, Washington, DC 20056.

Building Science Series-Disseminates technical information developed at the Institute on building materials, components, systems, and whole structures. The series presents research results, test methods, and performance criteria related to the structural and environmental functions and the durability and safety characteristics of building elements and systems.

Technical Notes-Studies or reports which are complete in themselves but restrictive in their treatment of a subject. Analogous to monographs but not so comprehensive in scope or definitive in treatment of the subject area. Often serve as a vehicle for final reports of work performed at NIST under the sponsorship of other government agencies.

Voluntary Product Standards - Developed under procedures published by the Department of Commerce in Part 10, Title 15, of the Code of Federal Regulations. The standards establish nationally recognized requirements for products, and provide all concerned interests with a basis for common understanding of the characteristics of the products. NIST administers this program in support of the efforts of private-sector standardizing organizations.

Order the following NIST publications-FIPS and NISTIRs-from the National Technical Information Service, Springfield, VA 22161.

Federal Information Processing Standards Publications (FIPS PUB)-Publications in this series collectively constitute the Federal Information Processing Standards Register. The Register serves as the official source of information in the Federal Government regarding standards issued by NIST pursuant t the Federal Property and Administrative Services Act of 1949 as amended, Public Law 89-306 (79 St: 1127), and as implemented by Executive Order 11717 (38 FR 12315, dated May 11, 1973) and Part Title 15 CFR (Code of Federal Regulations).

NIST Interagency Reports (NISTIR)-A special series of interim or final reports on work per NIST for outside sponsors (both government and nongovernment). In general, initial distributic by the sponsor; public distribution is by the National Technical Information Service, Springf: 


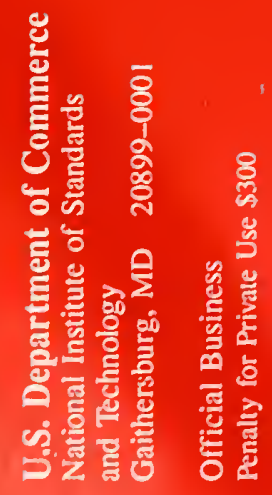

